\title{
NBSIR 74-574 \\ NBSLD, Computer Program for \\ Heating and Cooling Loads in Buildings
}

T. Kusuda

Center for Building Technology

Institute for Applied Technology

National Bureau of Standards

Washington, D. C. 20234

November 1974

Final Report

Prepared for

Housing and Urban Development

451 7th Street, S. W.

Washington, D. C. 20410 

NBSIR 74-574

NBSLD, COMPUTER PROGRAM FOR

HEATING AND COOLING LOADS IN

BUILDINGS

T. Kusuda

Center for Building Technology

Institute for Applied Technology

National Bureau of Standards

Washington, D. C. 20234

November 1974

Final Report

This report will be published in May 1975 as a National Bureau of Standards Building Science Series Publication.

Prepared for

Housing and Urban Development

4517 th Street, S. W.

Washington, D. C. 20410

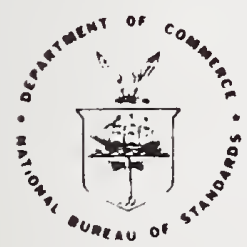

U. S. DEPARTMENT OF COMMERCE, Frederick B. Dent, Secretary 

U. S. DEPARTMENT OF COMMERCE

\author{
NBSLD \\ Computer Program for Heating and Cooling Loads in Buildings \\ National Bureau of Standards
}

Tamami Kusuda

Thermal Engineering Systems Section

Building Environment Division

Center for Building Technology

Institute for Applied Technology

National Bureau of Standards 



\section{Preface}

This document comprises the engineering manual for the computer program called the National Bureau of Standards Load Determination Program hereafter referred to as NBSLD. Presented herein are the algorithms for the exact calculation methodology that was developed in the Thermal Engineering Systems Section of the National Bureau of Standards to determine accurate heating and cooling loads for the thermal design of buildings. NBSLD, which is based upon the methodologies presented in this publication, has been available for some time for the purpose of evaluating various building constructions and systems. The program was originally deve1oped as a research tool because none of the commercially available programs had features or the sophistication to enable the evaluation of unconventional designs. NBSLD has been an indispensable tool for studies of numerous HUD housing systems, constructions of the Defense Department and the General Services Administration where non-conventional design conditions had to be evaluated.

As the existence and the capability of NBSLD became known, numerous requests were made to NBS to release the program for public use. This publication is in response to that request. Hopefully, engineers will be able to adopt some of the computational schemes described in this publication to their own programs. A complete Fortran program is attached, although NBS does not claim that the program is optimum from the standpoint of the computer memory allocation or computational economy. It will take additional improvements before the program becomes optimum from those viewpoints. The program documentation is being made available at this time so 
engineers can use it for accurate load determination as they seek to conserve energy through improved thermal design of buildings. The author would appreciate receiving reader's comments with respect to the accuracy of this text.

It should be mentioned that some of the subroutine algorithms listed in this publication have already been published in the well known ASHRAE booklet entitled "Procedure for Determining Heating and Cooling Loads for Computerized Energy Calculations". These subroutines were compiled by the author who served as the chairman of the Subcommittee on Heating and Cooling Load Calculations of the ASHRAE Task Group on Energy Requirements for Heating and Cooling of Buildings. The ASHRAE publication, however, contains several critical errors, which have been corrected for use in this volume.

The author is greatly indebted to Dr. J. E. Hill for this thorough editing of the text, to Mrs. Sharon D. Crampton for her skill and patience in typing the manuscript and to Mr. F. J. Powell for his encouragement to produce the document. 
1. Introduction . . . . . . . . . . . . 1

2. Fundamentals of Heating and Cooling Load Calculation . . 3

2.1 A Rigorous Method of Calculating Heating and Cooling Loads . . . . . . . . . . . . . 5

2.2 Approximate Methods of Calculating Heating and Cooling Loads . . . . . . . . . . . . 9

3. Unique Features of NBS Load Calculation Computer Program . 15

4. General Description of NBSLD Subroutines . . . . . . 22

5. NBSLD Logic Diagram . . . . . . . . . . 31

6. References .............. . . 33

7. Appendix A - ASHRAE Task Group Subroutine Algorithms

CLIMAT - Weather data processing . . . . . . . . la SUN - Basic solar position data ......... . 6 a CCF - Cloud cover factor . . . . . . . . . 15a SOLAD - Solar radiation intensity . . . . . . . 18a TAR - Glass transmission and absorption ....... 22a SHG - Solar heat gain through a window ....... 29a SHADOW - Sunlit area calculations ......... 3 la FIJ - Radiation heat transfer exchange factors .... 4 48a FI - Interior surface heat transfer coefficients . . . 6 64a FO - Outside surface heat transfer coefficients . . . 65a ACR - Air cavity heat transfer coefficients . . . . 68a XYZ - Conduction transfer functions ........ . 7la HEATW - Heat conduction through exposed surfaces . . . 79a SCHEDULE - Internal heat generation . . . . . . 86a Fundamentals of Room Temperature and Cooling (Heating)

Load Calculations . . . . . . . . . . 89a RMTMP - Exact room load calculation ........ 94a ATTIC - Exact attic temperature calculation . . . . . 108a IHG - Instantaneous heat gain concept . . . . . . 109a HLC - Heating/cooling load calculation by the transfer

function method ............. 115a RMRT - Transfer functions for the room temperature cal-

culations . . . . . . . . . . . 122a HEXT - Heat extraction rate calculation . . . . . . 128a INFIL - Building air exchange calculation . . . . . 129a 
Miscellaneous routines

DST - Daylight saving time indicator . . . . . . . . 144a

WKDAY - Day of week identifier . . . . . . . . . . 145a

HOLDAY - U. S. Holiday identifier . . . . . . . . . 149a

PSY - Psychrometric calculations . . . . . . . . . 150a

8. Appendix B - Weighting Factor Method for Calculating Heating and Cooling Loads and Space Temperature

9. Appendix C - NBSLD Data Forms

10. Appendix D - NBSLD Fortran Listing

11. ASHRAE Psychrometric Chart 


\section{NBSLD}

National Bureau of Standards Heating and Cooling

Load Determination Program

T. Kusuda

Thermal Engineering Systems Section

Building Environment Division

Center for Building Technology, IAT

\section{ABSTRACT}

A comprehensive computer program called NBSLD, the National Bureau of Standards Load Determination program, has been developed at NBS to reflect the time change of the many building parameters which are pertinent to accurate estimation of energy usage for heating and cooling. Current status of heating and cooling load techniques is reviewed. Of general interest are unique features of NBSLD which are not available in existing computer programs. A summary of various subroutines of NBSLD is given along with the detailed procedures for them. These subroutines constitute the recommended subroutine algorithms of the ASHRAE Task Group on Energy Requirements. Complete Fortran listing of NBSLD and data preparation forms are given for those who wish to use the program. The NBSLD computation is on the basis of the detailed solution of simultaneous heat balance equations at all the interior surfaces of a room or space. Transient heat conduction through exterior walls and the interior structures is handled by using conduction transfer functions. The use of heat balance equations, although time consuming in calculation, can avoid the vagueness and uncertainties inherent in the more popularly used weighting factor approach. 
In addition, it is more accurate for a specific building design.

Key Words: ASHRAE Task Group on Energy Requirements;

conduction transfer functions; heating and cooling load; National Bureau of Standards Heating and Cooling Load Computer Program 


\section{Introduction}

Numerous studies in recent years on the matter of energy shortage lead one to believe that the U. S. demand for energy will very shortly outstrip her power generating capacity and fossil fuel supply. According to a recent report of the Stanford Research Institutel/, space heating and cooling for residential and commercial buildings amounts to approximately $20 \%$ of the total energy consumed in the United States, which was 60 trillion Btu per year in 1968. Moreover, recent and frequent blackouts and brownouts in the east coast region of the United States are good indications that the electric power demand for summer air conditioning exceeds for certain times, the capability of supply and distribution by the power companies.

It is in this context that new and accurate methodology for energy calculations is most crucial for the design and analysis of the performance of space heating and cooling systems. This is especially true in view of the fact that the current load calculation procedures could lead to the over-design of heating and cooling equipment and imprudent use of energy •

It is generally accepted that buildings can be designed to be energy effective if their thermal insulation is increased; window size, air leakage, and lighting levels decreased; shading devices properly installed; heating and cooling systems adequately designed, installed, and maintained; and their heat storage capability most fully utilized. These energy saving features, however, must be considered with reference to numerous constraints, such as added costs for material, construction and maintenance, 
conformance to local building codes, occupancy life styles, aesthetics, construction practices, and availability of equipment.

In spite of these constraints, there is sufficient engineering information and technical basis that exist today to warrant extensive studies on various design alternatives for heating and cooling the building to minimize the wasteful use of energy. Design and operation of heating and cooling systems based upon conventional steady-state calculations, for example, usually result in oversizing of equipment and overheating or cooling of the space to be controlled. An over-design system usually operates at lower efficiency and needs more material (consequently more energy) to produce it, thus creating a vicious cycle.

One effective way to design the heating and cooling systems which is optimum from the standpoint of energy consumption, peak power demand and many practical constraints mentioned above, is to study the building thermal performance by using accurate simulations. Because the use of computer simulations make it possible to evaluate the sensitivity of various design alternatives on the net energy usage, they can be a very effective tool in the design process. In order for such design studies to be conducted on the computer however, the computer program to be used should be very comprehensive and should indicate the proper response to the change of the many parameters which are pertinent to energy usage. The intent of this document is to present a more detailed calculation methodology than is generally used to make it possible for engineers to reduce the area of approximation, where this is considered desirable, by a rigorous computer simulation of building systems, which consider and take into account most of the variables that affect the building and 
system operation.

Refined and sophisticated calculation procedures unfortunately are both time consuming and expensive. Without the use of advanced computer methods, they are literally impossible. The development of such calculation procedures can only be justified on the basis that the more accurate calculation will result in overall savings in energy usage and owning and operating costs and consequently in total life cycle cost due to better design of the building systems, more precise sizing of the equipment, and more carefully controlled operation of the heating and cooling system. There are many indications that such a justification is well warranted.

\section{Fundamentals of Heating and Cooling Load Calculation}

Calculation of the energy requirements of the heating and cooling system of a building involves three major steps which may be carried out simply to achieve approximate results, or with increasing degrees of complexity and sophistication as more accurate and more refined determination of system performance is required. First, is the calculation of heat loss or heat gain to the space which is heated or cooled. Second, is the determination of the heating and cooling load imposed on the system. Third, is the calculation of the energy input to all of the system components to satisfy that load.

The ASHRAE Handbook of Fundamentals ${ }^{2}$ / contains the basic information whereby the heating and cooling load of a building may be calculated. Customarily such load calculations are made for the so-called "design conditions" for sizing the equipment and developing the design of the heating and cooling system. However, the "design conditions" normally exist only 
for a very few hours, if at all, during a heating or cooling season. Consequently, the actual day-by-day and hour-by-hour heating and cooling load for energy consumption is quite different from that for the design condition. Thus the heating and cooling load calculation for the purpose of estimating "energy requirements" must reflect the actual weather conditions rather than a design condition.

Various methods have been developed in the past such as the "degree day" method or "bin" method for proportioning the design load, to obtain approximate monthly, daily, or hourly loads and consequently provide a basis for determining energy requirements. Insofar as such methods are based on valid approximation procedures and checked against actual operating experience, they provide the base for simplified determination of energy requirements acceptable for the needs of most engineers.

In this section a review of the rigorous methods of calculating heating and cooling loads by means of solving heat balance equations at all the interior surfaces of a room or space is given. Also described are approximate methods in which weighting factors are developed after the heat balance equations have been solved for one set of conditions. The NBSLD calculations follow the rigorous method while the ASHRAE Task Group procedures use the weighting factor method.

In NBSLD the transient heat conduction through exterior walls of the room or space is handled by using conduction transfer functions. The use of heat balance equations at the interior surfaces, although more time consuming, can avoid the vagueness and uncertainties inherent in the weighting factor approach. In addition, it is more accurate for a specific building design. 


\subsection{A Rigorous Method of Calculating Heating and Cooling Loads}

A cooling (heating) load is of course the amount of energy that is transferred to (from) the room and simultaneously removed (added) by the conditioning equipment at any given time of interest. To calculate this quantity directly requires a rather laborious solution of energy balance equations involving the room air, surrounding walls, infiltrating and ventilation air, and internal energy sources. The principle of calculation can be demonstrated by considering a fictitious space that is enclosed by 4 walls, a ceiling and floor, and having infiltration air as wel1 as normal internal energy sources. The six equations that govern energy exchange at each inside surface at a given time $t$ are:

$$
\begin{aligned}
& q_{i, t}=h_{c i}\left(t_{a, t}-t_{i, t}\right)+\sum_{\substack{j=1 \\
j \neq i}}^{m} g_{i j}\left(t_{j, t}-t_{i, t}\right)+R s_{i, t}+R L_{i, t}+R E_{i, t} \\
& \text { for } i=1,2,3,4,5,6
\end{aligned}
$$

where

$$
\begin{aligned}
& \mathrm{m}=\text { number of surfaces in the space } \\
& q_{i, t}=\text { rate of heat conducted into surface } i \text { at the inside } \\
& \text { surface at time } t \\
& \mathrm{~h}_{\mathrm{ci}}=\text { convective heat transfer coefficient at interior } \\
& \text { surface } i \\
& g_{i j}=\text { radiation heat transfer factor between interior } \\
& \text { surface } i \text { and interior surface } j \\
& t_{a, t}=\text { inside air temperature at time } t
\end{aligned}
$$




$$
\begin{aligned}
t_{i, t}= & \text { average temperature of interior surface } i \text { at time } t \\
t_{j, t}= & \text { average temperature of interior surface } j \text { at time } t \\
\mathrm{RS}_{i, t}= & \text { rate of solar energy coming through the windows and } \\
& \text { absorbed by surface } i \text { at time } t \\
= & \text { rate of heat radiated from the lights and absorbed } \\
\mathrm{RL}_{i, t} & \text { by surface } i \text { at time } t \\
\mathrm{RE} & \text { rate of heat radiated from equipment and occupants } \\
& \text { and absorbed by surface } i \text { at time } t
\end{aligned}
$$

The equations governing conduction within the six slabs cannot be solved independent of the above equations since the energy exchanges occurring within the room affect the inside surface conditions which in turn affect the internal conduction. Consequently, one is faced with solving six equations simultaneously with the governing equations of conduction within six slabs in order to calculate the cooling load at time of interest $\left(Q_{L_{, t}}\right)$ which would be given by:

$$
\begin{aligned}
Q_{L, t} & =\sum_{i=1}^{6} h_{c i}\left(t_{i, t}-t_{a, t}\right)+\rho c G_{L, t}\left(t_{o, t}-t_{a, t}\right) \\
& +\rho C G_{v, t}\left(t_{v, t}-t_{a, t}\right)+R S_{a, t}+R L_{a_{, t}}+R E_{a, t}
\end{aligned}
$$

where

$$
\begin{aligned}
\rho= & \text { air density } \\
\mathrm{C}= & \text { air specific heat } \\
\mathrm{G}_{\mathrm{L}, \mathrm{t}}= & \text { mass flow rate of outdoor air infiltrating into the } \\
& \text { space at } t \text { ime } t \\
t_{o, t}= & \text { outdoor air temperature at time } t
\end{aligned}
$$




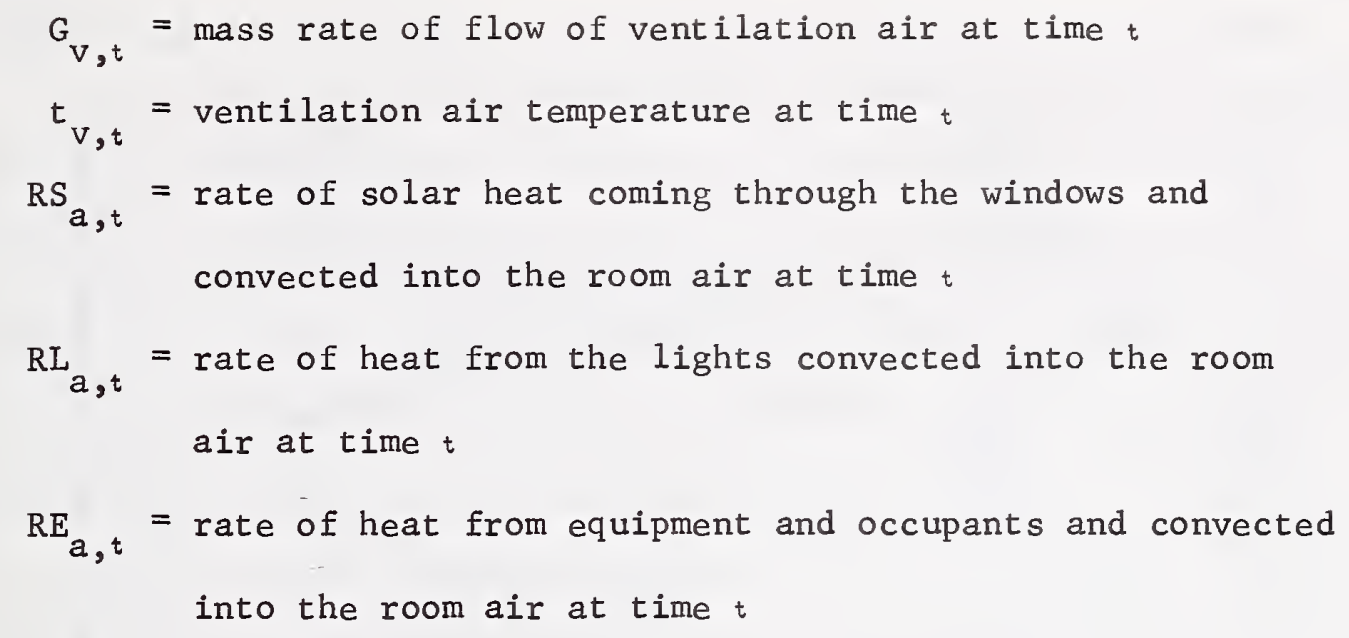

A rigorous approach such as this for calculating cooling load would be practically impossible if it were not for the speed at which such computations can be done by modern digital computers. Even so, there are very few computer programs in use today where instantaneous cooling loads are calculated in this exact manner. The concept, however, has been presented previously by Stephenson and Mitalas $3 /$, and by Buchberg 4 / .

Not to be ignored is the effect of air temperature deviation from some prescribed set point. This set point is the temperature for which the cooling (heating) load calculation is made and for which the design capacity of the cooling (heating) apparatus is usually selected. A recent study by Mitalas and Stephenson $[$ / shows that actual heat extracted from the space is considerably smaller than the cooling load calculated on the basis of a constant space temperature. This is due to the thermal storage effect of the building structure and internal furnishings. Figure 1 shows a result from that study and as can be seen, the calculated cooling load peaks at values considerably higher than the measured heat extraction rate. 
$211 / 116: 1$

$\sim \sim$

동

in 0 in

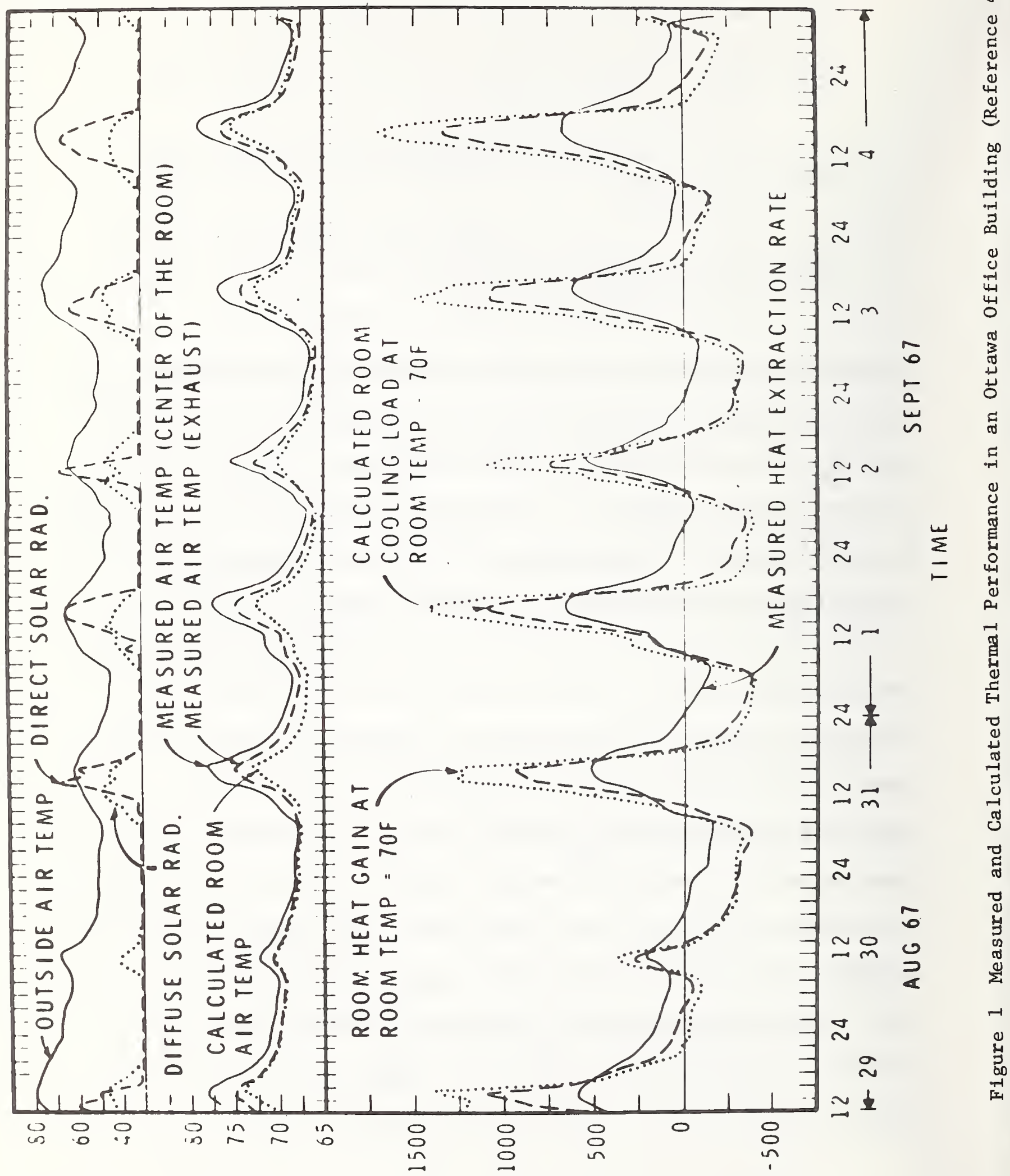

93019101

$11 \forall: 1$ 


\subsection{Approximate Methods of Calculating Heating and Cooling Loads}

Since the exact solution technique is extremely time consuming especially for the calculations done for a period of 8760 hours (one year), the ASHRAE Task Group on Energy Requirements recommends a transfer function concept to simplify the calculation procedure. The transfer function concept was first introduced by Mitalas and Stephenson ${ }^{3 /}$ using what they called room thermal response factors. Their procedure is as follows: the room surface temperatures and cooling or heating load are first calculated by a rigorous method as described in the previous section for several typical constructions representing offices, schools and dwellings of heavy, medium and lightweight construction. In these calculations, the components such as solar heat gain, conduction heat gain, or the heat gain from the lighting, equipment, and occupants are simulated by pulses of unit strength. The transfer functions are then calculated as numerical constants which represent the cooling load (or heating) corresponding to the input excitation pulses. Once these transfer functions are determined for a number of typical constructions, they are assumed to be independent of input pulses and the determination of cooling loads (or heating) is possible without resorting to the rigorous calculations. The calculation required is, instead, simple multiplication of the transfer functions by a time-series representation of heat gain and the subsequent summation of these products, which can be carried out on a small computer with little effort. 
Another way to shorten the computational effort for energy calculations is to determine regression parameters by fitting a simple algebraic equation to the results of rigorous calculations, which had been obtained not for an entire year but for a limited period in the year, such as for the months of January and/or July. Once this regression equation is determined with sufficient accuracy, an energy estimate is made by superimposing the weather conditions of the other months onto the relationships just determined.

An example of this approach is illustrated in Figure 2, which depicts the daily total heating and cooling load plotted against the daily average outdoor air temperature. This plot is a result of a lengthy rigorous calculation performed on a typical apartment in Jersey City using the annual hourly weather conditions that occurred in 1949. The straight lines superimposed on the figures were the least square regression lines that best fit the calculated loads for January and July. It was clear from this figure that the exact calculations for other months would not be necessary, at least for the purpose of determining daily loads, since the regression relationship determined from the January and July calculations were sufficiently accurate that they could be extrapolated to the remainder of the year.

Depending upon the type of building and its heating and cooling system, a good correlation such as illustrated in Figure 2 may not be possible. Figure 3 shows, for example, a similar plot for a test office building whose heating and cooling load were measured in a research project 


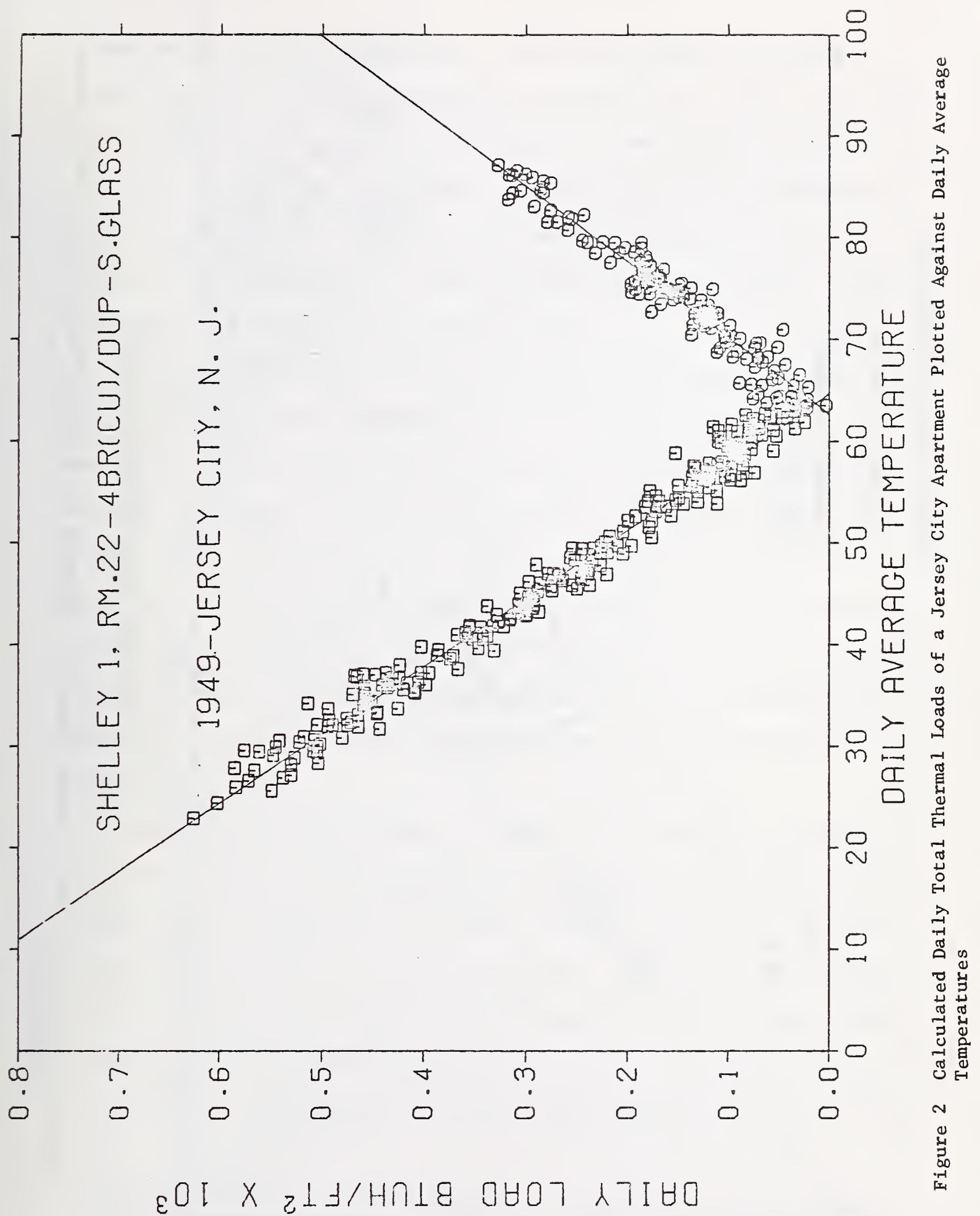



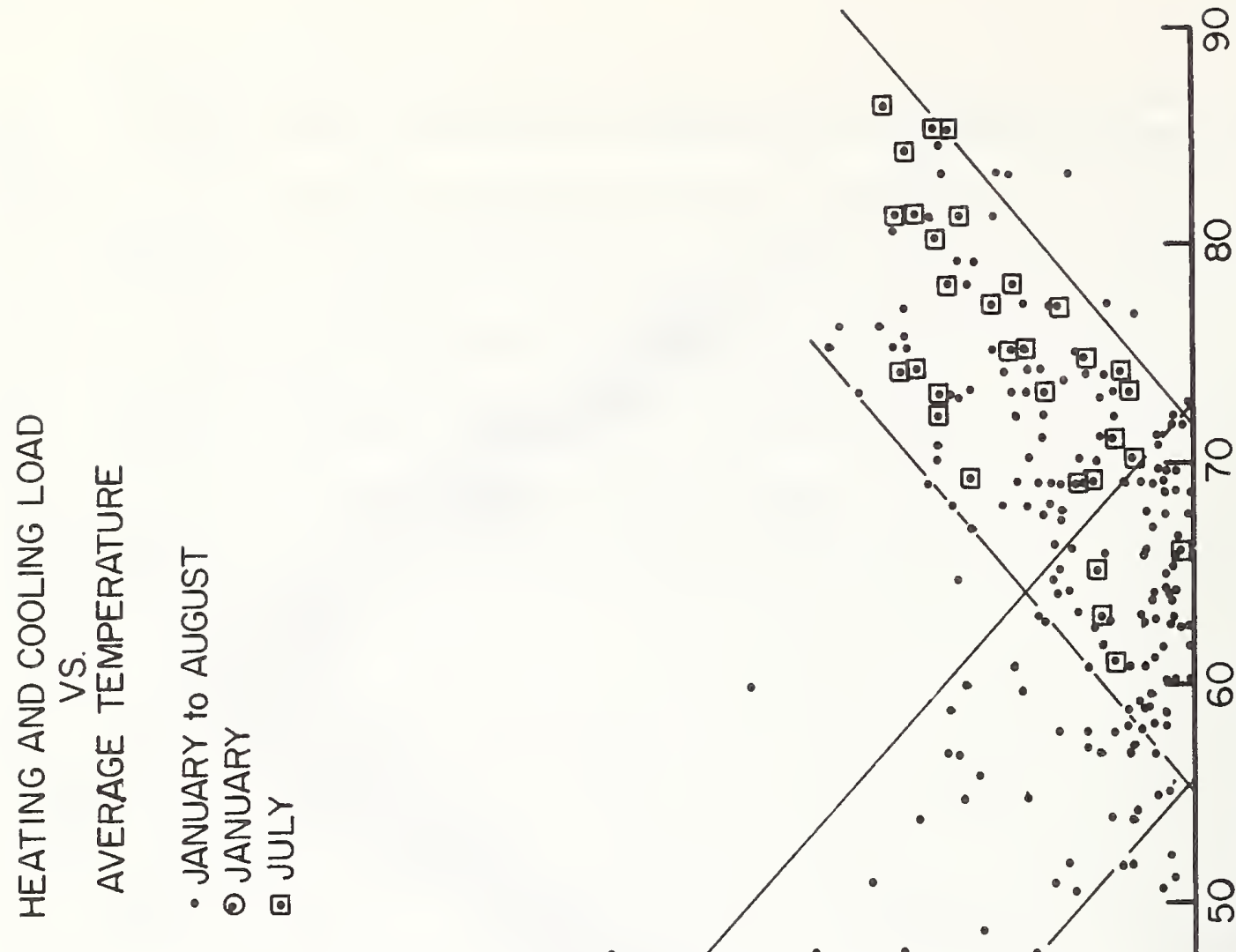

年

$\frac{\mathrm{d}}{\mathrm{d}}$

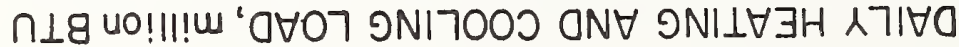


conducted by Ohio State University. The scatter appears considerably larger than the calculated relationship obtained in the Jersey City study. It is obvious that the thermal performance of commercial buildings are affected in a large way by the manner in which internal heat is generated in addition to the normal dependence on outdoor temperature. The inclusion of one or more additional statistical parameters dealing with these internal heat gains should improve the correlation.

Recently one additional method of predicting the heating and/or cooling load or the indoor temperature as a result of the excitation parameters such as outdoor temperature, solar radiation and internal heat generation has been demonstrated by Kusuda and Tsuchiya ${ }^{6 /}$ and further expanded by Kimura and Ishino I/. The method uses the concept of equivalent thermal mass of a building and attempts to fit the observed input and output data into a linear differential equation. The initial results are promising. Figure 4 shows a comparison of predicted and measured room temperature and heat extraction rate for a simple one room test building studied by Kimura and Ishino.

Calculated room temperature in Figure 4 is obtained by the transfer functions derived from the measured data of August 19, while the heat extraction was calculated by the transfer functions derived from the measured values of August 13. The good agreement indicated in Figure 4 implies that the detailed calculation is needed only for a limited number of days to derive accurate transfer functions based upon the equivalent thermal mass of the particular building under consideration.

* Private communication with Professor C. F. Sepsey and J. Jones of the Ohio State University. 

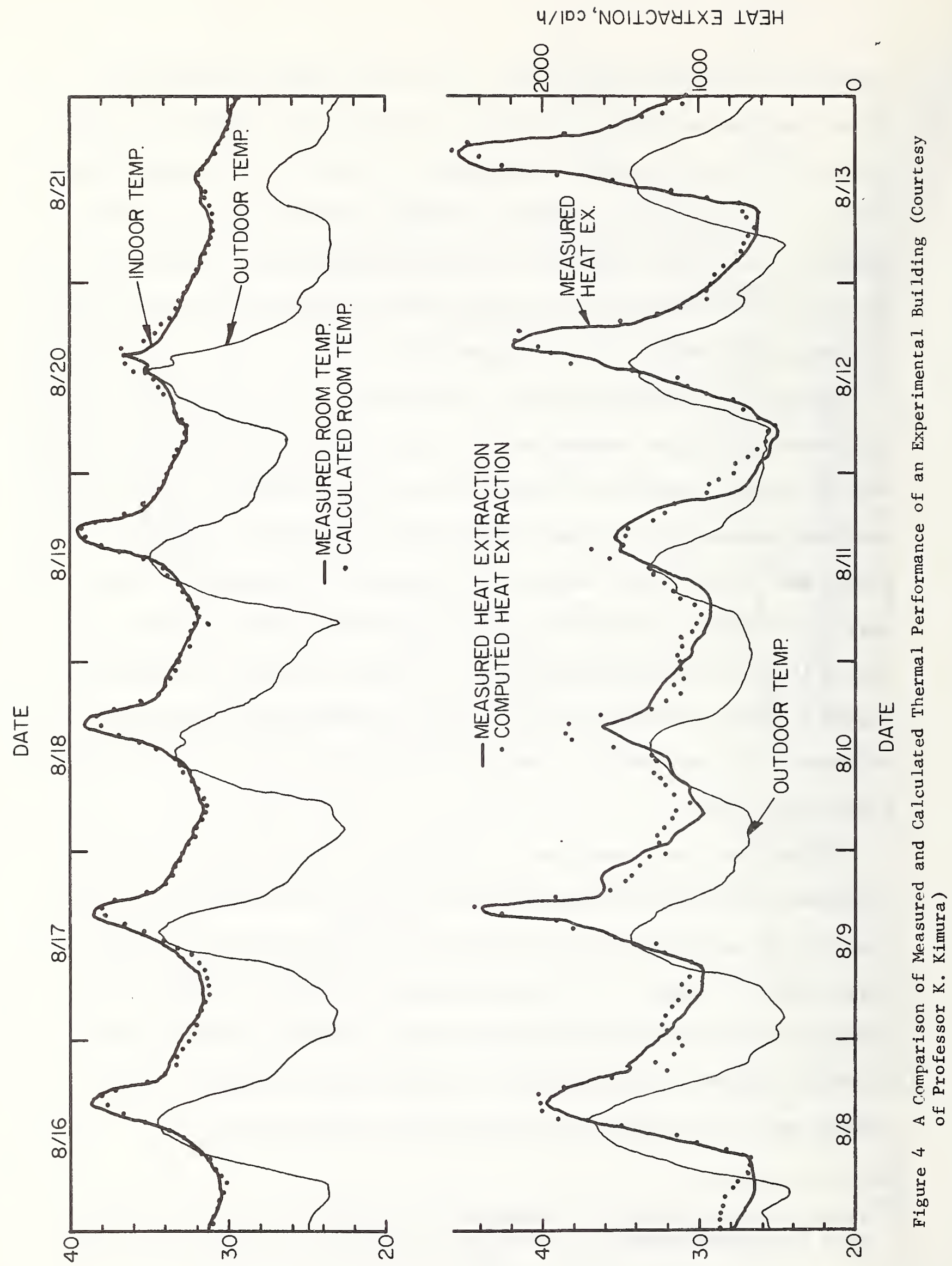

ว。‘ $\exists y \cap \perp \forall Y \exists d W \exists \perp$ 
3. Unique Features of NBS Load Calculation Computer Program

A comprehensive yet easy-to-use computer program for determining heating and cooling loads has been developed in the Thermal Engineering Systems Section of the Center for Building Technology at the National Bureau of Standards. This computer program is based upon extensive information accumulated over the past decades in various phases of building heat transfer problems, and is intended to be used for the design of equipment and air conditioning systems as we11 as for estimates of building energy requirements.

The major reason why NBS developed this comprehensive program is that despite the existence of numerous load calculation programs currently available, most of them are not suitable for the analysis of building designs where non-conventional or innovative ideas on structures, heating and cooling systems and controls are employed. Some of the unique aspects of building and system design and operation that can be handled by or studied by using NBSLD are:

1. Inside-out construction of exterior walls where the thermal insulation is placed on the outside of the building she11 as opposed to conventional walls having insulation on the inside. (These two walls could have the same $\mathrm{U}$-value and yet their thermal response would be quite different.)

2. Effect of interior partition walls or floor-ceiling sandwich structures on the heat storage characteristics of the room, 
3. Off-peak heating or cooling of buildings to shave the peak heating or cooling demand,

4. Evaluation of intentiona1ly undersized heating and cooling equipment by calculating the room temperature and humidity deviations from a design setpoint. (The results would indicate whether or not the indoor conditions would remain within acceptable limits.)

5. Evaluation of indoor thermal environment of various zones during the intermediate season, such as spring and autumn, when the heating or cooling requirements for these zones may not be in phase with that of the building as a whole. (This would apply to a case where a two-pipe system would be installed for example. The central system for the entire building might be switched to heating in late autumn and yet some zones, particularly those facing south may still require cooling. NBSLD can be used to determine the indoor thermal conditions of unheated or uncooled rooms.)

6. Use of solar energy for heating and cooling buildings as it relates to the thermal storage characteristics of the building,

7. Use of attic ventilation to reduce the cooling load since NBSLD can accurately predict attic temperatures,

8. Accurate determination of the need for heating and air conditioning in basement rooms, 
9. Design of heating and cooling systems and equipment on the basis of intermittent operation, such as the shutdown of air conditioning facilities during the nighttime or weekends,

10. Effective use of natural air conditioning such as ventilation, shading, increased ceiling insulation and the subsequent determination of the requirements for mechanical cooling,

11. Effective use of planned ventilation to minimize a building heating load during the winter season,

12. Accurate evaluation of indoor comfort conditions based upon air temperature, humidity and mean-radiant temperature,

13. Determination of the condition whereby moisture condensation takes place along interior surfaces of a building, and

14. The effect of interior furnishings of various simple shapes upon the heating and cooling loads.

Figure 5 depicts an overall calculation sequence to attain the hour by hour heating and cooling load of buildings. Shown in the double lined boxes are input data to be supplied whereas those in single lined boxes indicate calculations to be performed. The cycle indicators show the iteration cycles for the number of buildings, the number of rooms in a given building and the number of days for which the calculations are performed. More specific identification of the types of input data needed 


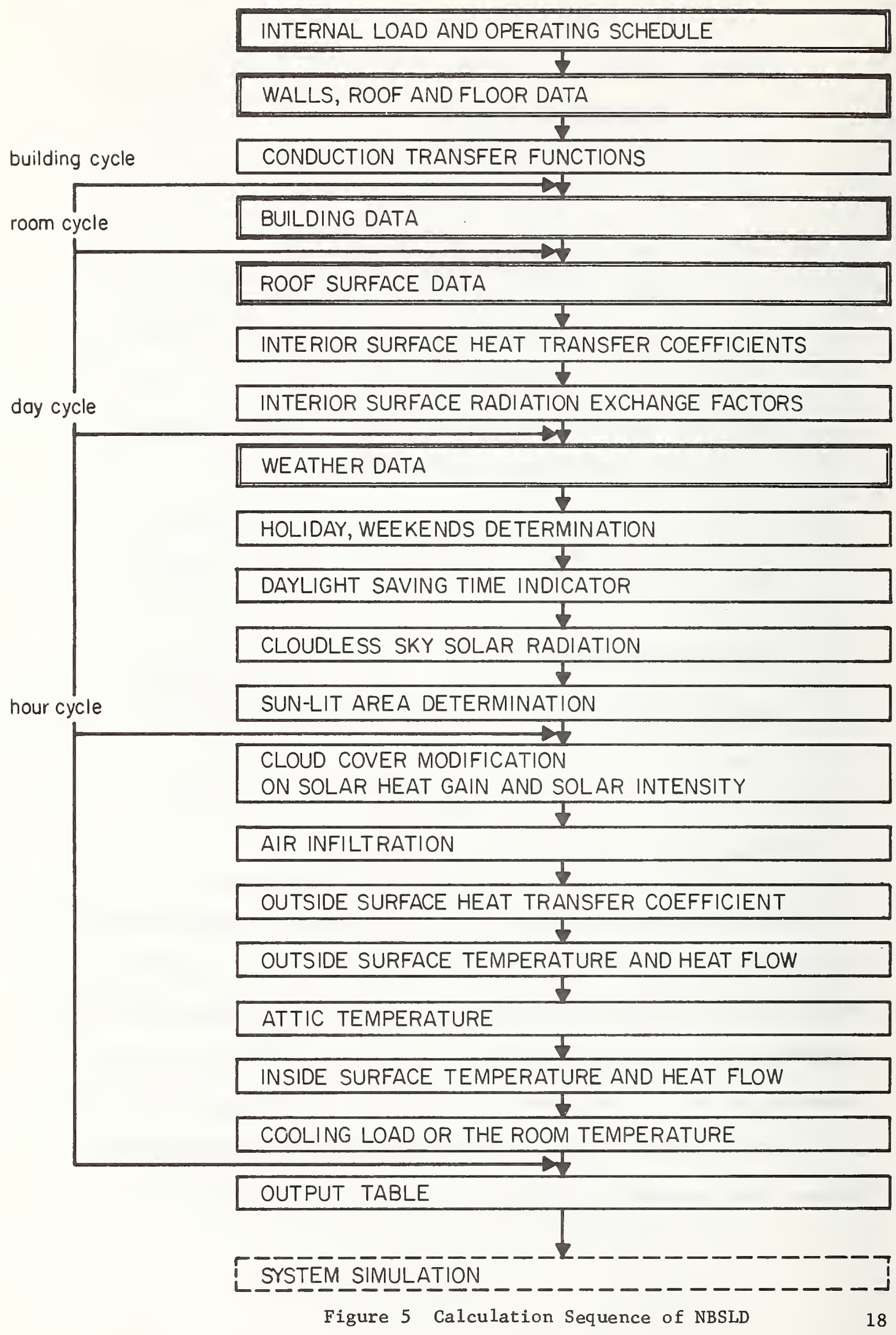




\section{INPUT - OPERATING DATA}

- ELECTRIC POWER TO LIGHTS, WATTS PER SQUARE FOOT OF FLOOR (QLITY)

- HOUR BY HOUR LIGHTING SCHEDULE (QLITX)

- ELECTRIC POWER TO EQUIPMENT, WATTS PER SQUARE FOOT OF FLOOR (QEQPX)

- HOUR BY HOUR EQUIPMENT SCHEDULE (QEQUX)

- SUPPLY AIR RATE (CFMS)

- AIR LEAKAgE RATE (CFML)

- SUPPLY AIR TEMPERATURE (TS)

Figure 6 
- ROOM NUMBER (ROOMNO)

- CEILING heIght (H)

- ROOM LENGTH (L)

- ROOM WIDTH (W)

- NUMBER OF OCCUPANTS (QCU)

- OCCUPANT SCHEDULE (QOCUP)

- WINTER WINDOW OVERALL HEAT TRANSFER COEFFICIENT (UGLAS)

- GROUND FLOOR HEAT TRANSFER COEFFICIENT (UG)

- SUMMER INFILTRATION, AIR CHANGES PER HOUR (ARCHGS)

- WINTER INFILTRATION, AIR CHANGES PER HOUR (ARCHGW)

- TYPE OF HEAT TRANSFER EXPOSURES (ITYPE)

-ROOFS-WALLS-WINDOWS-DOORS-FLOORS

- TYPE OF RESPONSE FACTORS TO BE USED (IRF) -HEAVY/LIGHT: ROOF, EXTERIOR WALIS, CEILING/FLOOR PARTITION

- U VALUE OF THE EXPOSURE (U) (ONLY WHEN RESPONSE FACTOR IS NOT CALCULATED)

- AREA OF tHe EXPOSURE (A)

- ORIENTATION OF THE EXPOSURE (AZW) -N,E,S,W (ONLY FOR EXTERNALLY EXPOSED SURFACES)

- WINDOW SHADING COEFFICIENT (SHADE)

- SOLAR HEAT ABSORPTION COEFFICIENT FOR THE EXTERIOR SURFACE (ABSP)

- TIME INCREMENT OF TEMPERATURE DATA USED

- PROPERTIES OF BUILDING MATERIALS - THICKNESS - THERMAL CONDUCTIVITY - DENSITY - SPECIFIC HEAT

- NUMBER OF SURFACES IN EACH WALL (NS,NW,NN,NE)

Figure 7 


\section{INPUT - WEATHER DATA}

- LATITUdE (LAT)

- LONGITUDE (LONG)

- TIME ZONE NUMBER (TZN)

- MONTH (MONTH)

- DAY (DAY)

- ELAPSED DAYS SINCE JANUARY 1 (ELAPS)

- MAXIMUM TEMPERATURE OF THE DESIGN DAY (DBMAX)

- DAILY TEMPERATURE RANGE OF THE DESIGN DAY (RANGE)

- DESIGN INDOOR TEMPERATURE CONDITION (DBIN)

- DESIGN OUTDOOR WET-BULB TEMPERATURE (WBMAX)

- DESIGN INDOOR WET-BULB TEMPERATURE (WBID)

- DESIGN WINTER OUTDOOR TEMPERATURE (DBMWT)

- DESIGN SUMMER GROUND TEMPERATURE (TG)

- DESIGN WINTER GROUND TEMPERATURE (TGW)

Figure 8 
are listed in Figures 6,7 and 8. The exact way the input data is put into the program is specified in Appendix C.

\section{General Description of NBSLD Subroutines}

In order to perform the chain of calculations depicted in Figure 5, a number of subroutines were developed at the National Bureau of Standards, the algorithms of which have already been published through the ASHRAE Task Group booklet entitled "Procedure for Determining Heating and Cooling Loads for the Computerized Energy Calculations". This booklet, however, contained several errors which have been corrected and is attached to this report as Appendix A. NBSLD incorporates most of the revised ASHRAE algorithms as they are written; however, some of them have been combined or split to fit the overall computational scheme in NBSLD. Listed below is a brief description of the NBSLD subroutines with their specific reference to the ASHRAE algorithms in parentheses.

1. $A B C D, A B C D P, A B C D 2, A B C D P 2, D E R V T, G P F, M U L T, R E S F$, RESFX, RESPTK: These routines are parts of the conduction transfer functions calculation package and are needed for the accurate evaluation of thermal time lag, damping, heat storage in exterior facing surfaces as well as the internal furnishings. (XYZ)

2. AIRCON: This routine is used to determine instantaneous values of the physiological indices for the space being studied such as ASHRAE's New Effective Temperature, Predicted Mean Vote (Fanger), Heat Stress Index, KSU Index, Resultant Temperature, Operative Tempera- 
ture, and Index of Thermal Stress (Givoni). - not included in the text

3. ATTIC: Attic space temperature and heat conduction through the ceiling into the room below are calculated by this routine for the vented or non-vented attics. (ATTIC)

4. CCM: This routine modifies the solar radiation computed for a cloudless sky by instantaneous cloud cover data. (CCF)

5. DPF: This routine calculates dew point temperature of atmospheric air when the partial vapor pressure is known. (PSY)

6. DST: This routine determines whether a given data is in a daylight saving time zone. The information is needed for the proper assignment of the energy usage schedule. (DST)

7. FCTR: This routine determines radiation exchange factors between any two surfaces which are part of a given room. For the room of six interior surfaces, for example, thirty radiation exchange factors are calculated. These factors are used in turn to determine the rate of heat exchange by radiation between all the interior surfaces. (FIJ)

8. F: This routine calculates radiation heat exchange factors (form factors) between two adjacent rectangular surfaces which are normal to each other, such as that between the floor and wall. (FIJ) 
9. FO: This routine calculates the surface heat transfer coefficients for externally exposed surfaces from weather data. (FO)

10. GLASS: This routine calculates solar heat gain through glass when the shading coefficient, orientation, and type of glass are given. (SHG)

11. HOLDAY: This routine identifies the national holidays in the United States so that the proper holiday schedule can be used for the energy calculation. (HOLIDAY)

12. OUTSID: This routine calculates the outside surface temperature and heat gain into the wall or roof by taking into account solar heating, back radiation to the sky, convective heat loss to the ambient air and transient heat conduction within the wall or roof. (HEATW)

13. PSY1: This is a psychrometric routine that determines the thermodynamic properties of moist air when the drybulb temperature, wet-bulb temperature and barometric pressures are given. (PSY)

14. PSY2: This routine is similar to PSYl except that the dew point temperature is required instead of the wetbulb temperature. (PSY)

15. PVSF: This routine determines the saturated vapor pressure of atmospheric air as a function of temperature. (PSY) 
16. RMTMP: This is the single most important subroutine of NBSLD since it determines the room temperature by solving matrix equations expressing a balance of heat gains, heat storage at the room surfaces, and cooling capacity of an air conditioning unit. However, the room temperature can be prescribed, in which case the routine will calculate the heating/cooling requirements to satisfy that prescribed temperature. (RMTMP)

17. ROOM: This routine reads in all the data required for the room heat transfer calculation such as dimensions, surface area, surface orientations, shading coefficients, surface solar absorptivity, etc.

18. SHG: This is the routine that calculates solar heat gain through glass. (SHG)

19. SOLVP: This routine solves the simultaneous linear algebraic equations that appear in RMTMP. (RMTMP)

20. SUN: Basic sun data such as solar angles, cloud cover, direct and diffuse radiation needed for solar heat gain and solar heating of the building exterior surfaces are calculated in this routine. (SUN, SOLAD)

21. TAR: This routine calculates transmission and absorption characteristics of glass. (TAR)

22. WBF: This is another psychrometric routine that calculates the wet-bulb temperature when the enthalpy of moist air and the barometric pressure are specified. (PSY) 
23. WKDAY: This subroutine determines the day of week when the date and year are given. The information is needed for the proper selection of energy usage schedules which are dependent upon whether the day is a weekday or not. (WKDAY)

24. WD, WDX, DECODE, ERROR, WEATHE: The weather data tape 1440 supplied by the National Climatic Center, Asheville, N. C. is prepared in a format which cannot be readily applicable in most of the Fortran programs. These routines are therefore necessary to read the 1440 tapes and decode them into meaningful weather parameters, which in turn can be used by UNIVAC 1108 Fortran of the National Bureau of Standards. If there are some data which are unreasonable, the data will be replaced by the arithmetic average of two adjacent data by the ERROR routine. (CLIMAT)

A11 the subroutines in the program may be used to form a separate main program for a specific job. Following are sample usages of some of the subroutines. 
1. Psychrometric Calculation

CALL PSY 1 (DB, WB, PB, DP, PV, W, H, V, RH)

where inputs are $\mathrm{DB}=\mathrm{dry}-\mathrm{bu} 1 \mathrm{~b}$ temperature

$$
\begin{aligned}
\mathrm{WB} & =\text { wet-bulb temperature } \\
\mathrm{PB} & =\text { barometric pressure } \\
\text { outputs are } \mathrm{DP} & =\text { dew point temperature } \\
\mathrm{PV} & =\text { vapor pressure } \\
\mathrm{W} & =\text { humidity ratio } \\
\mathrm{H} & =\text { enthalpy } \\
\mathrm{V} & =\text { volume } \\
\mathrm{RH} & =\text { relative humidity }
\end{aligned}
$$

There is also a routine called PSY2 (DB, DP, PB, WB, PV, $\mathrm{W}, \mathrm{H}, \mathrm{V}, \mathrm{RH}$ ) in which the inputs are $\mathrm{DB}, \mathrm{DP}$ and $\mathrm{PB}$ instead of $D B, W B$ and $P B$. In many cases $D B$ and $R H$ are the inputs and the vapor pressure and dew point temperature or the wet-bulb temperature at standard barometric pressure are the outputs. A possible algorithm that could be desired, for example, might be:

$$
\begin{aligned}
& \mathrm{PVS}=\mathrm{PVSF} \quad(\mathrm{DB}) \\
& \mathrm{PV}=\mathrm{PVS} * \mathrm{RH} / 100 \\
& \mathrm{DP}=\mathrm{DPF}(\mathrm{PV}) \\
& \mathrm{Ca} 11 \mathrm{PSY} 2(\mathrm{DB}, \mathrm{DP}, \mathrm{PB}, \mathrm{WB}, \mathrm{PV}, \mathrm{W}, \mathrm{H}, \mathrm{V}, \mathrm{RH})
\end{aligned}
$$




\section{Solar radiation}

Recently there has been increased interest in the application of solar energy for heating of hot water. SUN and GLASS routines should be valuable for evaluating various solar collectors at different locations in the United States at different times of the year. A sample use of these routines may be shown for a solar collector having the following characteristics (Figure 9)

$$
\begin{aligned}
& \text { location: latitude }=45^{\circ} \text {, longitude }=73^{\circ} \\
& \text { azimuth angle }=0^{\circ} \text { south } \\
& \text { tilt angle }=30^{\circ} \text { from horizontal surface } \\
& \text { area }=500 \mathrm{ft}^{2} \\
& \text { date }=\mathrm{July} 21 \\
& \text { time }=4: 00 \mathrm{p} \cdot \mathrm{m} . \\
& \text { glass cover }=\text { double sheet - clear glass } \\
& U_{\mathrm{R}}=\text { overall heat transfer coefficient between the collector } \\
& \quad \text { surface and the ambient, Btu/hr ft }{ }^{2}{ }^{\circ} \mathrm{F}^{*} \\
& \mathrm{U}_{\mathrm{W}}=\text { overall heat transfer coefficient between the collector } \\
& \quad \text { surface and water, which is being circulated under the } \\
& \quad \text { collector plate, Btu/hr ft }{ }^{2}{ }^{\circ} \mathrm{F}
\end{aligned}
$$$$
\text { TWI = water temperature entering the collector, }{ }^{\circ} \mathrm{F} \text {. }
$$$$
\text { TWL }=\text { water temperature leaving the collector, }{ }^{\circ} \mathrm{F}
$$$$
\text { GPM = water circulation rate in gallons per minute }
$$

When the collector temperature is less than $150^{\circ} \mathrm{F}$, the typical value of $U_{R}$ for a flat black collector with double glass cover may be 0.75 . The value increases to as much as 1.5 when the collector temperature is in the neighborhood of $300^{\circ} \mathrm{F}$. A special computer program is available for estimating the value of $U_{R}$ for various types of collectors. 
It is assumed that the collector is well insulated around the edges and its bottom.

The algorithm for the use of SUN and GLASS routines would then be:

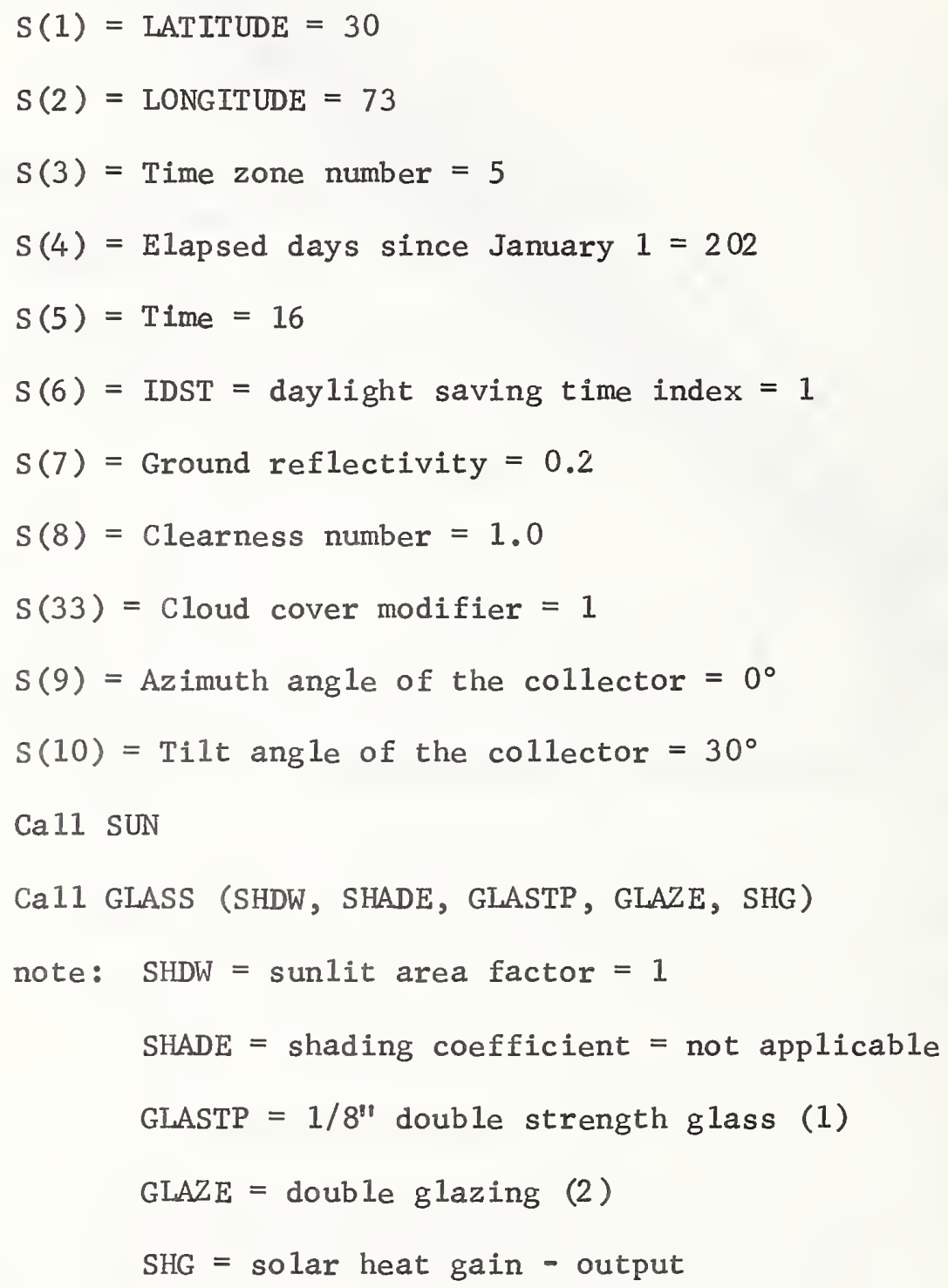


note: SUN and GLASS have $S$ in common using the solar heat gain through the glass plate; the following calculation would be needed to estimate TS, collector surface temperature and TWL, leaving water temperature from the collector:

$$
\begin{aligned}
& T S=\frac{U_{R} * D B+U_{W} * T_{W}+S H G}{U_{R}+U_{W}} \\
& T W L=T W I+(T S-T W I)\left(1-e^{-X}\right) \\
& \text { where } X=\frac{U_{W} * A}{500 * G P M}
\end{aligned}
$$

5. NBSLD Logic Diagram

Figure 10 shows the way in which the various subroutines of NBSLD fit together in the usage of the program. 


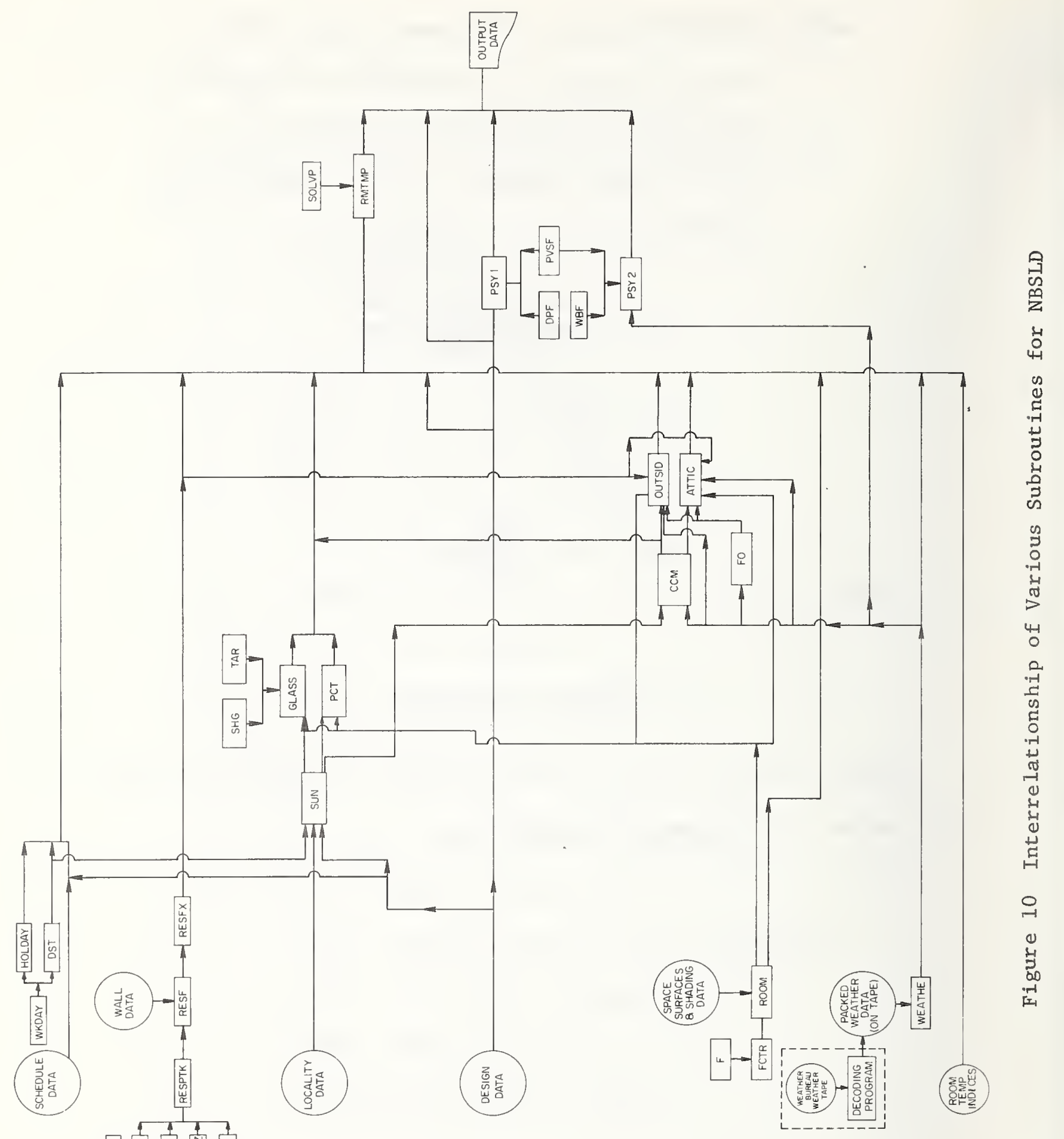




\section{References}

1. "Pattern of Energy Consumption in the United States", Stanford Research Institute Report, pp. 6-7, January 1972.

2. "Heating Load" and "Air-Conditioning Cooling Load", ASHRAE Handbook of Fundamentals, Chapters 21 and 22, pp. 375-445, 1972 .

3. Mitalas, G. P. and Stephenson, D. G., "Room Therma1 Response Factors", ASHRAE Transactions, 1967, Vo1. II, PP. III 2.1-2.10.

4. Buchberg, H., "Sensitivity of the Thermal Response of Buildings to Perturbations in the Climate", Building Science, Vol. 4, pp.43-61, Pergamon Press, 1969.

5. Mitalas, G. P., "An Experimental Check on the Weighting Factor Method of Calculating Room Cooling Load", ASHRAE Transactions, 1969, pp . 222232 .

6. Kusuda, T., Tsuchiya, T. and Powe11, F. J., "Prediction of Temperature by Using Equivalent Thermal Mass Response Factors", Proceedings of the 5 th Symposium on Temperature, National Bureau of Standards, 1971.

7. Kimura, K. and Ishino, H., "Air Conditioning Load Calculation by the Equivalent Mass Weighting Factor Method for the Computerized Control", Proceedings of the Japanese Architectural Society, pp. 249-250, Kyushu meeting, October 1972 and Proceedings for the Second Symposium on the Use of Computers for Thermal Engineering Related to Buildings, COSTIC, 1974. 

7. Appendix A

Subroutine Algorithms Prepared for the ASHRAE Task Group on Energy Requirements 



\section{CLIMAT}

A Procedure for Obtaining Climatic Weather Data

Climatic parameters needed for the hourly load calculations are:

DB: Dry-bulb temperature, F

DP or WB: Dew point or wet-bulb temperature, F

CT: Cloud type

TC: Total cloud amount

V: Wind speed, knots

DIR: Wind direction (clockwise from North), degrees

PB: Barometric Pressure, in. $\mathrm{Hg}$

ID: Direct' Solar Radiation, Btu per (hr) (sq ft)

$I_{d, s k y}:$ Sky diffuse radiation, Btu per (hr) (sq ft)

$I_{d, g r o u n d}:$ Ground diffuse radiation, Btu per (hr) (sq ft)

Rain, Snowfall: Precipitation data (Optional)

Hourly observations of these weather parameters for past years are available from the National Climatic Center either on magnetic tape or in card deck form. The hourly solar radiation data has been recorded for only approximately fifty stations throughout the United States (Table $\mathrm{A}-1$ ). These data are, moreover, limited in their durations and completeness, and scarcely useful for the comprehensive energy analysis. On the other hand, the data series 144 includes the hourly observations of all of the parameters listed above except the solar radiation for more than 300 weather stations (Table A-2) covering a period of from ten to thirty years. Since the 144 series data are very much complete, it is 
recommended that hour by hour energy calculations be made with this series of data supplemented by simulated solar radiation data. A method for simulating solar radiation will be described later in this booklet.

Because of the specific coding scheme employed by the National Climatic Center for storing the hourly weather data onto the magnetic tapes, the 144 series is not directly usable by the standard Fortran programs. Different computing systems such as IBM 370, CDC 6600 and UNIVAC 1108 have their own decoding routines to read these tapes. Included in this section is a listing of a Fortran program which illustrates a decoding scheme required to make use of the weather tapes. This listing was prepared by Mr. McKay, Data Reduction Section, of the National Climatic Center, Asheville, North Carolina.

For further information on the procurement of weather tapes and possible assistance in decoding, the following office may be contacted:

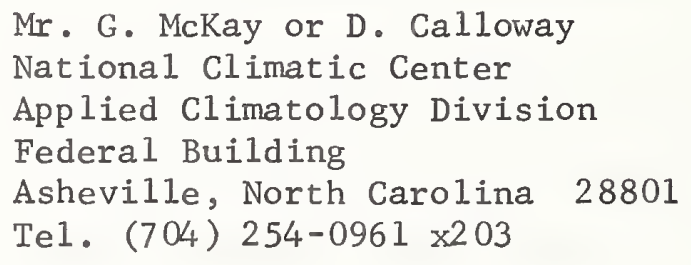




\author{
Albuquerque, New Mexico \\ Apalachicola, Florida \\ Barrow, Alaska \\ Bethe1, Alaska \\ Bismark, North Dakota \\ Blue Hill/Milton, Massachusetts \\ Boston, Massachusetts \\ Brownsville, Texas \\ Canton Is land \\ Cape Hatteras, North Carolina \\ Caribou, Maine \\ Charleston, South Carolina \\ Cleveland, Ohio \\ Columbia, Missouri \\ Dodge City, Kansas \\ E1 Paso, Texas \\ Ely, Nevada \\ Fairbanks, Alaska \\ Fort Worth, Texas \\ Fort Worth, Texas \\ Fresno, California \\ Grand Lake/Granby, Colorado \\ Great Falls, Montana \\ Hatteras, North Carolina \\ Inyokern, California
}

Lake Charles, Louisiana

Lake Charles, Louisiana

Lincoln, Nebraska

Lincoln, Nebraska

Los Angeles, Cali fornia

Madison, Wisconsin

Matanuska, Alaska

Medford, Oregon

Miami, Florida

Nashville, Tennessee

New York, New York

Oak Ridge, Tennessee

Omaha, Nebraska (North Omaha) Phoenix, Arizona

Riverside, California

Santa Maria, California

Santa Maria, California

Sault Ste. Marie, Michigan

Seattle, Washington

Sterling, Virginia

Tucson, Arizona

Upton, New York

Wake Island

Washington, D. C. 


\section{U.S. DEPARTMENT OF COMMERCE \\ NATIONAL OCEANIC AND ATMOSPHERIC ADMINISTRATION ENVIRONMENTAL DATA SERVICE}

Stations for which Local Climatological Data are issued, as of January 1, 1972

\begin{tabular}{|c|c|c|c|c|c|}
\hline & ALABAMA & & FLOR IDA & & MASSACHUSETTS \\
\hline$a b c$ & Birmingham & $a c$ & Apalachicola & $a b c$ & Boston \\
\hline$a b c$ & Huntsville & $a b c$ & Day tona Beach & ac & Blue Hill Obs. \\
\hline$a b c$ & Mobile & $a b c$ & Fort Myers & $a b c$ & Worcester \\
\hline \multirow[t]{3}{*}{ abc } & Montgomery & $a b c$ & Jacksonville & & \\
\hline & & $a b c$ & Key West & & MICHIGAN \\
\hline & ALASKA & $a c$ & Lake land & $a b c$ & Alpena \\
\hline$a b c$ & Anchorage & $a b c$ & Miami & & Detroit \\
\hline$a b c$ & Annet te & $a b c$ & Orlando & abc & City Airport \\
\hline$a b c$ & Barrow & $a b c$ & Pensacola & $a b c$ & Detroit Metro AP \\
\hline$a b c$ & Barter Island & $a b c$ & Tallahassee & $a b c$ & Flint \\
\hline$a b c$ & Bethe 1 & $a b c$ & Tampa & $a b c$ & Crand Rapids \\
\hline$a b c$ & Bettles & $a b c$ & West Palm Beach & $a b c$ & Houghton Lake \\
\hline$a b c$ & Big Delta & & & $a b c$ & Lansing \\
\hline$a b c$ & Cold Bay & & GEORCIA & ac & Marquette \\
\hline$a b c$ & Fairbanks & $a b c$ & Athens & $a b c$ & Muskegon \\
\hline$a b c$ & Gulkana & $a b c$ & Atlanta & $a b c$ & Sault Ste. Marie \\
\hline$a b c$ & Homer & $a b c$ & Augusta & & \\
\hline$a b c$ & Juneau & $a b c$ & Columbus & & MINNESOTA \\
\hline$a b c$ & King Salmon & $a b c$ & Macon & $a b c$ & Duluth \\
\hline$a b c$ & Kotzebue & ac & Rome & $a b c$ & International Falls \\
\hline$a b c$ & McGrath & $a b c$ & Savannah & $a b c$ & Minneapolis-St. Paul \\
\hline abc & Nome & & & $a b c$ & Rochester \\
\hline$a b c$ & St. Paul Island & & HAWAII & abc & St. Cloud \\
\hline$a b c$ & Shemya & $a b c$ & Hilo & & \\
\hline$a b c$ & Sumnit & $a b c$ & Honolulu & & MISSISSIPPI \\
\hline abc & Talkeetna & $a b c$ & Kahului & $a b c$ & Jackson \\
\hline$a b c$ & Unalakleet & $a b c$ & Lihue & $a b c$ & Meridian \\
\hline \multirow[t]{3}{*}{$a b c$} & Yakutat & & & & \\
\hline & & & IDAHO & & MISSOURI \\
\hline & ARIZONA & $a b c$ & Boise & $a b c$ & Columbia \\
\hline$a b c$ & Flagstaff & $a b c$ & Lewiston & $a b c$ & Kansas City \\
\hline$a b c$ & Phoenix & $a b c$ & Pocatello & $a b c$ & St. Joseph \\
\hline$a b c$ & Tucs on & & & $a b c$ & St. Louis \\
\hline$a b c$ & Winslow & & ILLINOIS & $a b c$ & Spring field \\
\hline \multirow[t]{2}{*}{$a b c$} & Yuma & ac & Cairo & & \\
\hline & ARKANSAS & $a b c$ & & & MONTANA \\
\hline$a b c$ & $\begin{array}{l}\text { ARKANSAS } \\
\text { Fort Smith }\end{array}$ & $a b$ & $\begin{array}{l}\text { Midway Alrport } \\
\text { O'Hare Airport }\end{array}$ & $a b c$ & Billings \\
\hline \multirow[t]{3}{*}{$a b c$} & Little Rock & $a b c$ & $\begin{array}{l}\text { OHare Airport } \\
\text { Moline }\end{array}$ & $\begin{array}{l}a b c \\
a b c\end{array}$ & Clas gow \\
\hline & & $a b c$ & Reoria & $a b c$ & $\begin{array}{l}\text { Great Falls } \\
\text { Havre }\end{array}$ \\
\hline & CALIFORNIA & $a b c$ & Rockford & $a b c$ & Helena \\
\hline$a b c$ & Bakersfield & $a b c$ & Springfield & $a b c$ & Kalispell \\
\hline$a b c$ & Bishop & & & $a b c$ & Miles City \\
\hline ac & Blue Canyon & & INDIANA & $a b c$ & Missoula \\
\hline ac & Eureka & $a b c$ & Evansville & & \\
\hline$a b c$ & Fresno & $a b c$ & Fort Wayne & & NEBRASKA \\
\hline$a b c$ & Long Beach & $a b c$ & Indianapolis & $a b c$ & Crand Is land \\
\hline$a b c$ & Los Angeles Airport & $a b c$ & South Bend & ac & Lincoln \\
\hline \multirow[t]{2}{*}{ ac } & Los Angeles & & & $a b c$ & Nor folk \\
\hline & Civic Center & & IOWA & $a b c$ & North Platte \\
\hline$a b c$ & Mt. Shasta & $a b c$ & Bur lington & $a b c$ & Omaha \\
\hline$a b c$ & Oakland & $a b c$ & Des Moines & $a b c$ & Scottsbluff \\
\hline$a b c$ & Red Bluff & $a b c$ & Dubuque & ac & Valentine \\
\hline$a b c$ & Sacramento & $a b c$ & Sioux City & & \\
\hline$a b c$ & Sandberg & $a b c$ & Water 100 & & NEVA DA \\
\hline \multirow[t]{2}{*}{$a b c$} & San Diego & & & $a b c$ & Elko \\
\hline & San Francisco & & KANSAS & $a b c$ & Ely \\
\hline$a b c$ & Airport & $a b c$ & Concordia & $a b c$ & Las Vegas \\
\hline ac & City & $a b c$ & Dodge City & $a b c$ & Reno \\
\hline$a b c$ & Santa Maria & $a b c$ & Coodland & $a b c$ & Winnemucca \\
\hline$a b c$ & Stockton & $a b c$ & Topeka & & \\
\hline & & $a b c$ & wichita & & NEW HAMPSHIRE \\
\hline & COLORADO & & & $a b c$ & Concord \\
\hline$a b c$ & Alamosa & & KENTUCKY & ac & Mt. Washington \\
\hline$a b c$ & Colorado Springs & $a b c$ & Lexington & & \\
\hline$a b c$ & Denver & $a b c$ & Louisville & & NEW JERSEY \\
\hline$a b c$ & Crand Junction & & & & At lantic City \\
\hline$a b c$ & Pueblo & & LOUISIANA & $a b c$ & Airport \\
\hline & & $a b c$ & Alexandria & a & State Marina \\
\hline & DONNECTICUT & $a b c$ & Baton Rouge & $a b c$ & Newark \\
\hline$a b c$ & Bridgeport & $a b c$ & Lake Charles & ac & Trenton \\
\hline$a b c$ & Hartford & $\begin{array}{l}a b c \\
a b c\end{array}$ & $\begin{array}{l}\text { New orleans } \\
\text { Shreveport }\end{array}$ & & 11,inton \\
\hline & DELAWARE & & Shre ve port & & NEW MEXICO \\
\hline$a b c$ & Wilmington & & MAINE & $a b c$ & Albuquerque \\
\hline & & $a b c$ & Caribou & ac & Clayton \\
\hline & DISTRICT OF COLUMBIA & $a b c$ & Portland & $a b c$ & Roswe 11 \\
\hline$a b c$ & Washingt on-National AP & & & & \\
\hline$a b c$ & Washington-Dulles Int'l AR & & MARYZAND & & NEW YORK \\
\hline & & $a b c$ & Baltimore & $a b c$ & Albany \\
\hline & & & & $a b c$ & Binghawton \\
\hline
\end{tabular}

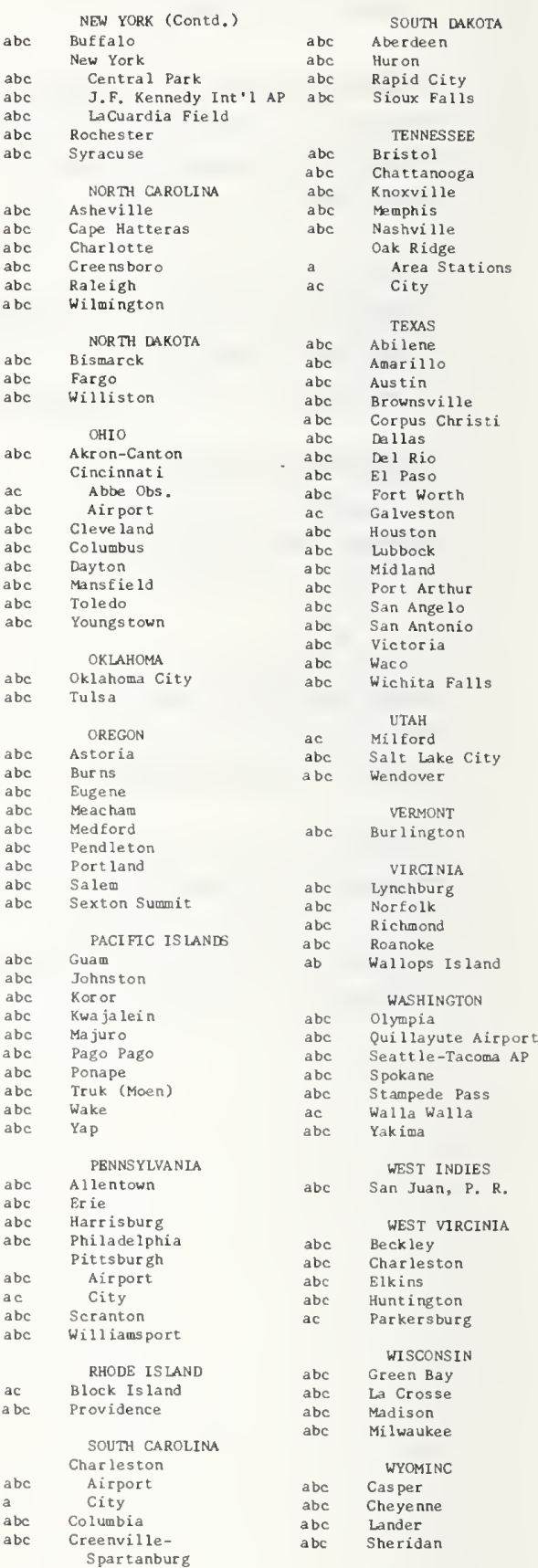


C THIS SUBROUTINE WILL TEST ANY PSYCHROMETRIC WITH A SIGN

C OVER UNITS POSITION READ AS A1 AND THE HIGH ORDER POSITION

C AS AN I SPEC OF PROPER WIDTH.

C THE SIGN SHOULD ENTER THE PARAMETER LIST AS ISGN,

C THE REMAINING PORTION AS IFLD.

C UPON RETURN FROM THIS ROUTINE, THE VALUE OF THE FIELD

C WILL BE AN INTEGER WITH PROPER SIGN.

C IT WILL BE THE USER RESPONSIBILITY TO CONVERT THIS TO REAL

C FORM WITH PROPER DECIMAL ALIGNMENT.

C INVALID CONDITION CAUSED IFLD TO BE SET TO 9999

DIMENSION IP (10), MIN (10), NUM(10)

DATA IP/'A', 'B', 'C', 'D', 'E', 'F', 'G', 'H', 'I', 'ø']

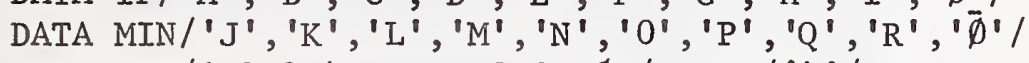

DATA NUM/ $1,2,3,4,5,6,7,8,9, \emptyset /$, IAST / $* 1 /$

IF (ISGN.EQ.IAST) GO TO 16

DO $14 \mathrm{~K}=1,10$

IF (ISGN.EQ. IP (K)) GO TO 20

IF (ISGN.EQ.MIN (K)) GO TO 22

14 CONTINUE

16 IFLD+9999

RETURN

20 IFLD $=$ IFLD $* 10+N U M(K)$

RETURN

22 IFLD $=-($ IFLD $* 10+N U M(K))$

RETURN

END 
An Algorithm to Find Solar Position, and Intensity of Direct Normal and Diffuse Radiation

SOLAR AZIMUTH, SAZM
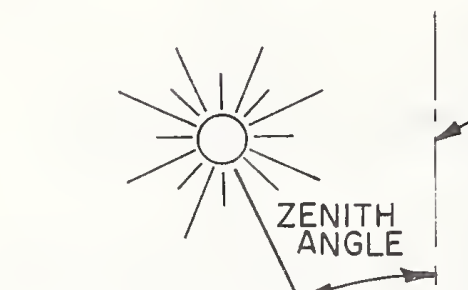

NORMAL TO HORIZONTAL SURFACE

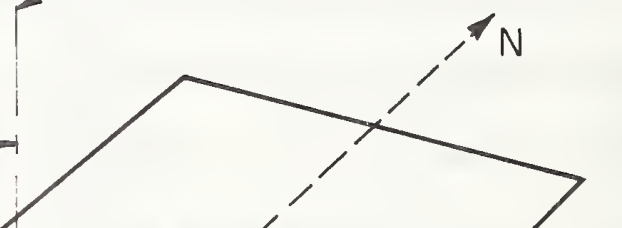

SOLAR ALTITUDE, SALT

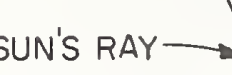

INCIDENT ANGLE, CONSIDERATION HORIZONTAL SURFACE

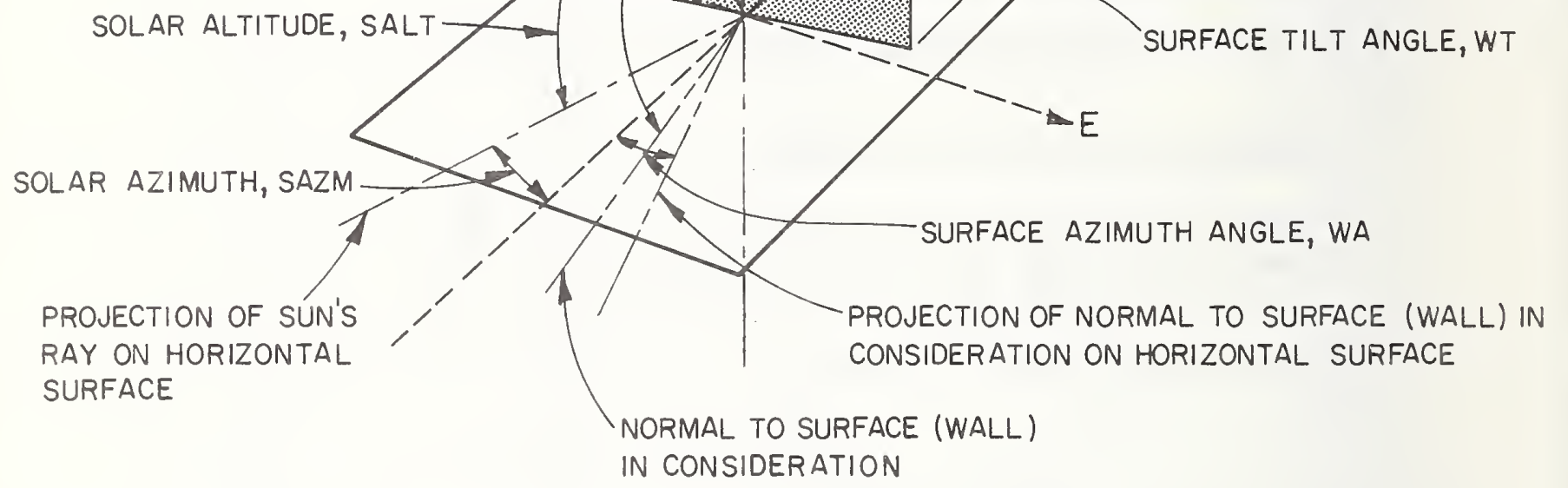

Figure A-1 Solar Angles for Tilted and Horizontal Surfaces 
Figure A-1 DEFINITIONS OF SOLAR ANGLE

\section{Data:}

L: Latitude, degrees, $\left[\begin{array}{l}\text { +North } \\ - \text { South }\end{array}\right]$

$\ell$ : Longitude, degrees, $\left[\begin{array}{l}\text { Hest } \\ \text {-East }\end{array}\right.$

TZN: Time zone number (hours behind Greenwich mean time), (see Figure $A-3$ and Table $A-4$ )

d: Date, days (from start of year), (1 - 366)

$t:$ Time, hours (after midnight), $(0-24)$

DST: Daylight saving time indicator (Output of DST), 0 for standard time and 1 for daylight saving time $\rho_{\mathrm{g}}:$ Ground reflectivity

$\mathrm{CN}$ : Clearness number (see Figure A-4) 


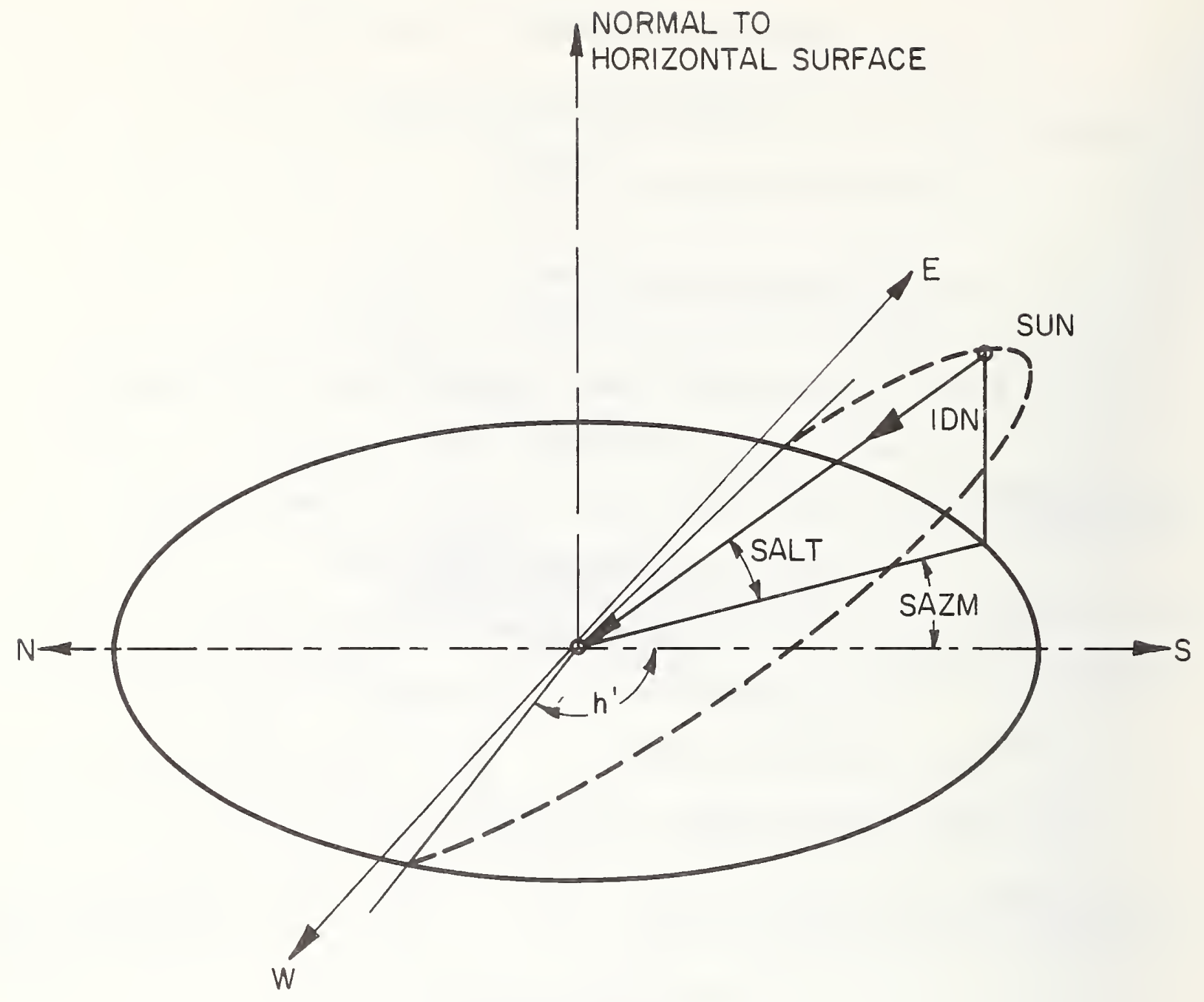

Figure A-2 Schematic Showing Apparent Path of Sun and Hour Angle 


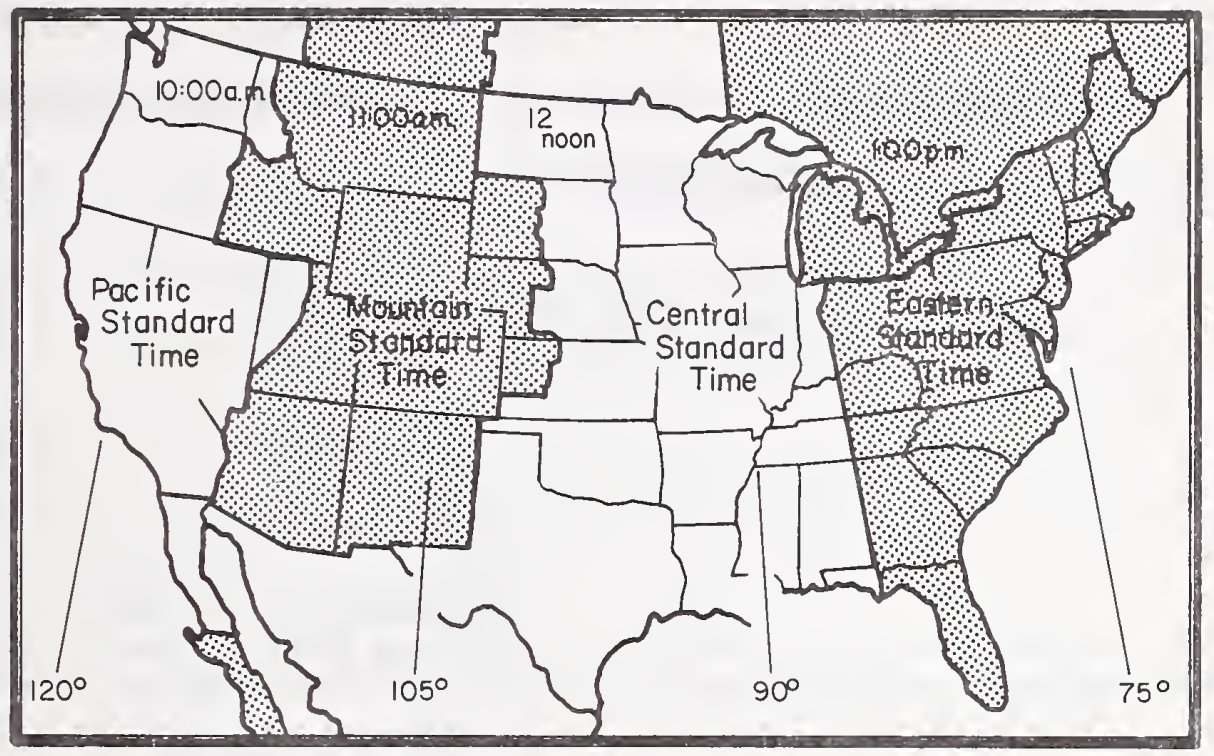

Table A-3 Time Zone Numbers in U. S. for Standard Time

\begin{tabular}{|l|c|}
\hline TIME ZONE & TZN \\
\hline At lantic & 4 \\
Eastern & 5 \\
Centra1 & 6 \\
Mountain & 7 \\
Pacific & 8 \\
\hline
\end{tabular}

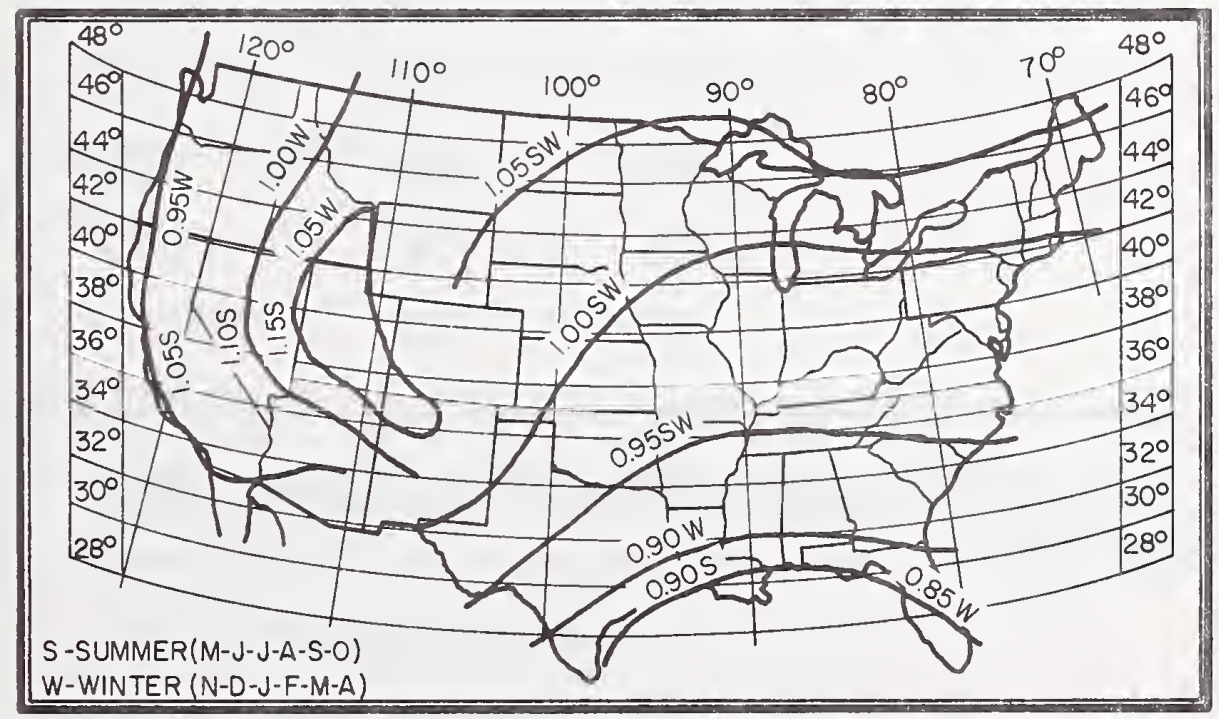

Figure A-4 Clearness Numbers of Non-Industrial Atmosphere in United States 
Table A-4 lists, as function of date, five variables related to solar radiation. These variables are declination angle, $\delta$; the equation of time, ET; the apparent solar constant, $A$; the atmospheric extinction coefficient, B; the sky diffuse factor, $C$.

TABLE A-4 VALUES OF $\delta$, ET, A, B AND $C^{*}$

A $\quad$ B $\quad$ C

\begin{tabular}{|c|c|c|c|c|c|}
\hline Date & $\begin{array}{c}\delta \\
\text { Degrees }\end{array}$ & $\begin{array}{l}\text { ET } \\
\text { Hours }\end{array}$ & $\begin{array}{l}\text { Btu Per } \\
(h r) \text { (sq } f t)\end{array}$ & Mass $^{-1}$ & \\
\hline Jan. 21 & -20.0 & -.190 & 390 & 0.142 & 0.058 \\
\hline Feb. 21 & -10.8 & -.230 & 385 & 0.144 & 0.060 \\
\hline Mar. 21 & 0.0 & -.123 & 376 & 0.156 & 0.071 \\
\hline Apr. 21 & 11.6 & .020 & 360 & 0.180 & 0.097 \\
\hline May 21 & 20.0 & .060 & 350 & 0.196 & 0.121 \\
\hline June 21 & 23.45 & -.025 & 345 & 0.205 & 0.134 \\
\hline July 21 & 20.6 & -.103 & 344 & 0.207 & 0.136 \\
\hline Aug. 21 & 12.3 & -.051 & 351 & 0.201 & 0.122 \\
\hline Sept. 21 & 0.0 & .113 & 365 & 0.177 & 0.092 \\
\hline Oct. 21 & -10.5 & .255 & 378 & 0.160 & 0.073 \\
\hline Nov. 21 & -19.8 & .235 & 387 & 0.149 & 0.063 \\
\hline Dec. 21 & -23.45 & .033 & 391 & 0.142 & 0.057 \\
\hline
\end{tabular}

* Derived from the 1972 ASHRAE Handbook of Fundamentals, Table 1, p. 387 , Chapter 22 . 


\section{Calculation Sequence:}

1. Determine $\delta$, ET, A, B, and C from Table A-4

2. $h^{\prime}=\cos ^{-1}(-\operatorname{TAN}(L) * \operatorname{TAN}(\delta)$ ) (see Figure A-2)

3. $Y=h^{\prime} * 12 / \pi$

4. Sunrise time (SRT) and sunset time (SST) in hr

$$
\begin{aligned}
& \mathrm{SRT}=12-\mathrm{Y}-\mathrm{ET}-\mathrm{TZN}+\ell / 15 \\
& \mathrm{SST}=2 \overline{4}-\mathrm{SRT}
\end{aligned}
$$

5. Hour angle $h$ in degrees

$$
h=15 *(t-12+T Z N+E T)-\ell
$$

If $/ \mathrm{h} />/ \mathrm{h}^{\prime} /$ skip all the remaining calculations in this

$$
\begin{aligned}
& \text { sequence and set } \\
& \text { IDN }=0 \\
& B S=0 \\
& B G=0
\end{aligned}
$$

6. Direction cosines of direct solar beam

$$
\begin{aligned}
& \operatorname{COS}(\mathrm{Z})=\operatorname{SIN}(\mathrm{L}) * \operatorname{SIN}(\delta)+\cos (\mathrm{L}) * \cos (\delta) * \cos (\mathrm{h}) \\
& \operatorname{COS}(\mathrm{W})=\cos (\delta) * \operatorname{SIN}(\mathrm{h}) \\
& \cos (\mathrm{S})=(1-(\operatorname{Cos}(\mathrm{Z})) * * 2-(\operatorname{COS}(\mathrm{W})) * * 2) * 0.5 \\
& \text { If } \cos (\mathrm{h})>\operatorname{TAN}(\delta) / \operatorname{TAN}(\mathrm{L}), \cos (\mathrm{S}) \text { is positive }
\end{aligned}
$$

7. Solar altitude angle in radians

$$
\operatorname{SALT}=\operatorname{SIN}^{-1}(\operatorname{COS}(\mathrm{Z}))
$$

8. Solar azimuth angle in radians

$$
\begin{aligned}
& \operatorname{SAZM}=\operatorname{SIN}^{-1}(\operatorname{COS}(\mathrm{W}) / \operatorname{COS}(\operatorname{SALT})) \text {, if } \operatorname{COS}(\mathrm{S})>0 \\
& \operatorname{SAZM}=\pi-\mathrm{SIN}^{-1}(\operatorname{COS}(\mathrm{W}) / \operatorname{COS}(\operatorname{SALT})) \text {, if } \operatorname{COS}(\mathrm{S})<0
\end{aligned}
$$

9. Intensity of direct solar radiation for a cloudless condition

$$
\operatorname{IDN}=A * \operatorname{CN} * \operatorname{Exp}(-B / \operatorname{COS}(Z))
$$


10. Diffuse sky radiation (sky brightness) for a cloudless condition

$$
\mathrm{BS}=\mathrm{C} * \mathrm{IDN} /(\mathrm{CN}) * 2
$$

11. Ground reflected radiation for a cloudless condition (ground brightness )

$$
B G=\rho_{g} *(B S+I D N * \cos (Z))
$$

\section{Calculation Modification for Southern Hemisphere:}

The preceding algorithm is applicable to the northern hemisphere only. For buildings in the southern hemisphere, the following modifications are required.

1. Shift values of $B$ and $C$ in Table $A-4$ by six months. Values of $\delta$, ET, A, B and $C$ for the southern hemisphere are shown in Table $\mathrm{A}-5$. 
A $\quad$ B $\quad$ C

\begin{tabular}{|c|c|c|c|c|c|}
\hline Date & $\begin{array}{c}\delta \\
\text { Degrees }\end{array}$ & $\begin{array}{c}\text { ET } \\
\text { Hours }\end{array}$ & $\begin{array}{l}\text { Btu per } \\
(\mathrm{hr})(\mathrm{sq} \mathrm{ft})\end{array}$ & $\begin{array}{l}\text { Air }-1 \\
\text { Mass }^{-1}\end{array}$ & \\
\hline Jan. 21 & -20.0 & -.190 & 390 & 0.207 & 0.136 \\
\hline $\mathrm{Feb} \cdot 21$ & -10.8 & -.230 & 385 & 0.201 & 0.122 \\
\hline Mar. 21 & 0.0 & -.123 & 376 & 0.177 & 0.092 \\
\hline Apr. 21 & 11.6 & .020 & 360 & 0.160 & 0.073 \\
\hline May 21 & 20.0 & .060 & 350 & 0.149 & 0.063 \\
\hline June 21 & 23.45 & -.025 & 345 & 0.142 & 0.057 \\
\hline July 21 & 20.6 & -.103 & 344 & 0.142 & 0.058 \\
\hline Aug. 21 & 12.3 & -.051 & 351 & 0.144 & 0.060 \\
\hline Sept. 21 & 0.0 & .113 & 365 & 0.156 & 0.071 \\
\hline Oct. 21 & -10.5 & .255 & 378 & 0.180 & 0.097 \\
\hline Nov. 21 & -19.8 & .235 & 387 & 0.196 & 0.121 \\
\hline Dec. 21 & -23.45 & .033 & 391 & 0.205 & 0.134 \\
\hline
\end{tabular}


If $L \geq 0$ and if $\operatorname{Cos}(h)>(\operatorname{Tan}(\delta) / \operatorname{Tan}(L)), \operatorname{Cos}(s)$ is positive, and if $\operatorname{Cos}(\mathrm{h}) \leq(\operatorname{Tan}(\delta) / \operatorname{Tan}(\mathrm{L})), \operatorname{Cos}(\mathrm{s})$ is negative.

If $\mathrm{L}<0$ and if $\operatorname{Cos}(\mathrm{h}) \leq(\operatorname{Tan}(\delta) / \operatorname{Tan}(\mathrm{L})), \operatorname{Cos}(\mathrm{s})$ is positive, if $\operatorname{Cos}(h)>(\operatorname{Tan}(\delta) / \operatorname{Tan}(\mathrm{L})), \operatorname{Cos}(\mathrm{s})$ is negative. 
An Algorithm for the Calculation of Cloudy Day Solar Radiation

This routine estimates the factor called CCF to modify the total solar radiation on a horizontal surface with the observed cloud cover data for a cloudy sky condition. The cloud cover observations are made every hour at major weather stations by experienced observers who estimate the amount of cloud on a scale of 0 to 10 and indicate the type of cloud in four different layers. Kimura and Stephenson ${ }^{1 /}$ analyzed 1967 Canadian data for observed solar radiation with respect to the cloud cover data, type of cloud, and the calculated solar radiation under a cloudless condition at the same solar time. Based upon their analysis, a comprehensive methodology was developed for calculating the cloudy day solar radiation. The value of CCF, Cloud Cover Factor, is first defined as follows:

$$
\mathrm{CCF}=\mathrm{ITHC} / \mathrm{ITH}
$$

where

ITHC: Total solar radiation on a horizontal surface under a cloudy sky of given cloud amount and types of cloud

ITH: Total solar radiation calculated for a horizontal surface under a cloudless sky at the same solar hour as of ITHC 
IS : Season index

$\mathrm{CA}_{\mathrm{j}}$ : Cloud amount at the $\mathrm{j}$-th layer, where $\mathrm{j}=1,2,3$, and 4 TOC $_{j}$ : Type of cloud at the $j$-th layer, where $j=1,2,3$, and 4 TCA: Tota1 cloud amount

\section{Calculation Sequence:}

1. $X=\left(\Sigma C A_{j}\right)_{\text {cirrus }}+\left(\Sigma C A_{j}\right)_{\text {cirrostratus }}+\left(\Sigma C A_{j}\right)_{\text {cirrocumulus }}$

2. Cloud cover

$\mathrm{CC}=\mathrm{TCA}-0.5 * \mathrm{X}$

3. Cloud cover factor

$\mathrm{CCF}=\mathrm{P}+\mathrm{Q} * \mathrm{CC}+\mathrm{R} * \mathrm{CC} * 2$

where $P, Q$, and $R$ are found in the following table

Table A-6

\begin{tabular}{lccc} 
Season & $\mathrm{P}$ & $\mathrm{Q}$ & $\mathrm{R}$ \\
\hline spring & 1.06 & 0.012 & -0.0084 \\
summer & 0.96 & 0.033 & -0.0106 \\
autumn & 0.95 & 0.030 & -0.0108 \\
winter & 1.14 & 0.003 & -0.0082 \\
\hline
\end{tabular}

The value of $P$, which is essentially the cloudless sky factor, depends upon the proportion of direct to diffuse sky radiation in reference to the standard ASHRAE values published in the 1972 Handbook of Fundamentals. If the value of $P$ is unity, this proportion of direct to diffuse solar radiation is such that the solar radiation evaluated for a hori- 
zontal surface under a cloudless sky should be equal to the value obtained by the method described in the 1972 ASHRAE Handbook of Fundamentals. If the value of $\mathrm{P}$ is different from unity, the direct to diffuse proportion is different from the standard values. 


\section{SOLAD}

An Algorithm for Determining Diffuse and Direct Radiation Falling Onto a Surface

This routine determines the total as well as the diffuse and direct components of solar radiation incident on a given surface under either clear or cloudy sky by using the cloudless sky data calculated in the SUN routine and the cloud cover factor CCF calculated as described in the previous section.

\section{Data:}

P: Cloudless sky factor shown in Table (A-6) in the CCF routine

C: Standard diffuse sky factor shown in Table A-4 in the SUN routine

CC: Cloud cover calculated in the $\mathrm{CCF}$ routine CCF: Cloud cover factor determined by the CCF routine WA: Azimuth angle of the surface under consideration in radians from south; + if west and - if east of south

WT: Tilt angle of the surface under consideration in radians from the horizontal surface; zero for the horizontal surface and $\pi / 2$ for the vertical walls. 


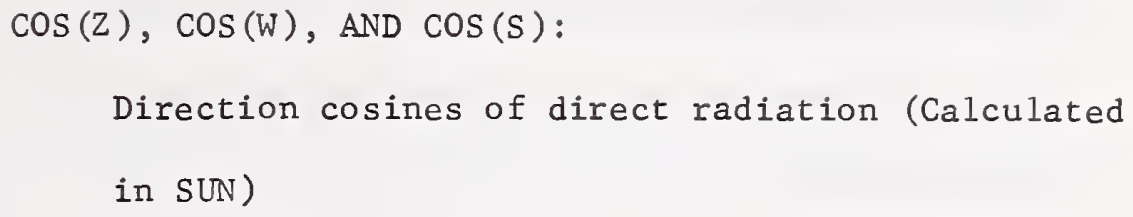

IDN: Intensity of the direct normal solar radiation for a cloudless condition in Btu per (hr) (sq ft) (Calculated in SUN)

BS and BG: Diffuse radiation from the cloudless sky and that from ground in Btu per (hr) (sq ft) (Calculated in SUN )

SALT: Solar altitude angle in radians (Calculated in SUN)

\section{Calculation Sequence:}

1. Let $X=\operatorname{SIN}($ SALT $)$

2. $Y=0.309-0.137 * X+0.394 * X * * 2$

3. $\mathrm{K}=\mathrm{X} /(\mathrm{C}+\mathrm{X})+(\mathrm{P}-1) /(1-\mathrm{Y})$

4. Direct radiation on a horizontal surface under a cloudless sky

$I D H=I D N * \operatorname{COS}(Z)$

5. Diffuse radiation on a horizontal surface under a cloudless sky

$I d H=B S$

6. Total radiation on a horizontal surface under a cloudless sky

$I T H=I D H+I d H$

7. Direct radiation on a horizontal surface under a cloudy sky $\mathrm{IDHC}=\operatorname{ITH} * \mathrm{~K} *(1-\mathrm{CC} / 10)$ 
8. Direction cosines of normal to the surface under consideration (the surface has an azimuth angle of WA and a tilt angle of WT)

$\alpha=\cos (\mathrm{WT})$

$\beta=\operatorname{SIN}(W A) * \operatorname{SIN}(W T)$

$\gamma=\cos (W A) * \operatorname{SIN}(W T)$

9. Cosine of the incident radiation on the surface under consideration

$\cos (\eta)=\alpha \cos (Z)+\beta \cos (W)+\gamma \cos (S)$

10. Direct radiation on a surface under consideration under a cloudless sky

$I D=I D N * \cos (\eta)$

$$
=0 \text { if } \cos (\eta) \leq 0
$$

11. Direct radiation on a horizontal surface under a cloudy sky $\mathrm{IDC}=\mathrm{ID}: \mathrm{IDHC} / \mathrm{IDH}$

12. Diffuse radiation for a cloudless sky

$\mathrm{Id}=\mathrm{BS}$ for the horizontal surface

$I d=B S * Y+B G / 2$ for the vertical surfaces*

where $Y=0.55+0.437 * U+0.313 * U * * 2$

$\mathrm{U}=\cos (\eta)$

if $U \leq-0.2, Y=0.45$

13. Diffuse radiation upon a horizontal surface under a cloudy sky

$$
\operatorname{IdHC}=\operatorname{ITH} *(\mathrm{CCF}-\mathrm{K} *(1-\mathrm{CC} / 10))
$$

Diffuse radiation data for surfaces other than vertical and horizontal ones have not been analyzed sufficiently to date to provide a calculation procedure. 
14. Diffuse radiation on a surface under consideration $\operatorname{IdC}=\operatorname{Id} * \operatorname{IdHC} / \mathrm{IdH}$

15. Total radiation upon a surface under a cloudy sky

$I T C=I D C+I d C$

When the cloud cover $\mathrm{CC}$ is zero,

$\mathrm{ITC}=\mathrm{IT}=\mathrm{ID}+\mathrm{Id}$ 
An Algorithm for Calculating Transmission, Absorption and Reflection Factors for Windows

\section{Data:}

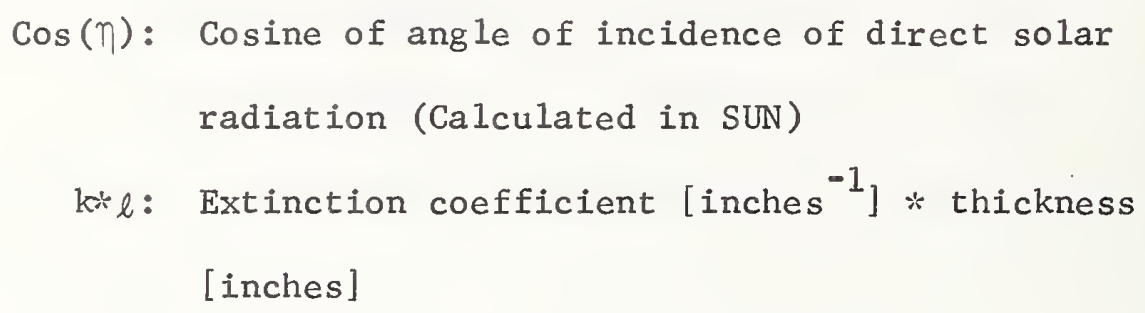

NOTE: In some cases, glass manufacturers provide the value of transmission at normal incidence. In this case, using the curve given in Figure A-5, it is possible to obtain the value of $k * 2$. The data for the curve are taken from reference 2 .

\section{Calculation Sequence:}

A. Single-Pane Glass

1. Cosine of refraction angle

$\cos (\xi)=\operatorname{SQRT}(1-(1-\cos (\eta) * 2) / n)$

where $\mathrm{n}=1.520$, which is the index of refraction for ordinary glass.

2. The fraction of radiation that is absorbed in a single pass through a sheet of glass of extinction coefficient kं $l$ $a=1-\operatorname{Exp}(-k * l / \operatorname{Cos}(\xi))$ 
3. Single glass air-glass interface reflectivity by the Fresnel's formula

vibration in parallel to the plane of glass

$r=(\operatorname{TAN}(\eta-\xi)) * * 2 / \mathrm{TAN}(\eta+\xi)$

vibration in normal to the plane of glass

$r^{\prime}=(\operatorname{SIN}(\eta-\xi)) * 2 /(\operatorname{SIN}(\eta+\xi)) * * 2$

4. Absorptivity for direct radiation

$$
\begin{aligned}
& A_{\eta}=0.5 *\left(x+x^{\prime}\right) \\
& \text { where } x=a *(1-r) *(1+r *(1-a)) /(1-r * r *(1-a) *(1-a)) \\
& \qquad \begin{aligned}
x^{\prime}= & a *\left(1-r^{\prime}\right)\left(1+r^{\prime} *(1-a)\right) /\left(1-r^{\prime} * r^{\prime} *(1-a) *\right. \\
& (1-a))
\end{aligned}
\end{aligned}
$$

5. Transmissivity for direct radiation

$$
\begin{aligned}
& T_{\eta}=0.5 *\left(y+y^{\prime}\right) \\
& \text { where } y=(1-r) *(1-r) *(1-a) /(1-r * r *(1-a) *(1-a)) \\
& y^{\prime}=\left(1-r^{\prime}\right) *\left(1-r^{\prime}\right) *(1-a) /\left(1-r^{\prime} * r^{\prime} *(1-a) *\right. \\
&(1-a))
\end{aligned}
$$

6. Absorptivity and transmissivity for diffuse radiation

$$
\begin{aligned}
& A_{d}=\int_{0}^{\pi / 2} A_{\eta} \operatorname{SIN}(2 \eta) d \eta \\
& T_{d}=\int_{0}^{\pi / 2} T_{\eta} \operatorname{SIN}(2 \eta) d \eta
\end{aligned}
$$


B. Double-Pane Glass

For the double-pane window, transmissivity and absorptivity for the outer and inner panes can be calculated separately first by using the single-pane procedure described above. Those calculated single glass properties can be designated here as follows:

$A_{1}$ : Absorptivity of inner pane for direct radiation

$\mathrm{A}_{2}$ : Absorptivity of outer pane for direct radiation

$\mathrm{T}_{1}$ : Transmissivity of inner pane for direct radiation

$\mathrm{T}_{2}$ : Transmissivity of outer pane for direct radiation

$A_{1 d}:$ Absorptivity of inner pane for diffuse radiation

$A_{2 d}:$ Absorptivity of outer pane for diffuse radiation

$\mathrm{T}_{1 \mathrm{~d}}$ : Transmissivity of inner pane for diffuse radiation

$\mathrm{T}_{2 \mathrm{~d}}$ : Transmissivity of outer pane for diffuse radiation

1. Reflectivity of inner and outer panes

$$
\begin{aligned}
& \mathrm{R}_{1 \eta}=1-\mathrm{A}_{1 \eta}-\mathrm{T}_{1 \eta} \\
& \mathrm{R}_{2 \eta}=1-\mathrm{A}_{2 \eta}-\mathrm{T}_{2 \eta} \\
& \mathrm{R}_{1 \mathrm{~d}}=1-\mathrm{A}_{1 \mathrm{~d}}-\mathrm{T}_{1 \mathrm{~d}} \\
& \mathrm{R}_{2 \mathrm{~d}}=1-\mathrm{A}_{2 \mathrm{~d}}-\mathrm{T}_{2 \mathrm{~d}}
\end{aligned}
$$

2. Absorptivity of the double-glazed system

a. Direct radiation

$$
\begin{aligned}
& \mathrm{A}_{\eta, \text { outer }}=\mathrm{A}_{2 \eta} *\left(1+\mathrm{R}_{1 \eta} * \mathrm{~T}_{2 \eta} /\left(1-\mathrm{R}_{1 \eta} * \mathrm{R}_{2 \eta}\right)\right) \\
& \mathrm{A}_{\eta, \text { inner }}=\mathrm{A}_{1 \eta} * \mathrm{~T}_{2 \eta} /\left(1-\mathrm{R}_{1 \eta} * \mathrm{R}_{2 \eta}\right)
\end{aligned}
$$


b. Diffuse radiation

$$
\begin{aligned}
& A_{d, \text { outer }}=A_{2 d}-\left(1+R_{1 d} * T_{2 d} /\left(1-R_{1 d} * R_{2 d}\right)\right. \\
& A_{d, \text { inner }}=A_{1 d} * T_{2 d} /\left(1-R_{1 d} * R_{2 d}\right)
\end{aligned}
$$

3. Transmissivity of the double

a. Direct radiation

$$
\mathrm{T}_{\eta}=\mathrm{T}_{1 \eta} * \mathrm{~T}_{2 \eta} /\left(1-\mathrm{R}_{1 \eta} * \mathrm{R}_{2 \eta}\right)
$$

b. Diffuse radiation

$$
\mathrm{Td}=\mathrm{T}_{1 \mathrm{~d}} * \mathrm{~T}_{2 \mathrm{~d}} /\left(1-\mathrm{R}_{1 \mathrm{~d}} * \mathrm{R}_{2 \mathrm{~d}}\right)
$$

Since the calculation of transmissivity and absorptivity are quite involved, they have been precalculated by Stephenson $3 /$ for various values of $\cos (\eta)$ and expressed as polynomial functions of $\cos (\eta)$. The polynomial coefficients are shown in Table A-3 for single and double glazed windows and the equations are as follows:

Single-pane, direct radiation transmission

$$
T_{\eta}=\sum_{j=0}^{5} t_{j} *(\operatorname{Cos}(\eta) * * j)
$$

Single-pane, diffuse radiation transmission

$$
T_{d}=2 * \sum_{j=0}^{5} t_{j} /(j+2)
$$


Polynomial representations of absorption factors for direct solar and diffuse radiation.

Double-pane, direct radiation transmission

$$
\begin{aligned}
& A_{\eta, \text { outer }}=\sum_{j=0}^{5} a_{j, \text { outer }} *((\operatorname{Cos}(\eta) * * j) \\
& A_{\eta, \text { inner }}=\sum_{j=0}^{5} a_{j, \text { inner }} *(\operatorname{Cos}(\eta) * * j)
\end{aligned}
$$

Double-pane, diffuse radiation transmission

$$
\begin{aligned}
A_{d, \text { outer }}=2 * \sum_{j=0}^{5} a_{j, \text { outer }} /(j+2) \\
A_{d, \text { inner }}=2 * \sum_{j=0}^{5} a_{j, \text { inner }} /(j+2)
\end{aligned}
$$




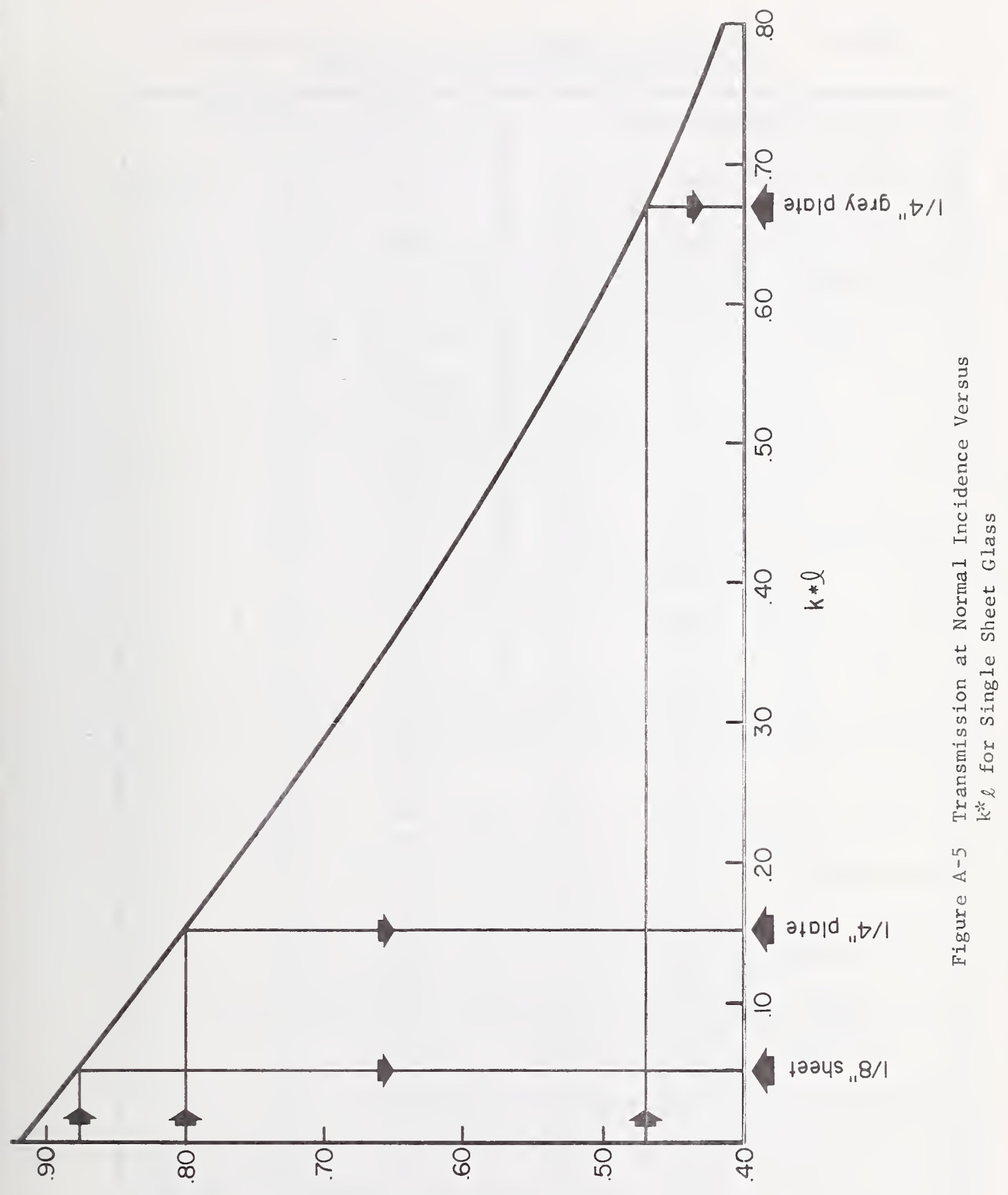

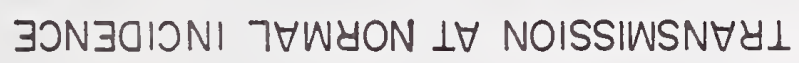


Table A-7 Polynomial Coefficients for Use in Calculation of Transmittance and Absorptance of Glass

\begin{tabular}{|c|c|c|c|c|c|c|}
\hline \multirow[b]{2}{*}{$k *$} & \multirow[b]{2}{*}{ j } & \multicolumn{2}{|c|}{ Single Glazing } & \multicolumn{3}{|c|}{ Double (ilazins; } \\
\hline & & ${ }^{a}{ }_{j}$ & $t_{j}$ & $a_{j, \text { outer }}$ & $a_{j}$, irrier & $t_{i}$ \\
\hline $\begin{array}{c}0.05 \\
1 / 8^{\prime \prime} \text { Sheet }\end{array}$ & $\begin{array}{l}0 \\
1 \\
2 \\
3 \\
4 \\
5\end{array}$ & $\begin{array}{r}0.01154 \\
0.77674 \\
-3.94657 \\
8.57881 \\
-8.38135 \\
3.01188\end{array}$ & $\begin{array}{r}-0.00885 \\
2.71235 \\
-0.62062 \\
-7.07329 \\
9.75995 \\
-3.89922\end{array}$ & $\begin{array}{r}0.01407 \\
1.06226 \\
-5.59131 \\
12.15034 \\
-11.78092 \\
4.20070 \\
\end{array}$ & $\begin{array}{r}0.00228 \\
0.34559 \\
-1.13908 \\
2.22366 \\
-2.05287 \\
0.72376 \\
\end{array}$ & $\begin{array}{r}-0.00401 \\
0.74050 \\
7.20350 \\
-20.11763 \\
19.68824 \\
-6.74585 \\
\end{array}$ \\
\hline 0.10 & $\begin{array}{l}0 \\
1 \\
2 \\
3 \\
4 \\
5\end{array}$ & $\begin{array}{r}0.01636 \\
1.40783 \\
-6.79030 \\
14.37378 \\
-13.83357 \\
4.92439\end{array}$ & $\begin{array}{r}-0.01114 \\
2.39371 \\
0.42978 \\
-8.98262 \\
11.51798 \\
-4.52064\end{array}$ & $\begin{array}{r}0.01819 \\
1.86277 \\
-9.24831 \\
19.49443 \\
-18.56094 \\
6.53940\end{array}$ & $\begin{array}{r}0.00123 \\
0.29788 \\
-0.92256 \\
1.58171 \\
-1.40040 \\
0.48316\end{array}$ & $\begin{array}{r}-0.00438 \\
0.57818 \\
7.42065 \\
-20.26848 \\
19.79706 \\
-6.79619\end{array}$ \\
\hline $\begin{array}{l}\quad 0.15 \\
\text { 1/4" Reg. } \\
\text { Plate }\end{array}$ & $\begin{array}{l}0 \\
1 \\
2 \\
3 \\
4 \\
5\end{array}$ & $\begin{array}{r}0.01837 \\
1.92497 \\
-8.89134 \\
18.40197 \\
-17.48648 \\
6.17544 \\
\end{array}$ & $\begin{array}{r}-0.01200 \\
2.13036 \\
1.13833 \\
-10.07925 \\
12.44161 \\
-4.83285 \\
\end{array}$ & $\begin{array}{r}0.01905 \\
2.47900 \\
-11.74226 \\
24.14037 \\
-22.64299 \\
7.89954 \\
\end{array}$ & $\begin{array}{r}0.00067 \\
0.26017 \\
-0.72713 \\
1.14950 \\
-0.97138 \\
0.32705 \\
\end{array}$ & $\begin{array}{r}-0.00428 \\
0.45797 \\
7.41367 \\
-19.92004 \\
19.40969 \\
-6.66603\end{array}$ \\
\hline 0.20 & $\begin{array}{l}0 \\
1 \\
2 \\
3 \\
4 \\
5\end{array}$ & $\begin{array}{r}0.01902 \\
2.35417 \\
-10.47151 \\
21.24322 \\
-19.95978 \\
6.99964 \\
\end{array}$ & $\begin{array}{r}-0.01218 \\
1.90950 \\
1.61391 \\
-10.64872 \\
12.83698 \\
-4.95199 \\
\end{array}$ & $\begin{array}{r}0.01862 \\
2.96400 \\
-13.48701 \\
27.13020 \\
-25.11877 \\
8.68895 \\
\end{array}$ & $\begin{array}{r}0.00035 \\
0.22974 \\
-0.58381 \\
0.84626 \\
-0.67666 \\
0.22102 \\
\end{array}$ & $\begin{array}{r}-0.00401 \\
0.36698 \\
7.27324 \\
-19.29364 \\
18.75408 \\
-6.43968 \\
\end{array}$ \\
\hline 0.40 & $\begin{array}{l}0 \\
1 \\
2 \\
3 \\
4 \\
5\end{array}$ & $\begin{array}{r}0.01712 \\
3.50839 \\
-13.86390 \\
26.34330 \\
-23.84846 \\
8.17372 \\
\end{array}$ & $\begin{array}{r}-0.01056 \\
1.29711 \\
2.28615 \\
-10.37132 \\
11.95884 \\
-4.54880\end{array}$ & $\begin{array}{r}0.01423 \\
4.14384 \\
-16.66709 \\
31.30484 \\
-27.81955 \\
9.36959 \\
\end{array}$ & $\begin{array}{r}-0.00009 \\
0.15049 \\
-0.27590 \\
0.25618 \\
-0.12919 \\
0.02859\end{array}$ & $\begin{array}{r}-0.00279 \\
0.16468 \\
6.17715 \\
-15.84811 \\
15.28302 \\
-5.23666\end{array}$ \\
\hline 0.60 & $\begin{array}{l}0 \\
1 \\
2 \\
3 \\
4 \\
5\end{array}$ & $\begin{array}{r}0.01406 \\
4.15958 \\
-15.06279 \\
27.18492 \\
-23.88518 \\
8.03650\end{array}$ & $\begin{array}{r}-0.00835 \\
0.92766 \\
2.15721 \\
-8.71429 \\
9.87152 \\
-3.73328\end{array}$ & $\begin{array}{r}0.01056 \\
4.71447 \\
-17.33454 \\
30.91781 \\
-26.63898 \\
8.79495\end{array}$ & $\begin{array}{r}-0.00016 \\
0.10579 \\
-0.15035 \\
0.06487 \\
0.02759 \\
-0.02317\end{array}$ & $\begin{array}{r}-0.00192 \\
0.08180 \\
4.94753 \\
-12.43481 \\
11.92495 \\
-4.07787\end{array}$ \\
\hline $\begin{array}{c}0.80 \\
50 \% \text { Trans. } \\
\text { H.A. Plate }\end{array}$ & $\begin{array}{l}0 \\
1 \\
2 \\
3 \\
4 \\
5\end{array}$ & $\begin{array}{r}0.01153 \\
4.55946 \\
-15.43294 \\
26.70568 \\
-22.87993 \\
7.57795 \\
\end{array}$ & $\begin{array}{r}-0.00646 \\
0.68256 \\
1.82449 \\
-6.95325 \\
7.80647 \\
-2.94454 \\
\end{array}$ & $\begin{array}{r}0.00819 \\
5.01768 \\
-17.21228 \\
29.46388 \\
-24.76915 \\
8.05040 \\
\end{array}$ & $\begin{array}{r}-0.00015 \\
0.07717 \\
-0.09059 \\
0.00050 \\
0.06711 \\
-0.03394 \\
\end{array}$ & $\begin{array}{r}-0.00136 \\
0.04419 \\
3.87529 \\
-9.59069 \\
9.16022 \\
-3.12776 \\
\end{array}$ \\
\hline 1.00 & $\begin{array}{l}0 \\
1 \\
2 \\
3 \\
4 \\
5\end{array}$ & $\begin{array}{r}0.00962 \\
4.81911 \\
-15.47137 \\
25.86516 \\
-21.69106 \\
7.08714\end{array}$ & $\begin{array}{r}-0.00496 \\
0.51403 \\
1.47607 \\
-5.41985 \\
6.05546 \\
-2.28162\end{array}$ & $\begin{array}{r}0.00670 \\
5.18781 \\
-16.84820 \\
27.90292 \\
-22.99619 \\
7.38140\end{array}$ & $\begin{array}{r}-0.00012 \\
0.05746 \\
-0.05878 \\
-0.01855 \\
0.06837 \\
-0.03191\end{array}$ & $\begin{array}{r}-0.00098 \\
0.02576 \\
3.00400 \\
-7.33834 \\
6.98747 \\
-2.38328\end{array}$ \\
\hline
\end{tabular}


An Algorithm for Calculating Solar Heat Gain Through Windows

\section{Data :}

IDN: Intensity of direct normal solar radiation, Btu per (hr) (sq ft), (Calculated in SUN)

BS: Sky brightness, Btu per (hr) (sq ft), (Calculated in SUN)

BG: Ground brightness, Btu per (hr) (sq ft), (Calculated in SUN)

Cos $(\eta)$ : Cosine of the angle of incidence of direct solar radiation, (Calculated in SUN)

FWS: Form factor between the window and the $\mathrm{sky} *$

FWG: Form factor between the window and the ground*

RO, RA, RI: Thermal resistances at outside surface, air space, and inside surface respectively, $(\mathrm{sq} f t)(\mathrm{hr})(\mathrm{F})$ per Btu

SLA: Sunlit area factor (Calculated in SHADOW)

SC: Shading coefficient if the window is shaded by drapes or blinds or if it has an interpane separation of more than 1 inch

* If more accurate data are not available, use FWS $=$ FWG $=0.5$. 
NOTE: When the value of SC is given, these transmission and absorption factors should be for the standard $1 / 8^{\prime \prime}$ thick double strength glass (or $\mathrm{k} * \ell=0.05$ of TAR) regardless of the type of glass used.

$\mathrm{T}_{\eta}, \mathrm{T}_{\mathrm{d}}$ : Transmission factors for direct and diffuse solar radiation for windows (Calculated in TAR)

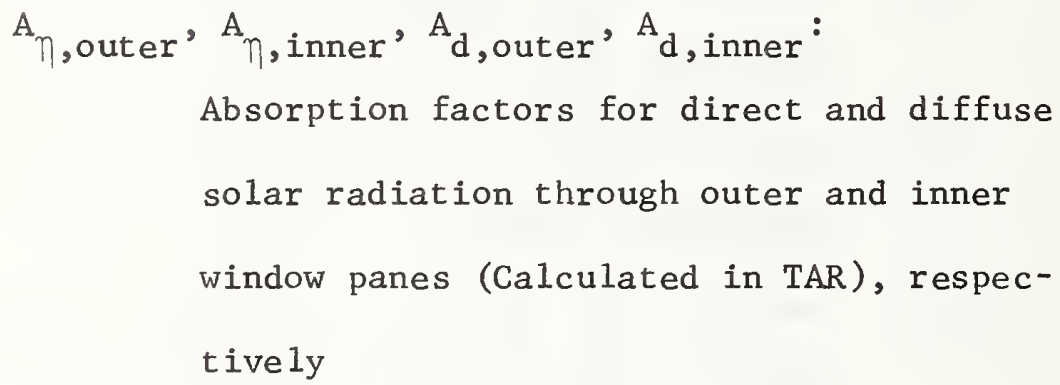

\section{Calculation Sequence:}

1. Inward flowing fraction of the radiation absorbed by the inner and the outer pane, respectively.

$$
\begin{aligned}
& N I=(R O+R A) /(R O+R A+R I) \\
& N O=R O /(R O+R A+R I)
\end{aligned}
$$

2. Let

$$
\begin{aligned}
& D=\operatorname{SLA} * I D N * \operatorname{Cos}(\eta) *\left(T_{\eta}+N O * A_{\eta} \text {, outer }+N I * A_{\eta} \text {, inner }\right)
\end{aligned}
$$

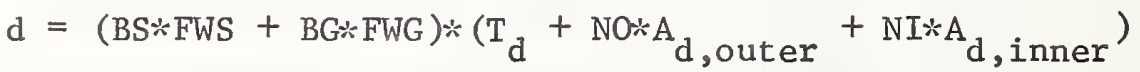

3. Solar heat gain through window.

If $\mathrm{SC}=0, \mathrm{SHG}=\mathrm{D}+\mathrm{d}$

If $S C \neq 0$, SHG $=(S C) *(D+d)_{k * l=0.05}$ 


\section{SHADOW}

A Brief Description of the Procedures for Calculating External Shadows on a Building

A major portion of the air conditioning load on modern commercial buildings comes from solar radiation. To improve the accuracy of load assessment, it is necessary to know how much of a building is shaded and how much lies exposed to the sun's rays.

A new technique developed by Groth and Lokmanhekim / employs the representation of all architectural forms as a series of plane polygons. Even curved surfaces can be so represented. For example, a sphere may be approximated by the 20 sides of a regular icosohedron This approximation gives a maximum error of only $3 \%$ in the shadow area cast by the sphere.

The output of the algorithm is not only the sunlit area, but also a pictorial display of the shadows and the surface upon which they are cast.

Coordinate Transformation:

Designate the polygons which cast shadows as shading polygons (SP) and those upon which shadows are cast as receiving polygons (RP). The vertex coordinates of each $R P$, and its relevant $S P$ 's, are transformed from a base coordinate system, $x y z$, to a new coordinate system, $x^{\prime} y^{\prime} z^{\prime}$, with origin 0 attached to the plane of the RP. The first three vertices, 
$V_{1}, V_{2}$, and $V_{3}$, of the RP being examined are used to define this new coordinate system. The $\mathrm{x}^{\prime}$ axis passes through $\mathrm{V}_{2}$ and $\mathrm{V}_{3}$, while the $\mathrm{y}^{\prime}$ axis passes through $\mathrm{V}_{1}$. In order that the $\mathrm{z}^{\prime}$ axis point outward from the surface, angle $V_{1} V_{2} V_{3}$ must be convex and the vertices must be numbered counterclockwise. The equation of transformation is written in matrix form as

$$
\vec{x}^{\prime}=A\left(\vec{x}-\vec{x}_{0}\right)
$$

where

$$
\begin{aligned}
& \vec{x}_{0}=\vec{x}_{2}+\gamma\left(\vec{x}_{3}-\vec{x}_{2}\right) \\
& \gamma \text {, A scaler }=\left(\vec{x}_{1}-\vec{x}_{2}\right) \cdot\left(\vec{x}_{3}-\vec{x}_{2}\right) /\left(\vec{x}_{3}-\vec{x}_{2}\right) \cdot\left(\vec{x}_{3}-\vec{x}_{2}\right) \\
& \text { Ist row of } A=\left(\vec{x}_{3}-\vec{x}_{0}\right) /\left|\vec{x}_{3}-\vec{x}_{0}\right| \\
& \text { 2nd row of } A=\left(\vec{x}_{1}-\vec{x}_{0}\right) /\left|\vec{x}_{1}-\vec{x}_{0}\right| \\
& 3 \text { rd row of } A=1 \text { st } \overrightarrow{\text { row }} \text { of } A \times 2 \text { nd } \overrightarrow{\text { row }} \text { of } A
\end{aligned}
$$

Solar altitude, $\alpha$, and azimuth, $\beta$, must also be transformed, into the solar direction vector, as

$$
\mathrm{x}_{\mathrm{s}}^{\prime}=\left(\begin{array}{c}
\sin \beta \cdot \cos \alpha \\
\sin \alpha \\
\cos \beta \cdot \cos \alpha
\end{array}\right)
$$

Clipping Trans formation:

Any part of an SP whose $z^{\prime}$ is negative cannot cast a shadow on the RP. These "submerged" portions of the SP's must be clipped off, prior to projection, lest they project "false" shadows (see Figure A-6). This 
is done by finding, through linear interpolation, the points $A$ and $B$, on the perimeter of the SP, which pierce the plane of the RP, and taking these points as new vertices. All submerged vertices are deleted. This results in a new polygon with line $A B$ as a side, which will project only real shadows.

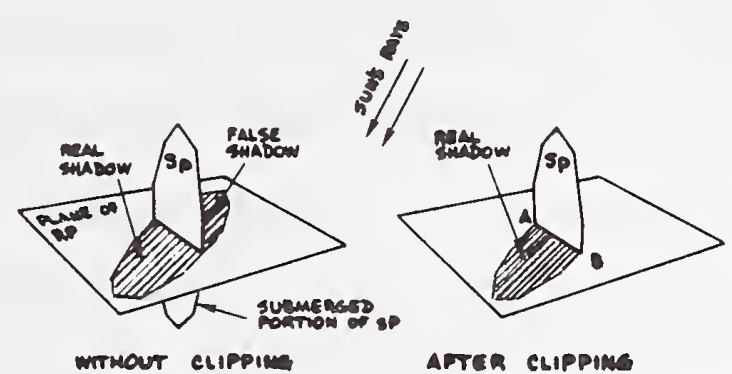

Figure A-6 Clipping

Projection Transformation:

To simulate the actual casting of a shadow, the following transformation projects, along the sun's rays, all the vertex points of the transformed and clipped RP's.

$$
\begin{aligned}
& X=x^{\prime}-\frac{x_{s}^{8}}{z_{s}^{1}} z^{\prime} \\
& Y=y^{\prime}-\frac{y_{s}^{8}}{z_{s}^{1}} z^{\prime}
\end{aligned}
$$


The coordinate, clipping and projection transformation have converted all RP and $\mathrm{SP}^{\prime} \mathrm{s}$ in space into two dimensional figures in the RP plane. It remains only to find the points in the RP plane which lie inside the RP and inside one or more of the SP projections, i.e., points of the RP which are shaded. At this point, the two-space $X Y$ is divided into a grid and the center of each element of this grid is tested for enclosure by the RP and the SP projections. A point, $\mathrm{P}$, whose coordinates are $\mathrm{X}_{\mathrm{P}} \mathrm{Y}_{\mathrm{P}}$, is inside of polygon $V_{1}, V_{2}, \ldots V_{n}$ if the following inequality holds.

$$
\sum_{i=1}^{n} \Delta \theta_{i} \neq 0
$$

The angular change, $\Delta \theta_{i}$, subtended at $\mathrm{P}$ by the ith side, and counted positive counterclockwise, is given by the following formulae.

$$
\begin{gathered}
\Delta \theta_{i}=\frac{\theta_{j}-\theta_{i}}{\frac{\left(\theta_{i}-\theta_{j}\right)\left(4-\left|\theta_{i}-\theta_{i}\right|\right)}{\left|\theta_{j}-\theta_{i}\right|}} \text { if }\left|\theta_{j}-\theta_{i}\right|<2 \\
j=\theta_{i} \mid \geq 2 \\
1 \quad \text { if } i<n \\
\text { if } i=n
\end{gathered}
$$




$$
\begin{aligned}
& \frac{Y_{i}-Y_{P}}{X_{i}-X_{P}+Y_{i}-Y_{P}} \quad \begin{array}{ll}
\text { in 1st } & \text { quadrant }
\end{array} \quad 1+\frac{X_{P}-X_{i}}{X_{P}-X_{i}+Y_{i}-Y_{P}} \quad \begin{array}{l}
\text { in 2nd } \\
\text { quadrant }
\end{array} \\
& \theta_{i} \sim 2+\frac{Y_{P}-Y_{i}}{X_{P}-X_{i}+Y_{P}-Y_{i}} \quad \begin{array}{l}
\text { in 3rd } \\
\text { quadrant }
\end{array} 3+\frac{X_{i}-X_{P}}{X_{i}-X_{P}+Y_{P}-Y_{i}} \quad \begin{array}{l}
\text { in 4th } \\
\text { quadrant }
\end{array}
\end{aligned}
$$

These approximate formulae, which express $\Delta \theta_{i}$ in right angles, replace the time-consuming square root and are cosine computer library routines. They have, by set theory, been proved adequate for the purpose.

Display Matrix and Sample Problem:

An alphameric matrix is created corresponding to the grid elements in the RP plane. A blank component represents a grid element either outside the RP or exposed to the sun. An asterisk component represents a shaded grid element or one on the RP's boundary. Grid elements shaded by a transmissive structure are randomly asterisked with a probability equal to the fraction of incident light stopped by the shading structure. Figure A-7 shows the solution of a typical problem involving a transmissive structure. 


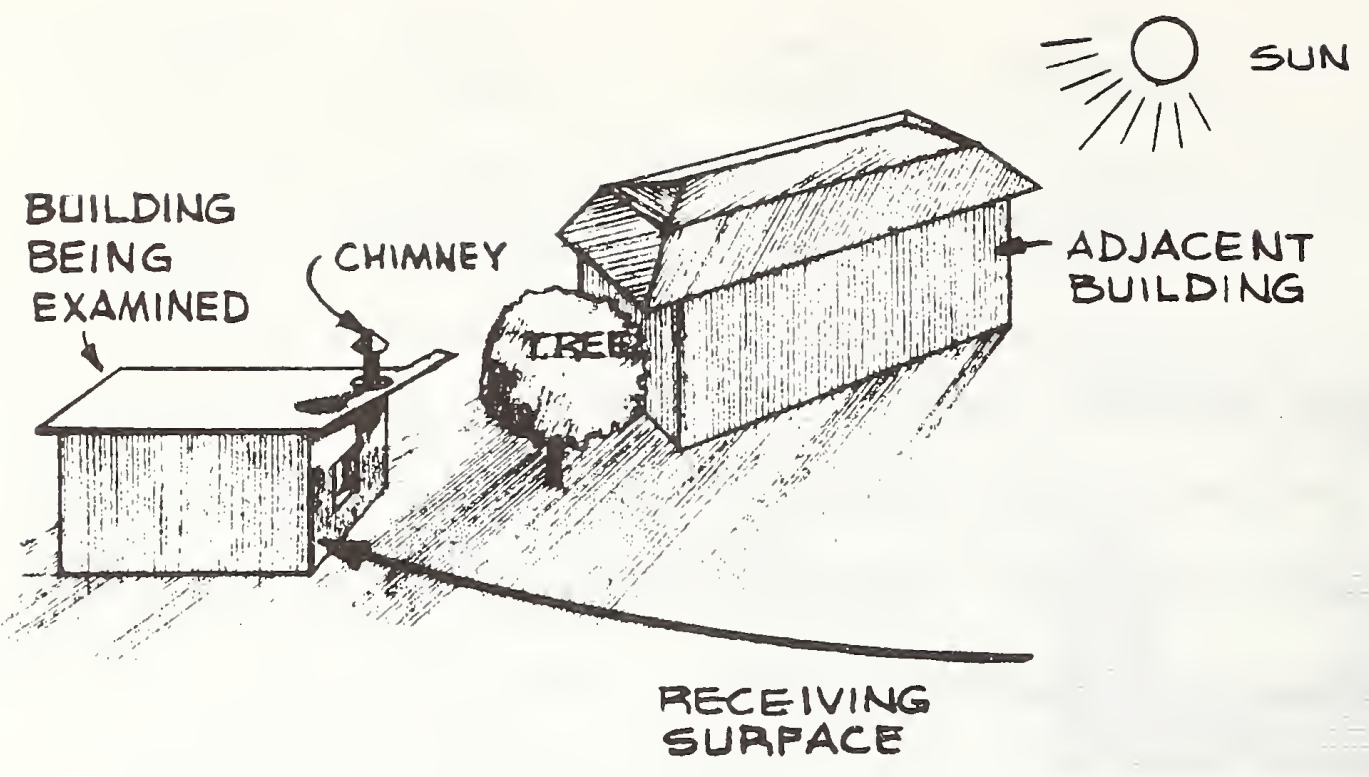

Figure A-7 The Computer Output of a Typical Problem 
An Algorithm to Find the Ratio of the Sunlit and Shaded Area of a Given Window Where the Shadows are Cast by Various Combinations of Overhang and Side Fins

Data:

(Variable names corresponding to the FORTRAN listing included in this section. Right and left is determined facing the window from outside - see Figure A-8).

HT : Window height

FL: Window width

FP: Depth of the overhang

AW: Distance from top of the window to the overhang

BWL: Distance of the overhang extended beyond the left edge of the window

BWR: Distance of the overhang extended beyond the right edge of the window

D: Depth of vertical projection at the end of the overhang FP1: Depth of the left fin

Al: Distance of the left fin extended above the top of the window

B1: Distance from the left edge of the window to the left fin

C1: Distance of the left fin stop short above the bottom of the window

FP2: Depth of the right fin

This section was contributed by Tseng-Yao Sun; Ayres and Hayakawa, Los Angeles, California. 


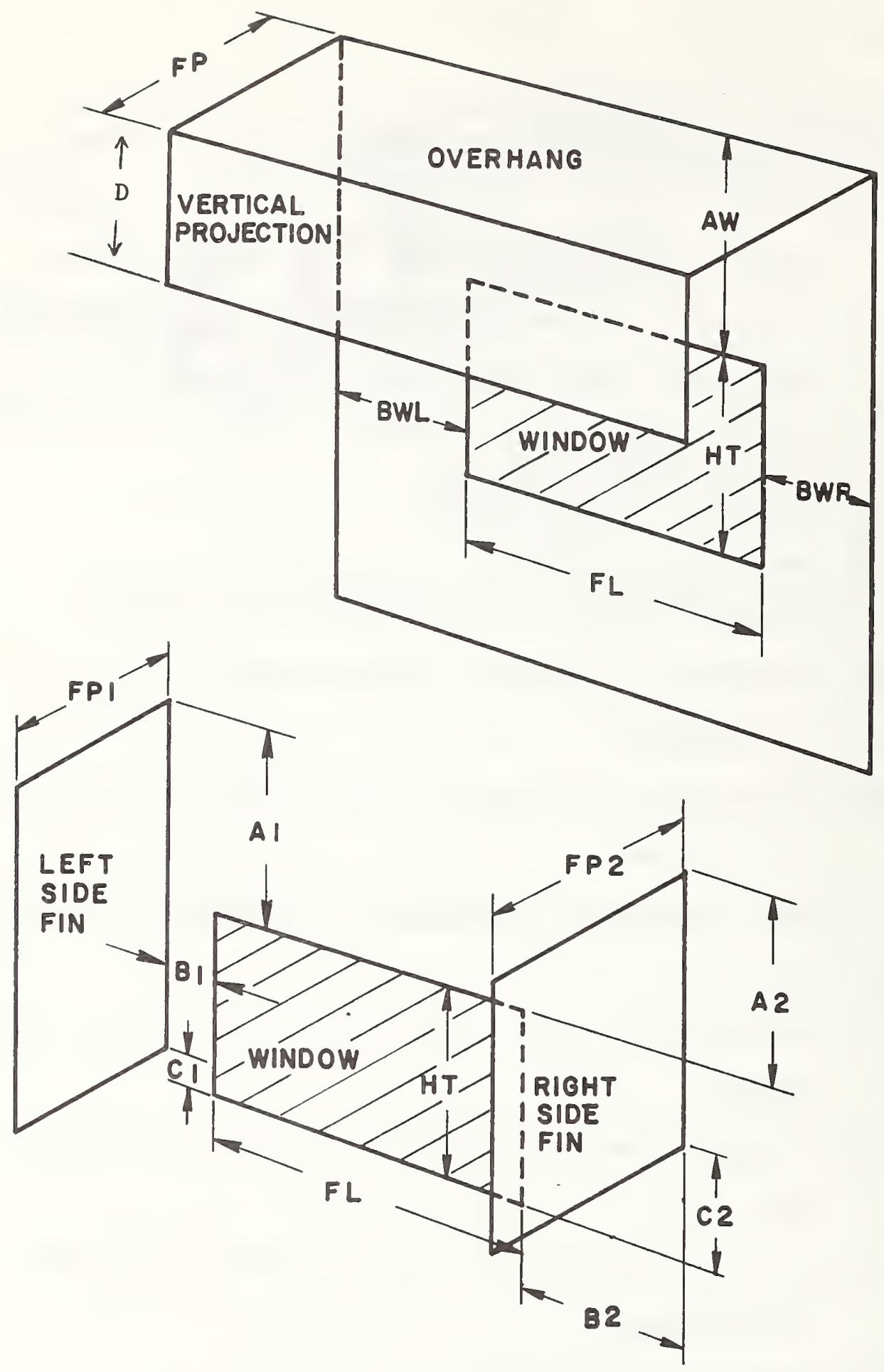

Figure A-8 Shadow 1 Input Data 
A2: Distance of the right fin extended above the top of the window

B2: Distance from the right edge of the window to the right fin

C2: Distance of the right fin stop short above the bottom of the window

PHI: Solar azimuth angle

WAZI: Window azimuth angle

COSZ: Cosine of solar zenith angle

\section{Calculation Sequence:}

The principle calculation sequence of this subroutine is described in reference 5 and the principle output of the subroutine is the variable SHRAT--the shade ratio or ratio of sunlit area to the total window area. The treatment of shadow overlapping cast by various shading devices is not discussed in the reference but is included in the FORTRAN 1isting. 
SUBROUTINE SHADOW (SHDX,PHI, COSZ, SHRAT)

DIMENSION SHDX (20)

$H T=S H D \times(1)$

$F L=S H D \times(2)$

$F P=S H D X(3)$

$A W=S H D X(4)$

$B W L=S H D X(5)$

$B W R=S H D \times(6)$

$D=S H D \times(7)$

$F D 1=S H D \times(B)$

$A l=S H D X(9)$

$B 1=S H D \times(10)$

$\mathrm{C} 1=\mathrm{SHOX}(11)$

$F P 2=S H O X(12)$

$A 2=S H D \times(13)$

$\mathrm{B} 2=\mathrm{SHO} \times(14)$

$C 2=S H O X(15)$

WAZI =SHDX (16)

THIS PROGRAM CALCULATES SHADOW CAST BY OVERHANG ANO SIDE FINS

PHI.... SOLAR AZIMUTH ANGLE

COS7... COSINE OF SOLAR TENITH ANGLE

SHRAT.. SHADE RATIO:RATIO OF THE SUNLIT AREA TO THE TOTAL WINDOW AREA HT.....WINDOW HEIGHT

FL......WINDOW WIDTH

FP....DEPTH OF THE OVERHUNG

AW.... OISTANCE FROM TOP OF THE WINDOW TO THE OVERHUNG

BWL.....DISTANCF OF THE OVERHUNG EXTENDED BEYOND THE LEFT EDGE OF THE WINDOW

BWR....DISTANCE OF THE DVERHUNG EXTENDED BEYOND THE RIGHT EOGE OF THE WINDOW D......DEPTH OF VERTICAL PROJECTION AT THE END OF THE OVERHUNG

FP $1 \ldots$... DEPTH OF THE LE.FT FIN

A1.... DISTANCE OF THE. LEFT FIN EXTENDED ABOVE THE TOP OF THE WINDOW

B1..... ISTANCE FROM THE LEFT EDGE OF THE WINDOW TO THE LEFT FIN

Cl....DISTANCE OF THE LEFT FIN STOP SHDRT ABOVE THE BOTTOM OF THE WINDOW

FP?...DEPTH OF THE RIGHT FIN

A2..... ISTANCE OF THE RIGHT FIN EXTENDED ABOVE THE TOP OF THE WINDOW

B?.... DISTANCE FROM THE RIGHT EDGE OF THE WINDOW TO THE RIGHT FIN

C?.... DISTANCE OF THE RIGHT FIN STOP SHORT ABOVE THE BOTTOM OF THE WINDOW

WAZI...WINDOW AZIMUTH ANGLE

SHRAT $=1$.

$A=A W$

$H=H T$

GAMMA $=$ PHI $-W A Z I$

$\cos (S=\cos (G A M M A)$

IF $(\operatorname{Cos} G) 100,100,104$

100 SHRAT $=0$.

GO TO 2000

104 CONTINUE

SBET $A=\operatorname{COSZ}$

IF (SBETA) $100,100,152$

15? SING =SIN(GAMMA)

VERT $=S B E T A / S Q R T(1,-S B E T A * S B E T A) / C O S G$

HOR I $7=$ ARS $($ SING) $/$ COSG

TCETA $=$ VERT/HORIZ 


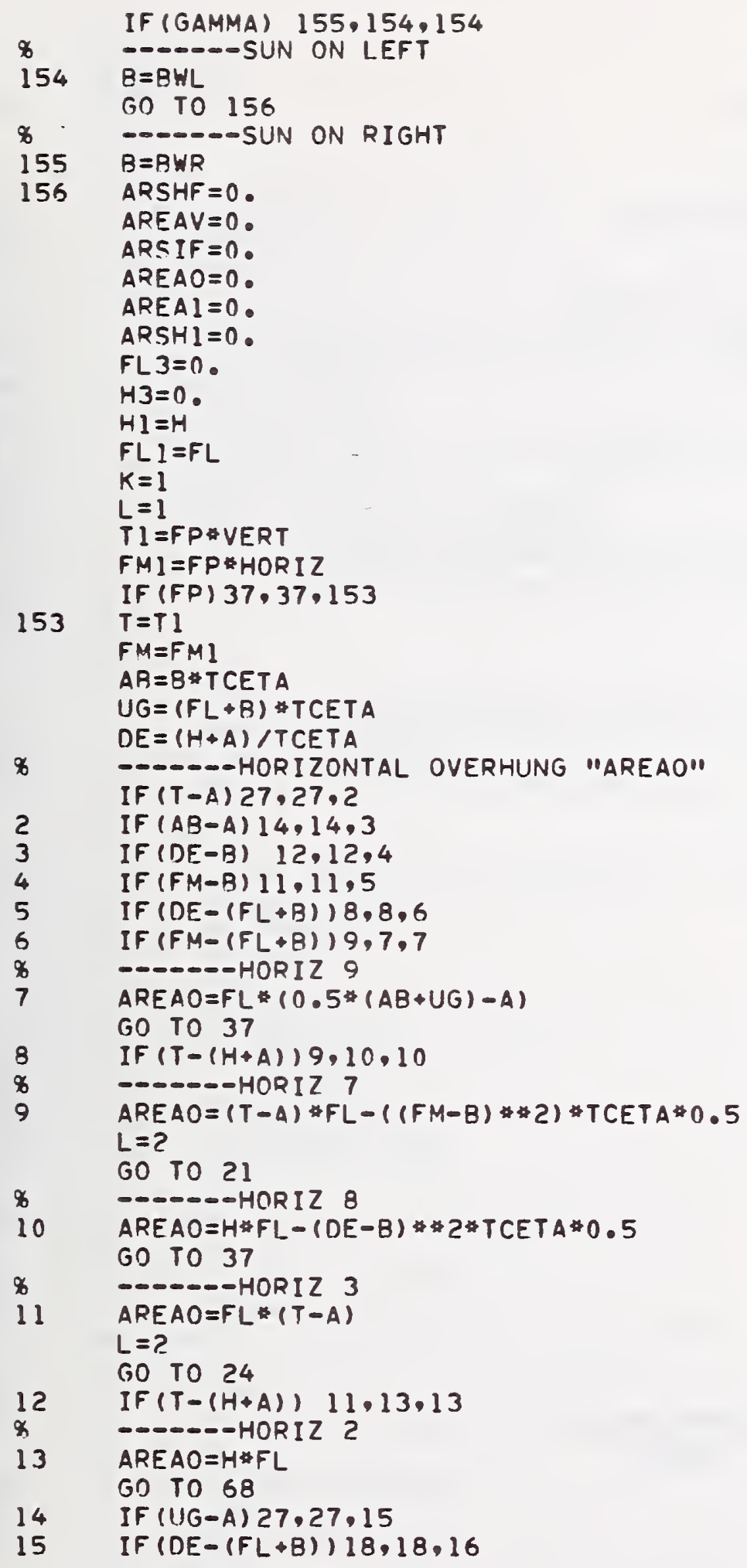




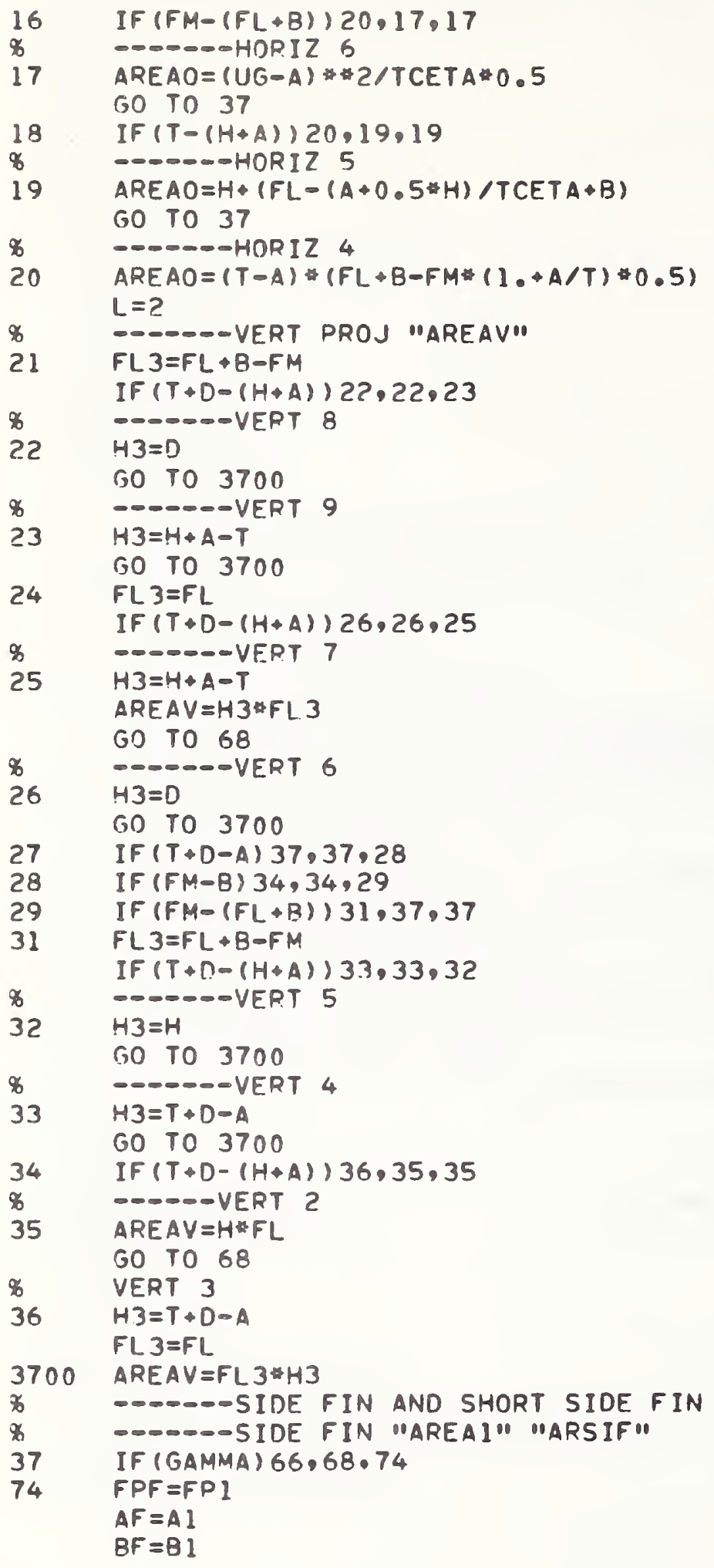




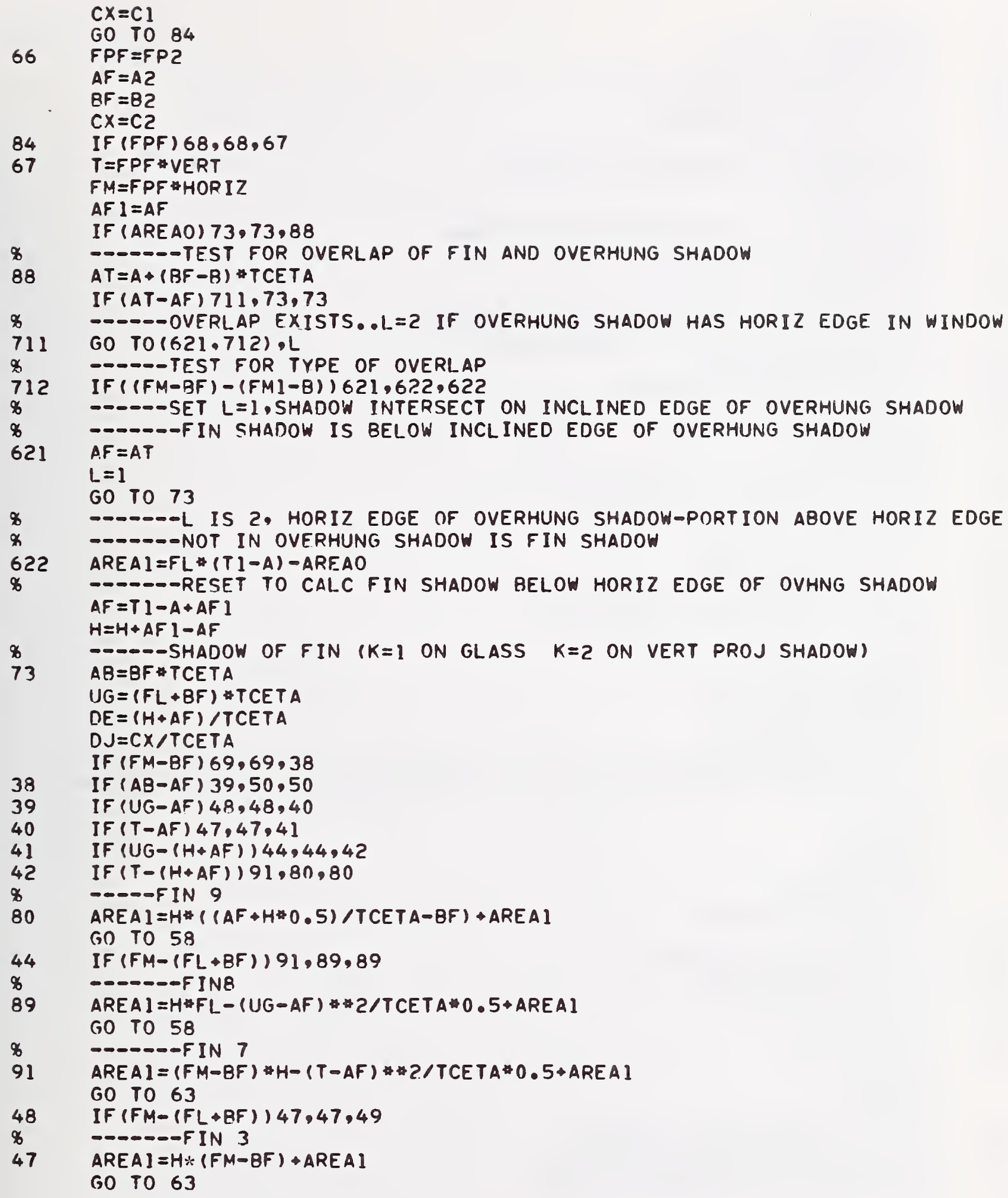




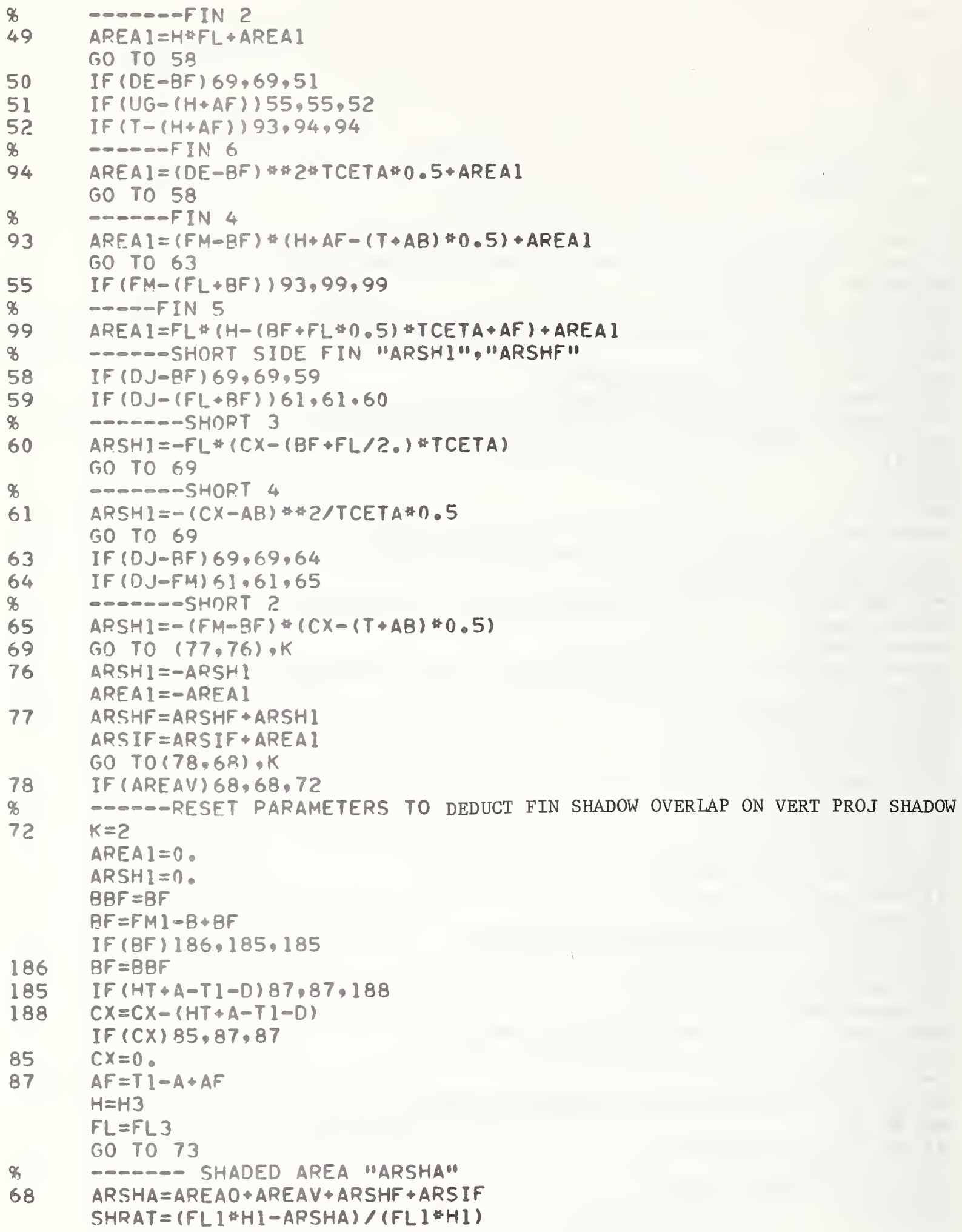


$\begin{array}{ll} & \text { FL }=F L 1 \\ 2000 & \text { CONTINUE }\end{array}$

RETURN

END 
An Algorithm to Determine Whether or Not a Given Window is Shaded by a Remote Object Such as an Adjacent Building

This algorithm is approximate and is applicable only where the window is relatively small in comparison to the shading object. Large windows may be subdivided into smaller segments for this consideration. The window is considered either completely shaded or completely in sun. Partially shaded window can be considered in either case depending on the location of the window reference point. Figure A-9 shows a typical window-shading object relationship.

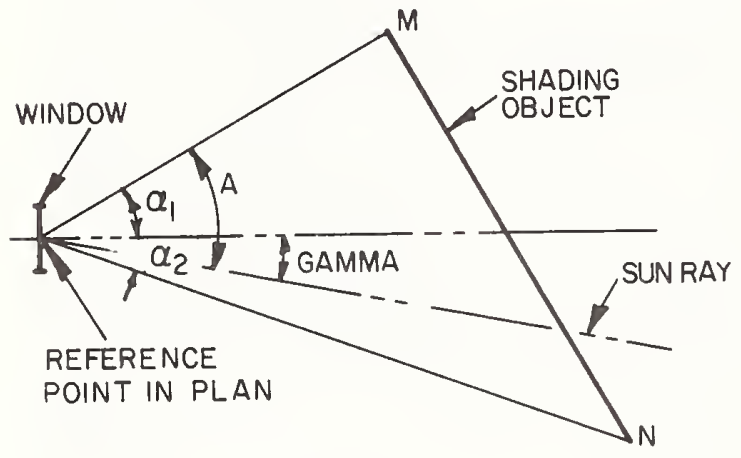

PLAN

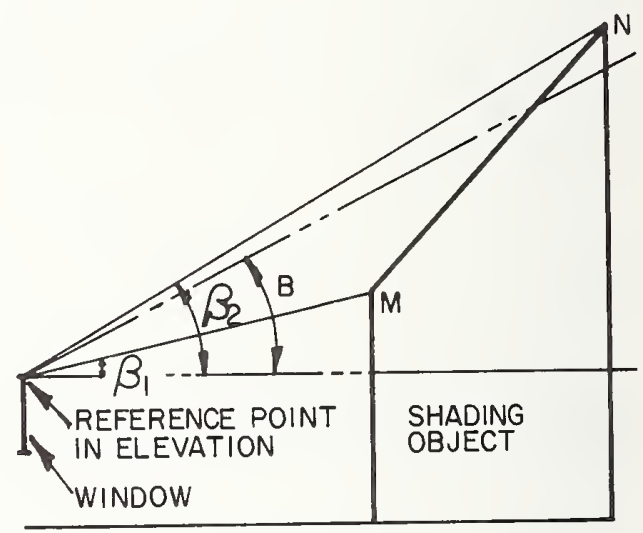

ELEVATION

Figure A-9 A Typical Window-Shading Object Relationship

Note that the reference point can be located at any point on the window. Locating the reference point at the top of the window as shown in the elevation in Figure A-9 is slightly conservative as compared to if the reference point is located at the center of the window.

This section was contributed by Tseng-Yao Sun; Ayres, Cohen and Hayakawa, Los Angeles, California. 


\section{Data:}

$\alpha 1, \alpha 2$ : Azimuth shadow 1imit angles. Right + , Left -

$\beta 1, \beta 2:$ Altitude shadow limit angles

WAZI: Window azimuth angle

PHI: Solar azimuth angle

BETA: Solar altitude angle

\section{Calculation Sequence:}

This subroutine determines whether the window is sunlit or shaded. for the given position of the sun.

1. Wa11-solar azimuth angle

GAMMA $=$ PHI - WAZI

2. If GAMMA $<\alpha 1$ or GAMMA $>\alpha 2$, the window is in sun

3. If $\alpha 2>$ GAMMA $>\alpha 1$,

$$
\begin{aligned}
& A=\text { GAMMA }-\alpha 1 \\
& B=\beta 1+A^{*}(\beta 2-\beta 1)
\end{aligned}
$$

4. If $\mathrm{BETA}>\mathrm{B}$, the window is in sun. Otherwise, the window is in shade. 
An Algorithm for Calculating Radiation Shape Factors Between Inside Surfaces of a Room

\section{Definition of Room}

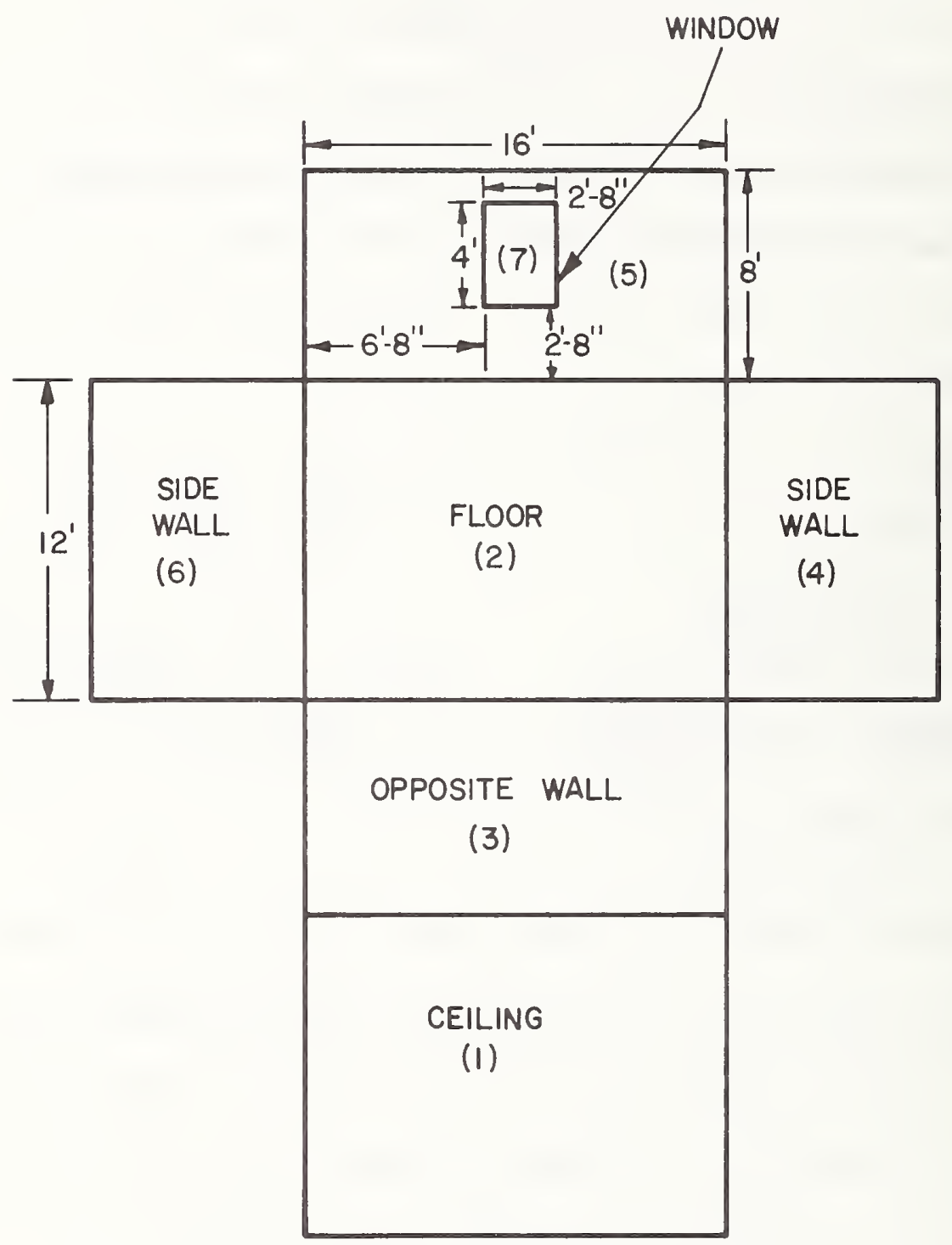

Figure A-10 Room Layout

This section was contributed by D. M. Burch and B. A. Peavy; Thermal Engineering Systems Section, Center for Building Technology, National Bureau of Standards, Washington, D. C. 
L: Length of room

W: Width of room

H: Height of room

A: Height of windows or doors

B: Width of windows or doors

C: Distance of left edge of window from left wall

D: Height of lower edge of window from floor

The primary variables determined by this subroutine are: $F_{m-n}:$ An array giving radiation shape factors between the various inside surfaces of a room

$$
\mathrm{m}, \mathrm{n}=1 \quad \text { Ceiling }
$$

2 Floor

3 Wall No. 1 (length by height)

4 Wall No. 2 (side wall)

5 Wall No. 3 (opposite wall)

6 Wall No. 4 (side wall)

7-14 Provision for windows and doors in walls 


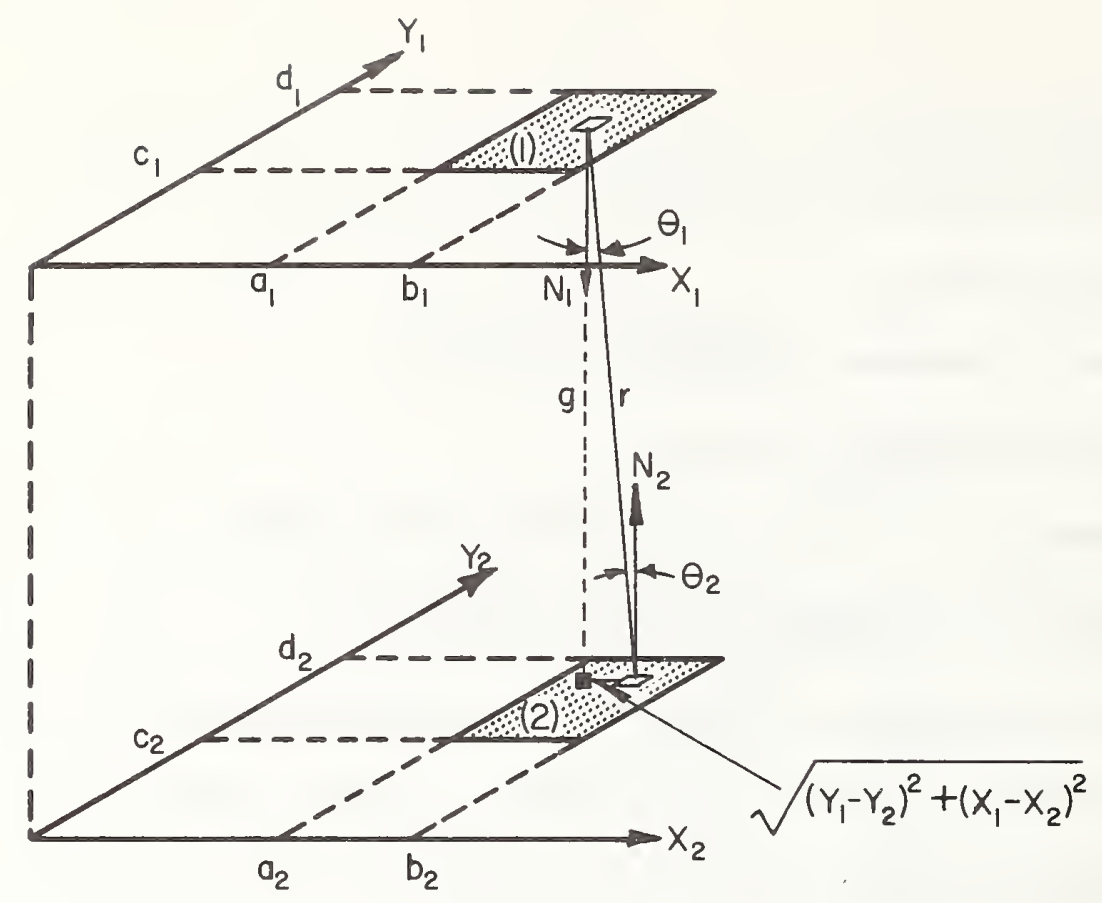

Figure A-11 Radiation Heat Exchange Between
Ceiling and Floor Surfaces

Radiation shape factor, $F_{1-2}$, between two parallel room surfaces

$$
\begin{aligned}
2 \pi\left(b_{i}-a_{1}\right)\left(d_{1}-c_{1}\right) F_{1-2} & =\left[P\left(b_{2}-b_{1}\right)+P\left(a_{2}-a_{1}\right)\right]\left[Q\left(c_{2}-c_{1}\right)+Q\left(d_{2}-d_{1}\right)-Q\left(c_{2}-d_{1}\right)-Q\left(d_{2}-c_{1}\right)\right] \\
+ & {\left[P\left(b_{2}-a_{1}\right)+P\left(a_{2}-b_{1}\right)\right]\left[Q\left(c_{2}-d_{1}\right)+Q\left(d_{2}-c_{1}\right)-Q\left(c_{2}-c_{1}\right)-Q\left(d_{2}-d_{1}\right)\right] }
\end{aligned}
$$

where

$$
\begin{aligned}
& \left.P\left(Z_{1}\right) Q\left(Z_{2}\right)=Z_{1} W \tan ^{-1} \frac{Z_{1}}{W}+Z_{2} V \tan ^{-1} \frac{Z_{2}}{V}-\frac{G^{2}}{Z} \ln \frac{\left(W^{2+Z_{1}}\right)}{W^{2}}\right) \\
& V^{2}=G^{2}+Z_{1}^{2}, W^{2}=G^{2}+Z_{2}{ }^{2}
\end{aligned}
$$




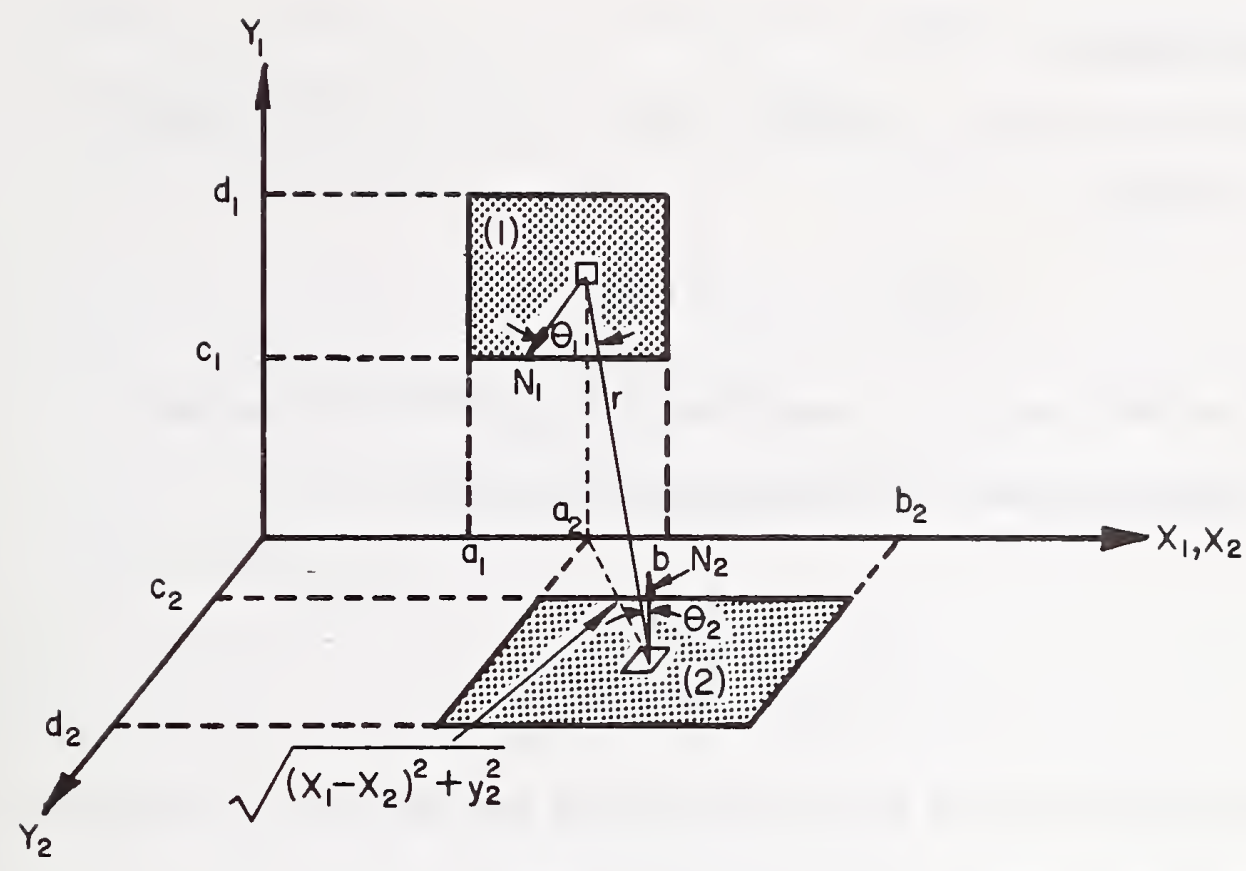

Figure A-12 Radiation Heat Exchange Between Wall and Floor Surfaces

Radiation Shape Factor, $\mathrm{F}_{1-2}$, between two perpendicular room surfaces

$$
\begin{aligned}
2 \pi\left(b_{1}-a_{1}\right)\left(d_{1}-c_{1}\right) F_{1-2} & =\left[R\left(b_{2}-b_{1}\right)+R\left(a_{2}-a_{1}\right)\right]\left[S\left(c_{2}-c_{1}\right)+s\left(d_{2}-d_{1}\right)-s\left(c_{2}-d_{1}\right)-s\left(d_{2}-c_{1}\right)\right] \\
+ & {\left[R\left(b_{2}-a_{1}\right)+R\left(a_{2}-b_{1}\right)\right]\left[s\left(c_{2}-d_{1}\right)+s\left(d_{2}-c_{1}\right)-s\left(c_{2}-c_{1}\right)-s\left(d_{2}-d_{1}\right)\right] }
\end{aligned}
$$

where

$$
\begin{gathered}
\mathrm{R}\left(\mathrm{Z}_{1}\right) \mathrm{S}\left(\mathrm{Y}_{2}+\mathrm{Y}_{1}\right)=\mathrm{TZ} \tan ^{-1} \frac{\mathrm{Z}_{1}}{\mathrm{~T}}+\frac{1}{4}\left(\mathrm{Z}_{1} \underline{2}^{2}\right) \ln \left(\mathrm{T}^{2}+\mathrm{Z}_{1}^{2}\right) \\
\mathrm{T}^{2}=\mathrm{Y}_{2}{ }^{2}+\mathrm{Y}_{1}{ }^{2}
\end{gathered}
$$




\section{Calculation Sequence:}

1. Determine areas of ceiling, floor, and walls (no windows or doors),

$$
A_{m}, m=1,2,3,4,5,6
$$

2. Calculate radiation shape factor $F_{m-n}$ for these surfaces using equations, and reciprocal relation

$$
F_{m-n}=\frac{A_{n}}{A_{m}} F_{n-m}
$$

3. Determine area of windows and doors and subtract from pertinent wall areas to give net wall areas.

4. Calculate radiation shape factors from windows and/or doors to ceiling and/or floor using the above shape factor equations and the reciprocal relation. The radiation shape factors from a ceiling or floor surface to a window, door, or a wall area is given by

$$
\mathrm{F}_{\mathrm{m}-\mathrm{n}_{\mathrm{k}}}=\mathrm{F}_{\mathrm{m}-\mathrm{n}}-\mathrm{F}_{\mathrm{m}-\mathrm{n}_{1}}-\mathrm{F}_{\mathrm{m}-\mathrm{n}_{2}}
$$

where $k$ denotes the surface which is applicable for a receiving surface, $A_{n}$ that has been subdivided into 2 or more surfaces.

5. Calculate radiation shape factors from windows and doors to walls using equations, above defined angle factor algebra and

$$
A_{m_{k}} F_{m_{k}-n}=A_{m} F_{m-n}-A_{m_{1}} F_{m_{1}-n}-A_{m_{2}} F_{m_{2}-n}
$$


which is applicable for a transmitting surface $A_{m}$ that has been subdivided into 2 or more surfaces.

6. The resulting array $F_{m-n}$ must be satisfied by the identity

$$
\sum_{k=1}^{p} F_{m-k}=1
$$

where $\mathrm{p}$ is the number of surfaces visible to the transmitting surface $\mathrm{A}_{\mathrm{m}}$. 


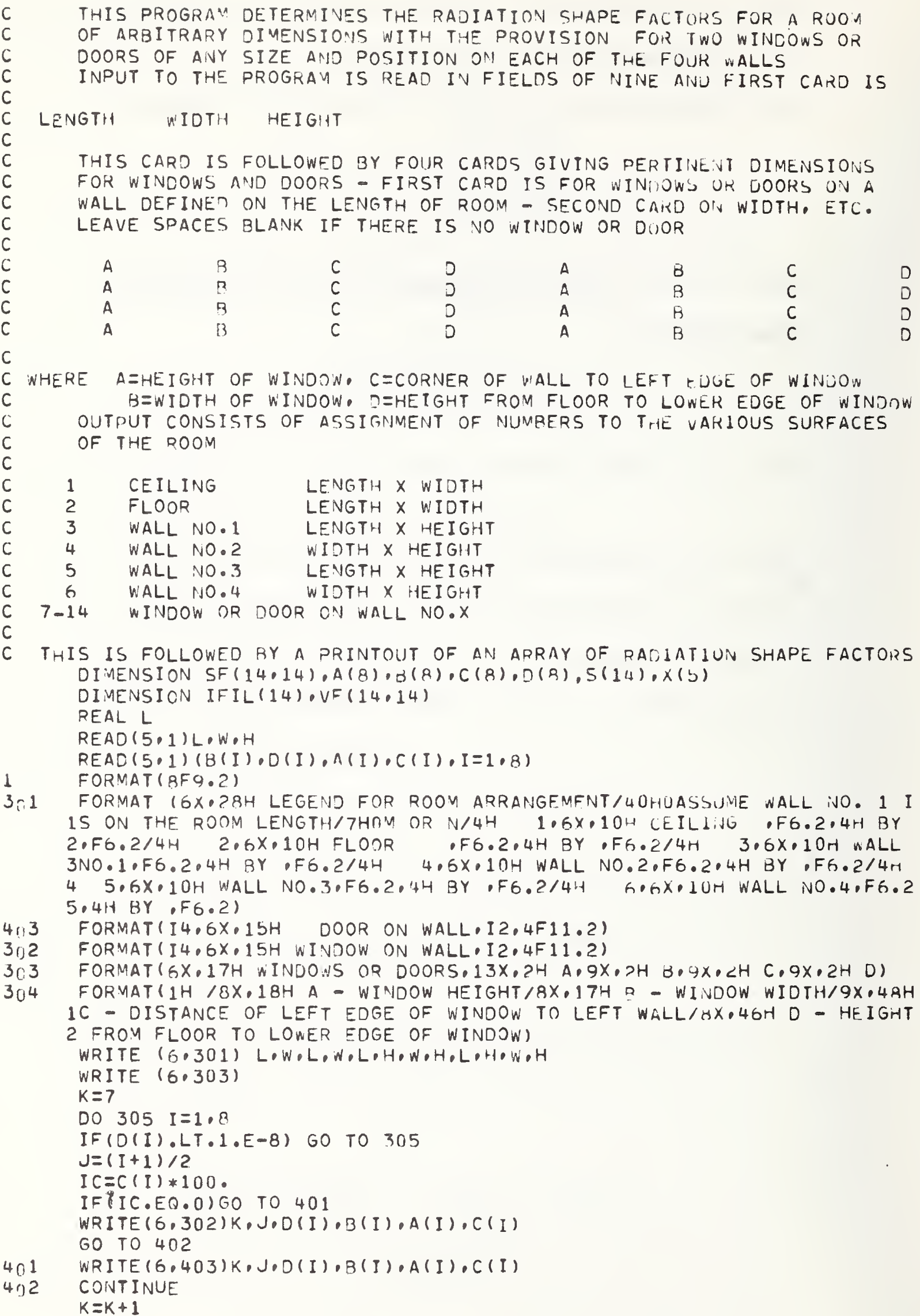


CONT INUE

WRITE $(6.304)$

DO $26 \quad I=1.8$

$B(I)=A(I)+B(I)$

26. $D(I)=C(I)+D(I)$

$S(1)=W * L$

$S(2)=S(1)$

DO $15 \quad I=1.8$

$S(I+G)=(B(I)-A(I)) *(D(I)-C(I))$

$I A=S(I+6)$

IF $(I A \cdot E Q \cdot 0) 5(I+6)=1 \cdot 0 E=08$

15 CONTINUE

DO $14 \quad I=1.5$

$\checkmark A R=L$

IF (I.EQ.2.OR,I EQ.4) VAR $=W$

$14 \quad X(I)=V A R$

DO $25 \quad I=1,4$

$I W=(I-1) * ?+7$

25 $\quad S(I+2)=X(I) * H$

DO $2 I=1.14$

$2 \quad S F(I, J)=0.0$

$\operatorname{SF}(1,2)=\operatorname{PF}(0,0, L, 0,0, W \cdot 0,0, L, 0,0, W \cdot H)$

$S F(1,3)=A F(0,0, L, 0,0, W \cdot \cap, 0, L, 0,0, H)$

$\operatorname{SF}(1,4)=A F(0,0, W, 0,0, L, 0.0, W, 0,0, H)$

$\operatorname{SF}(1,5)=\operatorname{SF}(1,3)$

$\operatorname{SF}(1,6)=\operatorname{SF}(1,4)$

$\operatorname{SF}(2,1)=\operatorname{SF}(1,2) * S(1) / 5(2)$

$\operatorname{SF}(2,3)=\operatorname{SF}(1,3)$

$\operatorname{SF}(2,4)=\operatorname{SF}(1,4)$

$\operatorname{SF}(2,5)=\operatorname{SF}(2,3)$

$\operatorname{SF}(2,6)=S F(2,4)$

$\operatorname{SF}(3,1)=S F(1,3) * S(1) / 5(3)$

$\operatorname{SF}(3,2)=\operatorname{SF}(2,3) * 5(2) / 5(3)$

$\operatorname{SF}(3,4)=A F(0,0, H, 0,0, L, 0,0, H, 0,0, W)$

$\operatorname{SF}(3,5)=P F\left(0,0, L, 0,0, H_{0} 0,0, L, 0,0, H_{0}(1)\right)$

$\operatorname{SF}(3,6)=\operatorname{SF}(3,4)$

$\operatorname{SF}(4,1)=\operatorname{SF}(1,4) * S(1) / 5(4)$

$S F(4,2)=S F(2.4) * S(2) / 5(4)$

$\operatorname{SF}(4,3)=\operatorname{SF}(3,4) * 5(3) / 5(4)$

$\operatorname{SF}(4,5)=\operatorname{SF}(4,3)$

$\operatorname{SF}(4,6)=P F\left(0,0, W \cdot 0 \cdot 0 \cdot H_{0}, 0,0 \cdot W_{0}, 0,0, H, L\right)$

$\operatorname{SF}(5,1)=\operatorname{SF}(1.5) * S(1) / 5(5)$

$\operatorname{SF}(5,2)=\operatorname{SF}(2,5) * S(2) / S(5)$

$S F(5,3)=S F(3,5) * S(3) / S(5)$

$\operatorname{SF}(5,4)=\operatorname{SF}(4,5) * S(4) / S(5)$

$\operatorname{SF}(5,6)=\operatorname{SF}(5,4)$

$\operatorname{SF}(6,1)=\operatorname{SF}(1,6) * S(1) / S(5)$

$\operatorname{SF}(6,2)=\operatorname{SF}(2,6) * S(2) / S(6)$

$\operatorname{SF}(6,3)=\operatorname{SF}(3,6) * S(3) / S(6)$

$\operatorname{SF}(6,4)=\operatorname{SF}(4,6) * S(4) / 5(6)$

$\operatorname{SF}(6.5)=\operatorname{SF}(5,6) * S(5) / 5(5)$

DO $250 \quad I=1,4$

$I W=(I-1) * 2+7$

$250 \quad S(I+2)=5(I+2)-5(I W)-5(I W+1)$

DO $3 K=1,4$

$J=(k-1) * 2$

DO $5 \quad I=1.2$

$N=I+J$

$N 6=N+6$

$S F(N 6,2)=A F(A(N), B(N), C(N), D(N), 0,0, x(K), 0,0 \cdot x(K+1))$

$S F(N G, 1)=A F(A(N), B(N), H-O(N), H-C(N), 0 \cdot 0 \cdot x(K), 0 \cdot 0, x(K+1))$ 
$S F(2 \cdot N 6)=S F(N G \cdot 2) * S(N G) / S(2)$

$S F(1, N 6)=5 F(N 6,1) * 5(N 6) / 5(1)$

$\operatorname{SF}(2 \cdot 2+K)=\operatorname{SF}(2 \cdot 2+K)-S F(2 \cdot J+7)-\operatorname{SF}(2 \cdot J+8)$

$\operatorname{SF}(1,2+K)=\operatorname{SF}(1,2+K)-\operatorname{SF}(1, J+7)-\operatorname{SF}(1, J+8)$

$S F(2+K \cdot 2)=S F(2,2+K) * S(2) / S(2+K)$

$\quad S F(2+K \cdot 1)=S F(1 \cdot 2+K) * S(1) / S(2+K)$

DO \& $K=1,2$

$N=(K-1) * 2$

SUM $=0.0$

DO $6 \quad J=1,2$

$N J=N+J$

$N J 6=N J+6$

$S F(N J 6, K+4)=P F(A(N J), B(N J) \cdot C(N J), O(N J) \cdot 0,0, x(K), 0,0, H \cdot x(K+1))$

$S U M=S U M+S(N J 6) * S F(N J G, K+4)$

$006 I=1,2$

$N I=N+I+4$

$N I G=N I+6$

$S F(N J 6 \cdot N I G)=P F(A(N J), B(N J), C(N J) \cdot D(M J), X(K)-B(N I) \cdot X(K)-A(N I), C(N T)$ 1. D (NI) $\times(K+1))$

SF (NI $6, N J 6)=S F(N J 6, N I 6) * S(N J 6) / S(N I G)$

DO $7 \mathrm{I}=1.2$

$N I=N+I+4$

$N I 6=N I+6$

$S F(N I 6, K+2)=P F(A(N I) \cdot B(N I) \cdot C(N I) \cdot D(N I), 0,0 \cdot Y(n) \cdot U \cdot 0, H \cdot x(K+1))$

$S F(N+7 \cdot K+4)=S F(N+7 \cdot K+4)-S F(N+7 \cdot N+11)-S F(N+7 \cdot N+12)$

$\operatorname{SF}(N+8 \cdot K+4)=S F(N+8 \cdot K+4)-S F(N+8 \cdot N+11)-S F(N+8 \cdot N+12)$

$5 F(N+11, K+2)=5 F(N+11 \cdot K+2)-5 F(N+11 \cdot N+7)-5 F(N+11 \cdot N+8)$

$\operatorname{SF}(N+12 \cdot K+2)=S F(N+12 \cdot K+2)-S F(N+1 ? \cdot N+7)-5 F(N+12 \cdot N+B)$

$5 F(K+4 \cdot N+7)=S F(N+7 \cdot K+4) * 5(N+7) / S(K+4)$

$5 F(K+4 \cdot N+9)=5 F(N+8 \cdot K+4) * 5(N+R) / 5(K+4)$

$S F(K+2 \cdot N+11)=S F(N+11 \cdot k+2) * S(N+11) / 5(K+2)$

$S F(K+2 \cdot N+12)=\operatorname{SF}(N+12, K+2) * S(N+12) / S(K+2)$

$S F(K+2 \cdot K+4)=(x(K) * H * 5 F(K+2 \cdot K+4)-5 U M) / 5(K+2)$

8

$S F(K+2, K+4)=S F(K+2 \cdot K+4)-S F(K+2 \cdot N+11)-S F(K+2 \cdot N+12)$

$S F(K+4 \cdot K+2)=S F(K+2 \cdot K+4) * 5(K+2) / 5(K+4)$

no $9 k=1 \cdot 4$

I $T=K+3$

$I F(K \cdot E Q .4) I T=3$

$I W=(K-1) * 2$

SUM $=0.0$

DO $10 \quad I=1.2$

$I K=I W+I$

$I K G=I K+6$

$S F(I K G, I T)=\Lambda F(C(I K), D(I K), x(K)-B(I K), x(K)-\Lambda(I K), 0, U, H, 0,0, x(K+1))$

$S U M=S U M+S(I K G) * S F(I K G, I T)$

ก० $10 \mathrm{~J}=1 \cdot 2$

$I M=J+I W+2$

$I F(K, E Q \cdot 4) I M=J$

$I M G=I M+6$

$S F(I K G \cdot I M G)=A F(C(I K) \cdot D(I K), X(K)-B(I K), X(K)-A(I K), C(I M) \cdot D(I M) \cdot A(I M)$ $1, B(I M))$

$10 \quad S F(I M G \cdot I K 6)=S F\left(I K G \cdot I M_{6}\right) * S\left(I K_{6}\right) / S(I M G)$

DO $11 \quad I=1,2$

$I L=I W+2+I$

$I F(K \cdot E Q, 4) I L=I$

$I L 6=I L+6$

$11 \quad S F(I L 6 \cdot K+2)=A F(C(I L) \cdot D(I L), A(I L), F(I L), 0,0, H \cdot(i \cdot 0, x(K))$

$I W 7=I W+7$

$I A C=I W 7+2$

$I W L=K+3$

IF (K.NE. 4) GO TO 12

I WL $=3$

I $A C=7$ 
SF (IW7,IWL $)=S F(I W 7, I W L)-S F([W 7, I A C)-S F(I W 7, T A C+1)$

$S F(I W 7+1, I W L)=S F(I W 7+1$, IWL $)-S F(I W 7+1 \cdot I A C)-S F(I A 7+1, \perp A C+1)$

$S F(I A C, I K)=S F(I A C, I K)-S F(I A C, I W 7)-S F(I A C, I W 7+I)$

$S F(I A C+I, I K)=S F(I A C+1, I K)-S F(I A C+1, I W 7)-S F(I A C+1, I W 7+1)$

$S F(I W L, I W 7)=S F(I W 7, I W L) * S(I W 7) / S(I W L)$

$S F(I W L, I W 7+1)=S F(I W 7+1$, IWL $) * S(I W 7+1) / S(I W L)$

$S F(I K, I A C)=S F(I A C, I K) * S(I A C) / S(I K)$

$S F(I K, I A C+1)=5 F(I A C+1, I K) * S(I A C+1) / S(I K)$

$K A C=I K+1$

IF $(K, E Q, 4) K A C=3$

$S F(I K, K A C)=(X(K) * H * S F(I K, K A C)-S U M) / S(I K)$

$S F(I K, K A C)=S F(I K, K A C)-S F(I K, I A C)-S F(I K, I A C+1)$

$9 \quad S F(K A C, I K)=5 F(I K, K A C) * S(I K) / S(K A C)$

$N P=0$

$0052 \quad I=1.14$

$I B=S F(1,1) * 1000$.

IF $(I . E Q .1) I R=1$

IF $(I B . E Q \cdot 0)$ GO TO 52

$N P=N P+1$

IF IL $(N P)=I$

52 CONTINUE

DO $16 \quad I=1$, ND

DO $16 \mathrm{~J}=1$, N N

$N I=I F I L(I)$

$N J=I F I L(J)$

16. $\quad \operatorname{VF}(I, J)=\operatorname{SF}(1 \mathrm{I}, \mathrm{NJJ})$

WI ITE $(6,3 \cap 7)$

3:7 FORMATIIH /4X,44H ADRAY FOR SHAPE FACTOPS FROW SURFACE Y TO W/1H) WRITE $(5,17)(I, I=1, N O)$

17 FORMAT $(4 \mathrm{H}$ M/N.I5.13I7)

DO $18 \quad I=1$, ND

18 WRITE $(6,19)(I,(V F(I, J), J=1, N P))$

19 FORVAT $(1 X, I 2,1 X, 14 F 7.5)$

STOP

END

FUNCTION PF $(A 1, B 1, C 1, D 1, A 2, B 2, C 2,02, G)$

C THIS FUNCTION SUBPROGRAM CALCULATES THE SHATE FACTUR FROM A

C PLANE RECTANGULAR SIJRFACE TO ANOTHER PARALLEL PLANE

C RECTANGULAR SURFACE.

$S=(B 1-A 1) *(D 1-C 1)$

$I P=S * 10$.

IF (IP.NE・O)GO TO 1

$P F=0.0$

RETURN

$1 \quad F=F 1(B 1, D 1,32, D 2, G)-F 1(B 1,01,32, C 2, G)$

$1-F 1(B 1, D 1, A 2, D 2, G)+F 1(B 1, D 1, A 2, C 2, G)$

$2-F 1(B 1, C 1, B 2, D 2, G)+F 1(B 1, C 1, B 2, C 2, G)$

$3+F 1(B 1, C 1, A 2, D 2, G)=F 1(B 1, C 1, A 2, C 2, G)$

$4-F 1(A 1, D 1, B 2, D 2, G)+F 1(A 1, D 1, B 2, C 2, G)$

$5+F 1(A 1, D 1, A 2, D 2, G)-F 1(A 1, D 1, A 2, C 2, G)$

$G+F 1(A 1, C 1, B 2, D 2, G)-F 1(A 1, C 1, B 2, C 2, G)$

$7-F 1(A 1, C 1, A 2, D 2, G)+F 1(A 1, C 1, A 2, C 2, G)$

$P F=F /(3.1415927 * S)$

RETURN

END 
FUNCTION $F 1(X 1, Y 1, X 2, Y 2, G)$

$U=X 2-X 1$

$V=Y 2-Y 1$

$U U=S Q R T(G * G+U * U)$

$V V=S \otimes R T(G * G+V * V)$

$W W=(G * G+U * U+V * V) /(G * G+V * V)$

$F I=U * V V * A T A N(U / V V)+V * U U * A T A N(V / U U)-G * G * L O G(W W) / 2$.

$F 1=F I / 2$.

RETURN

END

FUNCTION AF(A1,B1,C1,D1,A2,B2,C2,D2)

C THIS FUNCTION SURPROGRAM CALCULATES

c

C

PLANE RECTANGULAR SURFACE OF A ROOM

TO ANOTHER PERPENDICULAR

PLANE RECTANGULAR SURFACE.

$S=(B 1-A 1) *(D)-C 1)$

$I P=5 * 10$.

IF (IP.NE.0) GO TO 1

$A F=0.0$

RETURN

$1 \quad F=F 2(A 1, C 1, A 2, C 2)+F 2(B 1 \cdot D 1 \cdot B 2, D 2)$

$1=F 2(A 1, D 1, B 2, D 2)-F 2(B 1, D 1,32, C 2)$

$2+F 2(A 1 \cdot D 1 \cdot B 2 \cdot C 2)-F 2(B 1 \cdot D 1 \cdot A 2 \cdot D 2)$

$3+F 2(A 1, D 1, A 2 \cdot D 2)+F 2(B 1,01, A 2, C 2)$

$4-F 2(A 1, D 1, A 2, C ?)-F 2(B 1, C 1, B 2, D 2)$

$5+F 2(A 1, C 1, B 2, D 2)+F 2(B 1, C 1, B 2, C 2)$

$6-F 2(A 1, C 1,32, C 2)+F 2(31, C 1, A 2, D 2)$

$7-F 2(A 1, C 1, A 2, D 2)-F 2(B 1, C 1, A 2, C 2)$

$A F=F /(3.1415927 * S)$

RETURN

END

FUNCTION F2 $\left(X_{1}, Y_{1}, X_{2}, Y_{2}\right)$

$U=x 2-x 1$

$V=Y 1 * 2+Y 2 * * 2$

IF $(A B S(U * 2+V) \cdot L E \cdot 1 \cdot 0 E-7)$ GO TO 1

GO TO 2

$1 F 2=0.0$

GO TO 3

2 IF $(V \cdot L E, 1 . O F-7)$ GO TO 4

GO TO 5

$4 F 2=.5 * U * * 2 * \operatorname{LOG}(U * * 2)$

GO TO 3

$5 F 2=.5 *(U * 2-V) * L O G(U * * 2+V)+2 * U * S Q R T(V) * A T A N(U / S Q R T(V))$

3 F $2=F 2 / 4$.

RETURN

END 
ASSUME WALL NO. I IS ON THE ROOM LENGTH

$M O R N$

$\begin{array}{lllll}1 & \text { CEILING } & 16.00 & \text { BY } & 12.00 \\ 2 & \text { FLOOR } & 16.00 & 8 Y & 12.00 \\ 3 & \text { WALL NO.1 } & 16.00 & \text { BY } & 8.00 \\ 4 & \text { WALL NO.2 } & 12.00 & \text { BY } & 8.00 \\ 5 & \text { WALL NO.3 } & 16.00 & \text { BY } & 8.00 \\ 6 & \text { WALL NO.4 } & 12.00 & \text { BY } & 8.00\end{array}$

7 WINUOWS OR DOORS

$\begin{array}{rrr}A & R & C \\ 4.00 & 2.67 & 6.67 \\ 4.00 & 2.67 & 6.67\end{array}$

WINDOW ON WALL 2

WINDOW ON WALL 3

2.67

6.67
A - WINDOW HEIGHT
$B$ - WINDON WIDTH
C - DISTANCE OF LEFT EDGE OF WINDOW TO LEFT WALL
D - HEIGHT FROM FLOOR TO LOWER EDGE OF WINDOW

ARRAY FOR SHAPE FACTORS FROM SURFACE M TO N

$\begin{array}{ccccccccc}M / N & 1 & 2 & 3 & 4 & 5 & 6 & 7 & A \\ 1 & .00000 & .36405 & .18326 & .11766 & .16504 & .13472 & .01706 & .01822 \\ 2 & .36405 & .00000 & .18326 & .12078 & .16824 & .13472 & .01394 & .01501 \\ 3 & .27488 & .27488 & .00000 & .12759 & .15887 & .13715 & .00956 & .01706 \\ 4 & .26473 & .27176 & .19139 & .00000 & .16715 & .09464 & .00000 & .01033 \\ 5 & .27006 & .27531 & .17332 & .12157 & .00000 & .14066 & .01909 & .00000 \\ 6 & .126944 & .26944 & .18286 & .08412 & .17192 & .00000 & .01127 & .01095 \\ 7 & .130709 & .25086 & .11468 & .00000 & .01001 & .10144 & .00000 & .01592 \\ 8 & .32793 & .27026 & .20474 & .08261 & .00000 & .09853 & .01592 & .00000\end{array}$


An Algorithm for Calculating Radiation Shape Factors Between Attic Surfaces Where the Attic Has a Gabled Room

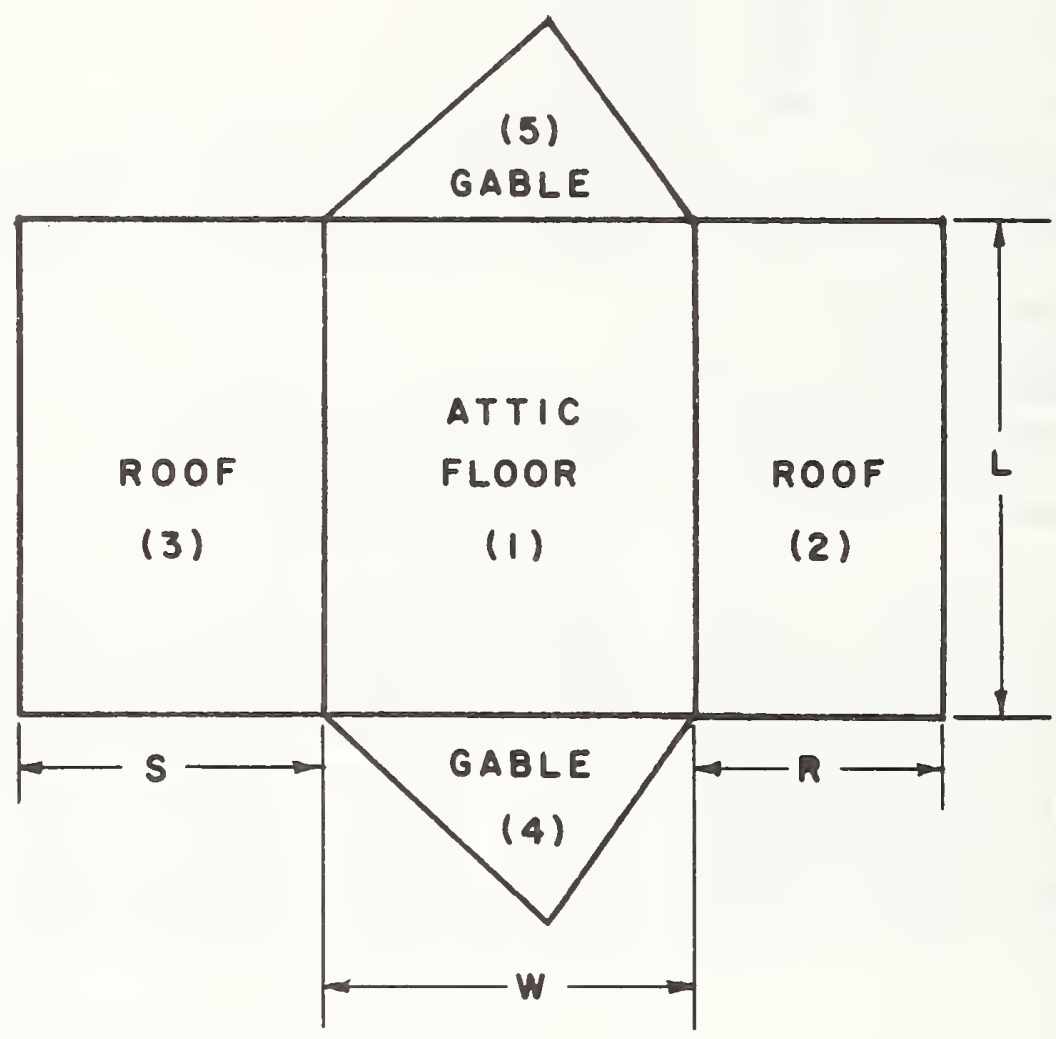

Figure A-13 Definitions of Attic Enclosure

Data:

$$
\begin{aligned}
& L=\text { Length of attic floor } \\
& W=\text { Width of attic }
\end{aligned}
$$

This section was contributed by B. A. Peavy and D. M. Burch, Thermal Engineering Systems Section, Center for Building Technology, National Bureau of Standards, Washington, D. C. 20234. 
The primary variables determined by this subroutine are:
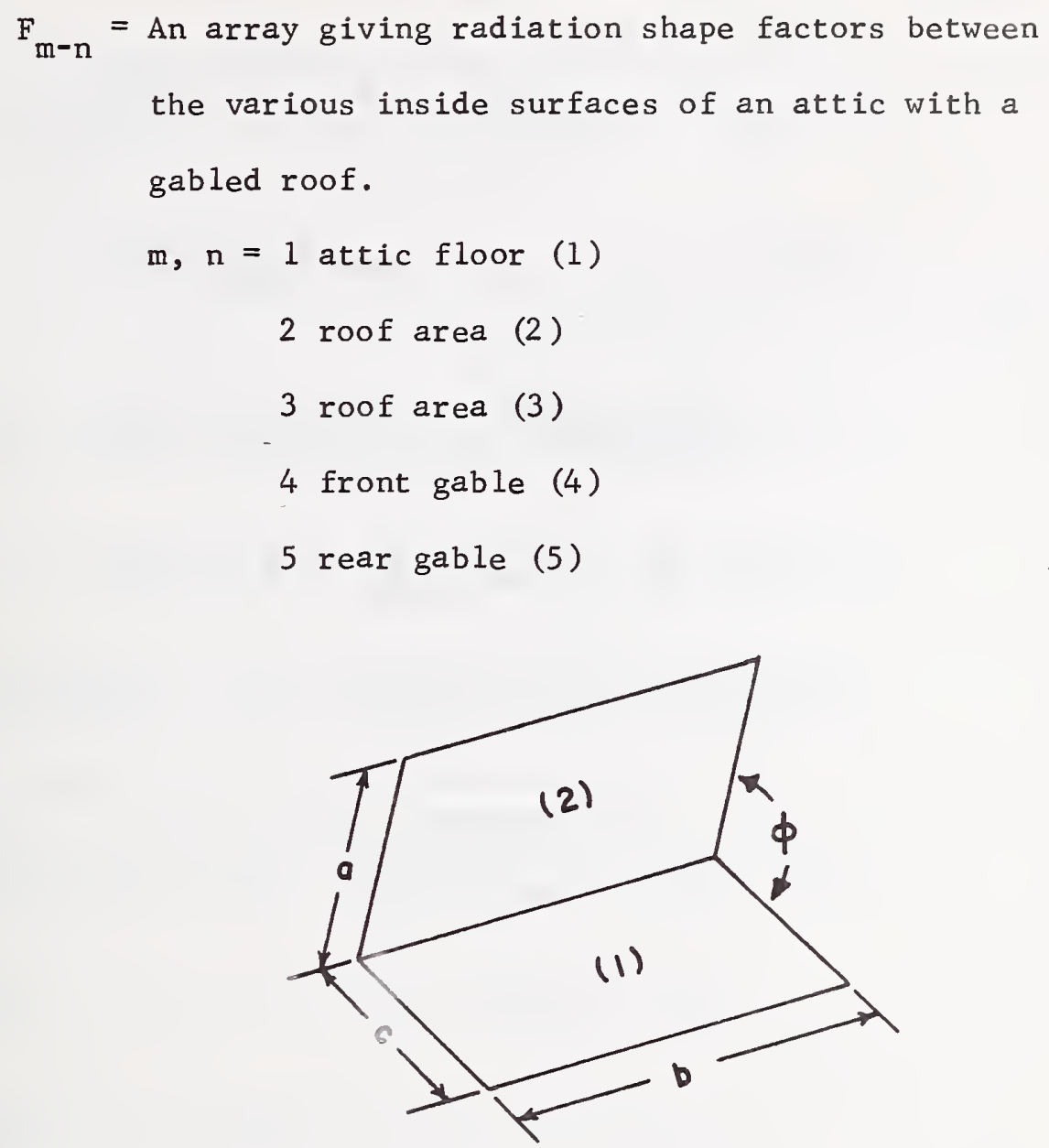
Figure A-14 Radiation Heat Ex- change Between Two Adjacent Surfaces

$$
X=\frac{a}{b}, Y=\frac{c}{b}, Z^{2}=X^{2}+Y^{2}-2 X Y \cos \phi
$$




$$
\begin{aligned}
& \pi Y F_{1-2}=-\frac{\sin 2 \phi}{4}\left\{X Y \sin \phi+\left(\frac{\pi}{2}-\phi\right)\left(X^{2}+Y^{2}\right)\right. \\
& \left.+Y^{2} \tan ^{-1}\left(\frac{X-Y \cos \phi}{Y \sin \phi}\right)+X^{2} \tan ^{-1}\left(\frac{Y-X \cos \phi}{X \sin \phi}\right)\right\} \\
& +\frac{\sin ^{2} \phi}{4}\left\{\left(\frac{2}{\sin ^{2} \phi}-1\right) \ln \left[\frac{\left(1+X^{2}\right)\left(1+Y^{2}\right)}{1+z^{2}}\right]\right. \\
& \left.+Y^{2} \ln \left[\frac{Y^{2}\left(1+Z^{2}\right)}{\left(1+Y^{2}\right) Z^{2}}\right]+X^{2} \cos 2 \phi \ln \left[\frac{1+X^{2}}{1+Z^{2}}\right]+2 x^{2} \ln \frac{X}{Z}\right\} \\
& +Y \tan ^{-1}\left(\frac{1}{Y}\right)+X \tan ^{-1}\left(\frac{1}{X}\right)-Z \tan ^{-1}\left(\frac{1}{Z}\right) \\
& +\frac{\sin \phi \sin 2 \phi}{2} \times \sqrt{1+X^{2} \sin ^{2} \phi}\left\{\tan ^{-1}\left[\frac{Y\left(1+X^{2} \sin ^{2} \phi\right)}{1+X^{2}-X Y \cos \phi}\right]\right\} \\
& +\cos \phi \int_{0}^{Y} \sqrt{1+\lambda^{2} \sin ^{2} \phi}\left\{\tan ^{-1}\left[\frac{x\left(1+\lambda^{2} \sin ^{2} \phi\right)}{1+\lambda^{2}-\lambda x \cos \phi}\right\} d \lambda\right. \\
& \sum_{m=1}^{5} F_{n-m}=1 \\
& \mathrm{~F}_{\mathrm{n}-\mathrm{m}}=\frac{\mathrm{A}_{\mathrm{m}} \mathrm{F}_{\mathrm{m}-\mathrm{n}}}{\mathrm{A}_{\mathrm{n}}}
\end{aligned}
$$

$A_{m}$ is area of surface $m$ 
Calculation Sequence:

1. $\mathrm{X}=\mathrm{R} / \mathrm{L}, \mathrm{Y}=\mathrm{W} / \mathrm{L}, \phi_{1}=\cos ^{-1}\left(\frac{\mathrm{W}^{2}+\mathrm{R}^{2}-\mathrm{S}^{2}}{2 \mathrm{WR}}\right)$

Compute $\mathrm{F}_{1-2}, \mathrm{~F}_{2-1}$ [Equations (1) and (3)]

2. If $S=R, \phi_{2}=\phi_{1}, F_{1-3}=F_{1-2}, F_{3-1}=F_{2-1}$, skip stage 3

3. $X=S / L, Y=W / L, \phi_{2}=\cos ^{-1}\left(\frac{W^{2}+S^{2}-R^{2}}{2 W S}\right)$

Compute $F_{1-3}, F_{3-1}$ [Equations (1) and (3)]

4. $\mathrm{X}=\mathrm{S} / \mathrm{L}, \mathrm{Y}=\mathrm{R} / \mathrm{L}, \phi_{3}=\pi-\phi_{1}-\phi_{2}$

Compute $\mathrm{F}_{2-3}, \mathrm{~F}_{3-2}$ [Equations (1) and (3)]

5. $\mathrm{F}_{\mathrm{m}-4}, \mathrm{~F}_{\mathrm{m}-5}, \mathrm{~m}=1,2,3$ [Equation (2)]

6. $\mathrm{F}_{4-\mathrm{m}}, \mathrm{F}_{5-\mathrm{m}}, \mathrm{m}=1,2,3$ [Equation (3)]

7. $\mathrm{F}_{4-5}, \mathrm{~F}_{5-4}$ [Equation (2)] 
An Algorithm for Approximating Inside Surface Heat Transfer

Coefficients Tabulated in Table 1, Page 357 of the 1972

ASHRAE Handbook of Fundamentals

\title{
Data:
}

IDIR: Heat flow direction index

\author{
1 Upward \\ $245^{\circ}$ upward \\ $\operatorname{IDIR}=3$ Horizontal \\ $445^{\circ}$ downward \\ 5 Downward \\ $\varepsilon$ : Emittance of the surface \\ IV: Moving air index (IV $=0$ corresponds to still air)
}

\section{Calculation Sequence:}

1. If IV $=0, \quad F I=h_{c}+1.02 * \varepsilon$

where

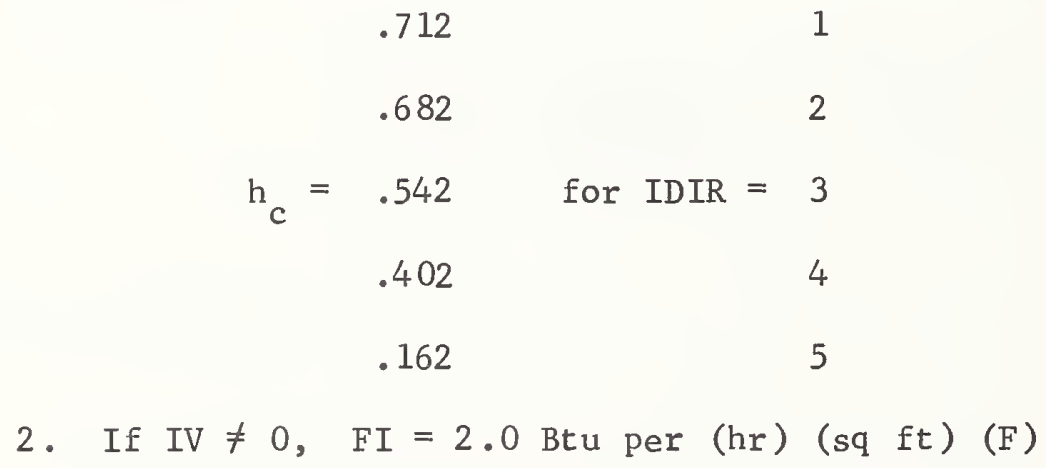


An Algorithm for Determining Outside Surface Heat Transfer

Coefficient As a Function of Air Velocity and the Type of Surface Constructions

\section{Data:}

$\mathrm{V}$ : Wind velocity, knots (Determined in CLIMATE)

DIR: Wind direction (Determined in CLIMATE)

IS: Outside surface index

$$
\begin{aligned}
& 1 \text { Stucco } \\
& 2 \text { Brick and rough plaster } \\
& 3 \text { Concrete } \\
& \text { IS }=4 \text { clear pine } \\
& 5 \text { Smooth plaster } \\
& 6 \text { Glass, white paint on pine }
\end{aligned}
$$

\section{Calculation Sequence:}

1. Conversion of the unit of wind velocity from knots into mph. $\mathrm{V}^{\prime}=1.153 * \mathrm{~V}$

2. Outside surface heat transfer coefficient. $F O=A *\left(V^{\prime} * * 2\right)+B * V^{\prime}+C$ where $A, B$ and $C$ are given in Table $A-8$ 
Table A-8

Value of Coefficients For Calculation
of Outside Heat Transfer Coefficient

IS

A

B

C

1

0.0

0.464

2.04

2

0.001

0.320

2.20

3

0.0

0.330

1.90

4

$-0.002$

0.315

1.45

5

0.0

0.244

1.80

$6 \quad-0.00125$

0.262

1.45

3. Relative wind direction to the wall surface.

$$
\begin{aligned}
& \text { RWD }=W A+180=\mathrm{DIR} \\
& \text { If }|\operatorname{RWD}|>180, \mathrm{RWD}=360-\mathrm{RWD}
\end{aligned}
$$

4. Conversion of the unit of wind velocity into m per sec.

$$
\mathrm{VV}=0.51479 \% \mathrm{~V}
$$

5. Air velocity close to wall surface

$$
\begin{aligned}
& \text { If } \mid \text { RWD } \mid<90 \text { (windward) } \\
& V C=0.25 * V V \text { for } V V>2 \\
& V C=0.5 \quad \text { for } V V \leq 2 \\
& \text { If } \mid \text { RWD } \mid \geq 90 \text { (leeward) } \\
& V C=0.3+0.05 * V V
\end{aligned}
$$


6. Convection component of the outside surface heat transfer coefficient.

$$
\text { FOC }=3.28 *((V C) * 0.605) *
$$

\footnotetext{
This equation was derived by $K$. Kimura based upon the recent data published in Reference 6.
} 


\section{$\underline{A C R}$ *}

An Algorithm for Determining Thermal Resistance Across the Air Cavity in Walls and Roofs

\section{Data:}

DT: Temperature difference across the air space, F

L: Thickness of the air space, in.

IDIR: Heat flow direction index

$$
\begin{array}{cll} 
& 1 \text { upward } \\
& 2 & 45^{\circ} \text { upward } \\
\text { IDIR }= & 3 & \text { horizonta1 } \\
4 & 45^{\circ} \text { downward } \\
& 5 \text { downward }
\end{array}
$$

$\varepsilon_{1}, \varepsilon_{2}$ : Emittance of the surfaces facing the air cavity

ATC: Average temperature of the air cavity, F

\section{Calculation Sequence:}

1. Let $x=\log (\mathrm{DT} *(\operatorname{L} * * 3))$

Then using the values for $A_{0}, A_{1}, A_{2}, A_{3}$, and $A_{4}$ which are given in Table A-9, calculate

$$
y=A_{0}+A_{1} * x+A_{2} *(x * * 2)+A_{3} *(x * * 3)+A_{4} *(x * * 4)^{* 1}
$$

$\star$

This polynomial has been derived to represent experimental data presented in Figure 6 of reference 7 and shown here in Figure A- 15 . 
Table A-9 VALUES OF $A_{0}, A_{1}, A_{2}, A_{3}$, and $A_{4}$ FOR CALCULATION OF RESISTANCE ACROSS THE AIR SPACE

\begin{tabular}{|c|c|c|c|c|c|c|}
\hline IDIR & Range of DT* (L**3) & ${ }^{A_{0}}$ & $\mathrm{~A}_{1}$ & $\mathrm{~A}_{2}$ & $\mathrm{~A}_{3}$ & $\mathrm{~A}_{4}$ \\
\hline 11 & Al1 the range & -1.5904 & 0.2824 & 0.0 & 0.0 & 0.0 \\
\hline 22 & $\begin{aligned} & 1 \leq \mathrm{DT} *(\mathrm{I} * * 3) \leq 10 \\
& 10<\mathrm{DT} *(\mathrm{I} * * 3) \leq 100 \\
& 100<\mathrm{DT} *(\mathrm{I} * 3)\end{aligned}$ & $\begin{array}{l}-1.7125 \\
-1.8546 \\
-1.7380\end{array}$ & $\begin{array}{r}-0.0875 \\
0.3124 \\
0.2910\end{array}$ & $\begin{array}{l}0.2437 \\
0.0 \\
0.0\end{array}$ & $\begin{array}{l}-0.0420 \\
0.0 \\
0.0\end{array}$ & $\begin{array}{l}0.0 \\
0.0 \\
0.0\end{array}$ \\
\hline 3 & $\begin{aligned} 1 & \leq \mathrm{DT} *(\mathrm{~L} * 3) \leq 10 \\
10<\mathrm{DT} *(\mathrm{~L} * 3) & \leq 100 \\
100 & <\mathrm{DT} *(\mathrm{~L} * 3)\end{aligned}$ & $\begin{array}{r}-1.7410 \\
1.0460 \\
-0.2141\end{array}$ & $\begin{array}{l}-0.0331 \\
-3.4660 \\
-0.6577\end{array}$ & $\begin{array}{l}0.0198 \\
1.5482 \\
0.1693\end{array}$ & $\begin{array}{l}-0.0146 \\
-0.2669 \\
-0.0095\end{array}$ & $\begin{array}{l}0.0 \\
0.01673 \\
0.0\end{array}$ \\
\hline 4 & $\begin{aligned} & 1<\mathrm{DT} *(\mathrm{I} * * 3) \leq 10 \\
& 10<\mathrm{DT} *(\mathrm{I} * * 3) \leq 100 \\
& 100<\mathrm{DT} *(\mathrm{~L} * 3)\end{aligned}$ & $\begin{array}{l}-1.7420 \\
-6.5410 \\
-0.1914\end{array}$ & $\begin{array}{l}0.0163 \\
5.5710 \\
6.1610\end{array}$ & $\begin{array}{l}-0.0409 \\
-2.3690 \\
-1.3390\end{array}$ & $\begin{array}{l}0.0204 \\
0.4467 \\
0.1339\end{array}$ & $\begin{aligned} & 0.0 \\
- & 0.0300 \\
- & 0.0050\end{aligned}$ \\
\hline 5 & $\begin{aligned} 1 & <\mathrm{DT} *(\mathrm{~L} * 3 * 3) \leq 10 \\
10 & <\mathrm{DT} *(\mathrm{~L} * 3)\end{aligned}$ & $\begin{array}{l}-1.770 \\
-1.745\end{array}$ & $\begin{array}{l}0.0 \\
0.0028\end{array}$ & $\begin{array}{l}0.0 \\
0.0029\end{array}$ & $\begin{array}{l}0.0 \\
0.0008\end{array}$ & $\begin{array}{l}0.0 \\
0.0\end{array}$ \\
\hline
\end{tabular}

2. Let $z=\operatorname{Exp}(y)$

$$
\begin{array}{ll}
\text { If } z>0.3 & \mathrm{~h}_{\mathrm{c}}=\mathrm{z} *(1-0.001 *(\mathrm{DT}-50)) / \mathrm{L} \\
\text { If } 0.2 \leq \mathrm{z} \leq 0.3 & \mathrm{~h}_{\mathrm{c}}=\mathrm{z} *(1+0.00035 *(\mathrm{DT}-50)) / \mathrm{L} \\
\text { If } \mathrm{z}<0.2 & \mathrm{~h}_{\mathrm{c}}=\mathrm{z} *(1+0.0017 *(\mathrm{DT}-50)) / \mathrm{L}
\end{array}
$$

3. $h_{r}=0.00686 *(((\operatorname{ATC}+460) / 100) * * 3)^{* * /}$

4. $\operatorname{RES}=1 /\left(\mathrm{h}_{c}+\left(1 /\left(1 / \epsilon_{1}+1 / \epsilon_{\mathfrak{Z}}-1\right)\right) * \mathrm{~h}_{r}\right)$

*: This polynomial has been derived to represent the curve presented in Figure 5 of reference 7 and shown here in Figure A-16. 


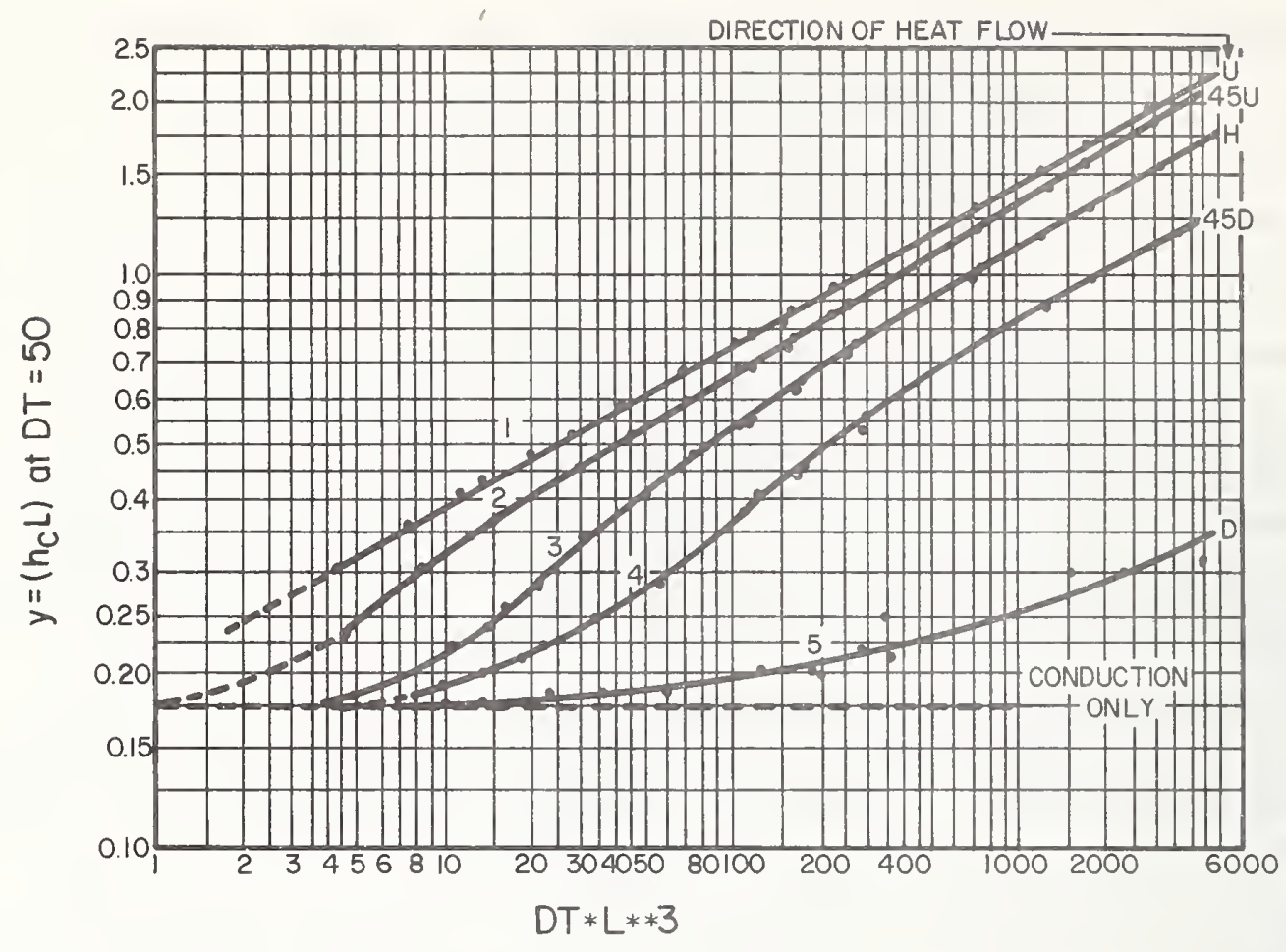

Figure A-15 Convection-Conduction Coefficient for Heat Transfer Across an Air Space for Five Orientations of the Air Space and Directions of Heat Flow

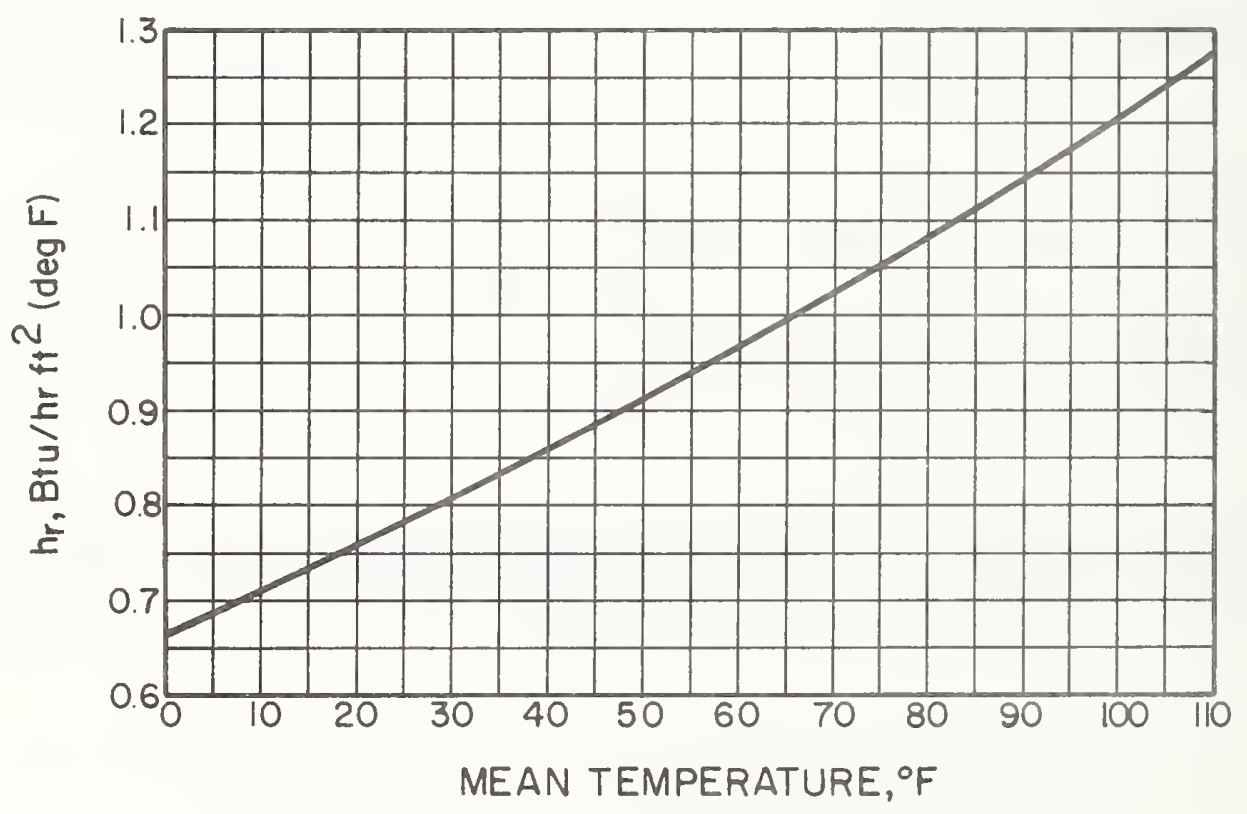

Figure A-16 Linear Radiation Coefficient for Heat Transfer Across an Air Space for a Radiation Interchange Factor 
A Description of the Calculation Procedure for Transient Heat Conduction Using Conduction Transfer Functions

Conduction transfer functions are used widely and considered as a convenient and effective tool for the evaluation of transient heat transfer in building construction components. The conventional steady state heat transfer equation for calculating heat loss:

$$
\mathrm{Q}=\mathrm{U} *\left(\mathrm{~T}_{\mathrm{a}}-\mathrm{T}_{\mathrm{o}}\right)
$$

where $U$ : overall heat transfer coefficient of roof or wall

$\mathrm{T}_{\mathrm{a}}$ : inside air temperature

$\mathrm{T}_{\mathrm{o}}$ : outside air temperature

is not sufficient for evaluating transient heat transfer. This equation becomes invalid because the outdoor temperature $\mathrm{T}_{\mathrm{o}}$ usually varies as affected by solar radiation, cloud cover and wind effect. The effect of the rapid change of the outdoor temperature will not be accounted for unless the structure is extremely lightweight, such as galvanized steel. Approximate calculation for a more accurate determination of the instantaneous heat transfer can be made by replacing $\mathrm{T}_{a}-\mathrm{T}_{0}$ of equation (1) by a Total Equivalent Temperature Difference (TETD) which is usually precalculated for typical building construction components and takes into account the thermal storage effect. Although very useful, the TETD concept is only valid when the outside temperature $T_{0}$ undergoes steady periodic changes. The TETD concept is therefore especially useful computing design heat transfer rates for the building where very warm or very cold 
conditions are assumed to occur for several successive days.

A more accurate formulation for conduction heat transfer from a room to randomly fluctuating outdoor conditions is to use the hourly history of temperatures in conjunction with Conduction Transfer Functions (CTF). For example, in calculating the energy transfer from a room at an inside surface, the equation would be:

$$
Q_{i, t}=\sum_{j=0}^{N} X_{j} * T_{a, t-j}-\sum_{j=0}^{N} Y_{j} * T_{o, t-j}+R * Q_{t-1}
$$

where $X_{j}, Y_{j}$ (for $j=0,1,2 \ldots N$ ), and $R$ are the Conduction Transfer Functions. In equation (2), $T_{0, t-j}$ and $T_{a, t-j}$ represent outdoor and room air temperatures respectively at jth hour prior to the time for which the value of $Q_{t}$ is needed. And $Q_{t-1}$ is the heat loss $Q_{t}$, from the room at the previous hour. By having a record of $\mathrm{T}_{0, t-1}, \mathrm{~T}_{0, t-2}, \mathrm{~T}_{0, t-3} \ldots$ $T_{o, t-j}$; and $T_{a, t-1}, T_{a, t-2} \cdots T_{a, t-j}$; it is possible to determine the instantaneous conduction transfer, provided that the values for $\mathrm{x}_{\mathrm{j}}$ and $Y_{j}$, and $R$ are available.

The number of terms involved for the calculation of $Q_{t}$ (or the value of $\mathrm{N}$ in equation (2)) depends upon the type of roof or wall construction. Genera1ly heavy constructions require a large value, although for most conventional constructions, it seldom exceeds 20. Stephenson amd Mitalas ${ }^{8} /$ have shown that the value of $\mathrm{N}$ can be further decreased by employing more than one past record of $Q_{t}$ (or $Q_{t-j}$ with $j$ being more than 1 ) in the following manner: 


$$
Q_{i, t}=\sum_{j=0}^{N^{\prime}} A_{j} * T_{a, t-j}-\sum_{j=0}^{N^{\prime}} B_{j} * T T_{0, t-j}-\sum_{j=1}^{N} D_{j} * Q_{i, t-j}
$$

where $A_{j}, B_{j}$, and $D_{j}$ are the Modified Conduction Transfer Functions according to Stephenson and Mitalas ${ }^{8 /}$. Table A-10 gives values of Conduction Transfer Functions calculated for a brick wall having an overall heat transfer coefficient of 0.418 . In this table, the factors designated by $z_{j}$ and $C_{j}$ are the additional transfer function to be used for evaluating the instantaneous heat loss $Q_{0, t}$ at the exterior side of the structure. The applicable equations for this side of the structure are then:

$$
Q_{o, t}=\sum_{j=0}^{N} Y_{j} * T_{a, t-j}-\sum_{j=0}^{N} Z_{j} * T_{0, t-j}+R * Q_{o, t-1}
$$

or

$$
Q_{o, t}=\sum_{j=0}^{N^{\prime}} B_{j} * T a, t-j-\sum_{j=0}^{N^{\prime}} C_{j} * T_{0, t-j}-\sum_{j=1}^{N^{\prime}} D_{j} * Q_{0, t-j}
$$

The table also shows that for the calculation of $Q_{0, t}$ the use of Stephenson type transfer functions would permit the reduction of $\mathrm{N}$ from 10 to $N^{\prime}=4$ with a corresponding increase of three terms in the past record of $Q_{0, t^{\circ}}$ 


\begin{tabular}{|c|c|c|c|c|c|}
\hline Construction & $\begin{array}{l}\text { Data } \\
\text { Thickness } \\
\quad(I) \\
\end{array}$ & $\begin{array}{c}\text { Thermal } \\
\text { Conductivity } \\
\text { Btuh/ft }\end{array}$ & $\begin{array}{l}\text { Density } \\
1 \mathrm{~b} / \mathrm{ft}^{3} \\
\end{array}$ & $\begin{array}{l}\text { Specific } \\
\text { Heat } \\
\text { Btu/lb }{ }^{\circ} \mathrm{F} \\
\end{array}$ & $\begin{array}{c}\text { Thermal } \\
\text { Resistance } \\
\text { sq ft hr } \\
\text { F/Btu } \\
\end{array}$ \\
\hline Surface & 0.000 & -- & -- & -- & .830 \\
\hline $\begin{array}{l}4 \text {-in com- } \\
\text { mon brick }\end{array}$ & 0.333 & .420 & 100.42 & .220 & .793 \\
\hline $\begin{array}{l}\text { 4-in face } \\
\text { brick }\end{array}$ & 0.333 & .770 & 125.00 & .220 & 0.432 \\
\hline $\begin{array}{l}\text { Outside } \\
\text { surface }\end{array}$ & 0.000 & -- & -- & -- & .330 \\
\hline $\begin{array}{l}\text { Time incremen } \\
\text { Overall heat }\end{array}$ & $\begin{array}{l}\text { nt: } 1 \text { hour } \\
\text { transfer } c c\end{array}$ & Eicient & 0.418 & & 2.385 \\
\hline
\end{tabular}

Conduction Transfer Functions (CTF)

$\begin{array}{rrrrr}j & X_{j} & Y_{j} & Z_{j} & R \\ 0 & .9194 & .0001 & 1.9833 & 0.8398 \\ 1 & -.9391 & .0080 & -2.1785 & \\ 2 & .0606 & .0243 & .1983 & \\ 3 & .0153 & .0186 & .0387 & \\ 4 & .0061 & .0090 & .0144 & \\ 5 & .0026 & .0039 & .0060 & \\ 6 & .0011 & .0017 & .0026 & \\ 7 & .0005 & .0007 & .0011 & \\ 8 & .0002 & .0003 & .0005 & \\ 9 & .0001 & .0001 & .0002 & \\ 10 & .0000 & .0001 & .0001 & \end{array}$

Stephenson Type Transfer Functions

$\begin{array}{rrrrr}j & \mathrm{~A}_{j} & \mathrm{~B}_{j} & \mathrm{C}_{j} & \mathrm{D}_{j} \\ 0 & 0.9194 & 0.0001 & 1.9833 & 1.000 \\ 1 & -1.4128 & 0.0079 & -3.2002 & -1.3552 \\ 2 & 0.5785 & 0.0202 & 1.3942 & 0.4699 \\ 3 & -0.0511 & 0.0064 & -0.1448 & 0.0315 \\ 4 & 0.0007 & 0.0002 & 0.0024 & 0.0002\end{array}$


NL: Number of layers to be considered for the analysis of a given structure: the number of layers should include surface resistance or air cavity resistance if they contribute significantly to the overall heat transfer of that particular structure

$\mathrm{K}_{\mathrm{i}}$ : Thermal conductivity of $i-t h$ layer in Btu per (hr) (ft) (F). This value is not needed for air cavities or for the surface resistance layers.

$\rho_{i}:$ Density of $i-t h$ layer in $1 \mathrm{~b}$ per (cu. ft). This value is not needed for air cavities or for the surface resistance layers

$C_{i}:$ Specific heat of $i-t h$ layer material in Btu per (1b) (F). This value is not needed for air cavities or for the surface resistance layers.

$\mathrm{L}_{i}$ : Thickness of the $i-t h$ layer in $\mathrm{ft}$. This value is not needed for the air cavities or for the surface resistance layers.

RES $_{i}$ : Thermal resistance of air cavities and surface resistance layers in (hr) (sq ft) (F) per Btu. This value is not needed whenever all of the remaining values such as $K_{i}, \rho_{i}, C_{i}$ and $L_{i}$ are given. 
DT: Time increment for the conduction transfer functions in hr (usually one hour for the building heat transfer calculations).

Subscript $i$ refers to $i-t h$ layer and it varies from 1 to NL.

The sequence of inputing the above property values for each layer is very important and must be consistent with the particular convention adopted for the specific calculation routine. The sequence must follow in order from the inside layer to the outside layer or vice versa. It should be noted that the inclusion of the surface thermal resistance as independent layers is optional depending upon the end use of the conduction transfer functions. If the inside surface temperature is to be computed as a balance of all the heat flow involved at that surface, the thermal resistance of the inside surface should not be included in the calculation of the conduction transfer functions. The same comment applies for the outside surface.

An algorithm for the calculation of the conduction heat transfer functions will not be given here, since it involves lengthy mathematical solutions to the standard transient heat conduction differential equation. Reference (9) provides an excellent background for this calculation. Several computer programs $\frac{10,11 /}{}$ are available for the calculation of conduction transfer functions for multi-layer walls, roofs and floor constructions. The program developed by the National Research Council of Canada $10 /$ requires the layer input to be placed in order from outside toward inside. It calculates the Stephenson type conduction transfer 
functions directly. The program of the National Bureau of Standards $11 /$ requires the input to be placed from the inside layer first and calculates the conduction transfer functions of plane, cylindrical and spherical walls. It also calculates the transfer functions for solid objects of plane, cylindrical and spherical shapes as well as the heat conduction systems involving semi-infinite solids, approximated by basement floors and underground constructions.

Under non-steady heat conduction, the heat lost from one side of a surface is not equal to the rate of heat entry at another side. Equations (2) and (3), however, must be valid also for the steady state heat transfer problems. One of the best ways to check the consistency of the conduction transfer functions is to use them in the solution of steady state problems and see if the following criteria is met: The room side surface temperature and the outdoor side surface temperature are maintained constant for many hours so that

$$
\begin{aligned}
& \operatorname{TOS}_{t}=\operatorname{TOS}_{t-1}=\ldots . \quad \operatorname{TOS}_{t-N} \\
& \mathrm{TIS}_{t}=\mathrm{TIS}_{t-1}=\ldots . \mathrm{TIS}_{\mathrm{t}-\mathrm{N}} \\
& Q I_{t}=Q O_{t}=Q O_{t-1}=Q I_{t-1}
\end{aligned}
$$

Thus

$$
\begin{aligned}
& \mathrm{QO}_{t}=\mathrm{TIS}_{t} * \Sigma \mathrm{Y}_{j}-\operatorname{TOS}_{t} * \Sigma \mathrm{Z}_{j}+\mathrm{R} * \mathrm{QO}_{t} \\
& \mathrm{QI}_{t}=\mathrm{TIS}_{t} * \Sigma \mathrm{X}_{j}-\operatorname{TOS}_{t} * \Sigma \mathrm{Y}_{j}+\mathrm{R} * \mathrm{Q} I_{t}
\end{aligned}
$$

In order to satisfy these two equations simultaneously, it is necessary that 


$$
\stackrel{N}{\Sigma} X_{j}=\stackrel{N}{\Sigma} Y_{j}=\stackrel{N}{\Sigma} Z_{j}=U H_{*}(1-R)
$$

In fact, the conduction transfer functions of the sample wall shown in Table A-10 can be shown to satisfy this requirement

$$
\Sigma X_{j}=\Sigma Y_{j}=\Sigma Z_{j}=0.0668
$$

and

$$
U *(1-R)=0.418 *(1-0.8398)=0.0669
$$


An Algorithm for Calculating Transient Heat Conduction Through Opaque Walls or Roofs Using Conduction Transfer Functions

\section{Data:}

$X_{j}, Y_{j}$ and $Z_{j}$ for $j=0,1,2, \ldots N$ : Conduction transfer functions in Btu per (hr) (sq ft), (Calculated as outlined in XYZ for the system that excludes the inside and outside heat resistance layers)

$\mathrm{R}$ : Common ratio of the conduction transfer function (Calculated as outlined in XYZ), $R=\frac{X_{j+1}}{X_{j}}=\frac{Y_{j+1}}{Y_{j}}=\frac{Z_{j+1}}{Z_{j}}$ for $j \geq N$

$\mathrm{N}$ : Number of the significant terms to be used for the conduction heat transfer calculation, (Calculated as outlined in $\mathrm{XYZ}$ )

FO ${ }_{t}$ : Outside surface heat transfer coefficient at time $t$, Btu per (hr) (sq ft) (F)

IT $_{t}$ : Total solar radiation intensity on the outside surface at time $t$, Btu per (hr) (sq ft), (Calculated in SOLAD)

TIS $_{t-j}:$ History of inside surface temperature at times $t-1, t-2, \ldots$ and $(t-N) t h$ hour, $F$

TOS $_{t-j}$ : History of outside surface temperature at times $t-1, t-2, t-3, \ldots$ and $(t-N)$ th hour, $F$ $\mathrm{DB}_{t}$ : Outdoor air dry-bulb temperature at time $t, F$ 
HEAT $_{t-1}$ : Heat loss at the interior surface to the outdoor environment at the previous hour, Btu per (hr) (sq ft)

$\mathrm{QO}_{\mathrm{t}-1}$ : Heat loss at the exterior surface to the outdoor environment at the previous hour, Btu per (hr) (sq ft)

a: Solar absorption coefficient at the exterior surface

$\alpha$ : Cosine of the angle subtended by a vertical line and the surface normal ... (Calculated in SUN) $\mathrm{TC}_{\mathrm{t}}$ : Total cloud amount ... (Calculated in CLIMATE) TM: A reference temperature (usually the inside design temperature), F

\section{Calculation Sequence:}

A. Exterior walls and roof

1. The heat balance equation at the exterior surface is given by $\mathrm{QR}_{t}+\mathrm{QA}_{\mathrm{t}}+\mathrm{QO}_{\mathrm{t}}-\mathrm{QS}_{\mathrm{t}}=0$

where

a) Incident solar radiation

$$
Q R_{t}=a * I T_{t}
$$

b) Convection heat transfer from the outdoor air

$$
Q A_{t}=F O_{t} *\left(D B_{t}-T O S_{t}\right)
$$


c) Conduction heat flow from the inside surface

$$
\begin{aligned}
Q O_{t} & =\sum_{j=0}^{N} Y_{j} *\left(T^{\prime} S_{t-j}-T M\right)-\sum_{j=0}^{N} Z_{j} *\left(T_{t-j}-T M\right) \\
& +R * Q O_{t-1} *
\end{aligned}
$$

d) Heat loss to the sky

$$
\mathrm{QS}_{\mathrm{t}}=2 * \alpha *\left(10-\mathrm{TC}_{\mathrm{t}}\right)^{* * *}
$$

2. Let

$$
\begin{aligned}
& \text { SUM1 }=\sum_{j=0}^{N} Y_{j} *\left(\text { TIS }_{t-j}-T M\right)+C R * Q O_{t-1} \\
& \text { SUM2 }=\sum_{j=1}^{N} Z_{j} *\left(\operatorname{TOS}_{t-j}-T M\right)
\end{aligned}
$$

3. Outside surface temperature

$$
\mathrm{TOS}_{\mathrm{t}}=\left(\mathrm{QR}_{\mathrm{t}}-\mathrm{QS}_{\mathrm{t}}+\mathrm{FO}_{\mathrm{t}} * \mathrm{DB} \mathrm{t}_{\mathrm{t}}+\mathrm{SUM1}-\mathrm{SUM} 2+\mathrm{Z}_{0} * \mathrm{TM}\right) /\left(\mathrm{FO}_{\mathrm{t}}+\mathrm{Z}_{0}\right)
$$

4. Using this new $\operatorname{TOS}_{t}$, the heat loss at the interior surface is then determined as follows:

$$
\begin{aligned}
\operatorname{HEAT}_{t} & =\sum_{j=0}^{N} X_{j} *\left(\operatorname{TIS}_{t-j}-T M\right)-\sum_{j=0}^{N} Y_{j} *\left(\operatorname{TOS}_{t-j}-T M\right) \\
& +\mathrm{R}_{*} \operatorname{HEAT}_{t-1}
\end{aligned}
$$

* Throughout this discussion a value of TM is always subtracted from the interior surface and exterior surface temperatures. This subtraction usually helps to minimize the digital errors which occur and are sometimes significant when a large number of numerical data are multiplied and added. Since $N$ N , the net effect of the subtraction is zero.

$$
\sum_{j=0} X_{j}=\sum_{j=0} Y_{j}
$$

$* *$

This expression was developed to yield a roof sky radiation of 20 Btu per ( $h r)$ (sq ft) for a cloudless condition, which was reported in reference (12). 


\begin{tabular}{|c|c|c|c|c|c|c|}
\hline $\begin{array}{l}\text { Layer } \\
\text { No. }\end{array}$ & $\mathrm{L}(\mathrm{I})$ & $\mathrm{K}(\mathrm{I})$ & $\rho(I)$ & $C(I)$ & $\operatorname{RES}(I)$ & $\begin{array}{l}\text { Description } \\
\text { of Layers }\end{array}$ \\
\hline 1 & 0 & 0 & 0. & 0. & 2.04 & Suspended Ceiling \\
\hline 2 & .167 & .025 & 13. & .320 & 0. & 2-in. Insulation \\
\hline 3 & .333 & 1.000 & 140 & .200 & 0. & 4-in. Concrete \\
\hline 4 & .031 & .110 & 70 & .400 & 0. & 3/4-in. Felt \\
\hline 5 & .042 & .830 & 55. & .400 & 0. & 1/2-in. Pitch Slag \\
\hline
\end{tabular}

Conduction Transfer Functions

$$
x_{j}
$$

$\mathrm{Y}_{\mathrm{j}}$

$z_{j}$

R

0

.21934

.00011

3.30513

.78793

1

$-.25485$

.00504

$-4.27082$

2

.04650

.01060

.97885

3

.00857

.00493

.00808

4

.00224

.00140

.00104

5

.00059

.00037

.00024

6

.00016

.00010

.00006

7

.00004

.00003

.00002

8

.00001

.00001

.00000

9

.00000

.00000

.00000 
Figure A-17 shows the energy balance that is involved in the above calculation sequence and the results of a typical calculation. Table A-11 gives the conduction transfer functions for the roof used in the calculations.

B. Interior walls and floor/ceiling sandwich

The calculation sequence for the partition wall and floor/ceiling sandwich is completely different from that of the exterior wall or roof. The difference is due to the fact that the air temperature at the exterior side of the construction can be assumed the same as at the interior side, at least for a climate controlled building. In order to take advantage of this fact, conduction transfer functions should be determined with the surface thermal resistance layer added at the exterior side of the structure. The heat loss through a partition wall is then calculated by

$$
\text { HEAT }_{t}=\sum_{j=0}^{N} X_{j} *\left(T I_{t-j}-T M\right)-\sum_{j=0}^{N} Y_{j} *\left(T A_{t-j}-T M\right)+R * H E A T_{t-1}
$$

where $\mathrm{TA}_{t-j}=$ room temperature at time $(t-j)$ th hour

If the room temperature were maintained constant at TM, which is usually the case, the terms involving the $\mathrm{Y}_{j}$ 's would then drop out of the equation.

\section{Slab on grade floor}

The heat loss to the ground through the floor on grade can be calculated by using conduction transfer functions determined on the basis of flooring, concrete, and 12 inches of ground layer 


$$
\operatorname{HEAT}_{t}=\sum_{j=0}^{N} X_{j} *\left(T I_{t-j}-T M\right)-\sum_{j=0}^{N} Y_{j} *(T G-T M)+R * H_{E A T} T_{t-1}
$$

Since usually TG is constant and

$$
\sum_{j=0}^{N} Y_{j}=U_{G} *(1-R),
$$

then

$$
\text { HEAT }_{t}=\sum_{j=0}^{N} X_{j} *\left(T I_{t-j}-T M\right)-U_{G} *(1-R) *(T G-T M)+R * H_{E A T}{ }_{t-1}
$$

The same method is applicable to a floor with a crawl space as long as the space is not vented. The conduction transfer functions for the floor with an unvented crawl space simply has an additional air resistance layer to account for the dead air space between the floor and the ground. In many cases it is safe to assume that $T G=T M$, and then the term involving $\mathrm{U}_{\mathrm{G}}$ would drop out of the equation.

D. Floor over the vented crawl space

The floor over a vented crawl space can be treated in the same manner as an exterior wall or roof except that the solar radiation and sky radiation terms would not be included in the energy balance and that the outside surface heat transfer coefficient is replaced by a value similar in magnitude to the inside surface heat transfer coefficient. If the conduction transfer functions include the outside surface heat transfer resistance, the calculation is simply

$$
\text { HEAT }_{t}=\sum_{j=0}^{N} X_{j} *\left(T I_{t-j}-T M\right)-\sum_{j=0}^{N} Y_{j} *\left(D B_{t-j}-T M\right)+R * H E A T T_{t-1}
$$




\section{SCHEDULE}

An Algorithm to Determine Heat Gains From Lighting, Equipment, Occupancy and Ventilation

Data:

1. Normalized 24 hour profiles $(j=1,2,3 \ldots 24)$ of operational schedules for weekdays $(i=1)$ and weekends and holidays $(i=2)$ are given for lighting, equipment use, occupancy, ventilation, indoor temperature setting, and humidity setting as follows:

QLITE $_{i, j}:$ Lighting schedules (fraction of some maximum)

QEQUP $_{i, j}$ : Equipment use schedules (fraction of some maximum)

QOCUP $_{i, j}:$ Occupancy schedule (fraction of some maximum)

QVENT $_{i, j}:$ Ventilation fan operating schedule (fraction of some maximum)

$\mathrm{ROOMDB}_{i, j}:$ Space thermostat setting schedule ROOMRH $_{i, j}$ : Space humidistat setting schedule

2. Maximum values of the parameters to be used with the schedules QLITX: Maximum electric power demand for lighting for the 24 hour period

QEQUPX: Maximum electric power demand for appliances for the 24 hour period, KW 
QOCUPX: Maximum number of equivalent sedentary adult occupants during the 24 hour period

QVENTX: Maximum amount of ventilation air supply during the 24 hour period, cu. ft per min.

QHTWTX: Maximum amount of hot water demand during the 24 hour period, gallons per hour

3. YEAR, MONTH AND DAY

These data are needed to determine whether the day is a weekday, weekend, or holiday, and whether the day falls within daylight savings time.

4. QOS(TA): Sensible heat loss of a sedentary adult at the room temperature TA, Btu per (hr) (occupant)

QOL(TA): Latent heat loss of a sedentary adult at the room temperature TA, Btu per (hr) (occupant) WO $(\mathrm{DB}, \mathrm{WB})$ : Humidity ratio of the outdoor air for a given outdoor air dry-bulb and wet-bulb temperature, Ib of water vapor per (1b of dry air)

WI(TA,WGA): Humidity ratio of the indoor air for a given dry-bulb temperature and wet-bulb temperature, $1 b$ of water vapor per (1b of dry air)

QWT: Heat needed to generate one gallon of hot water, Btu per gallon of water 


\section{Calculation Sequence:}

1. Determine the weekday indicator IWK from WKDAY

2. Determine the holiday indicator IHOL from HOLDAY

3. If $\operatorname{IWK}=1$ or $7 \quad i=2$

If IHOL $=1 \quad i=2$

Otherwise $\quad i=1$

4. Heat generated from lights (for $j=1 \ldots 24$ ), Btu per hr $\mathrm{QS}_{i, j}=\mathrm{QLITX}_{i, 3413 * \mathrm{QLITE}_{i, j}}$

5. Heat generated from equipment and occupants, Btu per hr (for $j=1,2 \ldots 24)$

Sensible heat

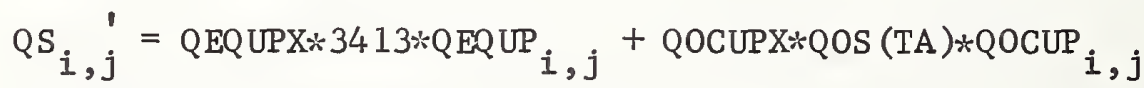

Latent heat

$\mathrm{QL}_{i, j}=\mathrm{QOCUPX}_{\mathrm{i}} * \mathrm{QOL}(\mathrm{TA}) * \mathrm{QOCUP}_{i, j} *$

6. Heat gain due to ventilation air, Btu per hr

Sensible heat

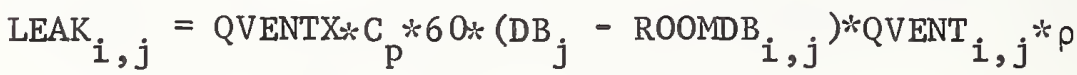

Latent heat

Determine $W I_{j}$ from PSY using $\operatorname{ROOMDB}_{i, j}$ and $\mathrm{ROOMRH}_{i, j}$ $\operatorname{LEAK}_{i, j}=\mathrm{QVENTX}_{i} * 60 *\left(\mathrm{WO}_{j}-\mathrm{WI}_{j}\right) * 1060 * \mathrm{QVENT}{ }_{i, j} * \mathrm{P}$

$C_{p}$ and $p$ on this page depict specific heat and density of air in the English units.

It has been assumed that there is no latent portion of the equipment heat gain. There can be exceptions to this. 
The basic energy transfer process that occurs in a room can best be illustrated by an electrical circuit network as shown in Figure A-18. The figure represents the phenomenon in a typical room having two exterior walls, each of which contains a window, and two interior partition walls, in addition to the roof and floor (see Figure A-19). Heat conduction paths through the walls, roof, and floor are depicted by resistance and capacitance circuits and these through windows are represented by resistance circuits, implying that the windows do not have significant thermal mass. Points $\mathrm{T}_{\mathrm{S} 1}$ through $\mathrm{T}_{\mathrm{S} 8}$ in Figure $\mathrm{A}-18$ indicate interior surfaces of the walls, roof, floor and windows, all of which receive conduction heat through solid material, solar radiation (represented by

q) through transparent surface and long wavelength radiation from other solid surfaces indicated by solid lines connecting the surface nodes; and they lose heat to the room air (represented by a point called TA) by the convection process (dashed lines).

At the top of Figure A-18, the radiation heat exchange between the room surfaces, the surfaces of lighting fixtures, equipment such as business machines, and occupants is depicted. Also indicated in this same location is the convective heat exchange between these items and the room air. Actual heat or power input to these internal heat sources are indicated by $\leftrightarrows$. Although not indicated in this figure, it is possible to represent the conduction heat gain from the inner core of lighting fixtures and equipment if they have sufficient thermal mass. This equipment could of course include the unit heaters or air conditioners 


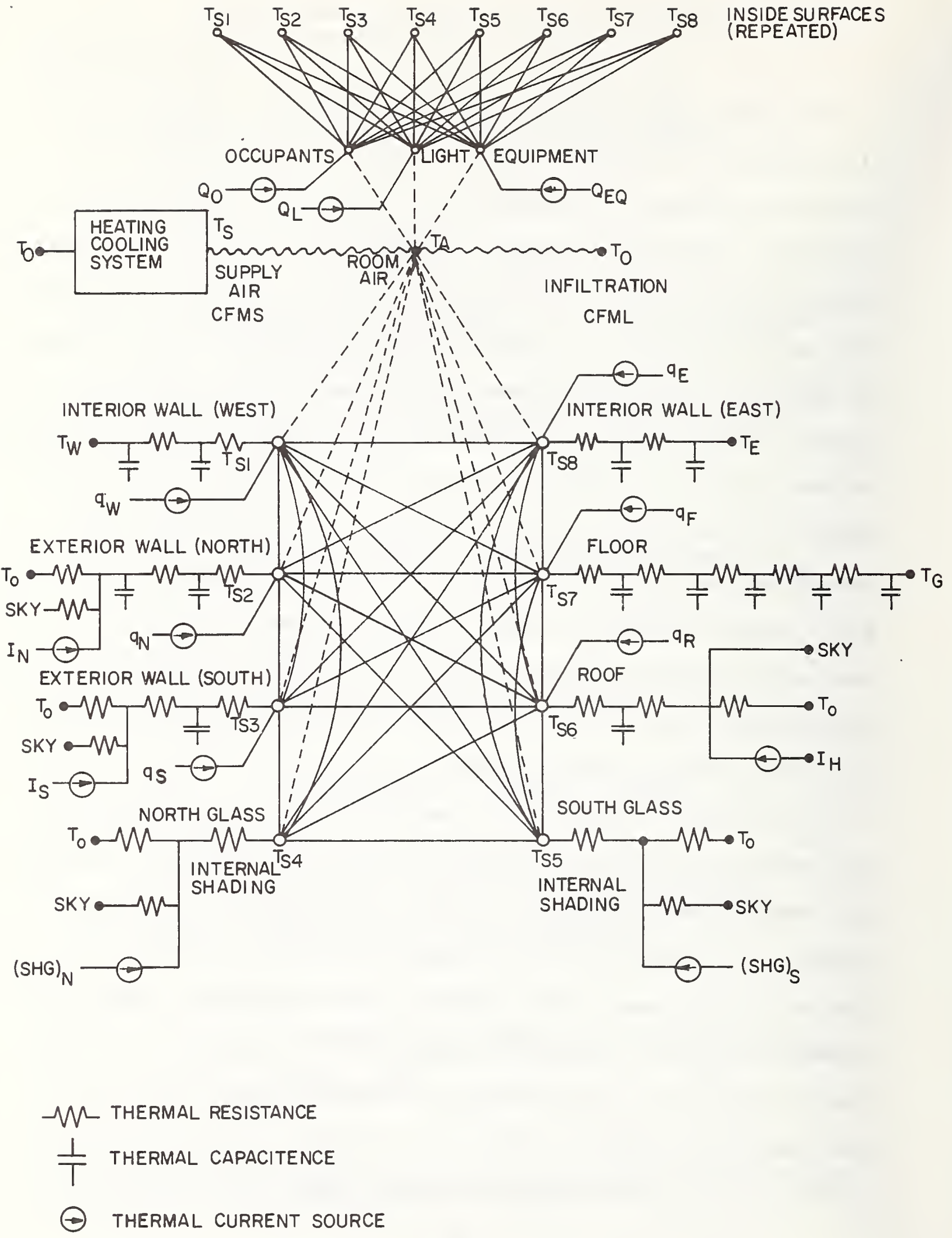

Figure A-18 Analogous Electric Circuit for Heat Exchange Process in a Room 


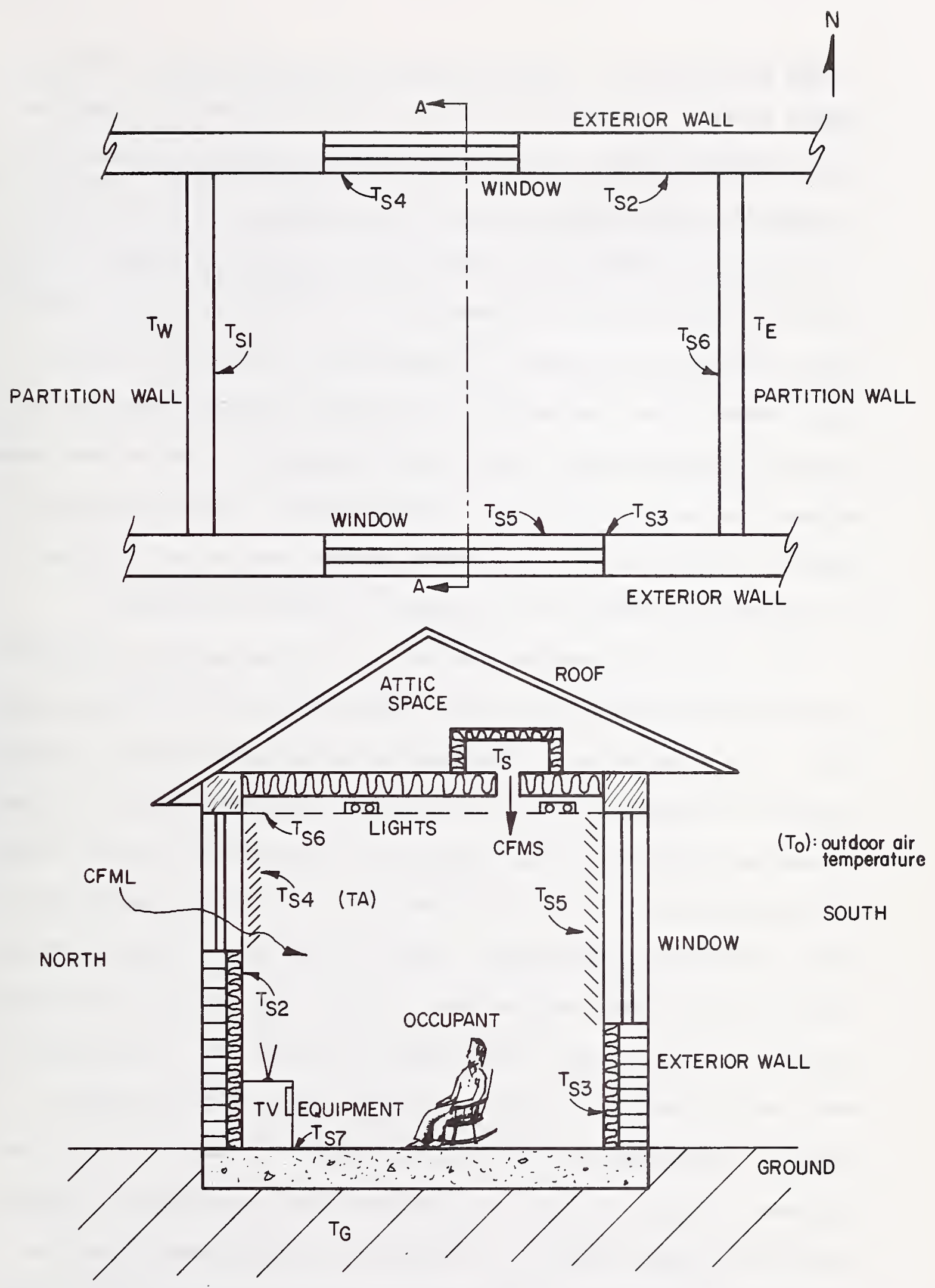

Figure A-19 Physical Model of a Typical Room Used in Figure A-18 
if they are the part of the room heat exchange system. The room air changes energy with outdoor air or with the conditioned air from the central climate control system (or the forced ventilation system) and is depicted in this figure by lines $\overline{\mathrm{T}_{s_{a}}}$ and $\overline{\mathrm{T}_{0} \mathrm{~T}_{a}}$. The heat exchange at the exterior surfaces with outdoor air, sky and sun (except for the partition walls and floor on grade) are also indicated using a normal design calculation procedure, the temperature or heat flow at the exterior sides of the room surfaces are usually available either by calculation or as input data. The exception occurs when two or more rooms adjacent one another are treated simultaneously. This latter case is commonly referred to as a "multi-room problem" and is very complex. No satisfactory solution for this case is presently available.

This electrical network problem can be solved and the corresponding calculation algorithm is called RMTMP (given in the following section). The solution can be obtained in two different modes: room temperature calculation mode or the room load calculation mode. The room temperature calculation mode requires the simultaneous solution of heat balance equations in order to determine all the surface temperatures together with the air temperature. On the other hand, the room cooling load calculation mode requires that the room temperature be prescribed and only the room surface temperatures are solved for. The convective heat exchange between the room air and the heat emitting surfaces is then the cooling load (or the heating load if the heat is lost to the surfaces). These two modes of computation can be combined to simulate the actual thermal behavior of a room and its environment where the temperature fluctuates. The floating temperature would be calculated 
as long as it remained between prescribed limits. A heating load would be computed when the room temperature fell to the lower limit and a cooling load would be calculated when the temperature rose to the upper limit. In this manner, the calculation of load and subsequent energy requirement would more closely correspond to actual building and system operation. 


\section{RMTMP}

An Algorithm to Calculate Thermal Load or Room Temperature

This routine calculates heating and cooling loads or room temperature by solving heat balance equations involving each of the room surfaces. A room surface receives conduction heat flow through the solid wal1, roof or floor material from behind, convection heat flow from the air and radiation heat flow from other surfaces and internal heat sources such as occupants, equipment and lighting fixtures.

\section{Data:}

NS: Total number of heat transfer surfaces contributing to the room heat balance

$S_{i}$ : Area of $i-t h$ heat transfer surface, sq. ft., where $i=1,2,3, \ldots \mathrm{NS}$

$$
\begin{aligned}
& X_{i, j}, Y_{i, j} \text { and } z_{i, j}: \\
& \text { Where } i=1,2,3, \ldots \text { NS } \\
& j=1,2, \ldots N_{i}
\end{aligned}
$$

Conduction transfer functions of $i$-th surface in Btu per (hr) (sq. ft.) ... (Calculated in XYZ). These conduction transfer functions are usually evaluated without the interior or room side surface thermal resistance. The thermal resistance layer of exterior surface is also omitted if the exterior surface temperature is to be computed as a result of a heat balance involving solar radia- 
tion, sky radiation and convective loss to the outdoor air.

$\mathrm{N}_{i}$ : Number of conduction transfer function terms to be used for the calculation of the $i$-th surface donduction heat gain

$R_{i}$ : Common ratio for the conduction transfer function of the $i-t h$ surface

$\operatorname{TOS}_{i, t-j}{ }^{*}:$ for $i=1,2,3, \ldots$ NS and $j=0,1,2, \ldots N_{i}$ Outside surface temperature history from present hour to that of $\mathrm{N}_{i}$ hours ago for $\mathrm{i}$-th surface, $\mathrm{F}$. (This information is available from HEATW routine.) $\operatorname{TIS}_{i, t-j}:$ for $i=1,2,3, \ldots$ NS and $j=1,2,3, \ldots N_{i}$ Inside surface temperature history from one hour ago to $\mathrm{N}_{i}$ hours ago for $i-t h$ surface, $F$. The present value (for $j=0$ ) will be computed in this routine and stored for future use.

$\mathrm{TA}_{t}$ : Air temperature of the room at time $t, F$ $\mathrm{DB}_{t}$ : Outdoor air temperature at time $t, F$ TS $_{t}$ : Supply air temperature from the central system at time $t, F$

$\mathrm{H}_{i}$ : Inside surface convection heat transfer coefficlent for $i$-th surface, Btu per (hr) (sq. ft.) (F)

Subscript $t$ refers to the present time $t$ and $t-j$ refers to the present time minus $j$ hours. 
$F_{i, k}:$ Radiation heat exchange view factor between the i-th surface and $k-t h$ surface

$$
F_{i, i}=F_{k, k}=0
$$

$E_{i}:$ Emissivity of the $i-t h$ surface

$R_{i, t}$ : Radiant heat flux impinging upon i-th surface at time t from various sources, which include solar radiation, radiation from lights, occupants and equipment, Btu per (hr) (sq.ft.)

$Q_{i, t}:$ Heat conducted into $i-t h$ surface at time $t$, Btu per $(\mathrm{hr})(\mathrm{sq} \cdot \mathrm{ft}$.

$\mathrm{GL}_{t}$ : Mass air flow rate due to air leakage at time $t, 1 b$ per hr

GS $_{t}$ : Mass air flow rate of the supply air from the central system at time $t, 1 b$ per $h r$

QEQUP: Internal heat generated from equipment such as business machines and computers, Btu per hr

QOCPS: Internal heat (sensible) generated from occupants (a function of room air temperature), Btu per hr

QLITE: Heat from lights, Btu per hr

RE: Fraction of internal heat gain from equipment that can be assumed to be convective

RO: Fraction of internal heat gain from occupants that can be assumed to be convective

RL: Fraction of heat gain from lights that can be assumed to be convective 
SHG $_{i, t}$ : Solar incident radiation on $i$-th surface at time $t$, Btu per (hr) (sq. ft.)

\section{Calculation Sequence:}

1. Heat balance equation at the $i-t h$ surface at time $t$

$$
\begin{aligned}
& Q_{i, t}=\sum_{j=0}^{N_{i}} X_{i, j} * T_{i, t-j}-\sum_{j=0}^{N_{i}} Y_{i, j} * \operatorname{TOS}_{i, t-j}+R_{i} * Q_{i, t-1} \\
& =H_{i} *\left(T A_{t}-T I S_{i, t}\right)+\sum_{k=1}^{N S} G_{i, k} *\left(T I_{k, t}-T I_{i, t}\right)+R_{i, t} \\
& \text { where } G_{i, k}=4 * E_{i} * F_{i, k} *\left(T_{t}+460\right) * * 3 * 0.1714 * 10 * *-8 \\
& R_{i, t}=S H G_{i, t}+\frac{((1-R E) * Q E Q U P+(1-R O) * Q O C P S+(1-R L) * Q L I T E)}{N_{S}} \\
& \sum_{i=1} S_{i}
\end{aligned}
$$

2. Heat balance for the room air

$$
\begin{aligned}
& \sum_{i=1}^{N} S_{i} *\left(T I S_{i, t}-T A_{t}\right)+G L_{t} * C_{p} *\left(D B-T A_{t}\right)+G_{t} * C_{P} * \\
& \left(T S_{t}-T A_{t}\right)+Q E Q U P * R E+Q O C P S * R O+Q L I T E * R L=0 \\
& \text { where } C_{p} \text { is the specific heat of air in Btu per (1b) (F) }
\end{aligned}
$$

The values of $\mathrm{GS}_{t}$ and $\mathrm{TS}_{t}$, supply air flow rate and its temperature, are the link between the load calculation and the system simulation. (More detailed explanation of this aspect is given in the final portion of this section.) 
3. Assigning matrix elements for $i=1,2,3, \ldots$ NS and for $\mathrm{k}=1,2,3, \ldots \mathrm{NS}$

$$
\begin{aligned}
& A_{i, i}=x_{i, 1}+H_{i}+\sum_{k=1}^{N S} G_{i, k} \\
& A_{i, k}=-G_{i, k}=A_{k, i}=-G_{k, k} \\
& \mathrm{~A}_{\mathrm{i}, \mathrm{NS}+1}=-\mathrm{H}_{\mathrm{i}} \\
& B_{i}=-\sum_{j=1}^{N_{i}} X_{i, j} * T_{i, t-j}+\sum_{j=0}^{N_{i}} Y_{i, j} * \operatorname{TOS}_{i, t-j}-R * Q_{i, t-1}+R_{i, t} \\
& \mathrm{~A}_{\mathrm{NS}+1, \mathrm{k}}=\mathrm{S}_{\mathrm{k}} * \mathrm{H}_{\mathrm{k}} \\
& \mathrm{B}_{\mathrm{NS}+1}=-\mathrm{QEQUP} * \mathrm{RE}+-\mathrm{QOCPS} * \mathrm{RO}-\mathrm{QLITE} * \mathrm{RL}-\mathrm{GL}_{\mathrm{t}} * \mathrm{C}_{\mathrm{p}} * \mathrm{DB}_{\mathrm{t}}-\mathrm{GS}_{\mathrm{t}} * \mathrm{C}_{\mathrm{p}} * \mathrm{TS} \mathrm{S}_{\mathrm{t}}
\end{aligned}
$$

4. Using these matrix elements, the following NS+1 equation should be solved simultaneously for $\operatorname{TIS}_{i, t}(i=1,2, \ldots$ NS) and for $\mathrm{TA}_{t}$ 


$\left[\begin{array}{lll}\mathrm{A}_{1,1} & \mathrm{~A}_{1,2} & \mathrm{~A}_{1, N S+1} \\ \mathrm{~A}_{2,1} & \mathrm{~A}_{2,2} & \mathrm{~A}_{2, \mathrm{NS}+1} \\ \mathrm{~A}_{\mathrm{NS}, 1} & \mathrm{~A}_{\mathrm{NS}, 2} & \mathrm{~A}_{\mathrm{NS}, \mathrm{NS}+1} \\ \mathrm{~A}_{\mathrm{NS}+1,1} & \mathrm{~A}_{\mathrm{NS}+1,2} & \mathrm{~A}_{\mathrm{NS}+1, \mathrm{NS}+1}\end{array}\right] *\left[\begin{array}{c}\mathrm{TIS}_{1, \mathrm{t}} \\ \mathrm{TIS}_{2, \mathrm{t}} \\ \\ \mathrm{TIS}_{\mathrm{NS}, \mathrm{t}} \\ \mathrm{TA}_{\mathrm{t}}\end{array}\right]=\left[\begin{array}{c}\mathrm{B}_{1} \\ \mathrm{~B}_{2} \\ \mathrm{~B}_{\mathrm{NS}} \\ \mathrm{B}_{\mathrm{NS}+1}\end{array}\right]$

5. When the value of $\mathrm{TA}_{t}$ has been specified, as in the case of a controlled condition, the following NS equations should be solved instead of the NS+1 equations given above.

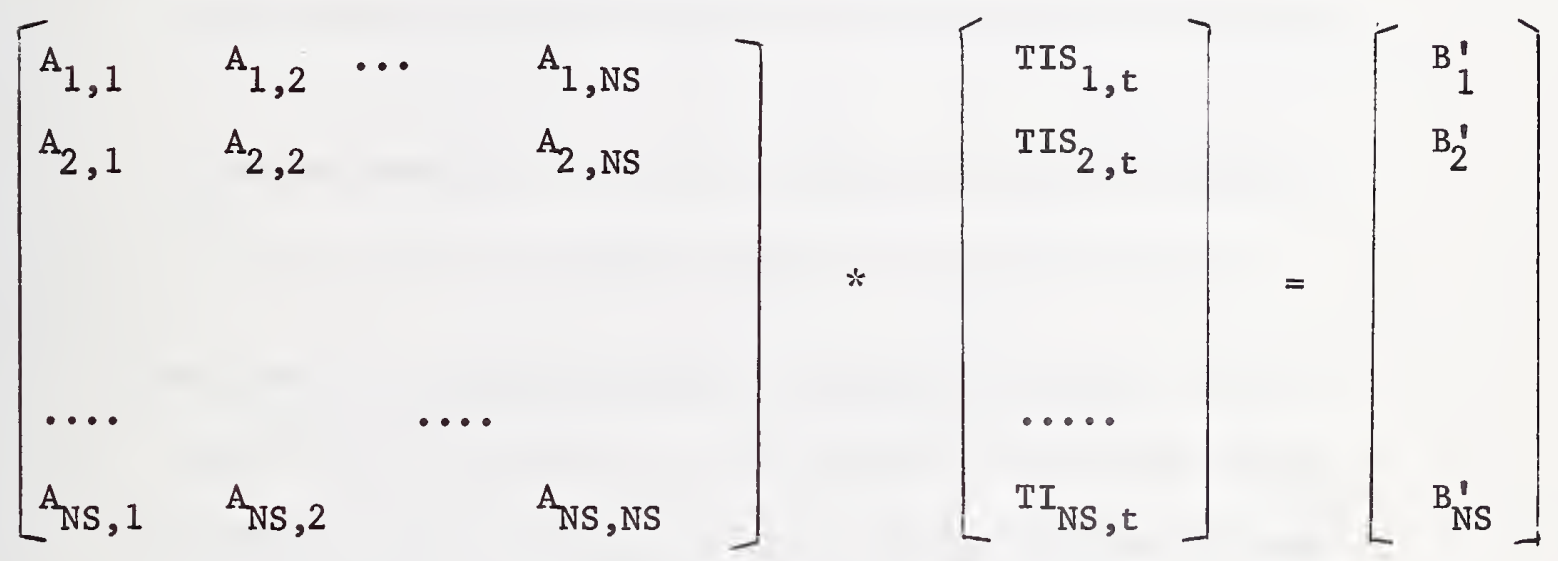

where

$$
B^{\prime}{ }_{i}=B_{i}-A_{i, N S+1} * T A_{t}
$$


6. Calculate the sensible load by

$$
\begin{aligned}
\mathrm{QLS}_{\mathrm{t}} & =\sum_{i=1}^{\mathrm{N}} \mathrm{S}_{i} *\left(\mathrm{TIS}_{\mathrm{i}, t}-\mathrm{TA}_{t}\right)+\mathrm{GL}_{\mathrm{t}} * \mathrm{C}_{\mathrm{p}} *\left(\mathrm{DB}_{\mathrm{t}}-\mathrm{TA}_{\mathrm{t}}\right) \\
& + \text { QEQUP } * \mathrm{RE}+\mathrm{QOCPS} * \mathrm{RO}+\mathrm{QLITE} * \mathrm{RL}
\end{aligned}
$$

In this expression, QL is a cooling load if positive and it is a heating load if negative. This is the heat picked up by the room air (or that lost by the room air) which has to be removed (or added) by the central air conditioning system。

Note that for ordinary load calculations, $\mathrm{GS}_{t}$ and $\mathrm{TS}_{t}$ are not used as long as the following condition is satisfied:

$$
\left|\mathrm{QLS}_{\mathrm{t}}\right| \leqq\left|\mathrm{GS}_{\mathrm{t}} * \mathrm{C}_{\mathrm{p}} *\left(\mathrm{TA}_{\mathrm{t}}-\mathrm{TS}_{\mathrm{t}}\right)\right| \ldots \text { Maximum capacity }
$$

of the heating or cooling system

In other words, the desired or prescribed room temperature can be maintained as long as the calculated load is less than the maximum capacity of the central system. When the above condition is not satisfied because of the inadequate values for either the air supply rate or the supply air temperature, the room temperature used for the load calculation is no longer valid. The calculation must then be revised, first calculating the room temperature as out lined in 3 above. 


\section{Latent Load}

If moisture condensation and absorption by room walls, or drying of the wall panels can be neglected, the latent load is the same as the latent heat gain or loss, provided the following condition is met:

$$
\begin{aligned}
& \mathrm{QLL}_{t} \leqq \mathrm{GS}_{t} * \lambda *(\text { WA }- \text { WS }) \text {, where } \lambda=\text { latent heat } \\
& \text { of vaporization } \approx 1061 \text { Btu per } 1 \mathrm{~b} \text { of water }
\end{aligned}
$$

In other words, the desired moisture level can be maintained as long as the latent load of the room or the building is less than the capacity of the central system to remove (add) water vapor. When the above condition is not satisfied because of the inadequate air flow rate of the air supply system or the value of WS, the room humidity ratio would change according to

$$
W I=\frac{G S_{t} * W S+G L_{t} * W A+Q L I / \lambda}{G S_{t}+G L_{t}}
$$

This equation becomes inderminate when there is no air supply or air leakage to or from the room. Theoretically the room relative humidity would reach $100 \%$ soon after the air supply or air leakage is stopped provided normal internal sources were still present. Under those conditions, seasonal value of WI to be used would be that corresponding to the dew point temperature which would be approximately equal to the average 
wall surface temperature of the space.

The most important application of RMTMP is for taking into account some of the performance characteristics of the room's (or space's) heating and cooling systems where the evaluation of heating and cooling load is linked to the system capacity. Presented in this section is a sample algorithm to illustrate how RMTMP can be used to account for the type of occupancy, temperature control scheme, and the system capacity. In this illustration, the heating/cooling load will be set equal to the maximum capacity of the system when the calculated load at a given time is greater than the maximum system capacity. The space or room temperature is then calculated on the basis of net load, which is the difference between the calculated load at a given design temperature and the maximum system capacity. If, on the other hand, the space temperature falls within the prescribed upper and the lower limits, the load is set equal to zero. The same procedure is applied to the latent load calculation. The details of the algorithm is depicted in the flow diagram (Figure A-20). The nomenclature for the figure is given in Table $\mathrm{A}-12$. 
RELATIONSHIP BETWEEN

TA,TLL,TUL,QLS, QCLDS, QHLDS
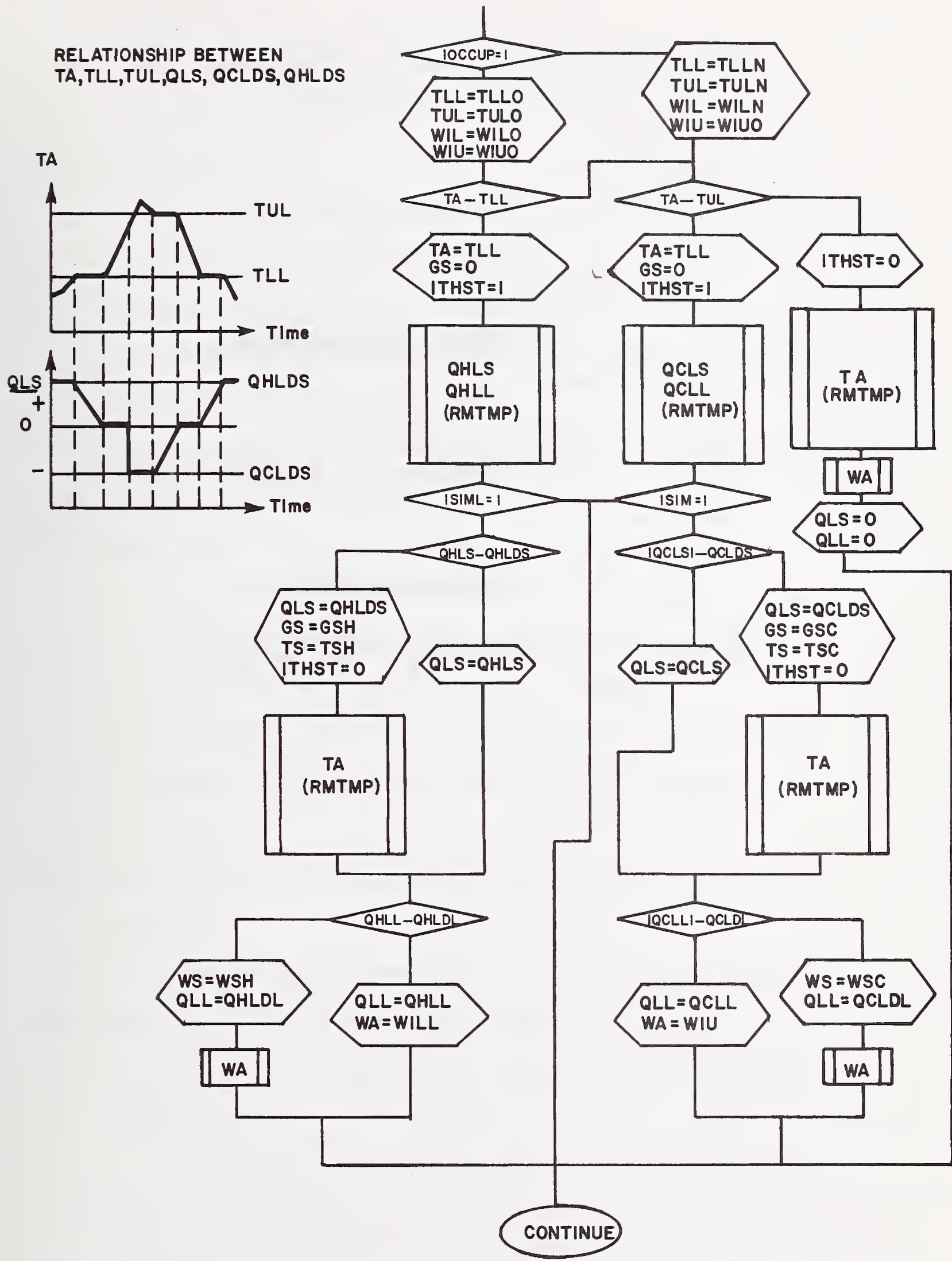

Figure A-20 Flow Diagram of the Room Temperature and the Room Thermal Load Calculation Steps 
Symbols used in the flow diagram, Figure $A-20$
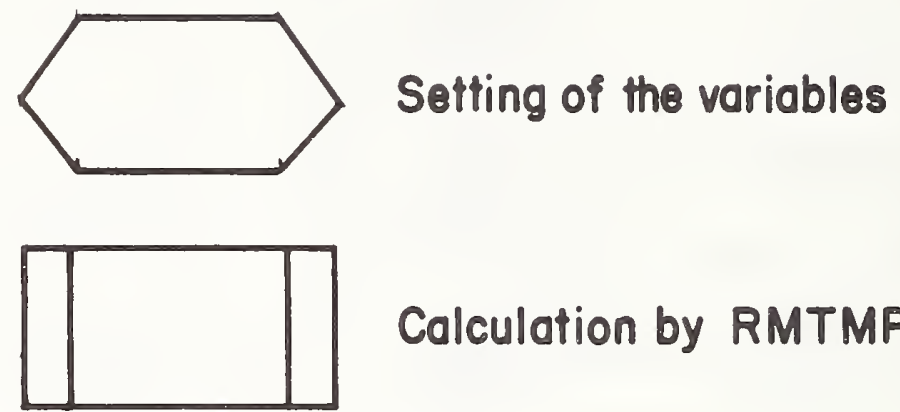

Calculation by RMTMP

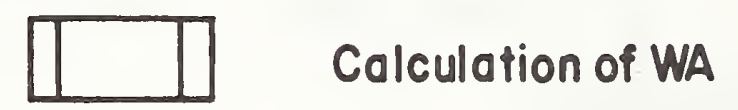

NO No Testing of "yes " or "no" YES 
Nomenclature for Figure $A-20$

IOCCUP: Occupancy index

1 if during the occupied period

0 if during the unoccupied period

ISIML: System capacity consideration index

1 if the calculated load is to be compared with the maximum capacity of the system

0 if the load is to be estimated without regard to the installed system capacity

ITHST: Room temperature control index

1 if a space temperature is prescribed at a given level and the heating and cooling load is to be calculated to meet this prescribed condition

0 if the space temperature is to be determined as a balance between the required load and the available capacity of the system

TLL: The lower limit of temperature, below which heating must be supplied

TLLO: The lower limit of temperature during the occupied period

TLLN: The lower limit of temperature during the unoccupied period TUL: The upper limit of temperature, above which cooling must be provided 
TULO: The upper limit of temperature during the occupied period

TULN: The upper limit of temperature during the unoccupied period WIL: The lower limit of humidity ratio, below which the room requires humidification

WILO: The lower limit of humidity ratio during the occupied period WILN: The lower limit of humidity ratio during the unoccupied period WIU: The upper limit of humidity ratio, above which the room requires dehumidification

WIUO: The upper limit of humidity ratio during the occupied period WIUN: The upper limit of humidity ratio during the unoccupied period

GS: Mass flow rate of air from the supply system

GSH: Maximum mass flow rate of air from the supply system during heating

GSC: Maximum mass flow rate of air from the supply system during cooling

TS: Air temperature of the supply air system

TSH: Maximum temperature of air from the supply system during heating

TSC: Minimum temperature of air from the supply system during cooling

WS: Humidity ratio of the air from the supply system

WSH: Maximum humidity ratio of air from the supply system during a period when heating and humidification occur

WSC: Minimum humidity ratio of air from the supply system during a period when cooling and dehumidification occur

$\mathrm{C}_{\mathrm{p}}:$ Specific heat of air 
$\lambda$ : Latent heat of vaporization

QHLDS: Maximum system capacity for heating, Btu per hr

$$
\text { QHLDS }=\mathrm{GSH} * \mathrm{C}_{\mathrm{p}} *(\mathrm{TSH}-\mathrm{TA})
$$

QHLDL: Maximum system capacity for humidification

$$
\text { QHLDL }=\text { GSH } * \lambda *(\text { WSH }- \text { WA })
$$

QCLDS: Maximum system capacity for cooling, Btu per hr

$$
\mathrm{QCLDS}=\mathrm{GSC} * \mathrm{C}_{\mathrm{p}} *(\mathrm{TA}-\mathrm{TSC})
$$

QCLDL: Maximum system capacity for dehumidification

$$
\mathrm{QCLDL}=\mathrm{GSC} * \lambda *(\mathrm{WA}-\mathrm{WSC})
$$

The primary variables that are determined by this mode of calculation are:

QHLS: Sensible heating load of the space

QHLL: Latent heating load of the space

QCLS: Sensible cooling load of the space

QCLL: Latent cooling load of the space

TA: Space temperature

WA: Space humidity ratio 


\section{ATT IC}

A Description of the Load Calculation for an Attic Space

In many cases the heating and cooling load in an attic space is affected strongly by the manner in which the attic conditions are maintained. The non-ventilated attic space may be treated as a simple air space within a roof structure and accounted for in the calculation of the conduction transfer functions. Where the attic space is ventilated during the summer to take advantage of the resulting natural cooling effect of the outdoor air, it has to be treated somewhat differently. Since it is reasonable to assume that the radiation heat exchange between the underside of the roof surface and the attic is as significant as the ventilation air rate in determining the attic thermal condition, RMTMP should be used. No additional algorithms are then required since all aspects covered in RMTMP apply directly to the attic heat transfer calculation. Of course, the solar radiation through windows, and internal heat gain from lighting and occupants would most likely be omitted. The floor should be treated as having its exterior surface exposed to the environmental conditions of the room below. The heat loss at the "exterior" surface of the floor then becomes the heat gain to the room beneath the ceiling.

FIJ 1 outlines the calculation procedure for obtaining the necessary shape factors where the attic has a gabled roof. 
An Algorithm to Calculate Instantaneous Heat Gain of a Space at Time $t$

\section{Data:}

Windows :

NY: Number of windows

$\mathrm{AY}_{\mathrm{k}}$ : Area of each window, sq $\mathrm{ft}$

$\mathrm{UY}_{\mathrm{k}}$ : Overall heat transfer coefficient for each

window, Btu per (hr) (sq ft) (f)

$\mathrm{SHG}_{\mathrm{k}}$ : Solar heat gain through each window, Btu per

(hr) (sq ft) (Calculated in SHG)

Exterior Walls and Roofs:

NX: Number of exterior walls and roofs

$\mathrm{Ax}_{\mathrm{k}}$ : Area of each exterior wall and roof, sq $\mathrm{ft}$

HEAT $_{k}$ : Heat gain through each exterior wall and roof,

Btu per (hr) (sq ft) (Calculated in HEATW)

where $k=1,2, \ldots \mathrm{NX}$

Lights :

NS: Number of different types of lights

$\mathrm{QS}_{\mathrm{k}}$ : Power input to each type of 1 ight, Btu per hr where $k=1,2, \ldots$ NS 
Internal Heat Source Other than Lights:

NS': Number of different types of internal sensible heat sources other than lights

$\mathrm{QS}_{\mathrm{k}}^{\prime}$ : Heat generation from each internal sensible heat source, where $k=1,2, \ldots$ NS $^{\prime}$

NL: Number of different types of internal latent heat sources

$\mathrm{QL}_{\mathrm{k}}$ : Latent heat gain from each internal latent heat source, Btu per hr, where $k=1,2, \ldots$ NL

Inside Doors:

ND: Number of inside doors

$\mathrm{AD}_{\mathrm{k}}$ : Area of each inside door, sq ft

$\mathrm{UD}_{\mathrm{k}}$ : Overall heat transfer coefficient of each inside door, where $k=1,2, \ldots \mathrm{ND}^{\prime}$

Outside Doors:

ND': Number of outside doors

$A D_{k}^{\prime}$ : Area of each outside door, sq $\mathrm{ft}$

$\mathrm{UD}_{\mathrm{k}}^{\prime}$ : Overall heat transfer coefficient of each outside door, Btu per (hr) (sq ft) (F), where $k=1,2$, ... ND ${ }^{\prime}$ 
Partitions:

NP: Number of partitions which separate the space from other spaces at different temperatures

$\mathrm{AP}_{\mathrm{k}}$ : Area of each of these partitions, sq ft

$\mathrm{UP}_{\mathrm{k}}$ : Overall heat transfer coefficient for each of these partition walls, Btu per (hr) (sq ft) (F) where $k=$ $1,2, \ldots \mathrm{NP}$

Underground Wa11s:

NG: Number of underground walls

$\mathrm{AG}_{\mathrm{k}}$ : Area of each underground wall, sq $\mathrm{ft}$

$\mathrm{UG}_{\mathrm{k}}$ : Overall heat transfer coefficient of each underground wal1, Btu per (hr) (sq $f t)(F)$, where $k=1,2, \ldots$ NG

Underground Floors:

NGF: Number of underground floors

$\mathrm{AGF}_{\mathrm{k}}$ : Area of each underground floor, sq ft

$\mathrm{UGF}_{\mathrm{k}}$ : Overal1 heat transfer coefficient of each underground floor, Btu per (hr) (sq ft) (F), where $k=1,2, \ldots$ NGF

\section{Internal Infiltration:}

NLK: Number of internal air leakage sources

LEAK $_{k}$ : Air leakage from each source, cfm (Calculated in INFIL), where $k=1,2, \ldots$ NLK 
Externa1 Infiltration:

NLK': Number of external air leakage sources

LEAK $_{k}^{\prime}$ : Air leakage from each external source, cfm (Calculated in INFIL), where $k=1,2, \ldots$

NLK'

Temperatures :

$\mathrm{TA}_{k}$ : Dry-bulb temperature of each adjacent space, $\mathrm{F}$, where $\mathrm{k}=1,2, \ldots \mathrm{ND}, \mathrm{NP}$ or $\mathrm{NLK}$

DB: Outside air dry-bulb temperature, F (Obtained from CLIMATE)

TG: Average ground water temperature at half underground basement depth, F

TGW: Ground water temperature, F

$\mathrm{TZ}$ : Space dry-bulb temperature, F

Humidity Ratios:

$\mathrm{WA}_{\mathrm{k}}$ : Humidity ratio of adjacent space, $1 \mathrm{~b}$ water per 1b dry air, where $k=1,2, \ldots N D, N P$ or NLK

WO: Outside air humidity ratio, $1 \mathrm{~b}$ water per $1 \mathrm{~b}$ dry air (Calculated in PSY)

WZ: Space humidity ratio, lb water per lb dry air 
The following heat gains are calculated in this subroutine:

HEATG Total hourly solar heat gain through windows, Btu or

HEATG' per hr

HEATK: Total hourly heat gain through exterior walls and roofs, Btu per hr

HEATIS: Total power input to lights, Btu per hr

HEATDP: Total sensible heat gain due to heat transfer through doors, partitions, underground walls and floors, and internal heat sources other than lights, Btu per hr

HEATVS: Total hourly sensible heat gain due to infiltration, Btu per hr

HEATL: Total hourly latent heat gain due to infiltration and internal heat sources, Btu per hr

\section{Calculation Sequence:}

$\begin{aligned} & \text { 1. } \\ & \text { HEATG }\end{aligned}=\sum_{k=1}^{N Y} A_{k} * S_{k} H_{k}$

NX

2. HEATX $=\sum_{\mathrm{k}=1} \mathrm{AX}_{\mathrm{k}} * \mathrm{HEAT}_{\mathrm{k}}$

3. HEATIS $=\sum_{\mathrm{k}=1}^{\mathrm{NS}} \mathrm{QS}_{\mathrm{k}}$

4. HEATDP $=\sum_{k=1}^{N D} \mathrm{AD}_{k} * \mathrm{UD}_{k} *\left(\mathrm{TA}_{k}-\mathrm{TZ}\right)+\sum_{k=1}^{N D^{\prime}} \mathrm{AD}_{k}^{\prime} * \mathrm{UK}_{k}^{\prime}(\mathrm{DB}-\mathrm{TZ})$ 


$$
\begin{aligned}
& +\sum_{k=1}^{N Y} A_{k} * U Y_{k} *(D B-T Z)+\sum_{k=1}^{N G}{A G_{k} * U G_{k} *(T G-T Z)}^{*} \\
& +\sum_{k=1}^{N G F} A_{k} * U G F_{k} *(T G W-T Z)+\sum_{k=1}^{N P} A_{k} * \mathrm{UP}_{k} *\left(\mathrm{TA}_{\mathrm{k}}-\mathrm{TZ}\right) \\
& \text { NS }{ }^{\prime} \\
& +\sum_{k=1} Q S_{k}^{\prime} \\
& \text { 5. HEATVS }=1.08 *\left(\sum_{k=1}^{N L K} \operatorname{LEAK}_{k} *\left(\mathrm{TA}_{k}-\mathrm{TZ}\right)+\sum_{k=1}^{N L K} \operatorname{LEAK}_{k}^{\prime} *(\mathrm{DB}-\mathrm{TZ})\right)^{* *} \\
& \text { 6. HEATL } \left.=4775 * \sum_{k=1}^{N L K} \operatorname{LEAK}_{k} *\left(W A_{k}-W Z\right)+\sum_{k=1}^{N L K^{\prime}} \operatorname{LEAK}_{k}^{\prime} *(W O-W Z)\right) \\
& +\sum_{k=1}^{N L} Q L_{k} * * /
\end{aligned}
$$

\footnotetext{
* The values of UG given in the 1972 ASHRAE Handbook of Fundamentals are based on TGW. A program for calculating basement wall losses using TC has been developed at the National Bureau of Standards. When using present ASHRAE values for UG, use TGW instead of TG.

** The coefficients 1.08 and 4775 in these equations are valid for the standard air density. If desired, they can be adjusted to actual conditions by multiplying both of them by $\frac{\rho}{0.075}$, where $\rho$ is the actual density of the air expressed in $\overline{0.075}$

lb per cu ft.
} 
A Simplified Procedure for Obtaining Approximate Cooling Load by the Use of Weighting Factors

The procedure presented here was developed by Mitalas and Stephenson of National Research Council of Canada $\frac{13,14 /}{1}$ in order to expedite the otherwise complex and time-consuming solution of the heat balance simultaneous equations. The rigorous solution similar to that described in RMTMP was first obtained for typical rooms in commercial buildings with pulse type excitations that simulate various heat gains. The solution for these pulse excitations were then converted into new types of transfer functions called Weighting Factors. Weighting Factors developed for typical office spaces of light, medium, and heavy constructions are shown in Tables A-13, A-14, and A-15 for solar heat gain with no internal shading devices; heat gain conduction through interior and exterior structure components, solar heat gain with interior shading devices and all internal sources except lighting; and the heat gain due to lighting. By multiplying these Weighting Factors to the history of respective heat gains in a convolution scheme, similar to the way the conduction transfer functions are multiplied to the temperature history, it is possible to calculate an approximate cooling load.

\section{Data:}

$$
\begin{aligned}
& A_{j} \text { for } j=0,1,2 \ldots M G \text { and } B G_{j} \text { for } j=1,2,3 \ldots M^{\prime} \\
& \text { Weighting Factors for the solar heat gain HEATG } \\
& \text { (no internal shading devices) }
\end{aligned}
$$


$\mathrm{AX}_{j}$ for $\mathrm{j}=0,1,2 \ldots \mathrm{MX}$ and $\mathrm{BX}_{j}$ for $\mathrm{j}=1,2 \ldots \mathrm{MX}^{\prime}$

Weighting factors for

HEAT : Conduction heat gain

HEATG: Solar heat gain where there are internal shading devices

HEATDP: Heat gain due to air leakage and internal sources except lighting

AIS $_{j}$ for $j=0,1,2 \ldots$ MIX and $B_{j}$ for $j=1,2,3 \ldots$ MIS $^{\prime}$

Weighting factors for the heat gain from lighting HEATIS

In order to make use of the weighting factor concept, it is necessary to have previous values of heat gains as well as values of cooling loads. By denoting the cooling load due to HEATG as HLCG, due to HEATX, HEATG', and HEATDP as HLCX and that due to HEATIS as HLCIS, the following set of the previous data are needed:

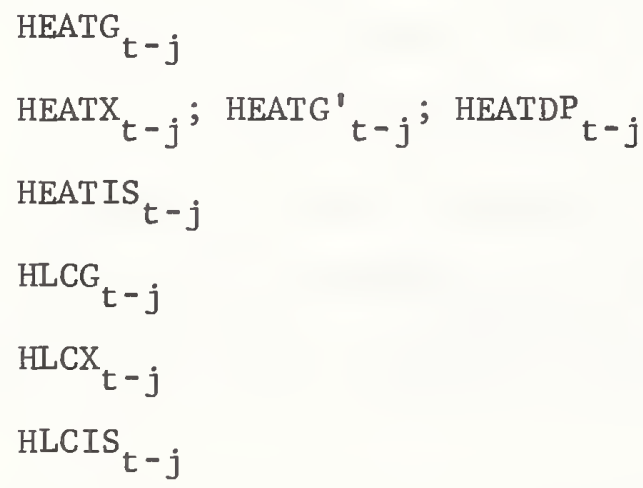

$$
\begin{aligned}
& \text { for } j=0,1,2 \ldots M G \\
& \text { for } j=0,1,2 \ldots M X \\
& \text { for } j=0,1,2,3 \ldots \text { MIS } \\
& \text { for } j=1,2,3 \ldots M^{\prime} \\
& \text { for } j=1,2,3 \ldots \mathbb{M X}^{\prime} \\
& \text { for } j=1,2,3 \ldots \text { MIS }
\end{aligned}
$$

\section{Calculation Sequence:}

1. Using the Weighting Factors* given in Tables A-13, A-14, and

The Weighting Factors given in Tables A-13, A-14, and A-15 are for typical office construction. They are obtained using the method described in Appendix B. 
A-15 and factor Fc defined by equation "d", calculate load components corresponding to the heat gains.

$$
\begin{aligned}
& \text { a. } \mathrm{HLCG}_{t}=\mathrm{Fc} \sum_{j=0}^{\mathrm{MG}} \mathrm{AG}_{j} * \mathrm{HEATG}_{t-j}-\sum_{j=1}^{M G^{\prime}} \mathrm{BG}_{j} * \mathrm{HLCG}_{t-j} \\
& \text { b. } \operatorname{HLCX}_{t}=\operatorname{Fc} \sum_{j=0}^{M X} \operatorname{AX}_{j} *\left(\operatorname{HEATX}_{t-j}+\operatorname{HEATG}_{t-j}+\operatorname{HEATDP}_{t-j}\right) \\
& M X^{\prime} \\
& -\sum \mathrm{BX}_{j} * \mathrm{HLCX}_{t-j} \\
& j=1 \\
& \text { c. } \text { HLCIS }_{t}=\text { Fc } \sum_{j=0}^{\text {MIS }} \operatorname{AIS}_{j} * \operatorname{HEATIS}_{t-j}-\sum_{j=1}^{\text {MIS' }} \text { BIS }_{j} * \text { HLCIS }_{t-j}
\end{aligned}
$$

The coefficients given in Tables $\mathrm{A}-13, \mathrm{~A}-14$, and $\mathrm{A}-15$ are for the case where all the heat gain energy appears eventually as cooling load. In most cases, a fraction of the input is lost to the surroundings. This fraction depends on the thermal conductance between the room air and the surroundings. One estimate of this fraction $\mathrm{Fc}$, is given by

d. $F c=1-0.02 \mathrm{~K}_{\mathrm{T}} \cdots$

$$
\begin{aligned}
& \text { for the range } 1.0>\mathrm{Fc}>0.7 \\
& \text { where } \mathrm{K}_{\mathrm{T}}=\frac{1}{\mathrm{~L}_{\mathrm{F}}}\left(\mathrm{U}_{\text {window }} \mathrm{A}_{\text {window }}\right. \\
& \\
& +U_{\text {exterior wall }} \mathrm{A}_{\text {exterior wall* }} \\
& \left.+U_{\text {corridor wall }} \mathrm{A}_{\text {corridor wall }}\right)
\end{aligned}
$$

A U*A product should also be included for walls that adjoin unconditioned spaces even though the walls are not exterior ones. 


$$
\begin{aligned}
L_{F} & =\text { Length of room exterior perimeter } \\
U & =U \text { value of the room enclosure element } \\
A & =\text { Area of the room enclosure element }
\end{aligned}
$$

2. Hour ly load

a. Sensible load

$$
\mathrm{SCL}_{t}=\mathrm{HLCG}_{t}+\mathrm{HLCX}_{t}+\text { HLCIS }_{t}+\text { HEATVS }_{t}
$$

b. Latent load

$$
=\text { HEATL }_{t}
$$

$$
\text { Table A-13 }
$$

WEIGHTING FACTORS FOR HEATG

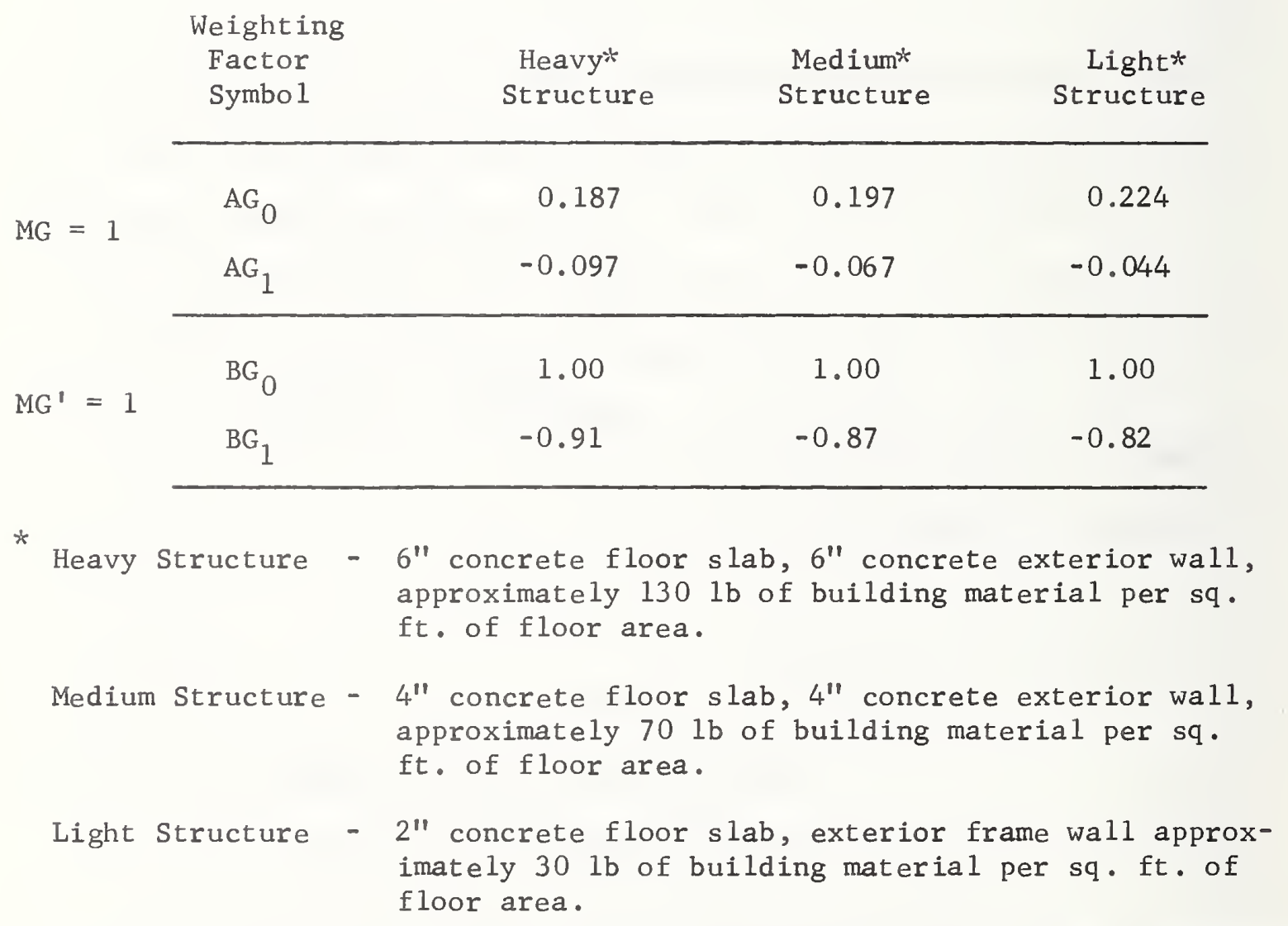


Table A-14

NORMALIZED WEIGHTING FACTORS FOR HEATX + HEATG' + HEATDP

Weighting

Factor

Symbo 1

Heavy

Medium

Structure

Light

Structure

Structure

$M X=1$

0.676

0.681

0.703

$\mathrm{AX}_{1}$

$-0.586$

$-0.551$

$-0.523$

$M X^{\prime}=1$

1.00

1.00

1.00

$\mathrm{BX}_{1}$

$-0.91$

$-0.87$

$-0.82$ 
Table A-15

WEIGHTING FACTORS FOR HEATIS

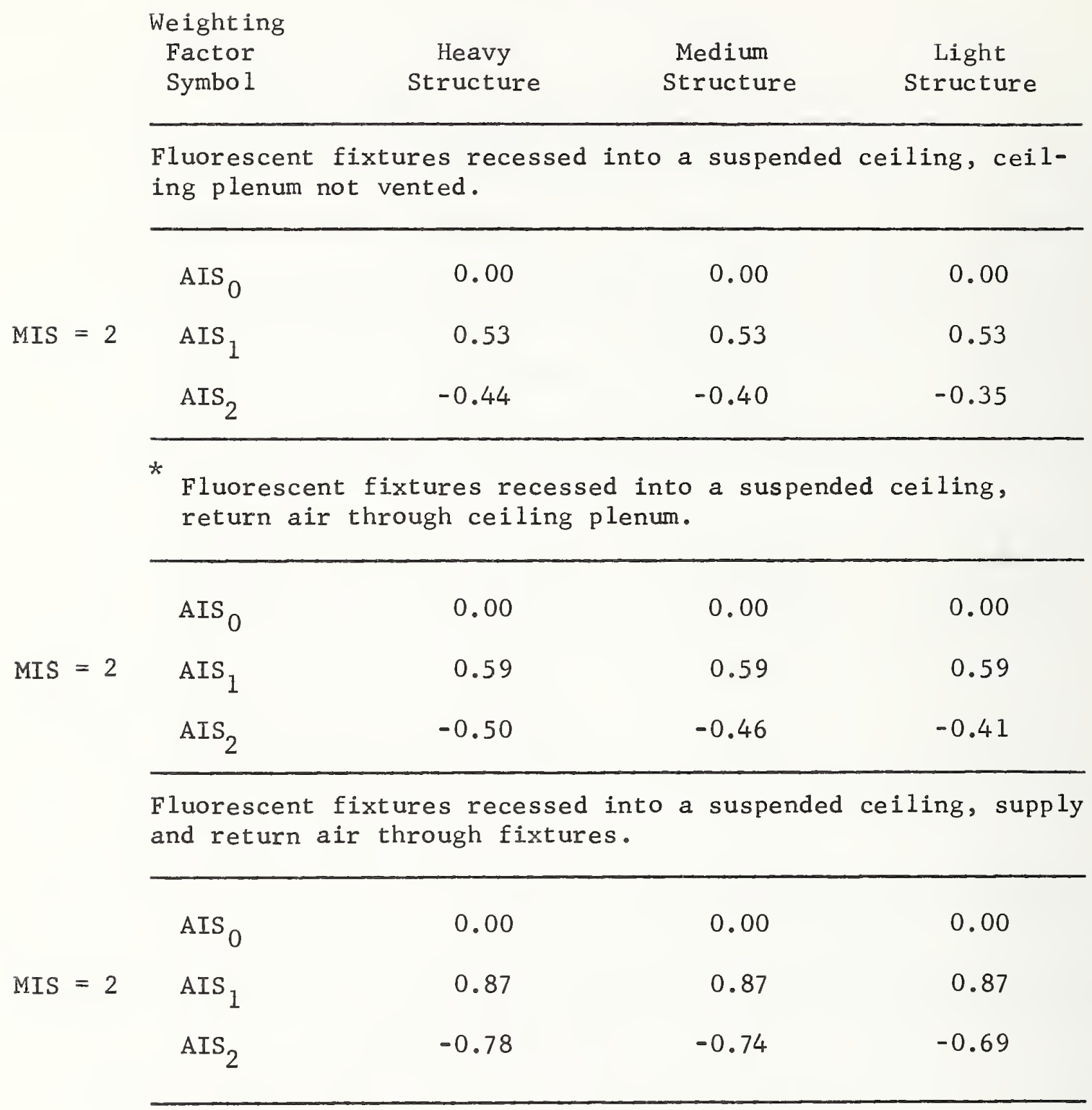

*

Manufacturer's data sheet must be consulted to obtain the fractions of light input energy that are picked up by the room air and by ventilation air in the ceiling plenum. 
Table A-15 continued

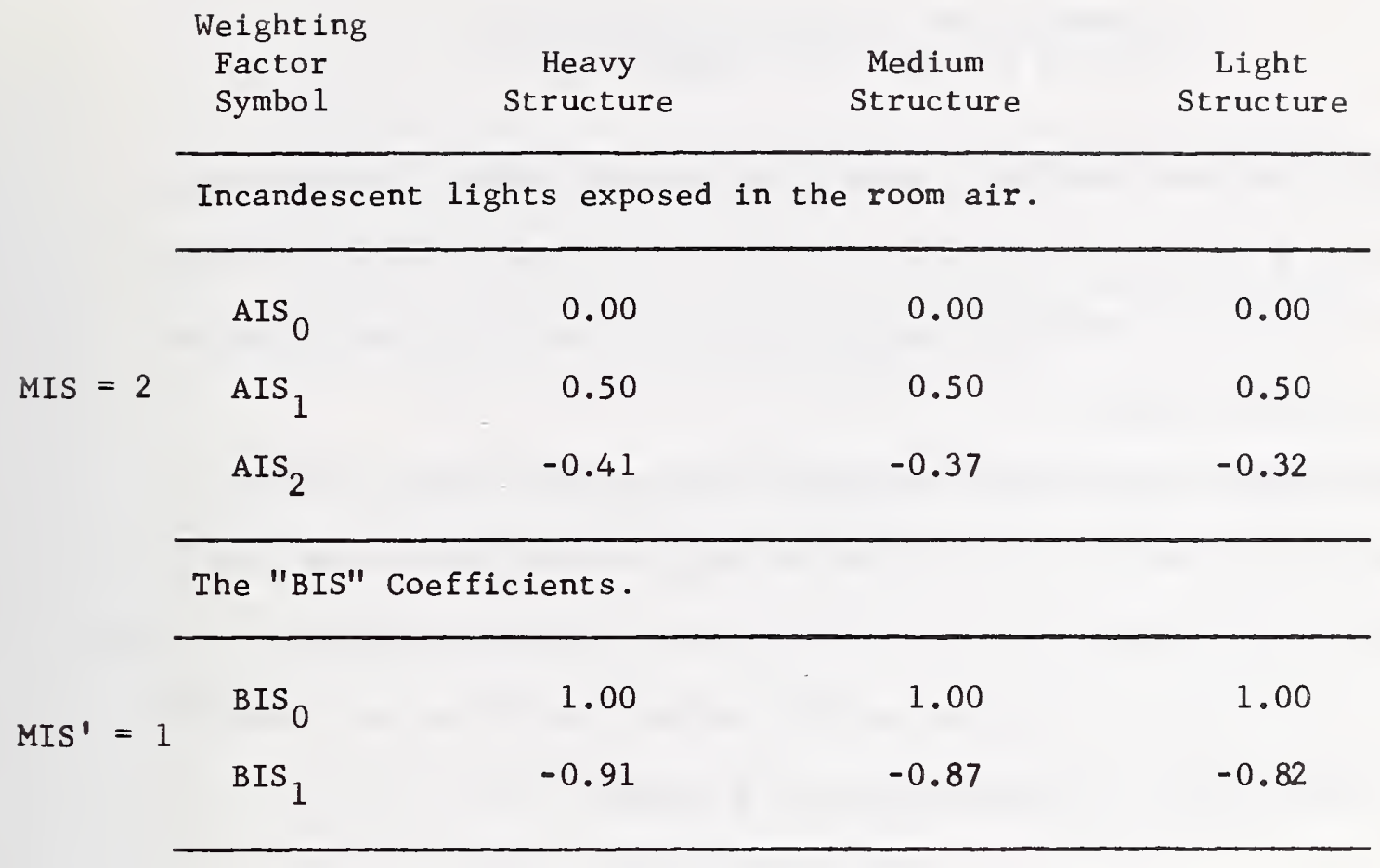


An Algorithm For Calculating Weighting Factors for Space Air Temperature

This algorithm provides a sample calculation method for obtaining the weighting factors for deviation of space temperature from the design value; the value at which the space heating/cooling loads are obtained for by the HLC routine.

This general algorithm illustrated here is for a space enclosure surrounded with spaces on both sides as well as above and below that are thermally at the same conditions. The space enclosure consists of an external wall, interior partition walls, corridor partition wall, ceiling, floor, furnishings, an outside door and a window.

\section{Data:}

AF: Floor area, sq. ft.

AC: Ceiling area, sq. ft.

AP: Interior partition wall area, sq. ft.

$\mathrm{AK}$ : Corridor wall area, sq. ft.

AW: Exterior wall area, sq. ft.

AG: Window glass area, sq. ft.

$A D$ : Door area, sq. ft.

AFN: Internal furnishings area, sq. ft.

$\mathrm{BF}_{\mathrm{j}}$ Transfer functions for floor, Btu per (hr) (sq. ft.)

$\mathrm{CF}_{\mathrm{j}}:$ (F), (Calculated in XYZ)

$\mathrm{DF}_{j}$ 
$\mathrm{BC}_{j}$ Transfer functions for ceiling, Btu per (hr) (sq. ft.)

$\mathrm{CC}_{j}:$ (F), (Calculated in XYZ)

$\mathrm{DC}_{j}$

BK ${ }_{j}$. Transfer functions for corridor wall, Btu per (hr) (sq.

$\mathrm{DK}_{\mathrm{j}}$ ft.) (F), (Calculated in XYZ)

$\mathrm{BP}_{j}$ Transfer functions for interior partition walls, Btu per

$\mathrm{CP}_{j}:$ (hr) (sq. ft.) (F), (Calculated in XYZ)

$\mathrm{DP}_{\mathrm{j}}$

CW ${ }_{j}$ Transfer functions for exterior walls, Btu per (hr) (sq.

$\mathrm{DW}_{\mathrm{j}}$ ft.) (F), (Calculated in XYZ)

CD ${ }_{j}$ Transfer functions for outside door, Btu per (hr) (sq.

$\mathrm{DD}_{\mathrm{j}}$ ft.) (F), (Calculated in XYZ)

$\mathrm{CFN}_{j}$. Transfer functions for internal furnishings, Btu per (hr)

$\mathrm{DFN}_{j}(\mathrm{sq} \cdot \mathrm{ft}).(\mathrm{F}),($ Calculated in $\mathrm{XYZ})$

where $j=0,1, \ldots, M$

UG: Heat transmission coefficient of window glass, Btu per

$(\mathrm{hr})(\mathrm{sq} \cdot \mathrm{ft}).(\mathrm{F})$

CFM: Rate of air flow through the room, cu ft per min.

(Ventilation rate) 


\section{Calculation Sequence:}

1. Conversion of the given transfer functions into single series $x_{j}, y_{j}$, and $z_{j}$. This calculation is a polynomial division*, i.e.,

$$
\begin{aligned}
& x_{0} z^{0}+x_{1} z^{-1}+x_{2} z^{-2}+x_{3} z^{-3}+\ldots \\
& =\frac{a_{0} z^{0}+a_{1} z^{-1}+a_{2} z^{-a}+\ldots}{1+b_{1} z^{-1}+b_{2} z^{-2}+b_{3} z^{-3}}+\ldots
\end{aligned}
$$

where

$$
\begin{aligned}
& x_{0}, x_{1}, x_{2} \ldots=\text { single series response factor set } \\
& a_{0}, a_{1}, a_{2} \ldots \text { and } \\
& b_{1}, b_{2}, b_{3} \ldots=\text { coefficient of the given numerator } \\
& \text { and denominator series respectively }
\end{aligned}
$$

For example, using given notation in this section for the outside wall, the $x^{\prime} s, a^{\prime}$ s and $b^{\prime}$ s are

$$
\begin{array}{lll}
\mathrm{x}_{0}=\mathrm{sCW}_{0} & \mathrm{a}_{0}=\mathrm{CW}_{0} & \mathrm{~b}_{0}=1.0 \\
\mathrm{x}_{1}=\mathrm{sCW}_{1} & \mathrm{a}_{1}=\mathrm{CW}_{1} & \mathrm{~b}_{1}=\mathrm{DW}_{1} \\
\mathrm{x}_{2}^{2}=\mathrm{sCW}_{2} & \mathrm{a}_{2}=\mathrm{CW}_{2} & \mathrm{~b}_{2}=\mathrm{DW}_{2} \\
\cdot & \mathrm{b}_{3}=\mathrm{DW}_{3}
\end{array}
$$
* The rules of polynomial division can be obtained from any standard
textbooks on numerical analysis. 
where the letter " $s$ " in front of $\mathrm{CW}_{j}$ denotes coefficients of the single series.

2. Calculation of the single series of Room Air Response Factors, sRMRT. The factors in this series are given by

$$
\begin{aligned}
& \mathrm{sRMRT}_{j}=\operatorname{AF}\left[\mathrm{sBF}{ }_{j}+\mathrm{sCF}_{j}\right] \\
& +\mathrm{AC}\left[\mathrm{sDC}_{j}+\mathrm{sCC}_{j}\right] \\
& +\mathrm{AP}\left[s B P_{j}+s_{j}\right] \\
& +\mathrm{AW}\left[\mathrm{sCW}_{\mathrm{j}}\right] \\
& +\mathrm{AD}\left[s C D_{j}\right] \\
& +\operatorname{AFN}\left[s^{-C F N}{ }_{j}\right] \\
& +\mathrm{AG}\left[\mathrm{UG}_{\mathrm{j}}\right]^{*} \\
& +1.08\left[\mathrm{CFM}_{j}\right]^{*}
\end{aligned}
$$

where $j>10$ calculate the ratio $R_{j}$

$$
R_{j}=\frac{s R M T_{j+1}}{s R M R T_{j}}
$$

and when $\left|R_{j}-R_{j+1}\right| \leq 0.001$ terminate sRMRT ${ }_{j}$ calculations.

3. Calculation of RMRT

The calculation of RMRT as a ratio of two series consists of three steps:

(a) Calculation of denominator, $D(z)$, $\mathrm{D}(\mathrm{z})=1.0-\mathrm{Rz}^{-1}$

where $\mathrm{R}$ is the last value of the ratio calculated in the sRMRT $_{j}$ calculations.

$*$

Note that $U_{j=1}=U G, C F M_{j=1}=C F M, U G_{j>1}=0.0$ and $C_{j>1}=0.0$. 
(b) Calculation of numerator, $\mathrm{N}(\mathrm{z})$,

$$
\begin{aligned}
N(z)=\operatorname{sRMRT}_{0} z^{0} & +\left(\operatorname{sRMRT}_{1}-(R) s R M R T_{0}\right) z^{-1} \\
& +\left(\operatorname{sRMRT}_{2}-(R) \operatorname{sRMRT}_{1}\right) z^{-2} \\
& +\left(\operatorname{sRMRT}_{3}-(\mathrm{R}) \mathrm{sRMRT}_{2}\right) z^{-3}
\end{aligned}
$$

(c) The RMRT's are then evaluated by equating the following equation to the one in (b) above

$N(z)=\frac{X_{0}+X_{1} z^{-1}+X_{2} z^{-2}}{Y_{0}+Y_{1} z^{-1}}$

Typical values are shown in Table $\mathrm{A}-16$. 
Table A-16

\section{WEIGHTING FACTORS FOR THE DEVIATION OF SPACE TEMPERATURE, RMRT' $\mathrm{S}$ -}

\section{Weighting \\ Factor \\ Symbol}

$M X=2$

$M Y=1$

\author{
Heavy \\ Structure
}

$-1.85$

$+1.95$

$-0.10$

1.00

$-0.91$
Medium

Structure

$-1.81$

$+1.89$

$-0.08$

1.00

$-0.87$
Light

Structure

$-1.68$

$+1.73$

$-0.05$

1.00

$-0.82$

*

The $X$ coefficients given in this Table are for a room with zero heat conductance to surrounding spaces and are normalized to unit floor area. To get the $x_{j}$ coefficients for a room with a total conductance $\mathrm{K}$ between room air and surroundings, ventilation rate $V_{t}$ and infiltration rate $V I_{t}$ it is necessary to multiply each $X_{j}$ value by room floor area and then add $\left[\mathrm{K}+\left(\mathrm{V}_{t}+\mathrm{VI}_{t}\right) 1.08\right]\left(1.00-\mathrm{Y}_{t}\right)$ to the resulting $X_{0}$ value (where $V_{t}$ and $V I_{t}$ are in $c$ fm and $K$ is in $B t u / h r{ }^{\circ} \mathrm{F}$.

Note: That $X_{0}$ value changes with the changes of $V_{t}$ and $V I_{t}$ values. 


\section{HEXT}

An Algorithm for Calculating the Rate at Which Sensible Heat is Extracted From the Space

Data:

$\mathrm{SCL}_{t}$ : Sensible cooling load at time $t$, which is calculated for a constant space design temperature of TM, Btu per hr (Calculated in HCL)

$x_{j}$ Weighting factors for use with $\theta_{t-j}$, for $j=0,1, \ldots$,

$\mathrm{Y}_{j}$ (Calculated in RMRT with typical values shown in Table A-16)

$\theta_{t-j}:$ History of hourly space air temperature deviation from the assumed constant value $T M$, for $j=1,2 \ldots, F$

C: Average heat extraction rate of the apparatus in a space when the space air temperature is TM, Btu per hr

D: Change in the rate of heat extraction of the apparatus caused by one degree change in space air temperature, Btu per (hr) (F)

$H E_{t-j}:$ History of heat extracted from the space, for $j=1,2$ ..., Btu per hr 


\section{INFIL}

An Algorithm for Calculating Air Infiltration

It is well recognized that the air infiltration constitutes as much as $30 \%$ of home heating load and a significant part of the load of nonpressurized commercial buildings. The air leakage of a building depends upon the tightness of its exterior walls, windows, and doors, the wind characteristics and temperature difference between the inside and outside, and to some extent how the building is operated with respect to the opening and closing of its door.

The rate of air infiltration can be empirically expressed by

$$
Q=C * A * \Delta P * * N
$$

where

$$
\begin{aligned}
& \text { Q: air flow rate } \\
& \text { C: flow coefficient } \\
& A: \text { flow opening area } \\
& N: \text { pressure exponent } \\
& \triangle P: \text { pressure difference }
\end{aligned}
$$

Unfortunately it is very difficult to determine accurate values of flow opening area and pressure difference for actual buildings, which consist of complex air leakage passages. A limited amount of data are given in the 1972 ASHRAE Handbook of Fundamentals for equivalent opening area of typical windows, doors and walls. The pressure difference depends upon the wind characteristics around the building and the temperature differ- 
ence between the inside and the outside of the building.

Compiled in this section is a methodology to approximately calculate the pressure difference between a given space and its adjacent space including the outdoor. The basic mathematical principle involved is to attain a solution to a set of pressure difference equations of the following type:

$$
\begin{aligned}
& \mathrm{Q}_{\mathrm{i}}=\Sigma \mathrm{Q}_{\mathrm{i}, \mathrm{k}}=0 \\
& \mathrm{Q}_{\mathrm{i}, \mathrm{k}}=\Sigma \mathrm{A}_{\mathrm{i}, \mathrm{k}} * \mathrm{C}_{\mathrm{i}, \mathrm{k}} *\left(\mathrm{P}_{\mathrm{i}}-\mathrm{P}_{\mathrm{k}}\right) * * \mathrm{~N}_{\mathrm{i}, \mathrm{k}}
\end{aligned}
$$

where

$$
\begin{aligned}
& Q_{i}: \text { net air flow out of space } i \\
& Q_{i, k}: \text { air exchange between space } i \text { and space } k \\
& A_{i, k}: \text { flow opening area between space } i \text { and } k \\
& C_{i, k}: \text { flow coefficient applicable to the air } \\
& \text { flow between the spaces } i \text { and } k \\
& N_{i, k}: \text { pressure exponent applicable to the flow } \\
& \text { between the spaces } i \text { and } k
\end{aligned}
$$

A special computational routine is required to solve this set of simultaneous, non-1inear equations.

As mentioned previously, air leakage through various openings such as doors, windows, window frames, pinholes in the wall and service shafts may be approximated by an equation of the following type: 


$$
\begin{aligned}
\text { LEAK } & =4000 * \mathrm{~A} * \mathrm{~K} *(\mathrm{DP}) * * \mathrm{~N} \\
& =\mathrm{C} *(\mathrm{DP}) * * \mathrm{~N}
\end{aligned}
$$

where

$$
\begin{aligned}
\text { LEAK } & =\text { air leakage in cu. ft per min. } \\
\mathrm{A} & =\text { opening area, } \mathrm{sq} \cdot \mathrm{ft} \\
\mathrm{K} & =\text { flow coefficient, dimensionless } \\
\mathrm{DP} & =\text { pressure difference across the opening, inches of water } \\
\mathrm{N} & =\text { pressure exponent, dimensionless } \\
\mathrm{C} & =\text { equivalent flow coefficient (EFC) }
\end{aligned}
$$

The values of $\mathrm{K}$ and $\mathrm{N}$ vary depending upon the type of opening. Moreover, the exact value of $\mathrm{A}$ is not well known for many types of openings, such as wall pinholes or cracks around the windows. Table A-17 lists the values of Equivalent Flow Coefficient $C$ and the flow exponent $N$ for various types of openings common to many buildings. These values are derived from the air leakage data compiled in Chapter 19 "Infiltration and Natural Ventilation" of the 1972 ASHRAE Handbook of Fundamentals. 
1. Double-hung wooden windows (locked)*

$\begin{array}{ccc}\text { non-weatherstripped loose fit } & 6 & 0.66 \\ \text { average fit } & 2 & 0.66 \\ \text { weatherstripped loose fit } & 2 & 0.66 \\ \text { average fit } & 1 & 0.66\end{array}$

2. Window frames*

$\begin{array}{lll}\text { masonry frame with no caulking } & 1.2 & 0.66\end{array}$

$\begin{array}{lll}\text { masonry frame with caulking } & 0.2 & 0.66\end{array}$

$\begin{array}{lll}\text { wooden frame } & 1 & 0.66\end{array}$

3. Swinging doors* $1 / 2 "$ crack $\quad 160 \quad 0.5$

$1 / 4^{\prime \prime}$ crack $\quad 80 \quad 0.5$

$1 / 8^{\prime \prime}$ crack $\quad 40 \quad 0.5$

4. Walls** $8^{\prime \prime}$ plain brick $\quad 1 \quad 0.8$

$\begin{array}{lll}8^{\prime \prime} \text { brick and plaster } & 0.01 & 0.8\end{array}$

13" brick $0.8 \quad 0.8$

13" brick and plaster $\quad 0.0040 .7$

13" brick, furring, lath and plaster $0.03 \quad 0.9$

frame wall, lath and plaster $0.01 \quad 0.55$

$24^{\prime \prime}$ shingles on $1 \times 6$ boards on $14^{\prime \prime} 9.66$ center

$16^{\prime \prime}$ shingles on $1 \times 4$ boards on $5^{\prime \prime} \quad 5 \quad 0.66$ center
24 " shingles on shiplap
$3.6 \quad 0.7$
$16^{\prime \prime}$ shingles on shiplap
$1.2 \quad 0.66$

Values of $\mathrm{C}$ listed for these openings are per ft of linear crack length.

**; Values of C listed for the walls are per unit area of the wall surface. 
In many instances, detailed information of air leakage characteristics is not available, but it is still possible to make a calculation. For a modern office building of $120 \mathrm{ft} \times 120 \mathrm{ft}$ plan dimension with the floor height of $12 \mathrm{ft}$, Tamura $\frac{15 /}{}$ lumped together all the leakage area for a given floor as follows:

\section{Table A-18}

\begin{tabular}{|c|c|c|c|c|c|}
\hline outside wa11 & 2.5 & sq . & ft & per & tor \\
\hline 4 elevator shaft doors & 4.5 & $"$ & $" 1$ & $"$ & $" 1$ \\
\hline 2 stair shaft doors & 0.5 & $"$ & $"$ & $"$ & $" 1$ \\
\hline floor & 3.7 & $"$ & $"$ & $"$ & $\|$ \\
\hline brench perimeter and interior air duct & 7.0 & $"$ & $"$ & $" 1$ & " \\
\hline return duct & 14.0 & $"$ & $"$ & $"$ & " \\
\hline
\end{tabular}

The value of $C$ corresponding to these data can be obtained by multiplying them by 2400 which corresponds to $\mathrm{K}=0.6$.

\section{Data:}

$\mathrm{V}$ : Wind speed measured at a $40 \mathrm{ft}$ elevation as taken from the weather tape, knots.

DIR: Wind direction measured clockwise from North, degrees (see Figure A-21)

This particular data were derived from a recent and unpublished experiment of the National Bureau of Standards conducted on two highrise buildings. 


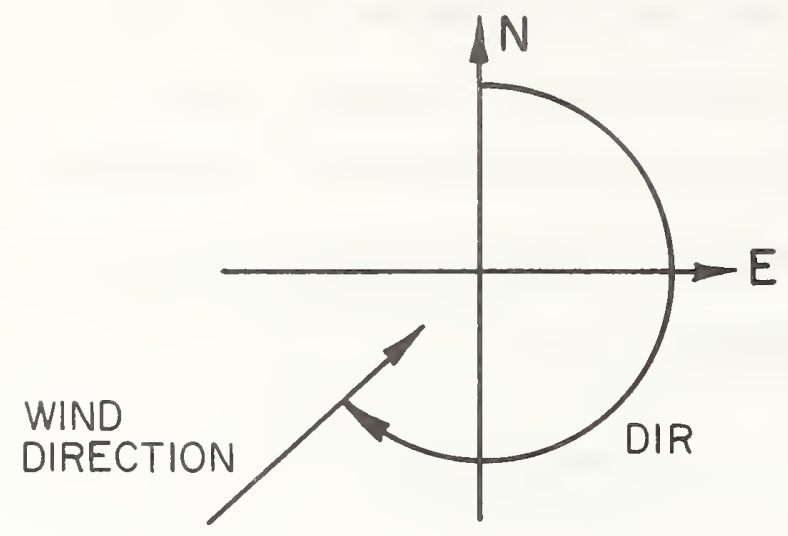

Figure A-21 Definition of Wind Direction Angle

BUILDING SURFACE

UNDER CONSIDERATION

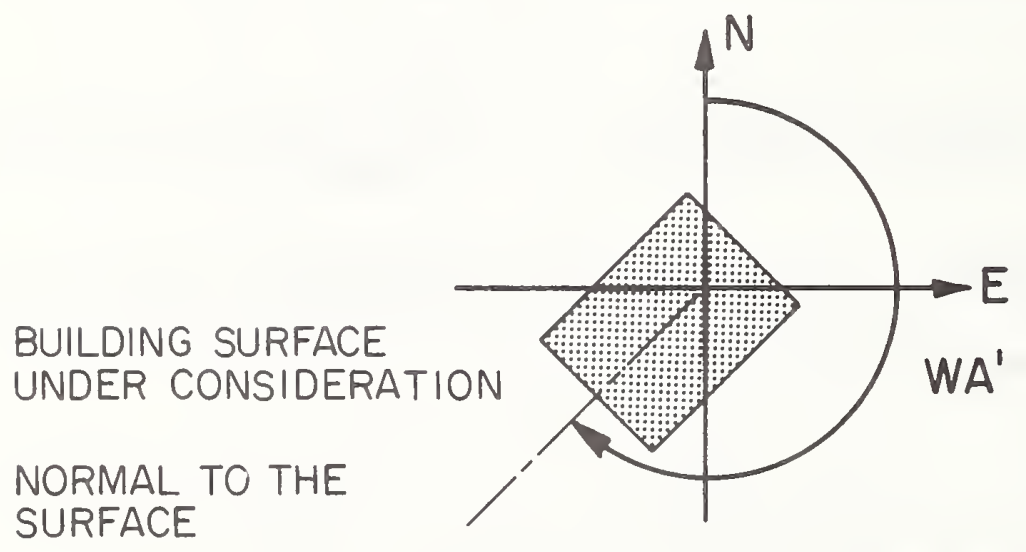

NORMAL TO THE SURFACE

Figure A-22 Definition of the Angle Between North and Normal of the Surface Under Consideration 
DB: Outdoor air dry-bulb temperature, F

$\mathrm{PB}$ : Barometric pressure, in. $\mathrm{Hg}$.

$\mathrm{NF}$ : Number of above-grade floors

HTT: Total height of building (from above-grade), ft.

TZ: Indoor air temperature, $F$

TS: Elevator and service shaft temperature

WA': Direction angle of the building as defined with respect to North and the normal of the principal surface of the building (see Figure A-22)

$\mathrm{HT}_{\mathrm{k}}$ : Height of the floor, ft, for $\mathrm{k}=1,2,3, \ldots \mathrm{NF}$

CFMSP $_{k}$ : Ventilation air supplied to the floor, cu ft per min, for $\mathrm{k}=1,2,3, \ldots \mathrm{NF}$

CFMEX $_{k}$ : Ventilation air exhausted from the floor, cu ft per min, for $k=1,2,3, \ldots N F$

\section{Calculation Sequence:}

1. $\mathrm{V}^{\prime}=1.153 * \mathrm{~V}$

$\mathrm{TO}=460+\mathrm{DB}$

$\mathrm{TI}=460+\mathrm{TZ}$

$\mathrm{PO}=0.4910 * \mathrm{~PB}$

$\mathrm{x}=\mathrm{DIR}-\mathrm{WA}^{\prime}$

2. Wind velocity, $\mathrm{VH}$, at height $\mathrm{HT}$ on the building, mph

$$
\mathrm{VH}=\mathrm{V}^{\prime} * 0.117 *(1+2.81 * \log (0.305 * \mathrm{HT}+4.75))
$$

3. Theoretical wind velocity pressure, PTWV on the building,

in. $\mathrm{H}_{2} \mathrm{O}$

$$
\text { PTWV }=0.000482 *(V * 2)
$$


4. Wind direction, BWD, relative to building surfaces

$$
\begin{aligned}
& \text { BWD = } 1 \quad \begin{array}{l}
\text { surface on windward side if, } \\
-45^{\circ}<\mathrm{x}<+45^{\circ}
\end{array} \\
& \begin{aligned}
\text { BWD }=2 \quad \text { surface on leeward side if, } \\
90^{\circ}<\mathrm{x}<270^{\circ}
\end{aligned} \\
& \begin{aligned}
\text { or }, & -90^{\circ}<\mathrm{x}<-270^{\circ} \\
\text { BWD }=3 \quad \text { surface on side if, } & 45^{\circ}<\mathrm{x}<90^{\circ} \\
\text { or }, & -45^{\circ}<\mathrm{x}<90^{\circ}
\end{aligned}
\end{aligned}
$$

\begin{tabular}{|c|c|c|c|c|c|c|c|c|c|}
\hline & \multicolumn{3}{|c|}{$T B=1$} & \multicolumn{3}{|c|}{$\mathrm{TB}=2$} & \multicolumn{3}{|c|}{$\mathrm{TB}=3$} \\
\hline NSB & $\begin{array}{l}\text { BWD } \\
=1 \\
\end{array}$ & $\begin{array}{l}\text { BWD } \\
=2 \\
\end{array}$ & $\begin{array}{l}\text { BWD } \\
=3\end{array}$ & $\begin{array}{l}\text { BWD } \\
=1\end{array}$ & $\begin{array}{l}\text { BWD } \\
=2\end{array}$ & $\begin{array}{l}\text { BWD } \\
=3\end{array}$ & $\begin{array}{l}\text { BWD } \\
=1\end{array}$ & $\begin{array}{l}\text { BWD } \\
=2\end{array}$ & $\begin{array}{l}\text { BWD } \\
=3\end{array}$ \\
\hline 0.5 & .1 & -.3 & -.8 & -.5 & -.25 & -.45 & .5 & .45 & .45 \\
\hline 1.0 & -.1 & -.25 & -.5 & -.5 & -.2 & -.3 & .45 & .3 & .3 \\
\hline 2.0 & .1 & -.25 & -.4 & .0 & -.2 & -.3 & .45 & .1 & .1 \\
\hline 3.0 & .1 & -.25 & -.4 & .1 & -.2 & -.35 & .45 & .0 & .0 \\
\hline 5.0 & .25 & -.35 & -.6 & .25 & -.25 & -.45 & .5 & -.1 & -.1 \\
\hline$\infty$ & .6 & -.35 & -.7 & .6 & -.35 & -.7 & .6 & -.35 & -.7 \\
\hline
\end{tabular}

5. Using Table A-19, determine the normal wind velocity pressure correction factor, PTKN.

Table A-19 Values of PTKN

where

$$
\begin{aligned}
& \mathrm{TB}=1: \text { Shorter building on windward side } \\
& \mathrm{TB}=2: \text { Equals taller building on windward side } \\
& \mathrm{TB}=3: \text { Taller building on leeward side }
\end{aligned}
$$


6. Wind velocity pressure correction factor, PTKO, for winds obliquely to the wall surface.

If $\mathrm{BWD}=1 \quad$ (windward side of building)

$$
(\mathrm{PTKO})_{\mathrm{m}}=\operatorname{Cos}(|\mathrm{x}|)
$$

If $\mathrm{BWD}=2$ (leeward side of building)

$$
(\mathrm{PTKO})_{1}=1.0
$$

If $B W D=3$ (side of building)

$$
(\mathrm{PTKO})_{\mathrm{S}}=\operatorname{Cos}(|\mathrm{x}|)
$$

\section{Example:}

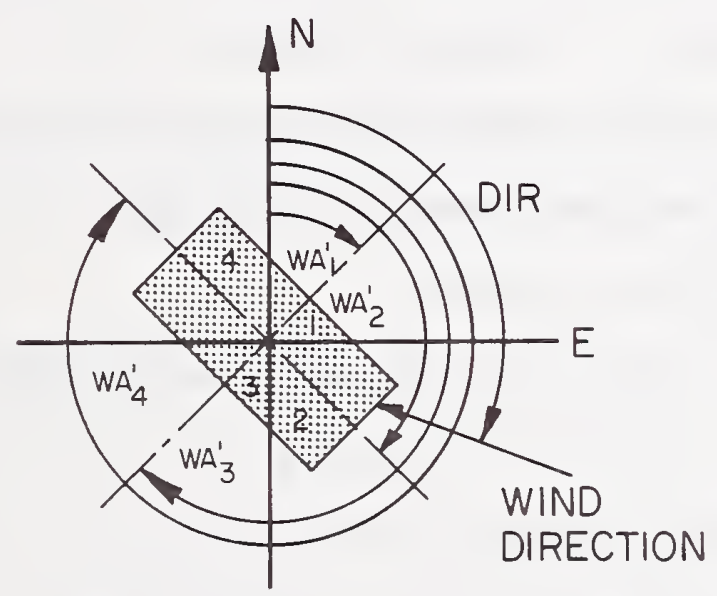

$$
\begin{aligned}
& \text { DIR }=110^{\circ} \\
& \mathrm{WA}_{1}^{\prime}=45^{\circ} \\
& \mathrm{WA}_{2}^{\prime}=135^{\circ} \\
& \mathrm{WA}_{3}^{\prime}=225^{\circ} \\
& \mathrm{WA}_{4}^{\prime}=315^{\circ}
\end{aligned}
$$

Figure A-23 DIR and WA' Angles of Example 


$$
\begin{aligned}
& \text { Side } \left.1, D_{\text {IR }}-W_{1}^{\prime}=110^{\circ}-45^{\circ}=65^{\circ} \text { (therefore, } B W D=3\right) \\
& \text { Side 2, } \mathrm{DIR}-\mathrm{WA}_{2}^{\prime}=110^{\circ}-135^{\circ}=-25^{\circ} \quad(\text { therefore, } \mathrm{BWD}=1 \text { ) } \\
& \text { Side 3, } \mathrm{DIR}_{\mathrm{W}} \mathrm{WA}_{3}^{\prime}=110^{\circ}-225^{\circ}=115^{\circ} \text { (therefore, } \mathrm{BWD}=2 \text { ) } \\
& \text { Side 4, } \mathrm{DIR}_{\mathrm{W}} \mathrm{WA}_{4}^{\prime}=110^{\circ}-205^{\circ}=205^{\circ} \quad(\text { therefore, } \mathrm{BWD}=2) \\
& \text { Side 1, }(\mathrm{PTKO})_{\mathrm{S}}=\operatorname{Cos}\left(+65^{\circ}\right) \\
& \text { Side. } 2,(\text { PTKO })_{\mathrm{m}}=\operatorname{Cos}\left(+25^{\circ}\right) \\
& \text { Side 3, }(\text { PTKO })_{1}=1.0 \\
& \text { Side 4, }(\text { PTKO })_{1}=1.0
\end{aligned}
$$

7. Actual wind pressure on the building at height (HT) corresponding to floor $(k):(\text { PAWV })_{k}$

$$
(\mathrm{PAWV})_{\mathrm{k}}=(\mathrm{PTKO})_{\mathrm{k}} *(\mathrm{PTKN})_{\mathrm{k}} *(\mathrm{PTWV}) \text {, }
$$

8. Stack effect pressure (PSE) on the outside of the building at building height ( $\mathrm{HT}$ ) and floor $(\mathrm{k})$, in. $\mathrm{H}_{2} \mathrm{O}$

$$
(\mathrm{PSE})_{\mathrm{k}}=-0.52 * \mathrm{PO} * \mathrm{HT} / \mathrm{TO}
$$

9. Total pressure on the outside of the building (PCO) at floor (k), in. $\mathrm{H}_{2} \mathrm{O}$

$$
(\mathrm{PCO})_{\mathrm{k}}=(\mathrm{PAWV})_{\mathrm{k}}+(\mathrm{PSE})_{\mathrm{k}}
$$

10. Pressure in the elevator and serve shafts (PSE) at height (HT) corresponding to floor $(k)$, in. $\mathrm{H}_{2} \mathrm{O}$

$$
(\mathrm{PSE})_{\mathrm{k}}=-0.52 * \mathrm{PO} * \mathrm{HT} / \mathrm{TI}+(\mathrm{PSE})_{1}
$$

11. Choose appropriate flow coefficients and pressure exponents for air leakage paths of each floor as follows:

Flow coefficients

CWD: Value of $\mathrm{C}$ for appropriate window in Table A-17 multiplied by the total crack length of all the windows 
CFM: Value of $\mathrm{C}$ for appropriate window frame in Table A-17 multiplied by the total crack length of all the window frames

CDR: Value of $\mathrm{C}$ for appropriate door in Table A-17 multiplied by the total crack length of all the doors

CWL: Value of $\mathrm{C}$ for appropriate walls in Table A-17 multiplied by the total wall area

CCL: Value of A for the ceiling from Table A-18 multiplied by 2400

CFL: Value of A for the floor from Table A-18 multiplied by 2400

CEL: Value of $\mathrm{C}$ for elevator doors

CSS: Value of $\mathrm{C}$ for the doors to the service shaft

CFS and CES: Value of the cross section of the shaft multiplied by 800

Pressure exponent

NWD: Value of $\mathrm{N}$ for the appropriate window in Table A-17

NFM: Value of $\mathrm{N}$ for the appropriate window frame in Table $A-17$

NDR: Value of $\mathrm{N}$ for the appropriate door in Table $\mathrm{A}-17$

NWL: Value of $\mathrm{N}$ for the appropriate wall in Table A-17

NCL : 0.5

NFL : $\quad 0.5$ 
NEL: $\quad 0.5$

NSS : 0.5

NFS : $\quad 0.5$

NSE : 0.5

12. Solution of $2 * \mathrm{NF}$ equations

Outdoor air leakage to k-th floor rooms* (see Figure A-23)

Window $\mathrm{k}$ leakage

LEAKWD $_{k, j}=\mathrm{CWD}_{k, j} *\left(P \mathrm{PO}_{k, j}-\mathrm{PI}_{k}\right) * * \mathrm{NWD}_{\mathrm{k}, j}$

Window frame leakage

LEAKFM $_{k, j}=$ CFM $_{k, j} *\left(P_{k, j}-P_{k}\right) * \star N F M_{k, j}$

Door leakage

$\operatorname{LEAKDR}_{k, j}=\mathrm{CDR}_{k, j} *\left(\mathrm{PCO}_{k, j}-\mathrm{PI}_{k}\right) * * \mathrm{NDR}_{k, j}$

Wa11 leakage

$\operatorname{LEAKWL}_{k, j}=$ CWL $_{k, j} *\left(P C O_{k, j}-P_{k}\right) * \star N W L_{k, j}$

Ce11ing leakage

LEAKCL $_{k}=$ CCI $_{k} *\left(P I_{k+1}-P I_{k}\right) * *$ NCL $_{k}$

Floor leakage

$\operatorname{LEAKFI}_{k}=$ CFL $_{k} *\left(P I_{k-1}-P I_{k}\right) * * N_{k} L_{k}$

*

In $a 11$ of above expressions, subscript $k$ refers to the $k-t h$ floor and subscript $j$ refers to the $j$-th side of the building where the convention is $j=1$ (south), 2 (west), 3 (north), and 4 (east). 


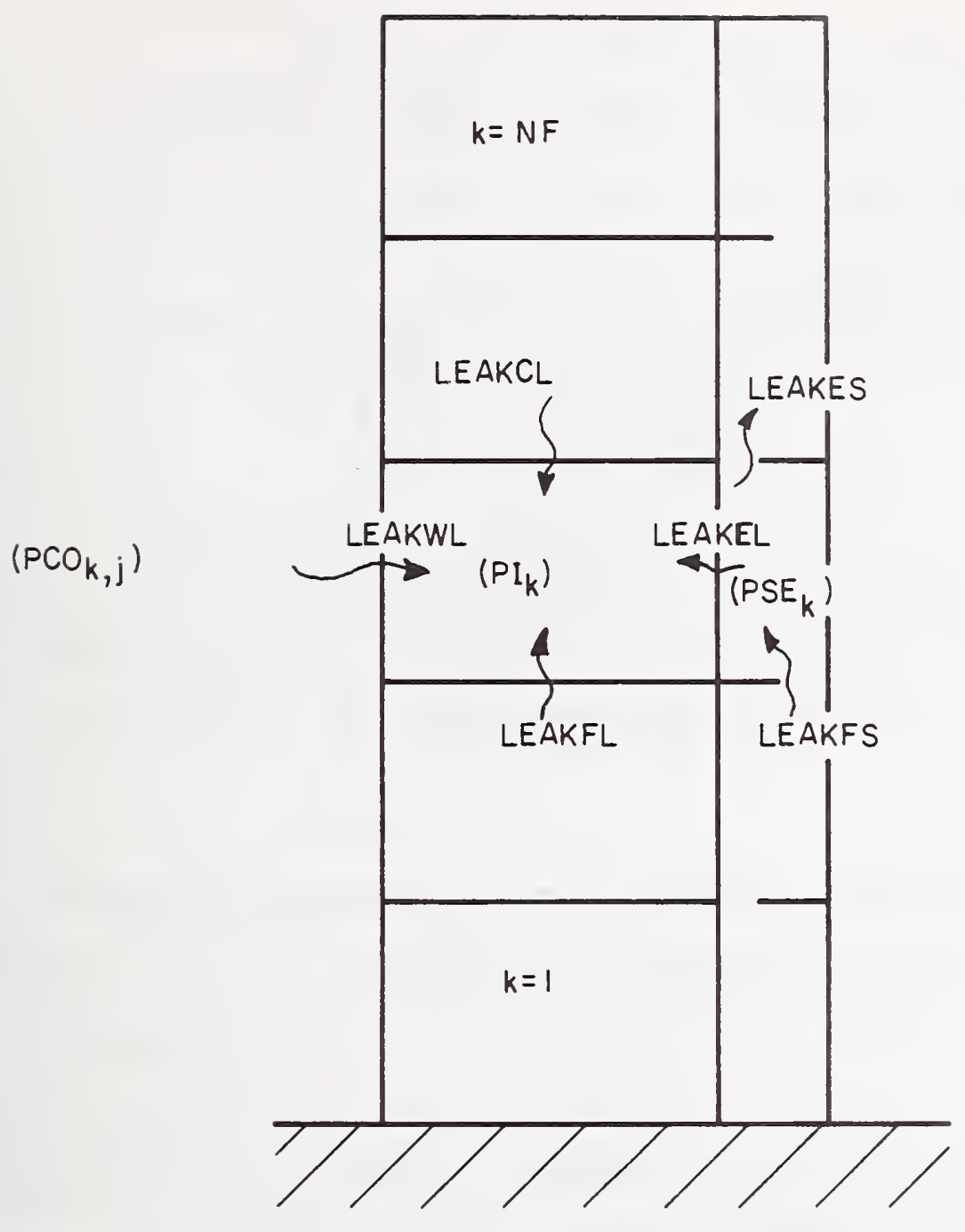

Figure A-23 Air Leakage Pattern of a High-Rise Building 
Leakage from the elevator and service shafts*

$$
\begin{aligned}
& \text { LEAKEL }_{k}=\mathrm{CEL}_{k} *\left(P S E_{k}-\mathrm{PI}_{k}\right) * * \mathrm{NEL}_{\mathrm{k}} \\
& \text { LEAKSS }_{k}=\mathrm{CSS}_{k} *\left(P S E_{k}-\mathrm{PI}_{\mathrm{k}}\right) * * \mathrm{NSS}_{\mathrm{k}}
\end{aligned}
$$

Air leakage between the floor levels within the shafts*/

$$
\begin{aligned}
& \text { LEAKFS }_{k}=\mathrm{CFS}_{k} *\left(\mathrm{PSE}_{\mathrm{k}-1}-\mathrm{PSE}_{\mathrm{k}}\right) * * \mathrm{NFS}_{\mathrm{k}} \\
& \text { LEAKES }_{k}=\mathrm{CES}_{\mathrm{k}} *\left(\mathrm{PSE}_{\mathrm{k}-1}-\mathrm{PSE}_{\mathrm{k}}\right) * \mathrm{NSE}_{\mathrm{k}}
\end{aligned}
$$

In the previous equations, unknowns are $\mathrm{PI}_{\mathrm{k}}$ for $\mathrm{k}=1,2,3$, $\ldots N F$ and $\operatorname{PSE}_{k}$ for $k-1,2,3 \ldots N F$ provided that the pressures in all the shafts are assumed equal at a given floor leve1.

Flow balance equations at the $\mathrm{k}$-th floor (the individual quantities come from equations 1-10 above)

Rooms

$$
\begin{aligned}
& \text { LEAKWD }_{k, j}+\text { LEAKFM }_{k, j}+\text { LEAKDR }_{k, j}+\text { LEAKWL }_{k, j}+\text { LEAKCL }_{k} \\
& + \text { LEAKFL }_{k}+\text { LEAKEL }_{k}+\text { LEAKSS }_{k}+\text { CFMSP }_{k}-\text { CFMEX }_{k}=0
\end{aligned}
$$

\footnotetext{
In all of above expressions, subscript $k$ refers to the $k$-th floor and subscript $j$ refers to the $j$-th side of the building where the convention is $j=1$ (south), 2 (west), 3 (north), and 4 (east).
} 
Elevator Shaft or Service Shaft

$$
\text { LEAKFS }_{k}+\text { LEAKES }_{k}-\text { LEAKEL }_{k}^{*}+\text { CFMSPS }_{k}-\text { CFMEXS }_{k}=0
$$

where CFMSPS $_{k}$ : ventilation air supplied at the $k$-th floor in the shaft

CFMEXS $_{k}$ : air exhausted from the shaft at the $k-t h$ floor

These $2 *$ NF sets of flow balance equations must be solved by an appropriate iteration technique to obtain the pressure profiles in the building and in the shafts. Then the calculated pressure values are used to determine the air leakage of the building.

Recently a comprehensive computer program that embodies the basic algorithm described in this section was published by D. M. Sander and G. T. Tamura of the National Research Council of Canada. The details of the program are given in an NRC booklet entitled "A Fortran IV Program to Simulate Air Movement in Multi-Storey Buildings", DBR Computer Program No. 35, (March 1973).

If this equation were for a service shaft, LEAKEL $_{k}$ would be replaced by LEAKES $_{k}$. 
An Algorithm for Determining the Dates of the Daylight Savings Time

Data:

YR: Year AD

MO: Month of the year

DAY: Day of the month

The main variables calculated in this subroutine are:

DSTX: The day when daylight savings time commences

DSTY: The day when standard time resumes

DST: The daylight savings time indicator

$$
\begin{aligned}
\text { DST }= & 0 \text { during the standard time period } \\
& 1 \text { during the daylight savings time period }
\end{aligned}
$$

\section{Calculation Sequence:}

1. If MO is less than 4 or greater than 10, DST $=0$.

If $\mathrm{MO}$ is greater than 4 and less than 10, DST $=1$.

2. If $\mathrm{MO}=4, \mathrm{DAY}$ is less than 25, $\mathrm{DST}=0$.

If DAY is greater than 23, call WKDAY subroutine.

If DAY is Sunday, DSTX = DAY.

If DAY is less than DSTX, DST $=0$, otherwise DST $=1$.

3. If $\mathrm{MO}=10, \mathrm{DAY}$ is less than 25, $\mathrm{DST}=1$.

If DAY is greater than 24, cal1 WKDAY subroutine.

If DAY is Sunday, DSTY = DAY.

If DAY is less than DSTY, DST $=1$, otherwise DST $=0$. 


\section{WKDAY}

An Algorithm Used to Identify the Day of the Week for Any Given Date of the Year From 1901 to 2000

\section{Data:}

YR: Year AD

MO: Month of the year

DAY: Day of the month

The variable calculated in this subroutine is WKDAY, the weekday indicator.

$$
\begin{array}{lll}
1 & \text { if Sunday } \\
2 & \text { if Monday } \\
3 & \text { if Tuesday } \\
\text { WKDAY }= & 4 & \text { if Wednesday } \\
5 & \text { if Thursday } \\
6 & \text { if Friday } \\
7 & \text { if Saturday }
\end{array}
$$

Calculation Sequence:

1. Let $\operatorname{FStdday}(1)=31, \operatorname{FSTDAy}(2)=59, \operatorname{FSTDAY}(3)=90, \operatorname{FSTDAY}(4)=120$

$$
\begin{aligned}
& \operatorname{FSTDAY}(5)=151, \operatorname{FSTDAY}(6)=181, \operatorname{FSTDAY}(7)=212, \operatorname{FSTDAY}(8)=243 \\
& \operatorname{FSTDAY}(9)=273, \operatorname{FSTDAY}(10)=304, \operatorname{FSTDAY}(11)=334, \operatorname{FSTDAY}(12=365
\end{aligned}
$$

2. Let $\mathrm{N}=$ Integer part of $\mathrm{YR} / 4$

$$
\begin{aligned}
& N D=N-485 \\
& I Y=2, I A D D=2 \\
& \text { If } N D=0 \text {, Go to (4) } \\
& \text { If ND is less than } 0, N D=-N D \text { and } I A D D=-2
\end{aligned}
$$


3. Repeat the following steps for ND times

$I Y=I Y-I A D D$

If $I Y$ is greater than $7, I Y=I Y-7$

If IY is equal to $0, \quad$ IY $=7$

If $I Y$ is less than $0, \quad I Y=I Y+7$

4. Let $\mathrm{MD}=\mathrm{YR}-\mathrm{N} * 4$

If $M$ is equal to $0 \quad$ IWK $=I Y$

If $M$ is equal to $1 \quad$ IWK $=I Y+2$

If $M$ is equal to $2 \quad$ IWK $=I Y+3$

If $M$ is equal to $3 \quad$ IWK $=I Y+4$

If IWK is greater than 7 , IWK $=$ IWK -7

If $M O$ is not equa 1 to 1 go to 5

$\mathrm{TDAY}=\mathrm{DAY}-1$

Go to 7

5. Repeat the following for $j=2$ through 12

If $\mathrm{MO}$ is equal to $j$, let $\operatorname{TDAY}=\operatorname{FSTDAY}(j-1)+\operatorname{Day}-1$

Otherwise Go to 6

6. If $M D$ is equal to 0 and $M O$ is greater than $2, \operatorname{TDAY}=\operatorname{TDAY}+1$

7. Let $\mathrm{NTX}=$ Integer part of $\mathrm{TDAY} / 7$

$\mathrm{NDX}=\mathrm{TDAY}-7 * \mathrm{NTX}+\mathrm{IWK}$

If NDX is greater than 7 , let $\mathrm{NDX}=\mathrm{NDX}-7$

8. Let $\mathrm{WKDAY}=\mathrm{NDX}$

9. If this routine is going to be applied for the period outside 1901-2000, the following additional algorithms must be added. $\mathrm{KV}=$ First two digits of $\mathrm{YR}$ 


$$
\begin{aligned}
& \text { KTEST = Last two digits of YR } \\
& \text { If } \mathrm{MO} \leq 2 \text { or } \mathrm{KTEST}=0, \mathrm{KV}=\mathrm{KV}-1 \\
& \text { LTEST }=\text { Remainder of } \mathrm{KV} / 4 \\
& \mathrm{KV}=4 * \mathrm{LV}+\mathrm{LTEST} \\
& \text { If } \operatorname{LTEST}=2, \text { WKDAY }=\text { WKDAY }+\mathrm{i} \\
& =1, \text { WKDAY }=\text { WKDAY }+ \text { : } \\
& =0, W K D A Y=W K D A Y+3 \\
& \text { Otherwise WKDAY }=\text { WKDAY }-3 *(L-4) \\
& \text { If } W K D A Y<0, W K D A Y=W K D A Y ~+7 \\
& \text { If } W K D A Y>7, W K D A Y=W K D A Y-7
\end{aligned}
$$

An alternate calculation

An alternate calculation sequence for WKDAY has been suggested*

***** ALL INTEGER ARITHMETIC *****

$1 \mathrm{MDAY}=3 \not \times(\mathrm{MO}-1)+(\mathrm{MO}-2) * 58 / 1 \emptyset \emptyset-1$

IF $(\mathrm{MO} \cdot \mathrm{LE} \cdot 2)$ MDAY=MDAY $+\mathrm{MO}$

$2 \quad \mathrm{NIVC}=I Y R-(I Y R / 4 \emptyset \emptyset) * 4 \emptyset \emptyset$

$\mathrm{NLYR}=\mathrm{NIVC} / 4$

NCEN=NIVC $/ 1 \emptyset \emptyset$

$\mathrm{NIC}=\mathrm{NIVC}-1 \emptyset \emptyset \times \mathrm{NCEN}$

$3 I Y=6-2 * N L Y R$

$4 \mathrm{MD}=\mathrm{NIVC}-\mathrm{NLYR} * 4$

$I F(M D \cdot G E \cdot 1) \quad I Y=I Y+1+M D$

$I Y=I Y-N C E N$

IF $(\mathrm{NIC} \cdot \mathrm{EQ} \cdot \emptyset \cdot \mathrm{AND} \cdot \mathrm{NIVC} \cdot \mathrm{GT} \cdot \emptyset) \quad I Y=I Y+1$

5 IDAYR $=$ MDAY+IDA

$6 \mathrm{IF}(\mathrm{NIC} \cdot \mathrm{EQ} \cdot \emptyset \cdot \mathrm{AND} \cdot \mathrm{NCEN} \cdot \mathrm{GE} \cdot 1)$ GO TO 7

$\mathrm{IF}(\mathrm{MD} \cdot \mathrm{EQ} \cdot \emptyset \cdot \mathrm{AND} \cdot \mathrm{MO} \cdot \mathrm{GT} \cdot 2) \mathrm{IDAYR}=\mathrm{IDAYR}+1$

$7 \quad \mathrm{JWK}=\mathrm{IDAYR}+\mathrm{IY}$

$\mathrm{NDX}=\mathrm{JWK}-(\mathrm{JWK} / 7) * 7$

IF $(\mathrm{NDX} \cdot \mathrm{LE} \cdot \emptyset) \quad \mathrm{NDX}=\mathrm{NDX}+7$

* This was contributed by A. W. Courtney, Scientific Programming, Box 508, Bloomfield Hills, Michigan 48013. 


\section{WKDAY=NDX}

NOTE: IDA FORMERLY CALLED "DAY"

IYR FORMERLY CALLED "YR"

IDAYR = NUMBER OF THE DAY OF THE YEAR

$\emptyset=$ NUMERICAL ZERO 


\section{$\underline{\text { HOLDAY }}$ \\ An Algorithm to Identify the National Holidays of the United States of America}

Simple modifications allow the identification of any holidays or any special days in any country as long as the Gregorian Calendar system is employed.

\section{Data:}

YR: Year AD

MO : Month

DAY: Day of the month

The primary variable calculated in this subroutine is HOL, the holiday indicator; it is 1 if the date is a holiday and zero if it is a non-holiday.

\section{Calculation Sequence:}

$$
\begin{aligned}
& \text { HOL }= 1 \\
& \text { If } \mathrm{MO}=1 \text { and } \mathrm{DAY}=1 \\
& \mathrm{MO}=12, \mathrm{DAY}=31 \text { and WKDAY }=6 \\
& \mathrm{MO}=1, \mathrm{DAY}=2 \text { and WKDAY }=2 \\
& \mathrm{MO}=2,22>\mathrm{DAY} \geq 15 \text { and WKDAY }=2 \\
& \mathrm{MO}=5, \mathrm{DAY} \geq 25 \text { and WKDAY }=2 \\
& \text { MO }=7 \text { and DAY }=4 \\
& \text { MO }=7, \mathrm{DAY}=3 \text { and WKDAY }=6 \\
& \text { MO }=7, \mathrm{DAY}=5 \text { and WKDAY }=2 \\
& \text { MO }=9,7>\mathrm{DAY} \text { and WKDAY }=2 \\
& \text { MO }=10,15>\mathrm{DAY} \geq 8 \text { and WKDAY }=2 \\
& \text { MO }=10,29>\mathrm{DAY} \geq 22 \text { and WKDAY }=2 \\
& \text { MO }=11,29>\mathrm{DAY}>21 \text { and WKDAY }=5 \\
& \text { MO }=12, \mathrm{DAY}=24 \text { and WKDAY }=6 \\
& \text { MO }=12, \mathrm{DAY}=26 \text { and WKDAY }=2 \\
& \text { otherwise HOL }=0
\end{aligned}
$$




\section{$\underline{\text { PSY* }}$}

Various Algorithms for Approximate Psychrometric Calculations

The following symbols are used throughout the PSY subroutines:

DB: Dry-bulb temperature, F (determined in CLIMATE)

DP: Dewpoint temperature, F (determined in CLIMATE)

WB: Wet-bulb temperature, F (determined in CLIMATE)

t: Temperature, either DB, WB, or DP, F

PB: Barometric pressure, in. Hg (determined in CLIMATE)

H: Enthalpy of moist air, Btu per lb of dry air

HS: Enthalpy of moist air saturated with water vapor, Btu per $1 b$ of dry air

PV: Partial pressure of water vapor in moist air, in. Hg

PVS: Partial pressure of water vapor in moisture saturated air, in. $\mathrm{Hg}$

$V$ : Volume of moist air, cu ft per lb of dry air

W: Humidity ratio of moist air, $1 b$ of water vapor per lb dry air

$\log (\mathrm{x})$ : Natural logarithm of $\mathrm{x}$

$\log 10(\mathrm{x}):$ Common logarithm of $\mathrm{x}$

*

When the exact Goff-Gratch method is required, algorithms described in Reference 17 should be used. Tables A-19 and A-20 taken from that reference list that the psychrometric properties calculated by the PSY routines and the exact Goff-Gratch method, respectively. From examination of these tables it can be seen that the values calculated by the PSY subroutines are in very good agreement with the values calculated by the exact Goff-Gratch method. 
The following algorithms are used for calculating the psychrometric properties of moist air. All of these are not required for load calculations but are presented here in a package and can be applied in a variety of engineering applications.

a. PVS (t)

1. Let $\mathrm{A}(1)=-7.90298$

$B(1)=-9.09718$

$A(2)=5.02808$

$B(2)=-3.56654$

$A(3)=-1.3816 \mathrm{E}-7$

$B(3)=0.876793$

$A(4)=11.344$

$B(4)=0.0060273$

$A(5)=8.1328 \mathrm{E}-3$

$A(6)=-3.49149$

2. Let $T=(t+459.688) / 1.8$

if $T$ is less than 273.16 , go to 3

Otherwise

$$
\begin{aligned}
& \text { Let } z=373.16 / \mathrm{T} \\
& \mathrm{P} 1=\mathrm{A}(1) *(z-1) \\
& \mathrm{P} 2=\mathrm{A}(2) * \log 10(\mathrm{z}) \\
& \mathrm{P} 3=\mathrm{A}(3) *(10 * *(\mathrm{~A}(4) *(1-1 / 2))-1) \\
& \mathrm{P} 4=\mathrm{A}(5) *(10 * *(\mathrm{~A}(6) *(z-1))-1)
\end{aligned}
$$

3. Let $z=273.16 / \mathrm{T}$

$\mathrm{P} 1=\mathrm{B}(1) *(z-1)$

$\mathrm{P} 2=\mathrm{B}(2) * \log 10(\mathrm{z})$

$\mathrm{P} 3=\mathrm{B}(3) *(1-1 / z)$

$\mathrm{P} 4=\log 10(\mathrm{~B}(4)$

4. $\mathrm{PVS}=29.921 *(10 * *(\mathrm{P} 1+\mathrm{P} 2+\mathrm{P} 3+\mathrm{P} 4))$ 
b. $\quad \underline{P V(D B, W B, P B)}$

1. $\mathrm{PVP}=\mathrm{PVS}(\mathrm{WB})$

$$
\begin{aligned}
& \mathrm{WS}=0.622 * \mathrm{PVP} /(\mathrm{PB}-\mathrm{PVP}) \\
& \mathrm{IF}=(\mathrm{WB} \leq 32) \text { go to } 3 \\
& \mathrm{HL}=1093.049+0.441 * \mathrm{DB}-\mathrm{WB} \\
& \mathrm{CH}=0.24+0.441 * \mathrm{WS} \\
& \mathrm{WH}=\mathrm{WS}-\mathrm{CH} *(\mathrm{DB}-\mathrm{WB}) / \mathrm{HL}
\end{aligned}
$$

2. $\mathrm{PV}=\mathrm{PB} * \mathrm{WH} /(0.622+\mathrm{WH})$

3. $\mathrm{PV}=\mathrm{PVP}-5.704 * 10^{-4} * \mathrm{~PB} *(\mathrm{DB}-\mathrm{WB}) / 1.8$

c. $\mathrm{W}(\mathrm{DB}, \mathrm{WB}, \mathrm{PB})$

1. $\quad \mathrm{VP}=\mathrm{PV}(\mathrm{DB}, \mathrm{WB}, \mathrm{PB})$

2. $\mathrm{W}=0.622+\mathrm{VP} /(\mathrm{PB}-\mathrm{VP})$

d. $\mathrm{H}(\mathrm{DB}, \mathrm{WB}, \mathrm{PB})$

$\mathrm{H}=0.24 * \mathrm{DB}+(1061+0.444 * \mathrm{DB}) * \mathrm{~W}(\mathrm{DB}, \mathrm{WB}, \mathrm{PB})$

e. $\underline{V(D B}, W B, P B)$

1. $W V=W(D B, W B, P B)$

2. $V=0.754 *(D B+459.7) *(1+7000 * W V / 4360) / P B$

f. $\mathrm{H}(\mathrm{DB}, \mathrm{DP}, \mathrm{PB})$

1. $W=0.622 * \mathrm{PVS}(\mathrm{DP}) /(\mathrm{PB}-\mathrm{PVS}(\mathrm{DP}))$

2. $\mathrm{H}=0.24 * \mathrm{DB}+(1061+0.444 * \mathrm{DB}) * \mathrm{~W}$

g. $\underline{W B(H, P B)}$

1. If $P B=29.92$ and $H>0$

Let $\mathrm{Y}=\log (\mathrm{H})$

For $\mathrm{H}<11.758$ 
$\mathrm{WB}=0.6040+3.4841 * \mathrm{Y}+1.3601 *(\mathrm{Y} * * 2)+0.9731 *(\mathrm{Y} * * 3)$

For $\mathrm{H}>11.758$

$W B=30.9185-39.682 * Y+20.5841 *(Y * * 2)-1.758 *(Y * * 3)$

If $\mathrm{PB} \neq 29.92$, or $\mathrm{H} \leq 0$ solve the following equation by iterating WB

$\mathrm{H}=0.24 * \mathrm{WB}+(1061+0.444 * W B) * \mathrm{~W}(\mathrm{WB}, \mathrm{WB}, \mathrm{PB})$

h. $\quad \underline{D P(P V)}$

1. Let $\mathrm{Y}=\log (\mathrm{PV})$

If $\mathrm{PV}$ is less than 0.18036

$\mathrm{DP}=71.98+24.873 * \mathrm{Y}+0.8927 *(\mathrm{Y} * * 2)$

Otherwise

$\mathrm{DP}=79.047+20.579 * \mathrm{Y}+1.8893 *(\mathrm{Y} * * 2)$

Attached to this section are the Fortran listings of subroutines developed at the National Bureau of Standards which incorporate the psychrometric algorithms described above.

$$
\begin{array}{ll}
\text { PVSF (X) } & \text { corresponds to PVS ( } t) \\
\text { DPF (PV) } & \text { corresponds to DP (PV) } \\
\text { WBSF (H,PB) } & \text { corresponds to WB }(H, P B)
\end{array}
$$

The routine entitled PSYl generates dewpoint temperature, vapor pressure, humidity ratio, enthalpy, specific volume, and relative humidity when the dry-bulb temperature, wet-bulb temperature and the barometric pressure are provided as input. This subroutine essentially combines all the algorithms described in this section. PSY2 is similar to PSY1 except that the dewpoint temperature is given in lieu of the wet-bulb temperature. 
SUBROUTINE PSYI(DB,WB,PB,DP,PV, $, H, V, R H)$

THIS SUBROUTINE CALCULATES VAPOR PRESSUREIPVIIHUMIDITY RATIO (W)

ENTHALPY (H), VOLUME (V),RELATIVE HUMIOITYIRH) AND DDEWAPOINT

TEMPERATURE WHEN THE DRY BULB TEMPERATURE (DB), WET-BULB TEMPERATUR

(WB) AND BAROMETRIC PRESSURE (PB) ARE GIVEN

$P V P=P V S F(W B)$

IF $(D B-W B) 4,4,5$

5 WSTAR=0.622*PVP/(PB-PVP)

IF $(W B-32,1), 1,2$

$1 P V=P V P-5.704 E-4 * P B *(D B-W B) / 1.8$

GO TO 3

$4 \quad P V=P V P$

GO TO 3

$2 C D B=(D B-32 \cdot 1 / 1 \cdot 8$

$C W B=(W B-32 \cdot 1 / 1 \cdot B$

$H L=597.31+0.4409 \cdot C D B-C W B$

$C H=0.2402+0.4409 * W S T A R$

$E X=(W S T A R-C H *(C D B-C M B) / H L) / 0.622$

$P V=P B * E X /(1,+E X)$

$3 W=0.622 * P V /(P B-P V)$

$V=0.754 \cdot(D B+459.7) *(1+7000 \cdot W / 4360) / P B$

$H=0.24 \cdot D B+(106 !+0.444 \cdot D B) \cdot W$

$D P=D P F(P V)$

$R H \equiv P V / P V S F(D A)$

RETURN

END

SUBROUTINE PSY 2 (DB,DP,PA,WB,PV,W,H,V,RHI

THIS SUBROUTINE CALCULATES THE FOLLOWINGS WHEN DRY-BULB TEMPERATURE (DB), DEW-POINT TEMPERATURE(DP), AND BAROMETRIC PRESSURE(PB) ARE GIVEN

WB WET-BULB TEMPERATURE

W HUMIDITY RATIO

H ENTHALPY

$\checkmark$ VOLUME

PV VAPOR PRESSURE

RH RELATIVE HUMIDITY

$P V=P V S F(D P)$

$P V S=P V S F(D B)$

$R H=P V / P V S$

$W=0.622 * P V /(P B-P V)$

$V=0.754 \cdot(D B+459.7) \cdot(1+7000 \cdot W / 4360) / P B$

$H=0.24 \cdot D B+(106)+0.444 \cdot D B) * W$

$W B=W B F(H, P B)$

RETURN

END 
FUNCTION WOFIH,PBI

THIS PROGRAM APPROXIMATES THE WET-BULB TEMPERATURE MHEN

ENTHALPY AND BAROMETRIC PRESSURE ARE GIVEN

IFIPB.NE.29.92) GO TO 2

$Y=\operatorname{LOG}(H)$

IF (H.GT.11.758) GO TO 3

$W B F=0.6041+3.4841 \cdot Y+1.3601 * Y * Y+0.97307 * Y * Y * Y$

60 TO 4

$3 W B F=30.9185-39 \cdot 68200 * Y+20.5841 * Y * Y-1.758 * Y * Y \cdot Y$

60 TO 4

$2 W B 1=150$.

$P V I=P V S F(N B I)$

$W 1=0.622 * P V \mid 1(P B-P V \mid)$

$X I=0.24 \cdot W B 1+(1061+0.444 \cdot W B !) \cdot W !$

$Y|=H-X|$

9 Q $W Z=W B 1-1$

$P \vee 2=P \vee S F(W B 2)$

$W 2=0.622 * P \vee 2 /(P B-P \vee 2)$

$X 2=0.24 \cdot W B 2+(1061+0.444 \cdot W B 2) \cdot W 2$

$Y Z=H-X 2$

$\mid F(Y \mid \cup Y Z) 6,7,8$

$8 W B !=W B 2$

$Y 1=12$

GO 10 ,

7 IF (1, 10,11,10

I 1 MBF $\triangle W B$ ।

GO TO 4

$10 W B F=W B 2$

GO TO 4

b $Z=A B S(Y \mid / Y Z)$

$H B F=(W B Z \cdot Z+W B \mid) /(1+Z)$

4 RETURN

END

FUNCTION DPFIPV)

THIS SUBROUTINE CALCULATES DEWOPOINT TEMPERATURE FOR GIVEN VAPOR PRESSURE $Y=L O G(P V)$

IF(PV.GT.0.1836) GO TO 1

$O P F=71.98+24.873 * Y+0.8927 * Y * Y$

60 TO 2

$1 D P F=79.047+30.579 \cdot Y+1.8893 \cdot Y \cdot Y$

2 RETURN

END 


\section{FUNCTION PVSF (X)}

OIMENSION A $(6) /=7.90298,5.02808,-1.3816 E-7,11.344,8,1328 E-3,-3,49 !$ $(49 /, 8(4) /=9.09718,-3,56654,0.876793,0.0060273 /, P(4)$

$T=(X+459.688) / 1.8$

IF (T.LT. 273.16$)$ GO TO 3

$Z=373.16 / T$

$P(1)=A(1) \cdot(Z-1)$

$P(Z)=A(Z) \cdot \operatorname{LOG}(0(Z)$

$Z 1=A(4) \cdot(1-1 / Z)$

$P(3)=A(3) \cdot(10 \div 21-1)$

$Z 1=A(6) \cdot(Z-1)$

$P(4)=A(5) \cdot(10 \cdot 2 ! 1-1)$

GO TO 4

$32=273.16 / T$

$P(1)=B(1) *(Z-1)$

$P(2)=3(2) \cdot \operatorname{LOG} 10(2)$

$P(3)=B(3) \cdot(1-1 / 2)$

$P(4)=$ LOG $10(B(4))$

$4 \quad S U M=01$

DO $51 \geq 1,4$

$5 \quad 5 \cup M=S U M+P(1)$

PVSF $=29.921 * 10 *$ SUM

RETURN

ENO 
DB WR DP

(\%)

PV

H

$$
\text { V }
$$

80.

80.0

80.0

80.0

80.0

79.0

78.7

$77 \cdot 3$

80.0

$78 . n$

76.0

80.0

77.0

74.5

100.0
95.7
91.6
87.5
83.5

1.0323

.02223

43.57

14.09

.9883 .02125

42.50

14.06

.9453 .02029

41.45

14.04

.9031 .01936

40.43

14.02

.8619 .01845

39.43

14.00

80 .

73.1

79.6

.8215

.01756

38.45

13.98

80.0

74.0

$71 \cdot 6$

75.8

.7820

.01669

37.50

13.97

72.0

.7433

.01584

68.6

68.3

.7054

.01502

36.57

13.95

80.0

$71 \cdot n$

67.0

64.7

.6682

.01421

35.67

13.93

80.0

70.0

65.4

$61 \cdot 2$

.6319

.01342

34.78

13.91

80.0

69.0

63. 7

57.8

.5963

.01265

33.92

13.89

80.0

$68 \cdot 0$

62.0

54.4

.5615

.01190

33.07

13.88

67.0

$51 \cdot 1$

.5273

.01116

32.24

13.86

80.0

6h.

58.4

47.8

.4939

.01044

31.44

13.84

30.65

13.83

80.0

65.0

56.5

44.7

.4611

.00974

29. 88

13.81

80.0

64.0

41.6

.4290

.00905

29. 12

13.80

52.5

80.0

6?.0

38.5

.3976

.00838

28.39

13.78

35.5

.3668

.00772

2.7 .66

13.77

80.0

61.0

49.0

.3366

.00709

26.96

13.76

80.0

$60 . n$

45.6

?9. 7

3070

.00645

26.27

13.74

80.0

$59 . ?$

43.0

26.9

. 2781

.00583

25.60

13.73

58.0

$4 \pi .2$

24.2

.2495

.00523

24.94

13.71

80.0

57.0

37.3

- 2216

.00464

24.29

13.70

18.8

.1943

.00407

23.66

13.69

80.0

55.0

30.4

16.2

.1675

.00350

23.04

13.68

80.0

54.0

26.7

13.7

.1412

.00295

22.43

13.67

$2 ? .4$

80.0

52.0

17.3

80.0

51.0

10.7

8.7

.1154

.00241

21.84

13.65

6.3

.0900

.00188

21.26

13.64

.0652

.00136

20.69

13.63

80.0

50.0

1.6

4. 0

.0408

.00085

20.13

13.62

1.6

.0169

.00035

19.59

13.61 
Table A-20

Moist Air Properties Calculated by the Exact Goff-Gratch Method

$\mathrm{PB}=29.92$ in. $\mathrm{Hg}$

DB

WB

DP

$\mathrm{RH}$

PV

W

$\mathrm{H}$

S

V

(\%)

\begin{tabular}{|c|c|c|c|c|c|c|c|c|}
\hline 80.0 & 80.0 & 80.0 & 100.0 & 1.0323 & .02233 & 43.69 & .0864 & 14.09 \\
\hline 80.0 & 79.0 & 78.7 & 95.7 & .9883 & .02135 & 42.61 & .0843 & 14.07 \\
\hline 80.0 & 78.0 & 77.3 & 91.6 & .9453 & .02039 & 41.56 & .0822 & 14.05 \\
\hline 80.0 & 77.0 & 76.0 & 87.5 & .9032 & .01945 & 40.53 & .0802 & 14.03 \\
\hline 80.0 & 76.0 & 74.6 & 83.5 & .8620 & .01854 & 39.53 & .0783 & 14.01 \\
\hline 0.0 & 75.0 & 73.1 & 79.6 & .8217 & .01764 & 38.55 & .0764 & 13.99 \\
\hline 80.0 & 74.0 & 71.7 & 75.8 & .7822 & .01677 & 37.60 & .0745 & 13.97 \\
\hline 80.0 & 73.0 & 70.2 & 72.0 & .7435 & .01592 & 36.67 & .0727 & 13.95 \\
\hline 80.0 & 72.0 & 68.6 & 68.4 & .7057 & .01509 & 35.76 & .0709 & 13.93 \\
\hline 80.0 & 71.0 & 67.1 & 64.8 & .6686 & .01428 & 34.87 & .0692 & 13.91 \\
\hline 0.0 & 70.0 & 65.5 & 61.2 & .6323 & .01349 & 34.00 & .0675 & 13.90 \\
\hline 80.0 & 69.0 & 63.8 & 57.8 & .5967 & .01271 & 33.15 & .0658 & 13.88 \\
\hline 80.0 & 68.0 & 62.1 & 54.4 & .5619 & .01196 & 32.32 & .0642 & 13.86 \\
\hline 0.0 & 67.0 & 60.3 & 51.1 & .5278 & .01122 & 31.51 & .0626 & 13.85 \\
\hline 0.0 & 66.0 & 58.5 & 47.9 & .4944 & .01050 & 30.72 & .0610 & 13.83 \\
\hline 80.0 & 65.0 & 56.6 & 44.7 & .4617 & .00979 & 29.95 & .0595 & 13.81 \\
\hline 80.0 & 64.0 & 54.6 & 41.6 & .4296 & .00910 & 29.19 & .0581 & 13.80 \\
\hline 80.0 & 63.0 & 52.5 & 38.6 & .3982 & .00843 & 28.45 & .0566 & 13.78 \\
\hline 80.0 & 62.0 & 50.4 & 35.6 & .3674 & .00777 & 27.73 & .0552 & 13.77 \\
\hline 80.0 & 61.0 & 48.1 & 32.7 & .3372 & .00712 & 27.02 & .0538 & 13.76 \\
\hline 80.0 & 60.0 & 45.6 & 29.8 & .3077 & .00649 & 26.33 & .0525 & 13.74 \\
\hline 80.0 & 59.0 & 43.1 & 27.0 & .2787 & .00587 & 25.66 & .0511 & 13.73 \\
\hline 80.0 & 58.0 & 40.3 & 24.2 & .2503 & .00527 & 24.99 & .0498 & 13.72 \\
\hline 80.0 & 57.0 & 37.3 & 21.5 & .2224 & .00468 & 24.35 & .0486 & 13.70 \\
\hline 80.0 & 56.0 & 34.0 & 18.9 & .1951 & .00410 & 23.71 & .0473 & 13.69 \\
\hline 80.0 & 55.0 & 30.5 & 16.3 & .1683 & .00353 & 23.09 & .0461 & 13.68 \\
\hline 80.0 & 54.0 & 26.8 & 13.8 & .1420 & .00293 & 22.49 & .0449 & 13.67 \\
\hline 80.0 & 53.0 & 22.6 & 11.3 & .1162 & .00244 & 21.89 & .0438 & 13.65 \\
\hline 80.0 & 52.0 & 17.5 & 8.8 & .0910 & .00191 & 21.31 & .0426 & 13.64 \\
\hline 80.0 & 51.0 & 11.0 & 6.4 & .0662 & .00138 & 20.74 & .0415 & 13.63 \\
\hline 0.0 & 50.0 & 2.0 & 4.1 & .0418 & .00087 & 20.18 & .0404 & 13.62 \\
\hline
\end{tabular}




\section{$\underline{\text { References }}$}

1. Kimura, K., and Stephenson, D. G., "Solar Radiation on Cloudy Days", ASHRAE Transaction, Pp. 227-233, Part I, 1969.

2. Mitalas, G. P., and Stephenson, D. G., "Absorption and Transmission of Thermal Radiation by Single and Double Glazed Windows", National Research Council of Canada Report 7104, December 1962.

3. Stephenson, D. G., "Tables of Solar Altitude, Azimuth, Intensity, and Heat Gain Factors for Latitudes from 43 to 55 Degrees North", National Research Counctl of Canada, Division of Building Research, Technical Paper No. 243, April 1967.

4. Groth, C. C., and Lokmanhekim, M., "Shadow - A New Technique for the Calculation of Shadow Shapes and Areas by Digital Computer", Second Hawaii International Conference on System Sciences, Honolulu, Hawaii, January 22-24, 1969.

5. Sun, Tseng-Yao, "Shadow Area Equations for Window Overhangs and Side Fins and Their Application in Computer Calculation", ASHRAE Semiannual meeting, Columbus, Ohio, February 5-8, 1968, Paper No. 2059.

6. Ito, N., and Kimura, K., "Convection Heat Transfer Coefficlent at the Exterior Surface of Buildings Exposed to Natural Wind", (Japanese), Transaction of Japanese Society of Architectural Engineering, 1968.

7. Robinson, H. E. and F. J. Powe11, "Thermal Resistance of Air Spaces and Fibrous Insulation Bounded by Reflective Surfaces", Building Material and Structures Report 151, National Bureau of Standards, 1957. 
8. Stephenson, D. G., and Mitalas, G. P., "Calculation of Heat Conduction Transfer Functions for Multi-Layer Slabs", ASHRAE Transactions, Vo1. 77, Part II, 1971.

9. Carslaw, H. S., and Jaeger, J. C., Conduction of Heat in Solids, Second Edition, 1959, page 326, Oxford at the Clarendon Press.

10. Mitalas, G. P. and J. G. Arseneault, "Fortran IV Program to Calculate Heat Flux Response Factors for Multi-layer Slabs, DBR Computer Program No. 23, National Research Council of Canada, 1967.

11. Kusuda, T., "Thermal Response Factors for Multi-layer Structures of Various Heat Conduction Systems", ASHRAE Transactions, pP. 250-269, Part I, 1969.

12. Hoglund, B. I., Mitalas, G. P., and Stephenson, D. G., "Surface Temperatures and Heat Fluxes for Flat Roofs", Journal of Building Science, Vo1. 2, No. 1, pp. 29-36, January 1967.

13. Stephenson, D. G. and Mitalas, G. P., "Cooling Load Calculations by Thermal Response Factor Method", ASHRAE Semiannual Meeting, Detroit, Michigan, January 20 - February 2, 1967, Paper No. 2018.

14. Mitalas, G. P. and Stephenson, D. G., "Room Thermal Response Factors", ASHRAE Transactions, P III $2.1-2.10$, Part I, 1967.

15. Tamura, G., "Computer Analysis of Smoke Control with Building Air Handling Systems", ASHRAE Journa 1, PP. 46-54, August 1972 .

16. Bailey, A., and Vincent, N. D. G., "Wind-Pressure on Buildings Including Effects of Adjacent Buildings", Journal, Institute of Civil Engineers, Vo1. 20, No. 8, October, 1943. 
17. Kusuda, T., "Algorithms for Psychrometric Calculations", Building Science Series 21, National Bureau of Standards, January 1970.

18. Tamura, G. T. and Wilson, A. G., "Building Pressures Caused by Chimney Action and Mechanical Ventilation", ASHRAE 74th Annual Meeting, Minneapolis, Minnesota, June 26-28, 1967, Paper No. 2047.

19. Brown, G., "Heat Transfer at Exterior Surfaces of Buildings", (Swedish), Transactions of National Swedish Coun. Building Res., Stockholm $27,1956$.

20. Brown, K. M., and Conte, S. D., "The Solution of Simultaneous Nonlinear Equations", Proceedings of 22nd National Conference, Association for Computing Machinery, pp. 111-114, 1967.

21. Haurwitz, B., "Insolation in Relation to Cloudiness and Cloud Density", Journal of Meteorology, Vol. 9, No. 4, September 1946.

22. Kimura, K. and Stephenson, D. G., "Theoretical Study of Cooling Load Caused by Lights", ASHRAE Annual Meeting, Lake Placid, New York, June 24-26, 1968, Paper No. 2087.

23. Mitalas, G. P., "An Experimental Check on the Weighting Factor Method of Calculating Room Cooling Load", ASHRAE Transactions, 1969.

24. Mitalas, G. P., "Calculation of Transient Heat Flow Through Walls and Roofs", ASHRAE Annual Meeting, Lake Placid, New York, June 2426, 1968, Paper No. 2086 .

25. Sun, Tseng-Yao, "Computer Evaluation of the Shadow Area on a Window Cast by the Adjacent Building", prepared for submission as a paper in the future.

26. Threlkeld, J. L., "Thermal Environmental Engineering", Prentice Hall, 1970. 



\section{Appendix B}

Weighting Factor Method of Calculating

Heating and Cooling Loads and Space Temperature */ $^{*}$

*/ This section was prepared by D. G. Stephenson and G. Mitalas of the National Research Council of Canada for the ASHRAE Task Group on Energy Requirements for Heating and Cooling. 

The weighting factor method is based on the assumption that the heat transfer processes occurring in a room can be described by linear equations; and thus that the superposition principle can be used for the calculation of cooling load and space temperature. This means that the relationship between any excitation (e.g., power input to lights) and the corresponding component of the cooling load can be expressed in the form of a characteristic transfer function. Once all the transfer functions have been determined for a room, they can be used to calculate the response to any excitation. The weighting factors are a convenient way of representing these characteristic transfer functions for a room: they relate the Z-transforms of the excitations to the Z-transforms of the corresponding cooling load components.

The 2 -trans form $1,2 /$

When a continuous signal, $f(t)$, is sampled at regular intervals of $\Delta$, the output of the sampling device is a train of pulses as shown in Figure B1. The Laplace transform of this output signal is

$$
f(0)+f(\Delta) e^{-s \Delta}+f(2 \Delta) e^{-2 s \Delta}+\ldots \ldots
$$

If $\mathrm{Z}$ is substituted for $\mathrm{e}^{\mathrm{s} \Delta}$, the transform of the output from the sampler is

$$
f(0)+f(\Delta) z^{-1}+f(2 \Delta) z^{-2}+\ldots .
$$

This polynomial in $Z^{-1}$ is the $z$-transform of the function $f(t)$. The chief advantage of this type of transform is that it can be obtained just by sampling the function at regular intervals: the successive outputs being the coefficients of successive powers of $\mathrm{Z}^{-1}$ in the $\mathrm{Z}$-transform. 

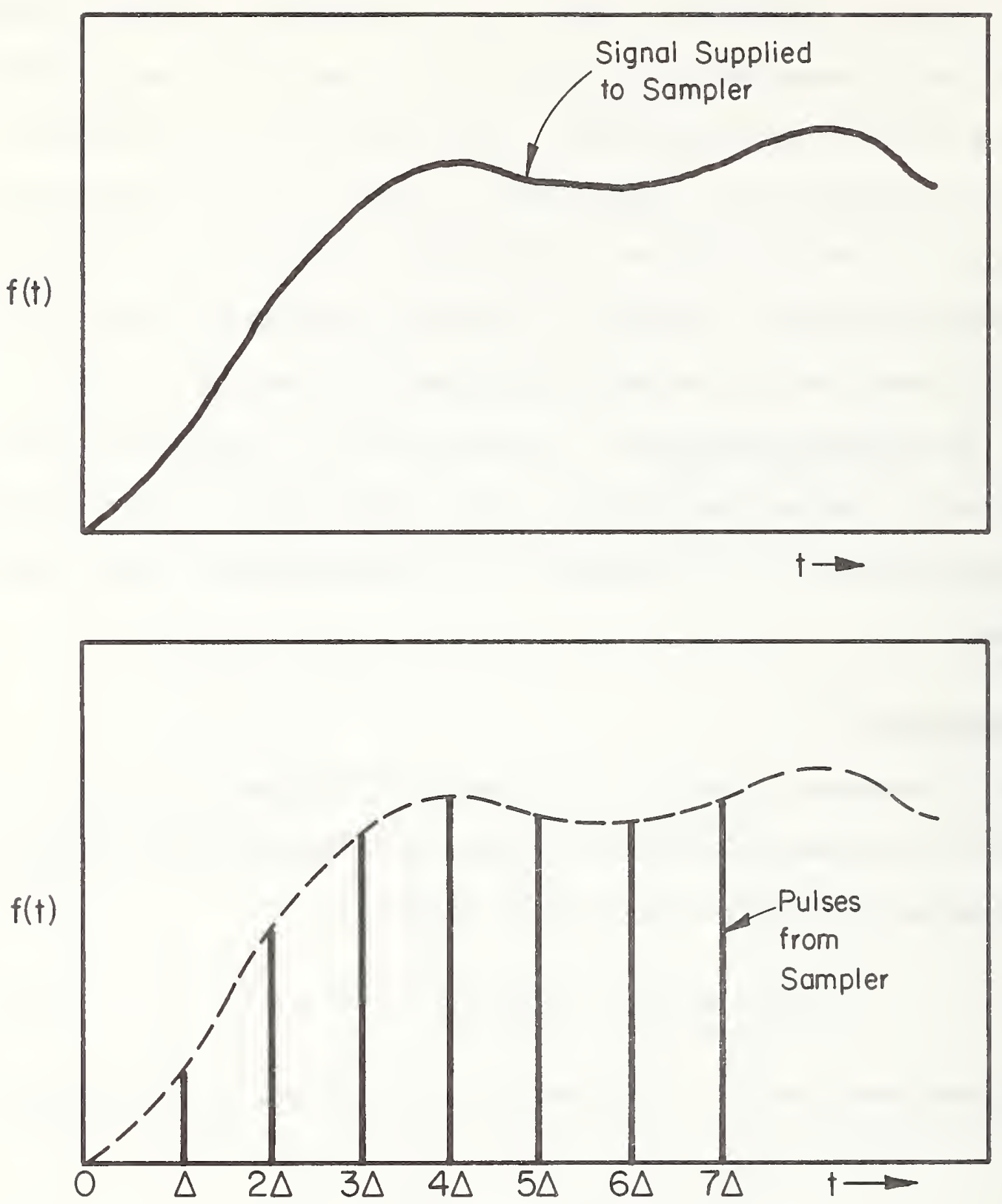

Figure B-1 Pulse Representation of a Continuous Function 
If both the input and output of a system are expressed in terms of their Z-transforms, the ratio of the output/input is a $z$-transfer function for the system. Assuming that such a transfer function, $K(Z)$, can be found, and that it can be expressed as the ratio of two polynomials in $-z^{-1}$

$$
\text { i.e., } \quad K(z)=\frac{a_{0}+a_{1} z^{-1}+a_{2} z^{-2}+\ldots}{b_{0}+b_{1} z^{-1}+b_{2} z^{-2}+\ldots}
$$

it follows that $O(Z)$, the $Z$-transform of the output that results from an input represented by $I(Z)$ is

$$
O(Z)=K(Z) \cdot I(Z)
$$

Both sides of this equation are polynomials so the coefficients of the various powers of $\mathrm{Z}^{-1}$ must be the same on the two sides of the equation. Thus, equating the coefficients of $z^{-n}$ gives

$$
\begin{aligned}
0_{n} \cdot b_{0}=I_{n} \cdot a_{0} & +I_{n-1} \cdot a_{1}+I_{n-2} \cdot a_{2}+\ldots \\
& -\left\{0_{n-1} \cdot b_{1}+0_{n-2} \cdot b_{2}+\ldots\right\}
\end{aligned}
$$

where the subscript $\mathrm{n}$ on 0 and $I$ indicates the value of the function at $t=n \Delta$, i.e., $o_{n}$ is the coefficient of $z^{-n}$ in the $z$-transform $O(z)$. This expression relates the output at any time $t=n \Delta$ to the input at that time and the values of the input and output at earlier times. The coefficients $a_{0}, a_{1}, \ldots$ and $b_{0}, b_{1} \ldots$, contain all the characteristics of the system. 
Using the Z-transfer functions approach, the cooling load is the output that results from the input, which is the heat gain. The weighting factor sets are the transfer functions relating the cooling loads to heat gains. The procedure for calculating cooling load is, therefore, first to calculate the various components of the heat gain, and then to combine them with the appropriate weighting factor sets to obtain the cooling load. An expression like equation (5) is used to compute each component of the cooling load.

The cooling load of a space depends on both the magnitude and the nature of its excitations (i.e., outside air temperature, direct and diffuse solar radiation, electric energy input to lights, etc.). The resulting cooling load also depends on the location of the element that absorbs the energy of the excitation. For example, the cooling load profile resulting from one unit of solar radiation absorbed by the window glass is quite different from that of one unit of solar radiation absorbed by the floor surface. To shorten the computation of cooling load, the heat gain must be subdivided into a limited number of components. For example, the total heat gain by a space can be represented by the following components:

(1) Heat gain through window. (HEATG and HEATǴ)

(2) Heat gain through exterior walls and roofs. (HEATX)

(3) Total power input to lights. (HEATIS)

(4) Heat gain through doors, partitions, underground walls and floors, and due to internal heat sources other than lights. (HEATDP)

(5) Sensible heat gain due to infiltration. (HEATVS) 
Each of these heat gain components is calculated on the basis of a constant air temperature in the space. The actual air temperature generally deviates from this reference value, and consequently the rate of heat extraction from the space, HE, differs from the cooling load. The calculation of actual room air temperature and heat extraction rate is the final step in the sequence of calculation: in this case, the previously calculated cooling load is the input along with the characteristics of the air conditioning unit; and heat extraction rate and air temperature are the outputs. If this transfer function is expressed in the form

$$
\frac{H E-C L}{\delta}=\sum_{0}^{v} x_{j} z^{-j} / 1+\sum_{1}^{w} y_{j} z^{-j} \text {, }
$$

or

$$
H E_{n}=C L_{n}+\sum_{0}^{v} x_{j} * \delta_{n-j}-\sum_{1}^{w} y_{j} *\left(H E_{n-j}-C L_{n-j}\right)
$$

where $\delta$ is the deviation of actual air temperature from the reference value used to calculate the heat gains.

The heat extraction rate given by equation (6) must match the rate given by the characteristic of the air conditioning unit. For example, a cooling unit with a simple proportional control system has a characteristic of the form

$$
H E_{n}=C+D * \delta_{n}
$$

where

$$
\begin{aligned}
& \mathrm{C}=\text { heat extraction rate of the unit operating in a room } \\
& \text { at the reference temperature }
\end{aligned}
$$



$D=$ change in the rate of heat extraction caused by one degree rise in room air temperature

Equations (6) and (7) can be combined to give an explicit expression for $\delta_{n}$

$$
\delta_{n}=\frac{C L_{n}-C+\sum_{1}^{v} x_{j} * \delta_{n-j}-\sum_{1}^{W} y_{j} *\left(H E_{n-j}-C L_{n-j}\right)}{D-x_{0}}
$$

and then equation ( 7 ) can be used to evaluate $\mathrm{HE}_{\mathrm{n}}$.

Equation ( 8 ) can be used to calculate $\delta_{n}$ even if the cooling equipment is off: when the equipment is not operating, $C$ and $D$ are both zero.

\section{Calculation of Room Weighting Factors}

The calculation of the room weighting factors is based on the solution of a set of heat balance equations for all the room air $3,4 /$ (RMTMP). A computer program for evaluating weighting factors has been developed by the National Research Council of Canada $/$, based on the procedure given in Reference 4.

Three different groups of room weighting factor sets are computed by this program:

(1) The first group is very large, consisting of a set of factors for each excitation at each surface.

(2) The second group combines all of the sets in group 1 that pertain to diffuse solar radiation into a single set; it combines all of the sets for direct solar radiation incident on the room surfaces other than inside window pane, floor, and furniture into another combined set; and lastly, it combines all the sets that 
pertain to excitation by the power supplied to the lights into a single set.

(3) The third group of factors carry the consolidation of the various sets of the limit: there is just one set of factors for each component of heat gain.

It is not intended that the first group should be used directly for room cooling or heating load calculations, as the second group give essentially the same results with considerably less computation ${ }^{6 /}$. The further simplication provided by the use of the third group require that the following assumptions be made:

(1) That the heat gain through room envelope components can be calculated with sufficient accuracy using combined inside surface heat transfer coefficient and that the room weighting factors are the same for heat gain through window, opaque outside wall, corridor wall and a roof.

(2) That the fraction of the solar radiation absorbed by the window glass and shade, and transmitted directly into the room as well as the portions absorbed by various room surfaces and furniture are constant during the day.

It is probable that the first assumption will not introduce significant errors; however, the second assumption is questionable. At this time, research information is lacking to establish the possible magnitude of the error introduced by this assumption. 
The procedures given in this report to convert room excitation to cooling load and heat extraction are based on the third group of room weighting factors, i.e., RMRG, RMRX, RMRT and RMRTS. In addition, simplified procedures are given for the calculation of the RMRT and RMRTS sets. If the highest possible precision is important, weighting factors in the second group should be used.

\section{$\underline{\text { References }}$}

(1) T. R. Ragazzini and G. F. Franklin, "Sampled-Data Control Systems", McGraw-Hi11 Book Company, Inc., 1958.

(2) E. I. Jury, "Theory and Application of the Z-transform Method", Wiley, 1964.

(3) D. G. Stephenson and G. P. Mitalas, "Cooling Load Calculations by Thermal Response Factor Method", ASHRAE Transactions, Vol. 73, Part 1,1967 .

(4) G. P. Mitalas and D. G. Stephenson, "Room Thermal Response Factors", ASHRAE Transactions, Vol. 33, Part 1, 1967.

(5) G. P. Mitalas and J. G. Arseneault, "Fortran IV Program to Calculate Weighting Factors for a Room".

(6) G. P. Mitalas, "An Experimental Check on the Weighting Factor Method of Calculating Room Cooling Load", presented at ASHRAE Denver Meeting, 1969.

(7) G. P. Mitalas, "Calculations of Transient Heat Flow Through Walls and Roofs, ASHRAE Transactions, Vol. 74, Part II, 1968. 
(8) D. G. Stephenson and G. P. Mitalas, "Transient Heat Conduction Through Walls and Roofs, prepared for submission to the International Journal of Heat and Mass Transfer.

(9) T. Kusuda, "Thermal Response Factors for Multi-layer Structures of Various Heat Conduction Systems, presented at ASHRAE Chicago Meeting, 1969.

(10) G. P. Mitalas and J. G. Arseneault, "Fortran IV Program to Calculate Heat Flux Response Factors for Multi-Layer Slabs, DBR Computer Program No. 23, National Research Council of Canada, 1967. 

9. Appendix C

NBSLD Data Forms 



\section{Introduction}

This manual contains the input data forms with instructions for preparing data needed to perform heating and cooling load calculations using NBSLD.

In addition, the manual contains engineering data needed for the computations so that the use of other handbooks or references are generally unnecessary. The required numerical data are to be filled into blank spaces provided on each DATA SHEET and then each sheet can be used directly at a computer terminal or to produce a data card if the program is being run in "batch mode" at a central facility. 


\section{General Instruction}

Figure C-1 shows the flow diagram or sequence for the data preparation.

Schedule Profile data sheets A, B, C and D are prepared for a building and are assumed the same for all zones or rooms within the building. DATA SHEETS 1 through 3 are prepared for each different building, thus need not be repeated for the analysis of rooms within the same building.

DATA SHEETS 6 and 7 usually need to be prepared only for the first room of the building, because other rooms that follow in the same building usually employ the same wall, roof, and floor constructions.

When two rooms have identical shape and construction and differ only in orientation, the second room is considered to be rotated with respect to the first room and requires only DATA SHEETS 4 and 5. 


\section{DATA SHEET PREPARATION GUIDE}

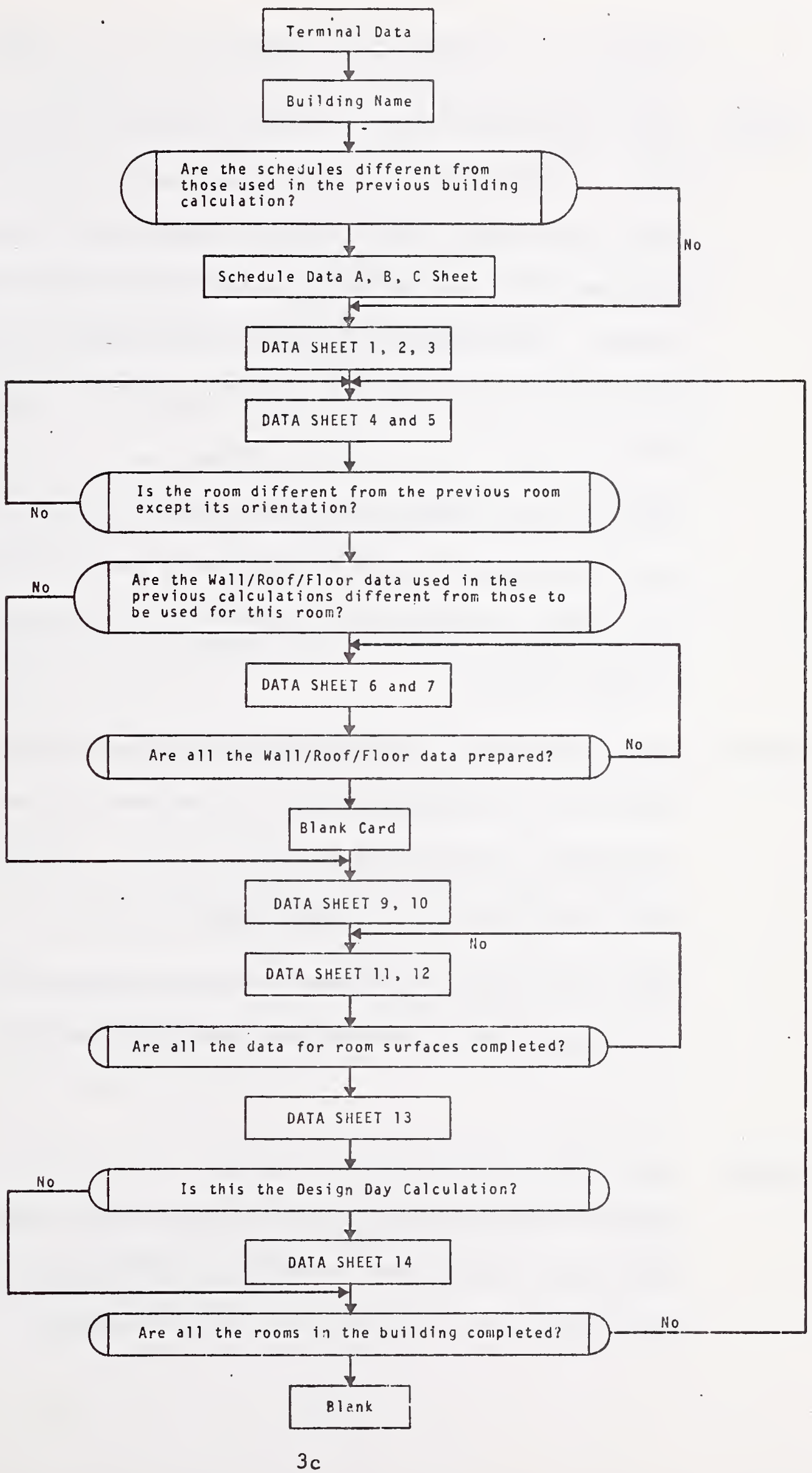


RUNID: Index for the calculation of Conduction Transfer Functions: RUNID = 1 if the load calculation being made for this particular run requires the generation of Conduction Transfer Functions for the walls, roof, ceilings and floors in the building. The Conduction Transfer Functions generated during the run will be stored in tape unit 8 for the future rerun.

RUNID $=2$ if the Conduction Transfer Functions have already been calculated and stored in tape unit 8 and this particular run does not require the generation of new Conduction Transfer Functions.

RUNTYP: Index for the types of calculations to be performed: RUNTYP = 1 if the calculation is for the hour by hour determination of heating and cooling load for a specified period by making use of weather data tape (unit 7). RUNTYP $=2$ if the calculation is for the design heating and cooling load. A weather data tape is not required for this run.

ASHRAE: Index for the weighting factor usage: ASHRAE $=0$ if the Weighting Factor Method of the ASHRAE Task Group is replaced by a more exact calculation procedure developed at the Nationa1 Bureau of Standards. 
ASHRAE $=1$ if the Weighting Factor Method of the ASHRAE Task Group is used to convert the heat gains and losses to loads.

IDETAL: Index for the output specification:

IDETAL $=0$ if output of the run is only the daily maximum and the daily tota 1 heating and cooling loads.

IDETAL $=1$, output of the run will display input data and details of intermediate results such as Conduction Transfer Functions, Radiation heat exchange factors, solar radiation and solar heat gain.

METHOD: Index for the treatment of room surface radiation heat exchange calculation: METHOD = 0 if the radiation exchange among the room surfaces are treated individually on room by room basis. METHOD = 1 if a building zone is treated as a box and al1 the interior partition walls and floor/ceiling sandwich constructions are treated as a single slab to be distributed uniformly on the floor of the box as an extra layer for that floor.

RFMTAP: Tape drive unit number for the tape to be used by the system simulation program of Ross F. Meriwether. If no tape is needed, $\operatorname{RFMTAP}=0$. 
(integer variables)

\begin{tabular}{|l|l|l|l|l|l|}
\hline RUNID & RUNTYP & ASHRAE & IDETAL & METHOD & RFMTAP \\
\hline & & & & & \\
& & & & & \\
\hline
\end{tabular}




\section{Building Name}

\section{NAMEBD}

Identification of the job, name of the building, address or other pertinent information may be used within the limit of 34 alphabetical/ numerical characters.

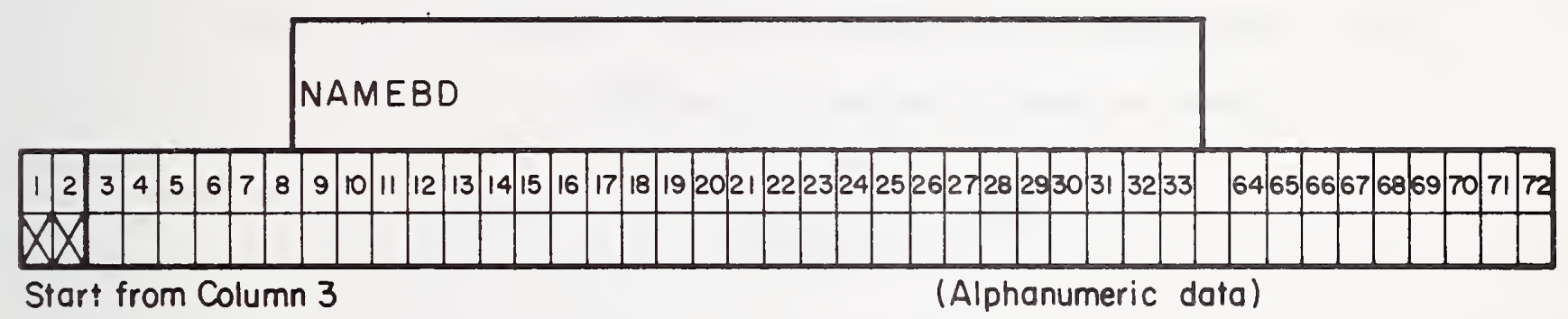




\section{Schedule Profile-A}

QLITX: Normalized* daily schedule (24-hour profile) or power input for lighting during the weekdays.

QEQUX: Normalized* daily schedule (24-hour profile) of power input for electrical appliances and other equipment (other than those involved for heating/cooling equipment) during the weekdays .

QOCUP: Normalized* daily śchedule (24-hour profile) of occupancy (number of adults) during the weekdays.

\section{QLITX}

\begin{tabular}{|l|l|l|l|l|l|l|l|l|l|}
\hline & & & & & & & & & \\
\hline & & & & & & & & & \\
\hline
\end{tabular}

\section{QEQUX}

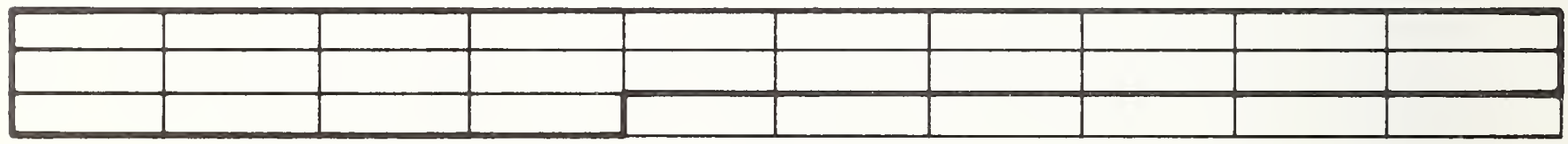

* Having a value between 0 and 1 . 
QOCUP

\begin{tabular}{|l|l|l|l|l|l|l|l|l|l|}
\hline & & & & & & & & & \\
\hline & & & & & & & & & \\
\hline & & & & & & & & & \\
\hline
\end{tabular}


Schedule Profile-B*

QLITX', QEQUX', QOCUP' are the same as QLITX, QEQUX and QOCUP respectively except that these data are for the weekends.

\section{QLITX'}

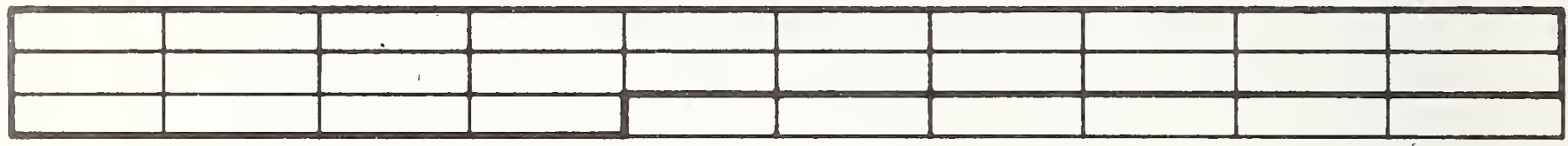

OEQUX'

\begin{tabular}{|l|l|l|l|l|l|l|l|l|l|}
\hline & & & & & & & & & \\
\hline & & & & & & & & & \\
\hline
\end{tabular}

\section{QOCUP}

\begin{tabular}{|l|l|l|l|l|l|l|l|l|l|}
\hline & & & & & & & & & \\
\hline & & & & & & & & & \\
\hline
\end{tabular}

* These data should be all zero for the design day calculation. 
Schedule Profile-C*

QLITX", QEQUX", QOCUP" are the same as QLITX, QEQUX, and QOCUP respectively except that these data are for the holidays.

\section{QLITX"}

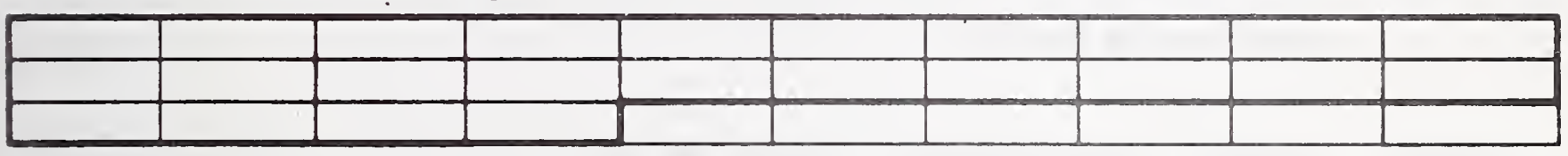

QEQUX"

\begin{tabular}{|l|l|l|l|l|l|l|l|l|l|}
\hline & & & & & & & & & \\
\hline
\end{tabular}

QOCUP"

\begin{tabular}{|l|l|l|l|l|l|l|l|l|l|}
\hline & & & & & & & & & \\
\hline & & & & & & & & & \\
\hline
\end{tabular}

* These data should be all zero for the design day calculations. 
Schedule Profile-D

Room Temperature and Humidity Schedule

RMDBS: 24 hour profile of room thermostat setting during the occupied cooling day, ${ }^{\circ} \mathrm{F}$.

RMDBW: 24 hour profile of room thermostat setting during the occupied heating day, ${ }^{\circ} \mathrm{F}$.

RMDBWO: Constant room thermostat setting during the unoccupied heating day, ${ }^{\circ} \mathrm{F}$.

RMDBSO: Constant room thermostat setting during the unoccupied cooling day, ${ }^{\circ} \mathrm{F}$.

RHW: Constant room relative humidity setting during the occupied heating days, \%.

RHS: Constant room relative humidity setting during the occupied cooling days, $\%$. 
RMDBS

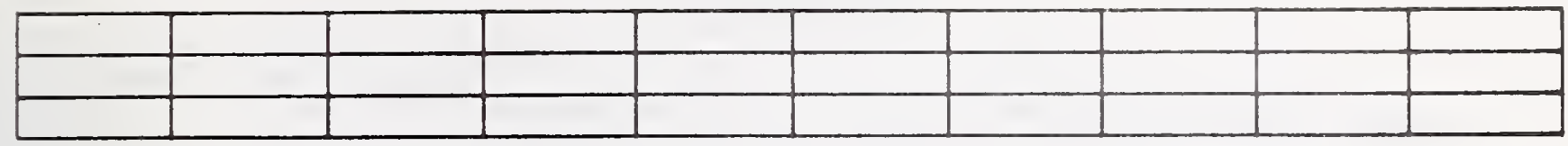

RMDBW
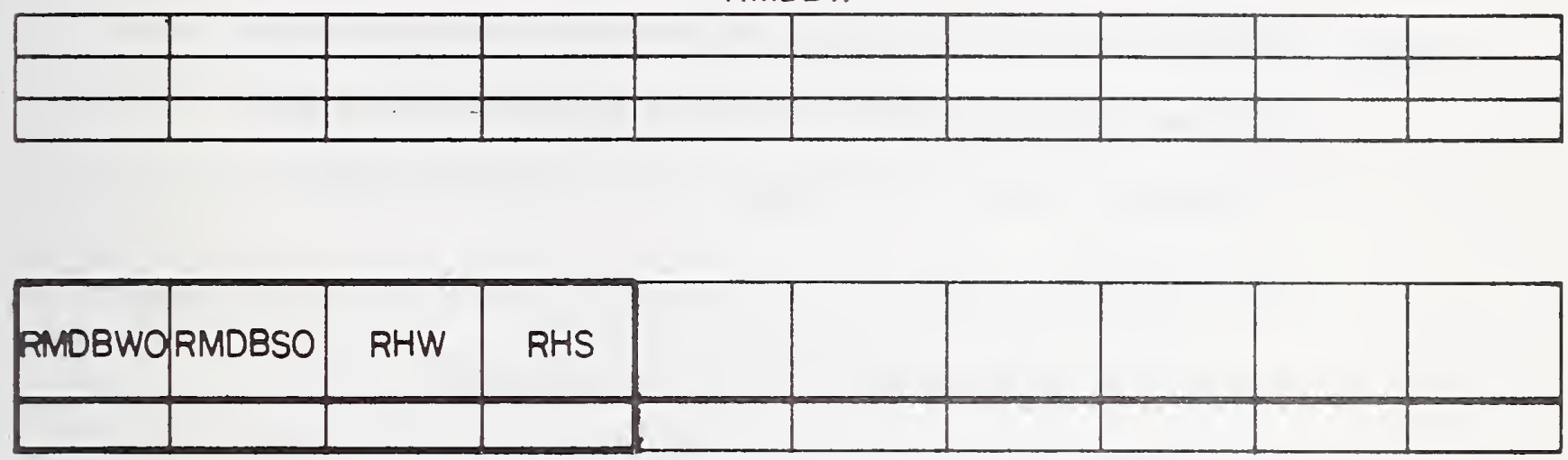
Data Sheet $1 *$

NDAY: Number of days for which the calculations are to be performed.

NSKIP: Number of days to be skipped in case the computation does not start from the first day of the weather tape, which is usually 00 hour, of January 1 if standard NCC 1440 tape is used.

TAPE 2: Tape unit or file number for the output tape, if 0 an output tape or file is not produced. The output tape or file contains the hourly load and weather data needed for the system simulation.

\begin{tabular}{|l|l|l|l|l|l|l|l|l|l|}
\hline NDAY & NSKIP & TAPE 2 & & & & & & & \\
\hline & & & & & & & & & \\
\hline
\end{tabular}

(integer data)

* For the design calculation or when RUNTYP is 2 , all three variables listed here can be input as 0 . 
Month: Month for which the calculation is to be done.

Day: Day of the month on which the calculation is to be done.

ELAPS: Number of days elapsed from January 1 to reach the design day. For example, it is 201 for July 21 of a nonleap year.

DBMAX: Maximum outdoor temperature of the design day for cooling (see Table Cl which has been taken from the 1972 ASHRAE Handbook of Fundamentals).

RANGE: Daily range of the outdoor temperature during the design day, ${ }^{\circ} \mathrm{F}$, (see Table Cl).

WBMAX: Summer design wet-bulb temperature, ${ }^{\circ} \mathrm{F}$, (see Table Cl).

DBMWT: Design outdoor air temperature for the heating load calculation, ${ }^{\circ} \mathrm{F}$, (see Table Cl).

TGS: Summer design ground temperature, ${ }^{\circ} \mathrm{F}$, (see Table Cl).

TGW: Winter design ground temperature, ${ }^{\circ} \mathrm{F}$, (see Table Cl).

*

If a weather tape is being used and a conventional design calculation is not being done, all variables listed here can be input as 0 except TGS, TGW and UG. 
UG: Ground heat transfer coefficient for design heating load calculations based upon Chapter 21, 1972 ASHRAE Handbook of Fundamentals, Btuh*, (use 0.1 if uncertain).

\begin{tabular}{|l|l|l|l|l|l|l|l|l|l|}
\hline MONTH & DAY & ELAPS & DBMAX & RANGE & WBMAX & DBMWT & TGS & TGW & UG \\
\hline & & & & & & & & & \\
\hline
\end{tabular}

${ }^{*}$ Btuh $=$ Btu per $(\mathrm{hr})(\mathrm{sq}$. ft. $)\left({ }^{\circ} \mathrm{F}\right)$. 
Data Sheet 3

LONG: Longitude of the building location, degrees.

LAT: Latitude of the building location, degrees (see Table Cl).

TZN: Time zone number:

5 Eastern Standard time zone

6 Central Standard time zone

7 Mountain Standard time zone

8 Pacific Standard time zone

ZLF: Room exterior wall perimeter, ft.*.

RHOW: Outdoor air relative humidity for a design heating load calculation, \%.

(real variable)

\begin{tabular}{|l|l|l|l|l|l|l|l|l|l|}
\hline LONG & LAT & TZN & ZLF & RHOW & & & & & \\
\hline & & & & & & & & & \\
\hline
\end{tabular}

$*$

For interior space, use the perimeter bounded by non-air conditioned spaces.

The value of $\mathrm{ZL}$ is needed only when ASHRAE $=1$. If the value is unknown use $\mathrm{ZL}=10$. For the case $\mathrm{ASHRAE}=0$ use $\mathrm{ZL}=0$. 


\section{Data sheet 4}

NAMERM

After this card, the data that follow will refer to this specific room or space in the building.

\section{NAME OF THE ROOM}

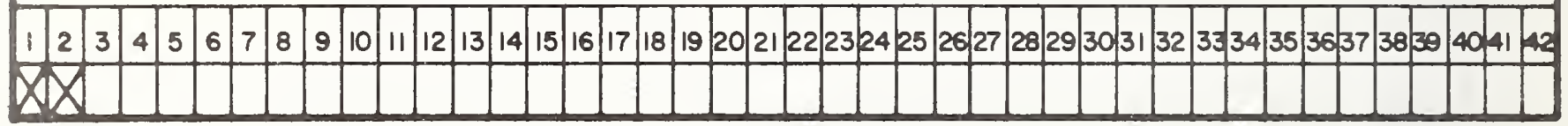

Start from Column 3

(Alphanumeric data; 34 columns maximum) 
IROT: Room rotation index:

$=0$ : if the room load is to be calculated without reference to any previously described room.

$=$ number of degrees: if this room is to be the same as the previous room except for rotation clockwise a specified number of integer degrees.

ISKIP: Wall/Roof/Floor construction data skip:

$=0$ : if the room requires a new set of wall/roof/floor construction data.

$=1:$ if the wall/roof/floor data used by the previous room is reused for this room. If ISKIP $=0$, data sheets 6 and 7 should be omitted.

INCLUD: Space load summation index:

= 1: space load not included in the summation.

$=0:$ space load included in a summation of the space load of the previous room.

(integer variables)

\begin{tabular}{|l|l|l|l|l|l|l|l|l|l|}
\hline IROT & ISKIP & INCLUD & & & & & & & \\
\hline
\end{tabular}




\section{Data Sheet 6}

\section{Wal1/Roof/Floor $-A$}

$\mathrm{N}$ : number of layers of composition in a given wall/roof/floor construction.

By referring to the data of Table C3 (taken from the 1972 ASHRAE Handbook of Fundamentals), give the following information for each of the layers starting from the innermost layer to the Nth layer, which is the outermost layer.

L: Thickness of the layer, ft.

$\mathrm{K}$ : Thermal conductivity of the layer, Btuh per (hr) (ft) $\left({ }^{\circ} \mathrm{F}\right)$.

P: Density of the layer material, lb per cu. ft.

$\mathrm{C}$ : Specific heat of the layer material, Btu per (lb) ( $\left.{ }^{\circ} \mathrm{F}\right)$.

R: Thermal resistance value of the layer in (hr) (sq. ft.) ( ${ }^{\circ} \mathrm{F}$ ) per Btu.

For the calculation where the ASHRAE weighting factor method is used (ASHRAE = 1), the inner most layer is always the inside surface thermal resistance. If $A S H R A E=0$, omit the inside surface thermal resistance. Outside surface thermal resistance is never used in all cases.

The value of $R$ is to be given only when the layer has no apparent thermal mass. If the value of $\mathrm{L}, \mathrm{K}, \mathrm{P}$, and $\mathrm{C}$ are given, $\mathrm{R}$ should be $\mathrm{zero}$. If $R$ is given, $L, K, P$, and $C$ should all be zero, in particular, $L$ should be zero even if it is physically non-zero. For the ground floor, add a finite thickness slab consisting of a $12^{\prime \prime}$ thick earth layer. 
Note: (1) At least one of the $\mathrm{N}$ layers should have non-zero values of $\mathrm{L}, \mathrm{K}, \mathrm{P}$, and $\mathrm{C}$.

(2) If two or more consecutive layers have no thermal mass, their thermal resistance values should be combined.

(3) If a particular wall is considered to have no appreciable thermal mass, or if it is desired not to consider the thermal mass effect, data for this particular wall should not be included in the data sheets.

(integer)

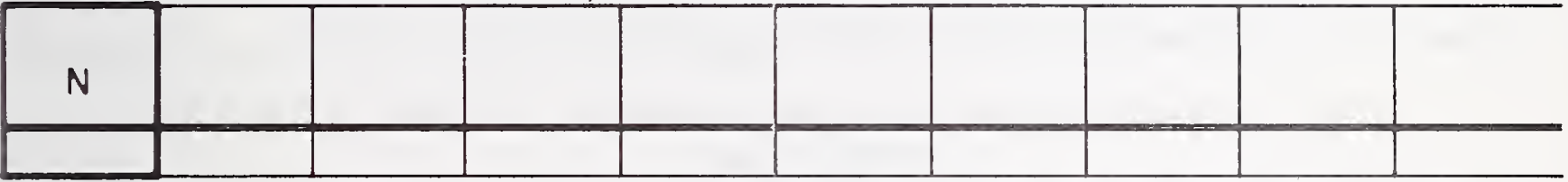

(rea1 number)

\begin{tabular}{|l|l|l|l|l|l}
\hline$L$ & $K$ & $P$ & $C$ & $R$ & \\
\hline & & & & & Ist LAYER-innermost \\
\hline & & & & & 2nd LAYER \\
\hline & & & & & 3rd LAYER \\
\hline & & & & & 4th LAYER \\
\hline & & & & & \\
\hline & & & & & \\
\hline & & & & & \\
\hline & & & & & \\
\hline & & & & & \\
\hline
\end{tabular}

IRF is not the input data in this data sheet. It is the identifier of the particular wall in the sheet. 
Data sheet 7

Wa11/Roof/Floor-B

Twenty-four characters are allowed for the brief description of each layer, such as "common brick" or "1/2" plaster board", etc.

The description should identify the corresponding layer given on Data Sheet 6 .

The set of wall/roof/floor data and accompanying description will be repeated as many times as there are number of different wa11/roof/floor constructions (with an upper limit of 9) pertinent to the room under consideration. Each new set of wall/roof/floor construction will be identified by the IRF number on DATA SHEET 6 (upper right hand corner).

After the last wall/roof/floor has been given, provide a line with 0 or a blank card to indicate that fact.

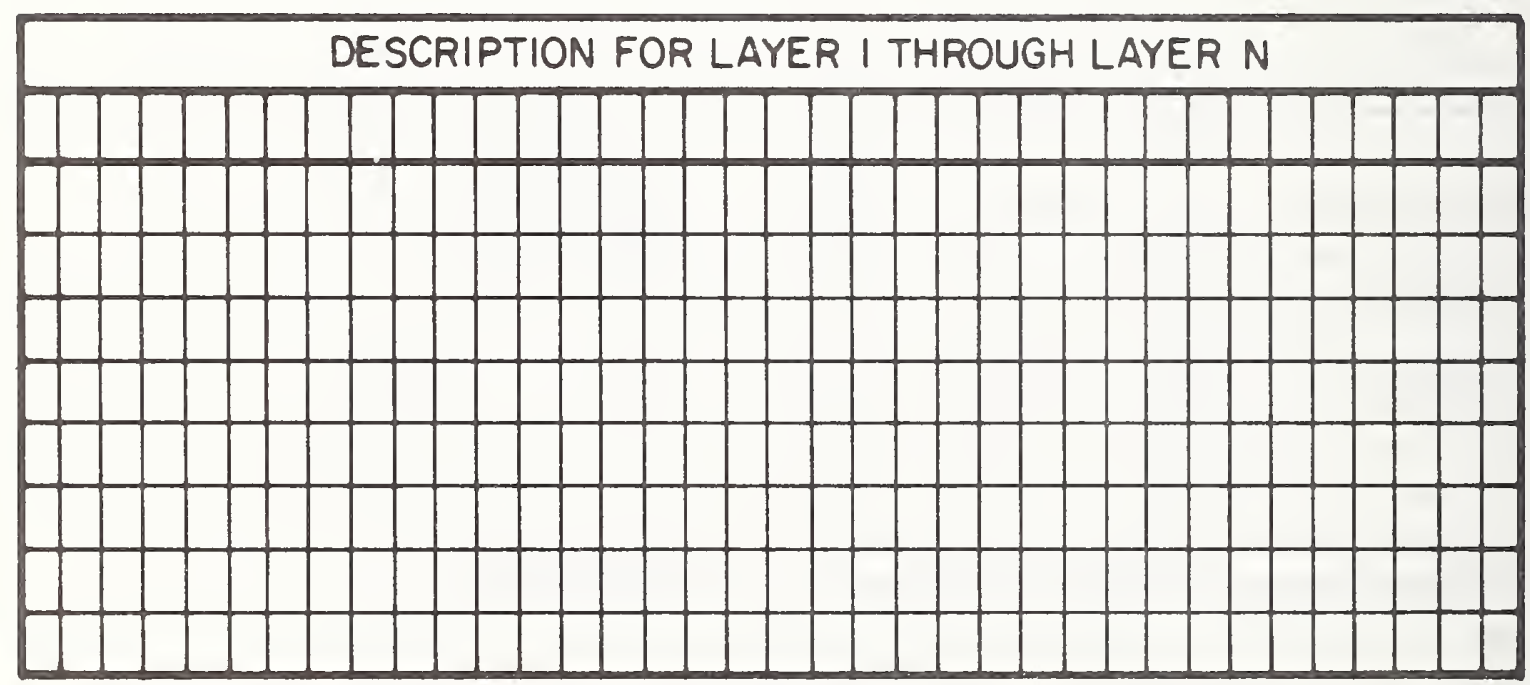

Blank card if this is the last wall/roof/floor

(Alphonumeric information) 


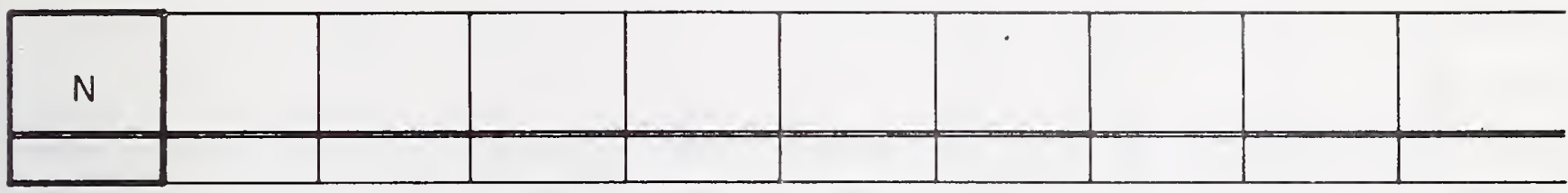

\begin{tabular}{|l|l|l|l|l|l}
\hline$L$ & $K$ & $P$ & $C$ & $R$ & \\
\hline \hline & & & & & Is LAYER-innermost \\
\hline & & & & & 2nd LAYER \\
\hline & & & & & 3rd LAYER \\
\hline & & & & & 4th LAYER \\
\hline & & & & & \\
\hline & & & & & \\
\hline & & & & & \\
\hline & & & & & \\
\hline & & & & & Nth LAYER \\
\hline
\end{tabular}

Data Sheet 7

DESCRIPTION FOR LAYER I THROUGH LAYER N
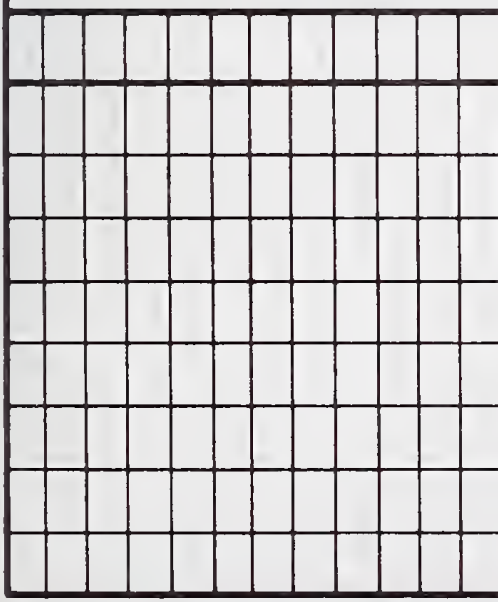

Blank card if this is the last wall/roof/floor

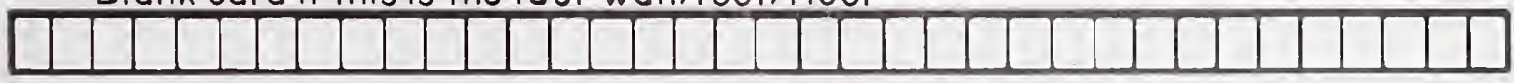

(Alphanumeric information) 
Data Sheet 6

\begin{tabular}{l}
\hline N \\
\hline N
\end{tabular}

Data Sheet 7

DESCRIPTION FOR LAYER I THROUGH LAYER N

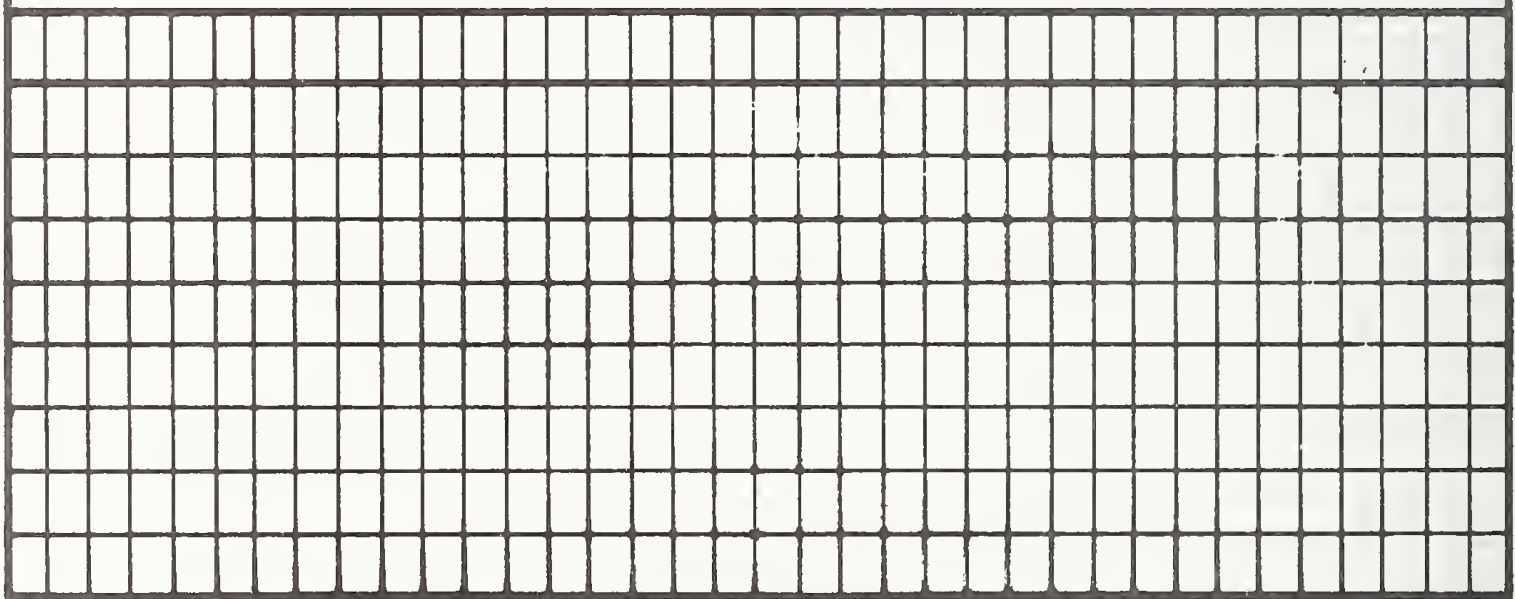

Blank cord if this is in last wall/roof/floor

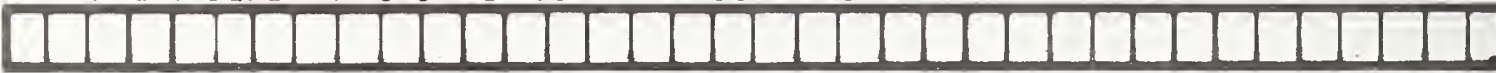

(Alphonumeric information) 
Data Sheet 6

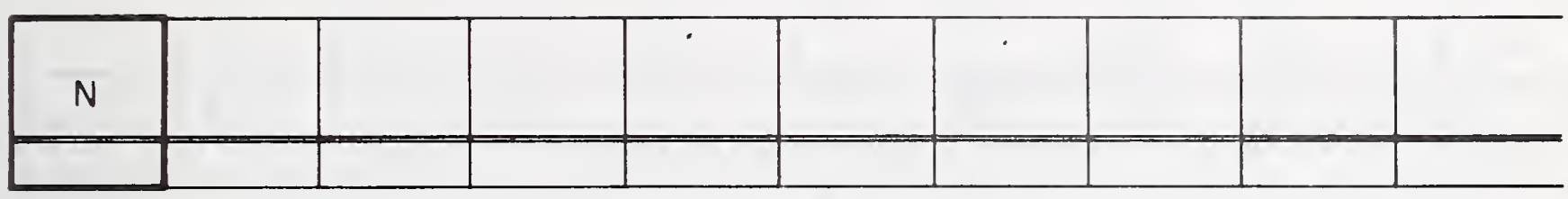

\begin{tabular}{|l|l|l|l|l|l}
\hline$L$ & $K$ & $P$ & $C$ & $R$ & \\
\hline \hline & & & & & Ist LAYER-innermost \\
\hline & & & & & 2nd LAYER \\
\hline & & & & & 3rd LAYER \\
\hline & & & & & 4†h LAYER \\
\hline & & & & & \\
\hline & & & & & \\
\hline & & & & & \\
\hline & & & & & \\
\hline
\end{tabular}

Data Sheet 7

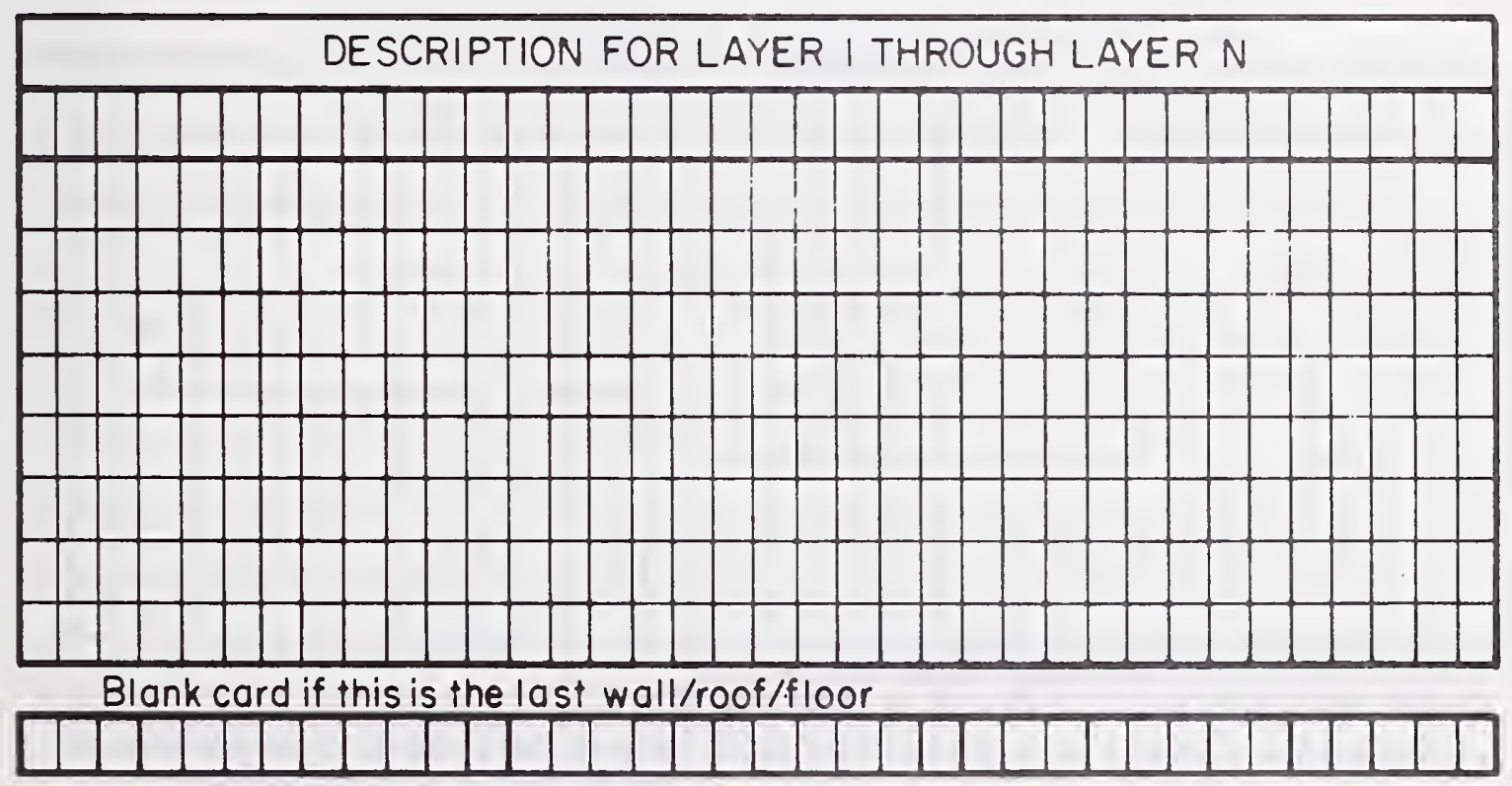

(Alphanumeric information) 


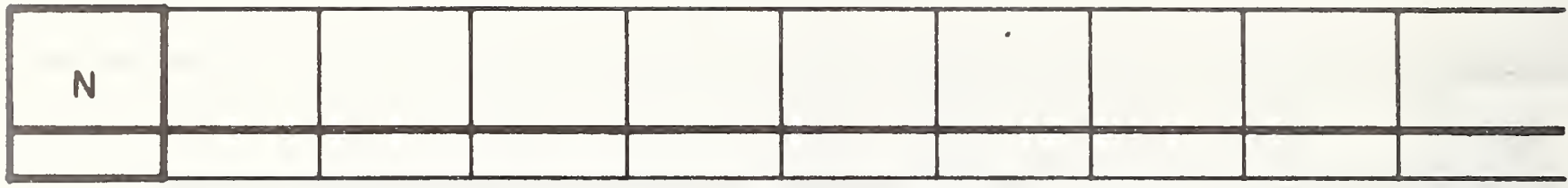

\begin{tabular}{|l|l|l|l|l|l}
\hline$L$ & $K$ & $P$ & $C$ & $R$ & \\
\hline & & & & & Ist LAYER-innermost \\
\hline & & & & & 2nd LAYER \\
\hline & & & & & 3rd LAYER \\
\hline & & & & & 4th LAYER \\
\hline & & & & & \\
\hline & & & & & \\
\hline & & & & & \\
\hline & & & & & \\
\hline
\end{tabular}

Data Sheet 7

DESCRIPTION FOR LAYER I THROUGH LAYER N

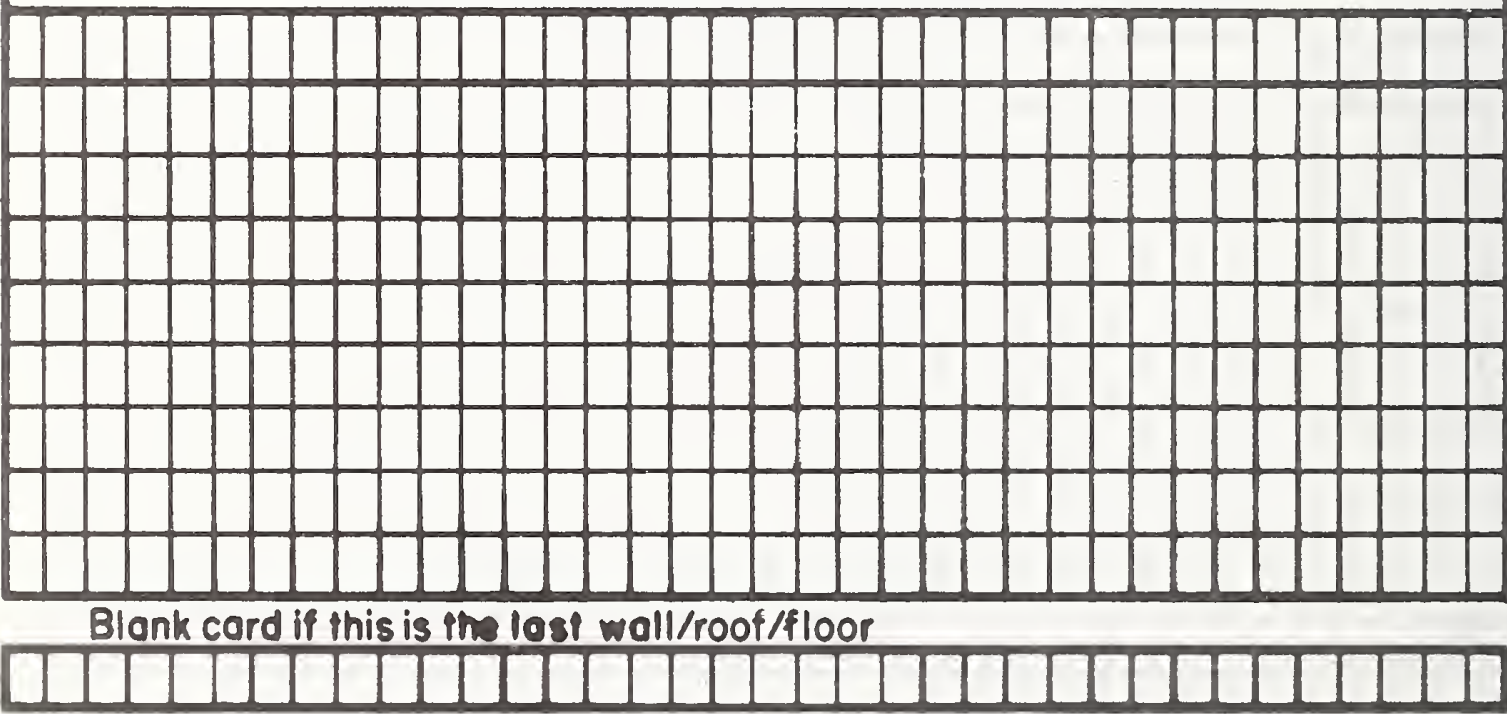

(Alphonumeric information) 
Data Sheet 6

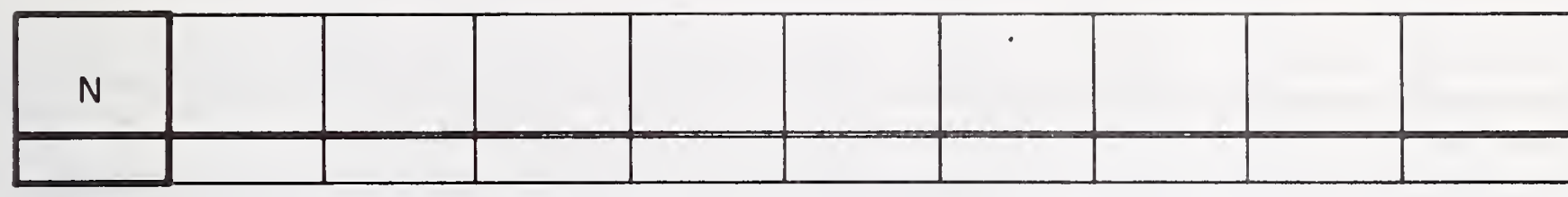

\begin{tabular}{|l|l|l|l|l|l}
\hline$L$ & $K$ & $P$ & $C$ & $R$ & \\
\hline & & & & & \\
\hline & & & & & Is LAYER-innermos \\
\hline & & & & & 2nd LAYER \\
\hline & & & & & 3rd LAY LAYER \\
\hline & & & & & \\
\hline & & & & & \\
\hline & & & & & \\
\hline & & & & & \\
\hline & & & & & Nih LAYER \\
\hline
\end{tabular}

Data Sheet 7

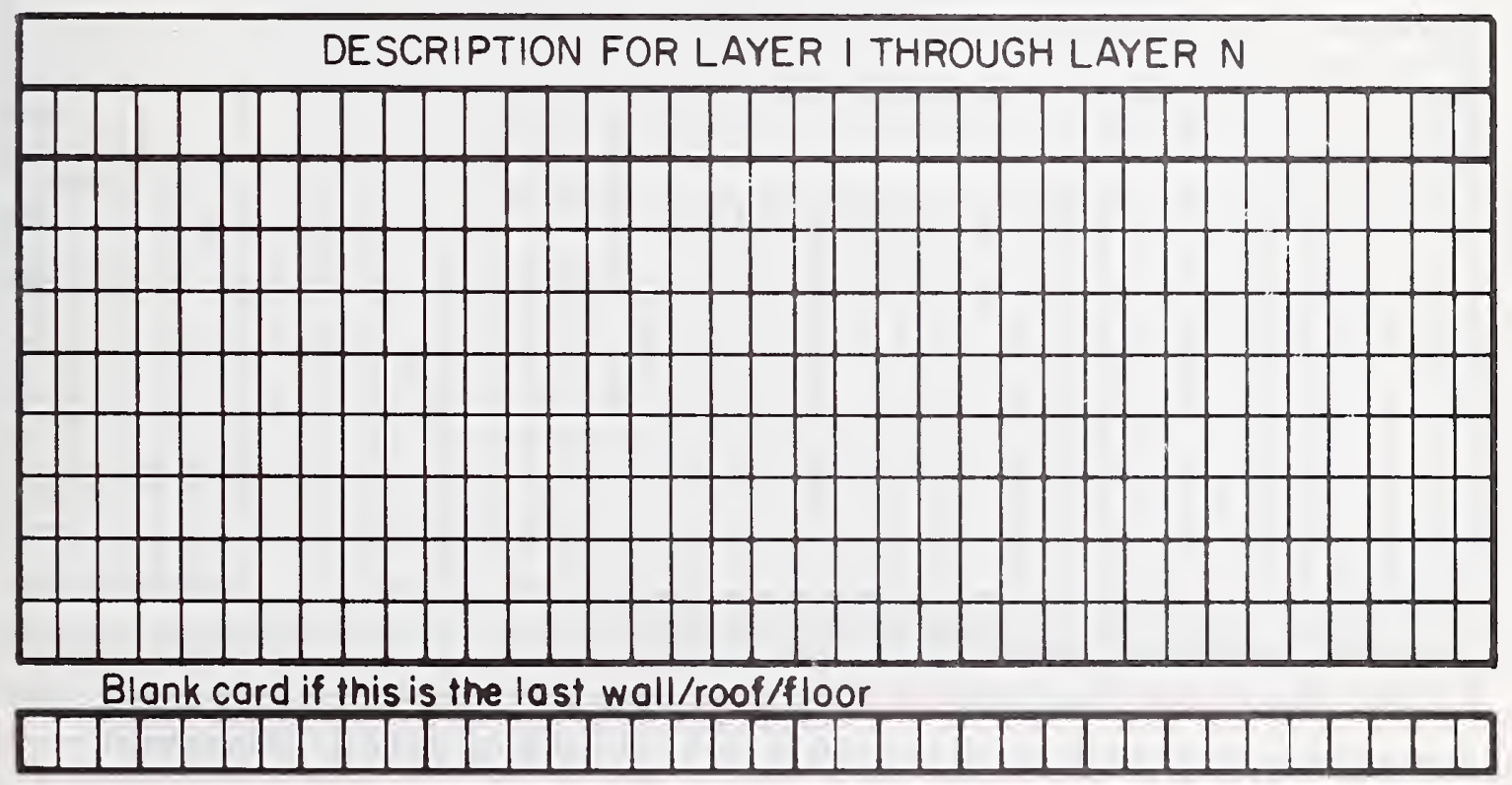

(Alphanumeric information) 
Data Sheet 6

\begin{tabular}{l}
\hline$N$ \\
\hline \multicolumn{1}{|l|}{} \\
\hline
\end{tabular}

Data Sheet 7

DESCRIPTION FOR LAYER I THROUGH LAYER N

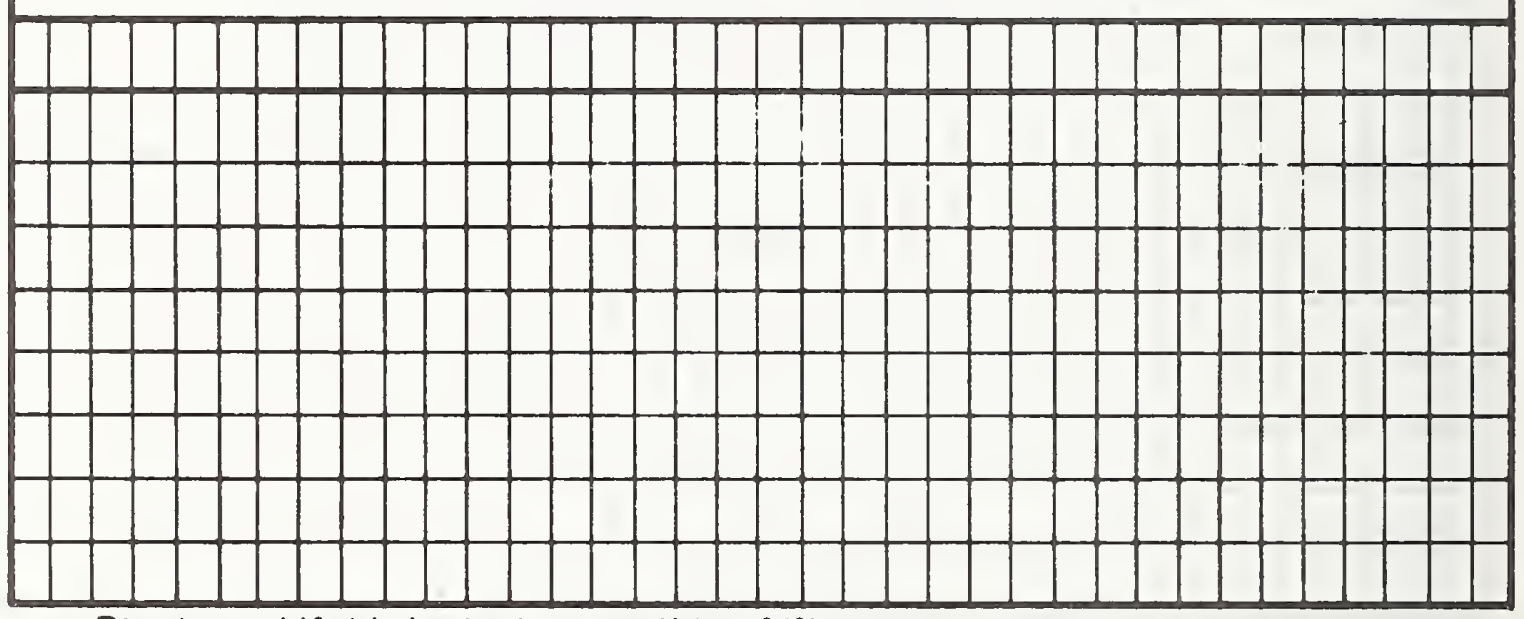
Blank card if this is the last wall/roof/floor

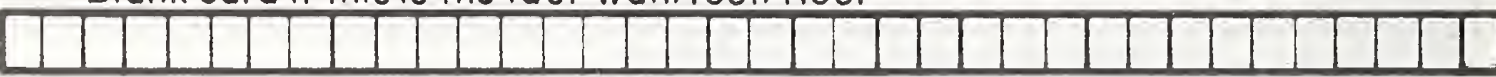

(Alphanumeric information) 
Wal1/Roof/Floor-A

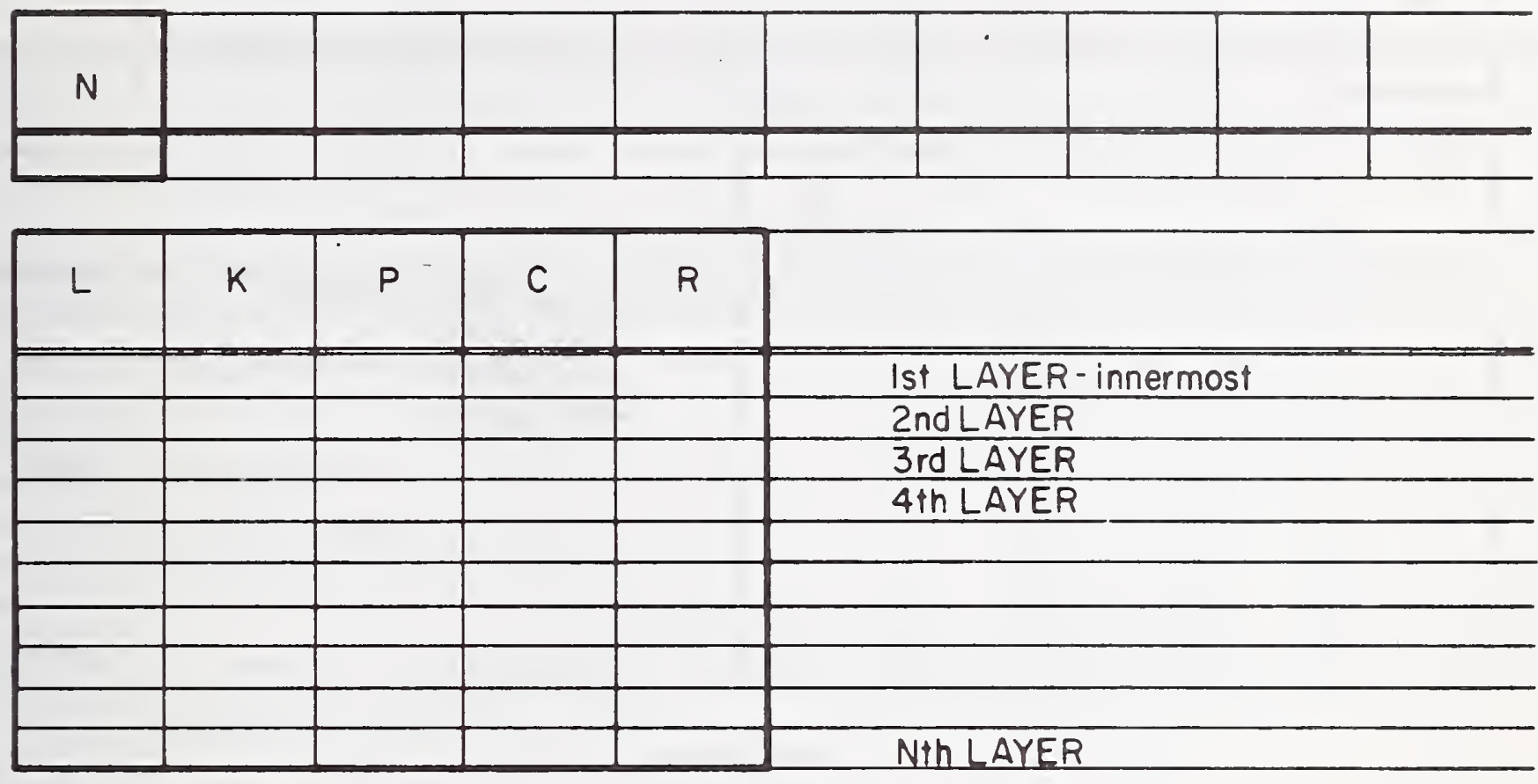

Data Sheet 7

DESCRIPTION FOR LAYER I THROUGH LAYER N

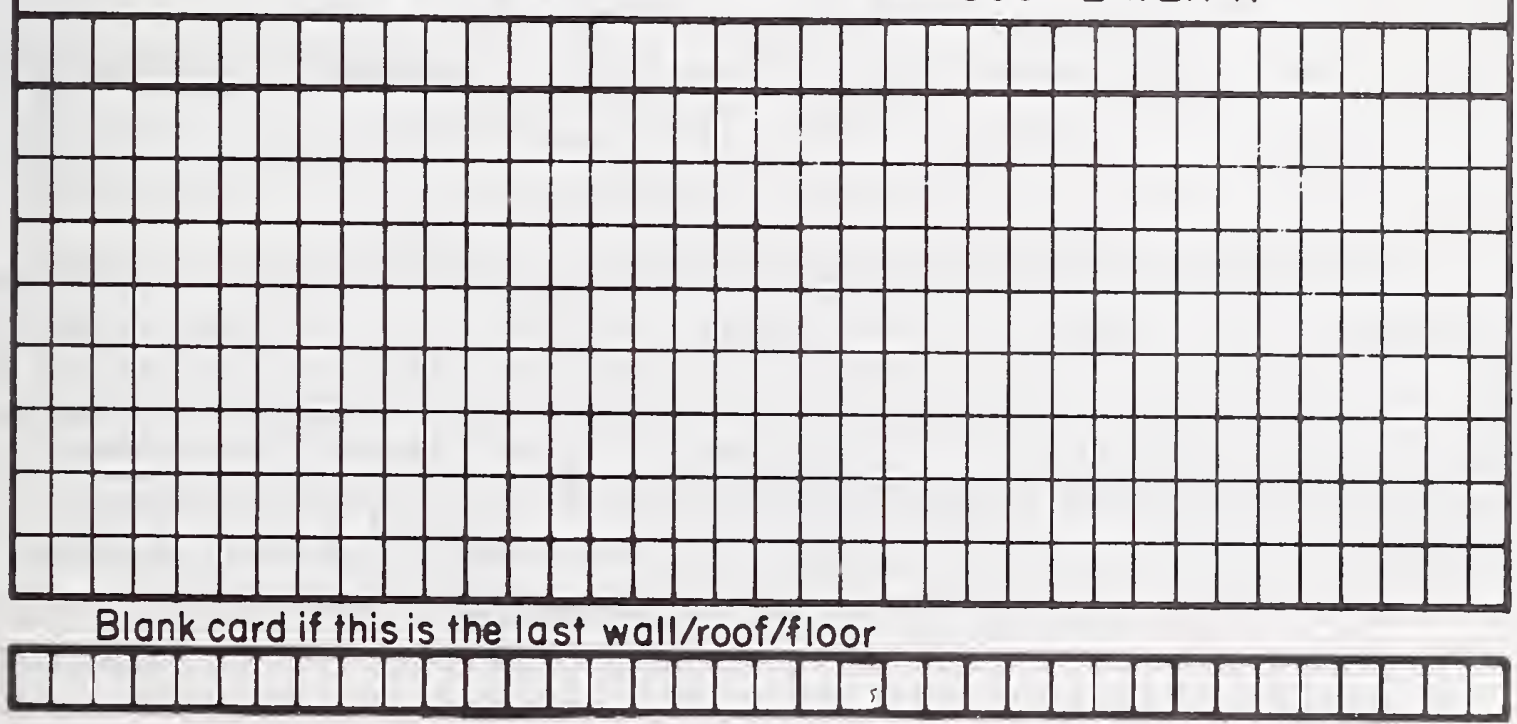

(Alphonumeric information) 
Data sheet 6

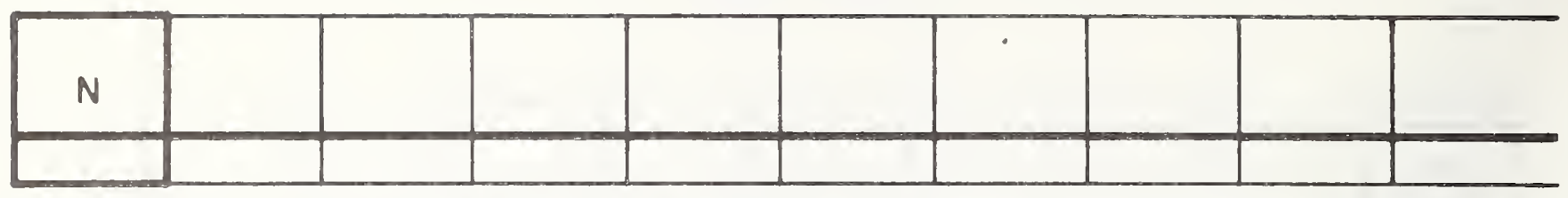

\begin{tabular}{|l|l|l|l|l|l}
\hline$L$ & $K$ & $P$ & $C$ & $R$ & \\
\hline & & & & & \\
\hline & & & & & Ist LAYER-innermost \\
\hline & & & & & 2nd LYYER \\
\hline & & & & & 4 LA LAYER \\
\hline & & & & & \\
\hline & & & & & \\
\hline & & & & & \\
\hline & & & & & \\
\hline
\end{tabular}

Data Sheet 7

DESCRIPTION FOR LAYER I THROUGH LAYER N

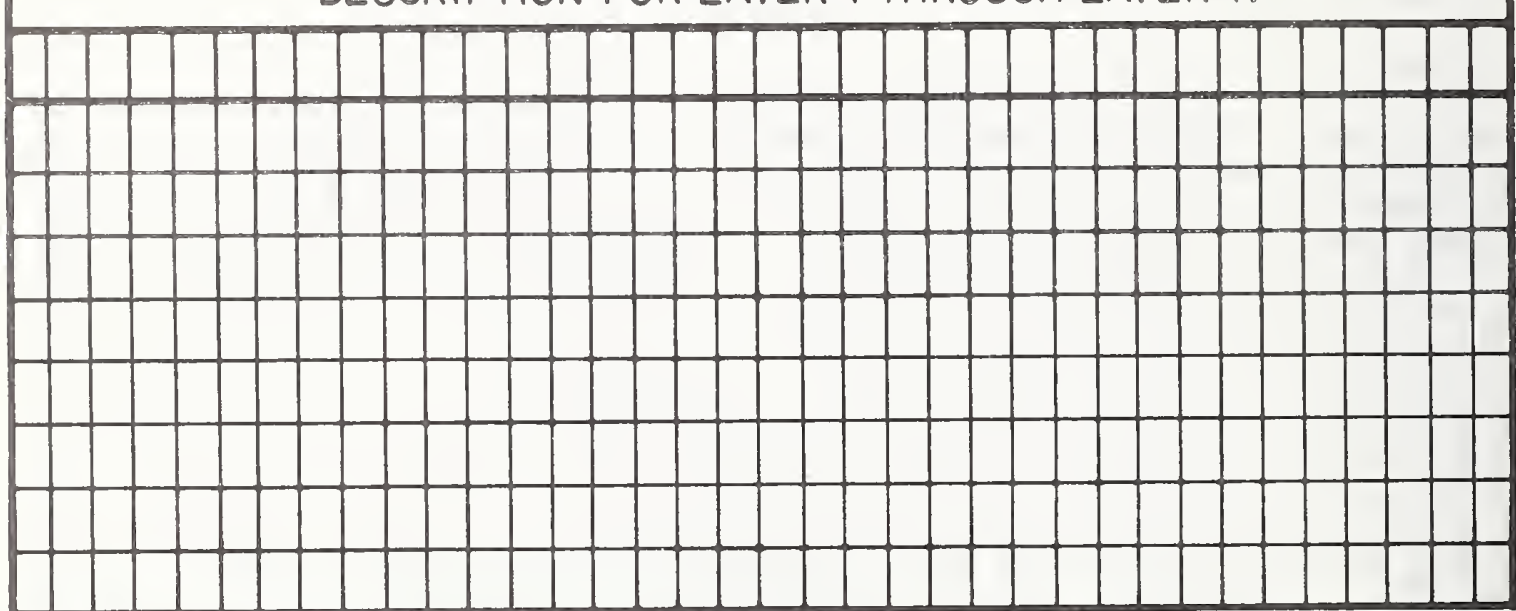

Blank card if this is the last wall/roof/floor

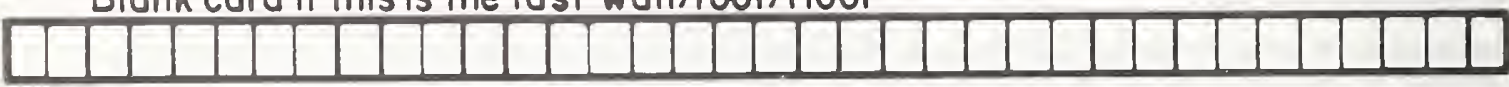

(Alphonumeric information)

*

IRF should not exceed 9 since IRF $=10$ is reserved for very lightweight wa1ls, doors and windows in Data sheet 11 . 
CFMS: Flow rate of outdoor air introduced for natural cooling purposes, cu. ft. per minute, for the temperature calculation, or the flow rate of outdoor air brought into the room by mechanical means during the occupied period to reduce the cooling load (NVENT $=1$ ). This data should be zero when RUNTYP (page 4c) $=1$.

ARCHGS: Infiltration in terms of number of air changes per hour during the summer* months.

ARCHGW: Infiltration in terms of number of air changes per hour during the winteri* months.

ARCHGM: Minimum infiltration in terms of air changes per hour when ARCHGS $=0$ and $A R C H G W=0$.

ZNORM: Number of rooms of the same type being described in the building.

* June through September.

** October through May.

\begin{tabular}{|l|l|l|l|l|l|l|l|l|l|}
\hline ROOMNO & QLITY & QEQPX & QCU & FLCG & FRAS & TS & CFMS & ARCHGS & ARCHGW \\
\hline & & & & & & & & & \\
\hline ARCHGM & ZNORM & & & & & & & & \\
\hline & & & & & & & & & \\
\hline
\end{tabular}


ROOMNO: Room identification number.

QLITY: Maximum lighting power input to the room, expressed as watts per sq. ft. of floor area (see Table C4).

QEQPX: Maximum electric power input for the appliances and other equipment in the room exclusive of the heating and air conditioning equipment, expressed as watts per sq. ft. of floor area (see Table C4).

QCU: Maximum number of adult occupants in the room during the day (count a child as 0.5 ).

FLCG: Fraction of electric power for lighting which can be assumed to go directly to the return air.

FRAS: Fraction of internal heat gains which can be assumed to be absorbed by the room surfaces instantaneously (as a result of radiation).

TS: Supply air temperature to the room from heating/cooling system, ${ }^{\circ} \mathrm{F}$, for the room temperature calculation, or the upper temperature limit on outdoor air which can be brought in during the occupied period to reduce the cooling load $($ NVENT $=1)-$ Data Sheet 16 . 
Data Sheet $9 *$

IW: Building weight index:

$I W=1$ Heavy structure (approximately $701 \mathrm{~b}$ per sq. ft. of floor use or above).

IW $=2$ Medium weight structure (between 30 and $701 \mathrm{~b}$ per sq. ft. of floor area).

$\mathrm{TW}=3$ Lightweight structure (below $30 \mathrm{lb}$ per sq. ft. of floor area).

IL: Lighting fixture index.

ISTART: Starting hour of occupancy.

ILEAVE: Ending hour of occupancy .

* This data is used only when ASHRAE $=1$. 
Data Sheet 10

\section{Temperature Control Data}

TUL: Upper limit of thermostat, above which the room requires cooling, ${ }^{\circ} \mathrm{F}$.

TLL: Lower limit of thermostat, below which the room requires heating, ${ }^{\circ} \mathrm{F}$.

QCMAX: Maximum sensible cooling capacity of the room air supply system, Btu per hour (for the design load calculation this data should be zero) ... non-negative value.

QHMAX: Maximum sensible heating capacity of the room air supply system, Btu per hour (for the design load calculation this data should be zero) ... non-negative value.

DBVMAX: Maximum outdoor temperature when the natural cooling by ventilation (economizer cycle) is used.

DBVMIN: Minimum outdoor temperature, below which the economizer cycle is disengaged.

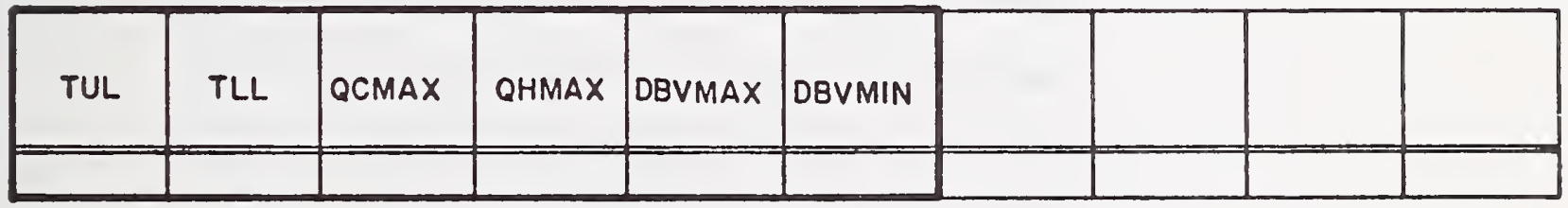


Data Sheet 11

Temperature Control Indices, ITHST and ITK

ITHST $=1, \operatorname{ITK}=0:$ The hourly profile of room temperature, either constant or night setback, is prescribed ... Figure C2.

ITHST $=0, \operatorname{ITK}=1:$ The room temperature is to be calculated for the room which is neither heated nor cooled... Figure C3.

ITHST $=1, \operatorname{ITK}=1:$ The upper and lower limit of the room temperature are given. The room will be heated if the room temperature falls below the lower limit TLL and the room is cooled if the room temperature rises above the upper limit TUL. As long as the room temperature is between these two limits, the room is neither heated nor cooled ... Figure $\mathrm{C} 4$.

ITHST $=0, \operatorname{ITK}=0:$ The same as above except that the maximum capacities of heating and cooling systems are introduced. If the room heating and cooling loads exceed the system heating and cooling capacities respectively, the room temperature drift from the set points TLL and TUL is calculated... Figure C5. 


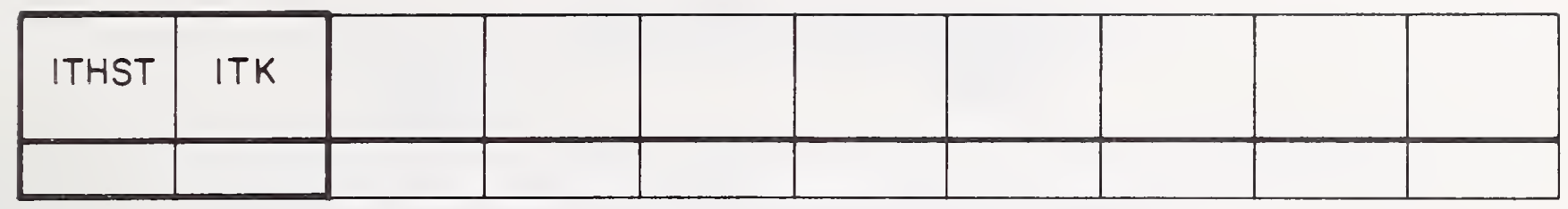


(I) CONSTANT TEMPERATURE MODE

(ITHST = I)

ITK = O

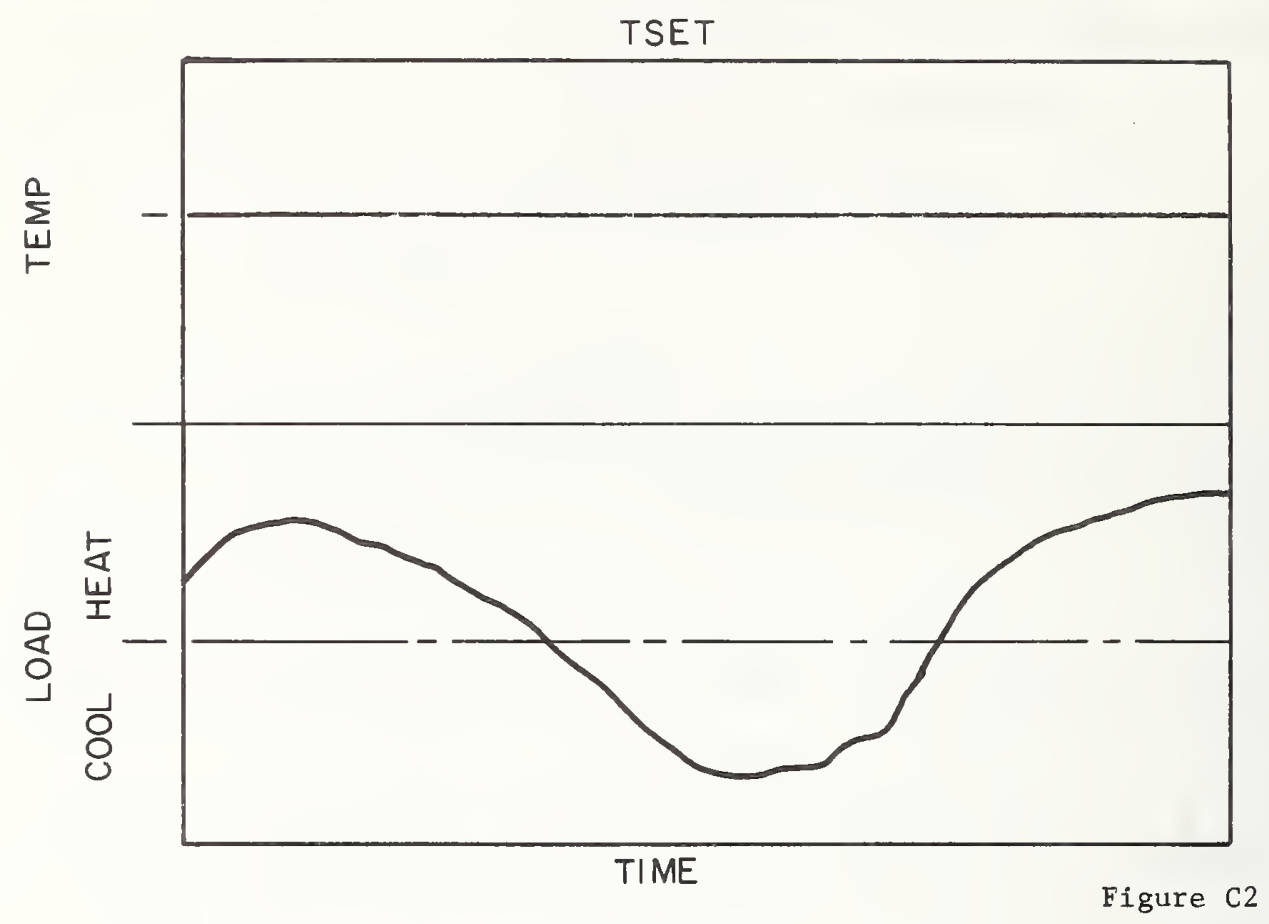

(2) FLOATING TEMPERATURE MODE

(ITHST $=0$

ITK =I

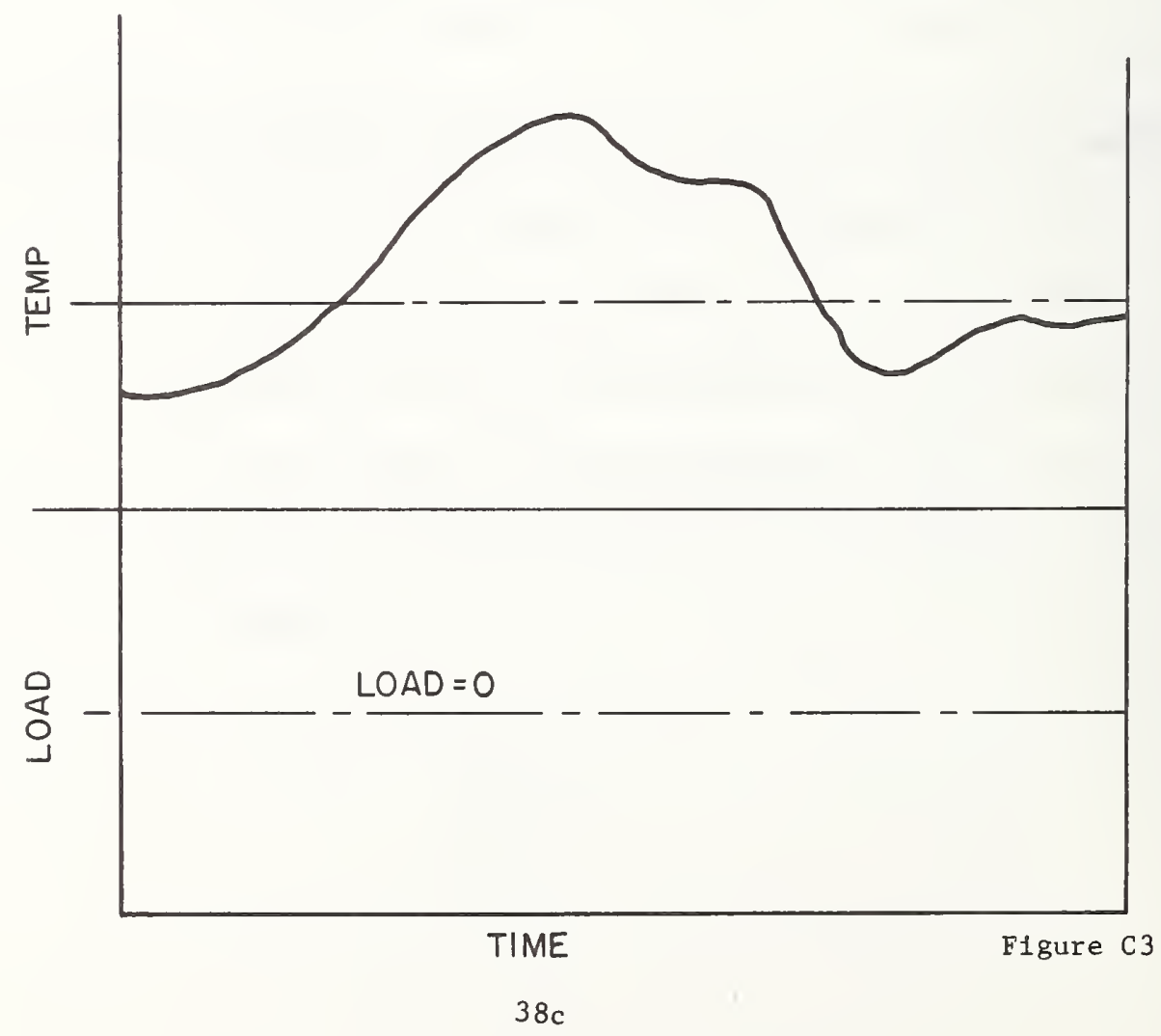


(3) PRESCRIBE TEMPERATURE LIMIT MODE $($ ITHST $=1)$

$($ ITK =1)

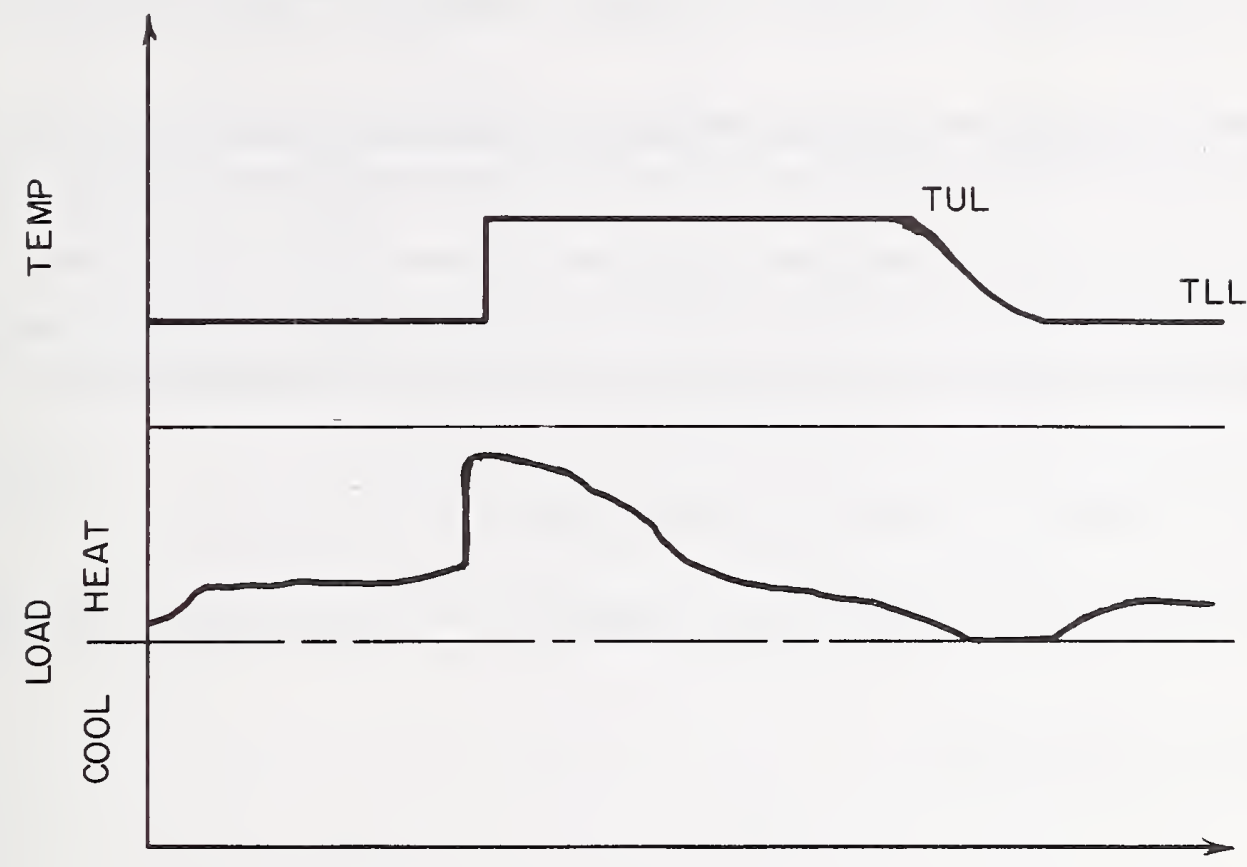

(4) CONTROL SIMULATION MODE

$(\mid T H S T=0)$

Figure $\mathrm{C} 4$

$($ ITK $=0)$

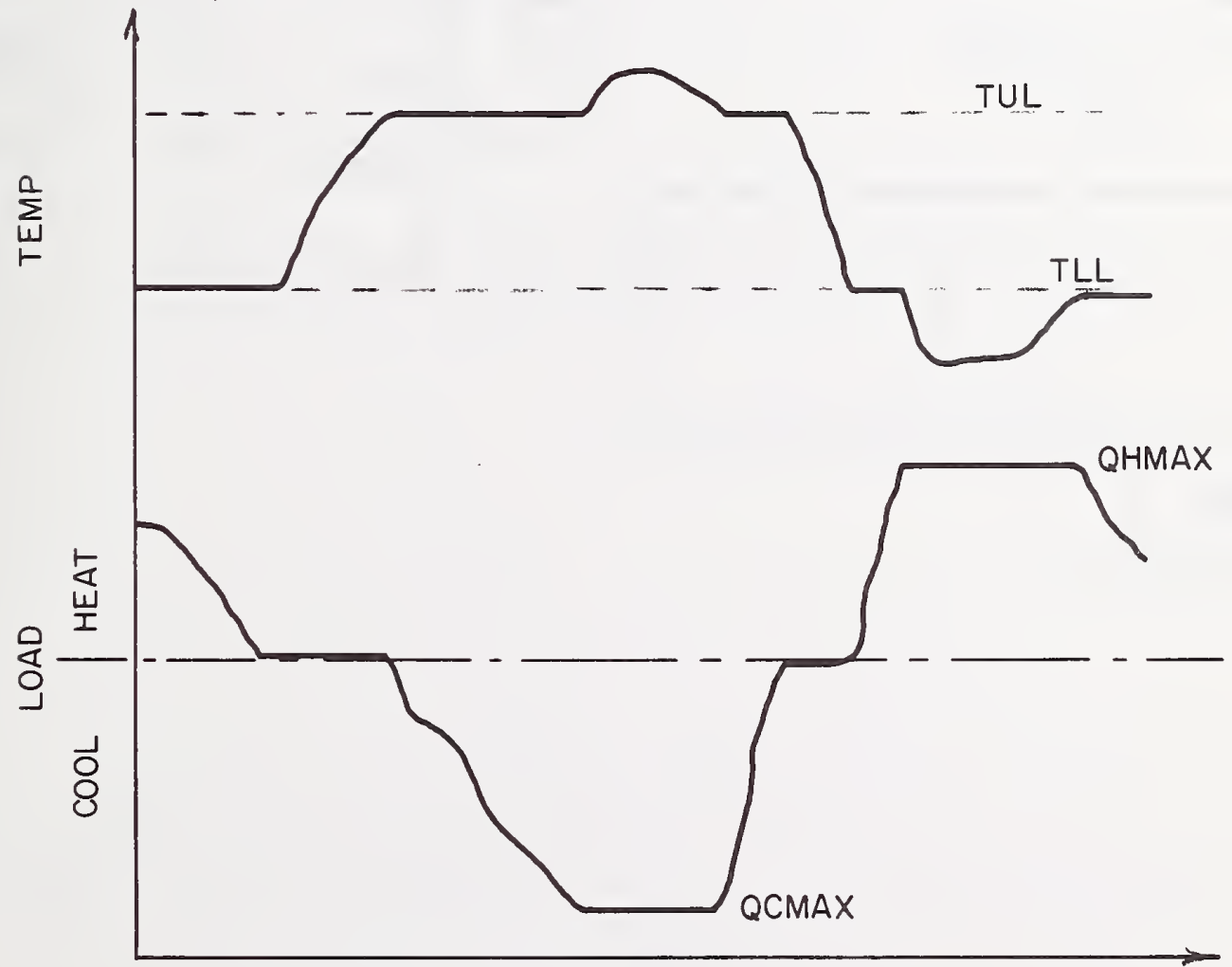

Figure C5 
NS: Number of different type heat transfer surfaces in the south wall.

NW: Number of different type heat transfer surfaces in the west wall.

NN: Number of different type heat transfer surfaces in the north wall.

NE: Number of different type heat transfer surfaces in the east wall.

L: Length of the room along the south wall, ft.

W: Width of the room along the west wall, ft.

H: Height of the room ft.
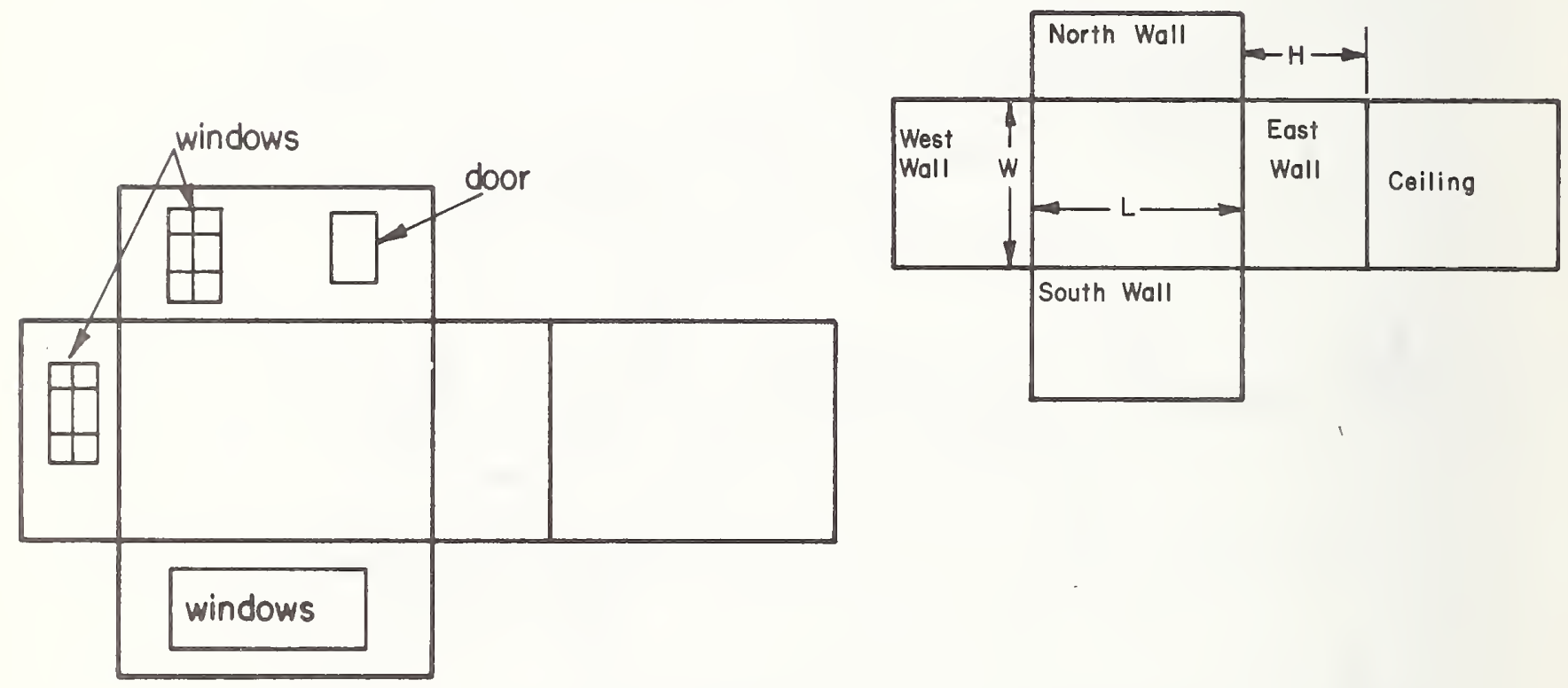
(integers)*

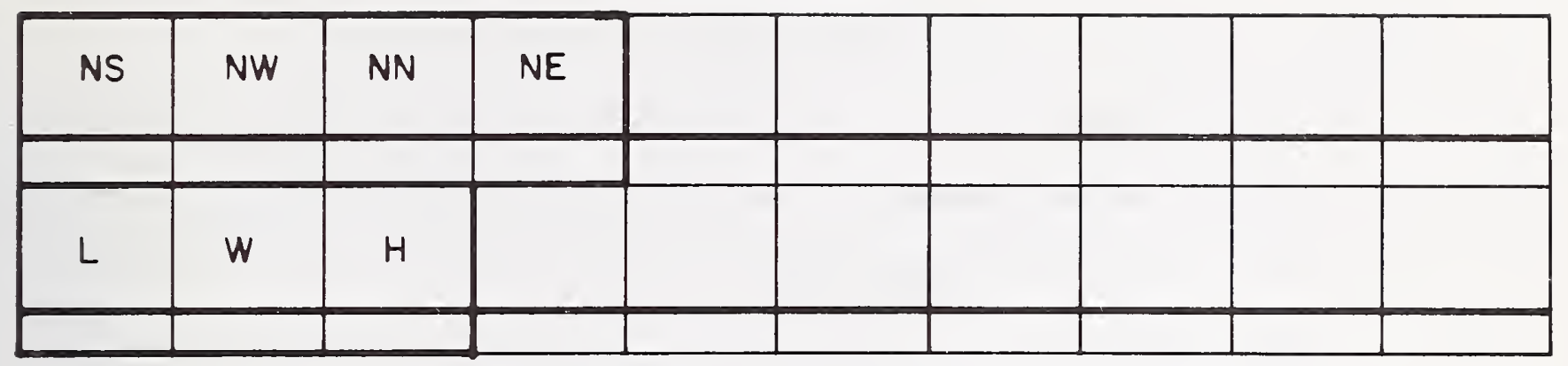

(real values)

* $\mathrm{NS}+\mathrm{NW}+\mathrm{NN}+\mathrm{NE}$ should not exceed 28 . 
ITYPE : Exposure surface type index:

$=1$ if roof.

$=2$ if exterior wall.

$=3$ if window or glass door.

$=4$ if door.

$=5$ if floor on ground or basement wall.

$=6$ if partition walls, party walls, floor/ceiling, furnishings and other internal mass.

$=7$ if completely open.

$=8$ if the adjacent space is not air conditioned and will be considered as having a temperature the same as the outdoors.

IRF : Roof/wa11/floor construction identifier index shown in the upper right corner of the roof/wall/floor data sheet 6. If not applicable (such as the cases for lightweight walls, doors and windows), which are not specified in data sheets 6 and $7 . \operatorname{IRF}=10$.

A: Area of the surface, sq. ft.

AZW: Surface orientation angle, degrees clockwise from south:

0 for south facing surface, roof/ceiling or floor. 45 for southwest facing surface.

* See note on data sheet 14 . 
90 for west facing surface.

135 for northwest facing surface.

180 for north facing surface.

-135 for northeast facing surface.

-90 for east facing surface.

U: Overall heat transfer coefficient of a surface (Btuh) for which the data for roof/wall/floor are not provided (IRF $=$ 10). For the surface for which roof/wall/floor data are provided (IRF $\neq 10$ ), U should be zero because it will be computed in the program.

SHADE: Shading coefficient for the ITYPE $=3$ surface (window or glass door) (see Table $\mathrm{C5}$ which has been taken from the 1972 ASHRAE Handbook of Fundamentals). For all other types of surfaces, this parameter should be zero.

ABSP : Solar absorption coefficient for the exterior surface (see Table C6 which has been taken from Thermal Radiation Properties Survey, G. G. Gubareff, J. E. Jansen, and R. H. Torborg, Honeywell Research Center, 1960). This value should be zero for the surfaces of ITYPE = $3,5,6$ and 7 , and 8 .

SHDW: Shadow parameter $=1$ if completely shaded by an adjacent building or an external shading device; = 0 if otherwise. 
integer

real variable

\begin{tabular}{|l|l|l|l|l|l|l|l|l|l|}
\hline ITYPE & IRF & A & AZW & $U$ & SHADE & ABSP & SHD & & \\
\hline & & & & & & & & & \\
\hline
\end{tabular}


Data Sheet $14 \%$

Room Surfaces - B

(Exterior Shading Device Data)

Data are given in ft. and as dictated by the figure below.

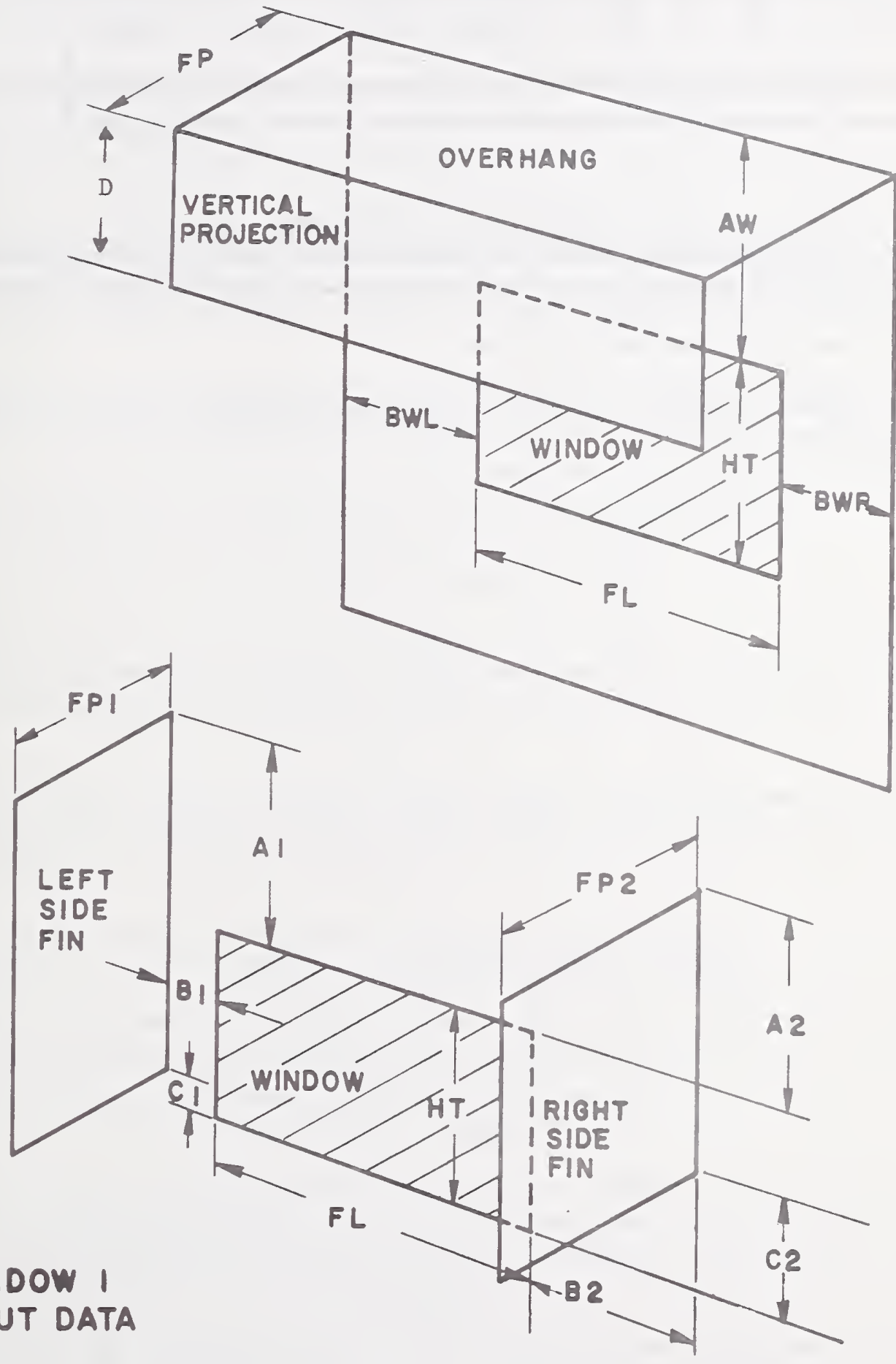




\begin{tabular}{|l|l|l|l|l|l|l|l|l|l|}
\hline FL & HT & FP & AW & BWL & BWR & D & & & \\
\hline \hline & & & & & & & & & \\
\hline
\end{tabular}

\begin{tabular}{|l|c|c|c|c|c|c|c|c|c|}
\hline FPI & Al & B1 & Cl & FP2 & A2 & B2 & C2 & & \\
\hline & & & & & & & & & \\
\hline
\end{tabular}

*

The sequence of input should be roof/ceiling, south facing surfaces, west facing surfaces, north facing surfaces, east facing surfaces and floor. While each vertical exposure can accommodate more than one type of surface such as wall, door and window, only one surface should be given for floor and roof/ceiling.

Data Sheets 11 and 12 are to be repeated for each of all the surfaces of the room. 


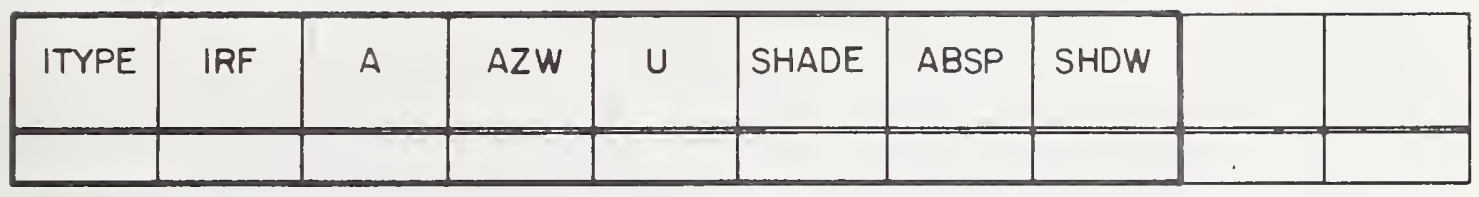

\begin{tabular}{|l|l|l|l|l|l|l|l|l|l|}
\hline FL & $H T$ & FP & AW & BWL & BWR & D & & & \\
\hline & & & & & & & & & \\
\hline
\end{tabular}

\begin{tabular}{|l|l|l|l|l|l|l|l|l|l|}
\hline $\mathrm{FPI}$ & $\mathrm{Al}$ & $\mathrm{BI}$ & $\mathrm{Cl}$ & $\mathrm{FP2}$ & $\mathrm{A} 2$ & $\mathrm{~B} 2$ & $\mathrm{C} 2$ & & \\
\hline \hline & & & & & & & & & \\
\hline
\end{tabular}

\begin{tabular}{|l|l|l|l|l|l|l|l|l|l|}
\hline ITYPE & IRF & $A$ & AZW & $U$ & SHADE & ABSP & SHDW & & \\
\hline & & & & & & & & & \\
\hline
\end{tabular}

\begin{tabular}{|l|l|l|l|l|l|l|l|l|l|}
\hline$F L$ & $H T$ & $F P$ & $A W$ & $B W L$ & $B W R$ & $D$ & & & \\
\hline & & & & & & & & & \\
\hline
\end{tabular}

\begin{tabular}{|l|l|l|l|l|l|l|l|l|l|}
\hline FPI & $A 1$ & $B 1$ & Cl & FP2 & A2 & B2 & C2 & & \\
\hline & & & & & & & & & \\
\hline
\end{tabular}

\begin{tabular}{|l|l|l|l|l|l|l|l|l|l|}
\hline ITYPE & IRF & A & AZW & U & SHADE & ABSP & SHDW & & \\
\hline & & & & & & & & & \\
\hline
\end{tabular}

\begin{tabular}{|l|l|l|l|l|l|l|l|l|l|}
\hline$F L$ & $H T$ & $F P$ & $A W$ & $B W L$ & $B W R$ & $D$ & & & \\
\hline & & & & & & & & & \\
\hline
\end{tabular}

\begin{tabular}{|l|l|l|l|l|l|l|l|l|l|}
\hline $\mathrm{FPI}$ & $\mathrm{Al}$ & $\mathrm{BI}$ & $\mathrm{Cl}$ & $\mathrm{FP} 2$ & $\mathrm{~A} 2$ & $\mathrm{~B} 2$ & $\mathrm{C} 2$ & & \\
\hline & & & & & & & & & \\
\hline
\end{tabular}


Repetition of Data Sheets 13 and 14

\begin{tabular}{|l|l|l|l|l|l|l|l|l|l|}
\hline ITYPE & IRF & A & AZW & $U$ & SHADE & ABSP & SHDW & & \\
\hline & & & & & & & & & \\
\hline
\end{tabular}

\begin{tabular}{|l|l|l|l|l|l|l|l|l|l|}
\hline FL & $H T$ & FP & AW & BWL & BWR & D & & & \\
\hline & & & & & & & & & \\
\hline
\end{tabular}

\begin{tabular}{|l|l|l|l|l|l|l|l|l|l|}
\hline FPI & $\mathrm{Al}$ & $\mathrm{BI}$ & $\mathrm{Cl}$ & $\mathrm{FP2}$ & $\mathrm{A} 2$ & $\mathrm{~B} 2$ & $\mathrm{C} 2$ & & \\
\hline & & & & & & & & & \\
\hline
\end{tabular}

\begin{tabular}{|l|l|l|l|l|l|l|l|l|l|}
\hline ITYPE & IRF & $A$ & AZW & $U$ & SHADE & ABSP & SHDW & & \\
\hline & & & & & & & & & \\
\hline
\end{tabular}

\begin{tabular}{|l|l|l|l|l|l|l|l|l|l|}
\hline FL & $H T$ & FP & AW & BWL & BWR & D & & & \\
\hline & & & & & & & & & \\
\hline
\end{tabular}

\begin{tabular}{|l|c|c|c|c|c|c|c|c|c|}
\hline FPI & Al & BI & Cl & FP2 & A2 & B2 & C2 & & \\
\hline & & & & & & & & & \\
\hline
\end{tabular}

\begin{tabular}{|l|l|l|l|l|l|l|l|l|l|}
\hline ITYPE & IRF & $A$ & AZW & U & SHADE & ABSP & SHDW & & \\
\hline & & & & & & & & & \\
\hline
\end{tabular}

\begin{tabular}{|c|c|c|c|c|c|c|c|c|c|}
\hline FL & HT & FP & AW & BWL & BWR & D & & & \\
\hline & & & & & & & & & \\
\hline FPI & $A 1$ & $B 1$ & $\mathrm{Cl}$ & FP2 & A2 & B2 & C2 & & \\
\hline
\end{tabular}


Repetition of Data Sheets 13 and 14

\begin{tabular}{|l|l|l|l|l|l|l|l|l|l|}
\hline ITYPE & IRF & $A$ & AZW & $U$ & SHADE & ABSP & SHDW & & \\
\hline & & & & & & & & & \\
\hline
\end{tabular}

\begin{tabular}{|l|l|l|l|l|l|l|l|l|l|}
\hline$F L$ & $H T$ & $F P$ & $A W$ & $B W L$ & $B W R$ & $D$ & & & \\
\hline & & & & & & & & & \\
\hline
\end{tabular}

\begin{tabular}{|l|l|l|l|l|l|l|l|l|l|}
\hline FPI & A1 & B1 & Cl & FP2 & A2 & B2 & C2 & & \\
\hline & & & & & & & & & \\
\hline
\end{tabular}

\begin{tabular}{|l|l|l|l|l|l|l|l|l|l|}
\hline ITYPE & IRF & A & AZW & $U$ & SHADE & ABSP & SHDW & & \\
\hline & & & & & & & & & \\
\hline
\end{tabular}

\begin{tabular}{|l|l|l|l|l|l|l|l|l|l|}
\hline$F L$ & $H T$ & $F P$ & $A W$ & $B W L$ & $B W R$ & $D$ & & & \\
\hline & & & & & & & & & \\
\hline
\end{tabular}

\begin{tabular}{|l|l|l|l|l|l|l|l|l|l|}
\hline FPI & $A 1$ & $B 1$ & Cl & FP2 & A2 & B2 & C2 & & \\
\hline & & & & & & & & & \\
\hline
\end{tabular}

\begin{tabular}{|l|l|l|l|l|l|l|l|l|l|}
\hline ITYPE & IRF & $A$ & AZW & U & SHADE & ABSP & SHDW & & \\
\hline & & & & & & & & & \\
\hline
\end{tabular}

\begin{tabular}{|l|l|l|l|l|l|l|l|l|l|}
\hline$F L$ & $H T$ & $F P$ & $A W$ & $B W L$ & $B W R$ & $D$ & & & \\
\hline & & & & & & & & & \\
\hline
\end{tabular}

\begin{tabular}{|l|l|l|l|l|l|l|l|l|l|}
\hline FPI & $A 1$ & $B 1$ & $C 1$ & FP2 & A2 & B2 & C2 & & \\
\hline & & & & & & & & \\
\hline
\end{tabular}


Repetition of Data Sheets 13 and 14

\begin{tabular}{|l|l|l|l|l|l|l|l|l|l|}
\hline ITYPE & IRF & A & AZW & $\cup$ & SHADE & ABSP & SHDW & & \\
\hline \hline & & & & & & & & & \\
\hline
\end{tabular}

\begin{tabular}{|l|l|l|l|l|l|l|l|l|l|}
\hline$F L$ & $H T$ & $F P$ & AW & BWL & BWR & $D$ & & & \\
\hline & & & & & & & & & \\
\hline
\end{tabular}

\begin{tabular}{|l|l|l|l|l|l|l|l|l|l|}
\hline FPI & Al & B1 & Cl & FP2 & A2 & B2 & C2 & & \\
\hline \hline & & & & & & & & & \\
\hline
\end{tabular}

\begin{tabular}{|l|l|l|l|l|l|l|l|l|l|}
\hline ITYPE & IRF & $A$ & AZW & $U$ & SHADE & ABSP & SHDW & & \\
\hline & & & & & & & & & \\
\hline
\end{tabular}

\begin{tabular}{|c|c|c|c|c|c|c|c|c|c|}
\hline$F L$ & $H T$ & $F P$ & $A W$ & $B W L$ & $B W R$ & $D$ & & & \\
\hline & & & & & & & & & \\
\hline
\end{tabular}

\begin{tabular}{|l|l|l|l|l|l|l|l|l|l|}
\hline FPI & $\mathrm{Al}$ & $\mathrm{BI}$ & $\mathrm{Cl}$ & $\mathrm{FP2}$ & $\mathrm{A} 2$ & $\mathrm{~B} 2$ & $\mathrm{C} 2$ & & \\
\hline \hline & & & & & & & & & \\
\hline
\end{tabular}

\begin{tabular}{|l|l|l|l|l|l|l|l|l|l|}
\hline ITYPE & IRF & $A$ & AZW & $U$ & SHADE & ABSP & SHDW & & \\
\hline & & & & & & & & & \\
\hline
\end{tabular}

\begin{tabular}{|c|c|c|c|c|c|c|c|c|c|}
\hline$F L$ & $H T$ & $F P$ & $A W$ & $B W L$ & $B W R$ & $D$ & & & \\
\hline & & & & & & & & & \\
\hline
\end{tabular}

\begin{tabular}{|l|l|l|l|l|l|l|l|l|l|}
\hline FPI & Al & BI & Cl & FP2 & A2 & B2 & C2 & & \\
\hline \hline & & & & & & & & & \\
\hline
\end{tabular}


UENDW: Overall heat transfer coefficient of the end walls (gables) of the attic space, Btuh.

UCELNG: Overall heat transfer coefficient of the ceiling under the attic, Btuh .

AENDW: Area of the attic end walls, sq. ft.

ATCHT: Attic space height, ft.

ARCHGA: Air change per hr. for attic.

AIRNT: Nighttime air change multiplier with respect to ARCHGA.

\begin{tabular}{|l|l|l|l|l|l|l|l|l|l|}
\hline UENDW & UCELNG & AENDW & ATCHT & ARCHGA & AIRNT & & & & \\
\hline & & & & & & & & & \\
\hline
\end{tabular}

* This data sheet provides information for the attic space with a flat roof. If gabled roof, it must be treated as an equivalent flat roof. 
IEXTED: Exterior shading control index:

IEXTED $=1$ if the exterior shading device is controlled to cut down the direct solar heat gain.

IEXTED $=0$ if the exterior shading device is not controlled.

IEXMS: The month at which the exterior shading device control starts.

IEXME: The month at which the exterior shading device control ends.

NTVNT: Ventilation air change per hour during the unoccupied period to precool the building. The ventilation system is assumed on only during the cooling season when
a. The room temperature exceeds $75^{\circ} \mathrm{F}$.
b. Outdoor temperature is below $70^{\circ} \mathrm{F}$.

NVENT: Natural ventilation index

NVENT = 1 if outdoor air is brought in during the occupied period to minimize the cooling load.

NVENT $=0$ otherwise.

(integer data)

\begin{tabular}{|l|l|l|l|l|l|l|l|l|l|}
\hline IEXTED & IEXMS & IEXME & NTVNT & NVENT & & & & & \\
\hline & & & & & & & & & \\
\hline
\end{tabular}


The step by step procedure to perform the heating and cooling load calculation by using NBSLD on the INFONET system is as follows:

1. Complete the data forms described in this manual.

2. Check the data for probable errors.

3. Turn the computer terminal on.

4. Dial the computer center and listen to the high-pitched tone.

5. Place the telephone receiver onto the acoustic coupler of the terminal.

6. Hit the key "T".

The computer responds with

"PORT:" Port number

"CENTER :"

Type in after "CENTER:" BB

The computer responds then with

"LOGON :"

Type in your identification number after "LOGON:".

7. The computer then returns the carriage of the terminal and types!

8. Every time the computer waits for your command, it responds with ! at the first position of the carriage. Following in the sequence of the commands needed to perform the load calculations. 
! EDIT NBSBLI

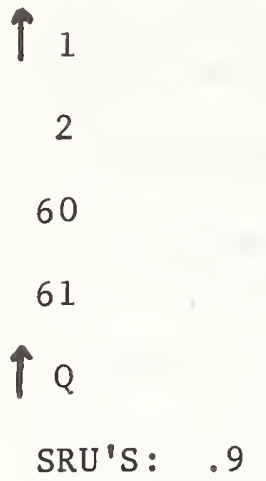

! EQUATE 7 WETDAT

! EQUATE 9 SPACE 1

! EQUATE 10 SPACE 2
Type in the data from your data forms as illustrated in Figure $\mathrm{Cl}$.

... all the data are completed.

close the data file.

computer time unit used in the data preparation.

Weather tape file name.

Output tape No. 1 .

Output tape No. 2 .

9. Instruction for the terminal data input

Type in the following terminal data:

RUNID, RUNTYP, ASHRAE, IDETAL, METHOD

At this point, the computer starts the load calculation and output such as shown in P103 will be typed out on the terminal. 
The use of Weather Data Tape 1440 provided by the National Climatic Center may be made as follows:

1. Request the tape containing data for specified years from the National Climatic Center

G. McKay or D. Calloway Environmental Data Services

Asheville, North Carolina 28801

Telephone: (704) 254-0961

Remember that beginning January 1, 1965 a new program was initiated for most Weather Bureau Stations reducing the number of hourly observations being recorded from 24 to 8 per day. This format is not compatible with NBSLD as it is presently written since it requires hourly weather data. Note that the tape is 7 channel, 556 BPI density and of even parity.

2. Have the tape mailed to INFONET computing center at the following address :

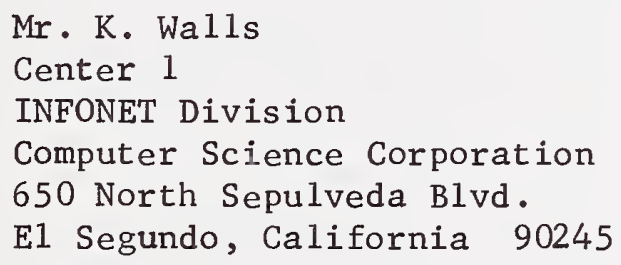

3. Ask INFONET to assign a Volume number such as US001.

4. The tape 1440 is then decoded and stored into a weather data file name of which may be obtained by the following INFONET commands : 
! DEVICES, QUEUE $0,0,1$

! EQUATE 9 WETDAT

! WETHER

VOL, DENS, PARITY, TRACK

VOL: Tape name.

DENS: Tape density in BPI.

PARITY: Date parity, either even or odd.

TRACK: Track number, either 7 or 9.

ISKIP, NDAY, IWRITE ... data

where

ISKIP: Number of days to be skipped from the beginning of the tape.

NDAY: Number of days for which the weather data are to be stored in the file.

IWRITE $=1:$ if the weather data are to be printed out on the terminal as they are processed and stored; otherwise zero.

5. The constants of WETDAT may be checked by a separate routine WETAP by

! EQUATE 9 WETDAT

! WETAP

NDAY, NSKIP

where NDAY: Number of days for which the weather data are to be displayed on the terminal.

NSKIP: Number of days to be skipped from the beginning of the file WETDAT. 
When the use is made of WETDAT in any other program, it can be read in the Fortran program as follows:

READ (9) DB, DP, WB, WS, PB, TC, NTOC, DAY, IYEAR, MONTH, ICITY where $\mathrm{DB}, \mathrm{DD}$, WB, WS, PB, TC, and NTOC are all dimensioned 24 and represent respectively dry-bulb temperature, dewpoint temperature, wet-bulb temperature, wind speed, barometric pressure, total cloud amount, and type of cloud. 

Table Cl

Design Weather Data

Reprinted by permission from the 1972 Handbook of Fundamentals, (American Society of Heating, Refrigerating and Air-Conditioning Engineers, 345 East 47th Street, New York), pp. 669-687. 
Climatic Conditions for United States and Canada*,

\begin{tabular}{|c|c|c|c|c|c|c|c|c|c|c|c|c|c|c|}
\hline \multirow{4}{*}{$\begin{array}{c}\text { Col. I } \\
\text { State and Station }{ }^{b}\end{array}$} & \multirow{4}{*}{\multicolumn{2}{|c|}{$\begin{array}{c}\text { Col. } 2 \\
\text { Lotifude } \\
0\end{array}$}} & \multirow{4}{*}{$\begin{array}{c}\text { Col. } 3 \\
\text { Elev, d } \\
\text { Fi }\end{array}$} & \multicolumn{4}{|c|}{ Winter } & \multicolumn{7}{|c|}{ Summer } \\
\hline & & & & \multicolumn{3}{|c|}{ Col. 4} & \multirow{3}{*}{$\begin{array}{c}\text { Col. } 5 \\
\text { Coinci- } \\
\text { dent } \\
\text { Wind } \\
\text { Ve- } \\
\text { locitye }\end{array}$} & \multirow{2}{*}{\multicolumn{3}{|c|}{$\begin{array}{c}\text { Col. } 6 \\
\text { Design Dry-Bulb }\end{array}$}} & \multirow{3}{*}{$\begin{array}{c}\text { Cal. } 7 \\
\text { Out. } \\
\text { door } \\
\text { Doily } \\
\text { Range' }\end{array}$} & \multirow{2}{*}{\multicolumn{3}{|c|}{$\begin{array}{c}\text { Col. } 8 \\
\text { Design Wet-Bulb }\end{array}$}} \\
\hline & & & & \multirow{2}{*}{$\mid \begin{array}{c}\text { Medion } \\
\text { of } \\
\text { Annual } \\
\text { Ex. } \\
\text { tremes }\end{array}$} & \multirow[b]{2}{*}{$99 \%$} & \multirow[b]{2}{*}{$97 \frac{1}{2} \%$} & & & & & & & & \\
\hline & & & & & & & & $1 \%$ & $2 \frac{1}{2} \%$ & $5 \%$ & & $1 \%$ & $2 \frac{1}{2} \%$ & $5 \%$ \\
\hline $\begin{array}{l}\text { ALABAMA } \\
\text { Alexander City }\end{array}$ & & & 660 & 12 & 16 & 20 & L & 96 & 94 & 93 & & & & \\
\hline Anniston AP... & 33 & 4 & 599 & 12 & 17 & 19 & $\mathrm{~L}$ & 96 & 94 & $\begin{array}{l}93 \\
93\end{array}$ & $\begin{array}{l}21 \\
21\end{array}$ & $\begin{array}{l}79 \\
79\end{array}$ & 78 & $\begin{array}{l}77 \\
77\end{array}$ \\
\hline Auburn...... & 32 & 4 & 730 & 17 & 21 & 25 & $\overline{\mathrm{L}}$ & 98 & 96 & 95 & 21 & 80 & 79 & 78 \\
\hline Birningham AP & 33 & 3 & 610 & 14 & 19 & 22 & $\mathrm{~L}$ & 97 & 94 & 93 & 21 & 79 & 78 & 77 \\
\hline Decatur...... & 34 & & 580 & 10 & 15 & 19 & $\mathrm{~L}$ & 97 & 95 & 94 & 22 & 79 & 78 & 77 \\
\hline Dothan AP. & 31 & 2 & 321 & 19 & 23 & 27 & $\mathrm{~L}$ & 97 & 95 & 94 & 20 & 81 & 80 & 79 \\
\hline Florence AP & 34 & 5 & 528 & 8 & 13 & 17 & $\mathrm{~L}$ & 97 & 9 & 94 & 22 & 79 & 78 & 77 \\
\hline Gadsden.... & 34 & 0 & 570 & 11 & 16 & 20 & $\mathrm{~L}$ & 96 & 94 & 93 & 22 . & 78 & 77 & 76 \\
\hline Huntsville AP. & 34 & 4 & 619 & -6 & 13 & 17 & $\mathrm{~L}$ & 97 & 95 & 94 & 23 & 78 & 77 & 76 \\
\hline Mobile AP.... & 30 & 4 & 211 & 21 & 26 & 29 & $\mathbf{M}$ & 95 & 93 & 91 & 18 & 80 & 79 & 79 \\
\hline Mobile CO. & 30 & 4 & 119 & 24 & 28 & 32 & M & 96 & 94 & 93 & 16 & 80 & 79 & 79 \\
\hline Montgomery A & 32 & 2 & 195 & 18 & 22 & 26 & $\mathrm{~L}$ & 98 & 9 & 93 & 21 & 80 & 79 & 78 \\
\hline Selma-Craig AFB. & 32 & 2 & 207 & 18 & 23 & 27 & $\mathrm{~L}$ & 98 & 9 & 94 & 21 & 81 & 80 & 79 \\
\hline Talladega....... & 33 & 3 & 565 & 11 & 15 & 19 & $\mathrm{~L}$ & 97 & 9 & 94 & 21 & 79 & 78 & 77 \\
\hline Tuscaloosa AP & 33 & 1 & $170 r$ & 14 & 19 & 23 & $\mathrm{~L}$ & 98 & 96 & 95 & 22 & 81 & 80 & 79 \\
\hline ALASKA & & & & & & & & & & & & & & \\
\hline Anchorage AP & 61 & 1 & 90 & -29 & -25 & -20 & VL & 73 & 70 & 67 & 15 & 63 & 61 & 59 \\
\hline Barrow & 71 & 2 & 22 & -49 & -45 & -42 & M & 58 & 54 & 50 & 12 & 54 & 51 & 48 \\
\hline Fairbanks AP. & 64 & 5 & 436 & -59 & -53 & -50 & VL & 82 & 78 & 75 & 24 & 64 & 63 & 61 \\
\hline Juneau AP... & 58 & 2 & 17 & -11 & -7 & -4 & $\mathrm{~L}$ & $7:$ & 7 & 68 & 15 & 66 & 64 & 62 \\
\hline Kodiak & 57 & 3 & 21 & 4 & 8 & 12 & M & 71 & 6 & 6 & 10 & 62 & 60 & 58 \\
\hline Nome AF & 64 & 3 & 13 & -37 & -32 & -28 & $\mathrm{~L}$ & 66 & 62 & 59 & 10 & 58 & 56 & 54 \\
\hline ARIZONA $†$ & & & & & & & & & & & & & & \\
\hline zlas A & 31 & 3 & 4098 & 13 & 18 & 22 & VL & 100 & 98 & 96 & 31 & 70 & 69 & 68 \\
\hline Flagstaf & 35 & 1 & 6973 & -10 & 0 & 5 & VL & 84 & 8 & 80 & 31 & 61 & 60 & 59 \\
\hline Fort Huachuca AP. & 31 & 3 & 4664 & 18 & 25 & 28 & VL & 9 & 9 & 9] & 27 & 69 & 68 & 67 \\
\hline Kingman AP.. & 35 & 2 & 3446 & 18 & 25 & 29 & VL & 103 & 100 & 97 & 30 & 70 & 69 & 69 \\
\hline Nogales & 31 & 2 & 3800 & 15 & 20 & 24 & VL & 100 & 98 & 96 & 31 & 72 & 71 & 70 \\
\hline Phoen & 33 & 3 & 1117 & 25 & 31 & $\cdot 34$ & VL & 108 & 106 & $10 t$ & 27 & 77 & 76 & 75 \\
\hline $\mathrm{Pr}$ & 34 & 4 & 5014 & 7 & 15 & 19 & VL & 96 & 9 & 91 & 3 & 67 & 6 & 65 \\
\hline Tucson A & 33 & 1 & 2584 & 23 & 29 & 32 & VL & 105 & 102 & 10 & 2 & 74 & 73 & 72 \\
\hline Winslov & 35 & 0 & 4880 & 2 & 9 & 13 & VL & 97 & 95 & 92 & 32 & 66 & 65 & 64 \\
\hline Yuma AP. . & 32 & 4 & 199 & 32 & 37 & 40 & VL & 111 & 109 & 107 & 27 & 79 & 78 & 77 \\
\hline ARKANSAS & & & & & & & & & & & & & & \\
\hline Bly'theville AFB.. & 36 & 0 & 264 & 6 & 12 & 17 & $\mathrm{~L}$ & 98 & 96 & 93 & 21 & 80 & 79 & 78 \\
\hline Camden & 33 & 4 & 116 & 13 & 19 & 23 & $\mathrm{~L}$ & 99 & 97 & 96 & 21 & 81 & 80 & 79 \\
\hline El Dora & 33 & 1 & 252 & 13 & 19 & 23 & $\mathrm{~L}$ & 98 & 9 & 9 & 21 & 81 & 80 & 79 \\
\hline Fayetter & 36 & 0 & 1253 & 3 & 9 & 13 & M & 97 & 95 & 93 & 23 & 77 & 76 & 75 \\
\hline Fort Smith AP. & 35 & 2 & 449 & 9 & 15 & 19 & $\mathbf{M}$ & 101 & 99 & 96 & 24 & 79 & 78 & 77 \\
\hline gs Nat. Pk.. & 34 & 3 & 710 & 12 & 18 & 22 & M & 99 & 97 & 96 & 22 & 79 & 78 & 77 \\
\hline Jonest & 35 & 5 & 345 & 8 & 14 & 18 & $\mathbf{M}$ & 98 & 9 & 9 & 21 & 80 & 79 & 78 \\
\hline Little R & 34 & 4 & 257 & 13 & 19 & 23 & M & 99 & 98 & 94 & 22 & 80 & 79 & 78 \\
\hline Pine Bluff AP. & 34 & 1 & 204 & 14 & 20 & 24 & I. & 99 & 96 & 9 & 22 & 81 & 80 & 79 \\
\hline Texarkana AP & 33 & 3 & 361 & 16 & 22 & 26 & $\mathbf{M}$ & 99 & 97 & 96 & 21 & 80 & 79 & 78 \\
\hline CALIFO & & & & & & & & & & & & & & \\
\hline Bakersfield AP & 35 & 2 & 495 & 26 & 31 & 33 & VL & 103 & 101 & 99 & 32 & 72 & 71 & 70 \\
\hline Barstow AP. & 34 & 5 & 2142 & 18 & 24 & 28 & VL & 104 & 102 & 99 & 37 & 73 & 72 & 71 \\
\hline Blythe AP. & 33 & 4 & 390 & 26 & 31 & 35 & VI, & 111 & 109 & 106 & 28 & 78 & 77 & 76 \\
\hline Burbank AP. & 34 & 1 & 699 & 30 & 36 & 38 & VL & 97 & 94 & 91 & 25 & 72 & 70 & 69 \\
\hline Chico. & 39 & 5 & 205 & 23 & 29 & 33 & VL & 102 & 100 & 97 & 36 & 71 & 70 & 69 \\
\hline Concord & 38 & 0 & 195 & 27 & 32 & 36 & VL & 96 & 92 & 88 & 32 & 69 & 67 & 66 \\
\hline
\end{tabular}

- Data for U.S. stations extracted from Evaluated Weather Data for Coolino Equipment Desion, Addendum No. 1 , Winter and Summer Data, with the permission of the publisher, Fluor Products Company, Ino., Box 1267, Santa Rosa, California

"Data conpiled from offici:l weather stations, where hourly weather observations are nade by trained observers, and from other sources. Table 1 prepared by ASHRAE Teclnical Connittee 2.2, Weather Data and Design Conditions. Percentage of unter dcsign data show the percent of 3-month period. December through February. Canadian data are based on January only. Percentage of summer design data show the percent of 4 -month period, June through September. Canadian

dsta are based on July only. Also see References 1 to 7 . folloned by "CO" came from office locations within an urban area and generally reflect an infuence of the surrounding area. Stations without designation can be considered semirural and may be directly compared with most airport data.

Latitude is given to thic ncarest 10 minutes, for use in calculating solar loads. For example, the latitude for Anniston, Alabama is given as 334 , or $33^{\circ} 40^{\prime}$

d Elevations arc ground elevations for each station as of 1964 . Temperature rcadings are generally made at an elevation of $5 \mathrm{ft}$ above ground, except for locations merked $r$, indicating roof exposure of thernoineter.

- Coincident wind velocitiv's derived from approximately coldest 600 hours out of 20,000 hours of December through February data per atation. Also see References 5 and 6. The four ingsitications arc:

$V L=$ Very Light, 70 percent or nuse of cold extreme hours $\leq 7 \mathrm{mph}$. $M=$ Moderate, 50 to 74 percent cold extreme hours $>7$ mph

$L=$ Light, 50 to 69 percent coid extreme hours $\leq 7 \mathrm{mph}$. The differencc between the averarc maximum and average minimam temperatures during the warmest month.

$\uparrow$ More dotailed data on A rizona, ('ahifornia, and Nevada nay be found in Kecommended Design Temperatures. Viorihern Colifornia, publiahed by the Golden Gato Chapter; and Recommended Desion Temperalures, Southern California, Arizona, Nevuda, publisised by the Southern California Chapter. 
Climatic Conditions for United States and Canada (Continued)*,a

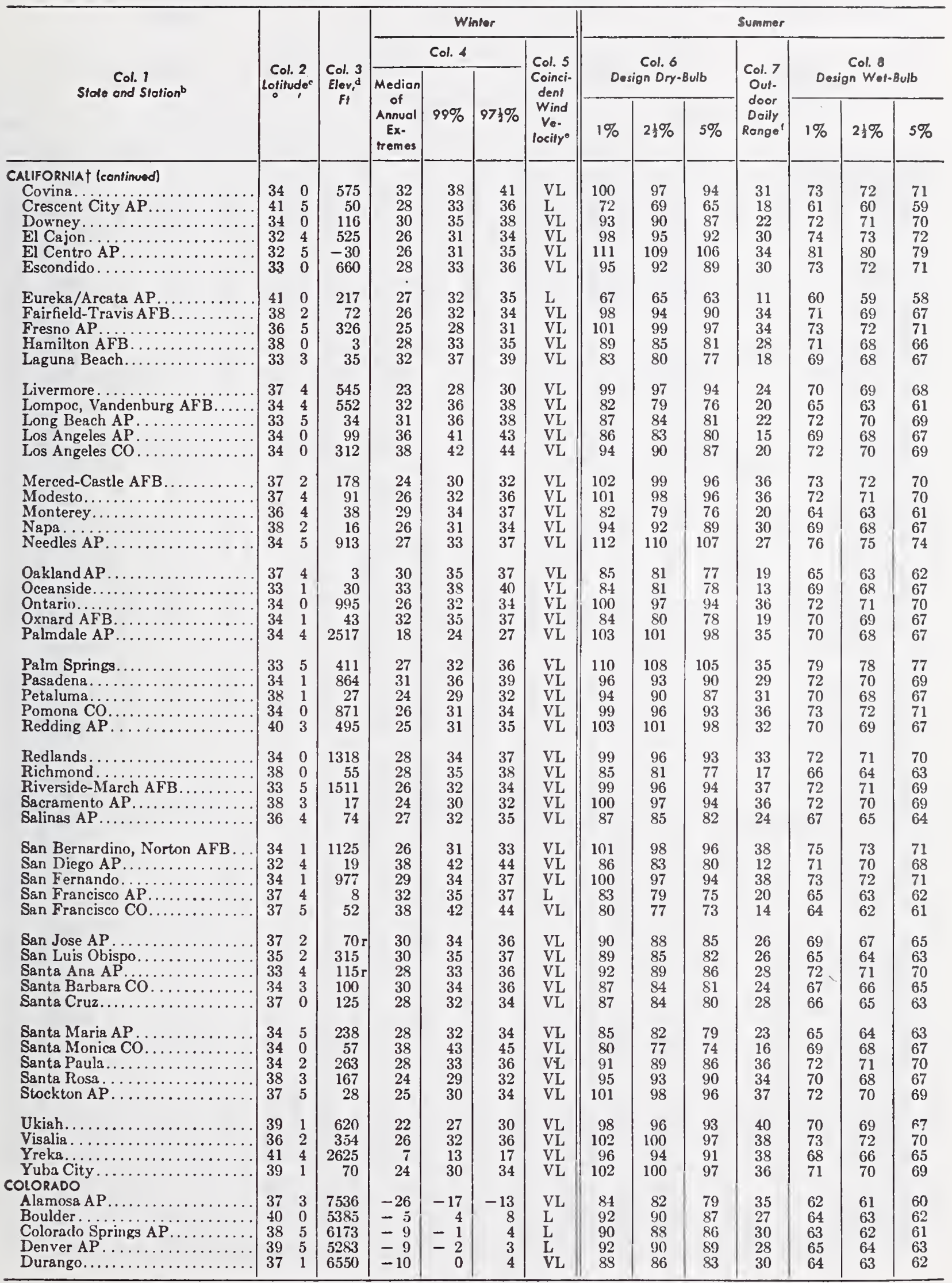


Climatic Conditions for United States and Canada (Continued)*,a

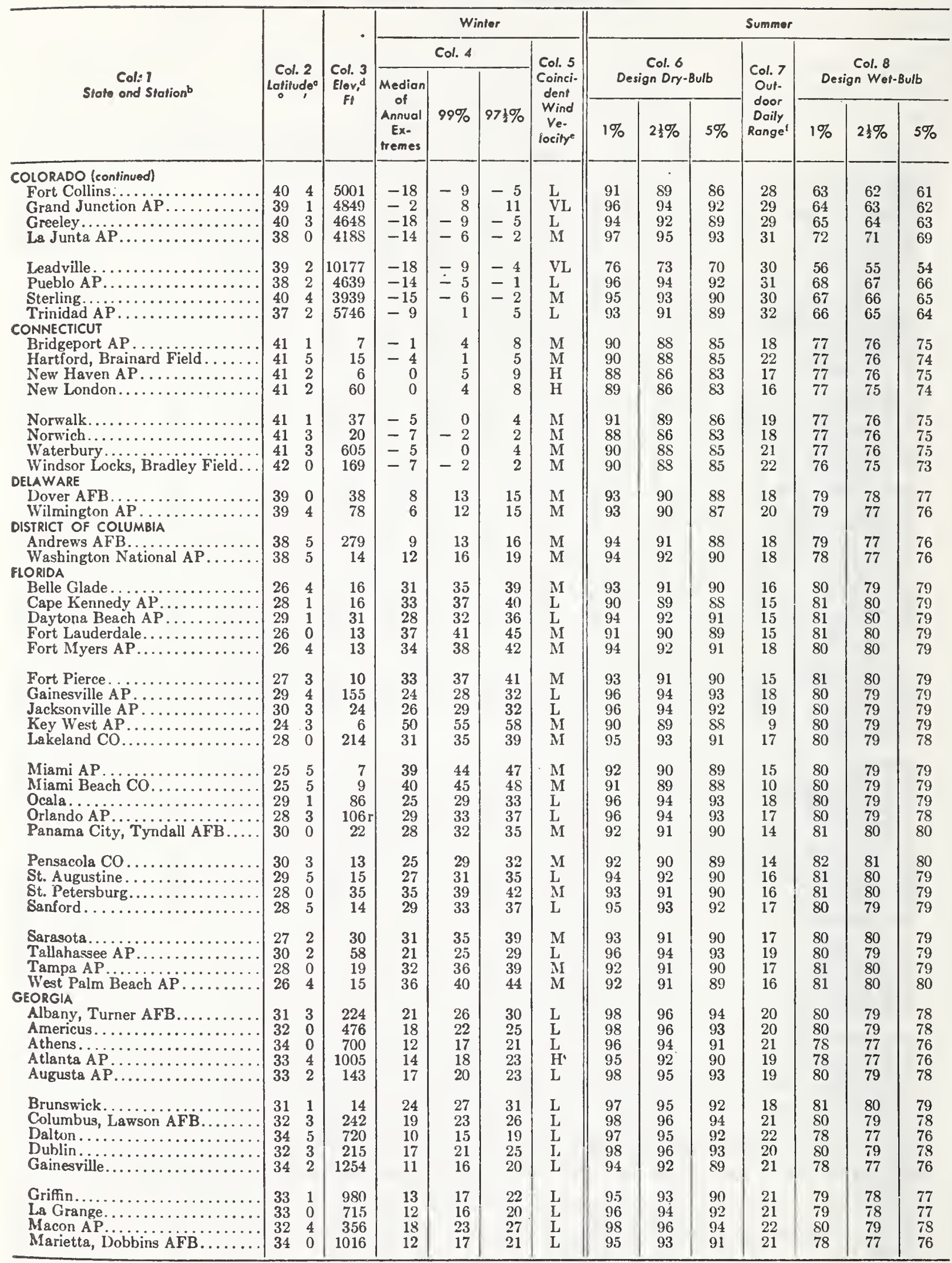


Climatic Conditions for United States and Canada (Continued)*

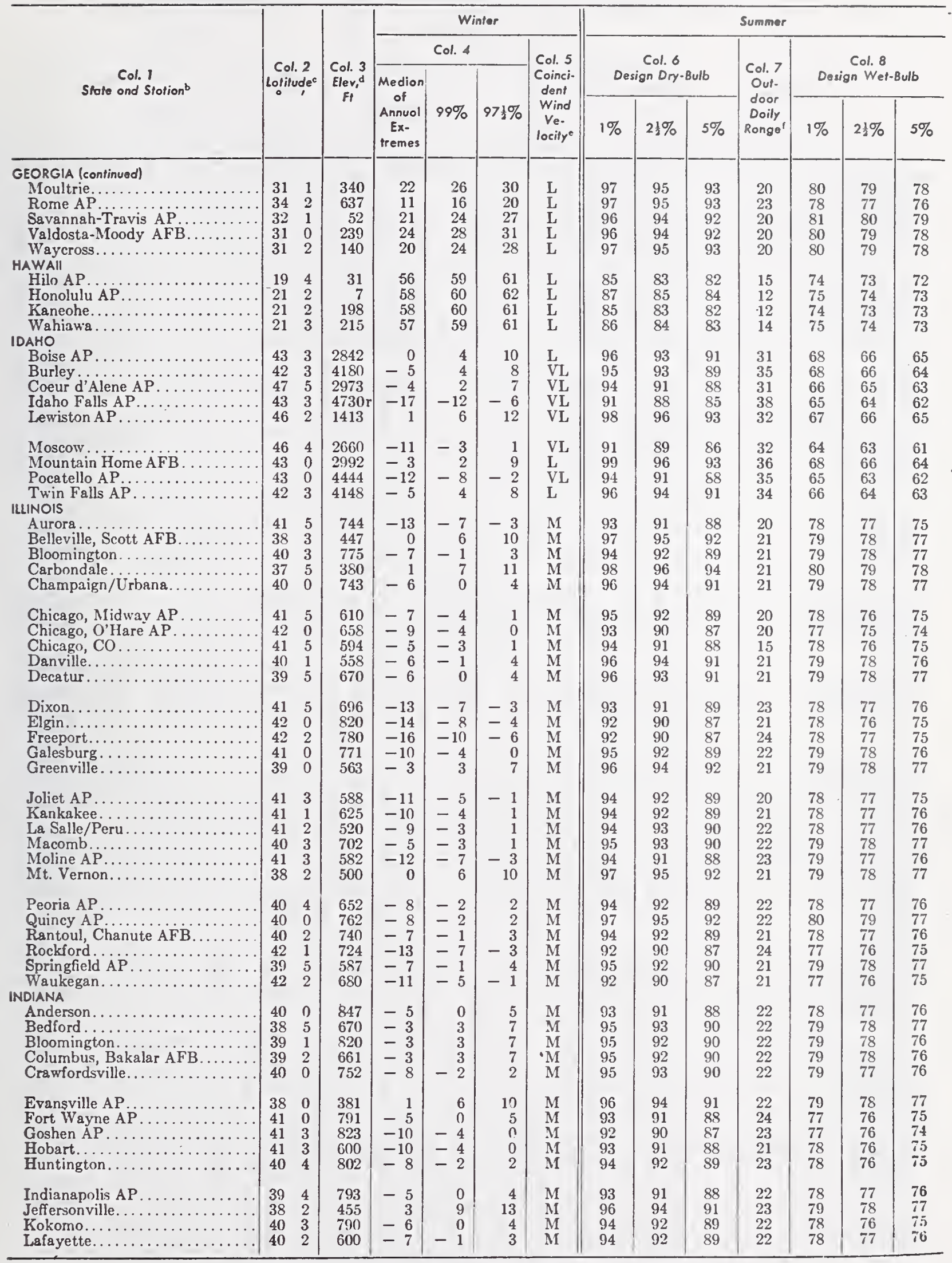


Climatic Conditions for United States and Canada (Continued)*:s

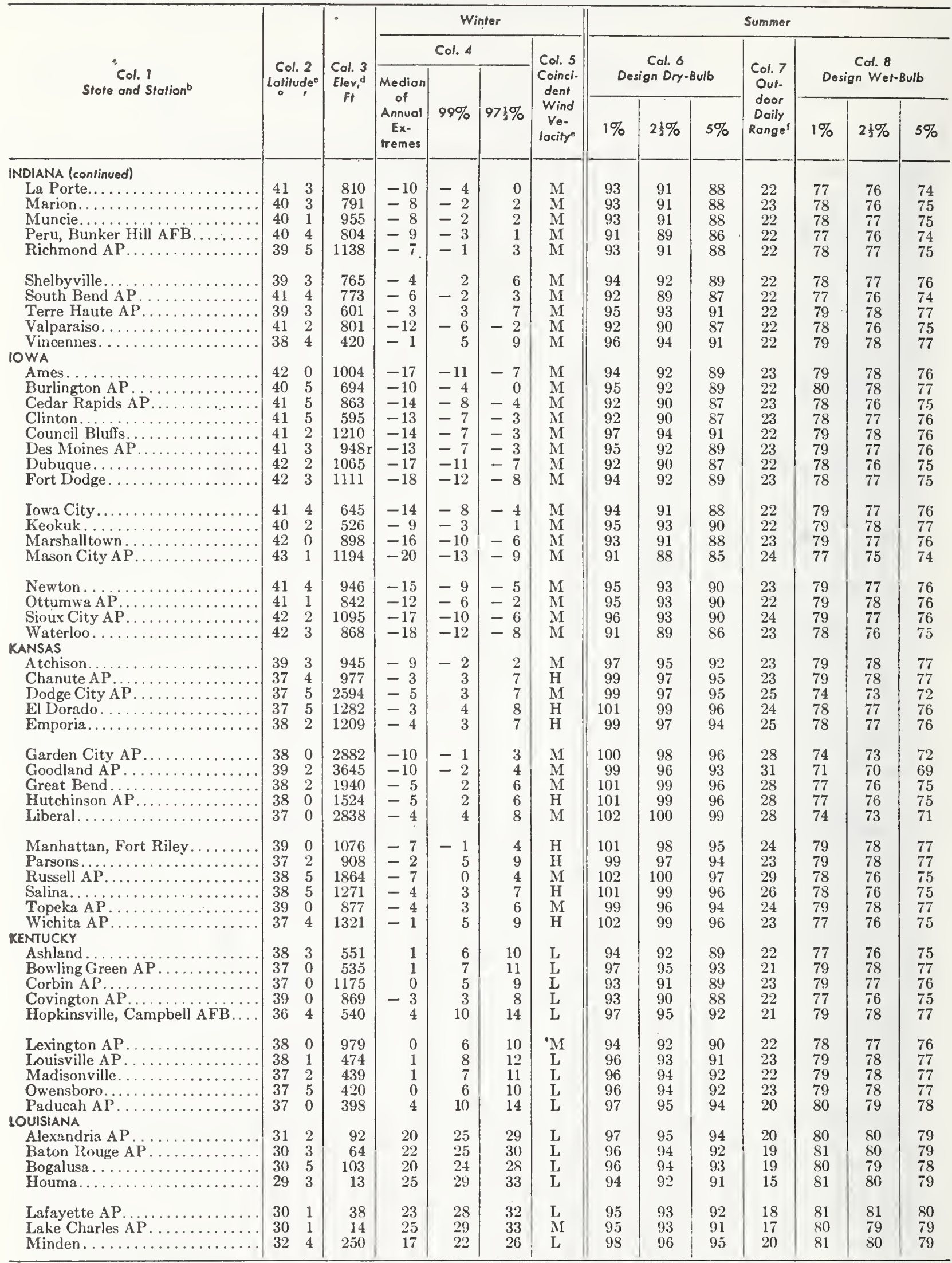


Climatic Conditions for United States and Canada (Continued)*, a

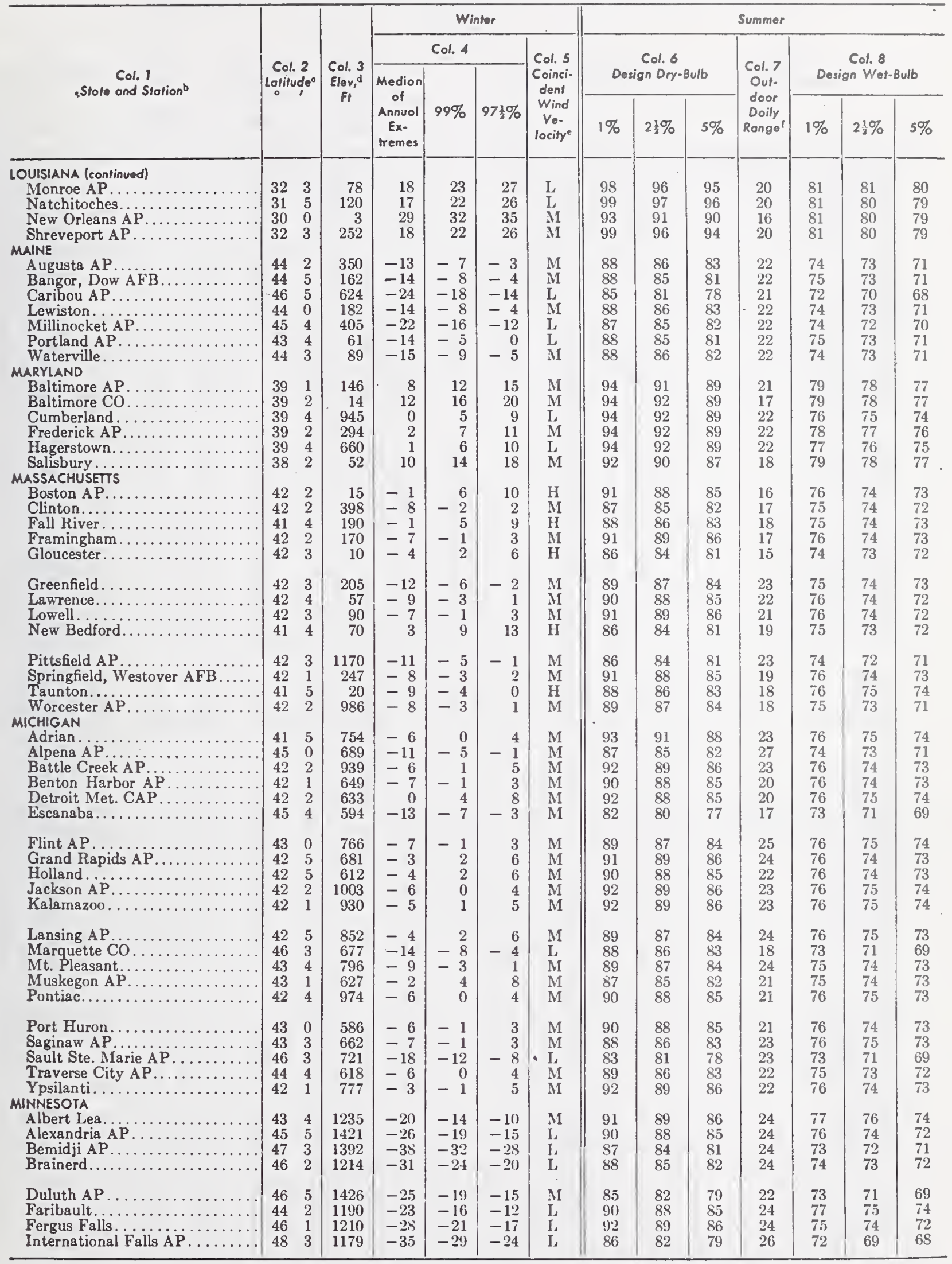


Climatic Conditions for United States and Canoda (Continued)*,a

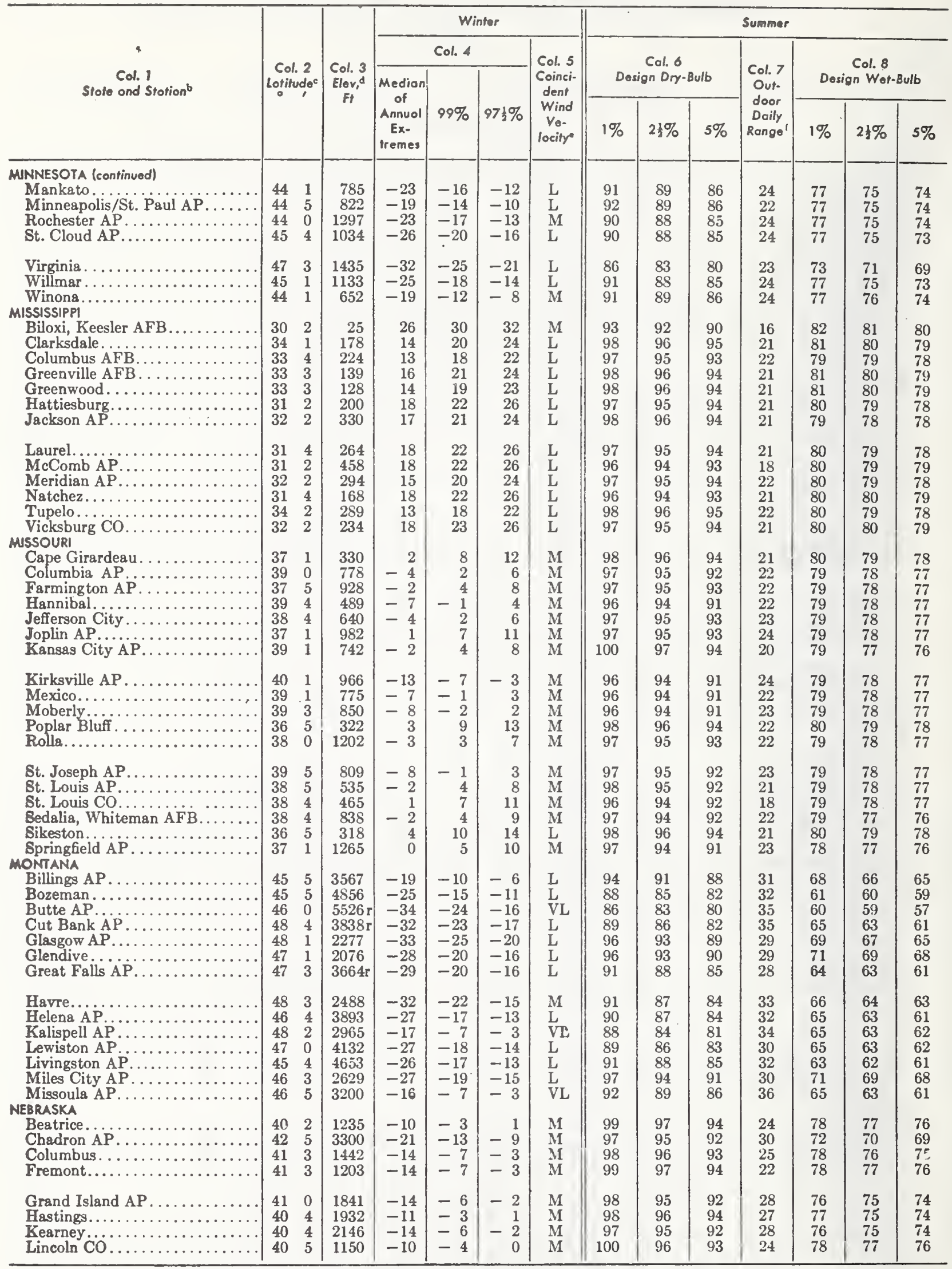


Climatic Canditions for United States and Canada (Continued)*:

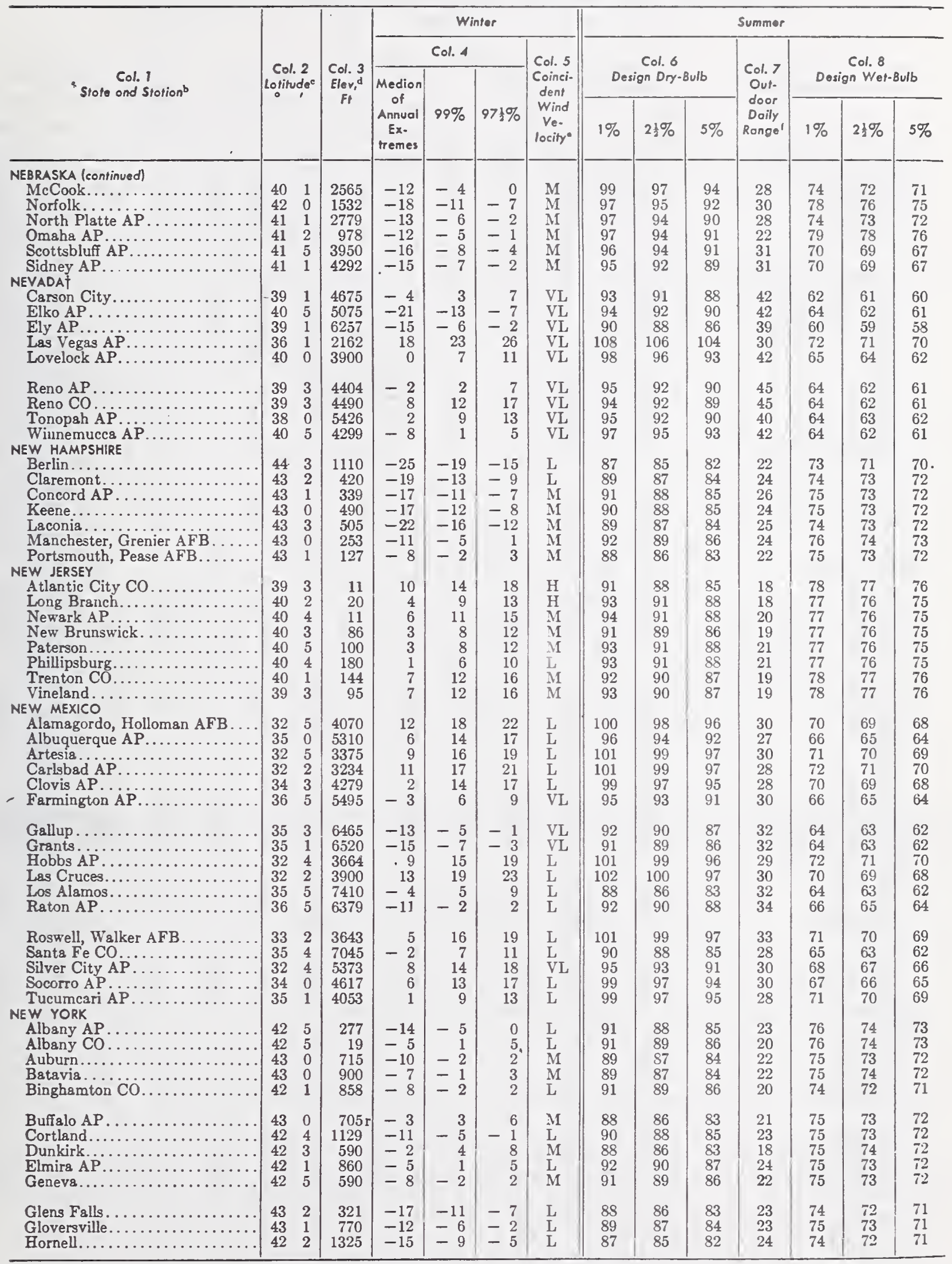


Climatic Conditions for United States and Canada (Continued)*,

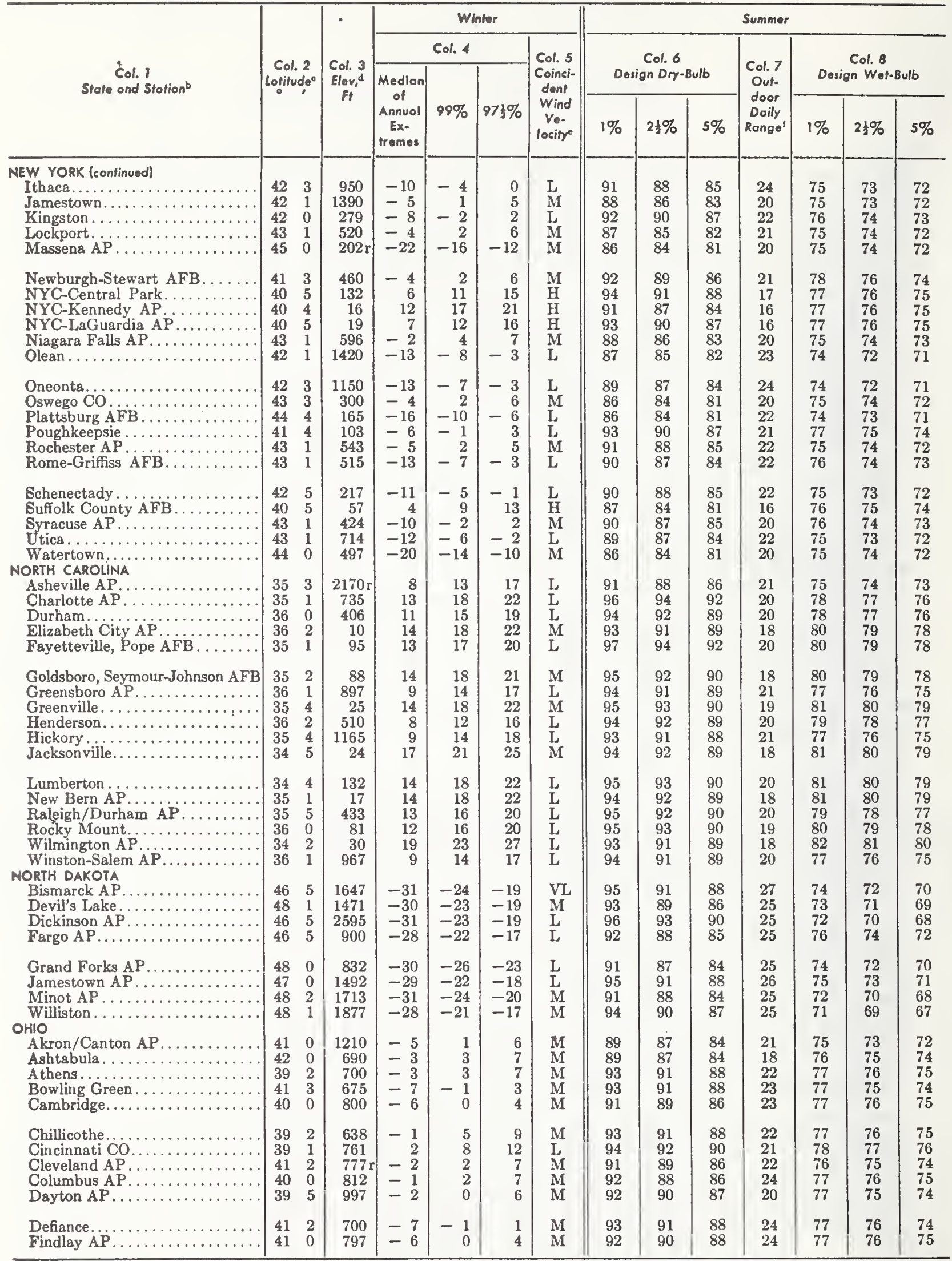


Climatic Conditions for United States and Canada (Continued)*a

\begin{tabular}{|c|c|c|c|c|c|c|c|c|c|c|c|c|c|c|}
\hline \multirow{4}{*}{$\begin{array}{l}\text { S Col. I } \\
\text { State and Stotion }\end{array}$} & \multirow{4}{*}{\multicolumn{2}{|c|}{$\begin{array}{c}\text { Col. } 2 \\
\text { Lafitude }\end{array}$}} & \multirow{4}{*}{$\mid \begin{array}{c}\text { Col. } 3 \\
\text { Elev, } \\
\text { Fi }\end{array}$} & \multicolumn{4}{|c|}{ Winter } & \multicolumn{7}{|c|}{ Summer } \\
\hline & & & & \multicolumn{3}{|c|}{ Col. 4} & \multirow{3}{*}{$\begin{array}{l}\text { Col. } 5 \\
\text { Coinci- } \\
\text { dent } \\
\text { Wind } \\
\text { Ve- } \\
\text { locity }\end{array}$} & \multirow{2}{*}{\multicolumn{3}{|c|}{$\begin{array}{c}\text { Col. } 6 \\
\text { Design Dry-Bulb }\end{array}$}} & \multirow{3}{*}{$\begin{array}{c}\text { Col. } 7 \\
\text { Out- } \\
\text { door } \\
\text { Doily } \\
\text { Ronger }\end{array}$} & \multirow{2}{*}{\multicolumn{3}{|c|}{$\begin{array}{c}\text { Col. } 8 \\
\text { Design Wet-Bulb }\end{array}$}} \\
\hline & & & & \multirow{2}{*}{$\begin{array}{c}\text { Medion } \\
\text { of } \\
\text { Annuol } \\
\text { Ex: } \\
\text { tremes }\end{array}$} & \multirow[b]{2}{*}{$99 \%$} & \multirow[b]{2}{*}{$97 \frac{1}{3} \%$} & & & & & & & & \\
\hline & & & & & & & & $1 \%$ & $2 \frac{1}{2} \%$ & $5 \%$ & & $1 \%$ & $2 \frac{1}{2} \%$ & $5 \%$ \\
\hline 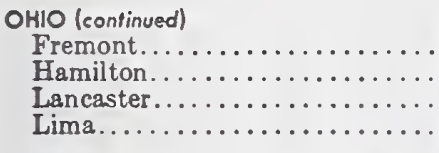 & $\begin{array}{l}41 \\
39 \\
39 \\
40\end{array}$ & $\begin{array}{l}2 \\
2 \\
4 \\
4\end{array}$ & $\begin{array}{l}600 \\
650 \\
920 \\
860\end{array}$ & $\begin{array}{l}-7 \\
-2 \\
-5 \\
-6\end{array}$ & $\begin{array}{r}-1 \\
4 \\
1 \\
0\end{array}$ & $\begin{array}{l}3 \\
8 \\
5 \\
4\end{array}$ & $\begin{array}{l}M \\
M \\
M\end{array}$ & $\begin{array}{l}92 \\
94 \\
93 \\
93\end{array}$ & $\begin{array}{l}90 \\
92 \\
91 \\
91\end{array}$ & $\begin{array}{l}87 \\
90 \\
88 \\
88\end{array}$ & $\begin{array}{l}24 \\
22 \\
23 \\
24\end{array}$ & $\begin{array}{l}76 \\
78 \\
77 \\
77\end{array}$ & $\begin{array}{l}75 \\
77 \\
76 \\
76\end{array}$ & $\begin{array}{l}74 \\
76 \\
75 \\
75\end{array}$ \\
\hline 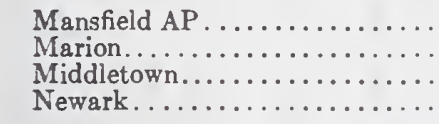 & $\begin{array}{l}40 \\
40 \\
39 \\
40\end{array}$ & $\begin{array}{l}5 \\
4 \\
3 \\
1\end{array}$ & $\begin{array}{r}1297 \\
920 \\
635 \\
825\end{array}$ & $\begin{array}{l}-7 \\
-5 \\
-3 \\
-7\end{array}$ & $\begin{array}{r}1 \\
1 \\
3 \\
-\quad 1\end{array}$ & $\begin{array}{l}3 \\
6 \\
7 \\
3\end{array}$ & $\begin{array}{l}M \\
M \\
M \\
M\end{array}$ & $\begin{array}{l}91 \\
93 \\
93 \\
92\end{array}$ & $\begin{array}{l}89 \\
91 \\
91 \\
90\end{array}$ & $\begin{array}{l}86 \\
88 \\
88 \\
87\end{array}$ & $\begin{array}{l}22 \\
23 \\
22 \\
23\end{array}$ & $\begin{array}{l}76 \\
77 \\
77 \\
77\end{array}$ & $\begin{array}{l}75 \\
76 \\
76 \\
76\end{array}$ & $\begin{array}{l}74 \\
75 \\
75 \\
75\end{array}$ \\
\hline 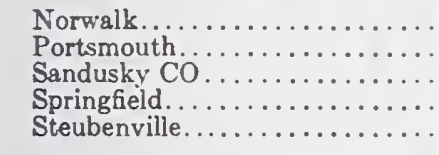 & $\begin{array}{l}41 \\
38 \\
41 \\
40 \\
40\end{array}$ & \begin{tabular}{l|}
1 \\
5 \\
3 \\
0 \\
2
\end{tabular} & $\begin{array}{r}720 \\
530 \\
606 \\
1020 \\
992\end{array}$ & $\begin{array}{l}-7 \\
0 \\
-2 \\
-3 \\
-2\end{array}$ & $\begin{array}{r}-1 \\
5 \\
4 \\
3 \\
4\end{array}$ & $\begin{array}{l}3 \\
9 \\
8 \\
7 \\
9\end{array}$ & $\begin{array}{l}\mathrm{M} \\
\mathrm{L} \\
\mathrm{M} \\
\mathrm{M} \\
\mathrm{M}\end{array}$ & $\begin{array}{l}92 \\
94 \\
92 \\
93 \\
91\end{array}$ & $\begin{array}{l}90 \\
92 \\
90 \\
90 \\
89\end{array}$ & $\begin{array}{l}87 \\
89 \\
87 \\
88 \\
86\end{array}$ & $\begin{array}{l}22 \\
22 \\
21 \\
21 \\
22\end{array}$ & $\begin{array}{l}76 \\
77 \\
76 \\
77 \\
76\end{array}$ & $\begin{array}{l}75 \\
76 \\
75 \\
76 \\
75\end{array}$ & $\begin{array}{l}74 \\
75 \\
74 \\
75 \\
74\end{array}$ \\
\hline 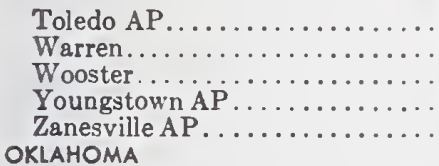 & $\begin{array}{l}41 \\
41 \\
40 \\
41 \\
40\end{array}$ & $\begin{array}{l}4 \\
2 \\
5 \\
2 \\
0\end{array}$ & \begin{tabular}{|r|}
$676 \mathrm{r}$ \\
900 \\
1030 \\
1178 \\
881
\end{tabular} & $\begin{array}{l}-5 \\
-6 \\
-7 \\
-5 \\
-7\end{array}$ & $\begin{array}{r}1 \\
0 \\
-\quad 1 \\
-1\end{array}$ & $\begin{array}{l}5 \\
4 \\
3 \\
6 \\
3\end{array}$ & $\begin{array}{l}M \\
M \\
M \\
M \\
M\end{array}$ & $\begin{array}{l}92 \\
90 \\
90 \\
89 \\
92\end{array}$ & $\begin{array}{l}90 \\
88 \\
88 \\
86 \\
89\end{array}$ & $\begin{array}{l}87 \\
85 \\
85 \\
84 \\
87\end{array}$ & $\begin{array}{l}25 \\
23 \\
22 \\
23 \\
23\end{array}$ & $\begin{array}{l}77 \\
75 \\
76 \\
75 \\
77\end{array}$ & $\begin{array}{l}75 \\
74 \\
75 \\
74 \\
76\end{array}$ & $\begin{array}{l}74 \\
73 \\
74 \\
73 \\
75\end{array}$ \\
\hline 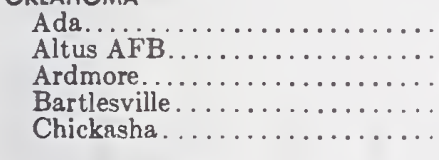 & $\begin{array}{l}34 \\
34 \\
34 \\
36 \\
35\end{array}$ & $\begin{array}{l}5 \\
4 \\
2 \\
5 \\
0\end{array}$ & $\begin{array}{r}1015 \\
1390 \\
880 \\
715 \\
1085\end{array}$ & $\begin{array}{r}6 \\
7 \\
9 \\
-\quad 1 \\
5\end{array}$ & $\begin{array}{r}12 \\
14 \\
15 \\
5 \\
12\end{array}$ & $\begin{array}{r}16 \\
18 \\
19 \\
9 \\
16\end{array}$ & $\begin{array}{l}\mathrm{H} \\
\mathrm{H} \\
\mathrm{H} \\
\mathrm{H} \\
\mathrm{H}\end{array}$ & $\begin{array}{l}102 \\
103 \\
103 \\
101 \\
103\end{array}$ & $\begin{array}{r}100 \\
101 \\
101 \\
99 \\
101\end{array}$ & $\begin{array}{l}98 \\
99 \\
99 \\
97 \\
99\end{array}$ & $\begin{array}{l}23 \\
25 \\
23 \\
23 \\
24\end{array}$ & $\begin{array}{l}79 \\
77 \\
79 \\
79 \\
77\end{array}$ & $\begin{array}{l}78 \\
76 \\
78 \\
78 \\
76\end{array}$ & $\begin{array}{l}77 \\
75 \\
77 \\
77 \\
75\end{array}$ \\
\hline 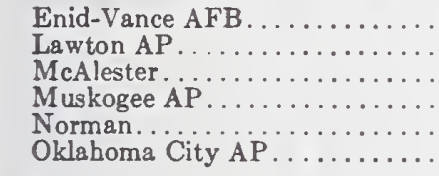 & $\begin{array}{l}36 \\
34 \\
34 \\
35 \\
35 \\
35\end{array}$ & $\begin{array}{l}2 \\
3 \\
5 \\
4 \\
1 \\
2\end{array}$ & $\begin{array}{r}1287 \\
1108 \\
760 \\
610 \\
1109 \\
1280\end{array}$ & \begin{tabular}{l|}
3 \\
6 \\
7 \\
6 \\
5 \\
4
\end{tabular} & $\begin{array}{l}10 \\
13 \\
13 \\
12 \\
11 \\
11\end{array}$ & $\begin{array}{l}14 \\
16 \\
17 \\
16 \\
15 \\
15\end{array}$ & $\begin{array}{l}\mathrm{H} \\
\mathrm{H} \\
\mathrm{H} \\
\mathrm{M} \\
\mathrm{H} \\
\mathrm{H}\end{array}$ & $\begin{array}{l}103 \\
103 \\
102 \\
102 \\
101 \\
100\end{array}$ & $\begin{array}{r}100 \\
101 \\
100 \\
99 \\
99 \\
97\end{array}$ & $\begin{array}{l}98 \\
98 \\
98 \\
96 \\
97 \\
95\end{array}$ & $\begin{array}{l}24 \\
24 \\
23 \\
23 \\
24 \\
23\end{array}$ & $\begin{array}{l}78 \\
78 \\
79 \\
79 \\
78 \\
78\end{array}$ & $\begin{array}{l}77 \\
77 \\
78 \\
78 \\
77 \\
77\end{array}$ & $\begin{array}{l}76 \\
76 \\
77 \\
77 \\
76 \\
76\end{array}$ \\
\hline 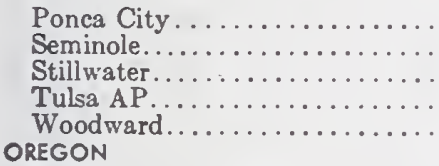 & $\begin{array}{l}36 \\
35 \\
36 \\
36 \\
36\end{array}$ & \begin{tabular}{l|l}
4 \\
2 \\
1 \\
1 \\
3
\end{tabular} & $\begin{array}{r}996 \\
865 \\
884 \\
650 \\
1900\end{array}$ & $\begin{array}{r}1 \\
6 \\
2 \\
4 \\
-3\end{array}$ & $\begin{array}{r}8 \\
12 \\
9 \\
12 \\
4\end{array}$ & $\begin{array}{r}12 \\
16 \\
13 \\
16 \\
8\end{array}$ & $\begin{array}{l}\mathrm{H} \\
\mathrm{H} \\
\mathrm{H} \\
\mathrm{H} \\
\mathrm{H}\end{array}$ & $\begin{array}{l}102 \\
102 \\
101 \\
102 \\
103\end{array}$ & $\begin{array}{r}100 \\
100 \\
99 \\
99 \\
101\end{array}$ & $\begin{array}{l}97 \\
98 \\
97 \\
96 \\
98\end{array}$ & $\begin{array}{l}24 \\
23 \\
24 \\
22 \\
26\end{array}$ & $\begin{array}{l}78 \\
78 \\
78 \\
79 \\
76\end{array}$ & $\begin{array}{l}77 \\
77 \\
77 \\
78 \\
74\end{array}$ & $\begin{array}{l}76 \\
76 \\
76 \\
76 \\
73\end{array}$ \\
\hline 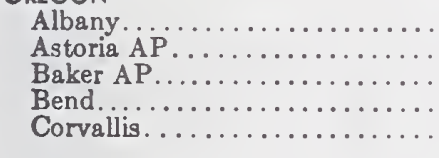 & $\begin{array}{l}44 \\
46 \\
44 \\
44 \\
44\end{array}$ & $\begin{array}{l}4 \\
1 \\
5 \\
0 \\
3\end{array}$ & $\begin{array}{r}224 \\
8 \\
3368 \\
3599 \\
221\end{array}$ & $\begin{array}{r}17 \\
22 \\
-10 \\
-7 \\
17\end{array}$ & $\begin{array}{r}23 \\
27 \\
-\quad 3 \\
0 \\
23\end{array}$ & $\begin{array}{r}27 \\
30 \\
1 \\
4 \\
27\end{array}$ & $\begin{array}{l}\text { VL } \\
\text { M } \\
\text { VL } \\
\text { VL } \\
\text { VL }\end{array}$ & $\begin{array}{l}91 \\
79 \\
94 \\
89 \\
91\end{array}$ & $\begin{array}{l}88 \\
76 \\
92 \\
87 \\
88\end{array}$ & $\begin{array}{l}84 \\
72 \\
89 \\
84 \\
84\end{array}$ & $\begin{array}{l}31 \\
16 \\
30 \\
33 \\
31\end{array}$ & $\begin{array}{l}69 \\
61 \\
66 \\
64 \\
69\end{array}$ & $\begin{array}{l}67 \\
60 \\
65 \\
62 \\
67\end{array}$ & $\begin{array}{l}65 \\
59 \\
63 \\
61 \\
65\end{array}$ \\
\hline 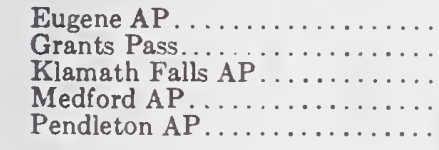 & $\begin{array}{l}44 \\
42 \\
42 \\
42 \\
45\end{array}$ & $\begin{array}{l}1 \\
3 \\
1 \\
2 \\
4\end{array}$ & $\begin{array}{r}364 \\
925 \\
4091 \\
1298 \\
1492\end{array}$ & $\begin{array}{r}16 \\
16 \\
-\quad 5 \\
-15 \\
-\quad 2\end{array}$ & $\begin{array}{r}22 \\
22 \\
1 \\
21 \\
3\end{array}$ & $\begin{array}{r}26 \\
26 \\
5 \\
23 \\
10\end{array}$ & $\begin{array}{l}\text { VL } \\
\text { VL } \\
\text { VL } \\
\text { VL } \\
\text { VL }\end{array}$ & $\begin{array}{l}91 \\
94 \\
89 \\
98 \\
97\end{array}$ & $\begin{array}{l}88 \\
92 \\
87 \\
94 \\
94\end{array}$ & $\begin{array}{l}84 \\
89 \\
84 \\
91 \\
91\end{array}$ & $\begin{array}{l}31 \\
33 \\
36 \\
35 \\
29\end{array}$ & $\begin{array}{l}69 \\
68 \\
63 \\
70 \\
66\end{array}$ & $\begin{array}{l}67 \\
66 \\
62 \\
68 \\
65\end{array}$ & $\begin{array}{l}65 \\
65 \\
61 \\
66 \\
63\end{array}$ \\
\hline 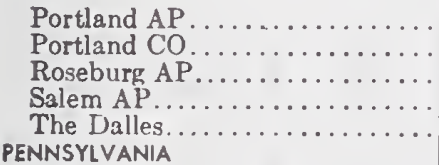 & $\begin{array}{l}45 \\
45 \\
43 \\
45 \\
45\end{array}$ & $\begin{array}{l}4 \\
3 \\
1 \\
0 \\
4\end{array}$ & $\begin{array}{r}21 \\
57 \\
505 \\
195 \\
102\end{array}$ & $\begin{array}{r}17 \\
21 \\
19 \\
15 \\
7\end{array}$ & $\begin{array}{l}21 \\
26 \\
25 \\
21 \\
13\end{array}$ & $\begin{array}{l}24 \\
29 \\
29 \\
25 \\
17\end{array}$ & $\begin{array}{l}\mathrm{L} \\
\mathrm{L} \\
\mathrm{VL} \\
\mathrm{VL} \\
\mathrm{VL}\end{array}$ & $\begin{array}{l}89 \\
91 \\
93 \\
92 \\
93\end{array}$ & $\begin{array}{l}85 \\
88 \\
91 \\
88 \\
91\end{array}$ & $\begin{array}{l}81 \\
84 \\
88 \\
84 \\
88\end{array}$ & $\begin{array}{l}23 \\
21 \\
30 \\
31 \\
28\end{array}$ & $\begin{array}{l}69 \\
69 \\
69 \\
69 \\
70\end{array}$ & $\begin{array}{l}67 \\
6 S \\
67 \\
67 \\
68\end{array}$ & $\begin{array}{l}66 \\
67 \\
65 \\
66 \\
67\end{array}$ \\
\hline 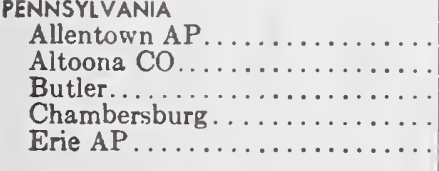 & $\begin{array}{l}40 \\
40 \\
40 \\
40 \\
42\end{array}$ & $\begin{array}{l}4 \\
2 \\
4 \\
0 \\
1\end{array}$ & $\begin{array}{r}376 \\
1468 \\
1100 \\
640 \\
732\end{array}$ & $\begin{array}{r}-2 \\
-4 \\
-\quad 8 \\
0 \\
1\end{array}$ & $\begin{array}{r}3 \\
1 \\
-2 \\
5 \\
7\end{array}$ & \begin{tabular}{r|}
5 \\
5 \\
2 \\
9 \\
11
\end{tabular} & $\begin{array}{l}\mathrm{M} \\
\mathrm{L} \\
\mathrm{L} \\
\mathrm{L} \\
\mathrm{M}\end{array}$ & $\begin{array}{l}92 \\
89 \\
91 \\
94 \\
\text { S8 }\end{array}$ & $\begin{array}{l}90 \\
87 \\
89 \\
92 \\
85\end{array}$ & $\begin{array}{l}87 \\
84 \\
86 \\
89 \\
82\end{array}$ & $\begin{array}{l}22 \\
23 \\
22 \\
23 \\
18\end{array}$ & $\begin{array}{l}77 \\
74 \\
75 \\
76 \\
76\end{array}$ & $\begin{array}{l}75 \\
73 \\
74 \\
75 \\
74\end{array}$ & $\begin{array}{l}74 \\
72 \\
73 \\
74 \\
73\end{array}$ \\
\hline 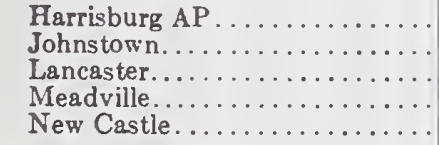 & $\begin{array}{l}40 \\
40 \\
40 \\
41 \\
41\end{array}$ & $\begin{array}{l}1 \\
2 \\
1 \\
4 \\
0\end{array}$ & $\begin{array}{r}335 \\
1214 \\
255 \\
1065 \\
825\end{array}$ & $\begin{array}{r}4 \\
-4 \\
-3 \\
-6 \\
-7\end{array}$ & $\begin{array}{r}9 \\
1 \\
2 \\
-\quad 1\end{array}$ & $\begin{array}{r}13 \\
5 \\
6 \\
4 \\
4\end{array}$ & $\begin{array}{l}\mathrm{L} \\
\mathrm{L} \\
\mathrm{L} \\
\mathrm{M} \\
\mathrm{MI}\end{array}$ & $\begin{array}{l}92 \\
91 \\
92 \\
88 \\
91\end{array}$ & $\begin{array}{l}89 \\
87 \\
90 \\
86 \\
89\end{array}$ & $\begin{array}{l}86 \\
85 \\
87 \\
83 \\
86\end{array}$ & $\begin{array}{l}21 \\
23 \\
22 \\
21 \\
23\end{array}$ & $\begin{array}{l}76 \\
74 \\
77 \\
75 \\
75\end{array}$ & $\begin{array}{l}75 \\
73 \\
76 \\
73 \\
74\end{array}$ & $\begin{array}{l}74 \\
72 \\
75 \\
72 \\
73\end{array}$ \\
\hline
\end{tabular}


Climatic Conditions for United States and Canada (Continued)*,a

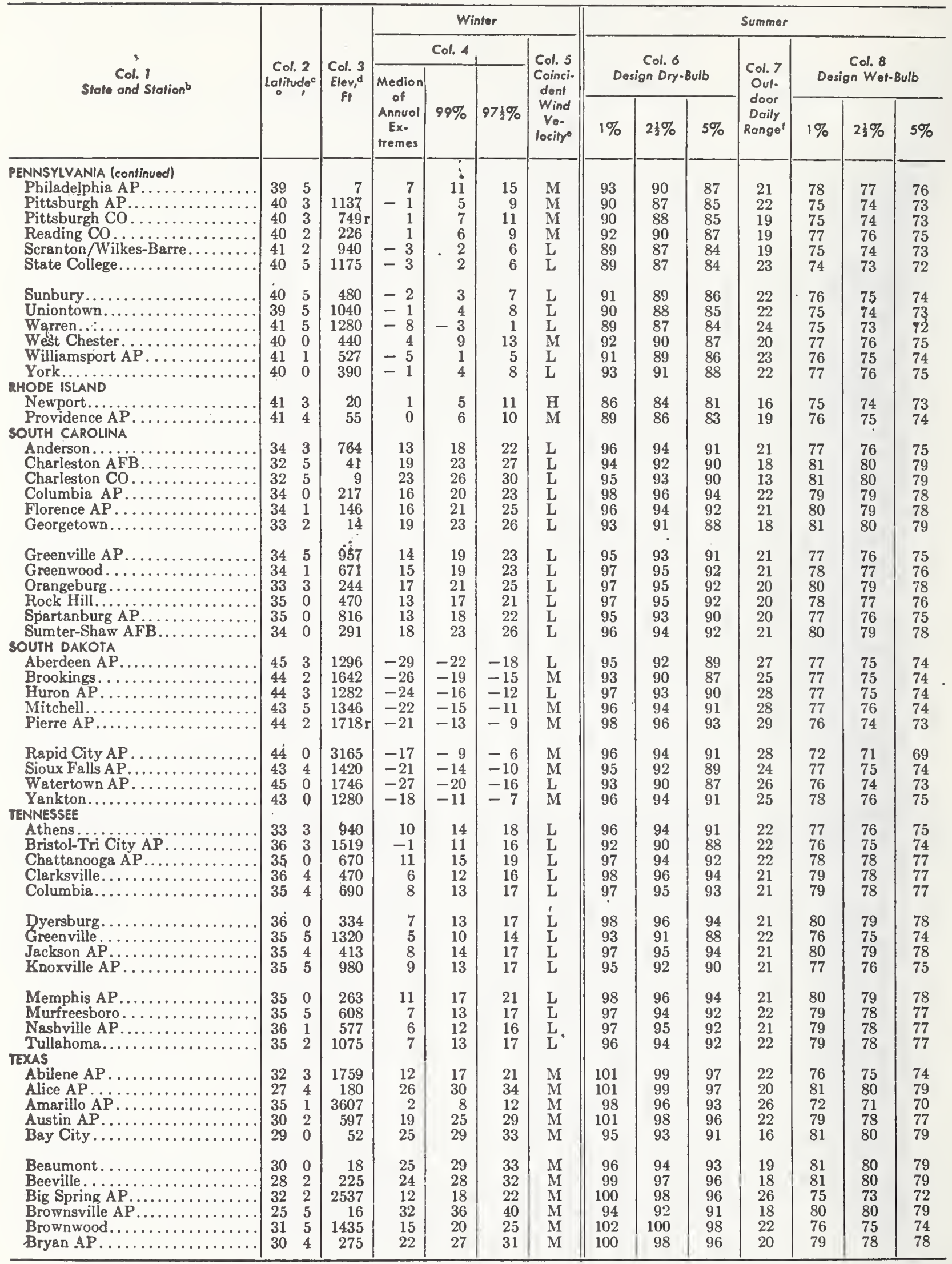


Climatic Conditions for United States and Canoda (Continued)*.a

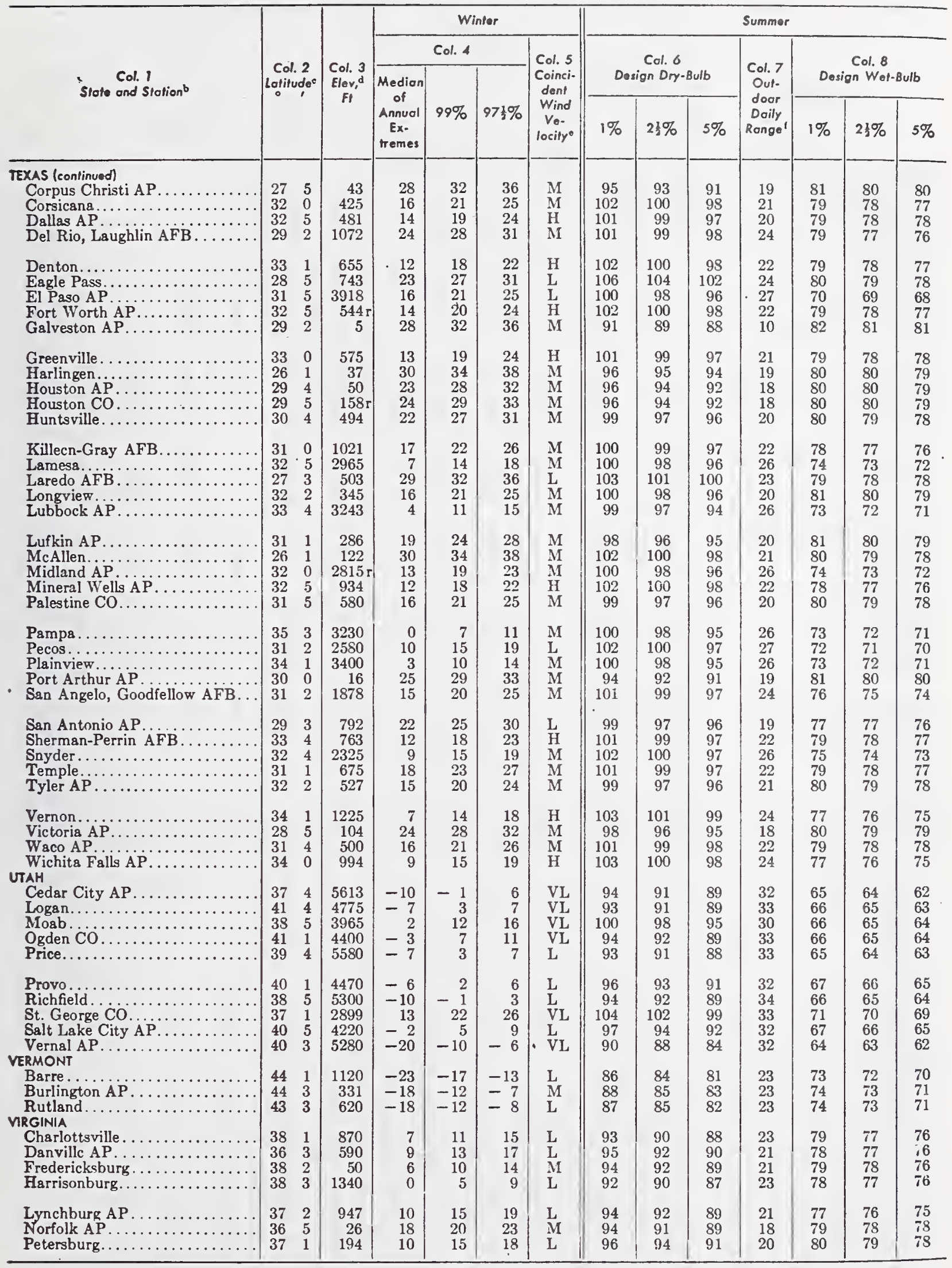


Climatic Conditions for United States and Canada (Continued) ${ }^{\text {*. }}$

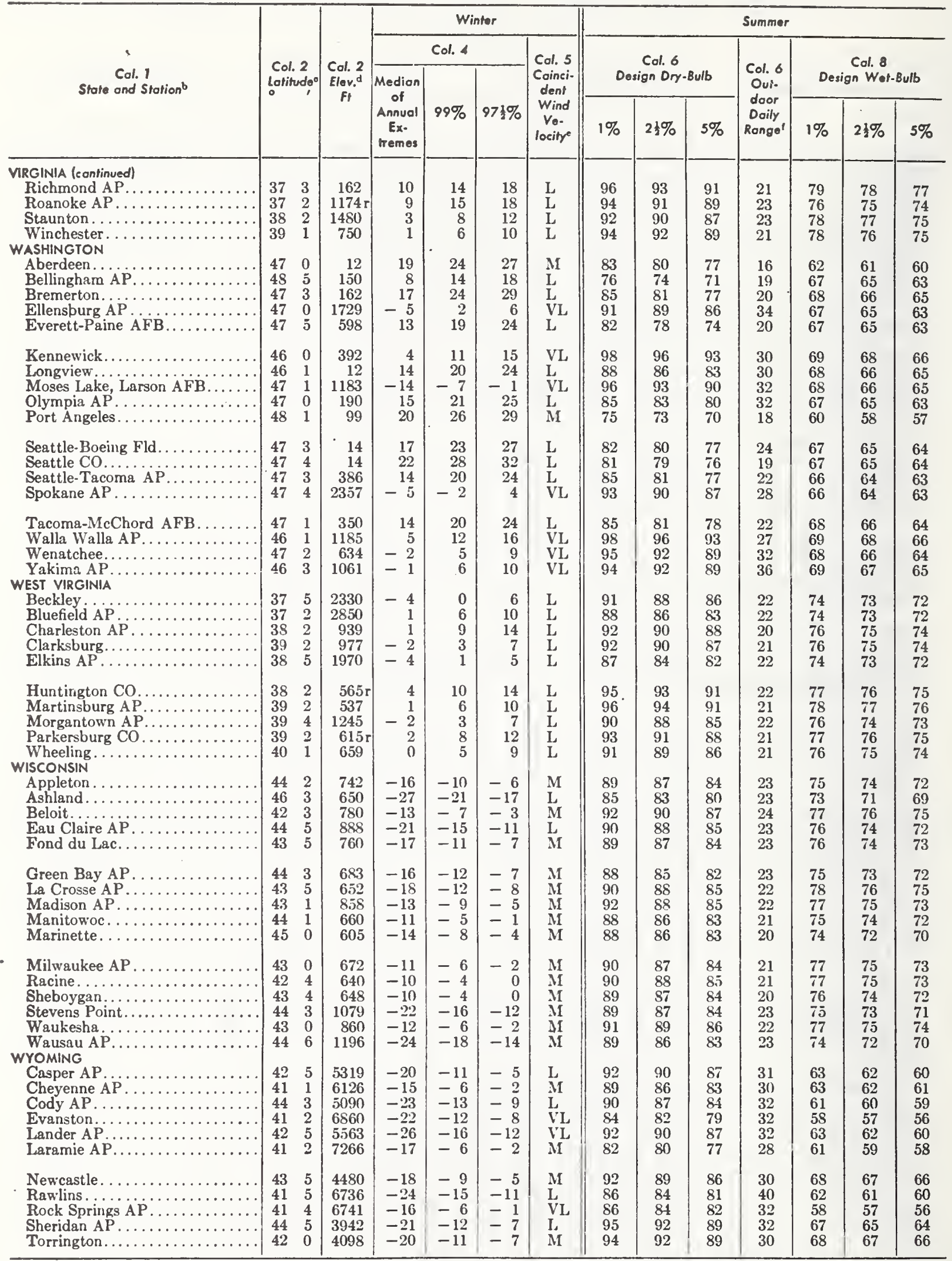


CANADA

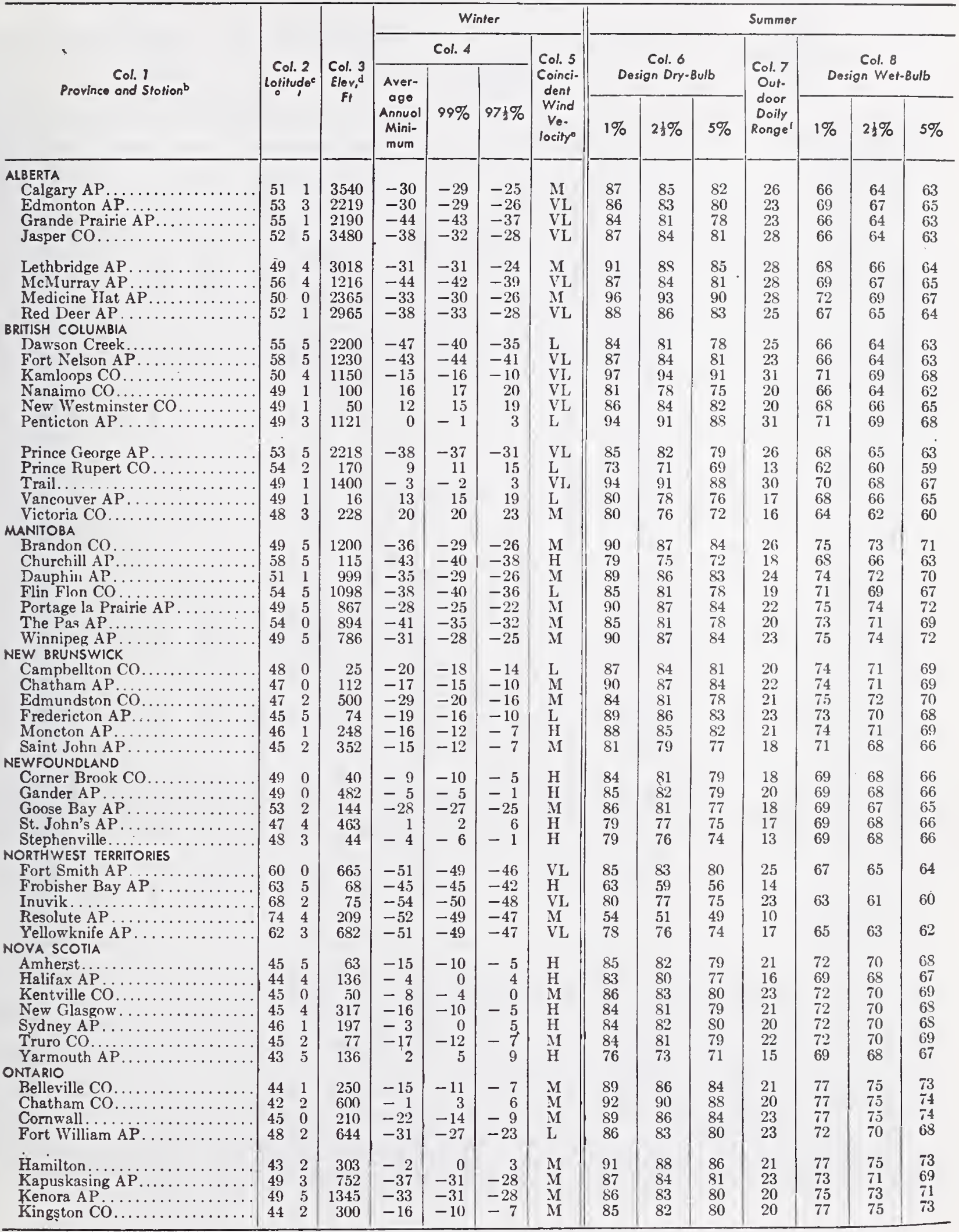


Climatic Conditions for United States and Canada (Coneluded)*,

\begin{tabular}{|c|c|c|c|c|c|c|c|c|c|c|c|c|c|c|}
\hline \multirow{4}{*}{$\begin{array}{l}\text { Col. } 1 \text { Province and Stotion } \\
\text { b }\end{array}$} & \multirow{4}{*}{\multicolumn{2}{|c|}{$\begin{array}{c}\text { Col. } 2 \\
\text { Lotifude } \\
\text { c }\end{array}$}} & \multirow{4}{*}{$\begin{array}{l}\text { Col. } 3 \\
\text { Elev, }^{\text {d }} \\
\text { Fi }\end{array}$} & \multicolumn{4}{|c|}{ Winter } & \multicolumn{7}{|c|}{ Summer } \\
\hline & & & & \multicolumn{3}{|c|}{ Col. 4} & \multirow{3}{*}{$\begin{array}{l}\text { Col. } 5 \\
\text { Coinei- } \\
\text { dent } \\
\text { Wind } \\
\text { Ve- } \\
\text { locity }\end{array}$} & \multirow{2}{*}{\multicolumn{3}{|c|}{$\begin{array}{c}\text { Col. } 6 \\
\text { Design Dry-Bulb }\end{array}$}} & \multirow{3}{*}{$\begin{array}{c}\text { Col. } 7 \\
\text { Out- } \\
\text { door } \\
\text { Daily } \\
\text { Range' }\end{array}$} & \multirow{2}{*}{\multicolumn{3}{|c|}{$\begin{array}{c}\text { Col. } 8 \\
\text { Design Wof-Bulb }\end{array}$}} \\
\hline & & & & \multirow{2}{*}{$\begin{array}{c}\text { Aver- } \\
\text { oge } \\
\text { Annuol } \\
\text { Mini- } \\
\text { mum }\end{array}$} & \multirow[b]{2}{*}{$99 \%$} & \multirow[b]{2}{*}{$97 \frac{1}{3} \%$} & & & & & & & & \\
\hline & & & & & & & & $1 \%$ & $2 \frac{1}{3} \%$ & $5 \%$ & & $1 \%$ & $2 \frac{1}{2} \%$ & $5 \%$ \\
\hline ONTARIO (continued) & & & & & & & & & & & & & & \\
\hline Kitchene & 43 & & 1125 & -11 & -3 & 1 & $\mathrm{M}$ & 88 & 85 & 83 & 24 & 76 & 75 & 74 \\
\hline London AP & & 0 & 912 & -9 & -1 & 3 & M & 90 & 88 & 86 & 22 & 76 & 75 & 74 \\
\hline North Bay AP & & 2 & 1210 & -27 & -21 & -17 & M & 87 & 84 & 82 & 18 & 71 & 70 & 69 \\
\hline 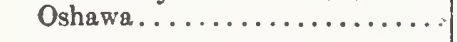 & & & 370 & -11 & -5 & -2 & M & 90 & 87 & 85 & 21 & 77 & 75 & 73 \\
\hline Ottawa AP & 45 & 2 & 339 & -21 & -17 & -13 & $\mathbf{M}$ & 90 & 87 & 84 & 21 & 75 & 74 & 73 \\
\hline Qwen & 44 & 3 & 597 & -9 & -5 & -1 & M & 87 & 84 & 82 & 21 & 74 & 72 & 71 \\
\hline Peterborough CO & 44 & 2 & 648 & -20 & -13 & -9 & M & 90 & 87 & 85 & 22 & 76 & 74 & 73 \\
\hline St. Catharines CO & 43 & 1 & 325 & 1 & 2 & 5 & $\mathrm{M}$ & 91 & 8 & 8 & 20 & 77 & 75 & 73 \\
\hline Sarnia... & 43 & 0 & 625 & -6 & 2 & 6 & $\mathbf{M}$ & 92 & 90 & 88 & 19 & 76 & 74 & 73 \\
\hline Sault Ste. Marie CO. & 46 & 3 & 675 & -21 & -20 & -15 & M & 88 & 85 & 83 & 22 & 72 & 70 & 68 \\
\hline Sudbury & 46 & 3 & 850 & -25 & -20 & -15 & VL & 89 & 8 & 84 & 2 & 72 & 70 & 69 \\
\hline Timmins $\mathrm{C}$ & 48 & 3 & 1100 & -37 & -33 & -28 & M & 90 & 8 & 84 & 2 & 73 & 71 & 69 \\
\hline Toronto AP. & 43 & 4 & 578 & -10 & -3 & 1 & M & 90 & 8 & 8 & 2 & 77 & 75 & 73 \\
\hline Windsor AP....... & 42 & 2 & 637 & -1 & 4 & 7 & M & 92 & 90 & 8 & 20 & 77 & 75 & 74 \\
\hline PRINCE EDWARD ISLAND & & & & & & & & & & & & & & \\
\hline Charlottet & 46 & 2 & 186 & -11 & -6 & -3 & $\mathbf{H}$ & 84 & 81 & 79 & 16 & 72 & 70 & 68 \\
\hline Summerside AP......... & 46 & 3 & 78 & -10 & -8 & -3 & $\mathrm{H}$ & 84 & 81 & 79 & 16 & 72 & 70 & 68 \\
\hline $\begin{array}{l}\text { QUEE } \\
\mathrm{BB}\end{array}$ & 48 & 2 & 536 & -35 & -26 & $-2 ?$ & VI & 88 & 84 & 81 & 20 & 72 & 71 & 60 \\
\hline$\ddot{\mathrm{CO}}$ & 48 & 3 & 150 & -31 & $\begin{array}{l}-20 \\
-24\end{array}$ & -20 & $V L$ & $\begin{array}{l}80 \\
87\end{array}$ & 8 & $\begin{array}{l}01 \\
80\end{array}$ & 20 & 72 & 71 & $\begin{array}{l}0 Y \\
69\end{array}$ \\
\hline Drummondville CO. & 45 & 5 & 270 & -26 & -18 & -13 & M & 88 & 8 & 82 & 2 & 76 & 74 & 72 \\
\hline Granby... & 45 & 2 & 550 & -23 & -17 & -12 & $\mathrm{~L}$ & 87 & 8 & 82 & 2 & 76 & 74 & 72 \\
\hline Hull. & 45 & 3 & 200 & -21 & -17 & -13 & M & 90 & 8 & 84 & 2 & 75 & 74 & 73 \\
\hline Mćgantic AP... & 45 & 4 & 1362 & -27 & -20 & -16 & M & 84 & 81 & 78 & 19 & 75 & 73 & 71 \\
\hline Mo & 45 & 3 & 98 & -20 & -16 & -10 & M & 88 & 8 & 8 & 1 & 76 & 74 & 73 \\
\hline Qué & 46 & 5 & 245 & -25 & -19 & -13 & M & 86 & 8 & 7 & 2 & 75 & 73 & 71 \\
\hline$\ldots$ & 48 & 3 & 117 & -18 & -16 & -12 & $\mathrm{H}$ & 78 & 7 & 7 & 1 & 71 & 69 & 68 \\
\hline St. J & 45 & 2 & 129 & -21 & -15 & -10 & $\mathbf{M}$ & 87 & 8 & 8 & 2 & 76 & 74 & 73 \\
\hline St & 45 & 5 & 310 & -30 & -18 & -1 & $\mathrm{~L}$ & 8 & 8 & 8 & 2 & 76 & 74 & 73 \\
\hline Sept Iles AP. & 50 & 1 & 190 & -29 & -27 & -22 & $\overline{\mathrm{L}}$ & 80 & 78 & 75 & 17 & 66 & 64 & 63 \\
\hline Shr & 46 & 3 & 306 & -27 & -20 & -15 & L & 88 & 8 & 8 & 2 & 76 & 74 & 72 \\
\hline Sher & 45 & 2 & 595 & -25 & -18 & -1 & $\mathrm{~L}$ & 87 & 8 & & 2 & & 73 & $7 \overline{1}$ \\
\hline ines. & 46 & 0 & 1020 & -25 & -19 & -14 & $\mathrm{M}$ & 86 & 8 & 8 & 2 & 7 & 73 & 71 \\
\hline Trois Rivières CO & 46 & 2 & 200 & -30 & -18 & -13 & M & 88 & 85 & 82 & 2 & 76 & 74 & 72 \\
\hline Val d'Or AP. & 48 & 0 & 1108 & -37 & -31 & -2 & L & 8 & 8 & 8 & 2 & 72 & 71 & 69 \\
\hline Valleyfield. & 45 & 2 & 150 & -20 & -14 & -9 & M & 87 & 85 & 83 & 21 & 76 & 74 & 73 \\
\hline SASKATCHEWAN & & & & & & & & & & & & & & \\
\hline Estevan A & 49 & 0 & 1884 & -32 & -30 & -25 & M & 93 & 89 & 86 & 25 & 75 & 73 & 71 \\
\hline $\mathbf{M}$ & 50 & 2 & 1857 & -33 & -32 & -27 & M & 93 & 8 & & 27 & & 71 & 69 \\
\hline eford AP. & 52 & 5 & 1796 & -33 & -33 & -29 & $\mathrm{~L}$ & 90 & 8 & 8 & 2 & 71 & 69 & 67 \\
\hline Prince Albert AP... & 53 & 1 & 1414 & -45 & -41 & -35 & VL & 88 & 84 & 81 & 25 & 72 & 70 & 68 \\
\hline Regina AP. & 50 & 3 & 1884 & -38 & -34 & -29 & M & 92 & 88 & 85 & 27 & 73 & 71 & 69 \\
\hline & 52 & 1 & 1645 & -37 & -34 & -30 & $\mathrm{M}$ & 90 & 8 & 8 & 2 & 71 & 69 & 67 \\
\hline Swift Cur & 50 & 2 & 2677 & -31 & -29 & -25 & M & 93 & 89 & 86 & 24 & 72 & 70 & 68 \\
\hline Yorkton AP. & 51 & 2 & 1653 & -38 & -33 & -28 & M & 89 & 85 & 82 & 23 & 74 & 72 & 70 \\
\hline RUKON TERRITORY & & & & & & & & & & & & & & \\
\hline Whitehorse AP & 60 & 4 & 2289 & -45 & -45 & -42 & VL & 78 & 75 & 72 & 22 & 62 & 60 & 59 \\
\hline
\end{tabular}

- Data for U.S. stations extracted from Evalualed Weather Dala for Cooling Equipment Desion, Addendum No. 1, Winter and Summer Dala, with the permission of the publiaber, Fluor Products Company, Inc., Box 1267, Santa Rosa, California.

Data compiled from official weather stations, where hourly weather observations are made by trained observers, and from other aources. Table 1 prepared by ASHRAE Technical Committee 2.2, Weather Data and Design Conditions. Percentage of uinter design data show the percent of 3-nonth period, Decenber through February. Canadian data are based on January only. Percentage of summer design data show the percent of 4-month period, June through September. Canadian

"When airport temperature observations were used to develop design data, "AP" follows station name, and "AFB" follows Air Force Bases. Data for stations followed by "CO" came from office locations uithin an urban area and kenerally reflect an influence of the surrounding area. Stations without deaignation can be considered semirural and may be directly compared with most airport data.

Latitude is piven to the nearest 10 minutes, for use in calculating solar loads. For example, the Iatitude for Anniston Alabama is given as 334 , or $33^{\circ} 40^{\prime}$

Flevations are ground elevations for each station as of 1964 . Temperature readings are generally made at an elevation of $5 \mathrm{ft}$ above around, except for locations marked $r$, indicating roof exposure of thermometer.

- Coincident wind velocities derived from approximately coldest 600 hours out of 20,000 hours of December through Februsry data per station. Also see Refer-

ences 5 and 6. The four classifications are:
$V L=$ Very Light, 70 percent or more of cold extreme hours $\leq 7 \mathrm{mph}$. M $=$ Moderate, 50 to 74 percent cold extreme hours $>7 \mathrm{mph}$.
$\mathrm{L}=$ Light, 50 to 69 percent cold extreme hours $\leq 7 \mathrm{mph}$. $\mathrm{L}=$ Light, 50 to 69 percent cold extreme hours $\leq 7 \mathrm{mph}$. $\quad H=1$ ligh, 75 percent or more cold extreme

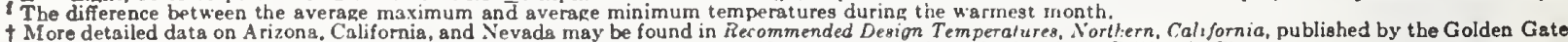
Chapter; and Recommended Design Temperalures, Southern Culifornia, Arizona, Nevada, published by the Southern Californis Chapter. 
Climatic Conditions for Other Foreign Countries

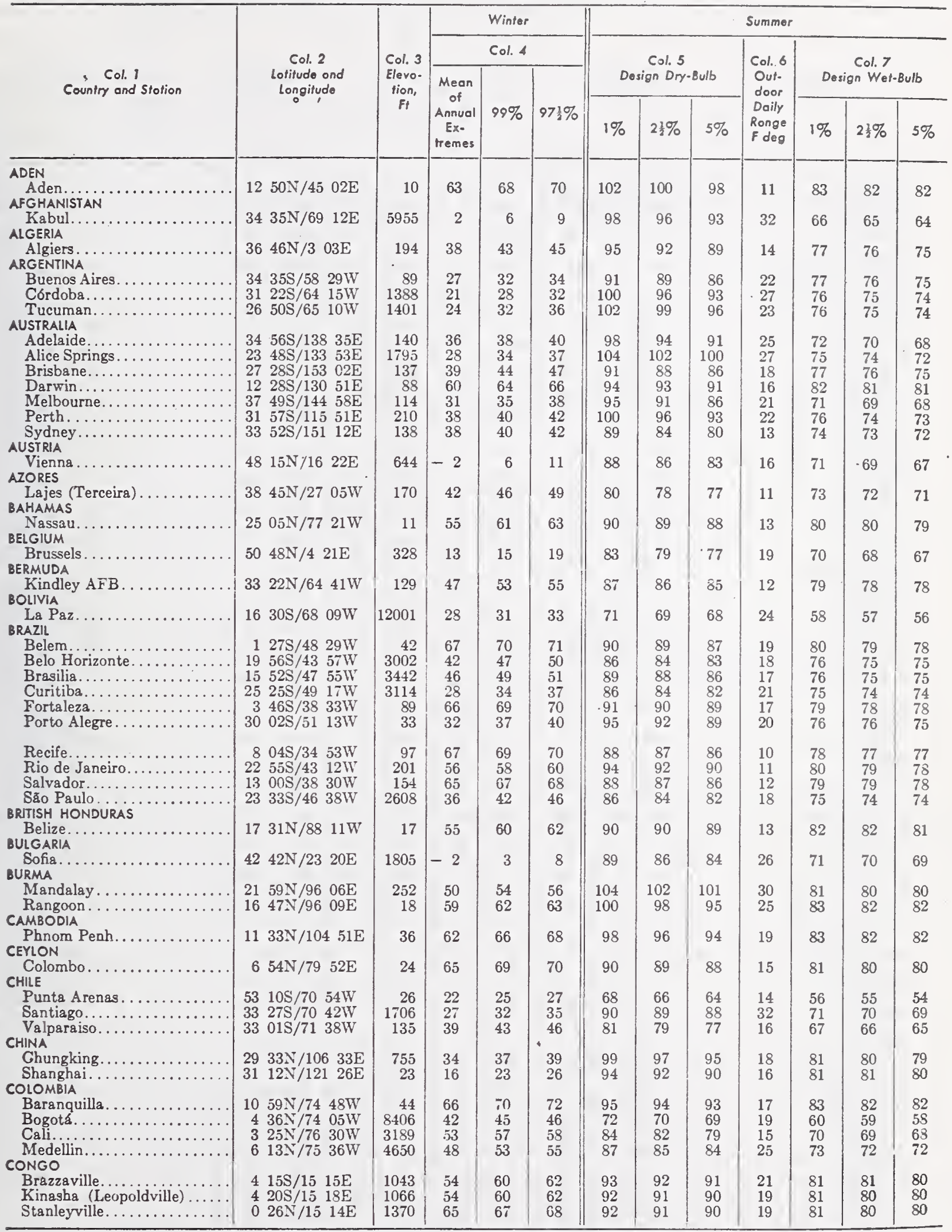


Climatic Conditions for Other Foreign Countries (Continued)

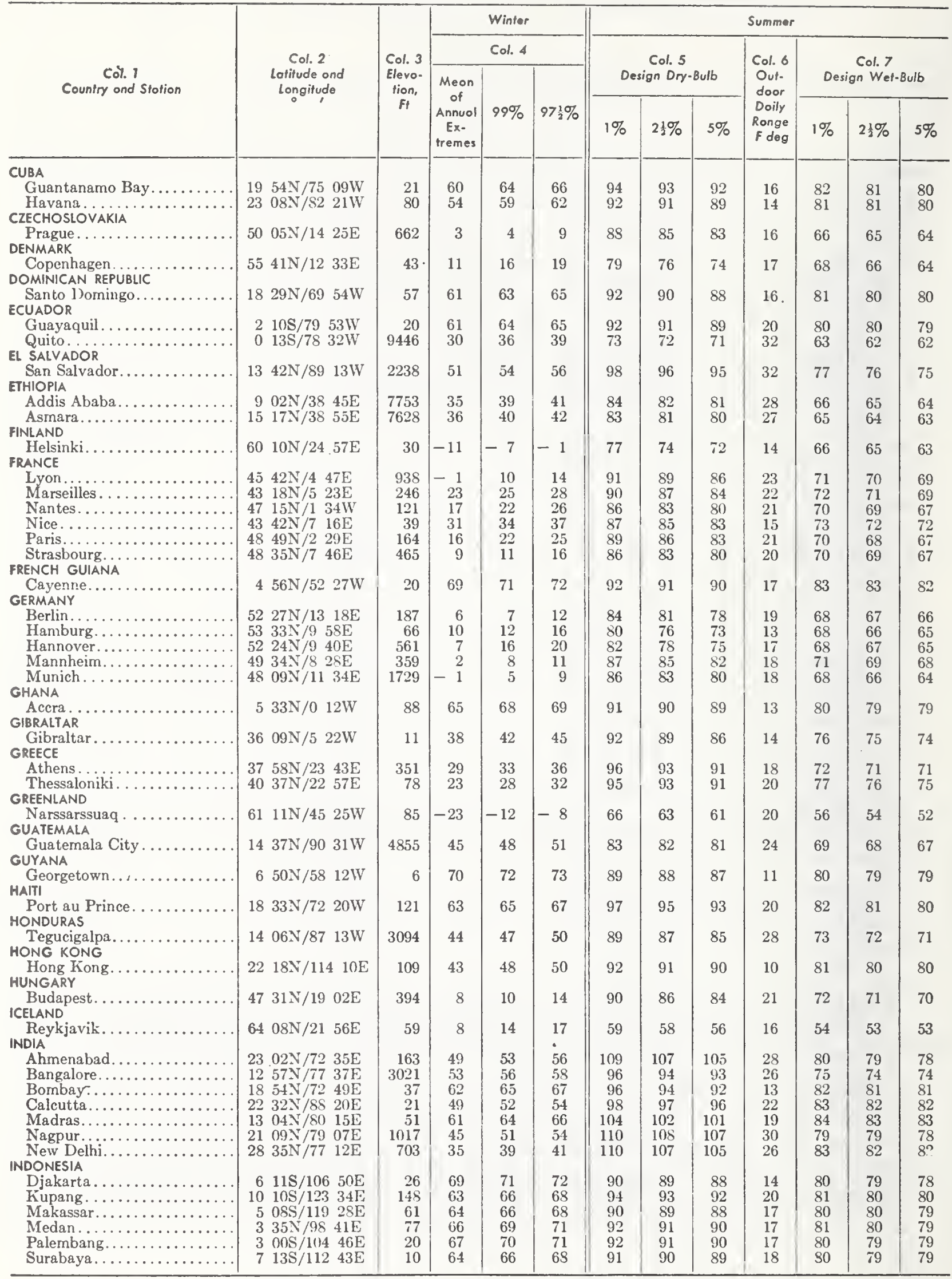


Climatic Conditions for Other Foreign Countries (Continued)

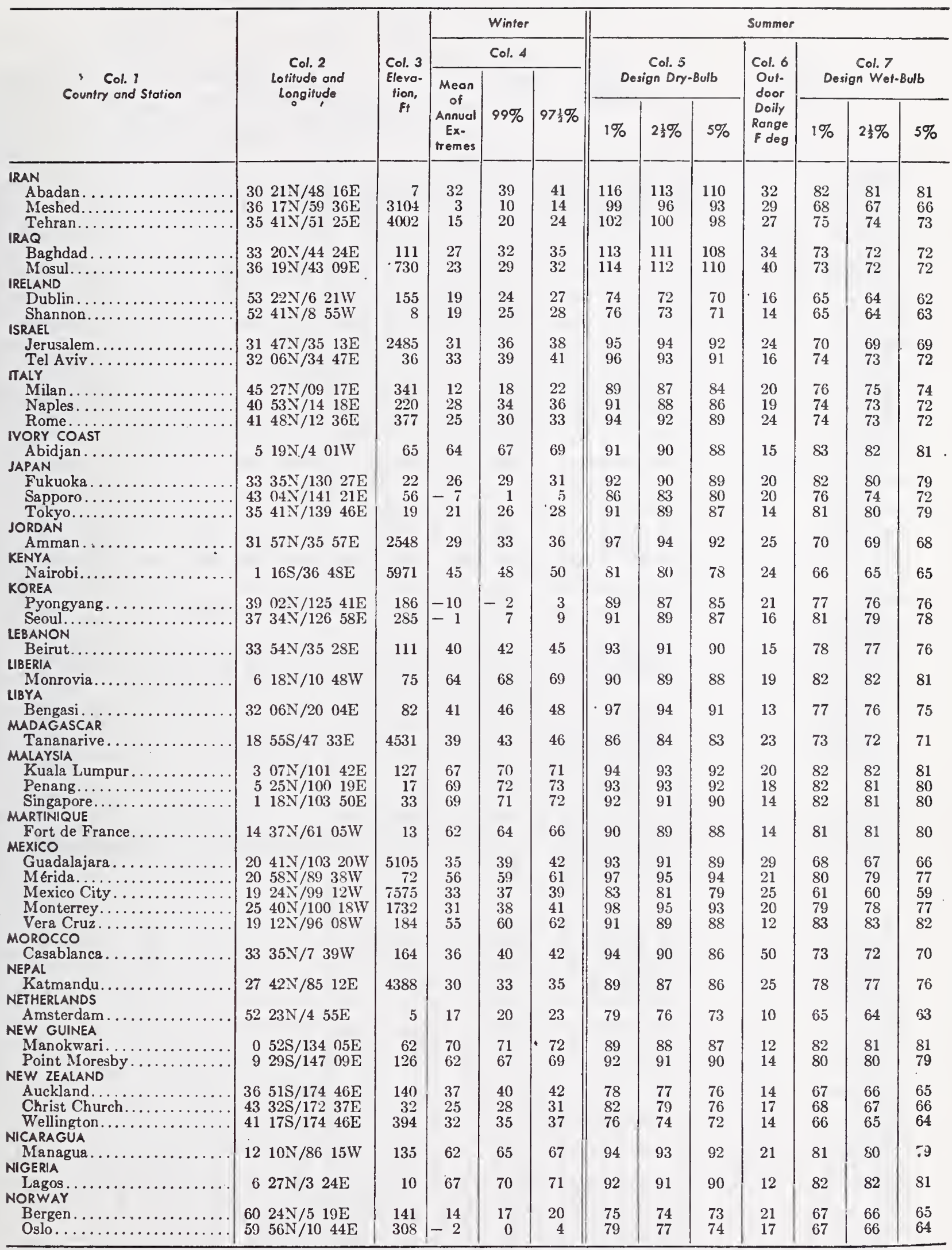


Climatic Conditions for Other Foreign Countries (Continued)

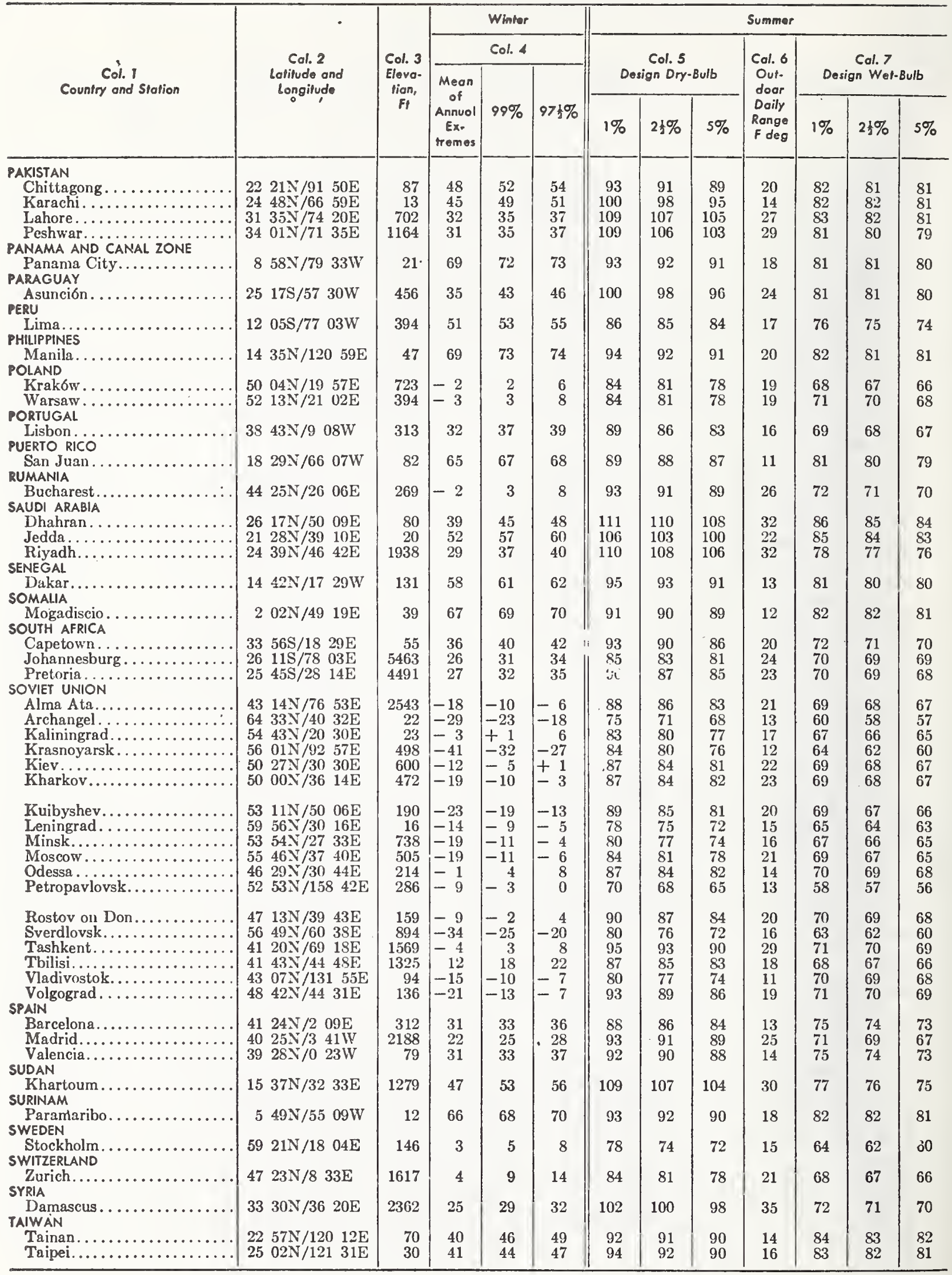




\author{
Table C2 \\ Earth Temperature Tables \\ for \\ Underground Heat Distribution System Design
}

The following Tables TG-1 through TG-11 were developed by applying monthly average temperatures prepared by the U. S. Weather Bureau for many localities in the United States to a technique described in the 1965 ASHRAE technical paper entitled "Earth Temperature and Thermal Diffusivity at Selected Stations in the United States" by T. Kusuda and P. R. Achenbach. These temperature data are, however, for the undisturbed earth. The earth temperature immediately under the building may be estimated by taking an arithmetic average of the building temperature and the design earth temperature found in the appropriate table. For example, the floor on grade in the Washington, D. C. area may be treated as a slab of $12^{\prime \prime}$ thickness with ground temperature of $70.5^{\circ} \mathrm{F}$ if the room temperature is $75^{\circ} \mathrm{F}$ and the summer design TG is determined from the data of Upper Marlboro, Maryland for ALPHA $=0.025$ which is $66^{\circ} \mathrm{F}$. 

AVERAGE EARTH TEMPERATURE IN DEG. F.

TG

THERMAL DIFFUSIVITY IN FT**2/HR

ALPHA $=.010$

STATION STATES
AUDURN, ALABAMA
DECATUK, ALABANIA
PALMER AAES, ALASKA
TEMPE, ARIZONA

WINTER

SPRING

SUMMER

FALL

YFAR

60. 61.

52 .

54 .

71 .

ก́5.

70 .

65.

42.

31.

31.

TUCSON. ARIZONA

64.

68.

69.

BKAWLEY, CALIFORINIA

$70 . \quad 73$.

DAVIS, CALIFORMIA

FT. COLLIIUS, COLO.

STORRS, CONN.

GAINESVILLE, FLA.

ATHENS, GEORGIA

MUSCOW, IUAHO

LEMONT, ILLINOIS

URBANA, ILLINOIS

WEST LAFAYETTE, IND

AMES, IOWA

44.45.

46.45.

65. 70 .

59. 61.

43. 42 .

46.45.

46.47.

47.47.

44.45 .

BUKLINGTON, IOWA

CASTANA, IOWA

CUUNCIL BLUFFS,IONA

SARATOGA, IOWA

SPENCER, IOWA

GARDEN CITY, KAISSAS

MUMIVHATTAN, KAINSAS

MOUND VALLEY.KANSAS

LEXINGTON, KENTUCKY

UPPER MARLBORO, MD.

EAST LAIJSING, MICH.

FAIRMONT, MININESOTA

FARIBAULT, MINNESOTA

ST. PAUL. MINNESOTA

WASECA. MINNESOTA

STATE UNIV.. MISS.

FAUCETT, MISSOURI

KAIVSAS CITY, MO.

SIKESTON, MISSOURI

SPICKARD, MISSOURI

BULEMAN, WONTANA

HUNTLEY, MONTANA

LINCOLN. INEBRASKA

NE.H BRUNSWICK, N.J.

ITHACA, NEW YORK

COLUMBUS, OHIO

COSHOCTON. OHIO

WUOSTER, UHIO

BARINSDALL, OKLAHOMA

LAKE HEFNER, OKLA.

PAVITUSKA, OKLAHOMA

OTIAWA, O.JTARIO

CURVALLIS, OREGOIN

47.

42.

47.

41.

42.

48.

48.

52.

51.

48.

45.

42.

40 .

42.

41.

50.

47.

48 .

52 .

50.

39.

44.

45 .

48.

44.

47.

46.

46.

56.

49.

42.

47.

40 .

42.

$5 \%$.

73.

77.

83.

72 .

58 .

58 .

77.

72 .

52.

59.

61.

62.

б.

66.

61.

62.

59.

58.

66.

64.

68.

65.

63.

57.

58.

55.

57.

59.

73.

61.

62.

67.

41.

74.

79.

84.

72.

56.

58.

77.

72 .

52.

59.

60.

61.

60.

65.

59.

62.

57.

57.

66.

64.

68.

64.

63.

57.

57.

53.

56.

54.

73.

61.

61.

67.

62.

60.

49.

37.

44.

45.

48.

43.

47.

46.

46.

56.

57.

54.

57.

42.

55.

50 .

39.

HUUUD RIVER, OREGOIN

46 .

51.

50 .

58 .

48 .

57.

60.

60.

60.

54.

54.

60.

58 .

58 .

69.

71.

68.

52 .

60.

57.

65.

59.

36.

68.

73.

77.

67.

51.

52.

73.

66.

47.

52.

53.

54.

52.

56.

51.

55.

49.

50 .

58.

56.

6ก.

58.

56.

50 .

50 .

47.

49.

50 .

67.

54.

55.

60 .

55.

43.

50 .

53.

54.

58.

68.

70 .

68.

54.

57.

49.

53.

52.

52.

63.

64.

61.

47.

55.

52. 
AVERAGE EAKTH TEMPERATURE IN DET. F. TG

THERMAL DIFFUSIVITY IN FT**2/HR ALPHA $=.010$

\begin{tabular}{|c|c|c|c|c|c|}
\hline STATION & WINTER & SPRING & SUMMER & FALL & YEAR \\
\hline MEUFORL, UREGON & 51. & 52. & 61. & 61. & 56. \\
\hline EIVELETON, OREGON & 46. & 49. & 61. & 60. & 54. \\
\hline TATE COLLEGE, PA. & 46. & 45. & 59. & 58. & 52. \\
\hline INGSTON, R. I. & 45. & 43. & 55. & 56. & 50. \\
\hline ALHOUN, S.CAROL INA & 56. & 58. & 70. & 69. & 63. \\
\hline AUISON. S. DAKOTA & 40 & 40. & 54. & 54. & 47. \\
\hline ACKSONO TENNESSFE & 53. & 55. & 66. & 64. & 59. \\
\hline EMPLE, TEXAS & 64. & 65. & 77. & 77 . & 71. \\
\hline ALT LAKE CITYOUYAI: & 44 & 45. & 56. & 55. & 50. \\
\hline KLINGTOV. VER VIII,VT & 42. & 40. & 54 . & 53. & 48. \\
\hline JLMAN, .ASHIFGTUis & 43. & 46. & 55. & 52 & 50 \\
\hline TTLE, wASHINGTÚ, & 48. & 50. & 56. & 56. & 53 \\
\hline TON, WYONING & 43. & 43. & 53. & 53. & \\
\hline
\end{tabular}


AVERAGE EARTH TEMPERATURE IN DEG. F, TG

THERMAL DIFFUSIVITY IN FT**2/HR

ALPHA $=.025$

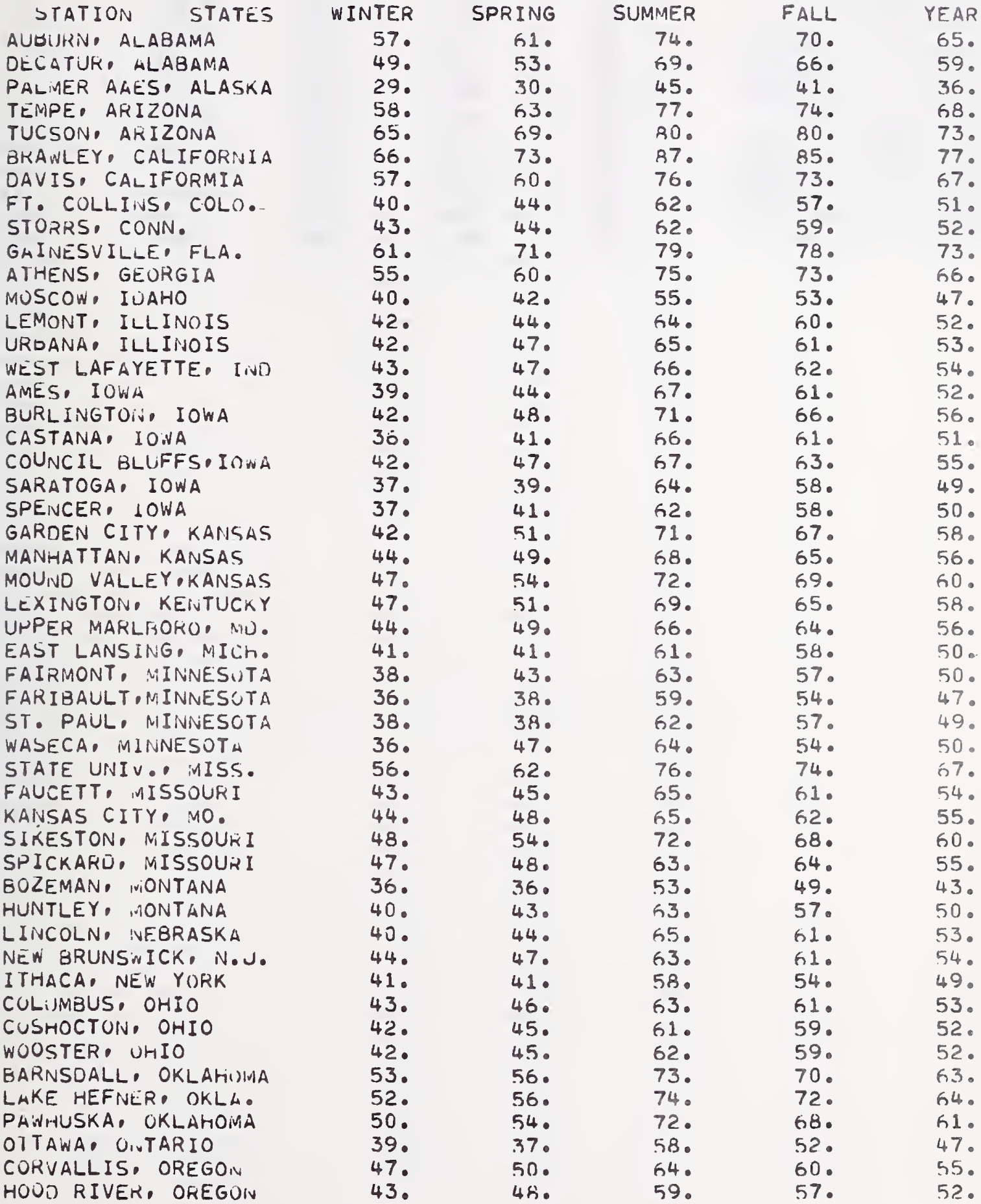




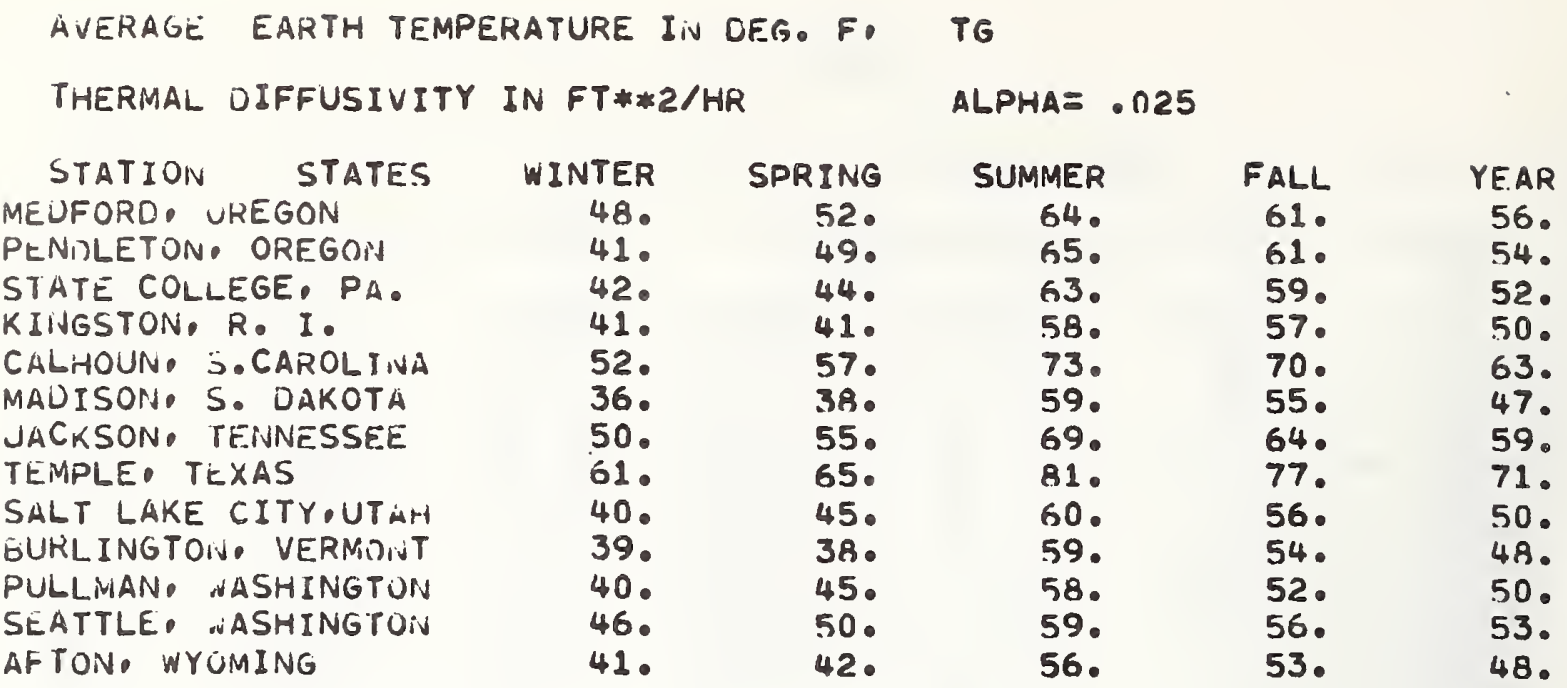


AVERAGE EARTH TFMPERATURE IN DEG. F. THERMAL DIFFUSIVITY IN FT**2/HR

STATION STATES

AUUIJRN, ALABAMA

DECATUR, ALABAMA

PALMER ALES. ALASKA

TEMPE, ARIZONA

TUCSON AKIZONA

BRANLEY, CALIFORNIA

DAVIS. CALIFORMIA

FT. COLLIIUS, COLO.

STORRS, CUIN.

GAINESVILLE, FLA.

ATMENS, GEORGIA

MOSCOW, IIJAHO

LEMIONT, ILLINOIS

UROANA, ILLINJOIS

WEST LAFAYETTE, IIVI)

AMES, IOW in

BURLINGTON. IOVIA

CASTANA, IOWA

COUIVCIL HLUFFS, I.JWA

SARATOGA, ICWA

SPLINCER, 1 OWA

GARTEN CITY, KANGAS MAIVHATTAIV, KAIVSAS

MUUi.J, VALLEY,KANSAS

LLAINGTON, KENTUCKY

UHPER MARLFORO MU.

EAST LAINSING, PICH.

FAIRMONT, MINNESOTA

FARI GAULT, MININESOTA

ST. PAUL, MINIVESOTA

WASECA, MINNESOTA

STATE UNIV.. MISS.

FAUCETT, WISSOURI

KAIVSAS CITY, MO.

SIKESTOIA WISSOURI

SPICKAKD, MISSUURI

GULFMAN, MONTANA

HUIVTLEY, "ONTANA

LINCOLN, AEBRASKA

NE" BRUNSWICK, N.U.

ITHACA, NEE YORK

CULINMBUS, OHIO

CUSHOCTON. OHIO

WUOSTER, UHIO

ESAR ISDALL, OKLAMIIIAA

LAKF HEFNER, OKLA.

PAWHUSKA. UKLAHOMA

OTTANAA, UIVTARIO

COKVALLIS, ORFGON

HUU, RIVER, OREGINV
WINTER SPRING

54. 61.

46.

27.

56.

62.

63.

55.

37.

40.

58.

52.

38 .

39.

39.

40.

35.

38 .

32 .

39.

33.

33.

38.

40 .

44.

44.

41.

39.

35.

34.

35.

31.

53.

41.

41.

45.

44.

34.

37.

36.

41.

39.

40.

40 .

40.

50.

49.

48.

37.

45.

41.
53.

30 .

64.

69.

73.

60 .

4.5 .

44.

72.

61.

42.

44.

47.

47.

44.

48.

42.

47.

39.

42.

52.

49.

55.

51.

49.

41.

43.

38.

38.

49.

62.

45.

48 .

54.

48.

35 .

43.

44.

47.

41.

47.

45.

45.

56.

57.

54.

37.

51.

49.
TG

ALPHA $=.050$

SUMMER

76.

71.

48.

79.

22 .

90 .

78.

65.

65.

Q1.

78.

57.

67.

68.

69.

70 .

74.

70 .

70 .

68.

66.

74.

72.

75.

72.

69.

n4.

67.

62.

65.

67.

78 .

68.

68.

75.

65.

57.

66.

68.

6.6.

61.

55.

64.

65.

75 .

77.

75.

61.

h7.

กิ1.
FALL

70 .

65.

41.

74.

81.

84.

73.

56.

59.

79.

73.

53.

60 .

60.

62.

61.

66.

61.

63.

58.

58.

67.

65.

6.9.

65.

64.

57.

57.

54.

57.

53.

74.

61.

61.

68.

64.

48.

57.

62.

62.

54.

61.

60.

59.

70.

73.

68.

51.

60.

57.

YEAR

65.

59.

36.

68.

73.

77.

67.

51.

52.

73.

66.

47.

52.

53.

54.

52.

56.

51.

55.

49.

50.

58.

56.

60.

58.

56.

50 .

50. 
AVERAGE EARTH TEMPERATURE IIN DEG. Fo

THERMAL DIFFUSIVITY IN FT**2/HR

$$
\text { SIATION STATES }
$$

MEUFORD, UREGON

PL.VIILETONE OREGO.V

STATE COLLEGE, PA.

KLIVISSTON. R. 1.

CALIOUN, S.CAROLINA

MADTSONN S. DAKOTA

JACKSON. TENINESSEE

TEMPLE, TEXAS

SALT LAKE CITY.UTAH

BURLINGTONO VERMOIVT

PULLMAN. WASHINGTON

SEATTLE, WASHINGTON

AFTONNO WYOMIING

$\begin{array}{rr}\text { WINTER } & \text { SPRING } \\ 46 . & 52 . \\ 38 . & 50 . \\ 40 . & 44 . \\ 39 . & 41 . \\ 49 . & 58 . \\ 33 . & 38 . \\ 48 . & 55 . \\ 58 . & 65 . \\ 37 . & 45 . \\ 37 . & 38 . \\ 37 . & 45 . \\ 44 . & 50 \\ 39 . & 42 .\end{array}$

TG

ALPHA $=.050$

SUMMER
66.
68.
66.
61.
76.
62.
72.
64.
62.
62.
60.
60.
59.

FALL

61.

60.

59.

57.

69.

55.

64.

77.

55.

54.

50 .

56.

53.

YEAR

56.

54.

52.

50.

63.

47.

59.

71.

50.

48.

50.

53.

48. 
Table C3

Thermophysical Properties of Wall/Roof/Floor

Reprinted by permission from 1972 Handbook of Fundamentals (American Society of Heating, Refrigerating and Air-Conditioning Engineers, 345 East 47th Street, New York), p. 431. 

Thermal Properties and Code Numbers of Layers Used in Calculations of Coefficients for Wall and Roof Transfer Functions

\begin{tabular}{|c|c|c|c|c|c|c|}
\hline \multirow{2}{*}{ Description } & \multirow{2}{*}{$\begin{array}{l}\text { Code } \\
\text { Number }\end{array}$} & \multicolumn{5}{|c|}{ Thickness and Thermal Properties } \\
\hline & & $l$ & K & $D$ & SH & $R$ \\
\hline Outside surface resistance & $\mathrm{AO}$ & & & & & 0.333 \\
\hline $\begin{array}{l}\text { 1' stucco (asbestos cement or wood siding } \\
\text { plaster, etc.) }\end{array}$ & A1 & 0.0833 & 0.4 & 116 & 0.20 & \\
\hline $4^{\prime}$ face brick (dense concrete) & A2 & 0.333 & 0.77 & 125 & 0.22 & \\
\hline $\begin{array}{l}\text { Steel siding (aluminum or other light-weight } \\
\text { cladding) }\end{array}$ & $\mathrm{A} 3$ & 0.005 & 26.0 & 480 & 0.10 & \\
\hline $\begin{array}{l}\text { Outside surface resistance, } \\
\text { fo slag, memhrane }^{\prime} \text { and if felt }\end{array}$ & A4 & $\begin{array}{l}0.0417 \\
0.0313\end{array}$ & $\begin{array}{l}0.83 \\
0.11\end{array}$ & $\begin{array}{l}55 \\
70\end{array}$ & $\begin{array}{l}0.40 \\
0.40\end{array}$ & 0.333 \\
\hline Outside surface resistance & A5 & & & & & 0.333 \\
\hline Finish & A6 & 0.0417 & 0.24 & 78 & 0.26 & \\
\hline 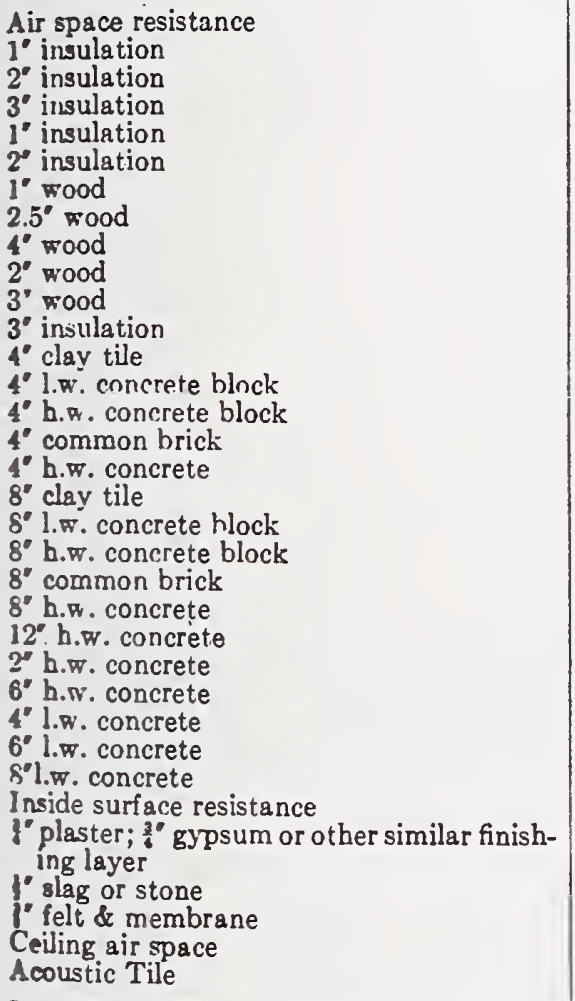 & $\begin{array}{l}\mathrm{B} 1 \\
\mathrm{~B} 2 \\
\mathrm{~B} 3 \\
\mathrm{~B} 4 \\
\mathrm{~B} 5 \\
\mathrm{~B} 6 \\
\mathrm{~B} 7 \\
\mathrm{~B} 8 \\
\mathrm{~B} 9 \\
\mathrm{~B} 10 \\
\mathrm{~B} 11 \\
\mathrm{~B} 12 \\
\mathrm{C} 1 \\
\mathrm{C} 2 \\
\mathrm{C} 3 \\
\mathrm{C} 4 \\
\mathrm{C} 5 \\
\mathrm{C} 6 \\
\mathrm{C} 7 \\
\mathrm{C} 8 \\
\mathrm{C} 9 \\
\mathrm{C} 10 \\
\mathrm{C} 11 \\
\mathrm{C} 12 \\
\mathrm{C} 13 \\
\mathrm{C} 14 \\
\mathrm{C} 15 \\
\mathrm{C} 16 \\
\mathrm{E} 0 \\
\mathrm{E} 1 \\
\mathrm{E} 2 \\
\mathrm{E} 3 \\
\mathrm{E} 4 \\
\mathrm{E} 5\end{array}$ & $\begin{array}{l}0.083 \\
0.167 \\
0.25 \\
0.0833 \\
0.167 \\
0.0833 \\
0.2083 \\
0.333 \\
0.167 \\
0.25 \\
0.25 \\
0.333 \\
0.333 \\
0.333 \\
0.333 \\
0.333 \\
0.667 \\
0.667 \\
0.667 \\
0.667 \\
0.667 \\
1.0 \\
0.167 \\
0.5 \\
0.333 \\
0.5 \\
0.667 \\
\\
0.0625 \\
0.0417 \\
0.0313 \\
0.0625\end{array}$ & $\begin{array}{l}0 \\
0.025 \\
0.025 \\
0.025 \\
0.025 \\
0.025 \\
0.07 \\
0.07 \\
0.07 \\
0\end{array}$ & $\begin{array}{r}2.0 \\
2.0 \\
2.0 \\
5.7 \\
5.7 \\
37.0 \\
37.0 \\
37.0 \\
37.0 \\
37.0 \\
5.7 \\
70.0 \\
38.0 \\
61.0 \\
120 \\
140 \\
70 \\
38.0 \\
61.0 \\
120 \\
140 \\
140 \\
140 \\
140 \\
40 \\
40 \\
40 \\
\\
100 \\
55 \\
70 \\
30 \\
\end{array}$ & $\begin{array}{l}0.2 \\
0.2 \\
0.2 \\
0.2 \\
0.2 \\
0.6 \\
0.6 \\
0.6 \\
0.6 \\
0.6 \\
0.2 \\
0.2 \\
0.2 \\
0.2 \\
0.2 \\
0.2 \\
0.2 \\
0.2 \\
0.2 \\
0.2 \\
0.2 \\
0.2 \\
0.2 \\
0.2 \\
0.2 \\
0.2 \\
0.2 \\
\\
0.2 \\
0.40 \\
0.40 \\
0.20\end{array}$ & 0.685 \\
\hline
\end{tabular}

\footnotetext{
- Unita: $L=$ feot. $K=\mathrm{Btu}$ per $(\mathrm{hr})(\mathrm{aq} \mathrm{ft})(\mathrm{F}$ deg). $D=\mathrm{lb}$ per cu ft. $S H=\mathrm{Btu}$ per $(\mathrm{lb})(\mathrm{F} \operatorname{deg}) . R=(\mathrm{hr})(\mathrm{gq} \mathrm{ft})(F \mathrm{deg})$ per Btu.
} 
Typical Watt/ft. ${ }^{2}$ of floor area data

\section{Lighting}

Apartment

Office

Department Stores

School
1.7

5.0

4.0

5.0
Equipment

1.2

1.0

0.0

0.0 


\section{Table C5}

\section{Shading Coefficients}

Reprinted by permission from the 1972 Handbook of Fundamentals (American Society of Heating, Refrigerating and Air-Conditioning Engineers, 345 East 47th Street, New York), pp. 402-408. 

Shading Coefficients for Single Glass and Insulating Glass ${ }^{\mathrm{a}}$

\begin{tabular}{|c|c|c|c|c|c|c|}
\hline \multicolumn{7}{|c|}{ A. Single Gloss } \\
\hline \multirow{2}{*}{ Type of Gloss } & \multirow{2}{*}{$\begin{array}{l}\text { Nominal } \\
\text { Thickness }\end{array}$} & \multirow{2}{*}{\multicolumn{2}{|c|}{ Solar Trans. $b$}} & \multicolumn{3}{|c|}{ Shoding Coefficien } \\
\hline & & & & \multicolumn{2}{|c|}{$h_{0}=4.0$} & $h_{0}=3.0$ \\
\hline $\begin{array}{l}\text { Regular Sheet } \\
\text { Regular Plate/ } \\
\text { Float }\end{array}$ & $\begin{array}{c}3^{\frac{2}{2}}, \frac{1}{8} \\
\frac{1}{1} \\
\frac{3}{2} \\
\frac{1}{2}\end{array}$ & \multicolumn{2}{|c|}{$\begin{array}{l}0.87 \\
0.80 \\
0.75 \\
0.71\end{array}$} & \multicolumn{2}{|l|}{$\begin{array}{l}1.00 \\
0.95 \\
0.91 \\
0.88\end{array}$} & $\begin{array}{l}1.00 \\
0.97 \\
0.93 \\
0.91\end{array}$ \\
\hline Grey Sheet & $\begin{array}{c}\frac{1}{8} \\
\frac{1}{16} \\
\frac{1}{32} \\
\frac{7}{32} \\
\frac{1}{2}\end{array}$ & \multicolumn{2}{|c|}{$\begin{array}{l}0.59 \\
0.74 \\
0.45 \\
0.71 \\
0.67\end{array}$} & $\begin{array}{l}0.78 \\
0.90 \\
0.66 \\
0.88 \\
0.86\end{array}$ & \multicolumn{2}{|c|}{$\begin{array}{l}0.80 \\
0.92 \\
0.70 \\
0.90 \\
0.88\end{array}$} \\
\hline $\begin{array}{l}\text { Heat-Absorbing } \\
\text { Plate/Floatd }\end{array}$ & $\frac{3}{16}$ & \multicolumn{2}{|c|}{$\begin{array}{l}0.52 \\
0.47 \\
0.33 \\
0.24\end{array}$} & $\begin{array}{l}0.72 \\
0.70 \\
0.56 \\
0.50\end{array}$ & \multicolumn{2}{|c|}{$\begin{array}{l}0.75 \\
0.74 \\
0.61 \\
0.57\end{array}$} \\
\hline \multicolumn{7}{|c|}{ B. Insulating Glass } \\
\hline \multirow{2}{*}{\multicolumn{2}{|c|}{ Type of Glass }} & \multirow{2}{*}{$\begin{array}{l}\text { Nom- } \\
\text { inal } \\
\text { Thick- } \\
\text { ness }\end{array}$} & \multicolumn{2}{|c|}{ Solar Trans.b } & \multicolumn{2}{|c|}{$\begin{array}{l}\text { Shading } \\
\text { Coefficient }\end{array}$} \\
\hline & & & $\begin{array}{l}\text { Outer } \\
\text { Pone }\end{array}$ & $\begin{array}{l}\text { Inner } \\
\text { Pane }\end{array}$ & $\begin{aligned} & h_{0} \\
= & 4.0\end{aligned}$ & $\begin{array}{l}h_{0} \\
=3.0\end{array}$ \\
\hline \multicolumn{2}{|c|}{$\begin{array}{l}\text { Regular Sheet Out, } \\
\text { Regular Sheet In }\end{array}$} & งैำ $\frac{1}{8}$ & 0.87 & 0.87 & 0.90 & 0.90 \\
\hline \multicolumn{2}{|c|}{$\left.\begin{array}{l}\text { Regular Plnte/Float Out, } \\
\text { Regular Plate/Float In }\end{array}\right\}$} & $\frac{1}{4}$ & 0.80 & 0.80 & 0.83 & 0.83 \\
\hline \multicolumn{2}{|c|}{$\begin{array}{l}\text { Heat-Abs Plate/Float Ont, } \\
\text { Regular Plate/Float In }\end{array}$} & $\frac{1}{4}$ & 0.46 & 0.80 & 0.56 & 0.58 \\
\hline
\end{tabular}

a Refers to factory-fabricated units with $\frac{1}{5}, \frac{1}{6}$, or $\frac{1}{3}$ in. air apace or to prime windows plus storm aindow's.

- Thickness of each pane of glass, not thickness of assembled unit.

d Refere to grey, bronze, and green tinted beat-absorbing plate/float glass. 
Shading Coefficients for Single Glass with Indoor Shading by Venetian Blinds and Roller Shades

\begin{tabular}{|c|c|c|c|c|c|c|c|}
\hline \multirow{4}{*}{ Typo of Glass } & \multirow{4}{*}{$\begin{array}{l}\text { Nominal } \\
\text { Thickness" }\end{array}$} & \multirow{4}{*}{$\begin{array}{c}\text { Salar } \\
\text { Trans. }\end{array}$} & \multicolumn{5}{|c|}{ Typo of Shading } \\
\hline & & & \multirow{2}{*}{\multicolumn{2}{|c|}{ Venetion Blinds }} & \multicolumn{3}{|c|}{ Raller Shade } \\
\hline & & & & & \multicolumn{2}{|c|}{ Opaque } & \multirow{2}{*}{$\frac{\text { Transiucent }}{\text { Light }}$} \\
\hline & & & Medium & Light & Dark & White & \\
\hline $\begin{array}{l}\text { Regular Sheet } \\
\text { Regular Plate/Float } \\
\text { Regular Pattern } \\
\text { Heat-Absorbing Pattern } \\
\text { Grey Sheet }\end{array}$ & 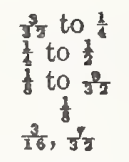 & $\left.\begin{array}{c}0.87-0.80 \\
0.80-0.71 \\
0.87-0.79 \\
0.74,0.71\end{array}\right\}$ & 0.64 & 0.55 & 0.59 & 0.25 & 0.39 \\
\hline $\begin{array}{l}\text { Heat-Absorbing Plate/Floatd } \\
\text { Heat-Absorbing Pattern } \\
\text { Grey Sheet }\end{array}$ & $\begin{array}{l}\frac{9}{16,} \frac{1}{4} \\
\frac{3}{16}, \frac{1}{1} \\
\frac{1}{8}, \frac{7}{3 \frac{1}{2}}\end{array}$ & $\left.\begin{array}{c}0.46 \\
0.59,0.45\end{array}\right\}$ & 0.57 & 0.53 & 0.45 & 0.30 & 0.36 \\
\hline $\begin{array}{l}\text { Heat-Absorbing Plate/Float } \\
\text { or Pattern } \\
\text { Heat-Absorbing Plate/Float }\end{array}$ & $\frac{3}{8}$ & $\left.\begin{array}{c}0.44-0.30 \\
0.34\end{array}\right\}$ & 0.54 & 0.52 & 0.40 & 0.28 & 0.32 \\
\hline $\begin{array}{l}\text { Heat-Absorbing Plate } \\
\text { or Pattern }\end{array}$ & - & $\left.\begin{array}{c}0.29-0.15 \\
0.24\end{array}\right\}$ & 0.42 & 0.40 & 0.36 & 0.28 & 0.31 \\
\hline $\begin{array}{l}\text { Reflective Coated } \\
\text { Glass } \\
\begin{aligned} & \text { S.C. }=0.30 \\
& 0.40 \\
& 0.50 \\
& 0.60\end{aligned}\end{array}$ & & & $\begin{array}{l}0.25 \\
0.33 \\
0.42 \\
0.50\end{array}$ & $\begin{array}{l}0.23 \\
0.29 \\
0.38 \\
0.44\end{array}$ & & & \\
\hline
\end{tabular}

- Refer to manufacturer's literature for values.

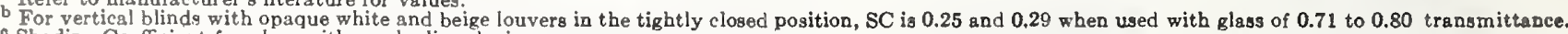

- Shading Coefficient for glass with no shading device.

d Refers to grey, bronze, and greez tinted heat-absorbing plate/foat glass.

Shading Coefficients for Insulating Glass ${ }^{\mathrm{a}}$ with Indoor Shading by Venetian Blinds and Roller Shades

\begin{tabular}{|c|c|c|c|c|c|c|c|c|}
\hline \multirow{4}{*}{ Type of Glass } & \multirow{4}{*}{$\begin{array}{l}\text { Naminal } \\
\text { Thickness, } \\
\text { each light }\end{array}$} & \multirow{2}{*}{\multicolumn{2}{|c|}{ Salar Trans. }} & \multicolumn{5}{|c|}{ Type of Shading } \\
\hline & & & & \multicolumn{2}{|c|}{ Venetion Blinds ${ }^{\circ}$} & \multicolumn{3}{|c|}{ Raller Shode } \\
\hline & & \multirow{2}{*}{$\begin{array}{l}\text { Oufer } \\
\text { Pane }\end{array}$} & \multirow{2}{*}{$\begin{array}{l}\text { Inner } \\
\text { Pone }\end{array}$} & & & \multicolumn{2}{|c|}{ Opaque } & Translucen? \\
\hline & & & & Medium & Light & Dork & White & light \\
\hline $\begin{array}{l}\text { Regular Sheet Out } \\
\text { Regular Sheet In } \\
\text { Regular Plate/Float Out } \\
\text { Regular Plate/Float In }\end{array}$ & $\begin{array}{c}\frac{3}{3} \frac{1}{8} \\
\frac{1}{4}\end{array}$ & $\begin{array}{l}0.87 \\
0.80\end{array}$ & $\left.\begin{array}{l}0.87 \\
0.80\end{array}\right\}$ & 0.57 & 0.51 & 0.60 & 0.25 & 0.37 \\
\hline $\begin{array}{l}\text { Heat-Absorbing Plate/Float }{ }^{d} \text { Out } \\
\text { Regular Plate/Float In }\end{array}$ & $\frac{3}{4}$ & 0.46 & 0.80 & 0.39 & 0.36 & 0.40 & 0.22 & 0.30 \\
\hline $\begin{array}{l}\text { Reflective Coated Glass } \\
\qquad \begin{array}{c}\mathrm{SC}^{\circ}= \\
0.20 \\
0.30 \\
0.40\end{array}\end{array}$ & & & & $\begin{array}{l}0.19 \\
0.27 \\
0.34\end{array}$ & $\begin{array}{l}0.18 \\
0.26 \\
0.33\end{array}$ & & & \\
\hline
\end{tabular}

Refers to factory-fabricated units with $\frac{1}{6}, 4$, or $\frac{1}{2}$ in. air space, or to prime windows plus storm hindows.

befer to manufacturer's literature for exact values.

- For vertical blinds with opaque white or beige louvers, tightly closed, SC is approximately the same as for opaque white roller shades.

Refers to bronze or green tinted heat-absorbing plate/float glass.

- Shading Coefficient for glass with no ahading device. 


\begin{tabular}{|c|c|c|c|}
\hline \multirow{2}{*}{ Indoor Shodo } & \multicolumn{3}{|c|}{$\begin{array}{l}\text { Solor Proportios } \\
\text { (Normal Incidence) }\end{array}$} \\
\hline & Trans. & Refect. & Absorp. \\
\hline \multicolumn{4}{|l|}{$\begin{array}{l}\text { Venetian Blinds (Ratio of slat } \\
\text { width to slat spacing } 1.2 \text {, slat } \\
\text { angle } 45 \mathrm{deg} \text { ) }\end{array}$} \\
\hline $\begin{array}{l}\text { Light Colored Slat } \\
\text { Medium Colored Slat }\end{array}$ & 0.05 & 0.55 & 0.40 \\
\hline $\begin{array}{l}\text { Medium Colored Slat } \\
\text { Vertical Blinds }\end{array}$ & 0.05 & 0.35 & 0.60 \\
\hline $\begin{array}{l}\text { White Louvers } \\
\text { Roller Shades }\end{array}$ & 0.00 & 0.77 & 0.23 \\
\hline $\begin{array}{l}\text { Roller Shades } \\
\text { Light Shades (Translucent) }\end{array}$ & 0.25 & 0.60 & 0.15 \\
\hline White Shade (Opaque) & 0.00 & 0.80 & 0.20 \\
\hline Dark Colored Shade (Opaque) & 0.00 & 0.12 & 0.88 \\
\hline
\end{tabular}

The values shown in this table and preceding tables are based on horizontal Venetisn blinds. However, tests show these values may be used for vertios blinds with good socuracy.

Shading Coefficients for Double Glazing with Between-Glass Shading

\begin{tabular}{|c|c|c|c|c|c|c|c|}
\hline \multirow{3}{*}{ Type of Glass } & \multirow{3}{*}{$\begin{array}{l}\text { Nominal } \\
\text { Thickness, } \\
\text { •och } \\
\text { pone }\end{array}$} & \multirow{2}{*}{\multicolumn{2}{|c|}{ Solar Trons." }} & \multirow{3}{*}{ Description of Air Spoce } & \multicolumn{3}{|c|}{ Type of Shoding } \\
\hline & & & & & \multicolumn{2}{|c|}{ Venetion Blinds } & \multirow{2}{*}{$\begin{array}{l}\text { Louvered } \\
\text { Sun Screon }\end{array}$} \\
\hline & & Pone & Pone & & Light & Medium & \\
\hline $\left.\begin{array}{l}\text { Regular Sheet Out } \\
\text { Regular Sheet In } \\
\text { Regular Plate Out } \\
\text { Regular Plate In }\end{array}\right\}$ & $\frac{3}{52, \frac{1}{8}}$ & $\left.\begin{array}{l}0.87 \\
0.80\end{array}\right\}$ & $\left.\begin{array}{l}0.87 \\
0.80\end{array}\right\}$ & $\begin{array}{l}\text { Shade in contact with glass or shade } \\
\text { separated from glass by air space. } \\
\text { Shade in contact with glass-voids } \\
\text { filled with plastic. }\end{array}$ & $\begin{array}{l}0.33 \\
-\end{array}$ & $\begin{array}{l}0.36 \\
-\end{array}$ & $\begin{array}{l}0.43 \\
0.49\end{array}$ \\
\hline $\left.\begin{array}{l}\text { Heat-Abs. } \\
\text { Plate/Flontb Out } \\
\text { Regular Plate In }\end{array}\right\}$ & $\frac{1}{6}$ & 0.46 & 0.80 & $\begin{array}{l}\text { Shade in contact with glass or shade } \\
\text { separated from glass by air space. } \\
\text { Shade in contact with glass-voids } \\
\text { filled with plastic. }\end{array}$ & $\begin{array}{l}0.28 \\
-\end{array}$ & $\begin{array}{l}0.30 \\
-\end{array}$ & $\begin{array}{l}0.37 \\
0.41\end{array}$ \\
\hline
\end{tabular}

- Refer to msaufacturer's literature for exact values.

- Refer to grey, bronze, and green tinted best-absorbing plete/font glese. 
Shading Coefficients for Single and Insulating Glass with Draperies

\begin{tabular}{|c|c|c|c|c|c|c|c|c|c|c|c|c|}
\hline \multirow{2}{*}{ Gloxing } & \multirow{2}{*}{$\begin{array}{l}\text { Glass } \\
\text { Trans. }\end{array}$} & \multirow{2}{*}{$\begin{array}{l}\text { Glass } \\
\mathrm{SC}^{\star}\end{array}$} & \multicolumn{10}{|c|}{ Shading Coofficient For Index Leffers in Fig. 10" } \\
\hline & & & A & B & $c$ & $D$ & E & $\mathbf{F}$ & G & H & 1 & J \\
\hline $\begin{array}{c}\text { Single Glass } \\
1 \text { in. Regular } \\
\frac{1}{4} \text { in. Regular } \\
\frac{1}{3} \text { in. Heat Abs. } \\
\frac{1}{4} \text { in. Heat Abs. } \\
\frac{5}{1} \text { in. Heat Abs. } \\
\frac{1}{2} \text { in. Heat }\end{array}$ & $\begin{array}{l}0.80 \\
0.71 \\
0.46 \\
0.34 \\
0.24\end{array}$ & $\begin{array}{l}0.95 \\
0.89 \\
0.67 \\
0.57 \\
0.50\end{array}$ & $\begin{array}{l}0.3 .5 \\
0.35 \\
0.33 \\
0.32 \\
0.30\end{array}$ & $\begin{array}{l}0.40 \\
0.39 \\
0.36 \\
0.34 \\
0.32\end{array}$ & $\begin{array}{l}0.45 \\
0.43 \\
0.39 \\
0.36 \\
0.33\end{array}$ & $\begin{array}{l}0.50 \\
0.48 \\
0.41 \\
0.38 \\
0.34\end{array}$ & $\begin{array}{l}0.55 \\
0.52 \\
0.44 \\
0.41 \\
0.36\end{array}$ & $\begin{array}{l}0.60 \\
0.56 \\
0.46 \\
0.43 \\
0.39\end{array}$ & $\begin{array}{l}0.65 \\
0.61 \\
0.49 \\
0.4 .5 \\
0.39\end{array}$ & $\begin{array}{l}0.70 \\
0.66 \\
0.52 \\
0.47 \\
0.40\end{array}$ & $\begin{array}{l}0.75 \\
0.70 \\
0.54 \\
0.49 \\
0.42\end{array}$ & $\begin{array}{l}0.80 \\
0.74 \\
0.57 \\
0.51 \\
0.43\end{array}$ \\
\hline $\begin{array}{l}\text { Reflective Coated } \\
\text { (See Manufacturers' literature } \\
\text { for exact values) }\end{array}$ & $\underline{-}$ & $\begin{array}{l}0.60 \\
0.50 \\
0.40 \\
0.30\end{array}$ & $\begin{array}{l}0.33 \\
0.31 \\
0.26 \\
0.20\end{array}$ & $\begin{array}{l}0.36 \\
0.33 \\
0.27 \\
0.21\end{array}$ & $\begin{array}{l}0.38 \\
0.34 \\
0.29 \\
0.21\end{array}$ & $\begin{array}{l}0.41 \\
0.36 \\
0.29 \\
0.22\end{array}$ & $\begin{array}{l}0.43 \\
0.39 \\
0.30 \\
0.23\end{array}$ & $\begin{array}{l}0.46 \\
0.39 \\
0.32 \\
0.23\end{array}$ & $\begin{array}{l}0.49 \\
0.41 \\
0.33 \\
0.23\end{array}$ & $\begin{array}{l}0.51 \\
0.42 \\
0.34 \\
0.24\end{array}$ & $\begin{array}{l}0.51 \\
0.44 \\
0.35 \\
0.24\end{array}$ & $\begin{array}{l}0.57 \\
0.46 \\
0.36 \\
0.25\end{array}$ \\
\hline $\begin{array}{l}\text { Insulating Glass ( } \frac{1}{2} \text { in. Air Space) } \\
\text { Regular Out and Regular In }\end{array}$ & 0.64 & $0 . \$ 3$ & $0: 35$ & 0.37 & 0.42 & 0.45 & 0.48 & 0.52 & 0.56 & 0.58 & 0.62 & 0.66 \\
\hline Heat Abs. Out and Regular In & 0.37 & 0.56 & 0.32 & 0.33 & 0.35 & 0.37 & 0.39 & 0.41 & 0.43 & 0.45 & 0.47 & 0.49 \\
\hline $\begin{array}{l}\text { Reflective Coated } \\
\text { (see Manufacturers' literature } \\
\text { for exact values) }\end{array}$ & E & $\begin{array}{l}0.40 \\
0.30 \\
0.20\end{array}$ & $\begin{array}{l}0.28 \\
0.24 \\
0.15\end{array}$ & $\begin{array}{l}0.28 \\
0.24 \\
0.15\end{array}$ & $\begin{array}{l}0.29 \\
0.2 .5 \\
0.16\end{array}$ & $\begin{array}{l}0.31 \\
0.25 \\
0.16\end{array}$ & $\begin{array}{l}0.32 \\
0.26 \\
0.17\end{array}$ & $\begin{array}{l}0.34 \\
0.26 \\
0.17\end{array}$ & $\begin{array}{l}0.36 \\
0.27 \\
0.18\end{array}$ & $\begin{array}{l}0.37 \\
0.27 \\
0.18\end{array}$ & $\begin{array}{l}0.37 \\
0.29 \\
0.19\end{array}$ & $\begin{array}{l}0.38 \\
0.29 \\
0.19\end{array}$ \\
\hline
\end{tabular}

* For glass alone, with no drapery.

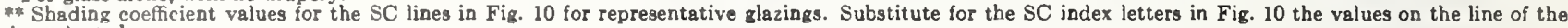
clasing selected.

Shading Coefficients for Louvered

Sun Screens

\begin{tabular}{|c|c|c|c|c|}
\hline \multirow{2}{*}{$\begin{array}{l}\text { Profile Angle, } \\
\text { deg }\end{array}$} & \multicolumn{2}{|c|}{ Group 1} & \multicolumn{2}{|c|}{ Group 2} \\
\hline & $\begin{array}{l}\text { Trans: } \\
\text { mittonce }\end{array}$ & SC & $\begin{array}{l}\text { Trans- } \\
\text { mittance }\end{array}$ & SC \\
\hline $\begin{array}{l}10 \\
20 \\
30 \\
40 \text { and above }\end{array}$ & $\begin{array}{l}0.23 \\
0.06 \\
0.04 \\
0.04\end{array}$ & $\begin{array}{l}0.35 \\
0.17 \\
0.15 \\
0.15\end{array}$ & $\begin{array}{l}0.25 \\
0.14 \\
0.12 \\
0.11\end{array}$ & $\begin{array}{l}0.33 \\
0.23 \\
0.21 \\
0.20\end{array}$ \\
\hline \multirow{2}{*}{$\begin{array}{c}\text { Profile Angle, } \\
\text { deg }\end{array}$} & \multicolumn{2}{|c|}{ Group 3} & \multicolumn{2}{|c|}{ Group 4} \\
\hline & $\begin{array}{l}\text { Trans. } \\
\text { mittance }\end{array}$ & SC & $\begin{array}{l}\text { Trans- } \\
\text { mittonce }\end{array}$ & SC \\
\hline $\begin{array}{l}10 \\
20 \\
30 \\
40 \text { and above }\end{array}$ & $\begin{array}{l}0.40 \\
0.32 \\
0.21 \\
0.07\end{array}$ & $\begin{array}{l}0.51 \\
0.42 \\
0.31 \\
0.18\end{array}$ & $\begin{array}{l}0.48 \\
0.39 \\
0.28 \\
0.20\end{array}$ & $\begin{array}{l}0.59 \\
0.50 \\
0.38 \\
0.30\end{array}$ \\
\hline
\end{tabular}

Group 1. Black, width over spacing ratio 1.15/1, 23 lourers per inch.

Group 2. Light color, high reflectance, otherwise same as Group 1.

Group 3. Black or dark color, $\mathrm{k} / \mathrm{s}$ ratio $0.85 / 1,17$ louvers per inch.

Group 4. Light color or unpainted aluninum, high reflectance, otherwise Group Group 3 .

$U$-value $=0.85 \mathrm{Btuh} /(\mathrm{sq} \mathrm{ft})(\mathrm{F} \mathrm{deg})$ for all groups when used with single slazing. 


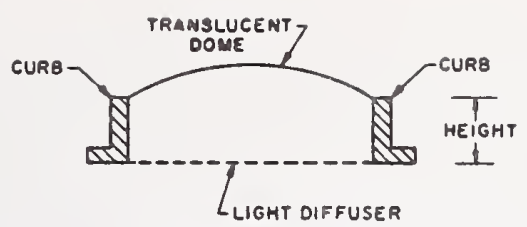

Fig. -... Terminology for Domed Skylights

Table $23 \ldots$... Shading Coefficients for Domed Skylights

\begin{tabular}{|c|c|c|c|c|c|}
\hline \multirow{2}{*}{ Dome } & \multirow{2}{*}{$\begin{array}{c}\text { light } \\
\text { Diffuser } \\
\text { (Tronslucent) }\end{array}$} & \multicolumn{2}{|c|}{ Curb (See Fig. ) } & \multirow{2}{*}{$\begin{array}{l}\text { Shoding } \\
\text { Coeffi- } \\
\text { cient }\end{array}$} & \multirow{2}{*}{ U-Volue } \\
\hline & & Height, in. & $\begin{array}{l}\text { Width to } \\
\text { Height Rotio }\end{array}$ & & \\
\hline $\begin{array}{l}\text { Clear } \\
\tau=0.86\end{array}$ & $\underset{\tau=0.58}{\text { y'es }}$ & $\begin{array}{r}0 \\
9 \\
18\end{array}$ & $\begin{array}{l}\infty \\
5 \\
2.5\end{array}$ & $\begin{array}{l}0.61 \\
0.58 \\
0.50\end{array}$ & $\begin{array}{l}0.46 \\
0.43 \\
0.40\end{array}$ \\
\hline $\begin{array}{l}\text { Clea } \bar{r} \\
\tau=0.86\end{array}$ & None & $\begin{array}{r}0 \\
9 \\
18\end{array}$ & $\begin{array}{l}\infty \\
5 \\
2.5\end{array}$ & $\begin{array}{l}0.99 \\
0.88 \\
0.80\end{array}$ & $\begin{array}{l}0.80 \\
0.75 \\
0.70\end{array}$ \\
\hline $\begin{array}{c}\text { Transilucent } \\
\tau=0.52\end{array}$ & None & $\begin{array}{r}0 \\
9 \\
18\end{array}$ & $\begin{array}{l}\infty \\
5 \\
2.5\end{array}$ & $\begin{array}{l}0.57 \\
0.51 \\
0.46\end{array}$ & $\begin{array}{l}0.80 \\
0.75 \\
0.70\end{array}$ \\
\hline $\begin{array}{c}\text { Translucent } \\
\tau=0.27\end{array}$ & None & $\begin{array}{r}0 \\
9 \\
18\end{array}$ & $\begin{array}{l}\infty \\
5 \\
2.5\end{array}$ & $\begin{array}{l}0.34 \\
0.30 \\
0.28\end{array}$ & $\begin{array}{l}0.80 \\
0.75 \\
0.70\end{array}$ \\
\hline
\end{tabular}

Shading Coeffieients for Hollow Glass Block Wall Panels ${ }^{\mathrm{a}}$

\begin{tabular}{|c|c|c|c|}
\hline \multirow{2}{*}{ Type of Gloss Blockb } & \multirow[b]{2}{*}{ Description of Glass Block } & \multicolumn{2}{|c|}{ Shoding Coefficientr } \\
\hline & & Ponels ${ }^{d}$ in the Sun & $\begin{array}{l}\text { Panelse in the Shode } \\
(N, N W, W, S W)\end{array}$ \\
\hline Type I & $\begin{array}{l}\text { Glass Colorless or Aqua } \\
\text { Smooth Face } \\
\text { A, D: Smooth } \\
\text { B, C: Smooth or wide ribs, or flutes horizontal or vertical, or shallow } \\
\text { E: None }\end{array}$ & 0.65 & 0.40 \\
\hline Type IA & $\begin{array}{l}\text { Same as Type I except } \\
\text { A: Ceramic Enamel on exterior face. }\end{array}$ & 0.27 & 0.20 \\
\hline Type II & $\begin{array}{l}\text { Same as Type I except } \\
\text { E: Glass fiber screen. }\end{array}$ & 0.44 & 0.34 \\
\hline Type III & $\begin{array}{l}\text { Glass Colorless or Aqua } \\
\text { A, D: Narrow vertical ribs or flutes. } \\
\text { B, C: Horizontal light-diffusing prisms, or horizontal light-directing } \\
\text { prisms. } \\
\text { E: Glass fiber screen. }\end{array}$ & 0.33 & 0.27 \\
\hline Type IIIA & $\begin{array}{l}\text { Same as Type III except } \\
\text { E: Glass fiber screen with green ceramic spray coating, } \\
\text { or glass fiber screen and gray glass, } \\
\text { or glass fber screen with light-selecting prisms. }\end{array}$ & 0.25 & 0.18 \\
\hline
\end{tabular}

- For glass block used in horizontal skylights gee Tables 28 and 29, Clapter 26 of the 1963 ASHR.AE. GuIDE AND DATA BoOK.

b All values are for $7 ! \times 7 ! \times 3\}$ in. block, set in light-colored mortar. For $11 ! \times 11\} \times 3\}$ in. block increasc coefficients by 15 percent, and fur $5 ! \times 3 / \times$ 8 in. blocks reduce coefficients by 15 percent.

- Shading coefficients are to be applied to Heat Gain Factors for one hour earlier than the time for which the load calculation is made to allow for heat stwar In the panel.

d Shading coefficients are for peak load condition, but provide a close approximation for other conditions. For more precise valucs for other conditions, the oreace 20.

- For NE, E, and SE panels in the shade add 50 percent to the values liated for panels in the shade. 

Table C6

Absorptivity of Materials to Solar Radiation

Reprinted by permission from Thermal Radiation Properties Survey (Honeywell Research Center, Minneapolis, Minnesota, 1966), pp. 245-248. 


\begin{tabular}{ll}
\hline \multicolumn{1}{c}{ Material } & Solar Absorptivity \\
\hline BRICKS & \\
Clay, cream, glazed & 0.36 \\
Clay, Fleton, dark portion & 0.63 \\
Clay, Felton, light portion & 0.40 \\
Lime clay, French & 0.46 \\
Gault, cream & 0.36 \\
Light buff & 0.516 \\
Light buff but darker than above & 0.60 \\
Mottled purple & 0.77 \\
Red & 0.699 \\
Red, common and tiles & 0.68 \\
Red, darker, glazed & 0.766 \\
Red, wire-cut & 0.52 \\
Stafford blue & 0.89 \\
Stock, light fawn & 0.57 \\
White glazed & 0.26 \\
White glazed (2 specimens) & $0.25-0.27$ \\
TILES & \\
Clay, purple (dark) & \\
Clay, dark purple, machine-made & 0.82 \\
Red & 0.81 \\
Red, hand-made & 0.67 \\
Red, light, Dutch & 0.60 \\
Red, light, machine- ade & 0.43 \\
Red, light, machine-made & 0.66 \\
Concrete, uncolored & 0.62 \\
Concrete, black & 0.65 \\
Concrete, dark & 0.91 \\
Concrete, brown & 0.91 \\
Concrete, brown, very rough & 0.85 \\
& 0.88
\end{tabular}

(Continued on neast page) 


\section{ASPHALT}

,New, 3 specimens

0.91

New, 3 specimens

0.91

New, another specimen

0.93

Pavement

Pavement, free from dust

0.852

0.928

Pavement, weathered, 3 specimens

0.82

0.83

0.89

\section{ROOFING}

Bituminous felt, aluminized

0.40

Bituminous felt

0.88

Bituminous felt

0.89

Bitumin-covered, brown

0.87

Sheet, green

0.86

Sheet, black matte surface

0.97

Sheet, black matte surface

0.97

\section{ASBESTOS CEMENT}

Aged

Aged 6 months

Aged 12 months

Aged 6 years, very dirty

Red

Red

Washed with soap and water

White

White (2 samples)

LIMESTONE

Anston

Bath

Clipsham

Indiana

Ketton

Portland

Steetley

SAND-LIME

Light-red

Red

White, fine sand

White, coarse sand

MARBLE

White

Ground, unpolished

Cleavage

GRANITE

Reddish

FELDSPAR

$\mathrm{K}_{2} \mathrm{O} \mathrm{Al}_{2} \mathrm{O}_{3} 6 \mathrm{SiO}_{2}$

MORTAR SCREENED
0.75

0.61

0.71

0.83

0.69

0.74

0.40

0.61

$0.49-0.42$

0.60

0.53

0.46

0.571

0.42

0.36

0.33

0.55

0.68

0.41

0.50

0.44

0.465

0.592

0.55

0.606

0.73 


\begin{tabular}{ll}
\hline \multicolumn{1}{c}{ Material } & Solar Absorptivity \\
\hline SANDSTONE & \\
Grey, Bristol pennant & 0.76 \\
Polmaise, light fawn & 0.54 \\
Stancliffe, light grey & 0.62 \\
Woolton, red & 0.73 \\
WHrTEwASH & \\
On galvanized iron & 0.22 \\
On galvanized iron & 0.22 \\
On galvanized iron & 0.26 \\
On galvanized iron, a very thick & 0.20 \\
layer & \\
SLATE & \\
Blue grey & 0.87 \\
Blue, grey & 0.85 \\
Clay, dark & 0.933 \\
Greenish, grey, rough & 0.88 \\
Grey, dark & 0.90 \\
Grey, dark, fairly rough & 0.90 \\
Grey, dark, fairly rough & 0.90 \\
Grey, dark, smooth & 0.89 \\
Purple & 0.86 \\
Silver-grey, Norwegian & 0.79 \\
\hline
\end{tabular}

\section{BUILDING MATERIALS, SOLAR ABSORPTIVITY}

\begin{tabular}{lc}
\hline \multicolumn{1}{c}{ Building Materials } & Solar Absorptivity \\
\hline Thickly tinned surface & 0.05 \\
Wood, smoothly planed & 0.78 \\
Basalt & 0.72 \\
Red sandstone & 0.60 \\
Marble (white) & 0.58 \\
Granite & 0.45 \\
Dolomite lime & 0.41 \\
Clay shale & 0.69 \\
Paris plaster & 0.78 \\
White plastered wall & 0.92 \\
Gravel & 0.29 \\
Sand & 0.76 \\
Glass & 0.93 \\
Sawdust & 0.75 \\
Clay & 0.39 \\
Red brick wall & 0.93 \\
\hline
\end{tabular}




\begin{tabular}{l|c}
\hline \multicolumn{1}{c|}{ Material } & - \\
\hline QM1, cotton sheeting bleached, 4 oz per yd & $0.62-0.66$ \\
QM2, cotton sateen prepared for dyeing, 9 oz per yd & $0.68-0.72$ \\
QM4, cotton sateen undyed, 9 oz per yd & $0.69-0.72$ \\
QM6, cotton sateen, medium gray, 9 oz per yd & 0.53 \\
QM7, cotton sateen dark gray, 9 oz per yd & 0.24 \\
50 percent wool, 50 percent cotton knit, undyed, 10.5 oz per yd & 0.62 \\
Cotton knit, undyed, 3 oz per yd & 0.60 \\
\hline
\end{tabular}

PARACHUTE CLOTH, SOLAR ABSORPTIVITY, REFLECTIVITY, AND TRANSMISSIVITY

\begin{tabular}{|c|c|c|c|}
\hline Material & Absorptivity & Renlectivity & Transmissivity \\
\hline $\begin{array}{l}\text { Dacron, } 100 \mathrm{lb} \\
\text { Dacron, } 300 \mathrm{lb} \\
\text { Dacron, } 600 \mathrm{lb} \\
\text { Dacron, } 800 \mathrm{lb}\end{array}$ & $\begin{array}{l}0.05 \\
0.11 \\
0.12 \\
0.19\end{array}$ & $\begin{array}{l}0.35 \\
0.54 \\
0.61 \\
0.62\end{array}$ & $\begin{array}{l}0.60 \\
0.35 \\
0.27 \\
0.19\end{array}$ \\
\hline $\begin{array}{l}\text { Nylon rip-stop } \\
\text { (orange) } 1.1 \text { oz per sq yd, } \\
\text { MIL-C-7020B Type I }\end{array}$ & 0.13 & 0.23 & 0.64 \\
\hline $\begin{array}{l}\text { Nylon rip-stop } \\
1.1 \text { oz per sq yd (white) } \\
\text { MIL-C-7020 }\end{array}$ & 0.08 & 0.27 & 0.65 \\
\hline $\begin{array}{l}\text { Nylon rip-stop } \\
1.6 \text { oz per sq yd (white) } \\
\text { MIL-C-7020B Type III }\end{array}$ & 0.06 & 0.22 & 0.72 \\
\hline $\begin{array}{l}\text { Nylon cloth } 2.25 \text { oz per sq yd, } \\
\text { MIL-C-7350B Type I } \\
\text { Nylon cloth } 4.30 \text { oz per sq yd, } \\
\text { MIL-C-8021 Type I } \\
\text { Nylon cloth } 7.0 \text { oz per sq yd, } \\
\text { MIL-C-8021 Type II } \\
\text { Nylon cloth } 14.0 \text { oz per sq yd, } \\
\text { MIL-C-8021 Type III }\end{array}$ & $\begin{array}{l}0.05 \\
0.08 \\
0.13 \\
0.11\end{array}$ & $\begin{array}{l}0.36 \\
0.44 \\
0.46 \\
0.62\end{array}$ & $\begin{array}{l}0.58 \\
0.48 \\
0.41 \\
0.27\end{array}$ \\
\hline
\end{tabular}



NBSLD

SAMPLE INPUT/OUTPUT 
CEILING TO COND. SPACE-3.16 W-NO SHADE-25( SOLARGKAY

$0,0,0,0,0,0,0,1,1,1,1,1,1,1,1,1,1,0,0,0,0,0,0,0$

$0,0,0,0,0,0,0,1,1,1,1,1,1,1,1,1,1,0,0,0,0,0,0,0$

$0,0,0,0,0,0,0,1,1,1,1,1,1,1,1,1,1,0,0,0,0, \overline{0}, \overline{0}, 0$

$0,0,0,0,0,0,0,0,0,0,0,0,0,0,0,0,0,0, \overline{0}, \overline{0}, \overline{0}, \overline{0}, \overline{0}, \tilde{0}$

$0,0,0,0,0,0, \overline{0}, 0,0,0,0,0, \overline{0}, \overline{0}, \overline{0}, \overline{0}, 0,0, \overline{0}, \overline{0}, 0, \overline{0}, \overline{0}, 0$

$0,0,0,0,0,0,0,0,0,0,0, \overline{0}, \overline{0}, \overline{0}, \overline{0}, \overline{0}, 0,0, \overline{0}, \overline{0}, \overline{0}, \overline{0}, \overline{0}, \overline{0}$

$0,0,0,0,0,0,0, \overline{0}, 0,0,0,0, \overline{0}, \overline{0}, \overline{0}, \overline{0}, \overline{0}, 0, \overline{0}, \overline{0}, 0, \overline{0}, \overline{0}, 0$

$0,0,0,0,0,0,0,0,0,0,0,0, \overline{0}, \overline{0}, \overline{0}, \overline{0}, \overline{0}, 0, \overline{0}, \overline{0}, \overline{0}, \overline{0}, \overline{0}, \overline{0}$

$0,0,0,0,0,0,0,0,0,0,0,0, \overline{0}, \overline{0}, \overline{0}, \overline{0}, 0,0, \overline{0}, \overline{0}, \overline{0}, \overline{0}, \overline{0}, \overline{0}$

$80,80,80,80,80,80,80,75,75,75,75,75,75,75,75,75,75,80,80,80,80,80,80,80$

$60,60,60,60,60,60,60,70,70,70,70,70,70,70,70,70,70,6 \underline{0}, 6 \underline{0}, 6 \underline{0}, 6 \underline{0}, 6 \overline{0}, 60,6 \overline{0}$

$60,80,20,50$

$31,0,10$

$7,21,201,97,20,67,20,60,50,0,1,87,42,6,13,5,60$

ROOM WITH GLASS AREA FACIÑG SOUTH

$0,0,0$

4

$0.167,1.0,140.0,0.2,0.0$

$0.334,0.025,5.7,0.2,0.0$

$0.0313,0.11,70.0,0.4,0.0$

$0.0417,0.83,55.0,0.4,0 . \overline{0}$

2-N HW CONCRETE

4" INSULATION

$3 / 8^{\circ}$ FELT \& MEMBRANE

$1 / 2^{*}$ SLAG

4

$0.005,26.0,480.0,0.1,0.0$

$0,0,0,0, .91$

$0.167,0.0133,2.5,0.38,0.0$

$0.005,26.0,480.0,0.1,0.0$

STEEL SIDING

AIR SPACE

INSULATION MODIFIED

STEEL SIDING

2

$0.5,1.0,140,0,0.2,0.0$

$0.3637,0.025,5.7,0.2,0.0$

6" CONCRETE

4.43" INSULATION

3

$0.04166,0.42,100 \cdot 0,0.2, \underline{0} \cdot 0$

$0,0,0,0,091$

$0.04166,0.42,100.0,0.2,0.0$

1/2" GYPSUM BOARD

AIR SPACE

1/2" GYPSUM BOARD

2

$0.5,1.0,140.0,0.2,0.0$

$0,0,0,0,1$.

G" CONCRETE

CEILING AIR SPACE

2 


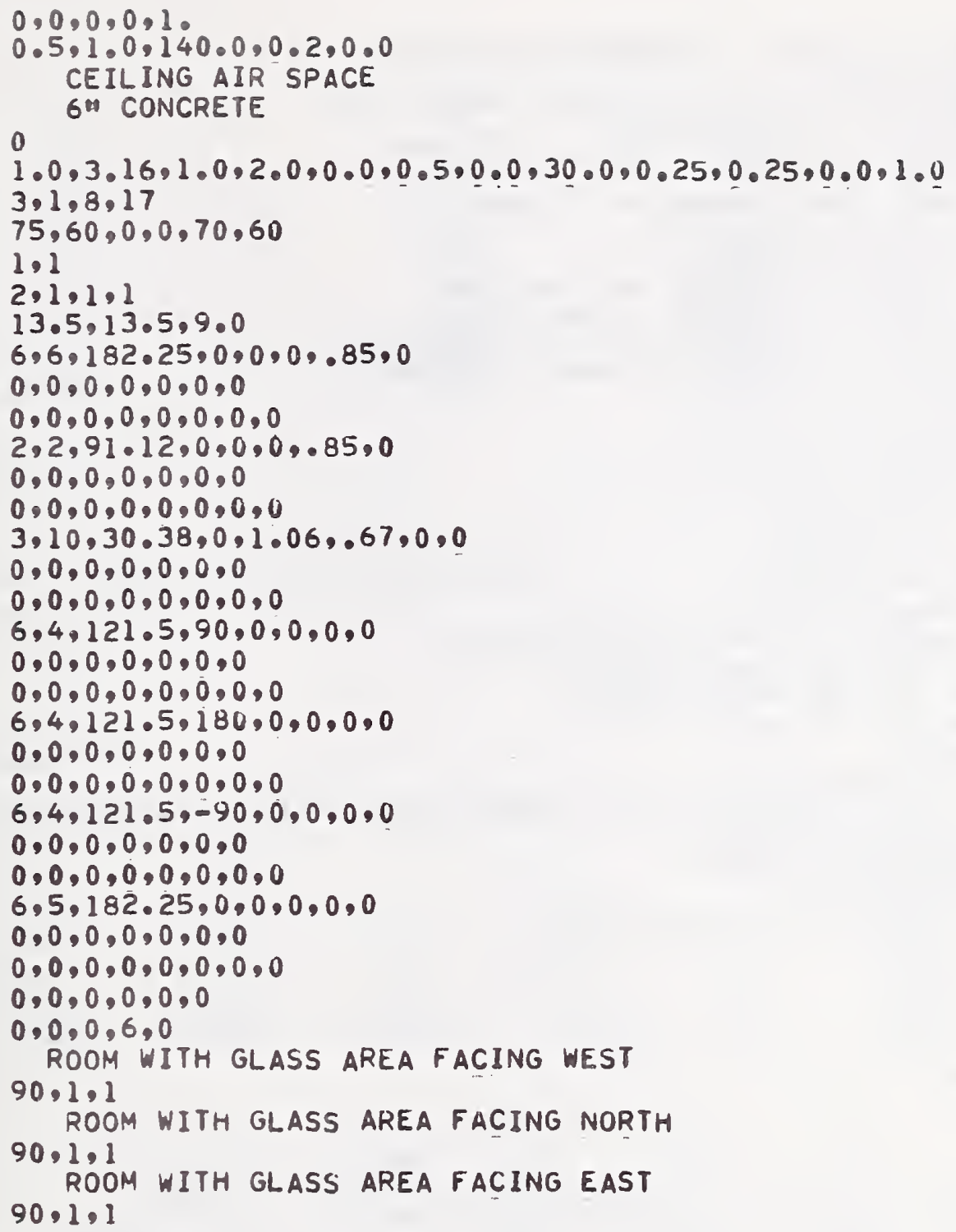

CONGRATULATIONS!! NOW YOU ARE ON NBSLD

WE ASSUME YOU HAVE ALREADY PREPAREU THE DATA ON NBS DATA FORMS.. IF YOU HAVE NOT, PLEASE TURN OFF THE TERMINAL AND HAVE YOUR DATA READY ON THE DATA FORMS

RUNID, RUNTYP, ASHRAE, IDETAL, METHOD, IRFMTP

RUNID........ IDENTIFICATION OF THE RUN

1 NEED RESPONSE FACTÕR DATA 


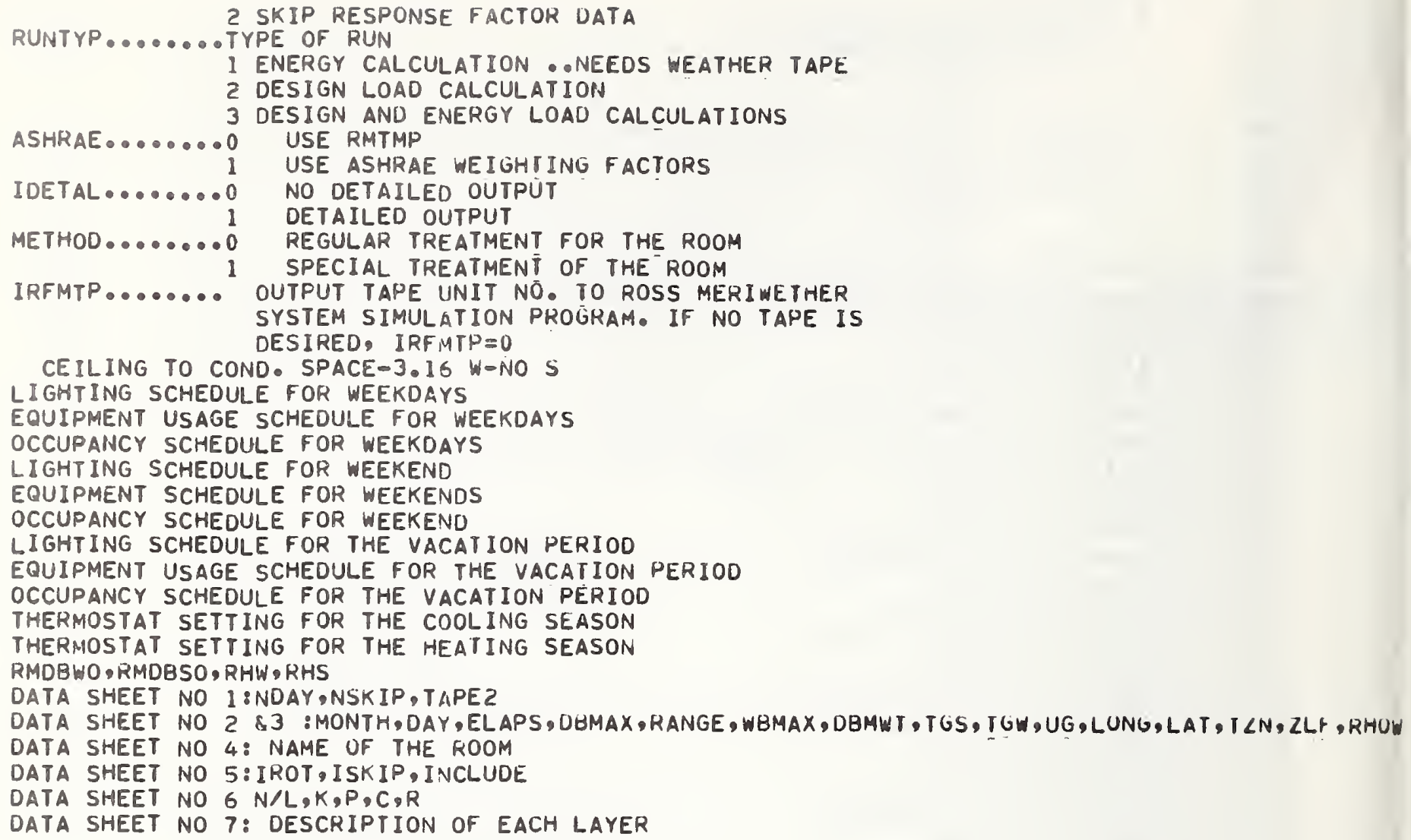


RESPONSE FACTORS

$\begin{array}{lccr}J & x & Y & Z \\ 0 & 4.6018 & .0039 & 1.9307 \\ 1 & -4.3324 & .0375 & -1.8332 \\ 2 & -.1798 & .0241 & -0.0213 \\ 3 & =.0150 & .0055 & -.0034 \\ 4 & =.0020 & .0010 & -.0006 \\ 5 & -.0003 & .0002 & -.0001 \\ 6 & -.0001 & .0000 & -.0000 \\ 7 & -.0000 & .0000 & -.0000 \\ 8 & -.0000 & .0000 & -.00000\end{array}$

COMMON RATIO CR $=.17519$

DATA SHEET NO 7: DESCRIPTION OF EACH LAYER

IRF =

2

WALL COMPOSITION

\begin{tabular}{|c|c|c|c|c|c|c|}
\hline $\begin{array}{l}\text { LAYER } \\
\text { NO }\end{array}$ & $L(I)$ & $K(I)$ & (I) & $\underline{C}(I)$ & RES (I) & $\begin{array}{l}\text { DESCRIPTION } \\
\text { OF LAYERS }\end{array}$ \\
\hline $\begin{array}{l}1 \\
2 \\
3 \\
4\end{array}$ & $\begin{array}{r}.005 \\
0 . \\
.167 \\
.005\end{array}$ & $\begin{array}{c}26.000 \\
0 . \\
.013 \\
26.000\end{array}$ & $\begin{array}{r}480.00 \\
0 . \\
2.50 \\
480.00\end{array}$ & $\begin{array}{l}: 100 \\
0 . \\
: 380 \\
\because 100\end{array}$ & $\begin{array}{l}0.91 \\
0.91 \\
0 .\end{array}$ & $\begin{array}{l}\text { STELL SIOING } \\
\text { AIR SHACE } \\
\text { INSULATION MOUIFIED } \\
\text { STEEL SIDING }\end{array}$ \\
\hline
\end{tabular}

TIME INCREMENT DT $=1$.

THERMAL CONDUCTANCE UT $=.074$

RESPONSE FACTORS

$\begin{array}{ccc}X & Y & Z \\ .3598 & .0467 & .3705 \\ -.2851 & .0271 & -.2958 \\ -.0004 & .0004 & -.0004 \\ -.0000 & .0000 & -.0000 \\ =.0000 & .0000 & -.0000\end{array}$


COMMON RATIO CR=.01336

DATA SHEET NO 7: DESCRIPTION OF EACH LAYER
IRF $=$
3
WALL COMPOSITION
LAYER
$L(I)$
$K(I)$
(I)
$C(I)$
RES (I)
DESCRIPTION
NO

$\begin{array}{ll}1 & .500 \\ 2 & .364\end{array}$
1.000
.025
.200
.200
0 .
OF LAYERS
140.00
5.70
0 .
6" CONCRETE
$4.4 \overline{3} 10$ INSÚLATIUN

TIME INCREMENT DT $=1$ 。

THERMAL CUNDUCTANCE

UT $=\quad .066$

RESPONSE FACTORS

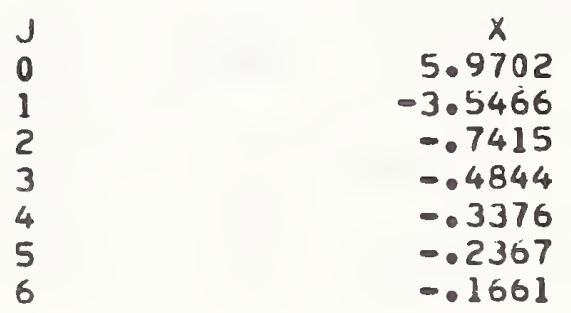

$Y$
.0001
.0043
.0129
.01134
.0104
.0075
.0053

2

.1906

. $.10 \overline{8} 8$

$-.0111$

$-.0025$

$-.0 \overline{007}$

$-.0003$

$-.0002$

COMMON RATIO CR $=.70105$

DATA SHEET NO $7:$ DESCRIPTION OF EACH LAYER

IRF $=$

4

WALL COMPOSITION

\begin{tabular}{|c|c|c|c|c|c|c|}
\hline $\begin{array}{l}\text { LAYER } \\
\text { NO }\end{array}$ & $L(I)$ & $K(I)$ & (I) & $\underline{C}(I)$ & RES (I) & $\begin{array}{l}\text { DESCRIPTION } \\
\text { OF LAYERS }\end{array}$ \\
\hline $\begin{array}{l}1 \\
2 \\
3\end{array}$ & $\begin{array}{l}.042 \\
.042\end{array}$ & $\begin{array}{l}.420 \\
0.420\end{array}$ & $\begin{array}{l}100.00 \\
0 \\
100.00\end{array}$ & $\frac{.200}{0.200}$ & $\begin{array}{l}0.91 \\
0.9\end{array}$ & $\begin{array}{l}\text { 1/2" GYPSUM BUAKO } \\
\text { AIR SPACE } \\
1 / 2 " \text { GYPSUM BUAKD }\end{array}$ \\
\hline
\end{tabular}


TIME INCREMENT DT $=1$.

$$
\text { THERMAL CONDUCTANCE UT }=.902
$$

RESPONSE FACTORS

$\begin{array}{llcc}J & x & Y & L \\ 0 & 1.6053 & .8321 & 1.0653 \\ 1 & -.7631 & 0.0701 & 0.7631 \\ 2 & 0 . & 0 . & 0.0 \\ 3 & 0 . & 0 . & 0.0\end{array}$

COMMON RATIO CR $=0$ 。

DATA SHEET NO 7: DESCRIPTION OF EACH LAYER

IRF =

5

WALL COMPOSITION

\begin{tabular}{|c|c|c|c|c|c|c|}
\hline $\begin{array}{l}\text { LAYER } \\
\text { NO }\end{array}$ & $L(I)$ & $K(I)$ & (I) & $C(I)$ & RES (I) & $\begin{array}{l}\text { OESCRIPTION } \\
\text { OF LAYERS }\end{array}$ \\
\hline$\frac{1}{2}$ & 0.500 & $\begin{array}{l}1.000 \\
0 .\end{array}$ & $\begin{array}{c}140.00 \\
0 .\end{array}$ & 0.200 & 0.00 & $\begin{array}{l}\text { 6" CONCKETE } \\
\text { CEILING AIR SPACE }\end{array}$ \\
\hline
\end{tabular}

THERMAL CONDUCTANCE

$U T=.667$

RESPONSE FACTORS

$J$
0
1
2
3
4
5
6

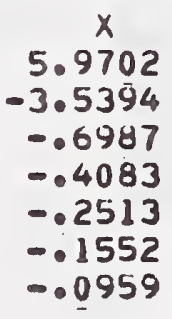
$Y$ .0308
.1876
.1689
.1067
.0660
.0408
.0252

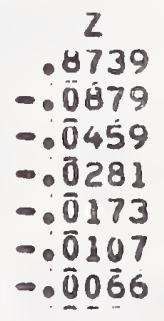


COMMON RATIO CR $=.61750$

DATA SHEET NO 7: DESCRIPTION OF EACH LAYER

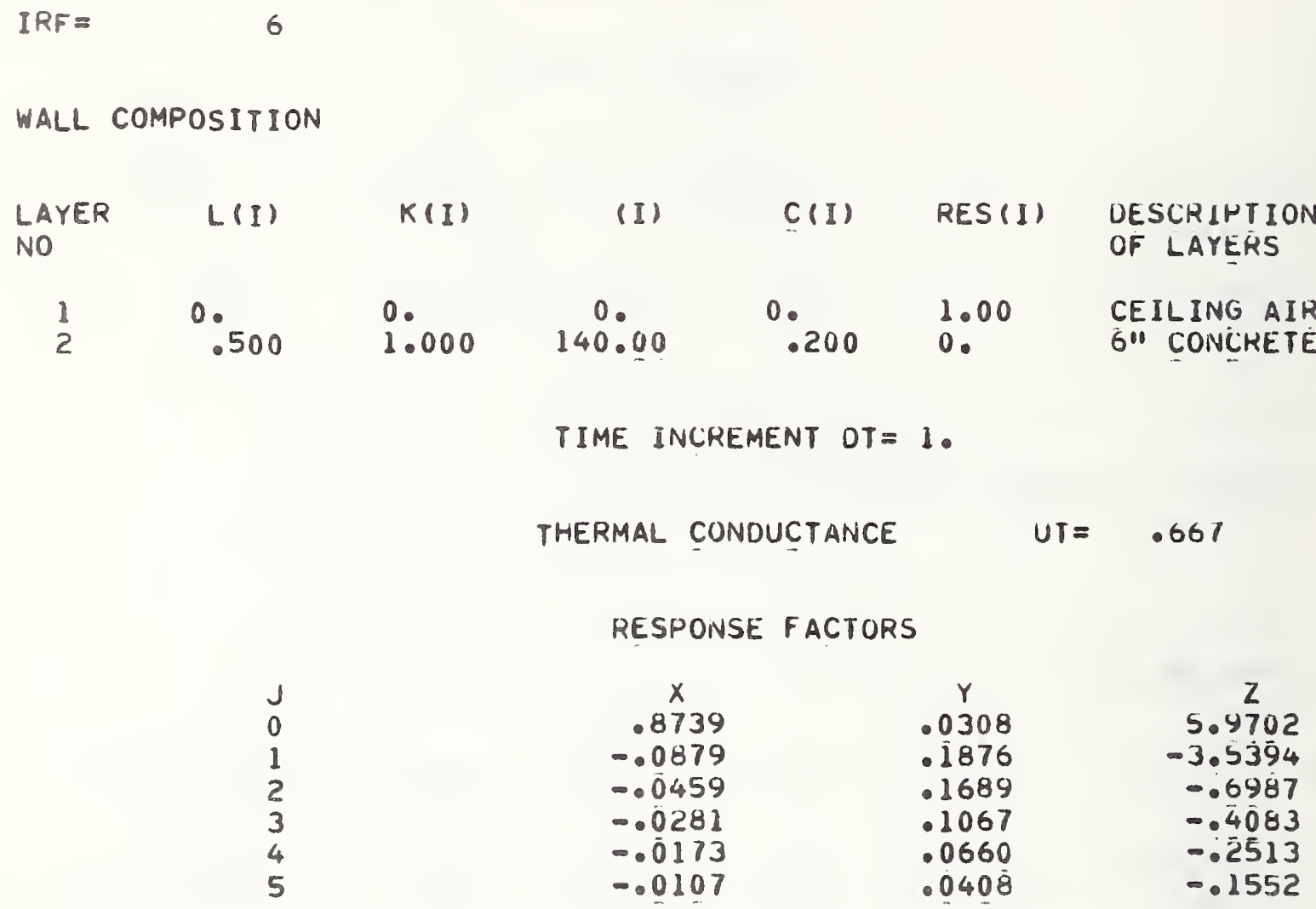

COMMON RATIO CR $=.61731$

$\underset{J}{\text { CONDUCTION TRANSFER FUNCTIONS FOR }} \underset{Y}{\operatorname{IR}} \underset{Z}{I R F}=\mathrm{CR}^{1}$

$\begin{array}{rrrrr}1 & 4.60175 & .00387 & 1.93073 & .17519 \\ 2 & -5.13862 & .03679 & -2.17146 & \\ 3 & .57926 & .01753 & .29987 & \\ 4 & .01645 & .00125 & .00035 & \\ 5 & .00065 & .00005 & .00000 & \\ 6 & .00002 & .00000 & -.00000 & \end{array}$

CONDUCTION TRANSFER FUNCTIONS FUR IRF = 


$$
\begin{array}{rrrrr}
J & X & Y & Z & C R \\
1 & .35979 & .04672 & .077049 & .01336 \\
2 & -.28990 & .02647 & -.030073 & \\
3 & .00338 & .00008 & .00350 &
\end{array}
$$

CONDUCTION TRANSFER FUNCTIONS FOR
$X$${\underset{Y}{I R F}}^{\text {IRF }} \mathrm{CR}^{3}$

$$
\begin{array}{rrrrr}
1 & 5.97021 & .00007 & .19055 & .70105 \\
2 & -7.73202 & .00429 & -.024238 & \\
3 & 1.74482 & .00983 & .06516 & \\
4 & .03547 & .00437 & .00527 & \\
5 & .00196 & .00102 & .00102 &
\end{array}
$$

$\underset{J}{\text { CONDUCTION TRANSFER FUNCTIONS FOR }} \underset{Y}{I R F=} \mathrm{Z}_{Z} \mathrm{CR}^{4}$

$$
\begin{array}{lllll}
1 & 1.66530 & 0 . & 1.66530 & 0 . \\
2 & -.76308 & 0 . & -.76308
\end{array}
$$

\begin{tabular}{ccccc} 
CONDUCTION TRANSFER FUNCTIONS FOR & IRF & \multicolumn{1}{l}{${ }^{5}$} & $\mathrm{CR}$
\end{tabular}

$$
\begin{array}{rrrrr}
1 & 5.97024 & .03084 & .07386 & .01750 \\
2 & -7.22605 & .06854 & -.02750 & \\
3 & 1.48689 & .05307 & .00839 \\
4 & .02317 & .00242 & .00024 \\
5 & .00080 & .00010 & .00001 &
\end{array}
$$

CONDUCTION TRANSFER FUNCTIONS FOR
$X$$\underset{Y}{I R F=} \mathrm{CR}^{6}$

$$
\begin{array}{rrrrr}
1 & .07386 & .03084 & 5.97024 & .61731 \\
2 & -.02732 & .16855 & -7.22487 & \\
3 & .00837 & .05311 & 1.48619 & \\
4 & .00023 & .00245 & .02303 &
\end{array}
$$

DATA SHEET NO 8: ROOMNO, QLITY, QEQPY, QCU, FLCG,FRAS, TS, CFMS, ARCHGS, ARCHGW, AKCHGM, ZNORM

DATA SHEET NO.9: IW,IL, ISTART, ILEAVE

DATA SHEET NO 10: TUL,TLL, QCMAX, OHMAX, DBVMAX,DBVMIN

DATA SHEET NO 11: ITHST,ITK

DATA SHEET NO 12: NS, NW,NN,NE,L,W,H

DATA SHEET 13 AND 14: ROOM SURFACE UATA ANO EXTERIOR SURFACE SHAUUW DATA

$\begin{array}{rrrrrrr}\text { ROOMNO } & H T & \text { AG } & \text { NOFLR } & \text { QCU } & \text { ARCHGS } & \text { ARCHGW } \\ 1.0 & 9.0 & 182.3 & 1.0 & 2.0 & .3 & .3\end{array}$




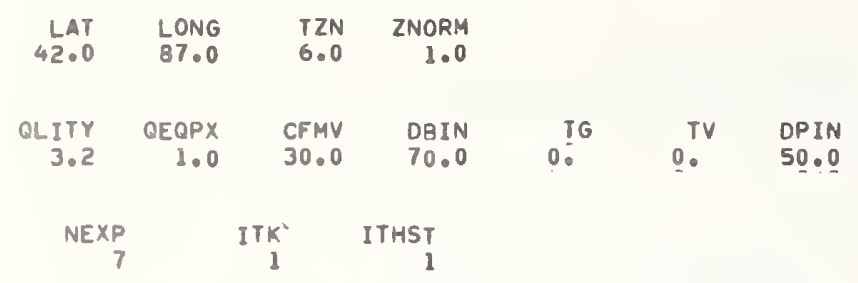

DATA SHEET NO 15: UENDW,UCELNG, AENDW,ATCHT, AIRCHG, AIRNT DATA SHEET NO $16:$ IEXTSD. IEXMS, IEXME,NTVNT , NVENT

\begin{tabular}{|c|c|c|c|}
\hline UENDH & UCI & LNG & \\
\hline SURF ${ }^{\circ}$ ' & NO & O. & \\
\hline 1 & No & 6 & \\
\hline 2 & & 2 & \\
\hline 3 & & 3 & \\
\hline 4 & & 6 & \\
\hline 5 & & 6 & \\
\hline 6 & & 6 & \\
\hline 7 & & 6 & \\
\hline
\end{tabular}

ATCHT

$\begin{array}{rr}\text { NDW } & \text { ATCHT } \\ 0 . & 0 \\ \text { IHT } & \text { IRF } \\ 1 & 6 \\ 1 & 2 \\ -1 & 10 \\ 1 & 4 \\ 1 & 4 \\ 1 & 4 \\ 1 & 5\end{array}$

\begin{tabular}{|c|c|c|c|c|}
\hline IRF & ABSP & $U$ & $H$ & A \\
\hline 6 & 0 & .46 & O. & 182.25 \\
\hline 2 & .85 & .07 & 6.00 & 91.12 \\
\hline 10 & 0. & 1.076 & 6.00 & $30 \cdot 38$ \\
\hline 4 & $\overline{0}$ & .56 & $\overline{0}$. & 121.50 \\
\hline 4 & 0 & .56 & 0. & 121.50 \\
\hline 4 & 0. & .56 & 6. & 121.50 \\
\hline 5 & $\underline{0}$. & .46 & ō. & 182.25 \\
\hline
\end{tabular}
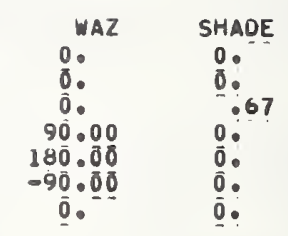

$\begin{array}{rr}\text { UT } & \text { HI } \\ .67 & .54 \\ 10.07 & .54 \\ .89 & .54 \\ .90 & .54 \\ .90 & .54 \\ .90 & .54 \\ .67 & .54\end{array}$

SHADOH CASTING DATA

\begin{tabular}{|c|c|c|c|c|c|c|c|}
\hline$F L$ & HT & $F P$ & $A W$ & BHL & $B W R$ & D & FPl \\
\hline 0. & 0. & 0. & 0. & 0. & 0 。 & $\underline{0}$. & $\underline{0}$. \\
\hline 0. & 0. & 0. & 0. & $\overline{0}$ & $\overline{0}$. & $\overline{0}$. & $\overline{0}$ 。 \\
\hline 0. & 0. & 0. & 0. & 0 . & 0̈。 & 0. & 0. \\
\hline 0. & 0. & 0. & 0. & 0. & 0 . & 0. & 0. \\
\hline 0. & 0. & 0. & 0. & 0. & $\overline{0}$. & $\overrightarrow{0}$. & 0。 \\
\hline 0. & 0. & 0. & 0. & 0 . & $\underline{0}$. & 0 . & $\overline{0}$. \\
\hline 0. & . & 0 & 0 & ō. & $\overline{\mathbf{n}}$ & $\overline{0}$ & 0 \\
\hline
\end{tabular}

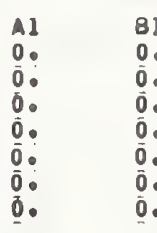

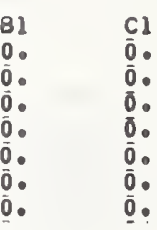

$\begin{array}{ll}C l & F P 2 \\ \overline{0} \cdot & 0 \\ \overline{0}: & \overline{0} \cdot \\ \overline{0} \cdot & \overline{0} \cdot \\ \overline{0} \cdot & \overline{0} \cdot \\ \overline{0} \cdot & \overline{0} \cdot \\ \overline{0} \cdot & \overline{0} \cdot \\ \overline{0}: & \overline{0} \cdot\end{array}$

A2
0.
0.
0.
0.
$\overline{0} \cdot$
$\overline{0} \cdot$
$\tilde{0} \cdot$

$B 2$
0.
0.
0.
0.
0.
0.
0.

$c 2$
0
0
0
0
0
0
0
0
0
0

RADIATION INTERCHANGE FACTORS

\begin{tabular}{|c|c|c|c|c|c|c|c|}
\hline SURF ACE & 1 & 2 & 3 & 4 & 5 & 6 & 7 \\
\hline 1 & 0. & .127 & .043 & .170 & .170 & .170 & .320 \\
\hline 2 & .255 & 0. & 0 . & .171 & .148 & .171 & .255 \\
\hline 3 & .255 & 0 . & 0 . & .171 & .148 & .171 & .255 \\
\hline 4 & .255 & .128 & .043 & 0 . & $.17 \overline{1}$ & .148 & .255 \\
\hline 5 & .255 & .111 & .037 & .171 & 0 . & 171 & 55 \\
\hline 6 & .255 & .128 & .043 & .148 & .171 & O. & \\
\hline
\end{tabular}


HEATING LOAD IN BTU PER MOUR

$\begin{array}{lr}\text { SENSIBLE LOAD }= & 3917 . \\ \text { LATENT LOAD }= & 317 . \\ \text { TOTAL LOAD } & \end{array}$

\section{SOLAR DATA (OSUN/OGLASS)}

\begin{tabular}{|c|c|c|c|c|c|c|c|c|c|c|c|c|c|c|c|c|c|c|c|c|c|c|}
\hline $\begin{array}{l}0 . \\
0 .\end{array}$ & $\begin{array}{l}0 . \\
0 \\
2\end{array}$ & $\begin{array}{l}0 . \\
0 .\end{array}$ & $\begin{array}{l}0 . \\
0 .\end{array}$ & $\begin{array}{l}0 . \\
0 .\end{array}$ & $\begin{array}{l}0 . \\
0 .\end{array}$ & $\begin{array}{l}0 . \\
0 .\end{array}$ & $\begin{array}{l}0 . \\
0 .\end{array}$ & $\begin{array}{l}0 . \\
0 .\end{array}$ & $\begin{array}{l}0 . \\
0 .\end{array}$ & $\begin{array}{l}0 . \\
0 .\end{array}$ & 0. & $\begin{array}{l}0 . \\
0 .\end{array}$ & $\begin{array}{l}0 . \\
0 .\end{array}$ & $\begin{array}{l}0 . \\
0 \\
0\end{array}$ & $\begin{array}{l}0 . \\
0 .\end{array}$ & $\begin{array}{l}0 . \\
0 .\end{array}$ & 0. & $\begin{array}{l}0 . \\
0 .\end{array}$ & $\begin{array}{l}0 . \\
0 .\end{array}$ & 8. & $\begin{array}{l}0 . \\
0 .\end{array}$ & $\begin{array}{l}0 . \\
0 .\end{array}$ \\
\hline $\begin{array}{l}0 . \\
0 .\end{array}$ & $\begin{array}{l}0 . \\
0 . \\
3\end{array}$ & $\begin{array}{l}0 . \\
0 .\end{array}$ & $\begin{array}{l}0 \\
0\end{array}$ & $\begin{array}{l}2 . \\
0 .\end{array}$ & $\begin{array}{r}13 . \\
0\end{array}$ & $\begin{array}{r}23 . \\
0\end{array}$ & $\begin{array}{r}44 . \\
0 .\end{array}$ & $\begin{array}{r}80 \\
0\end{array}$ & $\begin{array}{r}109 . \\
0 .\end{array}$ & $\begin{array}{r}128 \\
0\end{array}$ & $\begin{array}{r}133 \\
0\end{array}$ & $\begin{array}{r}125 . \\
0 .\end{array}$ & $\begin{array}{r}104 \\
0\end{array}$ & $\begin{array}{r}73 \\
0\end{array}$ & $\begin{array}{r}36 . \\
0\end{array}$ & $\begin{array}{r}21 . \\
0\end{array}$ & 110 & $\begin{array}{l}0 . \\
0 .\end{array}$ & $\begin{array}{l}0 . \\
0 .\end{array}$ & $\begin{array}{l}0 . \\
0 .\end{array}$ & $\begin{array}{l}0 . \\
0 .\end{array}$ & $\begin{array}{l}0 . \\
0 .\end{array}$ \\
\hline $\begin{array}{l}0 . \\
0 .\end{array}$ & $\begin{array}{r}0 . \\
0 . \\
4\end{array}$ & $\begin{array}{l}0 . \\
0 .\end{array}$ & $\begin{array}{l}0 . \\
0 .\end{array}$ & $\begin{array}{l}0 . \\
1 .\end{array}$ & $\begin{array}{l}0 . \\
9 .\end{array}$ & $\begin{array}{l}0 . \\
15 .\end{array}$ & $\begin{array}{l}0 \\
21\end{array}$ & 37. & $\begin{array}{r}0 . \\
56 .\end{array}$ & $\begin{array}{l}0 . \\
69 .\end{array}$ & 73 & $6 \%$ & $\begin{array}{l}0 . \\
53 .\end{array}$ & 33 & $\begin{array}{l}0 \\
19\end{array}$ & 14 & $\begin{array}{l}0 . \\
8:\end{array}$ & $\begin{array}{l}0 . \\
0 .\end{array}$ & $\begin{array}{l}0 . \\
0 .\end{array}$ & $\begin{array}{l}0 . \\
0 .\end{array}$ & $\begin{array}{l}0 . \\
0 .\end{array}$ & 0. \\
\hline $\begin{array}{l}0 . \\
0 .\end{array}$ & $\begin{array}{l}0 . \\
0 . \\
5\end{array}$ & $\begin{array}{l}0 . \\
0 .\end{array}$ & $\begin{array}{l}0 . \\
0 .\end{array}$ & $\begin{array}{l}0 . \\
0 .\end{array}$ & $\begin{array}{l}0 . \\
0 .\end{array}$ & $\begin{array}{l}0 . \\
0\end{array}$ & $\begin{array}{l}0 . \\
0 .\end{array}$ & o. & 8. & $\begin{array}{l}0 . \\
0 .\end{array}$ & $\begin{array}{l}0 . \\
0 .\end{array}$ & $\begin{array}{l}0 . \\
0 .\end{array}$ & $\begin{array}{l}0 . \\
0 .\end{array}$ & $\begin{array}{l}0 \\
0 \\
0\end{array}$ & $\begin{array}{l}0 . \\
0 .\end{array}$ & $\begin{array}{l}0 . \\
0 .\end{array}$ & 0. & $\begin{array}{l}0 . \\
0 .\end{array}$ & 0. & $\begin{array}{l}0 . \\
0 .\end{array}$ & $\begin{array}{l}0 . \\
0 .\end{array}$ & $\begin{array}{l}0 . \\
0 .\end{array}$ \\
\hline $\begin{array}{l}0 . \\
0 .\end{array}$ & $\begin{array}{l}0 . \\
0 . \\
6\end{array}$ & 0. & $\begin{array}{l}0 . \\
0 .\end{array}$ & $\begin{array}{l}0 . \\
0 .\end{array}$ & $\begin{array}{l}0 . \\
0 .\end{array}$ & $\begin{array}{l}0 . \\
0 .\end{array}$ & 0. & $\underline{0}$. & $\begin{array}{l}0 . \\
0 .\end{array}$ & 0 & $\begin{array}{l}0 . \\
0 .\end{array}$ & $\begin{array}{l}\mathbf{0} . \\
\underline{0} .\end{array}$ & $\begin{array}{l}0 . \\
\tilde{0} .\end{array}$ & $\begin{array}{l}0 . \\
\hat{0} .\end{array}$ & $\begin{array}{l}0 . \\
0 .\end{array}$ & $\begin{array}{l}0 . \\
\overline{0}\end{array}$ & $\begin{array}{l}0 . \\
0 .\end{array}$ & $\begin{array}{l}0 . \\
\overline{0}\end{array}$ & $\begin{array}{l}0 . \\
\overline{0}\end{array}$ & $\begin{array}{l}0 . \\
0 .\end{array}$ & $\begin{array}{l}0 . \\
0 .\end{array}$ & $\begin{array}{l}\mathbf{0} \\
\overline{0}\end{array}$ \\
\hline $\begin{array}{l}0 . \\
0 .\end{array}$ & 0 & $\begin{array}{l}0 . \\
0 .\end{array}$ & $\begin{array}{l}0 . \\
0 .\end{array}$ & $\begin{array}{l}0 . \\
0 .\end{array}$ & $\begin{array}{l}0 . \\
0 .\end{array}$ & $\begin{array}{l}0 . \\
0 .\end{array}$ & 0. & $\begin{array}{l}0 . \\
\overline{0}\end{array}$ & $\begin{array}{l}0 . \\
0 .\end{array}$ & $\begin{array}{l}0 \\
0\end{array}$ & $\begin{array}{l}0 . \\
0 .\end{array}$ & $\begin{array}{l}0 \\
0 \\
0\end{array}$ & $\begin{array}{l}0 . \\
0\end{array}$ & $\begin{array}{l}0 . \\
\underline{0}\end{array}$ & $\begin{array}{l}0 . \\
0 .\end{array}$ & $\begin{array}{l}\mathbf{0} \\
\underline{0}\end{array}$ & $\begin{array}{l}0 \\
0\end{array}$ & $\begin{array}{l}\mathbf{0} . \\
\overline{0} .\end{array}$ & $\begin{array}{l}0 . \\
0 .\end{array}$ & $\begin{array}{l}0 . \\
0 .\end{array}$ & $\begin{array}{l}0 . \\
0 .\end{array}$ & $\underline{0}$ \\
\hline $\begin{array}{l}0 . \\
0 .\end{array}$ & $\begin{array}{l}0 . \\
0 .\end{array}$ & $\begin{array}{l}0 . \\
0 .\end{array}$ & $\begin{array}{l}0 . \\
0 .\end{array}$ & $\begin{array}{l}0 . \\
0 .\end{array}$ & $\begin{array}{l}0 . \\
0 .\end{array}$ & $\begin{array}{l}0 . \\
0 .\end{array}$ & $\begin{array}{l}0 . \\
0 .\end{array}$ & o. & $\begin{array}{l}0 . \\
0 .\end{array}$ & $\begin{array}{l}0 . \\
0 .\end{array}$ & $\begin{array}{l}0 . \\
0 .\end{array}$ & $\begin{array}{l}\mathbf{0} . \\
0 .\end{array}$ & $\begin{array}{l}0 . \\
0 .\end{array}$ & $\begin{array}{l}0 \\
\underline{0}\end{array}$ & $\begin{array}{l}0 . \\
0 .\end{array}$ & $\begin{array}{l}0 . \\
0 .\end{array}$ & $\begin{array}{l}0 . \\
0 .\end{array}$ & $\begin{array}{l}0 . \\
0\end{array}$ & $\begin{array}{l}0 . \\
0 .\end{array}$ & $\begin{array}{l}0 . \\
0 .\end{array}$ & $\begin{array}{l}0 . \\
0 .\end{array}$ & $\begin{array}{l}0 \\
\overline{0}\end{array}$ \\
\hline
\end{tabular}

ROOM NAME $=$ ROOM WITH GLASS AREA FACING SOUTH

$\begin{array}{rrrrrrr}\text { MONTH } & \text { DAY } & \text { MHR } & \text { OLMAX } & \text { CLDAY } & \text { HLDAY } & \text { DHA } \\ 7 & 21 & 14 & -4483 . & =39486 . & 0.7\end{array}$

YEAR $=2000$ MONTH $=7$ DAY $=21$

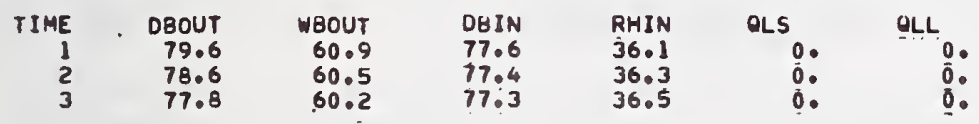




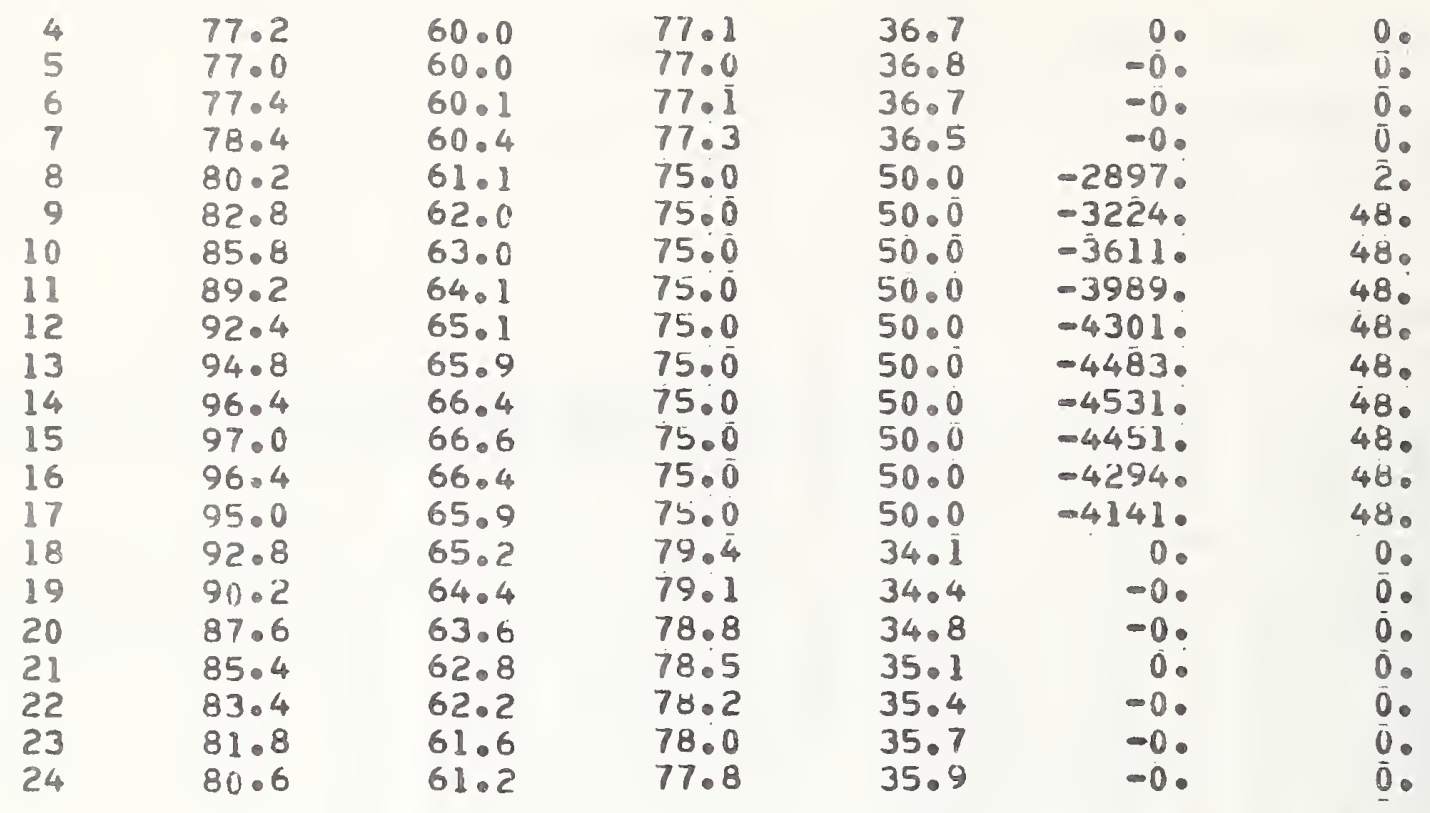

$D B A=85.74$

QLDSUM $=-39486$

TOTAL COOLING CONSUMPTION PER DAY $=-39486$. BTU

TOTAL HEATING CONSUMPTION PER DAY = 0. BTU

TOTAL COOLING CONSUMPTION FOR THE ROUM OVER THE I DAY PERIOD $=-.39486 E \$ 0 \$ B T U$

TOTAL HEATING CONSUMPTION FOR THE ROOM OVER THE I DAY PERIOD $=.42152 E-033$ BTU

TOTAL COOLING CONSUMPTION FOR I ROOMS $=-.39486 E \$ 05$ BTU

TOTAL HEATING CONSUMPTION FOR I ROOMS $=.42152 E=03$ BTU

DATA SHEET NO 4: NAME OF THE ROOM

STOP L

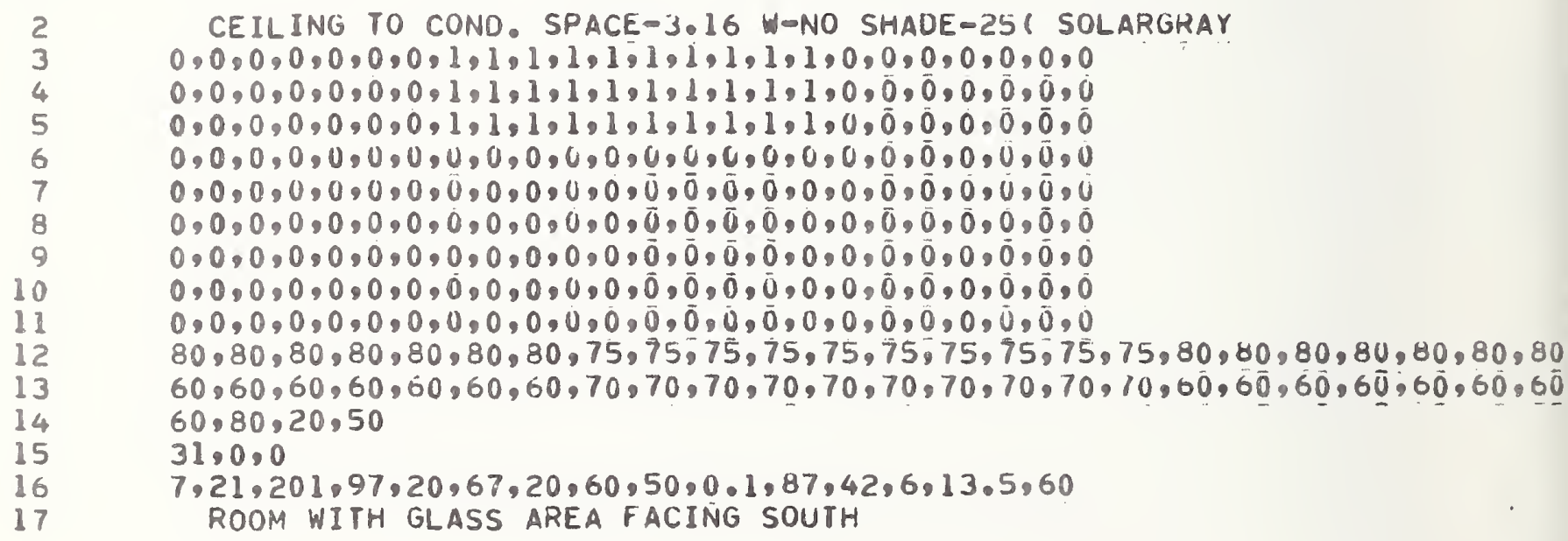




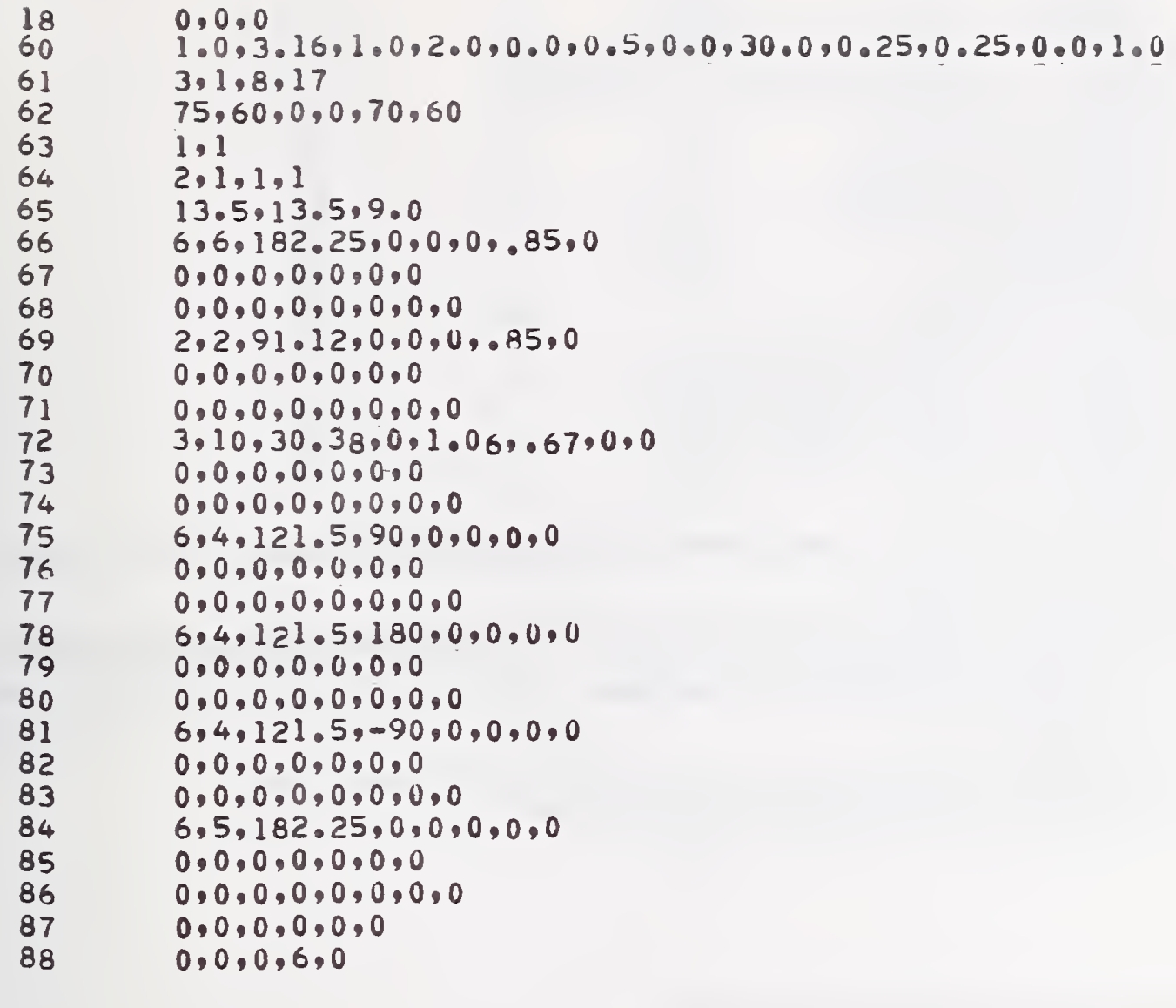

CONGRATULATIONS!! NOW YOU ARE ON NGSLD

WE ASSUME YOU HAVE ALREADY PREPARED THE DATA ON NBS DATA FORMS.. IF YOU HAVE NOT', PLEASE TURN OFF THE TERMINAL AND HAVE YOUR DATA READY ON THE DATA FORMS

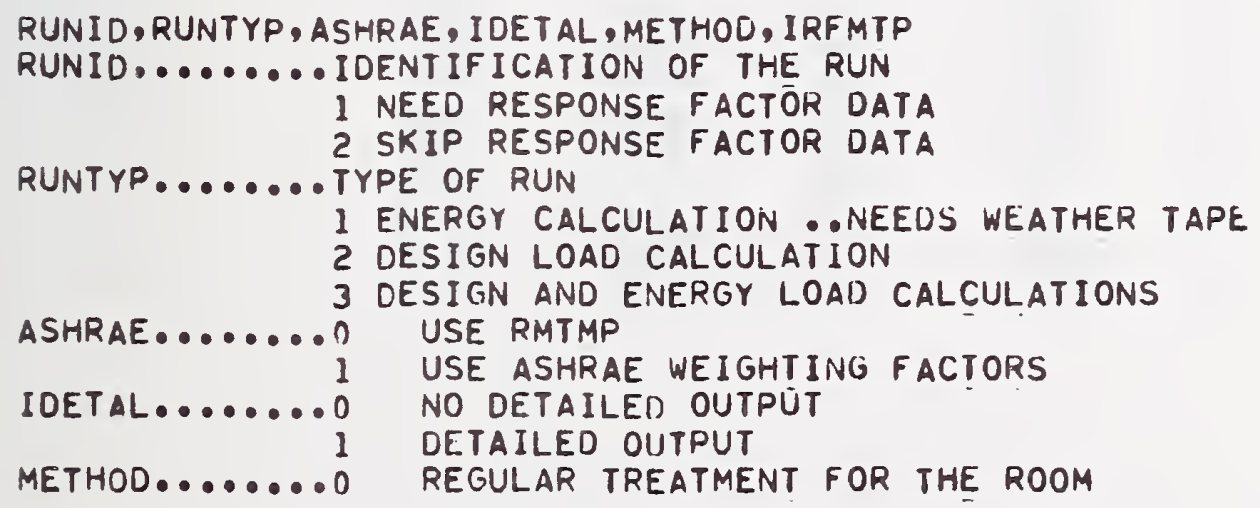


1 SPECIAL TREATMENT OF THE ROOM

OUTPUT TAPE UNIT NO. TO ROSS MERIWETHER

SYSTEM SIMULATION PROGRAM. IF NO TAPE IS

DESIRED, IRF $A T P=0$

CEILING TO CONO. SPACE-3.16 W-NO S

LIGHTING SCHEDULE. FOR WEEKDAYS

EQUIPMENT USAGE SCHEDULE FOR WEEKDAYS

OCCUPANCY SCHEDULE FOR WEEKDAYS

LIGHTING SCHEDULE FOR WEEKEND

EQUIPMENT SCHEDULE FOR WEEKENDS

OCCUPANCY SCHEDULE FOR WEEKEND

LIGHTING SCHEDIILE FOR THE VACATION PERIOD

EQUIPMENT USAGE. SCHEDULE FOR THE VACATIION PERIOD

OCCUPANCY SCHEDIIE FOR THE VACATION PERIOD

THERMOSTAT SETTING FOR THE COOLING SEÁSON

THERMOSTAT SETTIING FOR THE HEATING SEASON

RMDBWO, RMOBSO, RHW, RHS

DATA SHEET NO I:NDAY,NSKIP,TAPEZ

DATA SHEET NO 2 ¿ 3 :MONTH,DAY,ELAPS, UBMAX, RANGE, WBMAX, DBMWT, TGS, TGW, UG, LUNG,LAT, IZN, ZLF, RHOW

DATA SHEET NO \&: NAME OF THE. ROOM

DATA SHEET NO $5:$ IROT,ISKIP, INCLUDE

DATA SHEET NO 8: ROOMNO, QLITY, QEQPY, GCU,FLCG,FRAS, TS, CFMS, ARCHGS, ARCHGW, AKCHGM, ZNURM

DATA SHEET NO.9: IW, IL, ISTART, ILEAVE

DATA SHEET NO 10: TUL, TLL, OCHAX, QHMAX, OBVMAX, DBVMIN

DATA SHEET NO 11: ITHST,ITK.

DATA SHEET NO 1?: NS,NW,NN,NE,L,W,H

DATA SHEET 13 AND 14: ROOM SIJRFACE DATA AND EXTERIOR SURFACE SHAUUW UATA

DATA SHEET NO 15: UENDW, UCELNG, AENUW, ATCHT, AIRCHG, AIRNT

DATA SHEET NO 16: IEXTSO, IEXMS, IEXME,NTVNT,NVENT

ROOM NAME $=$ ROOM WITH GLASS AREA FACING SOUTH

\begin{tabular}{|c|c|c|c|c|c|c|}
\hline MONTH & UAY & MHR & QLMAX & CLDAY & HLDAY & UBA \\
\hline 1 & 1 & 13 & 0 . & -0 . & 0. & 33.4 \\
\hline 1 & 2 & 8 & 2558. & -0 . & 13858. & 24.0 \\
\hline 1 & 3 & 8 & 2625. & -0 . & 10834 & 28.8 \\
\hline 1 & 4 & 15 & -1074. & -4118 & 3971. & 41.8 \\
\hline 1 & 5 & 6 & 0 . & -0. & 0 . & 36.1 \\
\hline 1 & 6 & 20 & 0 . & -0 . & 0 . & 51.3 \\
\hline 1 & 7 & 8 & 2023 . & -0 . & 10091. & נל. 5 \\
\hline 1 & 8 & 8 & 1723. & -0 . & 9349. & 35.5 \\
\hline$i$ & 9 & 8 & 1372. & -0 . & 4460. & 36.7 \\
\hline 1 & 10 & 12 & -256. & -316 & 4195. & 37.6 \\
\hline 1 & 11 & 9 & 2710. & -0 . & 16146. & 28.5 \\
\hline i & 12 & 16 & 0 & -0 . & 0 & 32.6 \\
\hline 1 & 13 & 15 & 0 . & -0 . & 0 . & 37.5 \\
\hline 1 & 14 & R & 2667. & -0 . & $13764^{\circ}$ & 24.4 \\
\hline 1 & 15 & 9 & 3459. & -0 . & $24939^{\circ}$ & 17.4 \\
\hline
\end{tabular}




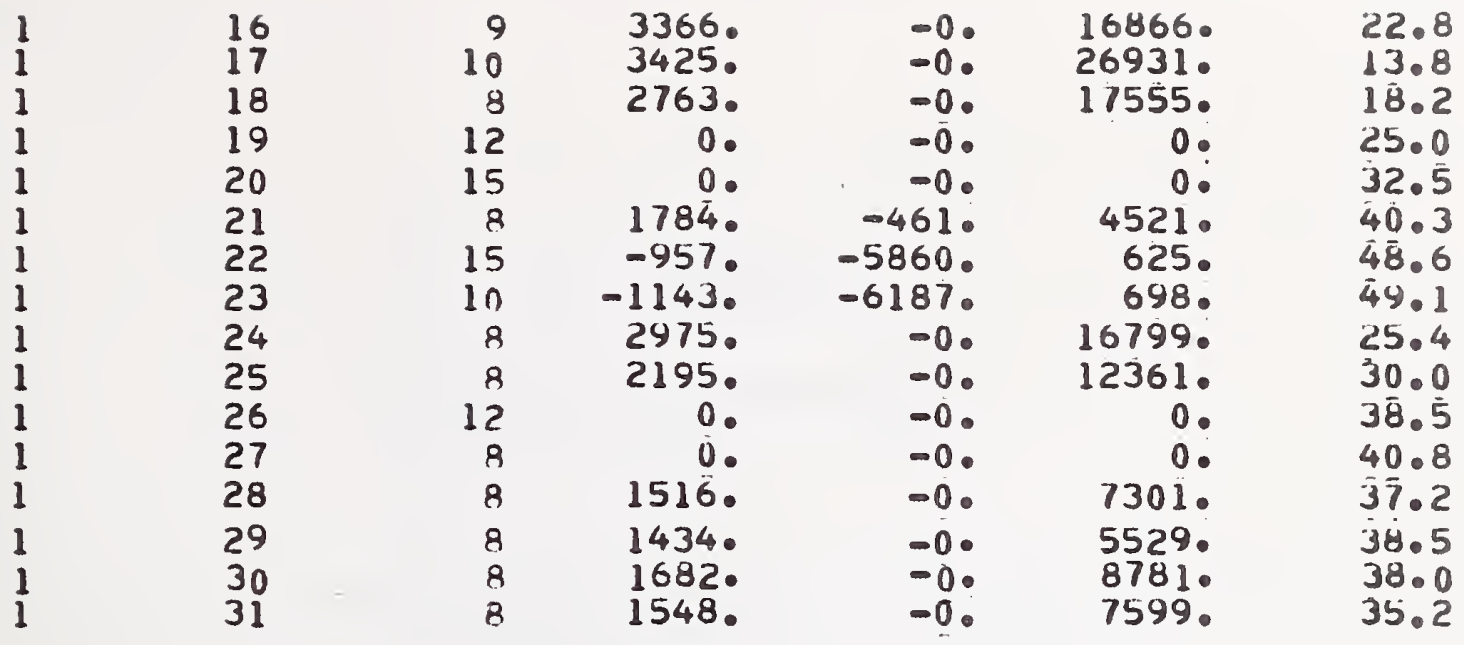

TOTAL COOLING CONSUMPTION FOR 1 ROOMS $=-.16941 E+05$ BTU TOTAL HEATING CONSUMPTION FOR 1 ROOMS $=.23717 E+06$ BTU DATA SHEET NO 4: NAME OF THE ROOM STOP 



\section{Appendix D}

\section{Fortran Listing of NBSLD}

Although the attached Fortran listing of the NBSLD routine basically embodies the algorithms of Appendix A, some of the subroutines are considerably simplified if compared with the exact adaptation of Appendix A.

It is cautioned also that the Fortran used herein is the INFONET version of Fortran V, which is somewhat different from the ANSI standard Fortran. 

1
2
3
4
5
6
7

8

9

10

11

12

13

14

15

16

17

18

19

20

2.1

2?

23

2.4

25

26

27

28

29

30

31

32

3.3

34

35

36

37
SURROUTINE ABCUR $(Z, K, L, G, A, B, C, D, N L)$

DIMFNSION AX(10), $B X(10), C X(10), 0 X(10), G(10)$ REAL K(IO),L (IC)

$P I=4 . \forall A T A N(1$.

$P P=P T$ H $(.5$

DO $50 \mathrm{I}=1$, NL

IF $(G(I)) \quad 40,40,10$

10

IF (7) $30,30,20$

20

$Z Q=\operatorname{S\cap RT}(Z / G(I))$

$Z O L=Z()+L_{-}(\mathrm{I})$

$C O=9 T N(Z O L)$

C $]=\cos (Z Q L)$

$\mathrm{SI}=\mathrm{C} \cap / \mathrm{ZQ1}$

$S 2=(S 1-C 1) / / Q L / Z O L$

$\mathrm{AX}(\mathrm{I})=\mathrm{C}, \mathrm{l}$

$B X(T)=L(I) / K(I) * S I$

$C X(T)=-Z O L * K(I) / L(I) * C . O$

$D \times(T)=C 1$

GO TO 50

30

$\Delta X(T)=1$.

$C X(T)=0$.

$D X(T)=1$.

$B X(T)=L_{-}(I) / K(I)$

GO TO 50

$40 \quad A X(T)=1$.

$R X(T)=1 / K(I)$

$\mathrm{CX}(\mathrm{T})=0$.

$D X(t)=1$.

50 CONTTNIIE

$A=A \times(1)$

$\mathrm{B}=\mathrm{B} \times(1)$

$\mathrm{C}=\mathrm{C} \times(1)$

$D=0 \times(1)$

IF (NL.LT.2) GO TO 60

CALI MILT $(A X, B X, C X, D X, A, H, C, D, N L)$

60

ENI) 
ABCDP2-PNC

1

2

3

4

5

6

7

8

9

10

11

12

13

14

15

16

17

18

19

20

21

22

23

24

2.5

26

27

28

29

30

31

32

33

PAGE I

SURROUTINE AHCDPZ (L,K,L,G,AP,HP,CP, I)P) REAI K,L

$P I=4$ * ATAN (1.)

IF (G) $30,30,10$

$10 \quad P P=P I / 4 \cdot / 6$

IF (7) $40,40,20$

$20 \quad Z Q=S \cap R T(Z / G)$

$Z \mathrm{QL}=7 \mathrm{Q}: \mathrm{L}$

$X=L * L=5 / G$

RE. $S=L / K$

$C O=S I N(Z O L)$

$C)=\operatorname{cns}(Z O L)$

$\mathrm{SI}=\mathrm{CO} / \mathrm{ZQL}$

$S 2=\left(S 1-C_{1}\right) / Z Q L / Z(I L$

$A P=X * S 1$

$B P=x * R F S * S 2$

$C P=x *(S 1+C 1) / R E S$

$D P=x * S 1$

GO TO 50

30

$A P=n$. :

$B P=$.

$C P=$ ?

$D P=n$.

SO TO 50

40 CONTINIJE

$X=L * L * 0.5 / G$

$A P=x$

$R P=x * L / K / 3$

$C P=K / L * X * 2$.

$\mathrm{DP}=\mathrm{X}$

GO TO 50

$5 n$

RETIIRN

END 
SUBROUTINF ADJUST (QL, (DLATNT, MONTH,NK, JJ)

IF (MONTH•GF. . ANI),MONTH・L.E.Q) GO TI) 1

IF (QL) 2.?.4

2. IF (JJ.GT.1) GO TO 5

IF (NK.LT.R.OR.NK.GT.17) GO TO 5

4 RETIIRN

1 I. $F(O L) \quad ., 5.5$

6 IF (.1.J.GT.1) GO rO 5

IF (NK.LT.Q.OR.NK.GT.17) GU TO 5

RFTURN

$5 \mathrm{AL}=0$.

(). $\triangle T N T=0$.

RETURN

END 
SURROIT INE ATTIC $(X, Y, Z, C R, N K, U X, F O, I) H, U S U, V, U S K Y, T O S, T I$, INEW, TA, I IM, OX

PAGE , 


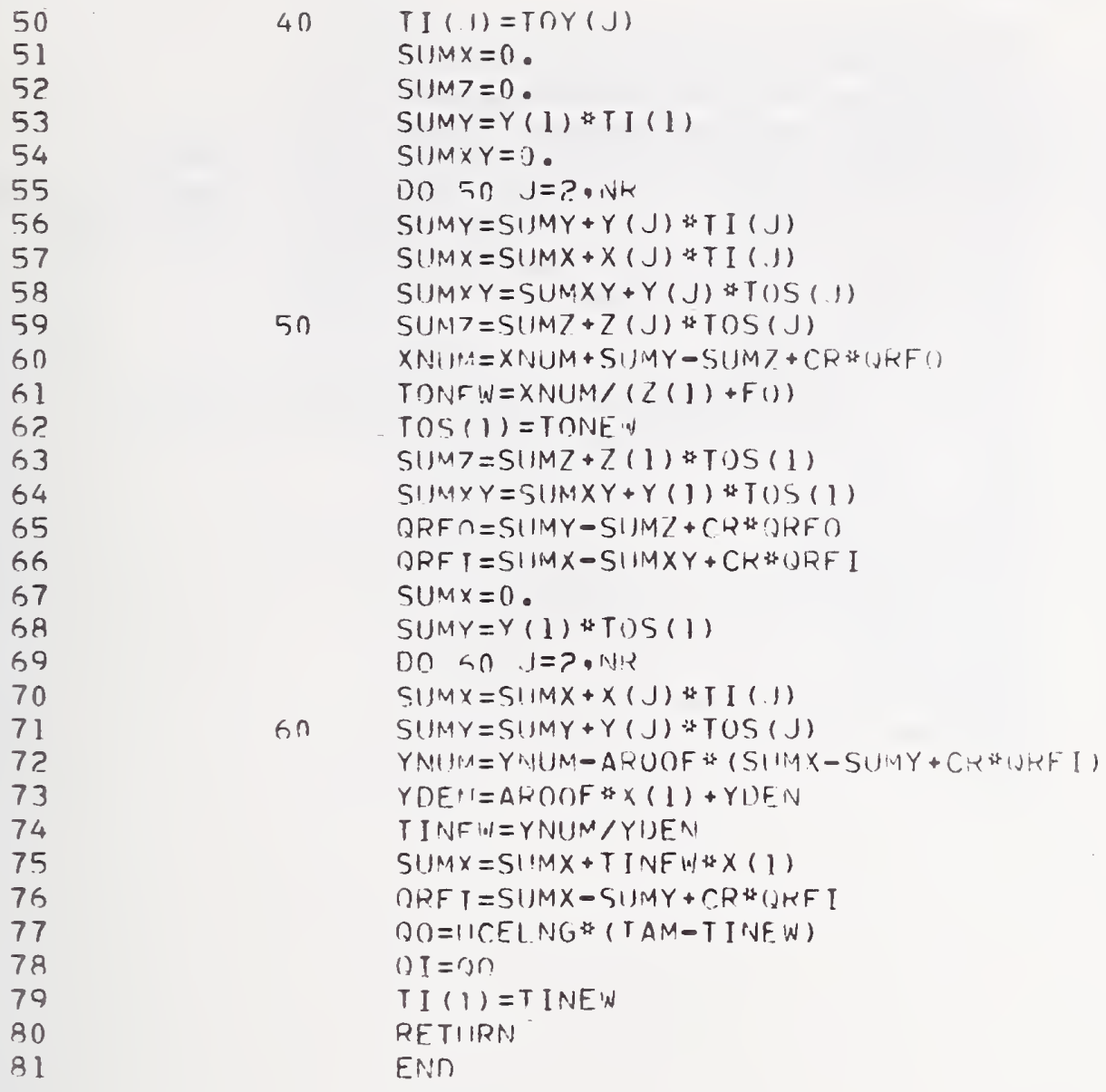


PAGE I

FUNCTION CCF (IS, CA, TOC, TCA,P, (Q,R,CC)

DIMFNSION CA $(4,3), T U C(4,3)$

DIMFNSIDN PP (4)/1.06.0.96.0.95,1.14/

DIMFNSION Q(2) 4 )/.012,.033..030,.003/

DIMFNSIDN RR (4)/-.0084,-.0106,-.0108,-.0082/

$\mathscr{H}$ IS: SEASON INDEX ( $1=$ SPRING, $2=$ SUMMER, $3=A U T U M N, \quad 4=$ WINTER)

$\alpha$ CA (T.J): AMOUNT OF I-TH TYPE CLOIII) AT J-TH LAYER TOC (I.J): I-TYPE CLOHD AT J-TH LAYEK

TCA: TOTAL CLOUID AMOUNT

CC: CLOUD COVER

CCF: CILOUD COVER FACTOR

P.R.R: TABLE A-6, PAGE 16A, NBSLD REF. MANUALL $x=0$

$D O \& I=1,4$

DO $1 \mathrm{~J}=1,3$

$1 \quad X=X+C A(I, J)$

$C C .=T C A-0.5 * x$

$P=P P($ IS $)$

$n=00($ I $S$ )

$R=R P(] S)$

$C C F=P+(J * C C+R * C C * 2$

RETIIRN

END 
CCM-PNC

1

2

3

4

5

6

6.1

6.?

6.3

6.4

7

8

9

10

11

12

13

14

15

16

17

18
PAGE I

FIJNCTION CCM (SALT, NTYPE, TC)

REAI CC1 (10)/.60,.60,.58,.54,.57,.53,.44..43,.3b,.27/

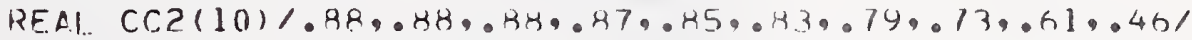

REAI CC3(10)/.84,.83,..43,.H?..80,.14..14,.67,.060,.44/

REAI. CC4 (10)/1.,1..1..1...94..98,.75,.90,.84,.741 IT $C=T C$

IF (ITC.NE, O) $\quad$ GO II) 5

C.CM=

GO TO 50

5 CONTINIIF

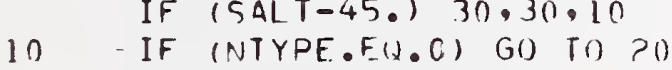

$C C M=C C ?(I \mathrm{TC})$

Gก $T \cap 50$

$20 \quad \mathrm{CCM}=\mathrm{CC}_{4}(\mathrm{ITC})$

(G) TO 50

30

IF (NTYPE.EW.0) GO TO 40

$C C M=C C I(I T C)$

(G) $T \cap 50$

$40 \quad$ CCM $=$ CC $3($ I TC)

50 HFTIIRI

ENI 
DRRH-PNC

$$
\begin{aligned}
& 1 \\
& 2 \\
& 3 \\
& 4 \\
& 5 \\
& 6
\end{aligned}
$$

PAGE I

SUBROUTINF DHRH $(D H, R H, W)$

$P V S=P V S F(\cap R)$

$P V=R H * P V S / 100$.

$W=0.62 ? * P V /(29.92-P V)$

RETURN

FND 
PAGE I

SUAROUT INE UECOLE (WPOSX, NI ONGX, NIJM,GUTPUI, MM, YK, MU, UAY,LOCAL)

THIS SUHROUTINE PRODUCFS HOIJLY DATA IOF UR TO 10 WEATHEK

PARMMETERS FOR D GIVEN YEAR, MO ANI UATE

TAPE OOSOITIUN FOP EACH OF TEN PARAME.TEKS AKE

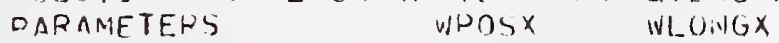

PAGE I 
54

55

56

57

58

59

60

61

62

63

64

65

66

67

68

69

70

71

72.

138
PAGE ?

2. $\operatorname{IPS}($ II $)=\operatorname{IPS}(I)+J * 498$

DO $? I=1,24$

$K I=T P S(I)$

$K L=K I+W L O N G-1$

DO $401 \quad L ?=K I, K L$

$I W=T C H A R(L ?)$

CALI. WDX (IW)

401 ICHAR $(L 2)=I \mathrm{~W}$

L.ONG =WL.ONG-1

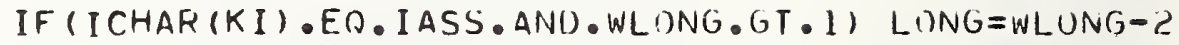
WORN =AHS (ICHAR (KL))

IF (I.ONG. $\mathrm{EQ} .0)$ GO TO 3

IPINP=

DO $5 J K=1$, LONG

$I P W D=I P W R * 10$

$5 W O R \cap=W O R D+I C H A R(K L-J K) * I P W R$

IF (ICHAR $(K L) \cdot L T .0) \quad W O R D=-W O R D$

3 DUTPIIT $(I \cdot K(U)=W O R D$

402 CONTINUE.

RETURN

EN() 


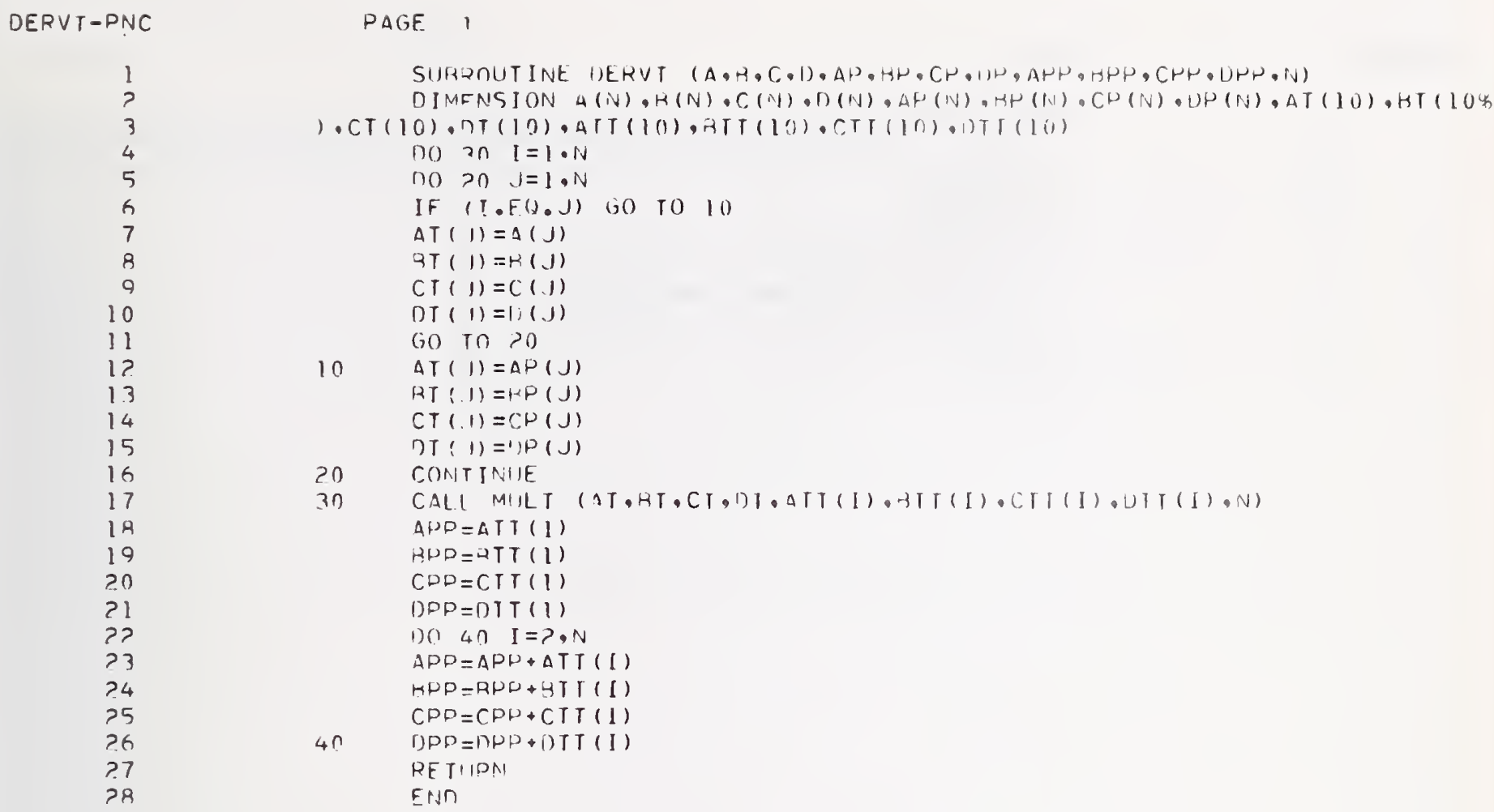


$D P F=P N C^{\circ}$

1

5

2.1

2.3

3

4

5

6

7

8

9
PAGE I

FUNCTION DPF (PV)

\% THIS SIJBROUTINF CALCULATES DEW-POINT TEMPERATURE HOR GIVEN VAPOR PRE IF (PV) $1 \cdot 1 \cdot 2$

1 GO TO 20

2 CONTINIIE

$Y=\operatorname{Ln} R(P V)$

IF (PV.GT. ח.lB36) GO) TO 10

$D P F=71.9 R+24.8734 Y+0.8927 * Y * Y$

GO TO ?0

10

$D P F=79 \cdot 047+30 \cdot 579 * Y+1.889 .3 * Y * Y$

?0 RETIIRN

ENI) 
DST - PNC

1

2

3

4

5

6

7

8

9

10

11
PAGE $\quad 1$

SURDOUTINE ISST (YK,MO,1)AY,1)STX,1)STY)

INTFGER YR, UAY, DSTX, DSTY

NDAY $=W K D A Y(Y R, M O,[) A Y)$

IF (MO).LT.4.OR.MO,GT.10) GO TO 10

IF (MO.EQ.4.AND,DAY.LT.24) 60 TO 10

IF (NDAY,EQ.1) DSTX $=1$ ) AY

IF (MO.E(J.10.ANI).DAY.L.T.24) GO Ti) 11)

IF (NDAY.E(J,I) DSTY $=$ DAY

IO CONTIMUE

RETIIRN

END 
ERROR-PNC

1.

?

3

4

5

6

7

8

9

10

11

12

13

14

15

16

17

18

19
PAGE I

SURPNUTINE ERROR(IDATA,K)

DIMFNSION MAX(10)/100,100,150,150,150,3500,10,10,99,999/

DIMFNSTON MIN $(10) / 0,0,-40,-40,-40, ? .000,0,0,0, n /$, IUATA (24)

DO,$J=1 \cdot 24$

$I Z=T \cap A T A(J)$

IF (T) OGT.MAX (K)) GO TO 1

IF (T7.LT.MIN(K)) GO TO l

GO in ?

1 CONTINUE

2 ID $A T A(1)=I Z$

DO $4 \quad J=2,24$

$I Z=\operatorname{InATA}(J)$

IF (IT • (IT.MAX (K)) GO TO 3

IF (TT.LT.MIN(K)) GO TO 3

GO $\ln 4$

$3 \operatorname{IDATA}(J)=\operatorname{IDATA}(J-1)$

4 CONTINIJE

RETIIRN

ENI 
FARC-PNC

1

PAGE 1

FUNCTION F $(A, H, C)$

\% $\quad$ RC = RECEIVING SIJRFACE

* $\quad A B=$ SENOING SURFACE

क $F(A, H, C)=F R O M \quad A H$ TO $B C$

क $\quad(A * A) * F(A, H, C)=(B * C) * F(C, H, A)$

क $\quad F(C, R, A)=F(A, H, C) * A / C$

$P I=2.14159$

$X=A / R$

$Y=C / H$

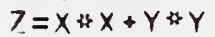

$A Z=A \operatorname{LOG}((1,+X * X) *(1,+Y * Y) /(1,+\angle))$

$A 3=Y * Y * A L O G(Y * Y *(1,+7) /(1,+Y * Y) / Z)$

$A 4=X * X$ i* $A L O G(X * X *(1,+7) /(1,+X * X) / 7)$

$A 5=Y * 4 T A N(1, / Y)$

$A G=X * A T A N(1, / X)$

$A 7=C D R T(Z) * A T A N(1 \cdot / S(J R T(L))$

$S(M A=(A 7+A 3+A 4) / 4 \cdot+A 5+\Delta G-A 7$

$F=S I I M / O I / Y$

RETIIPN

FII? 
$F C T R=P N C$

1

?

3

4

5

6

7

8

9

10

11
PAGE 1

SURROUTINE FCTH (L.W.H.SF)

REAI. L, SF $(6,6)$

THIS ROUTINE CALCULATES RASIC RAIIATIOV SHAPE FACTURS FUR A RUOM. RADIATIUN SHAPE FACTOR Tก

C CEIIING

S SOUTH WALL

W WEST WALL

N NORTH WALL

E EAST WALL

F FLOOR $F^{-}(H, L, W)=(H * L)=-*(L * W)$

FROM C S W W n Finl $H$ FLWH FWLH FLWH RMF

QM = REMAINDER

$F H L{ }^{\prime} d=F(H, L, W)$

$F H W=F(H, W, L)$

$F I V L H=F(W, L, H)$

$F W H I=F(W, H, L)$

$F L W H=F(L, W, H)$

$F L H I M)=F(L, H, W)$

$R M C=1 .-2 *(F H L W+F H I N L)$

$R M S=1 .-2 *(F W L H+F W H L)$

$R M W=1,-2 *(F L W H+F L H W)$

$R M N=R M S$

RME $=$ RMIN

$R M F=R M C$

$\operatorname{SF}(1 \cdot 1)=0$.

$\operatorname{SF}(1,2)=F H L W$

$S F(1,3)=F H W L$

$\operatorname{SF}(1.4)=F H L W$

$\operatorname{SF}(1.5)=F H$ WL

$S F(1,6)=R M C$

$\operatorname{SF}(2 \cdot 1)=F \mid V L H$

$\operatorname{SF}(?, 2)=0$.

$\operatorname{SF}(2.3)=F W H L$

SF $(?, 4)=$ PMS

SF $(? .5)=F W H L$

$\operatorname{SF}(>, 6)=F W L H$

$\operatorname{SF}(3,1)=F L W H$

$\operatorname{SF}(2.2)=F L H|a|$

$\operatorname{SF}(2.3)=0$.

$\operatorname{SF}(3.4)=F L H W$

$\operatorname{SF}(7.5)=R M N$

$\operatorname{SF}(2,6)=F L W H$

$\operatorname{SF}(4 \cdot 1)=F W L H$

$\operatorname{SF}(4 \cdot 2)=R M N$

$\operatorname{SF}(4,3)=F$ WHL

$\operatorname{SF}(4,4)=0$.

$\operatorname{SF}(4,5)=F W H L$

SF $(4,6)=F W L H$

$\operatorname{SF}(5,1)=F L W H$

PAGE I
FHL

$$
0
$$

FLHW

RMN

FLHW

FHLW

$W$
FHWL
FWHL
$\sigma$
FWHL
RME
FHWL

N

FHLW RMS

E

FHIWL

F WHL

FLHW RMW

$\mathrm{F}$ WHL

FLHW

F HLW

FHWL 
51

$5 ?$

53

54

55

56

57

58

59

60

61

6 ?

63
$\operatorname{SF}(5,2)=F L H W$

$\operatorname{SF}(5,3)=\operatorname{RME}$

$\operatorname{SF}(5.4)=F L H W$

$\operatorname{SF}(5.5)=0$.

$S F(5 \cdot 6)=F L W H$

$\operatorname{SF}(6 \cdot 1)=R M F$

$\operatorname{SF}(\kappa, ?)=F H L W$

$S F(6,3)=F H W L$

SF $(6,4)=F H L W$

$\operatorname{SF}(6,5)=F H W L$.

$S F(R \cdot 6)=0$.

RETIIRN

ENII 
THIS SUBROUTINE CALCULATES DUTSIUE SURFACE HEAT TRANSFEK COEFFICIENTS, FOT ANU FOC

FOT.... RADIATION PLUS CONVECTION

FOC.... CONVECTION

V.....WIND VIVLOC.ITY IN KNOTS

SURROUTINE FO (V, IS, FOC,FOT, IWD)

DIMENSION $A(6) / 0,01) .001,0 .,-0.002,0 .,-0.00125 /, B(6) / .464,0.320,0.38$

$30 \cdot 0.315 \cdot n \cdot 244 \cdot 0 \cdot 262 /, C(6) / 2 \cdot 04 \cdot 2 \cdot 20 \cdot 1 \cdot 90 \cdot 1 \cdot 45 \cdot 1.80 \cdot 1 \cdot 45 /$ $V P=V * 1.153$

$F D T=A(I S) * V P * V P+B(I S) * V P+C(I S)$

* IWID=1 IF THE SURFACE IS WINDWARU OK PAKALLEL TU THE WINO

* IWD=0 IF THE SIJRFACE IS L.FFIVARU

IF $(I W D \cdot E(\cdot \bullet \cdot)) \quad G O T O \quad 20$

IF $(\mathrm{VP}-7.0) 20, ? 0,10$

10

$F O C=0.23 * V P+1.02$

15

16

17

18

19

GD Tก 30

$20 \quad F O C=? .63$

30 RETIIRN

END 


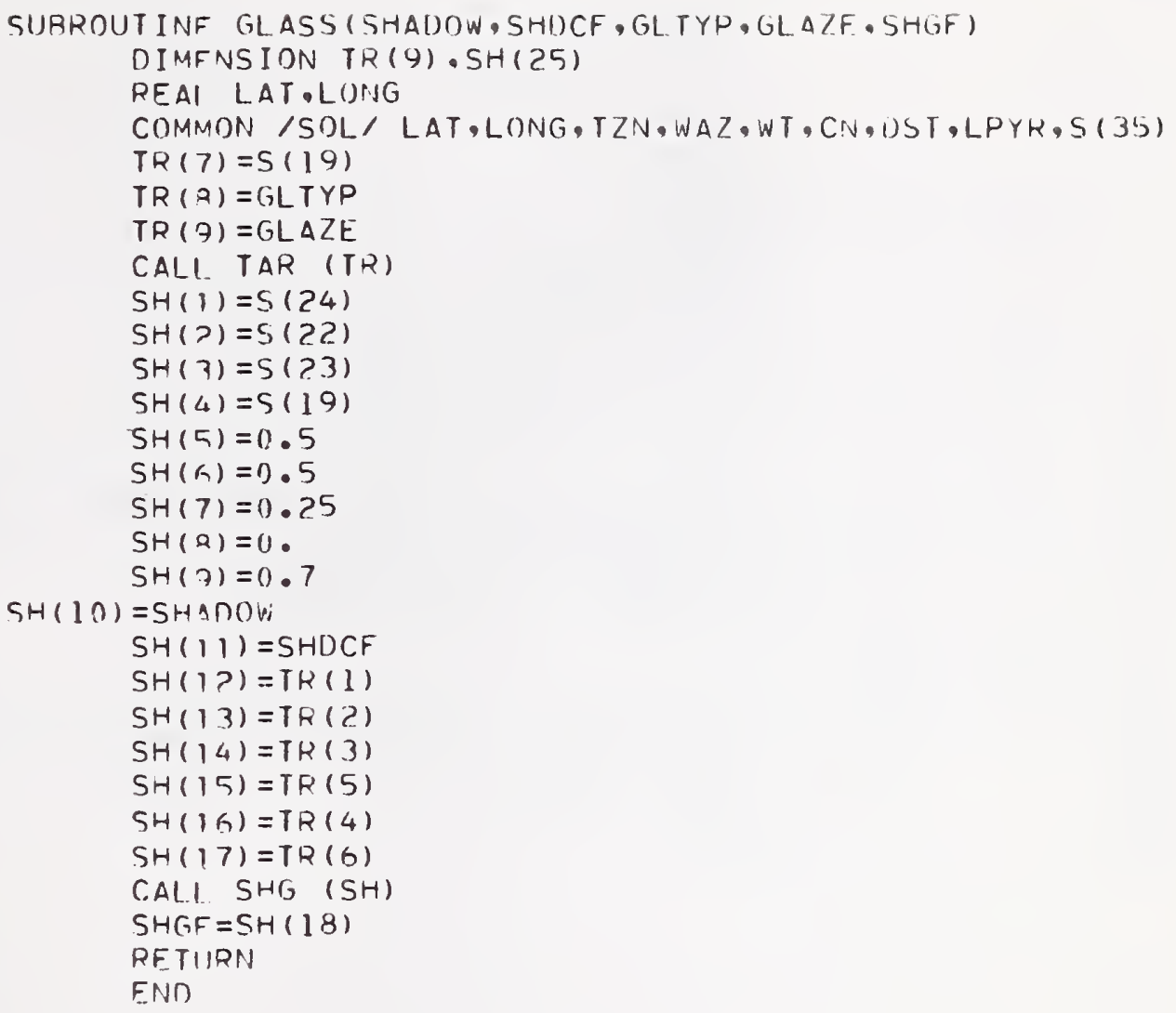


GPF - PNC

1

2

3

4

5

6

7

8

9

10

11

12

13

14

15

16

17

18

19

20

21

22

23

24

25
PAGE I

SURDOUTINE GPF $(U, Z L, Z)$

DIMFNSION Z(1)

$P I=4$. $A T A N(1$. SQTDT $=S O R T(P I)$

$D I 2=2 \cdot / P I$

$E B=0.001$

$n B=0.1$

WR ITF $(6,30)$

WRITF $(6,40)$

$Z(I)=2 * Z L * S(J R T(U) / S Q T P I$

$Z Z=7(1)$

$Z(2)=7(1) *(\operatorname{SQRT}(2)-2$.

DO $10 k=3,50$

$Z K=K$

$10 \quad Z(K)=Z(1) *(S Q R T(Z K)-2 * S R T(Z K-1)+S) H T(Z K-2)$. DO $>0 \quad K=1,50$

20 WRITF $(6,50) \quad K, Z(K)$

RE.TIIRN

$\%$

\%

$\%$

30

40

50

FORMAT $150 \mathrm{HO}$

FORIAAT $150 \mathrm{HO}$

RESPONSE FACTORS FOR

FORMAT (1I10,3F 10.5)

END 
HOLDAY - PNC

1

2

3

4

5

6

7

8

9

10

11

12

13

14

15

16

17

18

19

20

21

22

23

PAGE I

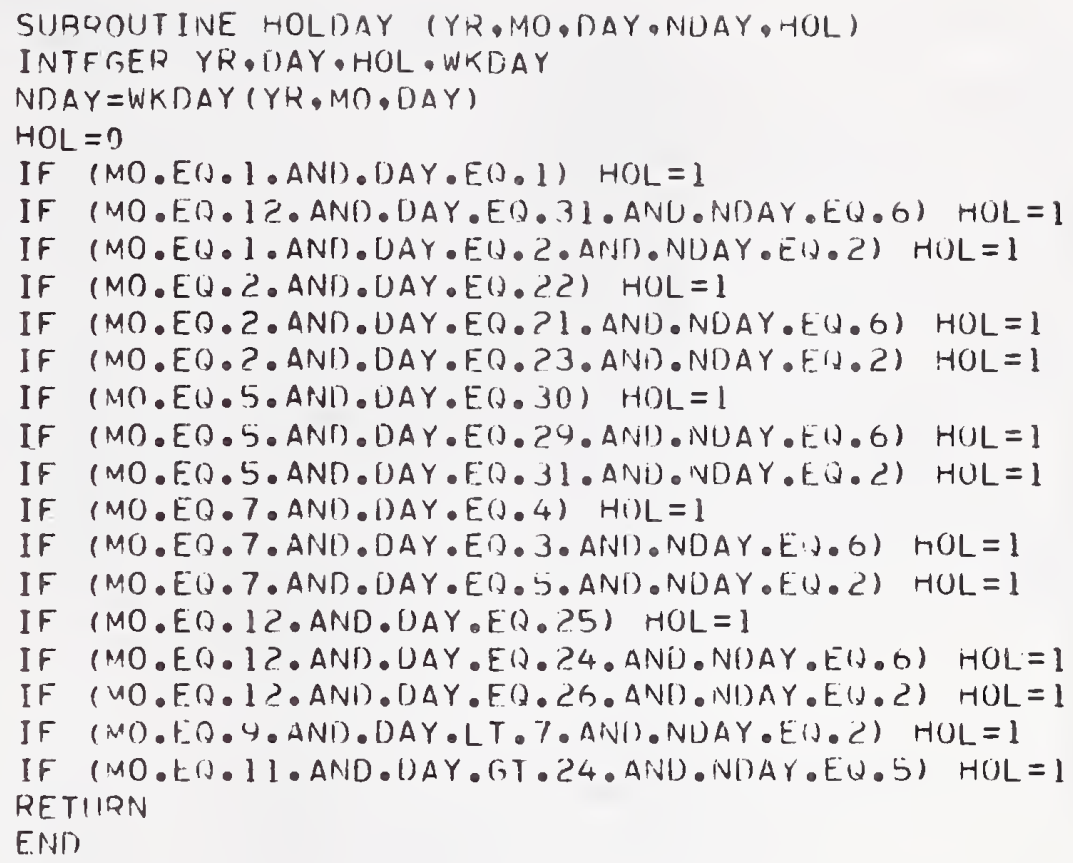


MUL T-PNC

]

2

3

4

5

6

7

8

9

10

11

12

13

14

15

16

17

18

19

20

21

2.2

23

PAGE I

SURROUTINE MULT $(A, B, C, D, A T, B T, C T, D T, N)$

DIMFNSION $A(N), B(N), C(N), D(N)$

$A T T=A(1)$

$B T T=R(1)$

$C T T=C(1)$

$D T T=D(1)$

IF (N.LT.Z) GO TO 20

DO $10 \quad \mathrm{~J}=5, \mathrm{~S}$

$A T=A T T * A(J)+B T T * C(J)$

$B T=A T T * B(J)+B T T * U(J)$

$C T=C . T T * A(J)+() T T * C(J)$

DT $=C T T * B(J)+U T r * D(J)$

$A T T=A T$

$B T T=B T$

$C T T=C T$

$10 \quad$ DTT $=$ DT

GO TO 30

$20 \quad A T=A T T$

$R T=A T T$

$C T=C T T$

DT $=\cap T T$

30

RETUIRN

END 
NRSLI-PNC

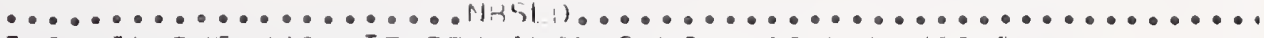

THIS IS THF ROOM TFMPFRAIURE CALCULAI IUN KIOUIINE

DF THF NATIONAI RIJNEAII UF STLNIIARISS

NHGI I) IS A RESEAKCH PROGHAM UF NHS FUR THE PUKPUSE OF STIIIYING, HEATING, ANU COULING LOAI) ANU RUOM TEMPERATURE ()F आIILUING, UNISER ACIIIAL WFATHER CONWITIUN

A(I) AREA IIF SURFACE I FTC

ARSO(I) SULAR HEAT AHSURPTIU'V CUEFFICIENI FUR SURFACE I. TIIS DATA RFOUIREU FIRR OPAUUE SURFACES UNLY.

AF Norit

$\Delta r$ A.WEA OF THE ATIIC ENI) NALL. FTZ

AIMCHE (अWUNA TEAT TLANSFFK AKEA. FTZ $(M A Y=U$.

A IF.UT

ARC.HAS ग. IF ATSIC AIR CHA.JGES PEK HK, DAYTIME

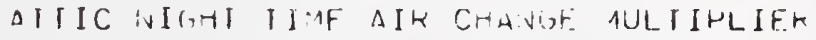
ADC:UR, '11. IF AIK CHANGES DER HK IN SUMMER N11. OF AIK CHAJGES PEK HR IN WINTER $\triangle \mathrm{TCACP}$ $\triangle V F H T$, Ni). OF ATIIC AIR CAANGES HEK TH (UAY UK NIGHT) AVERAGE HOUEIY HEAT GAIN ENTIRE BUILDING, BTU/HR ATW' (T)

HI $1, \cdots A x$ CFMI C.F M.IV CFM1.1T CI. IIAY WALL AZIMUTH ANGLE FOR SIIRFACF I, UEGREES SIUTH $=n$. NEST $=411$.

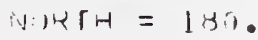
FiST $=-\rightarrow 1)$. MIILOFNG MAXIHUM SENSIHLF HEAI GAIN, BTU/HR SUMMEL INFII TRATION WATE, FTH/MIIN. VEITILATIUV KATE. FT3/UIV. NINTRL INF ILTHATII)N. FT3/AMIN. 1) ALr TUTAL ENERGY CUIVSUARIIUN FOH A GRUOP (NUWA OF THE H, JF QUUMS UF THE SAME CUNF IGI J A I ION, HTII

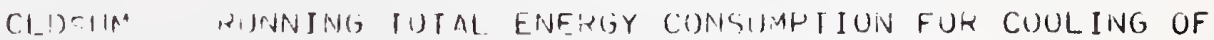
ALL THE RUDAS IN A HUILIMING UVER A SEI TIME HFR[1)i: HTI]

$\mathrm{CN}^{\mathrm{N}}$

Cri (1)

$D A Y$

1) $\triangle Y=K P$

CLEAWIE SS RUIIMISER

RE SPONSE FACTIR CIMMUN KAIIU FUR CONSTRICTION L liair TF YE $\triangle$ P

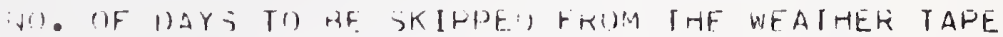
(FROM ITS LAST STARTING PUSIIIUNV)

(1) ${ }^{2}(1)$

1) HA

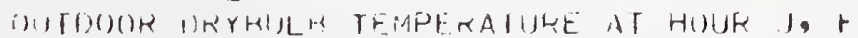

1) $\mathrm{H}^{2} \mathrm{I}^{2}$

Dhis

1) $R M \times x$ WAILY AVERAGE DITSIDE DKYAULH TEMPERATURE, F

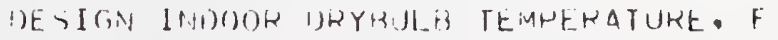
()) YNIJLH MEAN, F ISF. IITN (OITIOOI)R MAXIMUM ORYMULL TEMPËRAIURE, F

DHA, $1,1 T$ DE JIGN NINTEK (JUTUUOR DRYAULA IEMPEKATURE, F

DHNRS ( 1) FWACTION UF HANGF. TO USE FOK DESIGN PRUF ILE AT HOIJK,

1)P

1) $P$ In

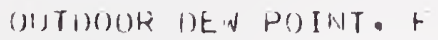
1) $P$ TN IIJOOOL DEW POINT. F DP (1) I)ESIGT INUDOR UE PUI PUT, F RF SWONSE FACTOR COMAON RATIU FUR CMASTRUCTIUN L ('AME. AS CR(L)) 
52

53

54

55

56

57

58

59

60

61

62

63

64

65

6h

67

68

59

70

71

$7 ?$

73

74

75

76

77

78

79

80

81

क?

83

84

85

86

87

89

89

9ก

91

9?

93

94

95

96

97

98

99

100

101

NHSL T-PNC

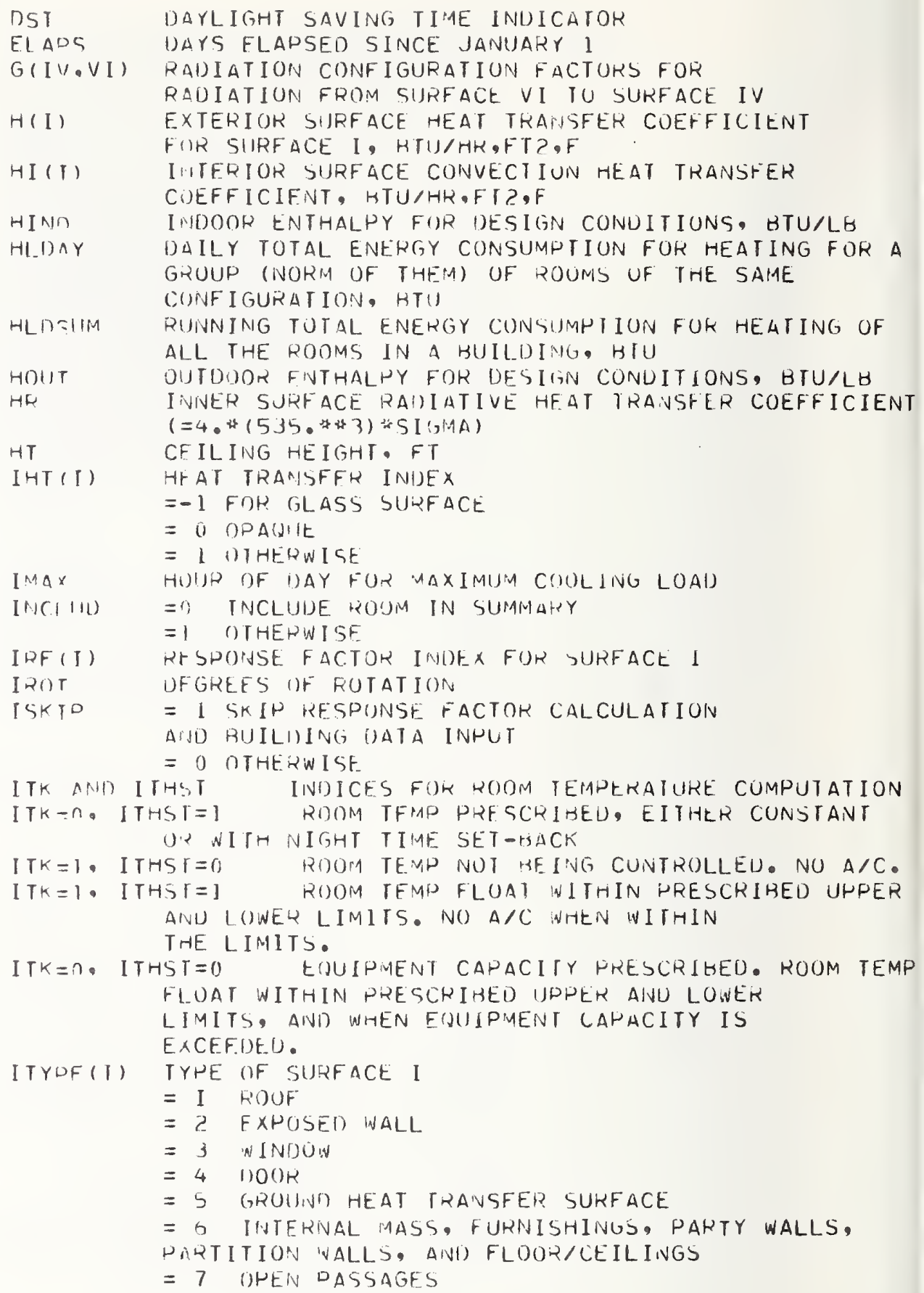




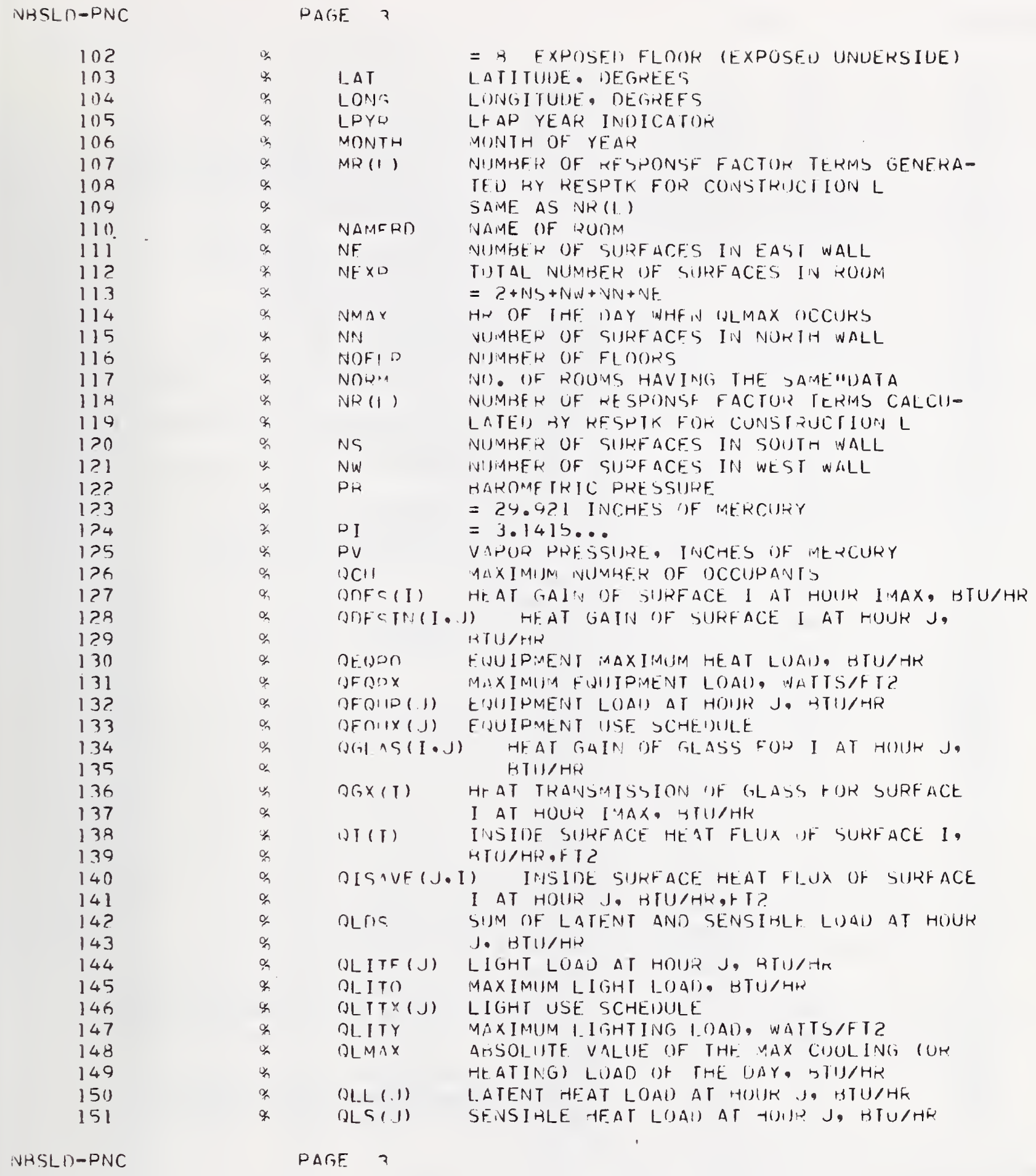




\begin{tabular}{|c|c|c|c|}
\hline INBSLク-PNC & & PAGE & \\
\hline 152 & $\alpha$ & $\partial O(T)$ & OIITSIDE SURFACE HEAT FLUX UF SURFACE I, \\
\hline 153 & $\%$ & & HTU/HR, FT? \\
\hline 154 & o & $\operatorname{OACPS}(1)$ & OCCIJPANT LOAI) AT HOUK J, HIU/HR \\
\hline 155 & * & $0 \cap C(I P(J)$ & OCCIIPAIVT SCHFUULE \\
\hline 156 & $\alpha$ & QPFOPL (J) & PEOPLE LATENT LOAA AT HUIJR J. HTU/HR \\
\hline 157 & $\mathscr{*}$ & DPLX & MAX UCCUPANT LATFNT LOAU, HTU/HK.PEKSUN \\
\hline 158 & $q$ & DPSX & MAX OCCUPANT SENSIRLF LOAU, BTU/HR. PFKSUN \\
\hline 159 & $\mathscr{x}$ & QSAVE $(M, J)$ & HEAT GAINS AND LOAUS AT HOUR J, HTU/HR \\
\hline 160 & 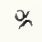 & & $M=1$ TIME. HK \\
\hline 161 & $\not h$ & & $M=?$ SFINSIBLE HEAT GAIN, BTU/HR \\
\hline 162 & $\alpha_{n}$ & & $M=3$ LATENT HEAT GAIN, HTU/HK \\
\hline 163 & $\%$ & & $M=4$ SENSIBLE LOAL, HTII/HR \\
\hline 164 & क & & $M=5$ TOTAL LOAN, HTU/HK \\
\hline 165 & o & (JSKY I I J) & HEAT KADIATED TO GKY HY SIJRFACE I T \\
\hline 166 & \% & & H()UR J, HTU/HK, FI? \\
\hline 167 & $\%$ & $1 S \mathrm{SIMT}$ & SUM OF TOTAL HEAT GAINS FUR 24 HUURS. \\
\hline 168 & * & & $B T U / H R$ \\
\hline 169 & $\%$ & OS(I:I(I.J) & IHCIDENT SOLAR KAOIATION FOH SURFACE I \\
\hline 170 & $\mathscr{h}$ & & AT HOIIR J, KTU/HR.FT2 \\
\hline 171 & o & DTL $(1)$ & LATENT HEAI GAIN FHUM INFILTRAIIUN AT \\
\hline $17 ?$ & \% & & HOUR J. HTI//HR \\
\hline 173 & q & OW INT & HFAT LOSS IN ININTFR. HTU/HK \\
\hline 174 & $c_{n}$ & RANGF & DAILY RANGE OF OUTDOOK URYHULK, F \\
\hline 175 & q & RHIV & DEISIGN INUOOR RELATIVE HIJWLOITY \\
\hline 176 & $\alpha$ & RHOIIT & DESIGN OUTDOOR RFLATIVE HIIMIIITY \\
\hline 177 & $\Psi$ & ROOMNOS & ROOM NUMHER \\
\hline 178 & क & $\mathrm{S}$ & INFORMATIUN ARRAY REQNUIREI) HSY SUIRUIJ- \\
\hline 179 & \% & & TINE SUN AIND GLASS \\
\hline 180 & क & SHANE (J) & SHADING CDEFFICIENT FOR SUKFACE I \\
\hline 181 & क & SIGMA & $=0.1714 \mathrm{E}-9$ \\
\hline 182 & क & $\operatorname{SITFLU}(J)$ & OVERALL CUOLINS; LI)AII AT THUR J. HTU/HR \\
\hline 183 & $\%$ & SITFOL (J) & OVERALL LATENT HEAT GAIN AI HUIJK J. \\
\hline 184 & $\mathscr{n}$ & & BTU/HR \\
\hline 185 & 常 & SITF()S (J) & OVERALL SEIVSIBLE HEATT GAIN AI HUIJR J. \\
\hline 186 & $\%$ & & HTU/HR \\
\hline 187 & $\%$ & SITF.TH(J) & OVERALL TOTAL HEAT GAIN IT HUUU J. \\
\hline 188 & क & & BTU/HR \\
\hline 189 & \% & SITMAX & OVERALL MAXIMIJM HEAT GAIN, HTU/HR \\
\hline 190 & क & SOTнTX & OVERALL HEAT GAIN AT HOIJR IMAX, HIU/HR \\
\hline 191 & क & SQLIN & TOTAL COOLING LOAD, BTU/HIR \\
\hline 192 & \% & SOWINT & OVERALL TOTAL HEAT LUSS, HTU/HR \\
\hline 193 & \% & TA & ROOM AIR TEMPERATURE, F \\
\hline 194 & \% & TASAVE (J) & RNOM AIR TEMPERATURE AT HOUR J, F \\
\hline 195 & 苏 & TCLLO & DAILY RUNNING TOTAL ENERGY CONSUMPTION \\
\hline 196 & $\%$ & & FUR COOLING FOR A GHOUP (INORM UF THEM) \\
\hline 197 & क & & OF ROOMS HAVING THE SAME CONF I GURAIION, \\
\hline 198 & \% & & BTU \\
\hline 199 & \% & TG & DESIGN SUMMER GROUNO TEMPEKATURE, F \\
\hline 200 & $\%$ & TGW & DESIGN WINTER GROUND TEMPERATUKE, F \\
\hline 201 & \% & THTLO & DAILY RUNNIJNG TOTAL ENERGY CUNSUMPTIUN \\
\hline$D-P N C$ & & $A G E$ & \\
\hline
\end{tabular}


PAGE $\square$

$202 \%$

203 \%

204 \%

205

206

207

208

209

210

211

212

213

214

215

216

217

218

219

220

221

222

223

224

225

226

227

228

229

230

231

232

233

234

235

236

237

238

239

240

241

242

243

244

245

246

247

248

249

250

251

NBSLD-PNC
क

$\%$

$\%$

क

\%

क

क

क

$\%$

क

क

$\%$

$\%$

\%

क

o

क

क

क

$\%$

$\%$

$\%$

q

क

क

क

\%

乐

$\%$

क

$\%$

क

\%

क

$\%$

क

$\%$

क

क

क

$\%$

$\%$

$\%$

क

\%

\%

\begin{tabular}{|c|c|}
\hline & $\begin{array}{l}\text { FOR HEATING FOR A GRUOP (NORM OF THEM) } \\
\text { OF ROOMS HAVING THE SAME CONFIGURATION, } \\
\text { BTU }\end{array}$ \\
\hline$(1)$ & $\begin{array}{l}\text { INSIDE SURFACE TEMPERATURE RELATIVE TO } \\
\text { THE REFERENCE TEMPERATURE AT HOUR J }\end{array}$ \\
\hline $\mathrm{F}$ & INSIDF. SURFACE TEMPERATURE AT HOUR J. \\
\hline 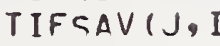 & 1) INSIDE SURFACE TEMPERATURE OF SUK \\
\hline & FACE I AT HOUR J, F \\
\hline IM & $\begin{array}{l}\text { INDOOR UESIGN MEAN (REFERENCE TEMPERA- } \\
\text { TURE), F }\end{array}$ \\
\hline 10 & INDOOR DESIGN TEMPERATURE, \\
\hline & $\begin{array}{l}\text { INSIDE SURFACE TEMPERATURE RELATIVE TO } \\
\text { THE REFERENCE TEMPERATURE OF SURFACE I } \\
\text { AT HOUR J,F }\end{array}$ \\
\hline IX & $\begin{array}{l}\text { INDOOR DESIGN DRYBULA TEMPERATURE AT } \\
\text { HOUR } J, F\end{array}$ \\
\hline NEII 11 & UPDATFD OUTSIDE SURFACE TEMPERATURE OF \\
\hline 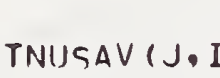 & $\begin{array}{l}\text { SURFACE I AT EVERY TIMF INCEMENT, F } \\
\text { (1) UPDATEO OUTSIDE SURFACE TEMPERA }\end{array}$ \\
\hline & OF SURFACE I AT HOUR J. F \\
\hline OS & DUTSIDE SURFACE TEMPERATURE \\
\hline & $\begin{array}{l}\text { REFERFNCE TEMPERATURE OF SURFACE I AT } \\
\text { HOUR J, F }\end{array}$ \\
\hline & TOTAL COOLING LOAD FOR A HUUM, BTU/HR \\
\hline & $\begin{array}{l}\text { ARRAY USED FOK TEMPORARY STORAGE OF } \\
\text { VALUES WHILF AUVANCING TEMPERATURE AS }\end{array}$ \\
\hline & REQUIRED BY RESPONSE FACTOR METHDO \\
\hline & MAXIMUM TOTAL COOLING LOAI), HTU/HK \\
\hline & $\begin{array}{l}\text { TOTAL OVERALL HEAT GAIN FOIK } 24 \text { HUURS, } \\
\text { BTU/HR }\end{array}$ \\
\hline TV & IEMPERATURF OF VENTILA \\
\hline & TIME ZONE NUMBEER \\
\hline & $\begin{array}{l}\text { OVERALL HEAT TRANSFER COEFFICIENT FOK } \\
\text { SURFACE I }\end{array}$ \\
\hline UCF.I.NG & $\begin{array}{l}\text { OVERALL HEAT TKANSFER COFFFICIENT UF } \\
\text { THE CEILING BETWEEN THE ATTIC AIR ANU } \\
\text { THE ROOM AIR BELOW }\end{array}$ \\
\hline UE! & $\begin{array}{l}\text { OVERALL HEAT TRANSFEK CUEFFICIENT OF } \\
\text { THE ATTIC ENIDWALL }\end{array}$ \\
\hline & GROUND HEAT TRANSFER COEFFIO \\
\hline & WINTER GLASS HEAT TRANSFER CDEFFICIENT \\
\hline & U VALUE WITHOUT SURFACE RESISTANCES \\
\hline & OOOR AIR SPECIFIC VOLIJME., FT $3 / \mathrm{LB}$ \\
\hline VOL & OUTDOOR AIR SPECIFIC V(ILUME, FT $3 / L H$ \\
\hline VT ( & ME AS UT (I) \\
\hline WA & $\begin{array}{l}\text { OUTDOOR AIR HUMIIITY RATIO, LS OF HZU } \\
\text { VAPOR PER LB OF DRY AIR (= WUUT) }\end{array}$ \\
\hline & $\begin{array}{l}\text { WALL AZIMUTH ANGLE MEASIIRED CLUCKWISE } \\
\text { FROM SOUTH, DEGREES }\end{array}$ \\
\hline & DESIGN INOOOR WETHULH TE \\
\hline
\end{tabular}

FOR HEATING FOR A GRUOP (NORM OF THEM) OF ROOMS HAVING THE SAME CONFIGURATION, INSIDE SURFACE TEMPERATURE RELATIVE TO THE REFERENCE TEMPERATURE AT HOUR J TIF (J) INSIDF. SURFACE TEMPERATURE AT HOUR J, F FACE I AT HOUR J, F
TIM INDOOR UESIGN MEAN IREFERENCE TEMPERA-
TIO TURE),$F$
INSIDE SURFACE TEMPERATURE RELATIVE TO THE REFERENCE TEMPERATURE OF SURFACE I HOUR J, F UPDATFD OUTSIDE SURFACE TEMPERATURE OF ) UPDATEU OUTSIDE SURFACE TEMPERATKE OUTSIDE SURFACE TEMPERATURE RELATIVE TO REFERFNCE TEMPERATURE OF SURFACE I AT

TOTHTX TOTAL COOLING LOAD FOR A HUUM, BTU/HR ARRAY USED FOK TEMPORARY STORAGE OF VALUES WHILF AUVANCING TEMPERATURE. AS TOTAL OVERALL HEAT GAIN FOM 24 HUURS, BTU/HR

TIME ZONE NUMBELR OVERALL HEAT TRANSFER COFFFICIENT FOK

THE CEILING BETWEEN THE ATTIC AIR ANU THE ROOM AIR BELOW

THE ATTIC ENIDWALL GROUND HEAT TRANSFER COEFFIICIENT U VALUE WITHOUT SURFACE RESISTANCES INDOOR AIR SPECIFIC VOLIJMF, FT $3 / \mathrm{LB}$ SAME AS UT (I) OUTDOOR AIR HUMIIITY RATIO, LE OF HCO VAPOR PER LB OF ORY AIR (= WUUT) FROM SOUTH, DEGREES

DESIGN INOOOR WETHULH TEMRERATURE, F

PAGE 5 
WJMAX UESIGN OUTDOOR WETHULB TFMPERATURE, F WBSAVE (J) INUOOR WETHULH TFMPERATURF AT HOUR J, F WID DESIGN INDOOR HUMIOITY RATIO, LB OF HZO VAPOR/LH OF ORY AIR

WIN INDOOR HIJMIOITY RATII), LM HQU/LE ORY AIL

WOIJT DESISIN OIJTDOOP HIJMIUITY RAIIO. LB HOO VAPOR/LB DRY AIR

WROT DEGREES OF ROTATION FOR RII)M

WT

WALL TILT ANGLE $(=9 i)$. IJE (gREE'S WMFN VERTICAL WALL)

WV VENTILATION AIR HIMIUIITY KAI [U, LH HPU VAPOR/LB DRY AIR

$X(L, N)$ $X X(N, L)$

$Y(L, N)$ RESPONSE FACTOLS FOK CUNSTRUCTIUN L TRANSPOSE OF ARRAY $X$ RESPOINSE FACTORS FOH CONSTHUCTIUN L $Y Y(N, L)$ $Z(\mathrm{I}, \mathrm{N})$ TRANSPOSF OF ARRAY Y RESPONSE FACTORS FOR COINSTKIJCTION L

ZRLIG INPUT ARRAY FOR HIILIIING ANU EXIFHNAL UATA ZPOOM INPUT ARRAY FUR ROOM WATA

$Z Z(N, 1)$

COMMON /CC/ X(10,IO0), Y $(10,100), Z(10,100),[1 Y Y P F(30), 1 H T(30)$, I RF $(30 \%$ ), AASP $(30), U(30), H(30), H I(30), A(30), U 1 T(30), T 1) S(30,4$ d), I [S $(30,4 H),(, k$

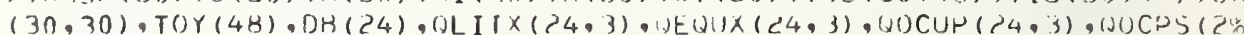

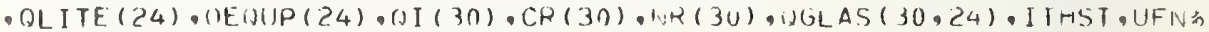

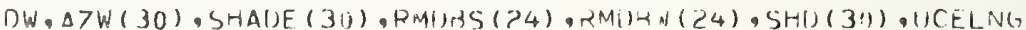
DIMFNSION $\times X(100,10), Y Y(100,10), Z \angle(100,10)$, TIUE W( 1100$)$, TI $(4 \pi), X 0) 1 M(1 \mathrm{~K}$

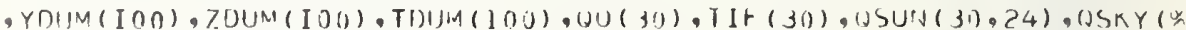

$30 \quad$ 24), NAMERM(9), NAMEBI) (7), VT (10), DR (10), MK $(10)$

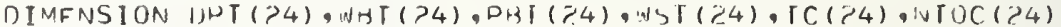
DIMFNSION SALT (2.4). IFDAY (1?) $115,46,74,106,135.100,196,2>7,258,280, \%$

$319, \quad 3491$

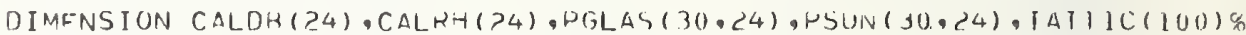
, OLS(24), (OLL (24) , LHLI)G(15), /ROO()M(1?) ,11W(30)

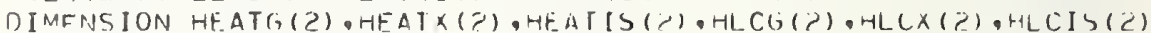
DIMFNSION I)HPF ( 24)/.87,.47,.46,.44, $1.01, .44, .43, .44, .71, .569 .346$

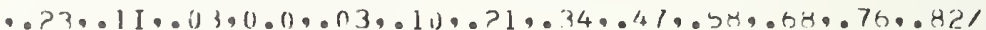
COMMONA/SHI) IV/SHAW $(30$, I 5$)$

DIMFNSION SH1JX(20), SHIJF $(30,24)$, AIRLK(24), (3) (1) ( $>4)$

DIMENSION V(15), PLAT (>4). AIRLAI (24), HALU( 24$), \forall A S E L(<4)$ INTFGER DSTX,DSTY,KUNII), RIINTYY, ASHLAE

RFAI LAT,LONG, NOFLR

INTFGER CITY, YEAR, TADF?

LOGICAL LLI,LL?

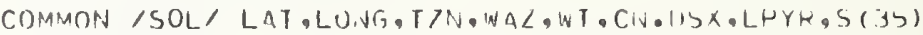
COMMUNON NSKP

$P I=? .1415927$

WiरITF $(6, I 0 b 1)$

WRITE (6, I05?)

PASE 
NBSLD-PNC

302

303

304

305

306

307

$30 R$

309

310

311

312

313

314

315

316

317

318

318.1

318.2

319

$3 ? 0$

321

322

323

324

325

326

327

328

329

330

331

332

3.33

3.34

335

336

337

338

3.39

340

341

342

343

344

345

346

347

348

349

NBSL $-P N C$

PAGE 7

WRITF (

WR ITF $(6,1054)$

WRITE $(6,998)$

998

FORMAT (// KUINID), RIINTYP, ASHRAE, IDE TAL, MEIHUU, NHAY /

- RIINID......... IDENTIF ICATION OF THE KUN $1 \%$

1 NEED RESPONSE FACTOR UATA $/ \%$

2 SKIP RESPONSE FACTUR UATA $1 /$ *

EIINTYP....... TYPE OF KUN $/ \%$

1 ENERgY CALCULATION .. NEEUS WEATHEK TAPE! /

2 DESIGN LOAI) CALCULATIUN $/ \%$

3 DESIGI ANI ENEKGY LUAU CALCULATIONS $/ \%$

ASHRAE_..... I ISSE RMTMP $/$ W

USE ASHRAE WEIGHTING FACTORS $/ \%$

NO DETAILED OUTDUT $/$ W

I)E TA ILEU OUTPUT?/为

REGULAR TREATMENT FOR IHE ROUM"/

SPECIAL TREATMENT (SF THE RUOMO/क

STANDARU SIMULAIIUN /

WET ROOF SIMULATIUN')

REAN (5, *) RIINID, RUNTYP, ASHRAF, IUE TAL, ME THUD, NHAY

CALI. OHEY ('EQIJATE \& RFTR',4)

IF (RINID,EQ.1) CALL OREY ('SWITCH ING:NHSBL 1, 5)

IF (DUNID.EU.Z) C.ALL TREY('SWITCH INB:NHSHLZ1,5)

CAL... OHEY ("EWUATE TAPE? (UUTI)AT', S)

REAR $(5,911)$ NAMERD

WRITF $(6,910)$ NAMEHD

REAT 24 HOIIR PROFILES FOR LIGMTING,EIUIWMENT ANU OCCUPANCY

$\mathrm{J} 3=3$

DO $10 \quad \mathrm{~J}=1 \cdot 33$

IF (1.FO.1) WRITE $(6,401)$

Qก 1 FORMAT(" LIFHTING SCHEDIILE FOH WEFKI) AYS')

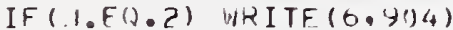

904 FONAAT(" LIGHTING SCHEDULE FOL WEEKFINLO)

IF ( 1.Fi. 3) WRITE $(6,4(17)$

907 FOR:"AT( LIGHTING SCHEI)ULE FUR IHE VACATIUN NERIUD')

REAO(5, *) (1)LITX(I, I) $I=1$, ? 4)

IF (1.FO.1) wKITE (6. Y0?)

902 FORMAT(" FQ:IIPMANT USAGE SCHEOULE FUH WFEKDAYSO)

IF $(1 . F \cap . ?)$ WiR ITF $(6.905)$

905 FOR"AT(" E(गIPNFNT SCHEI)ULE FOR WLEKENDS")

$\operatorname{IF}(1 . F \cap .3)$ WQITF $(6.90 \%)$

9OS FORYAT( EIUIPMENT USAGE SCHEUULE FIIR THE VACATIUN PERIOU')

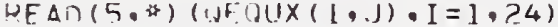

IF $(1 . F(1)$ 1) NRITE $(6,903)$

903

FORMAT ( OCCUPANCY SCHEI)ULE FOK WFFKI)AYS')

IF $(.1 . E() \cdot 2)$ WR ITE $(6, y 06)$

906 FONMAT (" OCCUPANCY SCHEI)ILE F()R IEEKENU')

IF (1.FO.3) WRITF $(5,4 \cap 9)$

909 FORMAT(" UCLUPANCY JCHFI)ILE F(JH THT VACAIIUN HFKIUD')

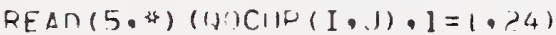

PALE 


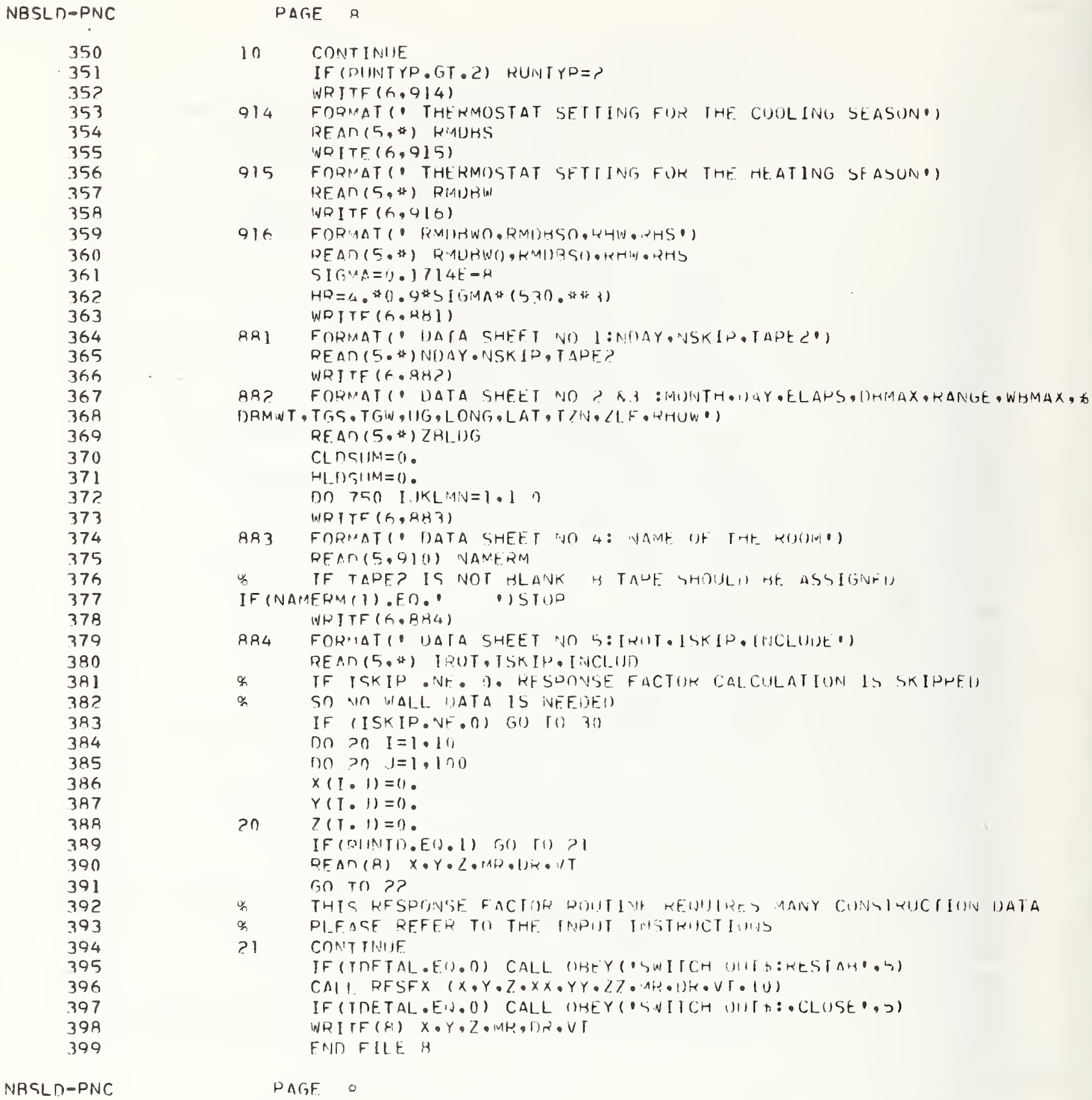


400

401

402

403

404

405

406

407

408

408.1

408.2

409

409.1

409.2

410

411

412

413

414

415

416

417

418

419

420

421

422

423

424

425

426

427

428

429

430

431

432

433

434

435

436

437

438

439

440

$44 I$

442

443

444

445

NBSLD-PNC
$2.2 P B=>9.921$

30 IF (JPOT.NE.0) GO TO 40 WROT $=0$.

WR I TF $(6,891)$

891 FORMAT ( DATA SHEET NO \&: ROOMNO, OLITY,UEUPY, UCU,FLCG,FRAS, IS, CFMS, ARCHGS, ARCHGW, ARCHGM, ZNORM,) REAN (5, \#) ZROOM WR I TF $(6,892)$

892 FORMAT ( OATA SHEET NO.9: IW, IL, ISTAKT, ILEAVEO)

REAก (5, क) IW, IL, ISTART, ILEAVE

WRITE $(6,893)$

893 FORMAT(' OATA SHEET NO IO: TUL, TLL, OCMAX, OHMAX \&UVMAX, DHVMINO) REAก (5, \#) TUL, TLL, (ICMAX, OHMAX, UBVMAX, DHVMIN

WRITF $(6,894)$

894 FORMAT ( UATA SHEET NO 11: IIHSI, IIK!)

RE AT (5, \#) ITHST, ITK

CALI ROOMX (NEXP,NS, NW,NN,NF, HT)

ROOMNO=ZROOM(l)

MONTH=ZBLDG(1)

$\triangle G=\Delta(N E \times P)$

NOFI $R=1$

$D C 1)=Z R O O M(4)$

$L A T=Z B L O G(12)$

LONG $=Z B L O G(I 1)$

$I Z N=7 R L D G(13)$

DAYSKP $=$ NSK IP

QL I TY $=Z R O O M(2)$

QEOPX $=Z R O O M(3)$

CFMYV=ZROOM( 8$)$

WAM $A X=Z B L O G(6)$

CFMS $=C F M V$

FLC,$=Z R O O M(5)$

$T G S=7 R L D G(B)$

TGW =7RLDG $(9)$

LDAY $=Z R L D G(2)$

$Y E A P=2000$

$D B W T=Z R L O G(7)$

OAM $\triangle X=Z B L D G(4)$

RHOW=ZBLDG (15)

$Z L F=Z B L D G(14)$

DAIN=RMDAW $(12)$

RHIN=RHW

IF (RUNTYP,EQ, $)$ ) CALL PSYI (DRMAX, WBMAX,PH,DPMAX, PV,WA,HA, VA, RHO)

$U G=7 R L D G(10)$

$T V=7 R O O M(7)$

$F R A C=Z R O O M(6)$

$Z N O R M=Z R O O M(I 2)$

$A R C H G W=Z R O O M(I 0)$

$C F M I T=\Delta G * H T * A R C H G W / 60$ • +CFMV

$A R C H G M=Z R O O M(1 I)$

CFMIN $=A G * H T * A R C H G M / 60$.

PAGE 9

PAGE 9

NBSLD-PNC 
NBSLD-PNC

446

447

448

449

450

451

451.1

452

453

454

455

456

457

458

459

460

451

462

463

464

465

466

467

467.1

468

469

470

471

472

473

474

475

476

477

478

479

480

481

482

483

484

485

486

487

488

488.1

489

490

491

492

NBSLD-PNC

PAGE I?

CNNST $=\triangle R$ CHGW/0.695

\% THFSF AIR CHANGF VALIJFS ARF FOR THF AITIC VENTILATIUN

\% RONM $\triangle T R$ CHANGF. VALUES WILL ME DFIERMINEU AS A RIMCTIUN

\% WJNT SPEFD AIND TEMPERATIRE WIFFFRENTIAL

40 CONT TNIIE

IF (INFTAL คF(Q.0) GO TO 50

WR JTF $(6.874)$

WRTTE $(6,790)$

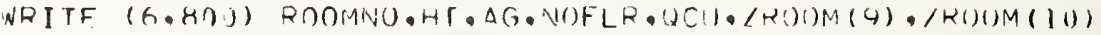

WRITF $(6.1010)$

50 CONTTINIE

$S(1)=L . \Delta T$

$S(?)=L O N G$

$S(3)=T 7 N$

IF (JDFTAL PF(X.U) GO TO) GO

WRITF $(6 . H 10)$

WRITF (6.8OO) LAT.LONG.TLN.ZNORM

WRITF $(6.1010)$

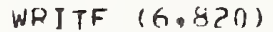

RHIAI=RHS

WRITF $(6,800)$ OLITY, DFINX,CF:AV,I)HIN.TG.TV, RHIN

WRITF $(6.1010)$

WDITF $(6,840) \quad$ NFXP, ITK, ITHST

WR ITF (6.874)

60 CONTINIUE

IF (TROT.NE. OI) GO TO 51

WRITF $(G \cdot 841)$

R41 FORMAT( DATA SHEET NO 15: UENOW,UCELIVG, AE NI)M A ACHT, AIHCHG.AIRHT I) RE.AD (5.*) UENDW,UCELNG,AENDW.ATCHT•AIKCHI), AIKIVT

WR ITF $(6,942)$

942 FORWAT(" DATA SHEET NO 16: IFXTSO, IFX:AS, IF XME NIVNT, VVVNT I/I

REAN (5. IEXTSD, IEXMS, IEXMF , NTVNT, YVFWI

$C F M N T=N T V N T * A G * H T / 60$.

61 CONTINUE

IF (IDETAL.E(1.0) GO TO 70

WRITF. $(6,1010)$

WR ITE $(6,830)$

WR ITE $(6.800)$ JENOW. IJCELNG, AENIJW, ATCH

70 CONTTINIE

IF (IROT.NE.O) GO TO $1 \mathrm{KO}$

SUPA $=0$.

DO $151 \quad I=1$, NEXP

$K=I P F(I)$

IF $(Y(K, 1), G T \cdot 1,) \quad \operatorname{IRF}(I)=10$

$N R(T)=M R(K)$

IF (IRF (I),$F Q \cdot 10) \quad N K(I)=1$

$U T(T)=V T(K)$

$C R(T)=D R(K)$

IF $(A P(I), E(0,0) \quad N R(I)=1$

IF $(N R R(I) \cdot G(\cdot 4 \pi) \quad N R(I)=48$

PAGE II 
NBSLD-PNC

493

494

495

496

497

498

499

500

501

502

503

504

504.1

505

506

507

508

509

510

511

512

51.3

514

515

516

517

518

519

519.1

520

521

522

52?.1

523

52.4

525

526

527

528

$5 ? .9$

530

531

532

533

533.1

533.2

533.3

534

535

536

NBSLD-PNC
PAGE 11

IF (ITYPE (I) EEQ.3) $\triangle A S P(I)=0$ 。

IF (ITYPE (I) .EQ.5) $\quad A B S P(I)=0$.

IF (TTYPE (I) , GE, G) ABSP(I) =0.

IHT $(I)=1$

IF (ITYPE ( I) EEQ.3) IHT (I) =- ]

$H(T)=S \cdot 0$

$H I(T)=1.46=H R$

IF (ITYPE (I) •Gt,5) H(I) $=0$.

IF (ITYPE (I) . E(J.1) HI (I) $=1.630-H R$

IF (ITYPE (I) .EO.5) HI (I) $=1.090-H R$

IF (TTYPF (I) .E(J.7) U (I) $=50$ n

IF (TTYPE (I) •E( $(1,8) \quad H(I)=1.46$

$I F(I R F(I), N E \cdot I n) \cup(I)=0$.

IF (1)(1)) $80,80,40$

$80 \quad R(1=1 . / U T(I)+1 . /(H I(I)+H 2)$

IF (TTYPE (I) .LT .5.OR.ITYPE (I) •F ( . . $) \quad W U=K U+I \cdot / H(I)$

US (I ) $=1 \cdot /$ HiU

QD CONTININE

IF $(x(k, 2)) 140,100 \cdot 140$

100 IF $(\mathrm{H}(\mathrm{I})) 110,120,11$ )

$110 R=1 . / U(I)-1 \cdot / H(I)$

(5) $10 \quad 130$

120) $R=1 . /(1)(I)$

$130 \quad U T(T)=1 . /(R-1 . /(H I(I)+H K))$

IF (IIT (I) $L L E \cdot 0$.$) UT (I )=? 8 . n$

IF (ITYPE (I) .EO.7) UT (I) $=500$.

140 CONTINIJE

IF (IICELNG) 150,150,141

141 IF (ITYPE (I).NF. I) GU TO 150

RTA $=1 . / U C F L N(;-) \cdot /(H I(I)+H R)$

IJT (T) $=1 . / R T A$

J50 CONTINIIE

IIW $(T)=U(I)$

IF (ITYPE. (I).GT •4) GO TO 15 I

SUM $=$ SUM $+A(I)$ WU(I)

15] CONT TNUE

Z $K=S ! J M / Z L F$

$F C=1 .-0.02+2 K$

160 IF (IRDT.EQ.0) GO TO 180

WROT $=$ IROT

DO $170 \quad I=1$, NEXP

$A Z W(T)=A Z W(I)+W R O T$

IF $\left(\Delta Z W(I) \cdot L L_{0}-180.\right) \quad \Delta Z W(I)=A Z W(I)+360$.

170 IF (AZW(I).GT.180.) AZW(I) $=A Z W(I)-360$.

DO IRI I=1 - NEXP

I) $181 \quad J=1$, NEXP

$181 \quad G(I, J)=R(I, J) / H R$

IRO CONTINIJE

IF (IDETAL.EQ(Q.0) GO TO 220

WRITF. $(6.950)$

PAGE 11 
NBSLD-PNC

537

538

539

540

541

$54 ?$

543

544

545

546

547

548

549

550

551

$55 ?$

55.3

554

555

556

557

$55 A$

559

560

561

561.1

561 .?

56?

56.3

564

565

566

566.1

567

567.1

568

569

โาก

57)

579

$57 ?$

574

575

576

577

578

579

580

दर 1

5०ग

NHSL DOPAI
PAGE I?

Dก $190 \quad I=I$, NEXP

WRITF (6.920) I I ITYHE (I), IHT (I), IKF (I), AGSH (I),U(I),H(I),A (I), $\triangle L W($ G

I) , SHADE (I), UT (I), HI (I)

190 CONTINUEE

WRITF $(6.961))$

DO $200 \quad I=I$. NEXP

2NO WRITF $(6,800)$ (SHAW $(I, J) \cdot J=1,(h)$

IF ( $\triangle S H R A E \cdot E(), 1)$ GO TO) 235

WRITE $(6.970)$

WRITF $(6,94 n)$

DO $P 10 \quad I=1$. NEXP

WRITF $(5,99:)) \quad I \cdot(G(I, J) \cdot J=1$, NEXN)

$? 10$ CONT TNIJE

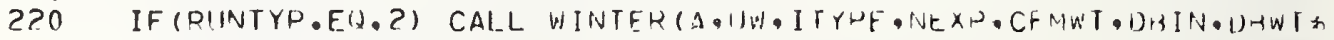
, 11G, TGW, RHW, KHOW)

DO $230 \quad I=1$, NEXP

I) $)>30 \quad \mathrm{~J}=1, \mathrm{~N}$, NEP

?30 $G(I, I)=H P * G(I, J)$

$235 \quad T I M=T U L$

QL. ITO $=($ IL ITY*AG*3.413*NOFLR

QF $D P \cap=(N E Q P X$ \&AG*3.413*NOFLR

DO) $240 \quad I=1$, NEXP

$(\partial \cap(T)=1)$.

$D I(T)=0$.

240 CONTTNUE

DRF $\cap=0$.

$D P F Y=0$.

क T)RM $=$ TIM = REFERENCE TFMPERATIIRE

$T A=T$ TM

$M \cap T=0$

TCLII $\cap=0$.

THTI $D=0$ 。

IF (T.JKLMN.(jT, I) (jO TO ? 243

CALI OHEY ('SWITCH INT: OCLOSE , ,

CONTITINIE

NENI =1)AYSKP+NI)AY

IF (PIINTYP.NE.?) GU TO 241

VENI $=7$

Dก $>4 ? . J=1 \cdot 24$

$D B(.1)=7 H L B(4)-Z$ BLDG (4) irl)HDF (J)

DPT $(.1)=$ BDMAX

WST $(.1)=0$.

PRT, $11=29.921$

$\operatorname{TC}(1)=0$.

NTIR $(J)=0$

242 CONIT TNIE

241 DO 740 NI $=1$, NENH

NSKD $=N(1-D A Y C i K P$

IF (RINTYP.E(J.?) GO TO ?h]

REAT (7) DH, IPT, WBT, WST, HHT , TC,NTOC,LUAY, YEAK, MONTH, CITY

PAGE 1? 


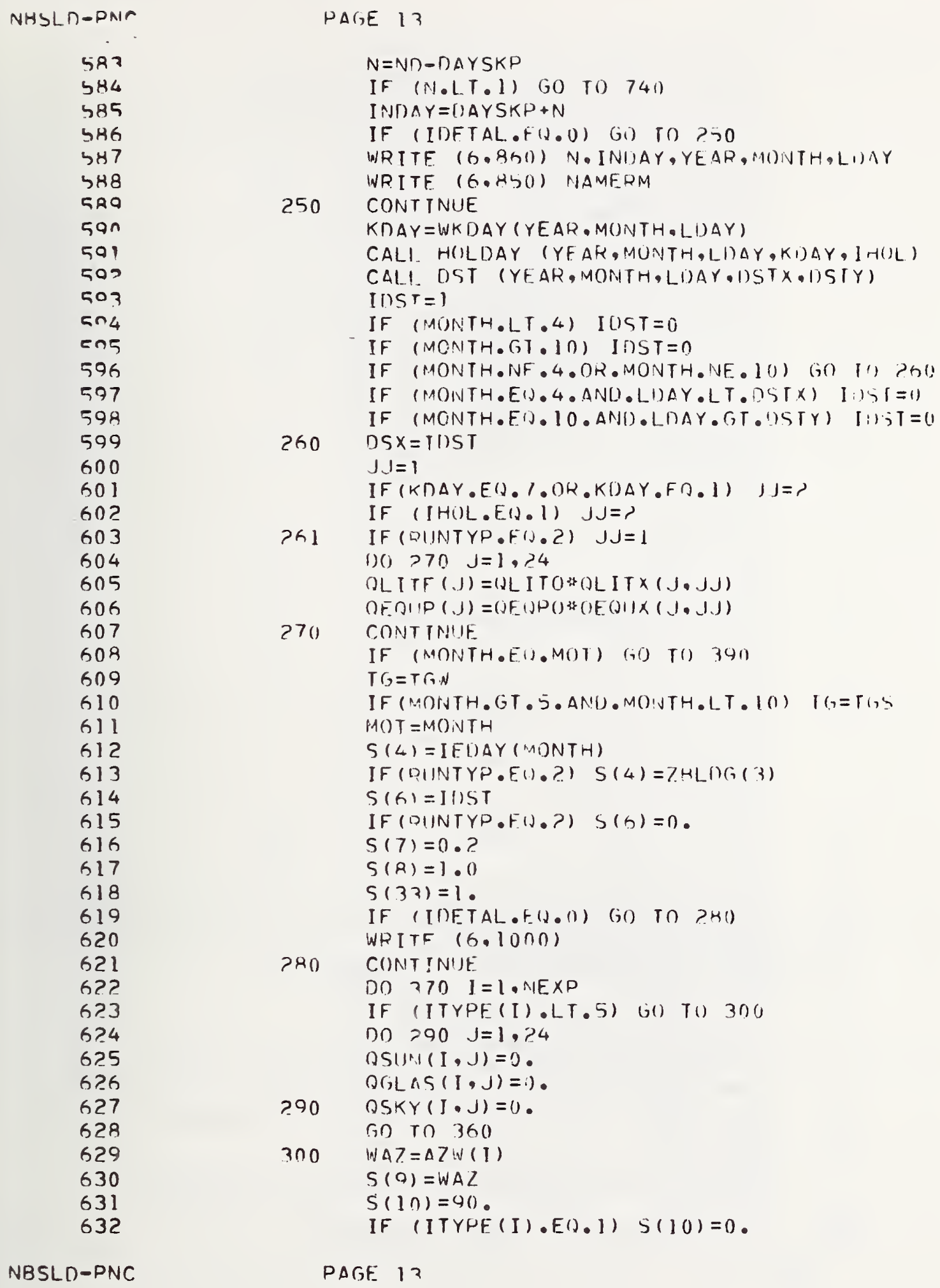

NHSLR-PNI

587

584

585

546

5자 7

५R8

SRO

$59 n$

591

50?

503

<n 4

en 5

596

597

598

599

600

601

$60 ?$

603

604

605

606

607

608

609

610

6) 1

612

613

614

615

616

617

618

619

620

621

6??

6?3

$6 ? 4$

625

$6 ? 6$

627

628

629

630

631

632

NBSLD-PNC

PAGE I

$N=N \cap-D A Y S K P$

IF (N.L.T.1) GO TO 741)

I NT) $\triangle Y=[) \triangle Y Y K P+N$

IF (IDFTAL. F $(1 \cdot 0)$ GO) TO $2>0$

WRTTE $(6,860) \quad N$, INIJAY, YEAR, M()ITH,LI)AY

WR ITF $(6$. प्रSO) NAMERM

250 CONTTNUE

KDAY =WKDAY (YEAR, MONTH,LDAY)

CALI. H(LLDAY (YFAK, MUNTH,LI) AY,KI)AY, IHUL)

CALI. DST (YEAR, MONTH,LI)AY,ISSTX,I)STY)

IIIST $=1$

IF (MON!TH.LT.4) ILST $=0$

IF (MONTH.GT.IN) IISST $=$ ?

IF (MONTH.NF.4.OR.MONTH.NE.10) (GO 11) ?h0

IF (MONTH.E().4.ANL.LI)AY.LT.DSTX) Ii)ST=1)

IF (MONTH.EO. 10.ANI) LNAY.GT.!STY) I:ITT=0

$260 \quad$ DS $=$ IIIST

$J \sqrt{ }=1$

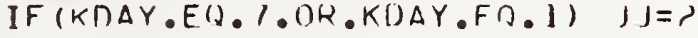

IF $(I H() L \cdot E() \cdot I) \quad J J=?$

PGI IF (DINTYP.FI.Z) JJ=1

() () $>70 \mathrm{~J}=1,24$

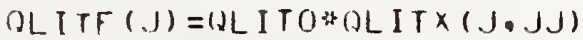

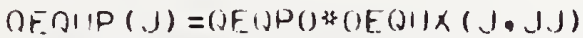

270 CONTTINIE

IF (MONTH.EO.MOT) (,O) TO 390

$T G=T G N$

IF (MONTH. GT.5.ANUU.MO!JTH.LT. IO) TG=TGS

MOT $=$ MONTH

$S(L)=I F D A Y(M D N T H)$

IF (PIINTYP.E().?) $S(4)=7$. HLI)(i (3)

$S(K)=I N S T$

IF (DIINTYP.F(N.?) $S(b)=0$.

$S(7)=0 . ?$

$S(R)=1 \cdot 0$

$S(37)=1$.

IF (IDETAL.F (1. (I) (iO) TO $2 H()$

WRITF $(6,10 \cap 0)$

PQO CONT!NIJE

DO $770 \mathrm{~J}=\mathrm{I}$. NEXP

IF (ITYPE (I).LT.5) (j) T() 300

DO $>90 \quad J=1,24$

$\operatorname{DS}(J),(I, J)=0$.

B(itAS $(I, J)=$ ).

290

DSKY $(J \cdot J)=0$.

Gก $T \cap 360$

300

W $A 7=\Delta Z W(I)$

$S(Q)=W A Z$

$S(10)=90$.

IF $(I T Y P F(I) \cdot E() .1) \quad S(10)=0$.

PAGF 12 
NBSL D-PNC

633

634

635

636

637

638

639

640

641

642

643

644

645

646

647

648

649

650

651

653

654

655

656

657

658

659

660

661

662

663

664

665

666

667

668

669

670

671

672

673

674

675

676

677

678

679

680

681

682

683

NASLD - PNC
PAGE 14

IF (ITYPE (I).NE.3) GO TO 301

$\operatorname{SHOX}(1)=\operatorname{SHAW}(I, 1)$

$\operatorname{SHDX}(?)=\operatorname{SHAW}(I, ?)$

$\operatorname{SHDX}(3)=\operatorname{SHAM}(I, 3)$

$\operatorname{SHOX}(4)=\operatorname{SHAW}(I, 4)$

$\operatorname{SHD} \times(5)=\operatorname{SHAW}(I, 5)$

$\operatorname{SHOX}(6)=\operatorname{SHAW}(I, 6)$

$\operatorname{SHO} \times(7)=\operatorname{SHAW}(I, 7)$

$\operatorname{SHDX}(8)=\operatorname{SHAW}(I, 8)$

$\operatorname{SH} \times(9)=\operatorname{SHAW}(I, 9)$

$\operatorname{SH} \times(10)=\operatorname{SHAN}(I, 10)$

$\operatorname{SHOX}(11)=\operatorname{SHAW}(1,11)$

$\operatorname{SHOX}(12)=\operatorname{SHAW}(1,12)$

$\operatorname{SHD} \times(13)=\operatorname{SHAW}(1,13)$

$\operatorname{SHD} \times(14)=\operatorname{SHAW}(I, 14)$

SHOX $(15)=$ SHAW $(I, 15)$

301 CONTINIJE

Dก $750 \quad J=1,24$

$\operatorname{SSKY}(I \cdot J)=0$.

TIMF $=J$

$S(5)=T$ IME

CALI SUN

$\operatorname{SALT}(J)=S(20)$

IF $(S(25) \cdot G T \cdot 0) \quad G()$. TO 310

$\operatorname{OSUN}(I, J)=0$.

OGLAS $(I \cdot J)=$ ).

GO) TO 350

$310 \quad$ QSUPAI I. J) $=S(25) * \operatorname{AHSP}(I)$

$D G L A S(I, J)=0$.

$\mathrm{PHI}=\mathrm{S}(2])$ PI $/ 180$ 。

$X Q=S($ ? O) $34 \mathrm{PI} / 180$.

$\operatorname{COS} 7=\operatorname{SIN}(X Q)$

IF (SHD(I)) $311,311,312$

$312 \operatorname{SHDF}(I, J)=0$.

GO Tn 345

$311 \operatorname{SHDF}(I \cdot J)=1$.

IF (SHDX(1)) $345,345,316$

$316 \quad S H D \times(16)=S(9) * P I / 180$.

CALL. SHADOW (SHDX,PHI, COSL, SHUF $(I, J))$

345 CONTINIIE

IF (TTYPE (I) , NE. 3) GO TO 346

IF (TEXTSD,EQ.0) GO TO 347

IF (MONTH,GE.IEXMS • AND.MONTH.LE. IEXME) SHUF $(I, J)=0$ •

347 CONTINIJE

CALI GLASS (SHDF $(I, J), \operatorname{SHAIJE}(I), 1,1, \ldots,(, L A S(I, J))$

346 CONTINUE

$5.34=5(25)-S(26)-5(27)$

QSIN $(I, J)=(S 34$ SHDF $(I, J)+S(26)+S(27))$ *AHSP (I)

350 CONTINUE

360 IF (IDETAL.NE.0) WRITE $(5.930)$ I

PAGE 14 
NBSL $D-P N C$

684

685

686

687

688

689

690

691

692

693

694

695

696

697

698

699

700

701

702

703

704

705

706

707

708

709

710

711

712

713

714

715

716

717

718

719

7?0

721

7??

$7 ? 3$

724

725

726

727

$7>8$

729

730

731

732

733

NASL M-PNC
PAGE IF

IF (JDFTAL,NE. O) WRITF $(0,940)$ (1)SUP. $(1, \cdot),, J=1,74)$

IF (IDFTAL.NE.0) WRITF $(6,940) \quad((N G L A S(I, J), J=1,24)$

370 CONT INIIE

DO $280 \quad 1=1$, NEXP

กก $380 \quad J=1,2.4$

$P G L A S(I, J)=(J G L A S(I \cdot J)$

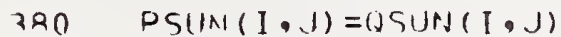

390 CONTINIJE

IF (N. NIF . I) GO TO 440

DO $400 \quad \mathrm{~J}=1, ? 4$

DO $\angle A 00 \quad \mathrm{I}=1$, $\mathrm{HE} \times \mathrm{PP}$

$4 \cap 0 \quad \operatorname{TOS}(T \cdot)=,D B(24-J+1)-T T_{M}$

1) 4 4 $10 \quad J=25,48$

DO $410 \quad I=1$, ME $\times P$

$410 \operatorname{TCS}(I, J)=\operatorname{Tos}(I, J-24)$

DO 4 ? $\mathrm{I}=1$, I. JE $\times P$

$1004>0 \quad J=1.48$

420 TIS $(I, 1)=0$.

$T A=T I M$

1) $0430 \quad J=1.48$

$\mathrm{TNF}^{\prime \prime}(J)=0$.

$430 \quad$ TATTIC $(J)=1)$.

IF (ASHEAE) $440,440,441$

441 กO $443 \mathrm{I}=1$. VEXP

ก) $1,42 \mathrm{~J}=1,24$

$442 \operatorname{TIS}(T \cdot J)=K M+B S(24-J+1)-T I M$

$100443 \mathrm{~J}=25,4 \mathrm{~K}$

$443 \quad \operatorname{TIS}(T, 1)=\operatorname{TIS}(I, J-24)$

on $4 l_{4}$ II $=1 \cdot 2$

HEATR (II) =0.

HEATX (II) = !).

HEATIS $(I I)=0$.

HLCS $(I T)=0$

HL.CX(I I ) $=0$.

464 HI. C.

440 CONT INIIE

* EAD IIF INITIALIZATIUN

W TIMF CALCULATION HEGTNS HFHF

1) 0 4 $70 \quad N K=1 \cdot 24$

LL. I =NK • GE . ISTART A AND. NK . LF . ILEAVE

$L L ?=N K . L T \cdot$ ISTART.OK. INK . GT. ILEAVE

IF (TTK.NF. (I) GO TO 459

IF (TTHST.NE. I) (BO TU 454

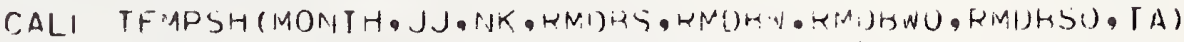

459 CONT INIJE

IF (OINTYP.NE.?) OU TO 451

$F \cap T=4$.

$A C H C=75 O \cap M(4)$

$\mathrm{CM}=1$.

(G) IO 45 ?

PAGE 15 
NRSL $-P N C$

734

735

736

7.37

738

739

740

741

742

743

744

745

746

747

748

749

750

751

$75 ?$

753

754

755

756

757

758

759

760

761

76 ?

763

764

765

766

767

768

759

770

771

777

773

774

775

776

777

778

779

780

781

781.1

787

NRSLIN-PNC
PAGF IK

$451 \quad$ WSTX $=W S T$ (NKK)

CAL I FO (NSTX, 3.FOC D FOT T (1)

$\%$ AIR CHANGE AS A FINCTIIII OF MING SHETH

* COHIENT ANI ACHENHACH LGR3 ASHHAF TRA.VSACIIUN

$A C H=0.15+0 .(113 * 45 T(1 V K)+0.005$ it $A K S(1) A(V K)-T A)$ $\triangle C H T=A C H * C O N I S T$

$C M=C C M(S A L T(N K), N T O C(N K), T C(, N K)$,

452

$C F M 1=A(1) * A C H G$ i $H T / A U,+C F: A N$

CFMI $X=C F M L$

CFMV $=$ CFMS

IF $(111.1) \quad G() \quad T 045.3$

C.FMV $=0$.

(s) Tी 454

453 IF (1.1. GT. 1) CFMV $=0$.

454 CONTINIIE

C) $4+70 \quad I=1 \cdot$. I. $\mathrm{E} \times \mathrm{P}$

$N D R=N R(I)$

OSUAN $(I \cdot N K)=P S(I N)(I, N K) * C M$

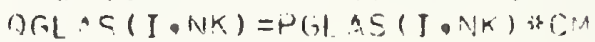

()SKY (]$\cdot N K)=[$.

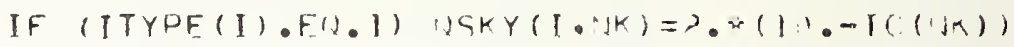

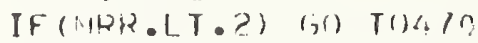

DO 450 NTT $=2$. NPL

$450 \quad$ TOY $(A T T)=T O S(I \cdot N T T-1)$

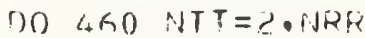

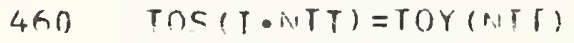

470 CONTTAMIE

D) $250 \quad \mathrm{I}=1$, a d

$N D R=\operatorname{TH}(I)$

IF (ASHRAF.GI.0) TIS I I I) :IA-TI:A

$K=\operatorname{ITS} F(1)$

DO $44(4) \quad J=1,(4 R R$

$x \cap 1 \operatorname{lin}(, J)=x(k, J)$

$Y[H \ln (J)=Y(K \cdot J)$

$7 \Gamma(1)+1(J)=7(K \cdot J)$

$\operatorname{TO}(j)(J)=\operatorname{TOS}(1 \cdot \mathrm{J})$

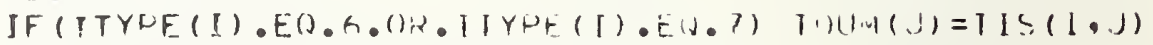

TF (JTYPE (I) EE().S) TIUUM(J) =TG-TIM

$T I(1)=T I S(I, J)$

480 Conttinte.

(1) $x=11($ I)

IF (H(I)) $500,500.491)$

$490 \quad H(T)=F() T$

$R X=1 . / 1) T(I)+1 . /(H I(I)+H H)$

$R X X=R X+1 \cdot / H(I)$

I) $(1)=1 \cdot / R \times X$

$U X=1 . / 1 R X$

500 CONTINUE

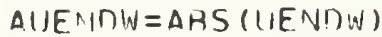

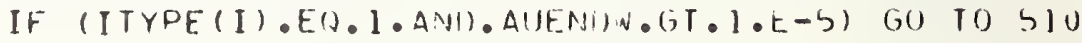

PATE IF 
NRSLD-PNC

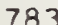

784

785

786

787

$7 R 2$

789

790

791

79?

793

794.01

794.02

794.03

794.04

794.05

794.06

794.07

794.08

794.09

794.1

794.11

794.12

794.13

794.14

794.15

794.16

795

795

797

$79 R$

799

300

R० I

802

203

804

805

305

R० 7

ค० 8

809

810

Q11

8)?

8 13

R 14

R 15

Q16

R 17

NBSL. $\cap-P N C$ $\sim \triangle G E \quad 17$

G) $\operatorname{Tn} 530$

$510 \quad \triangle T C A C G=A T R C H G * A I R N T$

IF $(11.1) \quad A T C A C G=\triangle I K C H G$

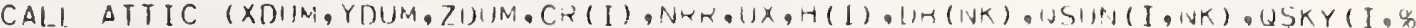

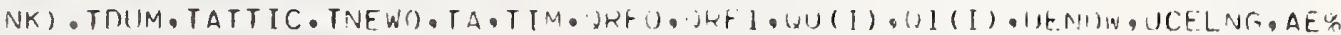
NDW, $A(I), A T C H T, A T C A C S)$

DO द?O J=1. ARR

$\left.\operatorname{TNF} \operatorname{To}^{\prime}(J)=\operatorname{TD}\right)(J M(J)$

L?U TOS $(1 \cdot \mathrm{J})=\operatorname{TATtIC}(\mathrm{J})$

GO TO 550

530 CONT INUE

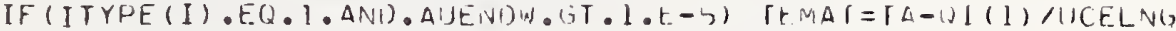

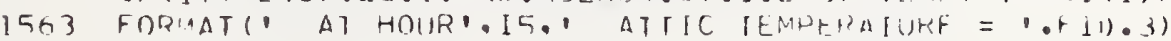

$H I R A=H(I)$

IF ( H HAY . NE . I) $G(0)$ IO GOUY

IF (ITYPE (I) . NE . I) GO TC TIIIU

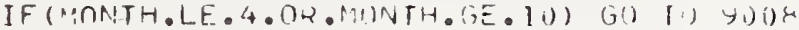

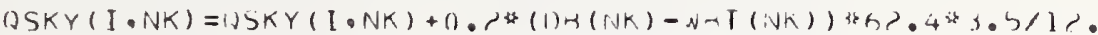

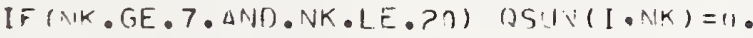

IF $(A K \cdot(i E \cdot 7, \Delta N \mid) \cdot N K \cdot D E \cdot P 0) \quad(J S K Y(1, N K)=0$.

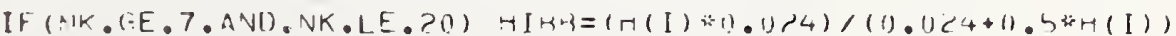

in in 9009

900 H IF (NK.L.E.7.1)R.NK.GF. 211$)(J S K Y(1 \cdot N K)=1$.

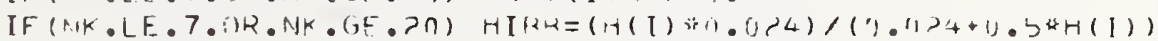

UnO) CONTIN:JE

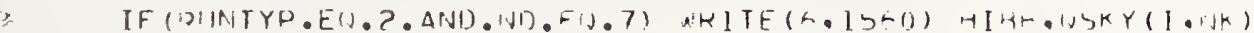

ISOR FOR:AT (ISFR.1)

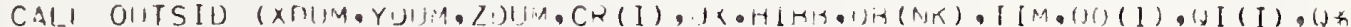

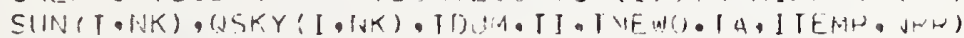

DO) 54()$\quad J=1$, PHKK

$540 \quad \operatorname{TOS}([,)=.\operatorname{THIIM(.1)}$

550 CONTINIJE

$\operatorname{OACDS}(P K K)=(J) C U P(N K \cdot J J)$ is 10 . is $(100 .-1 A) \times(J C)$

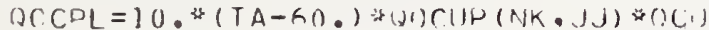

IF (TA-100.) 570.560 .560

SAO DOCDS $(N K)=1)$.

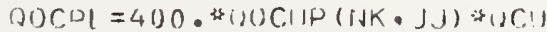

GO TO 590

570 IF (TA-A5.) bमू. ל40.590

$580 \quad$ (JnCos $(\mathrm{NK})=350.2(00 \mathrm{CIIP}(\mathrm{NK}, J . J)$ iri)CU

OOCDI $=40 . \Rightarrow(J) C I J P(N K, J J) *(J \mathrm{Cl})$

$590 \quad D O<P 0 \quad I=1$, SEE XP

NRS $=\ln (I)$

IF (,$D R \cdot L T \cdot ?)$ (in TO $6>0$

1) $0<n O N T T=\dot{R} \operatorname{NQP}$

AOO TOY (RTT) $=T[S(I \cdot N T T-])$

DO \&ID NTT = ?.M.RR

GIO TIS (T,NTT) $=$ TOY (NTT)

GOO CONTINUE

IF (ASHKAF) |S2I・ISतI.AP)

PAr,F 17 
NRSLDD-PNC

RाR

Rा 9

8?0

921

R>?

9. 3

R24

$9>5$

$8 ? 6$

ค2 7

$8>8$

R? 9

830

831

83?

R.33

834

835

8.36

837

838

839

840

841

84?

843

844

845

846

847

$84 R$

849

850

951

9.52

853

854

855

856

857

ห5ค

859

RGO

861

862

863

864

865

866

867

NRSLID-PNC
PAGE I\&

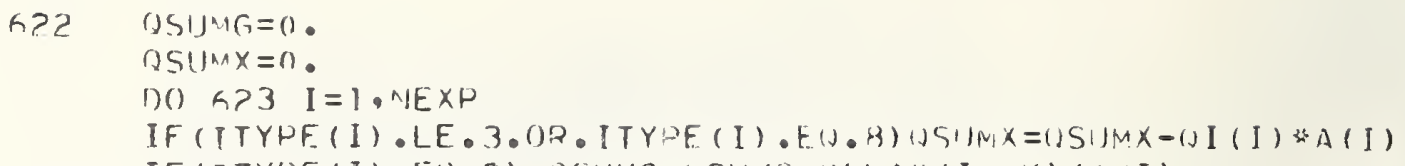

PAGE I I 


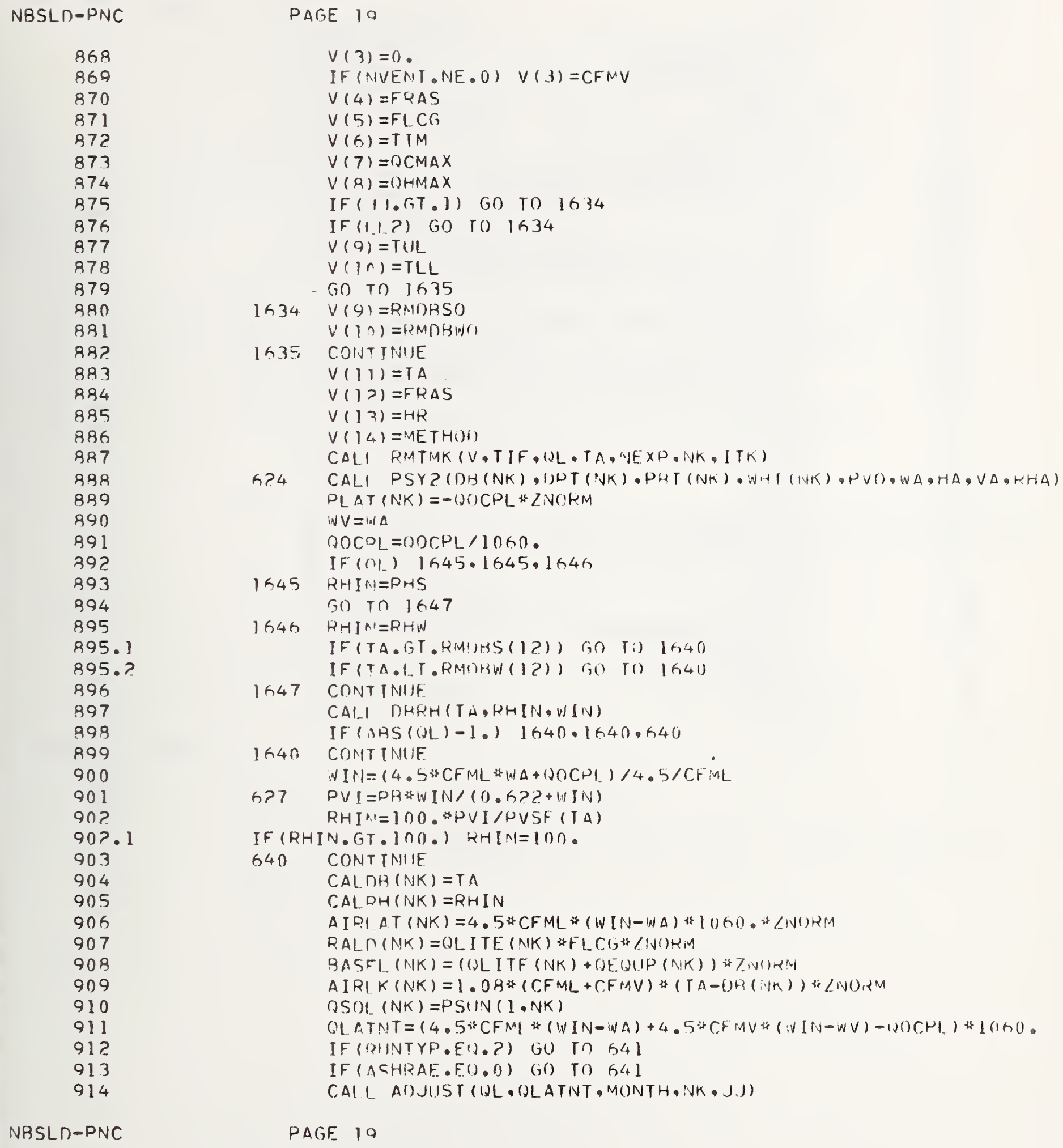




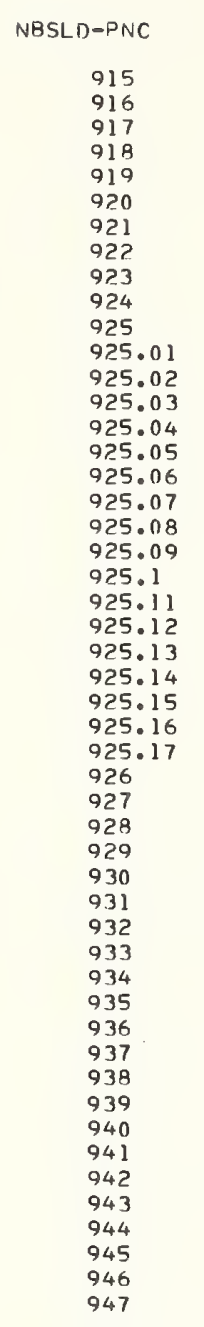

NBSLD-PNC
PAGE $2 ก$

641 CONTINUE

$Q L=O L+1.08 * C F M V *(T A-D R(N K))$

$O L S(N K)=Q L+Z N O R M$

QLL $(N K)=O L A T N T * Z N O R M$

IF (ARS (OLS $(N K))=1.1642,642.643$

642 OLL $(N K)=0$.

643 CONTINUF

IF (AIJENOH.LT.1.E-5) GO TO 114 ?

$650 \quad N R R=N R(1)$

OO 6 GO $j=1$, NRR

$660 \quad T O S(1, \pi)=T N E W(J)$

1147 IF (RIINTYP.NE.2.OR.NU.LT.7) GO TO 670

क

1562 FORMAT $16: 156$ ?

$\triangle P T \cap T=0$.

DO $9910 \mathrm{I}=1$. NEXP

$\mathrm{OBH}=0$.

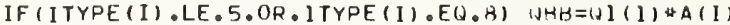

IF (ITYPE (I),EQ,3) $\quad B B B=-(I G L A S(1, N K) * A(I)+(1 B H$

$O Z=O A R / A(1)$

QPTOT $=0 P T O T+Q B R$

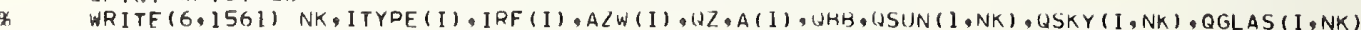

1561 FORMAT (3I10,7F12.3)

R9IO CONTINUE

QDTOT=OPTOT-QOCPS $(N K)-D E Q U P(N K)-() L L T E(N K)$

IF (ITYPE (I),EO, I.ANU.AUENDW.GT.1.E-b) WKITE (6.1 663 ) NK, TEMAT

* WRITF $(6,1564)$ OPTOT

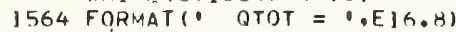

670 CONTINUE

IF (RIINTYP.E(1.2.AND.NO.LT.7) GO TO 140

OLMAX $=$ ABS $(O L S(1))$

NMA $X=1$

TS $U^{M}=0$.

QLD $\triangle U M=0$ 。

CLDAY $=0$.

HLDAY $=0$.

DO $7 ? 0 \quad \mathrm{NK}=1.24$

IF (OLMAX-AHS(OLS(NK))) 680,690,690

GRO OLMAX $=A B S(O L S(N K))$

NMA $K=N K$

GO TO 690

690 CONTINUE

$T S U M=T S U M+D B(N K)$

$O L \cap S I) M=Q L D S U M+O L S(N K)+O L L(N K)$

$Q L D S=O L S(N K)+Q L L(N K)$

IF (OLDS) $700,700,710$

$700 \quad$ CLDAY $=$ CLDAY +()$L O S$

GO TO 720

$710 \quad$ HLDSY $=$ HLDAY +QLDS

7?0 CONTINIJE

PAGE 20
PAGE 20

NBSLD-PNC

AREA

LOAD

PER CENT",

NBSLO-PNC 


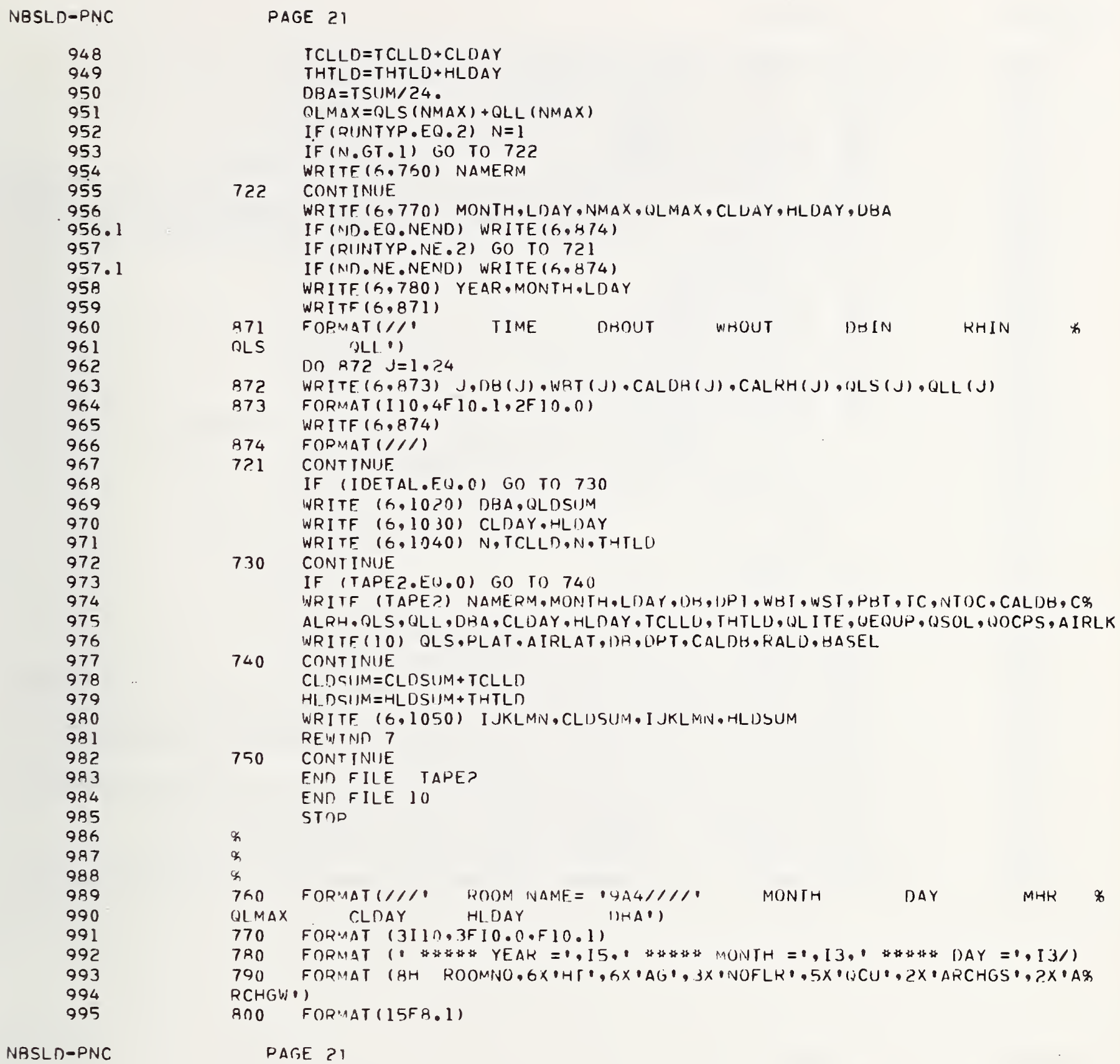

$T C L L D=T C L L D+C L D A Y$

THTLD $=$ THTLD+HLDAY

DBA $=T S U M / 24$.

QLM $\triangle X=Q L S(N M A X)+Q L L(N M A X)$

IF (RINTYP.EQ.2) $N=1$

IF (N.GT.1) GO TO 722

WRITE $(6.750)$ NAMERM

722 CONTINUIE

WRITF $(6,770)$ MONTH, LI)AY, NMAX, (ILMAX, CLUAY, HLUAY, UBA

IF (ND.EQ.NEND) WRITE $(6,9874)$

IF (RIINTYP.NE.2) GO TO 721

IF (NID.NE.NEND) WRITE $(6,874)$

WRITF $(6,780)$ YEAR,MONTH,LDAY WR I TF $(6,871)$

971 FOPMAT(//, TIME DROUT WHOUT DऽIN RHIN

OLS DO $R 72 \mathrm{LL} J=1.24$

872 WRITE (6.873) J,DB(J),WRT (J),CALDH(J),CALRH(J), (JLS (J), QLL (J)

873 FORMAT $(110,4 \mathrm{~F} 10.1,2 \mathrm{~F} 10.0)$

WR I TF $(6,874)$

874 FOPMAT $(/ / /)$

7?1 CONTINUE

IF (IDETAL.EQ.O) GO TO 730

INRITE $(6,1020)$ DBA, QLDSIJM

WRITF $(6,1030)$ CLDAY,HLOAY

WRITF $(6,1040) \quad \mathrm{N}$, TCLLD,N,THTLO

730 CONTINUE

IF (TAPEZ.E (1.0) GO TO 740

WRITF (TAPE?) NAMERM,MONTH,LOAY,OH,I,PI, WHT, WST, PHT, TC,NTOC, CALDB, C\% ALRH, OLS, QLL, DHA, CLDAY, HLDAY, TCLLU, THTLU, (UL I TE, WEQUP, QSOL, WOCPS, AIRLK WRITE( 10$)$ QLS, PLAT, AIRLAT, 1)P, LHT, CALDH,RALD, BASEL

740 CONTINUE

CL.DSIIM $=$ CLDSUM + TCLLD

HI_DSIJM $=$ HLDSIIM+THTLח

WRITF $(6,1050)$ I JKLMN,CLISUM, I JKLMN, HLDSUM

REMTINT 7

750 CONTINIJE

ENO FILE TAPE?

END FILE I0

STOP

$x$
$x$
7

7GO FORMATI/// ROOM NAME = $944 / / / / 1$ MONTH DAY MHK

PASE ? 1 
NBSLD-PNC

996

997

998

999

1000

1001

1002

1003

1004

1005

1006

1007

1008

1009

1010

1010.1

1011

1012

1013

1014

1014.1

1015

1016

1017

1018

1019

1020

1021

1022

1023

1024

1025

1026

1027

1028

1020

1030

1031

1032

1033

1034

1035

1036

1037

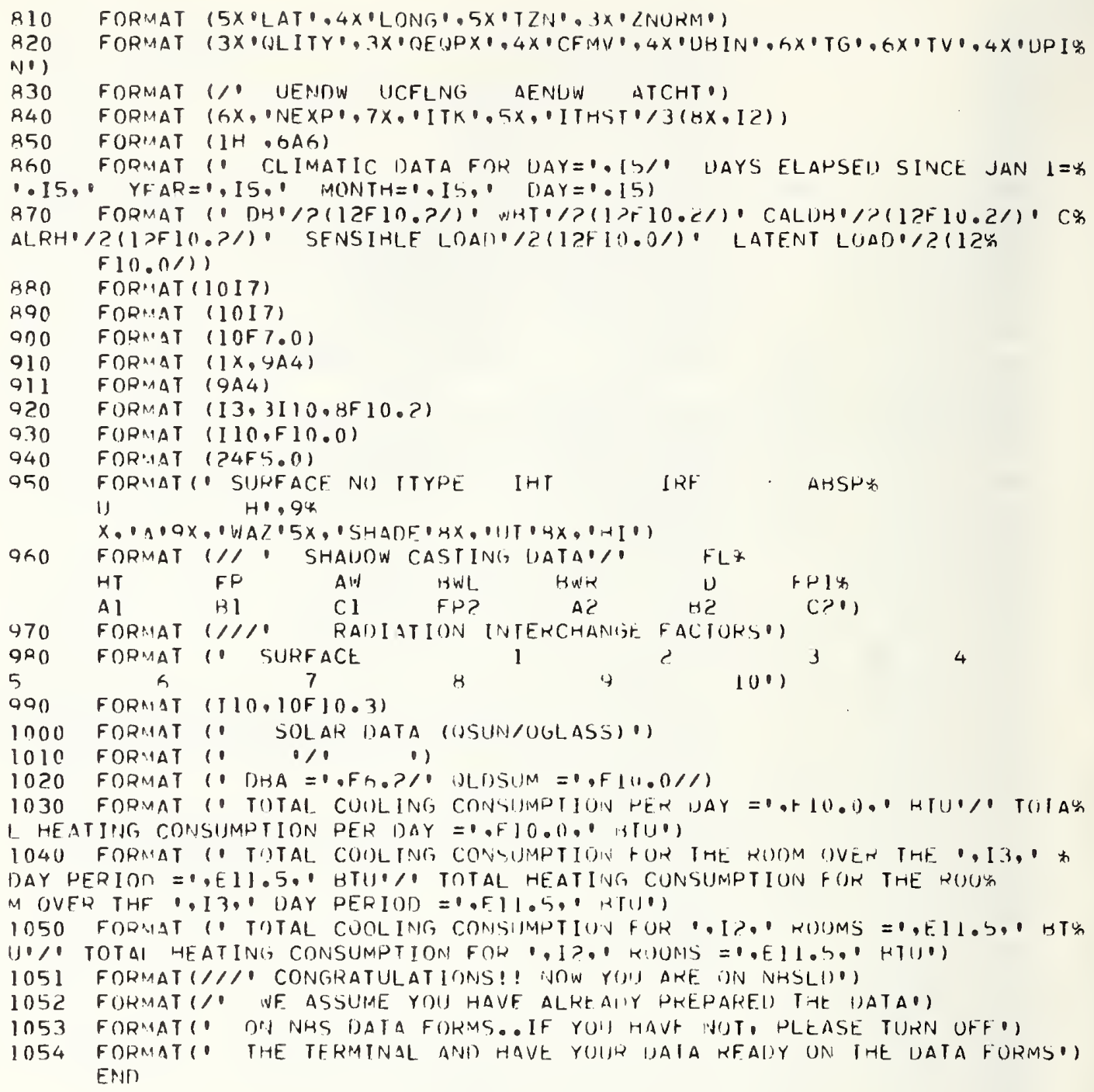


OUTSID-PNC

2

3

5

7

9

10

11

12

13

14

15

16

17

19

19

20

21

22

23

24

25

26

27

28

29

30

31

32

33

33.1

34

35
PAGE I

SURROUTINE UUTSIU (X,Y,Z,CR,UX,FO,DH, TIM, UU,UI,USUN, USKY, TU, I I, TUNF $F W, T A, I T E M P, N R$ )

1) IMFNSION $T()(1) \cdot T I(1), X(1), Y(1), Z(1)$

$X N I J M=Q S U N-(D S K Y+F U *(D H-T I$ i⿻ $)$

IF (NR.NE. I) GO TO 50

In IF (FO) $20 \cdot 20 \cdot 30$

?ח TONF $\mathrm{W}=\mathrm{TO}(1)$

G() TO 40

$30 \quad T A M=T A-T I M$

TONFWI $=(X N U M+U X * T A M) /(11 X+F O)$

40 CONT INIJE

$D O=(I X *(T \triangle M-T U N E W)$

IF $\left.\left(I T E M P, E^{\prime}\right) \cdot 0\right) \quad(I=(x)$

TO $(1)=$ IONEW

GO TO 40

5n SIMY $=0$.

SIIMY $=Y(1) * T I(1)$

$\operatorname{Sin} x=X(1) * T I(1)$

$\operatorname{Sin} \times Y=0$ ).

DO $411,1=$ ? Nit

SIJMY $=S 11 M Y+Y(J) * T I(J)$

SI) $M X=S(i M X+X(J)+T I(J)$

SIIM $X Y=\operatorname{Sin} X Y+Y(J) \Rightarrow[() i J)$

hก

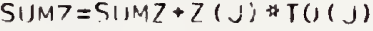

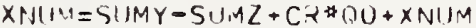

TONF $W=X N I M /(Z())+\vec{F} O)$

IF (Fח) 70,7(1, 30)

$7 \cap \quad T O N F W=T U(1)$

Sก $\quad T O(1)=T O N E W$

$S(1) M 7=S(1 M 7+Z(1) * \mathrm{TO}(1)$

SIM $X Y=S U M X Y+Y(1) * I O(1)$

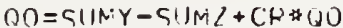

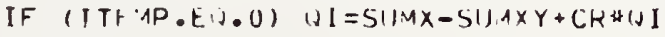

90

CINTT I VIIF

RE.TIIRN

ENI)

PAGE , 
SURROUTINF PSYI (DH,WR,PB, OP,PV,W,H,V,RH)

$10 \quad$ WST $\triangle R=0.622 * P V P /(P H-P V P)$

IF $(W H-32) \quad .20 . ? 0,40$

2ก $\quad P V=P V P-5.704 E-4 * P H *(D A-W B) / 1.8$

GO TO 50

$30 \quad P V=P V P$

GO TO 50

10

40

$\mathrm{CDB}=(\mathrm{DB}-32 \cdot) / 1 \cdot 8$

$C W R=(W R-32 \cdot) / 1 \cdot R$

$H_{L}=507.31+0.4409 * \mathrm{COH}-\mathrm{CWH}$

$\mathrm{CH}=0.240 ?+0.4409 *$ WSTAR

$E X=(W S T A R-C H *(C O H-C N R) / H L) / 0.622$

$P V=D R$ 品 $F x /(1,+E X)$

50 $W=0.6 ?$ ? $\quad$ is $P V /(P B-\mu V)$

$V=0.754(D B+459.7) *(1+7000 * 14360) / \mathrm{PB}$

$\mathrm{H}=0.24 * \mathrm{DH}+(106 \mathrm{l}+0.444 * \mathrm{DH}) * \mathrm{WH}$

IF (PV.LE. O) GO TO 60

18.1

18.2

18.3

18.4

18.5

18.6

19

20

21

22

IF (DR.NE.WR) GO TU) 70

$D P=D B$

$\mathrm{RH}=1$.

GO TO 60

70 CONTINIIF.

$D P=\cap P F(P V)$

RH=PV/PVSF (1)B)

60 RETURN

ENI) 


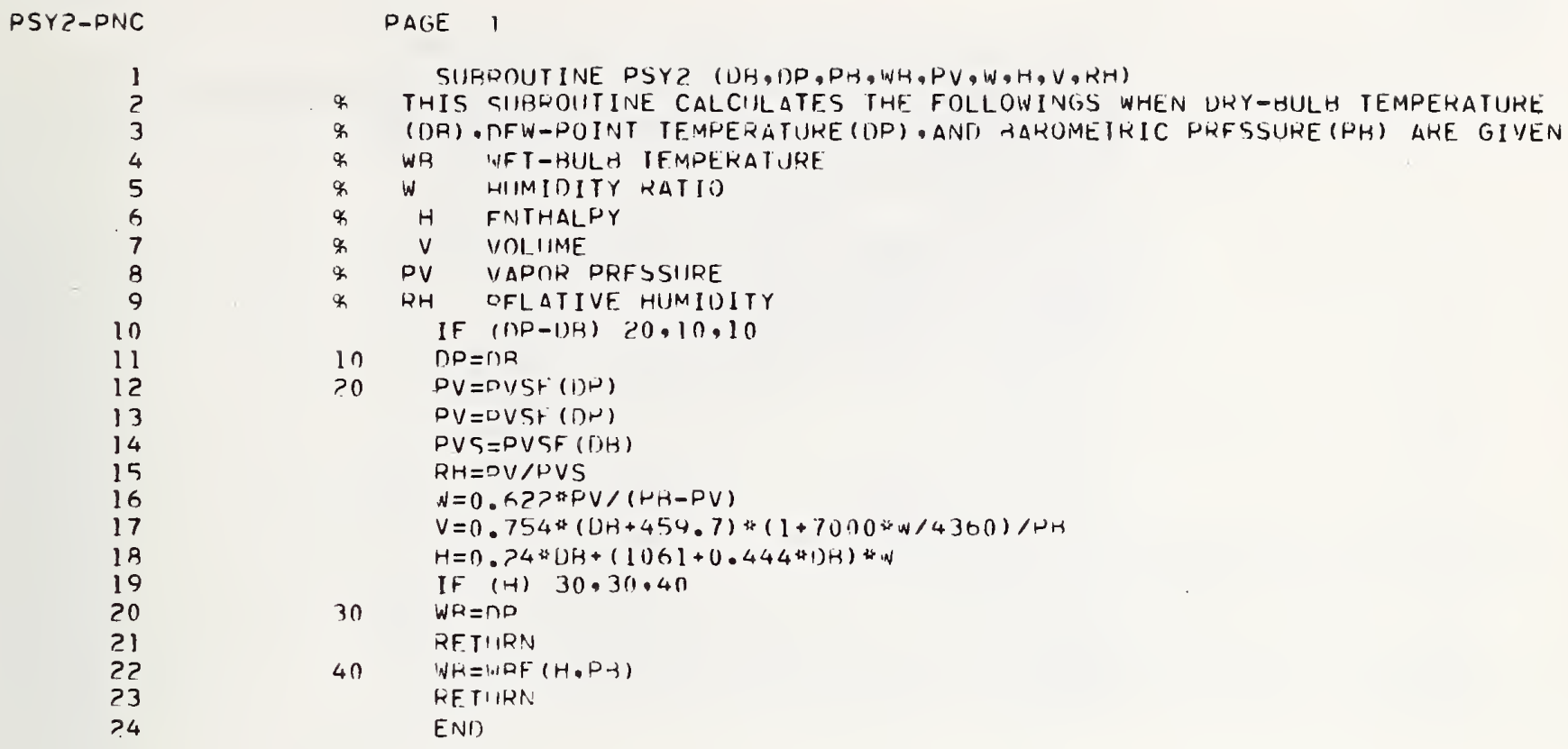

PAGE I

SURROUTINE PSYZ. (UH,DP,PH, WH,PV,W,H,V,RH)

\%

s

क

\%

\%

禾

$\%$

ฬ

$\ln$

$>0$

30

40

THIS GIIBHOUITINE CALCIILATES THE FOLLOWINGS WHEN URY-BULH TEMPERATURE (DR) , NFW-POINT TEMPERATURE (DP), ANI) TAROMEIKIC PRFSSURE (PH) ARE GIVEN WR WFT-HULA IFMPERATURE

W HIMIDITY RATIi)

H FNTHALPY

$V$ VOLIIME

PV VAPOR PRFSSIJRE

RH OFLATIVE HUMIUITY

IF (MP-I)R $20,10,10$

$D P=I) R$

$P V=R V S F^{\circ}($ (i)P)

PV=DVSF $(D N)$

PVSAPVSF (DH)

RH=DV/PVS

$N=0 . K 2>* P V /(H A-P V)$

$V=0.754 *(\mathrm{DH}+454.7) *(1+7000 * w / 4300) / \mathrm{NH}$

$H=0.24 \mathrm{UH}+(106 \mathrm{l}+0.44441) H) * w$

IF (H) $30 \cdot 30 \cdot 40$

WR $=\cap D$

RF.TIIRN

WH $=$ W. $P F(H, P-\beta)$

RETIIRN

END 
PVSF - PNC

1

3

4

5

6

.7

8

9

10

11

12

13

14

15

16

17

19

19

20

21

5?

23

24

PAGE I

FIINCTION PVSF $(x)$

DIMFNSION $A(6) /=7.90294,5.0 ? 408,-1.3816 E-7,11.344,8.1328 E-3,-3.441 \%$ $49 /, A(4) /-9.09718,-3.56654,0.876793,0.0050273 /, P(4)$

$T=(x+459.644) / 1.8$

IF (T.LT.273.16) GO TO 10

$Z=373.16 / T$

$P(1)=A(1) *(1)-1)$

$P(2)=A(Z)$ LOG $10(Z)$

$Z 1=A(4) *(1-1 / Z)$

$P(3)=A(3) *(10 * 21-1)$

$7.1=\Delta(6) *(Z-1)$

$P(4)=A(5) *(11) * 71-1)$

GO TO 20

$10 \quad Z=273.16 / T$

$P(1)=P(1) *(Z-1)$

$P(2)=R(2) * L \cap G 10(Z)$

$P(3)=B(3) *(1-1 / Z)$

$P(4)=L 0 G 10(H(4))$

$20 \quad$ SIM $=$ ?

DO $711 \quad 1=1.4$

$30 \quad S U M=S U M+P(I)$

DVSF $=24.921$ * $10 * S U M$

RFTIIRN

END 


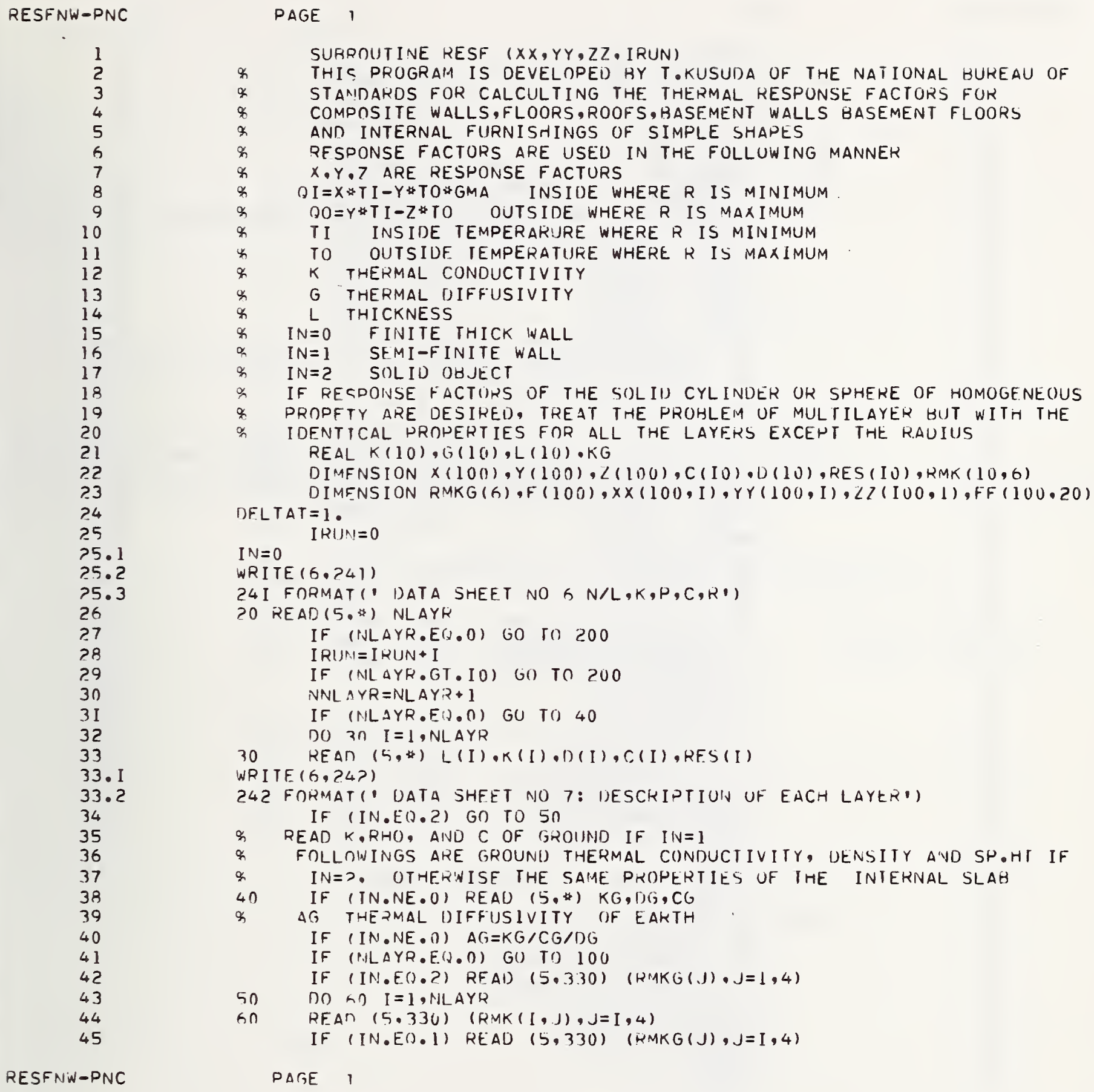

SURROUTINE RESF ( $X X, Y Y, Z Z$, IRUN)

THIS PROGRAM IS DEVELOPEI) RY T.KUSUDA OF THE NATIONAL BUREAU OF STAMIDARDS FOR CALCULTING THE THERMAL RESPUNSE FACTORS FUR COMPOSITE WALLS, FLOORS, ROOFS, BASEMENT WALLS BASEMENT FLOORS AND INTERNAL FURNISHINGS OF SIMPLE SHAPES

RESPONSE FACTORS ARE USEU IN THE FOLLUWING MANNEK $X, Y, 7$ ARE RESPONSE FACTURS

$O I=X * T I-Y * T O * G M A$ INSIDE WHERE $R$ IS MINIMUM

OO=Y\$TI $Z$ Z TO OUTSIDE WHERE R IS MAXIMUM

TI INSIDE TEMPERARURE WHERE R IS MINIMUM

TO OUTSIDF TEMPERATURE WHERE $R$ IS MAXIMUM

K THERMAL CONDUCTIVITY

G THERMAL DIFFUSIVITY

L THICKNESS

IN=0 FINITE THICK INALL

IN $=1$ SEMI-FINITE WALL

IN=2 SOLID OBJECT

IF RECDONSE FACTORS OF THE SOLIU CYLINDER OR SPHERE OF HOMOGENEOUS PROPFTY ARE DESIRED, TREAT THE PROHLEM UF MULTILAYER BUT WITH THE IDENTTCAL PRONERTIES FOR ALL THE LAYEKS EXCEHT THE R.AUIUS REAL K(10), G(10),L $(10) \cdot K G$

DIMFNSION $X(100), Y(100), \angle(100), C(I 0), D(10), \operatorname{RES}(I 0), \operatorname{RMK}(10,6)$ DIMENSION RMKG $(6), F(100), X X(100, I), Y Y(100, I), \angle Z(I 00,1), F F(100,20)$ DF. LTAT $=1$.$$
\text { I } N=0
$$$$
\text { IRUNI }=0
$$

\section{WRITE $(6.241)$}

24 I FORMAT(' DATA SHEET NO $5 \mathrm{~N} / L, K, P, C, R \cdot)$

?O READ (5.*) NLAYK

IF (INLAYR.EQ.0) GO TO 200

I RIJAI = I RUN+I

IF (NLAYR.GT.IO) GO TO 200

NNL $A Y R=N L A Y Z+1$

IF (NLAYR.E(). O) GU TO 40

DO $3 \cap \quad I=1$, NLAYR

$30 \operatorname{REAN}(5, \$) L(I), K(I), D(I), C(I), \operatorname{RES}(I)$

WRITE $(6,2.4$ ?)

242 FORMAT( UATA SHEET NO 7: DESCKIPTIUN UF EACH LAYER')

IF (IN.EO. S) GO TO 50

क READ K.RHO, AINO C OF GROIND IF IN=1

* FOLLOWINGS ARE GROUNI) THERMAL CONDUCTIVITY, DENSITY A'VD SP.HT IF

* IN=?. OTHER'NISE THE SAME PKOPERTIES UF IHE INIEKNAL SLAB

40 IF (IN.NE.0) REAU (5,*) KG,D),CG

\% $\triangle G$ THERMAL DIFFUSIVITY OF EAKTH

IF (IN.NE・O) $A G=K G / C G / D G$

IF (P.ILAYR.E( $(1,0)$ GU T!) 100

IF $(I N \cdot E() .2) \quad \operatorname{READ})(5,330) \quad(\operatorname{HMKG}(, J), J=1,4)$

50 DO KO I I, NLAYR

6n REAN $(5.330)$ (RMK $(I, J), J=I, 4)$

IF (IN.EO. 1) READ $(5,330) \quad(\operatorname{RMKG}(J), J=I, 4)$

PASE I 


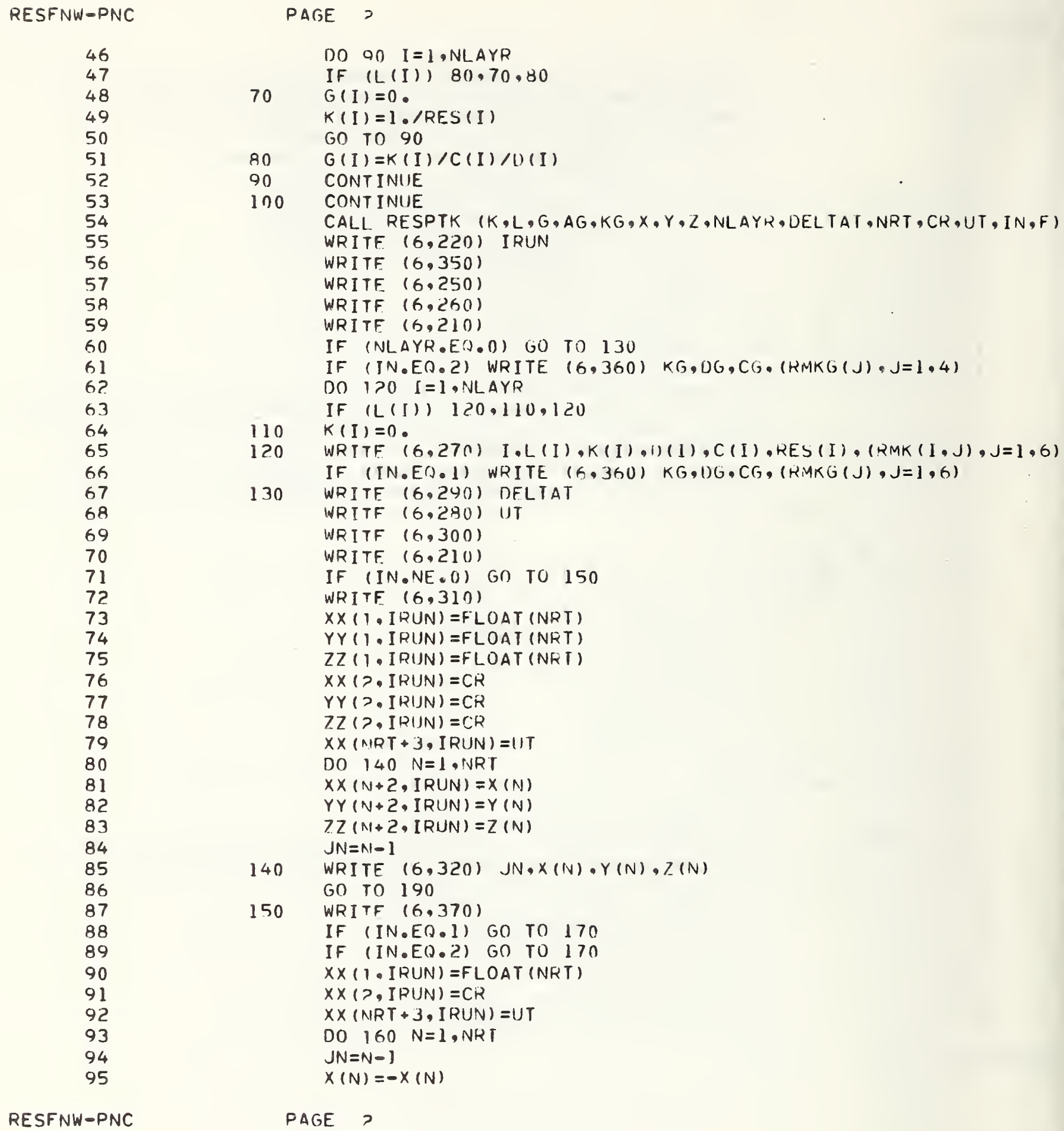


RESFNW-PNC

96

97

98

99

100

101

102

103

104

105

106

107

108

109

110

111

11 ?

113

114

115

116

117

118

119

120

121

$12 ?$

123

124

125

126

127

128

129

130

131

132

133

134

135

136

137

PAGE ?

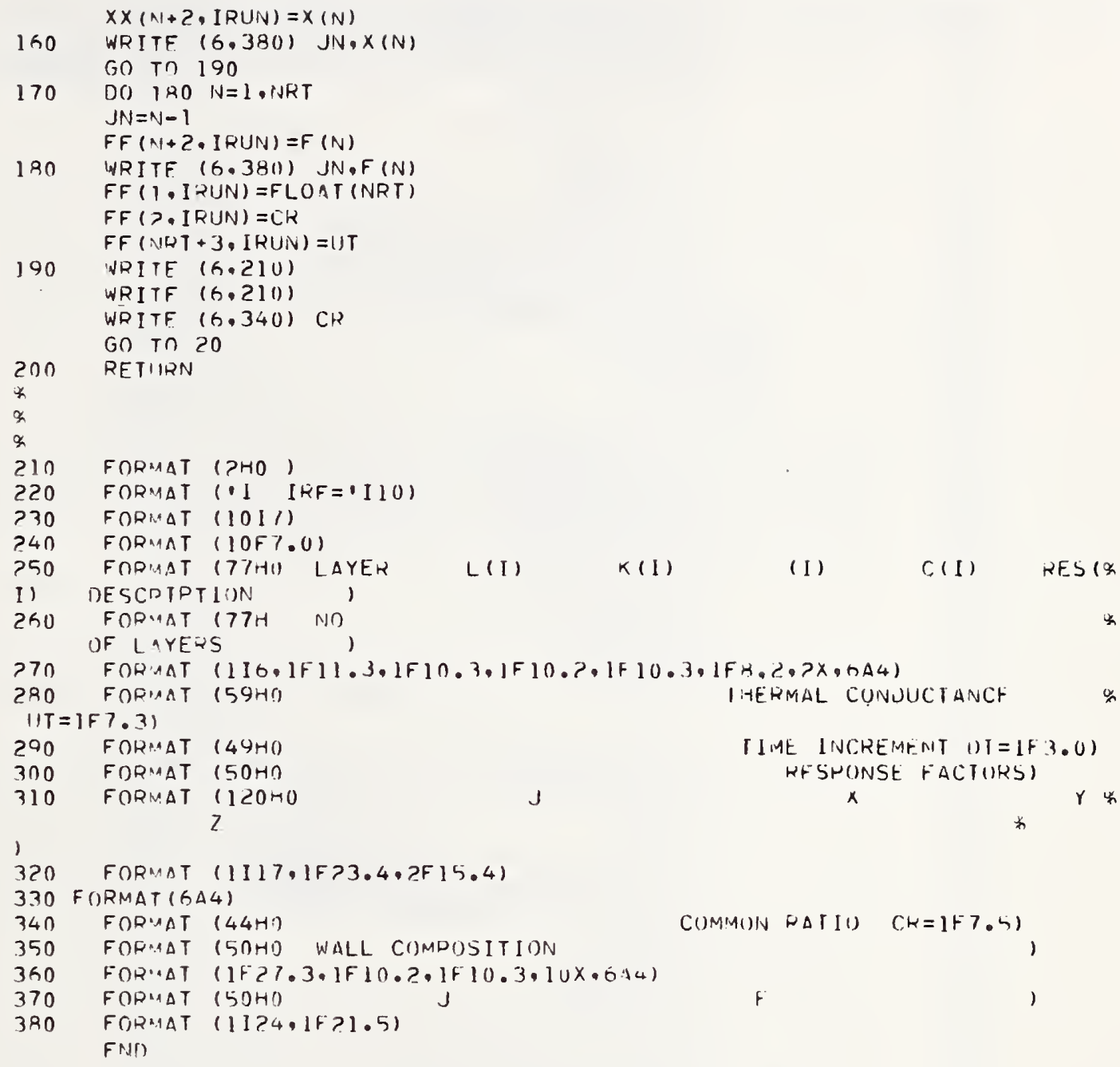


RESPTK-PNC

1

2

3

4

5

6

7

8

10

11

12

13

14

15

16

17

18

19

20

21

22

23

24

25

26

27

28

29

30

31

32

33

34

35

36

37

38

39

40

41

4?

43

44

45

46

47

$4 R$

49

50

RESPTK-PNC

PAGE ।

SURROUTINE RESPTK $(K, L, G, A G, K G, X, Y, Z, N L, U T, N K, C H, U, I S, F)$

DIMFNSION K $(10), L(10), G(10), X(100), Y(100), Z(10 n), A H(10), H P(10), C P(\%$

$10), D P(10), A(10), H(10), C(10), 1)(10), Z R 1(3), Z K 2(3), R B(3), H A P(3), R O W T h$

$(100), R A(2,100), Z R K(3,100), R \times(100), R Y(100), A Z(100), F(100))$

REAI K,L,KG

$P I=4$. * $A T A N(1$,

$M 3=3$

IF (IS.NE. I) GO TO 10

$Z L=K G / I 0$.

USY $=100 . / A G / U T$

CALL GHF (UY,ZL,AZ)

IF (IS.EQ.1.AND.NL.EQ.0) GO TO 330

in CALI AACDC $(0,, K, L, G, A X, B X, C X, D X, N L)$

$\operatorname{RA}(1)=1) \times$

$R R(?)=1$.

$R R(3)=\Delta x$

$U=1 . / R X$

DO $>\cap \quad I=1, N L$

$P X=n$

CALL. AKCDP? (PX,K(I),I (I),G(I), AP (I), UP (I),CP(I),IPP(I))

20 CALI AHCDZ (PX,K(I),L(I),G(I),A(J),H(I),C(I),U(I),I)

IF (NL.LT. S) GO TO 3 On

CALI DERVT $(A, H, C, 1), A D, B D, C P, U R, A N D, A H R, C P R, U H P, N L)$

(S) $T \cap 40$

$30 \quad \triangle P P=A P(1)$

HPP $=$ QP $(1)$

$C P P=C P(1)$

$D P P=\cap P(1)$

$4 n \quad R A P(1)=D P P$

$\operatorname{RAP}(?)=0$.

$\operatorname{RAP}(3)=A P P$

DO) 5 ก $[=1 \cdot 3$

$C I=C A P(I) / H X / D T$

$C ?=12 R(I) \& B P P / B \times / H x / I) T$

$7 R ?(1)=-\mathrm{Cl}+\mathrm{C} 2$

$50 \quad Z R I(I)=-Z R 2(I)+R B(T) / H X$

* ROOTS OF $H(P)=0$.

NMAX $=10$

TESTMX $=4 n$.

$P X=n, 00]$

DP $\cap=0.1 / D T$

$n L x=0.1) \cup 01$

$M Y=$ !)

Sn $D L=N O O$

CALI AFCO? $(P X, K, L, G \cdot A x \cdot R X, C X, D) \cdot N L)$

$70 \quad P X P=P X+U L$

CALI $\triangle H C D) 2(P X P, K, L,(i, \triangle X F, B X, \cdot(X P, 1) \times H, F L)$

Rก) $P X=\cap \times P$

$R \times=4 \times P$

PAGE I 


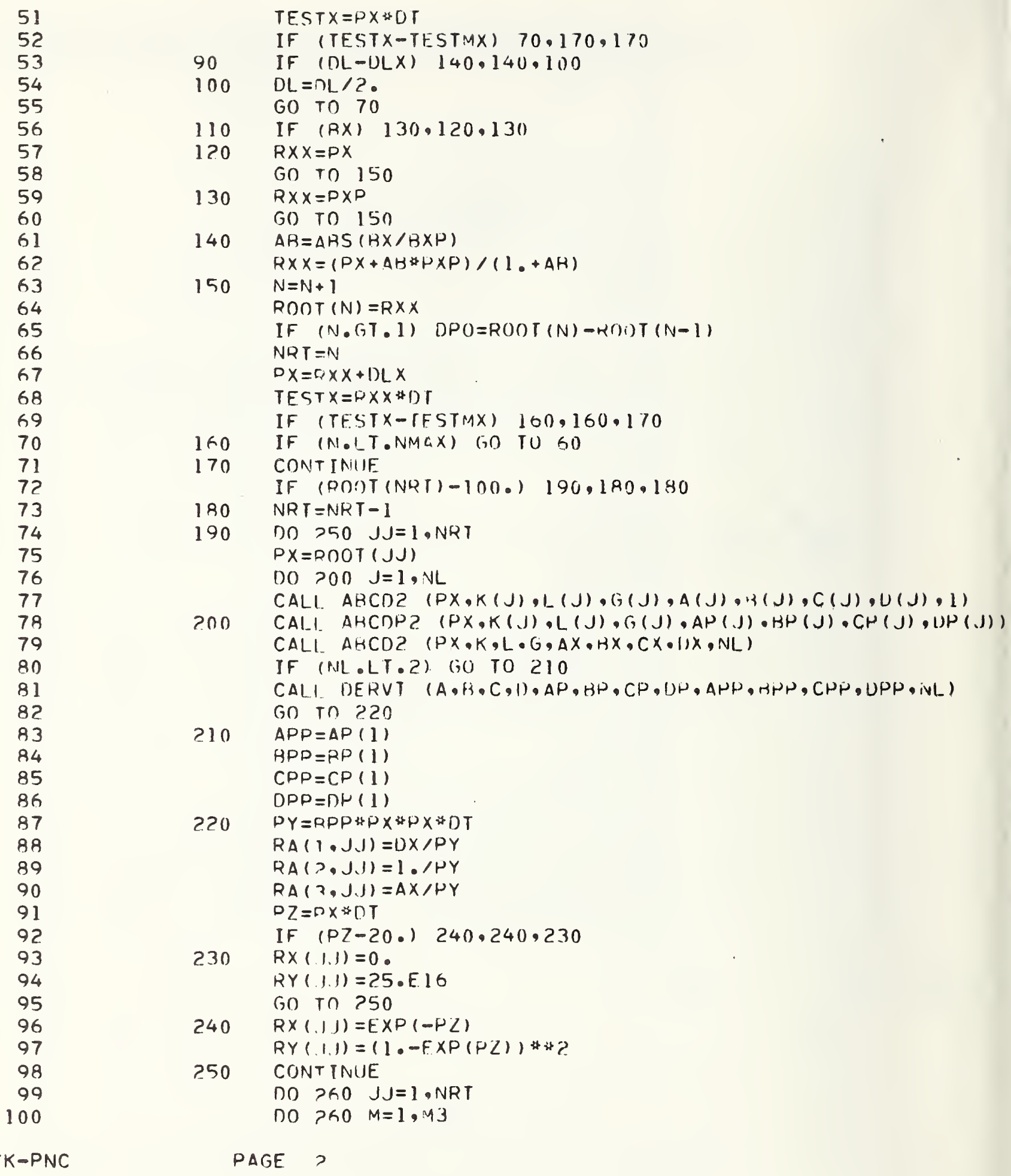




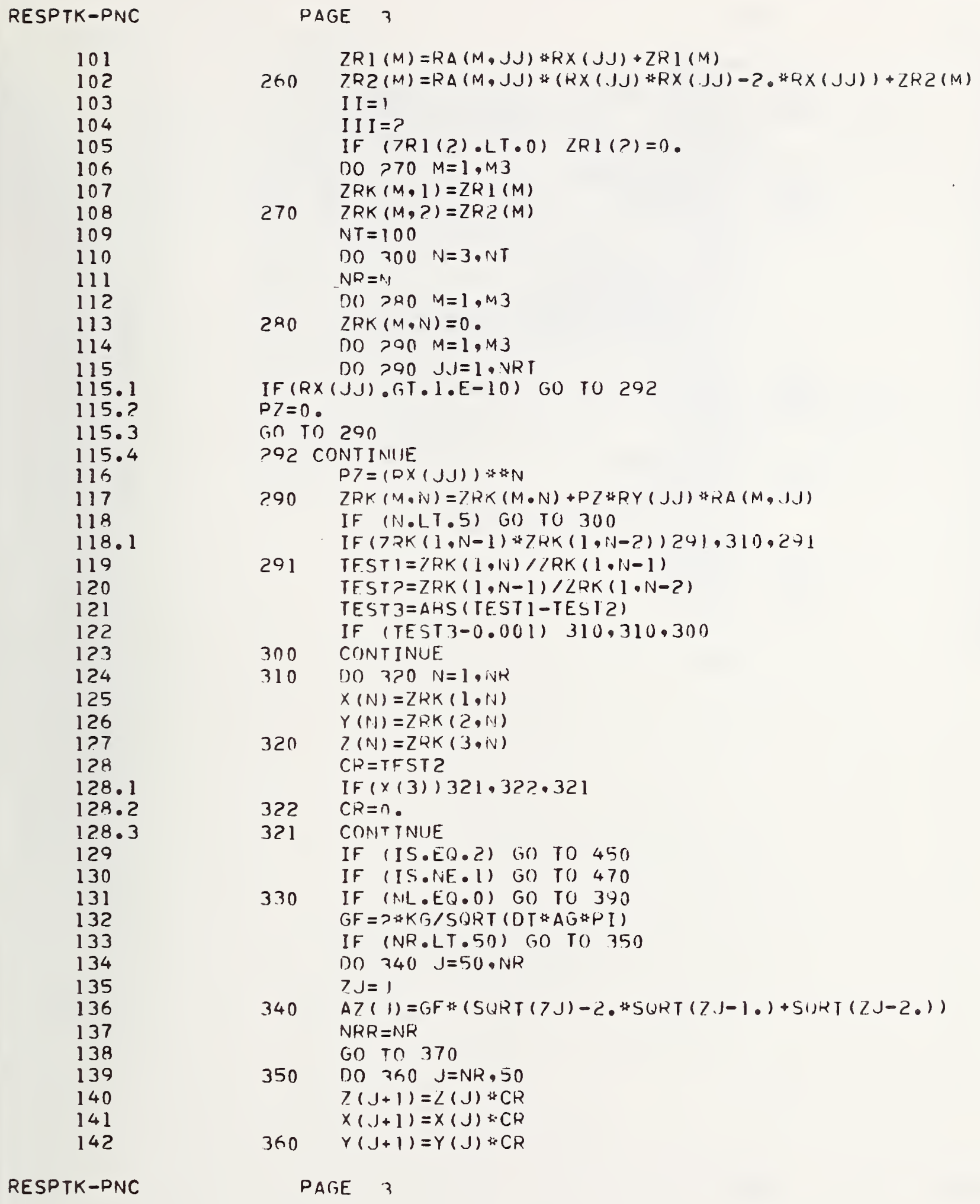

101

102

103

104

105

106

107

108

109

110

111

112

113

114

115

115.1

115. ?

115.3

115.4

116

117

118

118.1

119

120

121

122

123

124

125

126

$1 ? 7$

128

128.1

128.2

12.8 .3

129

130

131

132

133

134

135

136

137

138

139

140

141

142

RESPTK-PNC

$Z R 1(M)=R \Delta(M, J J) * R x(J J)+Z R I(M)$

$260 \quad 7 R 2(M)=R \Delta(M, J J) *(R X(. J J) * R X(. J J)-2 . * R X(J J))+Z R Z(M)$

$I I=I$

I I I =?

IF $(7 R I(?) \cdot L T \cdot 0) \quad Z R I(?)=0$.

DO $>70 \quad M=1, M 3$

$Z R K(M, 1)=Z R I(M)$

$270 \quad Z R K(M, 2)=Z R 2(M)$

$N T=100$

DO $300 \mathrm{~N}=3 . \mathrm{NT}$

$N R=M_{1}$

D) $>90 \quad M=1, M 3$

$290 \quad Z R K(M \cdot N)=0$.

DO $>00 \mathrm{M}=1, M 3$

DO $>90 \quad J J=1, N R T$

IF $(R \times(J J) \cdot G T \cdot 1 \cdot E-10)$ GO TO 292

$P 7=0$.

GO TO 290

?92 CONTINIIE

?.90 ZRK $(M \bullet i N)=Z R K(M \bullet N)+P Z * R Y(J J) * R A(M, J J)$

IF (N.LT.5) GO TO 300

IF $(72 K(1, N-1)$ iै ZRK $(1, N-2)) 241,311,291$

$291 \quad$ TF.ST $1=7 R K(1, \mid N) / / R K(1, N-1)$

TEST $?=Z R K(1, N-1) / Z R K(1, N-2)$

TEST $3=A H S(T E S T 1-T E S T 2)$

IF (TEST3-0.001) 310.310 .300

300 CONTINUE

310 DO $320 \quad \mathrm{~N}=1$, INK

$X(N)=Z R K(1, N)$

$Y(P, H)=Z R K(2, N)$

$320 \quad Z(\mathrm{~N})=Z 2 K(3, \mathrm{~N})$

$\mathrm{CH}=$ TFST 2

IF $(x(3)) 321 \cdot 32 ? \cdot 321$

$322 \quad C R=n$.

321 CONTINUE

IF (IS.EQ.2) GO) TO 450

IF (IS.NE.I) GO TO 470

330 IF (NL.EQ.0) GO TO 390

$G F=>K G / S O R T$ (DT*AG*PI)

IF (NR.LT.50) GO TO 350

DO $740 \quad J=50, N R$

$Z J=1$

$340 \quad A Z(1)=G F *(\operatorname{SURT}(7 J)-2 . * \operatorname{SURT}(Z . J-1)+.\operatorname{SIJRT}(Z J-2.1)$ $N R R=N R$

GO TO 370

350 DO $360 \quad J=N R, 50$

$Z(J+1)=\angle(J) * C R$

$x(J+1)=x(J) \approx C \cdot C$

$360 \quad Y(J+1)=Y(J) \div C R$

PAGE 3 
RESPTK-PNC

143

144

145

146

147

148

149

150

151

152

153

154

155

156

157

158

159

160

161

162

163

164

165

166

167

168

169

170

PAGE 4

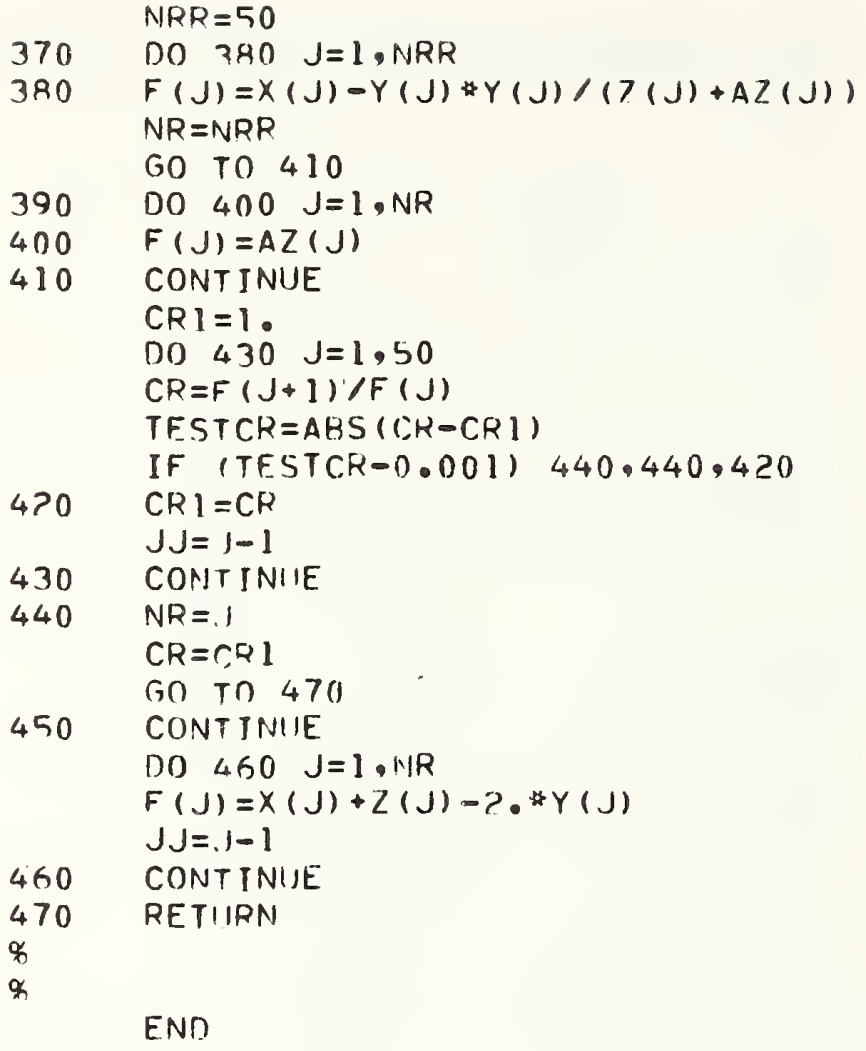


SIIBROUTINF RMRT (HEATG, HLCG, HEATX, HLCX, HEATIS, HLCIS, IW, IL, FC, ISC) \% FC: CORRECTION FACTORFOR THE HEAT LOST IO THE SURRUIINOINGS \% ISC:SHAIIING CIUEFFICIENT INDEX IF ISC=O EXTERNAL SHAUING $\%$ OTHEKWISE INTERNAL SHADING

DIMENSION HEATG(2), HLCG(2), HEATX (?), HLCX (?), HEATIS (2), HLCIS (?)

DIMENSION AG() (3), AGI (3), AXI) (3), AISI $(4,3), A[S C(4,3),(6)(3), A X I(3)$ DATA AG()/1,.187.0.197.0.224/.4(31/-0.097.-0.067.-0.044/

ПATA $B 1 /-0.91,-0.87,-0.82 /$

DATA $A X \cap / n .6 ? 6,0.081,0.703 / . A \times 1 /-0.586,-0.501,-0.523 /$

กATA (AISI (1,J), J $=1,3) / 0.53,0.53,0.53 /$

DATA $(\Delta[S>(1, J), J=1,3) /-0.44,-0.40 \cdot-0 \cdot 35 /$

DATA (AISI (2.J), J=1.3) $/ 0.59 \cdot 0.54 \cdot 0.59 /$

DATAI $\triangle I S>(2, J), J=1,3) /-0,5 C,-0.4 n,-0.41 /$

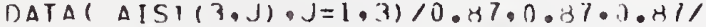

DATAI $\triangle I S P(3, J), J=1,3) /-0.78,-0.74,-0.69 /$

กATAR $\triangle I S I(4, J) \cdot J=1 \cdot 3) / 0.50 \cdot 0.50 \cdot 0.50 /$

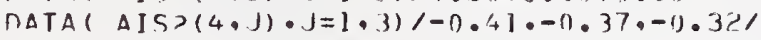

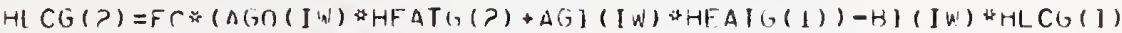

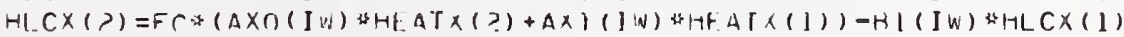

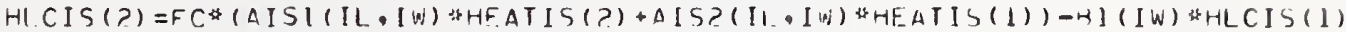
IF (ISC.EOD.O) RFTUIRN

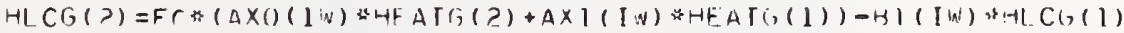
PF TIIRN

ENI) 
RMTMK-PNC

1

2

3

4

5

6

7

8

9

10

11

12

13

14

15

16

17

18

19

20

21

22

23

24

25

26

27

28

29

30

31

32

33

34

35

36

37

38

39

40

41

42

43

44

45

46

47

48

49

50

RMTMK - PNC
PAGE 1

SUBROUTINE RMTMK ( $, T I F, Q L, T A, N E X P, N X, I T K)$

COMMON/CC/ X(10,100),Y(10,100),Z(10,100), ITYPE $(10) \%$ - IHT $(30), \operatorname{IRF}(30), \operatorname{ABSP}(30), U(\overline{30}), H(\overline{30}), \bar{H} I(30), \bar{A}(3 \bar{U}) \%$ , UT $(30), \operatorname{TOS}(30,48), \operatorname{TIS}(30,48), G(30,30), \operatorname{TUY}(48), \mathrm{U} \overline{\mathrm{B}}(24) \approx$ , QLITX $(24,3)$, OEQUX $(24,3)$, OOCUP $(24,3), 00 \mathrm{CHS}(24)$, OLITE $(24) \times$ , QEQUP $(24), 0 I(30), C R(30), N R(30)$, QGLAS $(30,24)$, ITHES I, UENDW , AZW (30), SHAUE (30), RMDBS (24), RMDBW (24), 5 HU (30), UCELNG DIMENSION AA $(30,30), B B(30)$, TT $(30)$, TIF $(30), A 2730,30) \%$ $, B 2(30), B 3(30), \operatorname{GSUMM}(30), V(15)$

$T S=V(1)$

$C F M L=V(2)$

$C F M S=V(3)$

RROOM $=V(4)$

RCELG $=V(5)$

RROOML $=V(12)$

$T I M=V(t)$

QCM $\Delta X=V(7)$

$\triangle H M \Delta K=V(B)$

TUL $=V(9)$

$T L L=V(10)$

TSET $=V(11)$

$H R=V(13)$

$M E T=V(14)$

$D B N X=D B(N X)=T I M$

$T U=T S-T I M$

NEXPZ $=N E X P+1$

DO $10 \quad I=1$, NEXP

$B B(T)=0$.

$B 2(I)=0$.

DO $10 \mathrm{~J}=1$, NEXP

$A 2(I, J)=0$.

10

$A A(J, J)=0$.

$S H G=0$.

$H S U M=0$.

$\triangle S U M=0$.

$\triangle S U M T=0$.

DO $70 \quad I=1$, NEXP

$N R R=N R(I)$

$S H G=S H G * Q G L A S(I, N X) * A(I)$

$\triangle S U M T=A S U M T+A(I)$

$\operatorname{GSUM}(I)=0$.

DO $20 \mathrm{~J}=1, N E X P$

20

$\operatorname{GSUM}(I)=\operatorname{GSUM}(I)+G(I, J)$

IF (ITYPE (I).NE, 3) ASUM $=A S U M \bullet A(I)$

IF (MET.NE. O) GSUM(I) =HR

$H S U M=H S U M * H I(I) * A(I)$

$I R=I R F(I)$

$C R X=C R(I)$

IF (NRR.GE.Z) GO TO 40

$X(I R, I)=U T(I)$

PAGE । 


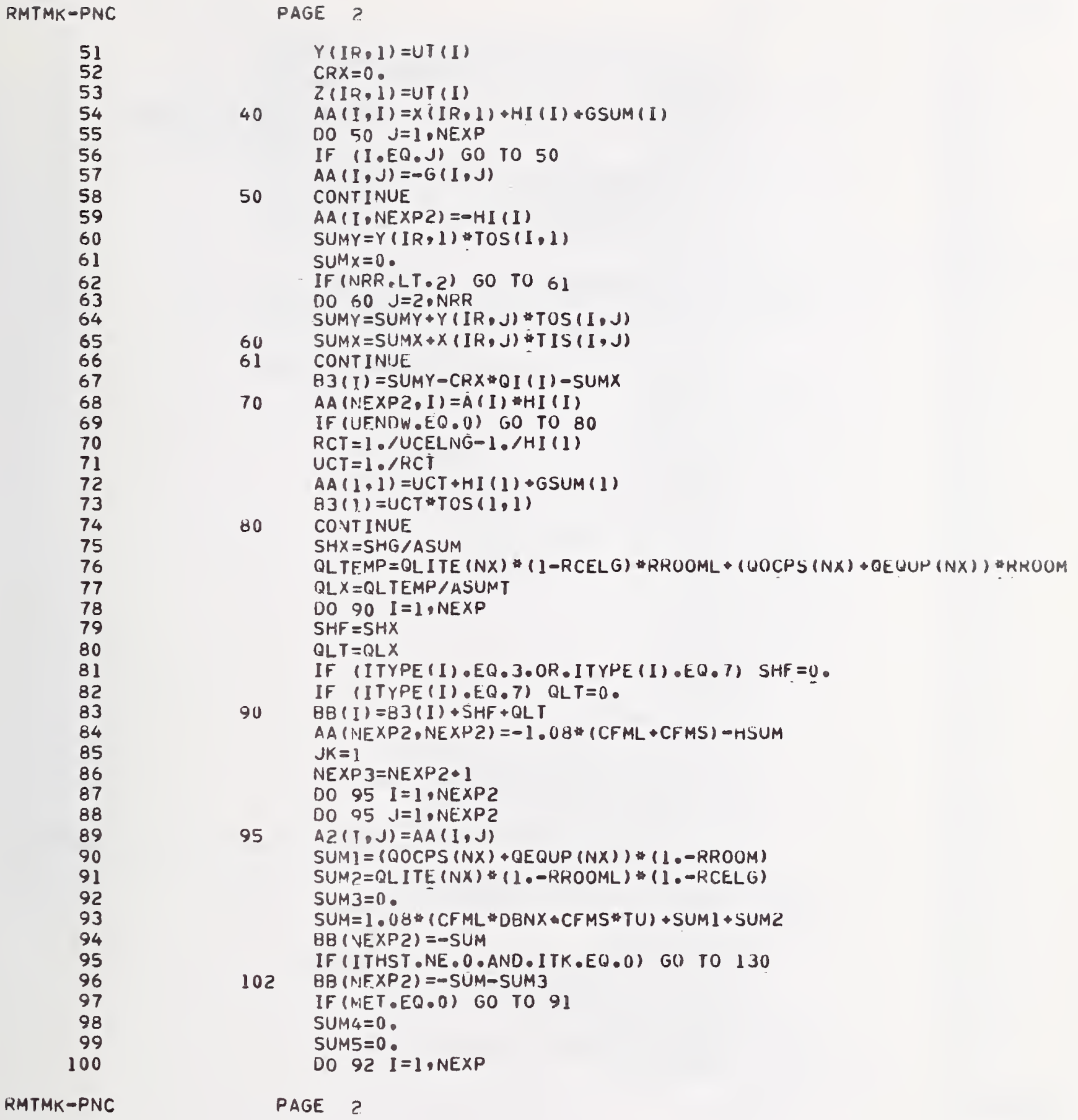


RMTMK-PNC

101

102

103

104

105

106

107

108

109

110

111

112

113

114

115

116

117

118

119

120

121

122

123

124

125

126

127

128

129

130

131

132

133

134

135

136

137

138

139

140

141

142

143

144

145

146

147

148

149

150

RMTMK $=$ PNC
PAGE 3

SUM4 $=S U M 4 *(H I(I) * A(I) * B B(I)) / A A(I, I)$

$S U M 5=S U M 5 * H I(I) * A(I) *(H I(I) * H K) / A A(I, I)$

92 CONTINUE

$T T(N E X P 2)=($ SUM $4-B B($ NEXP2) $) /(-A A(N E X P 2$.NEXP2)-SUMS)

GO TO 94

91 CONTINUE

CALL SOLVP(NEXP2,NEXP3, AA,BB,TT, 30)

$94 \quad T A=T T(N E X P 2)+T I M$

IF (ITHST.EQ.0.AND.ITK.EQ.1) GO TO 133

IF $(J K \cdot E Q, 2)$ GO TO 133

GO TO 103

130 DO $100 \quad I=1, N E \times P 2$

$100 \quad B 2(I)=B B(I)-A A(I, N E X P Z) *(T A-T I M)$

IF (MET.EQ.O) GO TO 131

DO $132 I=1$; NEXP

$T T(I)=((H I(I)+H R) *(T A-T I M)+B B(I)) / A A(I, I)$

132 CONTINUE

GO TO 13.3

131 CONTINUE

CALL. SOLVP (MEXP,NEXP2,A2,BZ,TT,30)

133 CONT INUE

$Q L=S U M-1.08 *(C F M L * C F M S) *(T A-T 1 M)$

GO TO 140

103 IF (TA-TUL) $111,112,112$

111 IF (TA-TLL) $114,114,133$

112 TA=TUL

GO TO 130

$114 \quad \mathrm{TA}=\mathrm{TLL}$

GO TO 130

140 SUMQ $=0$.

DO $160 \quad I=1$, NEXP

$K=I R F(I)$

TIS $(I, 1)=T T(I)$

TEST $=A B S(T T(I))$

IF (TEST.GT.100.) GO TO 170

IF (ITYDE (I),EQ,10) $\quad X(K, 1)=U T(I)$

$D I(I)=X(K, 1) * T T(I)-B 3(I)$

IF (ITYPE (I),F..7) QI I I $=0$ 。

IF (UENDW.NE.0.AAND.ITYPE (I) E EQ.1) QI $(1)=U T(1) *(I I(1)-\operatorname{TUS}(1,1))$

$\operatorname{TIF}(I)=T T(I)+T I M$

IF (ITYPE (I) $\bullet E Q .7) \quad \operatorname{TIF}(I)=T A$

$150 \quad S U M Q=S U M Q+A(I) * H I(I) *(T A-T I F(I))$

160 CONTINUE

$Q L=-Q L+S U M Q$

IF (ITHST.NE. O.OR.ITK.NE.0) GO TO 1 GS

IF (JK.EQ.2) GO TO 185

IF (QL) $183,185,184$

183 QLTEST =ABS $(Q L)$

IF $($ QL.TEST-QCMAX) $\quad 185,185,182$

182 SUM $3=-0$ CMAX

PAGE 3 


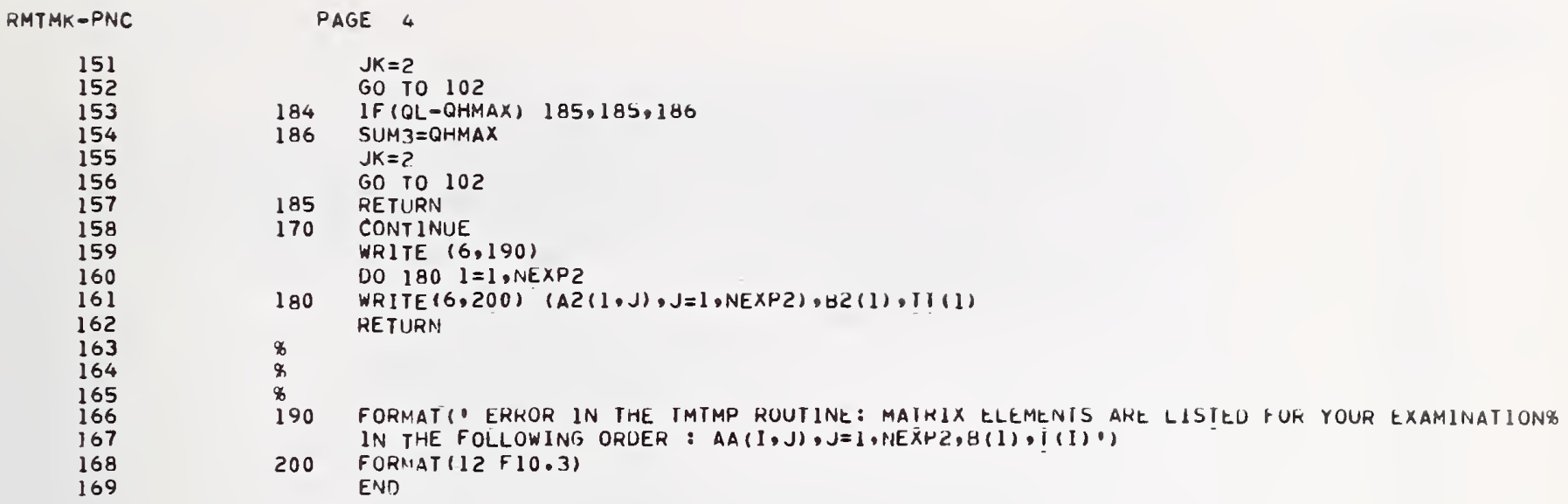

RMTMK - HNC

PAGE 4

$61 d$ 
SIBBROITINF RUOMX (IVEXP.NS, NV,NIV, NE,H)

DIMFMSION NVEXP(4)

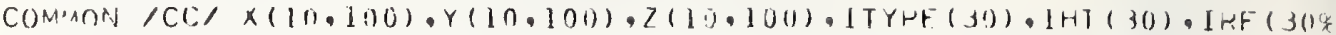

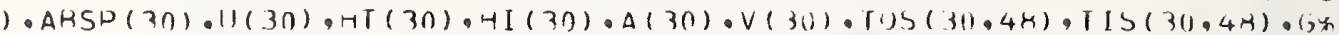

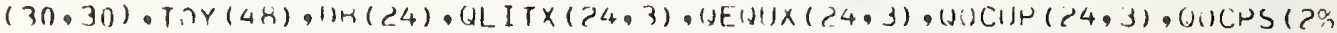

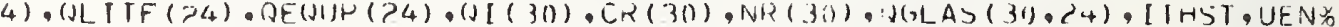

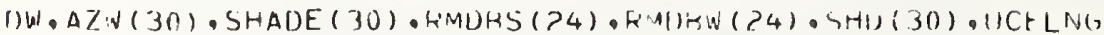
RFAI L.FS $(6,6)$ COMMON/SHOU/SHALN(3ח.1S)

o

q.

$\alpha$

$\alpha_{0}$

$\alpha$

h

x

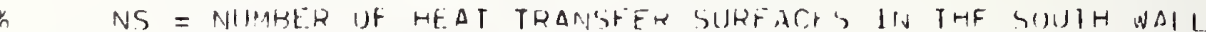

o NW = MIMBEK UF HFAT TPANSFFK SIJKFACFS IN THF WHSI WALI

\& NN = NIIMRER OF HEAT TRANSFFR SUJFACFS IRI IHF NUSTH WAIL

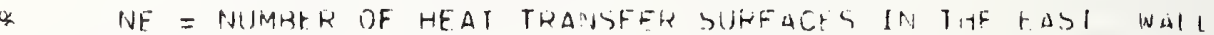

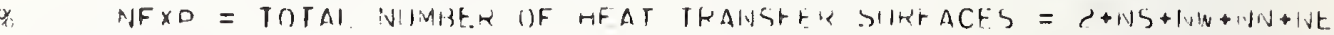
WL ITF $(6, \ln 1)$

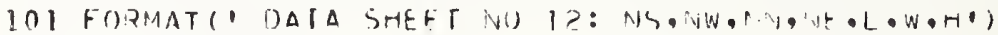

REAI)(5, it) NAR XP

NS $=$ MNA $\times$ N (1)

$N W=A$ IRIF $\times F(2)$

$N N=\operatorname{IAIFXP(3)}$

$N F=\times 1 \times 1 F \times P(4)$

$N F \times O=S+N S+N, N+N H+N E$

Q 1 = DOMM LFMIITH ALONG THE SIIITH WALI.

o. IN $=$ DOIIM NIHITH ALOVG THE WFST WALL

Q H $\quad H$ LOION CEILIAT, HEICHT

RF $A !)(5,4) !, W, H$

CAI FCTP (1. N.H, HS)

$N S=-1 S+1$

$N: N=+5+\cdots w$

$N N=1,1+1, N$

$A F=3 F+i d N$

$A S=1$ ir $\mathrm{H}$

$A \cdot N=1,1$ in

$\Delta P !=A S$

$A F=A \cdot 1$

$A Q=1$ is 1 !

$\Delta F=1 B$

(A) ITF (h, 111)

PARE I 
47.3

48

49

50

51

52

53

53.1

54

55

56

57

58

59

60

61

62

63

64

65

66

67

68

69

70

71

111 FORMAT(" DATA SHEET 13 ANI) 14: RUOM SURFACE IBATA APH) EXTFHIOK SURFACE SHADOW DATAO? DO IO $I=1$ - NE XP

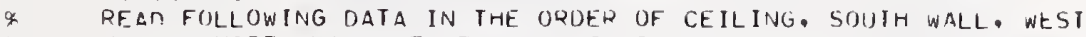

\% WAII. NIDRTH WAILL, EAST WALL, FLOOR.

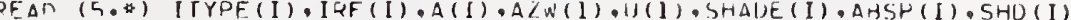

Q RFAI) SHADON INFOKMATION

RF $\triangle D(5$, * $)(S H A D W(I, J) \cdot J=1,7)$

$\operatorname{REAO}(5, *)(\mathrm{SHALW}(1, J) \cdot J=B, 15)$

in CONTTNIE

DO $>0 \quad I=1$, NE XP

IF $(I, E O .1) \quad i M=1$

IF (I.GT,I.AND.I,LF.NS) $M=$ ?

IF (I.GT,NS.AND. I.LE.NW) $M=3$

IF (J.GT,NN,AND,I.LE.NN) $M=4$

IF $(I,(3 T, N N \cdot A N D, I, L E \cdot N E) \quad M=5$

IF ( $1, E Q, N E \times P) \quad M=5$

1) 0 ) $>=1$, NEE $\times P$

IF $\left(J, F\left(J_{0}, 1\right) G(I, J)=F S(M, 1)\right.$

IF $(1,1, T, 1, A N D, J . L E$. NS $)(,(1, J)=F S(A, C)$ \# $(J) / A S$

IF $(1,1, G T \cdot N S \cdot A \mid N i), 1 \cdot L E \cdot N W) \quad G(I, J)=F S(1 A, J)+\Delta(J) / A \cdot d$

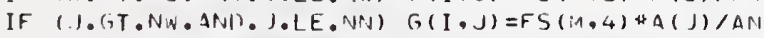

IF $(1, G, T, N N, A N I) \cdot J \cdot L E$. NE $) G(1, J)=F S(M, 3)+4(1) / A E$

20 CONTINIIE

IF $(1 . \mathrm{F}(\mathrm{O}, \mathrm{NHF} \times P) \quad(;(I, J)=F S(M, h)$

RETIIRN

Fin 
PAGE I

SUBROUTINE SHADOH(SHDX,PHI, COSZ, SHKAT).

DIMENSION SHDX (20)

$H T=S H D X(1)$

$F L=S H D X(2)$

$F P=S H D X(3)$

$A W=S H D X(4)$

$B W L=S H D X(5)$

$B W R=S H D X(6)$

$D=S H D X(7)$

$F P l=\operatorname{SHDX}(8)$

$A]=S H D X(9)$

$81=\operatorname{SHD} \times(10)$

$\mathrm{C}]=\operatorname{SHDX}(\mathrm{I} \overline{1})$

$F P 2=S H D X(12)$

$A 2=S H O \times(13)$

$B 2=S H D X(14)$

$C 2=5 H D \times(15)$

WAZI $=S H D X(10)$

\% THIS PROGRAM CALCULATES SHADOW CAST BY UVERHANG ANU SIUE FINS

THIS PROGRAM HAS BEEN DEVELOPEU BY TSENG-YAO SUN

PHI.... SOLAR AZIMUTH ANGLE

COSZ ... COSINE OF SULAR ZENITH ANGLE

SHRAT.. SHADE RATIU:RATIO UF THE SUNLIT AKEA TU IHE TOTAL WINUUW AKEA

HT ....WINDOW HEIGHT

FL.....WINDOW WIDTH

FP.....DEPTH OF THE OVERHUNG

AW..... UISTANCE FROM TOP OF THE WINUUW TO THE OVLRHUNG

BWL....DISTANCE OF THE OVERHUNG EXILNUED HEYOND IHE LEF I LUGE OF IHE WINOOOW BWR....DISTANCE OF THE OVERHIJNG EXTENUEU BEYOND IHE KIGF̈I LUGE OF THE WINOUW D......DEPTH OF VERTICAL PROJECTIUN AI IHE ENU UF THE UVERHUNG

FP $1 \ldots .$. DEPTH OF THE LEFT FIN

A 1.... DISTANCE OF THE LEFT FIN EXIENUEU ABOVE IHE TOP OH THE WINUOW

B 1..... DISTANCE FROM THE LEFT EUGE OF THE WINUOD IU THE LEFT + IN

C.... DISTANCE OF THE LEFT FIN STOP SHUKT ABOVE IHE BOITUM UF THE WINDOW FP2....DEPTH OF THE RIGHT FIN

A2.... DISTANCE OF THE RIGHT FIN E.XTENUEU ABUVE IHE TUP OF THE WINUUW

B2.... DISTANCE FROM THE RIGHT EDGE OF IHE WINOUW IO THE RIGHI FIN

C2..... DISTANCE OF THE RIGHT FIN STUP SAORT ABOVE THE BUTIOM OF THE WINOOW WAZI ...WINDOW AZIMUTH ANGLE

SHR $\triangle T=1$.

$1103 A=A W$

$H=H T$

GAMMA $=P H I-W A Z I$

$\operatorname{COSG}=\operatorname{COS}($ GAMMA)

IF $(C O S G) 100,100,104$

100 SHRAT $=0$.

GO TO 2000

104

CONT INUE

SBETA $=\operatorname{COS} \angle$

IF (SBETA) I $00,100,152$

SHADOW-PNC

PAGE I 
SHADOW-PNC

51

52

53

54

55

56

57

58

59

60

61

62

63

64

65

66

67

68

69

70

71

72

73

74

75

76

77

78

79

80

B1

82

83

84

85

86

87

88

89

90

91

92

93

94

95

96

97

98

99

100

SHADOW-PNC
PAGE 2

152 SING $=$ SIN (GAMMA)

VERT $=S B E T A / S Q R T(1 \bullet-S B E T A \# S B E T A) / C O S G$

HOR I $Z=A B S(S I N G) / C O S G$

TCETA $=V E R T / H O R I Z$

IF (GAMMA) $155,154,154$

$\% \quad-\infty-\infty--S U N$ ON LEFT

$154 \quad B=B N L$

GO TO 156

\% $-\infty-\infty-\infty$ SUN ON RIGHT

$155 B=B W R$

$156 \quad A R S H F=0$.

AREAV $=0$.

ARSIF $=0$.

AREAO $=0$.

AREAI $=0$.

$A R S H I=0$.

$F L 3=0$.

$H 3=0$.

$\mathrm{Hl}=\mathrm{H}$

$F L I=F L$

$K=1$

$L=1$

$T 1=F P * V E R T$

$F M I=F P * H O R I Z$

$153 \quad T=T_{1}$

$F M=F M 1$

$A B=B * T C E T A$

$U G=(F L+B) \backsim T C E T A$

$D E=(H \leftrightarrow A) / T C E T A$

\% $\infty-\infty$ HORIZONTAL OVERHUNG "AREAO"

IF $(T-A) 27,27,2$

2 IF $(A B-A) 14,14,3$

3 IF (DE-B) $12,12,4$

4 IF $(F M-B) 11,11,5$

5 IF $(D E-(F L+B)) 8,8,6$

6 IF $(F M-(F L+B)) 9,7,7$

$\%$ - $0-\infty-O H O R I Z 9$

$7 \quad A R E A O=F L *(0.5 *(A B+U G)-A)$

GO TO 37

$8 \quad$ IF $(T-(H+A)) 9,10,10$

$\%$ - $D-O H D R I Z 7$

$9 \quad A R E A O=(T-A) \# F L-((F M-B) * 2) * T C E T A * 0.5$

$L=2$

GO TO 21

$\% \quad 0-\infty-H O R I Z 8$

$10 \quad A R E A O=H \# F L-(O E-B) * 2 \# T C E T A \# 0.5$

GO TO 37

$\% \quad=-\infty-\infty-H O R I Z 3$

$11 \quad A R E A O=F L(T-A)$

PAGE ? 
SHADOW-PNC

101

102

103

104

105

106

107

108

109

110

111

112

113

114

115

116

117

118

119

120

121

122

123

124

125

126

127

128

129

130

131

132

133

134

135

136

137

138

139

140

141

142

143

144

145

146

147

148

149

150

PAGE 3

$L=2$

GO TO 24

12 If $(T-(H+A)) \quad 11,13,13$

\& $\infty-\infty-\infty=H O R I Z 2$

$13 \quad A R E A O=H * F L$

GO TO 68

14 If $(U G-A) 27,27,15$

15 IF $(D E-(F L+B)) 18,18,16$

16 IF $(F M=(F L+B)) 20,17,17$

$\% \quad-\infty-\infty \rightarrow-H O R I Z 6$

$17 \quad A R E A O=(U G-A)$ * $2 / T C E T A * 0.5$

GO TO 37

18 IF $(T-(H+A)) 20,19,19$

$\%$ - $\infty-\infty-\infty$ HORIZ 5

19 AREAO $=H+(F L-(A+0.5 * H) / T C E T A * B)$

GO TO 37

\% $-\infty-\infty-\infty$ HORIZ 4

$20 \quad \triangle R E A O=(T-A)=(F L+B-F M+(1 * A / T) * 0.5)$

$\%$ PAREAV"

$21 \quad F L 3=F L+B-F M$

If $(T+D=(H+A)) 22,22,23$

$\%$ - $\$-\infty-\infty$ VERT 8

$22 \quad \mathrm{H} 3=\mathrm{D}$

$\%$ GD TO

$23 \quad \mathrm{H} 3=\mathrm{H}+\mathrm{A}-\mathrm{T}$

GO TO 3700

$24 \quad F L 3=F L$

IF $(T+D-(H+A)) 26,26,25$

$\%$ H $-\infty-\infty-D E R T 7$

$25 \quad H 3=H+A-T$

AREAV $=H 3$ HL 3

GO TO 68

$\%$ - $-\infty-\infty-$ VERT 6

$26 \quad H 3=0$

GO TO 3700

27 If $(T+D-A) 37,37,28$

28 IF $(F M-B) 34,34,29$

29 IF $(F M=(F L+B)) 31,37,37$

$31 \quad F L 3=F L+B-F M$

IF $(T+D-(H+A)) 33,33,32$

\% $-\infty-\infty--V E R T$ T

$32 \quad H 3=H$

GO TO 3700

\& $-\infty-\infty-\infty E \overline{R T} 4$

$33 \quad H 3=T+D-A$

GO TD 3700

34 IF $(T+D-(H+A)) 36,35,35$

$\%$ \& $\infty-\infty$ VERT 2

SHADOW-PNC

PAGE 3 
SHADOW $-P N C$

151

152

153

154

155

156

157

158

159

160

161

162

163

164

165

166

167

168

169

170

171

172

173

174

175

176

177

178

179

180

181

182

183

184

185

186

187

188

189

190

191

192

193

194

195

196

197

198

199

200

SHADOW-PNC
PAGE 4

35 AREAV $=$ HWL

GO TO 68

\% VERT 3

$36 \quad H 3=T+D-A$

$F L 3=F L$

3700 AREAV $=F L 3 * 13$

$\%$ - $\%---S I D E$ FIN AND SHORT SIDE FIN

$\%$ - $\%-\infty-$ SIOE FIN "AREAI" "ARSIF"

37 IF (GAMMA) $66,68,74$

$74 \quad F P F=F P \perp$

$A F=A 1$

$B F=R I$

$\mathrm{CX}=\mathrm{Cl}$

GO TO 84

$66 \quad F P F=F P 2$

$A F=A 2$

$B F=B 2$

$C X=C 2$

84 IF (FPF) $68,68,67$

$67 T=F P F \forall V E R T$

$F M=F P F \triangle H O R I L$

$A F I=A F$

IF (AREAO) $73,73,88$

$\%$ -

$88 \quad A T=A+(B F-B) *$ TCETA

$1 F(A T-A F) 711,73,73$

* $-\infty--$ OVERLAP EXISTS..LL 2 IF OVERHUNG SHAUUW HAS HORIL EUGE IN WINDOW

711 GO TO $(621,712), L$

\% - - - - TEST FUR TYPE OF OVERLAP

$712 \quad 1 F((F M-B F)-(F M 1-B)) 621,622,622$

\%

8

621

- - - SET L=l,SHAUOW INTERSECT UN INCLINEU EOGE UF OVERHUNG SHADOW

-..-- FIN SHADOW IS BELOW INCLINEO EUGE UF UVERHUNG SHAUUWW

$A F=A T$

$L=1$

GO TO 73

\% - - - L IS 2. HORIZ EDGE OF OVERHUNG SHADUW-PORIION ABUVE HOKIL EDGE

\% O-D-ONOT IN OVERHUNG SHADOW IS FIN SHAUUW

622 AREAI $=F L \$(T I-A)-A R E A O$

\% O-- - KESET TO CALC FIN SHADOW BELOW HUKIL LUGE UF OVHNG SHAUOW

$A F=T 1-A+A F 1$

$H=H+A F I-A F$

* - - SHADOW OF FIN $(K=1$ ON GLASS $K=2$ ON VERT PRUJ SHAUUW)

$73 \quad A B=B F * T C E T A$

$U G=(F L+B F) \backsim T C E T A$

$D E=(H \bullet A F) / T$ CE TA

$D J=C X / T C E T A$

IF (FM-BF) $69,69,38$

38 IF $(A B-A F) 39,50,50$

39 IF (UG-AF) $48,48,40$

40 IF $(T-A F) 47,47,41$

PAGE 4 


\begin{tabular}{|c|c|c|}
\hline SHADOW-PNC & & $G E$ \\
\hline 201 & 41 & IF $(U G-(H+A F)) 44,44,42$ \\
\hline 202 & 42 & IF $(T-(H+A F)) 91,80,80$ \\
\hline 203 & $\%$ & $-\infty-\infty$ F IN 9 \\
\hline 204 & 80 & AREA $1=H *((A F \bullet H * 0.5) / T C E T A-B F) \leftrightarrow A R E A 1$ \\
\hline 205 & & GO TO 58 \\
\hline 206 & 44 & IF $(F M=(F L+B F)) 91,89,89$ \\
\hline 207 & $\%$ & $-\infty-\infty-\infty$ ING \\
\hline 208 & 89 & AREA $1=H * F L-(U G-A F) * 2 / T C E T A * 0.5 * A K E A 1$ \\
\hline 209 & & GO TO 58 \\
\hline 210 & $\mathscr{x}$ & $-\infty-\infty-\infty$ F IN 7 \\
\hline 211 & 91 & AREA $=(F M-B F)=H-(T-A F) * 2 / T C E T A * 0 . S+A R E A 1$ \\
\hline 212 & & Go TO 63 \\
\hline 213 & 48 & IF $(F M-(F L+B F)) 47,47,49$ \\
\hline 214 & $\mathscr{s}$ & $-\infty-\infty-\infty$ IN 3 \\
\hline 215 & 47 & $A R E A I=H(F M-8 F)+A K E A I$ \\
\hline 216 & & Go To oj \\
\hline 217 & क & $-\infty-\infty-\infty$ F IN 2 \\
\hline 218 & 49 & AREAI $=H * F L+A R E A 1$ \\
\hline 219 & & GO TO 58 \\
\hline 220 & 50 & IF $(D E-B F) 69,09,51$ \\
\hline 221 & 51 & If $(U G-(H+A F)) 55,55,52$ \\
\hline 222 & 52 & IF $(T-(H+A F)) 93,94,94$ \\
\hline 223 & $\%$ & $-\infty-\infty$ IN 6 \\
\hline 224 & 94 & $A R E A 1=(D E-B F) * 2 * T C E T A * 0.5+A R E A 1$ \\
\hline 225 & & GO TO 58 \\
\hline 226 & \% & $-\infty-\infty \operatorname{IN} 4$ \\
\hline 227 & 93 & $A K E A 1=(F M-B F) *(H+A F-(T+A B) * 0 . S)+A K E A 1$ \\
\hline 228 & & GO TO 63 \\
\hline 229 & 55 & IF $(F M-(F L+B F)) 93,99,99$ \\
\hline 230 & $\%$ & $-\infty--$ FIIN 5 \\
\hline 231 & 99 & AREA $1=F L *(H=(B F+F L * 0.5) * T C E T A * A F)+A R E A 1$ \\
\hline 232 & $\%$ & $-\infty-$ SHUKT SIDE FIN "ARSHI" "ARSHF" \\
\hline 233 & 58 & IF (D)J-BF) $69.69,59$ \\
\hline 234 & 59 & IF $(D J=(F L+B F)) 61,61,60$ \\
\hline 235 & $\%$ & $-\infty-\infty-5 H O R T 3$ \\
\hline $\begin{array}{l}236 \\
237\end{array}$ & 60 & $\begin{array}{l}\text { ARSHI }=-F L *(C X-(B F+F L / 2,) \text { TCETA }) \\
\text { GO TO } 69\end{array}$ \\
\hline 238 & \& & $=----$ SHORT 4 \\
\hline 239 & 61 & ARSH $1=-(C X-A B) * 2 /$ TCETA 0.5 \\
\hline 240 & & GO TO 69 \\
\hline 241 & 63 & IF $(D J=B F) 69,69,64$ \\
\hline 242 & 64 & If $(D J-F M) 01,01,65$ \\
\hline 243 & $\%$ & $-\infty-\infty-\infty H O R T 2$ \\
\hline 244 & 65 & $A R S H I=-(F M-\forall F) *(C X-(T+A B) * 0.5)$ \\
\hline 245 & 69 & GO TO $(77,76), \mathrm{K}$ \\
\hline 246 & 76 & $A R S H 1=-A R S H I$ \\
\hline 247 & & $A K E A 1=-A R E A 1$ \\
\hline 248 & 77 & $A R S H F=A K S H F+A K S H I$ \\
\hline 249 & & $A R S I F=A K S I F+A R E A I$ \\
\hline 250 & & GO TO $(78,68) \cdot K$ \\
\hline HADOW-PNC & & GE S \\
\hline
\end{tabular}


SHADOW-PNC

251
252
253
254
255
256
257
258
259
260
261
262
263
264
265
266
267
268
269
270
271
272
273
274

PAGE 6

78 IF (AREAV) 68,68,72

$\%$ KE

$72 \quad K=2$

AREAI $=0$.

$A R S H I=0$.

$B B F=B F$

$B F=F M I-B+B F$

IF (RF) $186,185,185$

$186 \quad B F=R B F$

185 IF $(H T+A-T 1-D) 87,87,188$

$188 \quad C X=C X-(H T+A-T 1-D)$

IF $(C X) 85,87,87$

$85 \quad C X=0$.

$87 \quad A F=T 1-A+A F$

$\mathrm{H}=\mathrm{H} 3$

$F L=F L 3$

GO TO 73

8 - SHAUEU AREA "ARSHA"

$68 \quad A R S H A=A R E A U+A R E A V+A R S H F+A R S I F$

SHRAT $=(F L 1 * H I-A R S H A) /(F L I * H I)$

$F L=F L 1$

2000 CONTINUE

RETURN

END 
SUBROUTINE SHG (SH)

DIMENSION SH(2O)

$\%$

SH(I) =INTENSITY OF UIRECT NORMAL SOLAK RAUIATION

SH(2) =INTENSITY OF DIFFUSE SKY RAUIATION

SH(3) =INTENSITY OF GROUND REFLECTLU UIFFUSE RADIAIION

SH(4) =COSINE OF INCIDENCE OF DIRECT SULAR RADIAIIUN

SH(5) =FORM FACTOR BETWEEN THE WINUOW ANO THE SK $\bar{\gamma}$

SH(6) =FORM FACTOR BETWEEN THE WINUOW ANU THE GRUUINU

SH(7) = THERMAL RESISTANCE AT OUTSIUE. SURFACE

SH $(8)=$ THEKMAL RESISTANCE AT THE AIR SPACE (DUUULE GLAZING)

SH(9) =THERMAL RESISTANCE AT THE INNNER SÜKFFACE

SH(10) $=$ SUNLIT AREA FACTOR

SH(II)=SHADING CUEFFICIENT, NON-LERO VALUE WILL BE GIVEN ONLY WHEN THE WINUUW IS SHADEU BY DRAPES OK BLINDS OR IF IT HAS AN INTERPANE SEPARATION UF MORE THAAN I-INCH

SH $(12)=$ TRANSMISSION FACTOR FOR DIKECT RAUIATION

SH $(13)=$ TRANSMISSION FACTOR FOR OIFFUSE RAOIATION

SH $(14)=A B S U R P T I O N$ FACTOR FOR UIRECT RADIAIION (UUIER PANE) SH $(15)=A B S O R P T I O N$ FACTOR FOR DIREC) RADIATION (INNER PANE) SH(16) =ABSORPTION FACTOR FOR UIFFÜS KAUIATION(UUIER PANE) SH $(17)=A B S O K P T I O N$ FACTOR FOR DIFFUSE KAUIATION (INNER PANE) SH $(18)=$ SOLAF HEAT GAIN

COMMON /SOL/ LAT,LONG,TZN,WAL,WT, CN,UST,LPYR,S (3')

REAL LAT, LONG,NI, NO

$N I=(S H(7)+S H(8)) /(S H(7)+S H(8)+S H(9))$

$N O=(S H(7)) /(S H(7)+5 H(8)+5 H(9))$

$0=S H(I 0) * S H(1) * S H(4) *(S H(12)+N 0 * S H(I+) * N I * S H(15))$

$D D=(S H(2) * S H(5)+S H(3) * S H(6)) *(S H(13)+N O \# S H(16) * N 1 * S H(17))$

IF $(S H(I 1)) 20,10,20$

10

$S H(18)=D+D D$

GO TO 30

20

$S H(I 8)=(D+D D) \star S H(11)$

30

RETURN

END 
SUBROUTINE SULVP $(M, N, C, D, X, 1)$

क THIS IS A RUUTINE FOR SOLVING SIMULIANEUUS LINEAR tQUATIUNS

\% THE ROUTINE WAS DEVELOPEU BY B.A. PLAVY UF NBS
$\%$ ROUIINE FAILS WHEN ANY UF THE UIAGUTAL ELEMENIS IS LERO DIMENSIUN A $(100,101), C(I, 1), 0(1), X(1)$

DI) 10 I $X=1, M$

DO 10 IY $=1, M$

$10 \quad A(I X, I Y)=C(I X, I Y)$

$2000 \quad 20 \quad I Z=1, M$

$20 \quad A(I Z, N)=D(I Z)$

$L=1$

$30 \quad A A=A(L, L)$

$40 \quad D O 40 \quad K=L, N$

$40 \quad A(L, K)=A(L, K) / A A$

DO fo $K=1, M$

IF $(K, E Q . L)$ iU TO 60

$A A=-A, K, L)$

DO 50 I $A=L, N$

50

$A(K, I A)=A(K, I A)+A A \otimes A(L, I A)$

60 CONTINUE

$L=L+1$

IF (L.LE.M) GO TO 30

70

DO 70 IP $=1, M$

$X(I P)=A(I P, N)$

RETURN

ENJ 
1

2 
SUN-PNC

51

52

53

54

55

56

57

58

59

60

61

62

63

64

65

66

67

68

69

70

71

72

73

74

75

76

77

78

79

80

81

82

83

84

85

86

87

88

89

90

91

92

93

94

95

96

97

98

99

100

SUN-PNC
PAGE 2

$x=2 * P I / 366 * S(4)$

$\mathrm{Cl}_{1}=\cos (x)$

$\mathrm{c} 2=\cos (2 * x)$

$\cos =\cos (3 * x)$

$\operatorname{SI}=\operatorname{SIN}(x)$

$\sin =\sin (2 * x)$

$\operatorname{Sin}=\operatorname{SIN}(3 * x)$

DO $10 \mathrm{~K}=1.5$

$K S=(K-1)+28$

$10 \quad S(K S)=A 0(K)+A 1(K) * C 1+A 2(K) * C 2+A 3(K) * C 3+\forall I(K) * S 1+B C(K) * S 2+B 3(K) * S 3$

$S(29)=S(29) / 60$.

LATD $=S(1)$

LONG $=S(2)$

MERID $=15 * S(3)$

LOND $=$ LONG-MERIO

$Y=S(28)$ PI/ 180.

$Y Y=L A T O \# P I / 180$.

$H P=-T A N(Y) * T A N(Y Y)$

$T R=12 / P I A C O S(H P)$

$S(11)=(12-T R)-S(29)+$ LOND $/ 15$.

$S(12)=24 \cdot-5(11)$

$H=15+(S(5)-12+5(3)+5(29)-S(6))-5(2)$

$S(35)=H$

S13=SIN $(Y Y) * S I N(Y)+\operatorname{COS}(Y Y) * \operatorname{COS}(Y) * \operatorname{COS}(H \# P I / 180$.

$\mathrm{S}(13)=S 13$

$H P l=180 . * A C O S(H P) / P I$

$X 1=A B S(H P 1)$

$X_{2}=A B S(H)$

If $(x]-x 2) \quad 130,20,20$

$20 S S(14)=\operatorname{COS}(Y) * S I N(H * P I / 180$.

$S(15)=S Q R T(1:-S(13) \approx S(13)-S(14) \backsim S(14))$

STEST $=S(15)$

STEST $1=\operatorname{COS}(H \# P I / 180)-.T A N(Y) / T A N(Y Y)$

IF (STEST1) $40,30,30$

$30 \quad 5(15)=S T E S T$

GO TO 50

$40 \quad 5(15)=-5$ TEST

$50 \quad S(Z 20)=A S I N(S(13))$

If $(5(15)) \quad 70,60,60$

$60 S(21)=A S I N(S(14) / \operatorname{Cos}(S(20)))$

GO TO $\dot{8} 0$

$70 S S(21)=P I-A S I N(S(14) / \operatorname{Cos}(S(20)))$

$80 \quad S(20)=180.45(2 \dot{)}) / P I$

$S(21)=180 . \$ S(21) / P I$

$\operatorname{IF}(S(21)-180,1) 81,81,82$

$82 \quad S(21)=360 .-5(21)$

81 CONTINUE

$S(24)=5(30) * S(8) * S(33) * E \times P(-5(31) / S(13))$

$S(22)=S(32) * S(24) / S(8) / S(8)$

$S(23)=S(7) *(S(22)+5(24) * S(13))$

PAGE ? 
SUN-PNC

101

102

103

104

105

106

107

108

109

110

111

112

113

114

115

116

117

118

119

120

121

122

123

124
PAGE 3

$W Y=S(10) * P 1 / 180$.

$S(16)=\operatorname{COS}(W Y)$

$W A=S(9) \Rightarrow P I / 180$ 。

$S(16)=\cos (W Y)$

$S(17)=S I N(W A)$ SIN $(W Y)$

$S(1 B)=\operatorname{COS}(W A)$ *SIN $(W Y)$

$S(19)=S(16) * S(13)+S(17) * S(14)+S(18) * S(15)$

$S(34)=S(24) * S(19)$

$Y=0.45$

IF $(S(19)+0.2) 100,100,90$

$90 Y \quad Y=0.55 * 0.437 * S(19)+0.313 * S(19) * 2$

100 IF $(5(19)) 110,110,120$

$110 \quad S(19)=0$.

$S(34)=0$.

120 CONTINUE

$S(26)=S(22) * Y$

$S(27)=S(23) *(1-S(16)) / 2$.

$S(25)=S(34)+S(26)+S(27)$

GO TO 150

$130 \quad 00 \quad 140 \quad J=14,26$

$140 \quad S(J)=0$.

$S(34)=0$

150 RETURN

END 
TAR-PNC

PAGE 1

SUBROUTINE TAR (TR)

REAL Al $(6) / 0.01154,0.77674,-3.94657,8.51881,-8.38135,3.01188 /$

REAL A2(6)/0.01636,1.40783,-6.79030,14.37378,-13.83357,4.42439/

REAL A3 $(6) / 0.01837,1.92497,-8.89134,18.40197,-17.48648,6.17544 /$

REAL A4 (6)/0.01902,2.35417,-10.4715,21.24322,-19.45978,6.99964/

REAL A5(6)/0.01712,3.50839,-13.8639,20.34330,-23.84846,8.11372/

REAL A6(6) /0.01406,4.15958,-15.0628,27.18492,-23.88518,8.03650/

REAL A7(6)/0.01153,4.55946,-15.4329,26.10568,-22.87943,1.51195/

REAL $A 8(6) / 0.00962,4.81911,-15.4714,25.86516,-21.09106,1.08714 /$

REAL T1 $(6) /=0.00885,2.71235,-0.62062,-7.07329,9.73995,-3.89922 /$

REAL T2 (6) $/=0.01114,2.39371,0.42978,-8.98262,11.51790,-4.52064 /$

REAL T3(6)/-0.01200,2.13036,1.13833,-10.01925,1<́.44161,-4.83285/

REAL T4 $(6) /-0.01218,1.90950,1.61391,-10.64872,12.83698,-4.95199 /$

REAL TS $(6) /=0.01056,1.29711,2.28615,-10.037132,11.45884,-4.54880 /$

REAL T6(6)/-0.00835,0.92766,2.15721,-8.11429,9.87152,-3.13328/

REAL T7 (6) / $0.000646,0.68256,1.82499,-6.95325,1.8064 \%,-2.94454 /$

REAL TB(6)/-0.00496,0.51043,1.47607,-5.41985,6.00546,-2.28162/

REAL A01 (6) $10.01407,1.06226,-5.59131,12.15034,-11.78092,4.20070 /$

REAL AO2 $(6) / 0.01819,1.86277,-9.24831,19.49443,-18.56094,6.53940 /$

REAL AO3 $(6) / 0.01905,2.47900,-11.7421,24.14037,-22.64299,7.89954 /$

REAL AO4 $(6) / 0.01862,2.96400,-13.4870,27.13020,-25.11877,8.68895 /$

REAL A05 (6) /0.01423,4.14384,-16.6670y,31.30484,-21.81955, $4.36959 /$

REAL AU6(6)/0.01056,4.71447,-17.33454,30.91781,-26.63896, $6.79495 /$

REAL A07 (6)/0.00819,5.01768,-17.21<28,29.40388,-24.7691b.8.05040/

REAL A08(6)/0.00670,5.18781,-16.84820,27.90292,-2L.99619,7.38140/

REAL AII (6)/0.00228,0.34559,-1.19908,2.22336,-2.03287,0.72376/

REAL AI $2(6) / 0.00123,0.29788,-0.92256,1.38171,-1.40040,0.48316 /$

REAL AI3(6)/0.00061,0.26017,-0.72/13,1.14950,-0.47138,0.32705/

REAL AI $4(6) / 00.00035,0.22974,-00.58381,0.84626,-0.61666,0.221021$

REAL AI5 (6)/-0.00009,0.15049, =0.21590,0.25018, $=0.12919,0.02859 /$

REAL AI $6(6) /-0.00016,0.10579,-0.15035,0.06481,0.02759,-0.023111$

REAL AI7 (6) / $0.00015,0.07117,-0.09059, \overline{0} .00050,0.000111,-0.033394 /$

REAL AI8 $(6) /=0.00012,0.05746,-0.05878,=0.01855,0.06837,=0.031 \mathrm{yl} /$

REAL TDI $(6) /=0.00401,0.74050,7.20350,-20.11763,1 y-68824,-6.74585 /$

REAL TD $2(0) /=0.00438,0.57818,7.42065,-20.26848,19.79706,-6.79019 /$

REAL TD $3(6) /=0.00428,0.457 y 7,7.41367,-19.92004,19.4096 \overline{9},-6.60603 /$

REAL TO4(6) $/=0.00401,0.36698,7.27324,-19.29364,18.75408,-6.43968 /$

REAL TO5 $(6) /=0.00279,0.16468,6.17715,-15.84811,15.24302,-5.23666 /$

REAL TD6(6)/-0.00192,0.08180,4.94/53,-12.43481,11.92495,-4.0778//

REAL TD7 (6)/ $100.00136,0.04419,3.87529,-9.59069,9.10022,-3.12776 /$

REAL TD8 $(6) /=0.00098,0.02576,3.00400,-4.33834,6.98747,-2.38328 /$

DIMENSION TR $(9), A(8,6), T(8,6), A O(8,6), A I(8,6), T U(8,6)$

TR(I) = TRANSMISSIUN FACTOR, UIRECT

TR $(2)=$ TRAN'SMISSION FACTOR, DIFFUSE

$T R(3)=$ ABSORPTION FACTOR ,DIRECT, OUIEN

$\operatorname{TR}(4)=$

$\operatorname{TR}(5)=$

- DIFFUSE, OUTÉK

$\operatorname{TR}(6)=$

$T R(7)=$ - DIRECI , INNER - DIFFUSE, ININÉR

$T R(8)=T Y P E$ OF 
PAGE ?

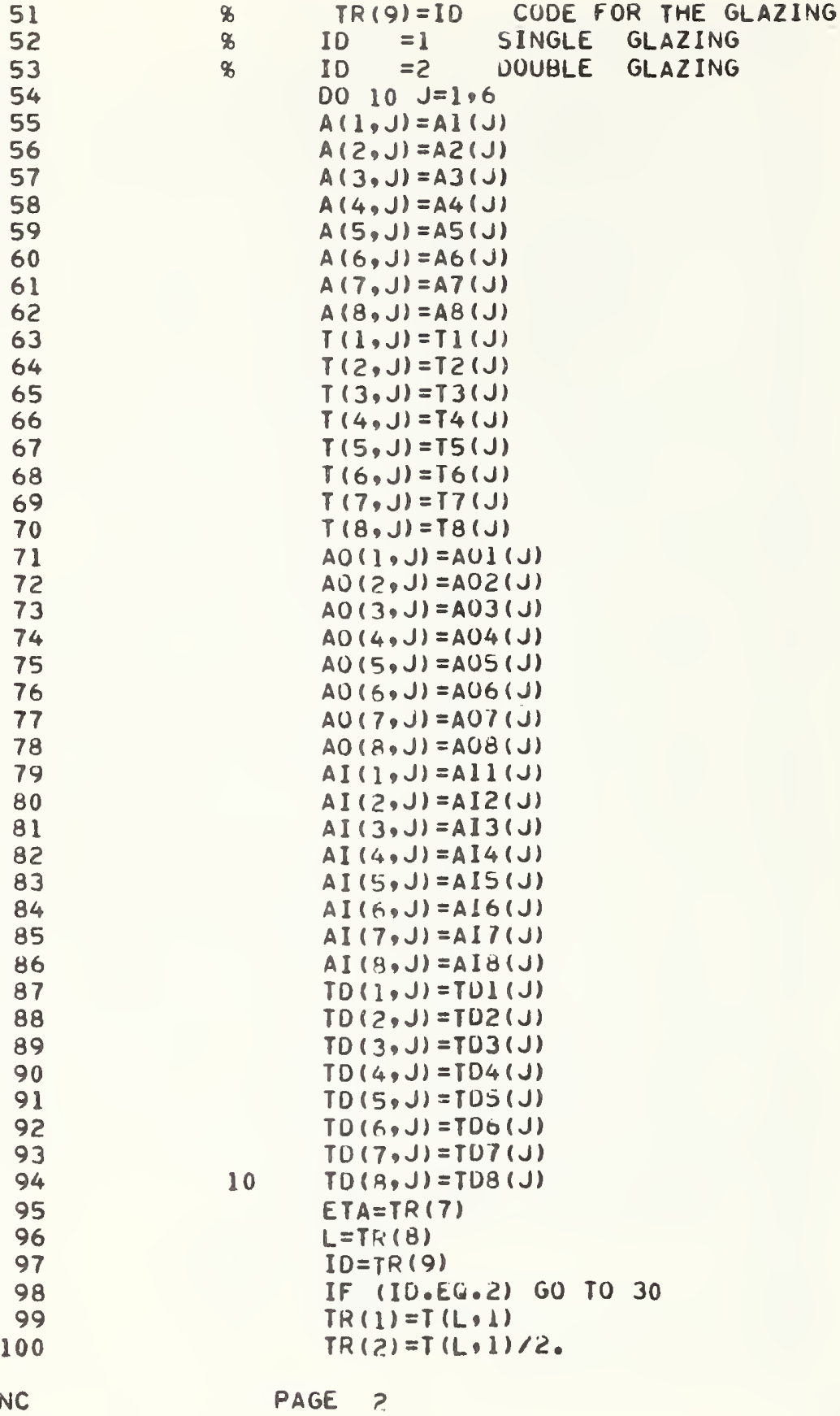

TAR-PNC

PAGE ? 
TAR-PNC

101

102

103

104

105

106

107

108

109

110

111

112

113

114

115

116

117

118

119

120

121

122

123

124

125

126

127

128

129

PAGE 3

$\operatorname{TR}(3)=A(L, 1)$

$\operatorname{TR}(4)=A(L, 1) / 2$.

DO $20 \mathrm{~J}=2,6$

$T R(1)=\operatorname{TR}(1)+T(L, J)$ *(ETA\#(J-1))

$T R(2)=T R(2)+T(L, J) /(J+1)$

$\operatorname{TR}(3)=\operatorname{TR}(3) \rightarrow A(L, J) *(E T A *(J-1))$

20

$T R(4)=T R(4)+A(L, J) /(J+1)$

$T R(5)=0$

$\operatorname{TR}(\sigma)=0$

GO TO 50

30

$T R(1)=T O(L, 1)$

$T R(2)=T D(L, 1) / 2$.

$\operatorname{TR}(3)=A O(L, 1)$

$\operatorname{TR}(4)=A O(L, 1) / 2$.

$\operatorname{TR}(5)=A I(L, 1)$

$\operatorname{TR}(6)=A I(L, 1) / 2$.

DO $40 \mathrm{~J}=2.6$

$X=E T A *(J-1)$

$T R(1)=T R(1)+T D(L, J) \oplus X$

$T R(2)=T R(2)+T D(L, J) /(J+1)$

$T R(3)=T R(3)+\bar{A} O(L, J) \# X$

$T R(4)=T R(4)+A O(L, J) i(J+1)$

$\operatorname{TR}(5)=\operatorname{TR}(5)+A I(L, J) \otimes X$

40

$\operatorname{TR}(6)=T R(6)+A I(L, J) /(J+1)$

$50 \quad T R(2)=2 * T R(2)$

$\operatorname{TR}(4)=2 \pi T H(4)$

$\operatorname{TR}(6)=2 * \operatorname{TR}(6)$

RETURN

END 
TEMPSH-PNC

1
2
3
4
5
7
8
9
10
11
12
13
14
15
16

PAGE I

SUBROUTINE TEMPSH(MONTH, JJ,NK, RMOBS, RMDGW, RMUUWU, RMOBSO, TA) DIMENSION RMDBS (24), RMOBW (24)

IF (MONTH.GE.6.AND.MONTH.LE•9) GO TO 6

IF (JJ.GT.L) GO TO 7

$T A=R M D B W(N K)$

GO TO 10

$7 \quad T A=R M O B W O$

GO TO 10

6 IF (JJ.GT.1) GO TO 5

$T A=R M D B S(N K)$

GO TO 10

$5 \quad T A=R M D B S O$

10 CONTINUE

RETURN

END 
WBS -PNC

1
2
3
4
5
6
7
8
9
10
11
12
13
14
15
16
17
18
19
20
21
22
23
24
25
26
27
28
29
30
31
32
33
34

PAGE 1

FUNCTION WHF $(H, P B)$

क THIS PKOGRAM APPROXIMATES THE WET-BULB IEMPEKATUKE WHEN

\% ENTHALPY IS GIVEN

IF (H) $20,20,5$

5 CONTINUE

$Y=L O G(H)$

IF (H.GT.11.758) GO TO 10

$W B F=0.6041+3.4841 * Y+1.3601 * Y * Y+0.97307 * Y * Y * Y$

GO TO 90

$10 \quad W B F=30.9185-39.6820 U * Y+20.5841 * Y * Y-1.758 * Y * Y * Y$

GO TO 90

$20 \quad W B 1=150$.

PVI =PVSF ( WBI)

$W 1=0.622 * P V I /(P B-P V I)$

$X I=0.24 * W B I+(1061+0.444 * W B I) * W I$

$Y 1=H-X 1$

$30 \quad W B 2=W B 1-1$

PVZ=PVSF (WHZ)

$W 2=0.622 * P V Z /(P B-P V Z)$

$X_{2}=0.24 * W B 2+(1061 * 0.444 * W B 2) * W 2$

$Y 2=H-X 2$

IF $(Y 1 * Y 2) \quad 80,50,40$

$40 \quad W B 1=W B 2$

$Y 1=Y 2$

GO TO 30

50 IF (YI) $70,60,70$

$60 \quad W B F=W B 1$

GO TO 90

$70 \quad W B F=W B 2$

$G 0$ TO 90

$80 \quad \angle=A B S(Y 1 / Y<)$

$W B F=(W B Z Z Z+W B 1) /(1+Z)$

90 RETIIRN

END 
WD-PNC

1
2
3
4
5
6
7
8
9
10
11
12
13
14
15
16
17
18
19
20
21
22
23
24
25
26
27
28
29

PAGE I

SUBROUTINE WO(INPUT)

INTEGER INPUT (1100), INCM(83)

COMMON NRUN, ISKIP, VOL (2), DENS, PARITY, IRACK

DATA TST/O..I

LEN $=83$

IF (NRUN.NE.0) GO TO 42

IF IDENS.EQ.' ') GO TO 42

CALL TPROP (INCM,LEN, STATUS, VOL, DENS, PARIIY, TRACK)

GO TO 41

42 CONTINUE

IF (DENS.NE.' 1$)$ GO TO 70

READ (1) INCM

$70-$ CONTINUE

CALL TPRRU (INCM,LEN, STATUS, VOL)

41 IF (STATUS.EU.TST) GO TO 40

WRITE $(6,50)$

50 FORMAT (" TAPE ERROR")

STOP

40 CONTINUE

NRUN $=N R U N+1$

IF (NRUN.LT.ISKIP) GO TO 42

DO $30 \mathrm{~J}=1$, LEN

DO $30 K=1,6$

$J J=(K-1) * 6$

$J K=(J-1) \approx 6+K$

30

$\operatorname{INPUT}(J K)=F L U(J J, 6, \operatorname{INCM}(J))$

RETURN

END

WD-PNC

PAGE I 
WOX-PNC

1

3

6

7

8

9

10

11

12

13

14

15

16

17

18

19

20

PAGE 1

SUBROUTINE WDX (IW)

DIMENSION IUATA $(10) / 012,01,02,03,04,05,06,07,010,011 /$, JUAIA (10)/072\% $, 061,062,063,064,065,066,067,070,0 / 1 /, K D A T A(10) / 052,041,042,043,0448$ $, 045,046,047,050,051 /$

DATA KX/040/

DO $50 \quad K K=1,10$

IF (IW.EQ.IDATA $(K K))$ GO TO 60

IF (IW.EQ.JUAIA $(K K))$ GO TO 60

IF (IW.EQ.KDATA(KK)) GO TO 61

50 CONTINUE

IF (IW.EQ.KX) GO TO 62

$I W=1000000$

60 I $W=k K=1$

GO TO $4 \mathrm{U}$

61 I $W=-(K K-1)$

62 GO TO 40

$I W=10$

40 RETURN

END 
WETHER-PNC

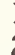

1

2

4

5

6

7

8

10

11

12

13

14

15

16

17

18

19

20

21

22

23

24

25

26

27

28

29

30

31

32

33

34

35

36

37

38

39

40

41

42

43

44

45

46

47

48

49

50

WETHER-PNC

PAGE

\% THIS PROGRAM DECOUES WEATHER TAPE 144 ANU CREATE A BINARY TAPE\%

\% WHICH IS USEFUL FOR THE LOAU CALCULATIOB̈ PिROGRĀM NBSLO DIMENSION DB(24), DPT (24), WHT (24), WST (24), PBT (24), IC (24), NTOC (24) INTEGER WPOS(10)/13,11,16,19,22,34,43,46,68,70/,WLONG(10)/3,2,3,

3, $3,4,1,1,2,3 /$, OUTPUT $(24,10)$, UAY, CI IY, YEAK, UAYSKK, INPUT (IIUU) COMMON NRUN, DAYSKP, VOL (2), DENS, PAKITY, IKACK

READ $(5,200$, PROMPT $=0$ VOL,DENS, PARITY, TKACK: ) VOL, UENS, PAKIIY, TRACK

200 FORMAT (5A 4 )

NRUN $=0$

WR ITE $(6,92)$

92 FORMAT " ISKIH NOAY IWRITE')

READ (5, *) ISKIP,NUAY, IWRITE

DAYSKP $=$ ISKIP\#4

CALL WONEW (INPUT)

DO $102 \quad I=1$, IVUAY

CALL DECOOH (WPOS, WLONG, 10, OUTPUT, O, YEAR, MUNTH, DAY, CITY)

3 DO $2 \mathrm{~K}=1,10$

2 CALL ERRON $(O U T P U T(I, K), K)$

IF (I.GT.1) iO TO 199

WRITE $(6,4)$

WRI TE $(6,5)$

WRITE $(6,6)$ CITY, YEAR,MONTH,UAY

$\begin{array}{lll}4 & \text { FORMAT }(50 H O & \\ 5 & \text { FOR START } \\ 7 & \text { FORMAT }(1 / 1 & \text { CITY } \\ & \text { TC DB } & \\ 6 & \text { FORMAT }(5 I 10) & \\ & \text { IF IWRITE.NE.0) } & \text { WRITE }(6,7)\end{array}$

199

DO $90 \mathrm{~J}=1,24$

I $W S=0 U T P U T(J, 1)$

IDR=OUTPUT $(J, 2)$

$K A=O U T P U T(J, 3)$

LA=OUTPUT $(J, 4)$

IDP $=$ OUTPUT $(J, 5)$

IATM $=$ OUTPUT $(J, 6)$

ITCA $=$ OUTPUT $(J, 7)$

I TOC $=2$

ITK $=$ OUTPUT $(J, 8)$

IF (ITK.EQ.2) ITOC $=1$

IF (ITK.EQ.8.OR.ITK.EQ.9) ITOC =0

IPR $=$ OUTPUT $(J, 9)$

IPS $=$ OUTPUT $(j, 10)$

$D B(J)=K A$

$W B T(J)=L A$

$\operatorname{DPT}(J)=I O P$

PUT $(J)=I$ ATM/ 100 .

$T C(J)=I T C A$

NTOC $(J)=I T O C$

WST $(J)=I W S$

IF (IWRITE.EQ.0) SO TO 90

PAGE 1 
WETHER-PNC

51

52

53

54

55

56

57

58

59

60

61
PAGE ?

WRITE $(6,91)$ DB (J),DPT (J), WBT (J),WST (J),PBT (J),TC(J),NTOC (J)

91 FORMAT (6F $10.2,110)$

90 CONTINUE

100 WRITE (9) DU, DPT, WHT, WST, PBT, TC, NTOC, UAY, YEAR, MONIH, CITY IF (IWRITE.E(H.0) WRITE $(6,103)^{\circ}$ MONTH; DAY

103

102 FORMAT (2I IO)

CONTINUE

CALL TPRCL

END FILE 9

STUP

END 
WINTR-PNC

1

2

3

4

5

6

7

8

9

10

11

12

13

14

15

16

17

18

19

20

21

22

23

24

25

PAGE I

SUBROUTINE WINTER (A,U, ITYPE,NEXP,CFMWT,UUIN, DUWI,UG,TGW,KHI,RHO) DIMENSION $A(30), U(30)$, ITYPE $(30)$

CALL DBRH (DEWT, RHU, WO)

CALL DBRH (DBIIN,RHI,WI)

$D T=D B I N-D B W T$

$D W=W I-W 0$

QWINTS $=1.08 *$ CFMWT\#DT

QWINTL $=4.5 * C F M H T * U W=1060$.

DO $30 \quad I=1$, NEXP

IF (ITYPE (I).EQ.6.UR.ITYPE (I).EQ.7) GU TU 30

IF (ITYPE (I).NE.5) GO TO 20

QWINTS $=Q W I N T S+U G * A(I) *(D B I N-T G W)$

20

GO TO 30

CONTINUE

30 CONTINUE

TOTAL $=Q W I N T S+Q W I N T L$

WRITE $(6,40)$ UWINTS, UWINTL, TOTAL

40

FORMAT $1 / /^{\circ}$ HEATING LOAD IN BTU PEK HOUR $\%$

-

1

SENSIBLE LUAD = IF10.0\%

LATENT

LOAD $=$ IF $10.0 / \%$

-

RETURN

END

TUTAL $L O A D=1 F 10.01111^{-}$

WINTER - PNC

PAGE 1 
PAGE I

FUNCTION WKDAY (YR, MO, DAY)

WKDAY = I SUNDAY

WKDAY $=2$ MONDAY

WKDAY $=3$ TUESDAY

WKDAY $=4$ WEÜNESUAY

WKDAY $=5$ THURSDAY

WKDAY $=6$ FRIDAY WKDAY $=7$ SATURDAY

INTEGER YR,UAY,WKDAY, TDAY,FSTUAY

DIMENSION + STDAY (12)/31, 59,90,120,1 $1,181,212,24\rfloor, 273,304,334,365 /$ $N=Y R / 4$

$N D=i v-485$

I $Y=$ ?

IF $-(N D \cdot E Q .0) \quad$ GO TO 40

IF $(N O . L T .0)$ GO TO 10

$I A D D=2$

GO TO 20

$10 \quad N O=-N D$

$$
I A D D=-2
$$

20

$$
\text { DO } 30 \mathrm{~J}=1 \text {, NU }
$$

$I Y=I Y-I A D D$

IF $(I Y, G T \cdot 7) \quad$ IY $=I Y=7$

IF $(I Y, E Q \bullet \cup) \quad I Y=7$

IF $(I Y \bullet L T \cdot 0) \quad$ I $Y=I Y+7$

30 CONTINUE

$40 \quad M D=Y R-N \$ 4$

IF $(M D \bullet E Q \bullet U)$ I WK $=I Y$

IF $(M D \cdot E Q \cdot 1)$ I WK $=I Y+2$

IF $(M D \cdot E Q \cdot 2)$ I $W K=I Y+3$

IF $(M D \cdot E Q \cdot 3) \quad I W K=I Y+4$

IF (IWK.GI.7) I WK =IWK-7

IF (MO.NE. 1) GO TO 50

TDAY $=0 A Y-1$

GO TO 80

50 DO $60 \mathrm{~J}=2,12$

IF (MO.NE.J) GO TO 60

$\operatorname{TDAY}=F \operatorname{STOAY}(J-1)+D A Y-1$

GO TO 70

60 CONTINUE

70 IF $(M O, E Q, 0, A N D, M O, G T, 2)$ TUAY = TUAY +1

$80 \quad N T X=T U A Y / 7$

$N D X=T O A Y-7 N T T X+I W K$

IF (NDX,GT, I) NOX=NUX-7

WKDAY $=$ NOX

$K V=Y R / 100$

KTEST $=Y H-K V \& 100$

IF (MU.GT.2.OR.KTEST.NE.0) GO TO 90

$K V=K V-1$

90

$L V=K V / 4$

LTEST $=K V-L V \# 4$

PAGE 1 
WKDAY - PNC

51

52

53

54

55

56

57

58

59

PAGE ?

IF (LTEST•EQ.2) WKDAY $=W K D A Y+1$

IF (LTEST,EQ.1) WKDAY =WKOAY +2

IF (LTEST•EQ•0) WKDAY =WKUAY + 3

WKDAY $=W K D A Y=3 *(L V-4)$

100

IF $(W K D A Y \cdot L E \bullet 0)$ WKDAY =WKDAY +7

IF (WKDAY.LE.O) GO TO IOU

IF (WKUAY.GT.7) WKDAY=WKDAY-7

REETURN

END 

NBS.114A (REV. 7.73)

\begin{tabular}{|c|c|c|c|}
\hline $\begin{array}{l}\text { U.S. OEFIT. OF COMM. } \\
\text { BIBLIOGRAPHIC DATA } \\
\text { SHEET }\end{array}$ & $\begin{array}{l}\text { 1. PUBLICATION OR REPORT NO. } \\
\text { NBSIR } 74-574\end{array}$ & $\begin{array}{l}\text { 2. Gov't Accession } \\
\text { No. }\end{array}$ & 3. Recipient's Accession No. \\
\hline \multicolumn{3}{|c|}{$\begin{array}{l}\text { 4. IITLE AND SUBTITLE } \\
\text { NBSLD, Computer Program for Heating and Cooling Loads in Build } \\
\text { ings }\end{array}$} & \begin{tabular}{|l|} 
5. Publication Date \\
November I, 1974 \\
6. Performing Orgunizarion Code
\end{tabular} \\
\hline \multicolumn{3}{|l|}{$\begin{array}{l}\text { 7. AUTHOR(S) } \\
\text { Tamami Kusuda }\end{array}$} & 8. Performing Organ. Report No. \\
\hline \multicolumn{3}{|c|}{$\begin{array}{l}\text { 9. PERFORMING ORGANIZATION NAME AND ADDRESS } \\
\text { NATIONAL BUREAU OF STANDARDS } \\
\text { DEPARTMENT OF COMMERCE } \\
\text { WASHINGTON, D.C. } 20234\end{array}$} & \begin{tabular}{|l|} 
10. Project/Task/Work Unit No. \\
11. Contract/Grant No.
\end{tabular} \\
\hline \multicolumn{3}{|c|}{ 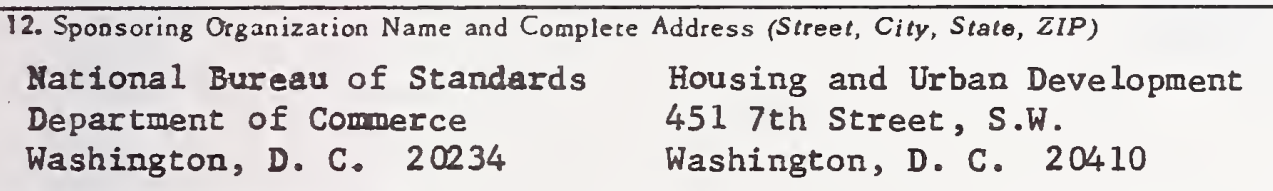 } & $\begin{array}{l}\text { 13. Type of Report \& Period } \\
\text { Covered } \\
\text { Final Report } \\
\text { 14. Sponsoring Agency Code }\end{array}$ \\
\hline
\end{tabular}

15. SUPPLEMENTARY NOTES

16. ABSTRACT (A 200-word or less factusl summary of most significant information. If document includes a significant bibliography or literature survey, mention it here.)

A comprehensive computer program called NBSLD, the National Bureau of Standards Load Determination program, has been developed at NBS to reflect the time change of the many building parameters which are pertinent to accurate estimation of energy usage for heating and cooling. Current status of heating and cooling load techniques is reviewed. Of general interest are unique features of NBSLD which are not available in existing conputer programs. A sumary of various subroutines of NBSLD is given along with the detailed procedures for them. These subroutines constitute the recomended subroutine al gorithms of the ASHRAE Task Group on Energy Requirements. Complete Fortran listing of NBSLD and data preparation forms are given for those who wish to use the program. The NBSLD computation is on the basis of the detailed solution of simultaneous heat balance equations at all the interior surfaces of a room or space. Transient heat conduction through exterior walls in the interior structures is handled by using conduction transfer functions. The use of heat balance equations, although time consuming in calculation, can avoid the vagueness and uncertainties inherent in the more popularly used weighting factor approach. In addition, it is more accurate for a specific building de sign.

17. KEY WORDS (six to twelve entries; alphabetical order; capitalize only the first letter of the first key word unless a proper name; separated by semicolons) ASHRAE Task Group on Energy Requirements; conduction transfer functions; heating and cooling load; National Bureau of Standards Heating and Cooling Load Computer Program

18. AVAILABILITY $\quad$ Unlimized

For Official Distribution. Do Not Release to NTIS

Order From Sup. of Doc., U.S. Government Printing Office

Washingron, D.C. 20402, SD Car. No, C13

X Order From National Technical Information Service (NTIS) Springfield, Virginia 22151

\begin{tabular}{|l|c|}
\hline $\begin{array}{l}\text { 19. SECURITY CLASS } \\
\text { (THIS REPURT) } \\
\text { UNCL ASSIFIED }\end{array}$ & 21. NO. OF PAGES \\
\hline $\begin{array}{l}\text { 20. SECURITY CLASS } \\
\text { (THIS PAGE) }\end{array}$ & 22. Price \\
UNCLASSIFIED & USCOMM-OC 29042.274 \\
\hline
\end{tabular}


